\title{
Update of ASHRAE Standard 140 Section 5.2 and Related Sections (BESTEST Building Thermal Fabric Test Cases)
}

Energy Systems Division 


\begin{abstract}
About Argonne National Laboratory
Argonne is a U.S. Department of Energy laboratory managed by UChicago Argonne, LLC under contract DE-AC02-06CH11357. The Laboratory's main facility is outside Chicago, at 9700 South Cass Avenue, Lemont, Illinois 60439. For information about Argonne and its pioneering science and technology programs, see www.anl.gov.
\end{abstract}

\title{
DOCUMENT AVAILABILITY
}

Online Access: U.S. Department of Energy (DOE) reports produced after 1991 and a growing number of pre-1991 documents are available free at OSTI.GOV (http://www.osti.gov/),

a service of the US Dept. of Energy's Office of Scientific and Technical Information.

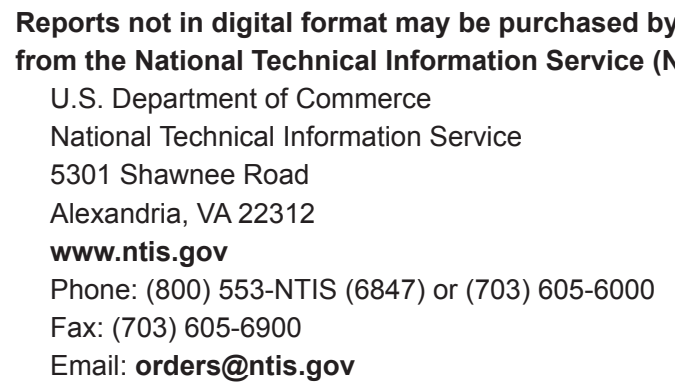

Reports not in digital format are available to DOE and DOE contractors from the Office of Scientific and Technical Information (OSTI):

U.S. Department of Energy

Office of Scientific and Technical Information

P.O. Box 62

Oak Ridge, TN 37831-0062

www.osti.gov

Phone: (865) 576-8401

Fax: (865) 576-5728

Email: reports@osti.gov

\begin{abstract}
Disclaimer
This report was prepared as an account of work sponsored by an agency of the United States Government. Neither the United States Government nor any agency thereof, nor UChicago Argonne, LLC, nor any of their employees or officers, makes any warranty, express or implied, or assumes any legal liability or responsibility for the accuracy, completeness, or usefulness of any information, apparatus,

product, or process disclosed, or represents that its use would not infringe privately owned rights. Reference herein to any specific commercial product, process, or service by trade name, trademark, manufacturer, or otherwise, does not necessarily constitute or imply its endorsement, recommendation, or favoring by the United States Government or any agency thereof. The views and opinions of document authors expressed herein do not necessarily state or reflect those of the United States Government or any agency thereof, Argonne National Laboratory, or UChicago Argonne, LLC.
\end{abstract}


ANL-20/26

\section{Update of ASHRAE Standard 140 Section 5.2 and Related Sections (BESTEST Building Thermal Fabric Test Cases)}

by

J. Neymark' ${ }^{1}$, R. Judkoff², M. Kummert ${ }^{3}$, and R. Muehleisen ${ }^{4}$

${ }^{1} \mathrm{~J}$. Neymark \& Associates, United States

${ }^{2}$ National Renewable Energy Laboratory, United States

${ }^{3}$ Polytechnique Montréal, Canada

${ }^{4}$ Argonne National Laboratory, United States

with

A. Johannsen ${ }^{5}$, N. Kruis ${ }^{6}$, J. Glazer ${ }^{7}$, R. Henninger ${ }^{7}$, M. Witte ${ }^{7}$, E. Ono ${ }^{8}$, H. Yoshida ${ }^{9}$, Y. Jiang ${ }^{10}$, X. Zhou ${ }^{10}$, T. McDowell ${ }^{11}$, M. Hiller ${ }^{12}$, J. An ${ }^{13}$, D. Yan ${ }^{13}$, J. Allison ${ }^{14}$, and P. Strachan ${ }^{14}$

${ }^{5}$ Alec Johannsen Consulting Engineers, South Africa

${ }^{6}$ Big Ladder Software, United States

${ }^{7}$ GARD Analytics, Inc., United States

${ }^{8}$ Kajima Technical Research Institute, Japan

${ }^{9}$ Kyoto University (professor emeritus), Japan

${ }^{10}$ Southeast University, China

${ }^{11}$ Thermal Energy System Specialists, United States

${ }^{12}$ Transsolar Energietechnik $\mathrm{GmbH}$, Germany

${ }^{13}$ Tsinghua University, China

${ }^{14}$ University of Strathclyde, United Kingdom

Link to Accompanying Zipped Data Files (100 MB)

July 2020 


\section{Acknowledgments}

The work described in this report is a cooperative effort involving the members of the American Society of Heating, Refrigerating and Air-Conditioning Engineers (ASHRAE) Standing Standard Project Committee (SSPC) 140, Standard Method of Test for the Evaluation of Building Energy Analysis

Computer Programs, and other international participants. We are grateful for the ASHRAE organizational framework that facilitated this project. We are also grateful to Mark Owen of ASHRAE for granting permission to use material from ANSI/ASHRAE Standard 140-2017; see the notes at the beginning of Part I and Part II, Section 2.4, of this report.

The project participants who provided the majority of early simulation-trial work, preliminary sensitivity tests, feedback on the test specification, and modeler reports are listed as co-authors. We also gratefully acknowledge others that contributed in the early stages, ran preliminary simulations, and/or reviewed various drafts of the test specification, including:

- Mike Kennedy, Mike D. Kennedy, Inc., United States

- Bruno Peuportier, School of Mines ParisTech, France

- Chip Barnaby and Bruce Wilcox, California Simulation Engine authors, United States

- Siyue Guo, Tsinghua University, China.

We are particularly grateful for the support and guidance of Amir Roth, program manager with the U.S. Department of Energy, Building Technologies Office.

A substantial portion of the funding for this work was provided by the Alliance for Sustainable Energy, LLC, Managing and Operating Contractor for the National Renewable Energy Laboratory for the U.S. Department of Energy.

The research effort by Argonne National Laboratory was supported by the Building Technology Office of the U.S. Department of Energy's Office of Energy Efficiency and Renewable Energy under Contract Number DE-AC02-06CH11357.

The authors are also grateful to Elizabeth Stefanski of Argonne National Laboratory for reviewing and editing this report. 


\section{Table of Contents}

[Note to Users: Section numbering applied in this report facilitates adaptation to Standard 140.]

Acknowledgments

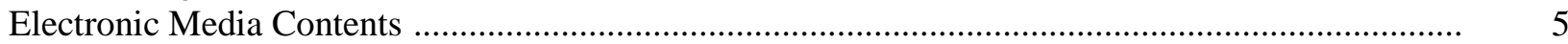

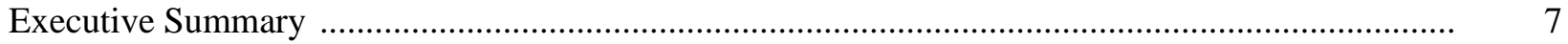

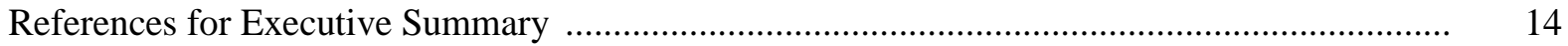

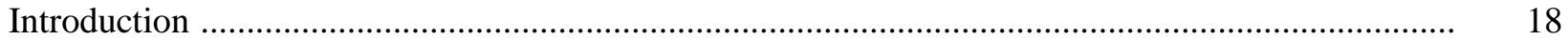

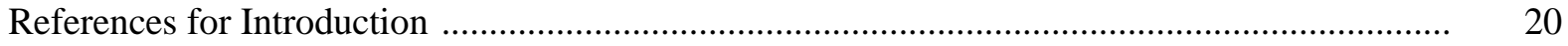

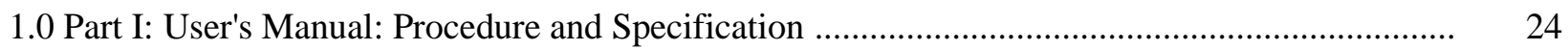

1. Introduction

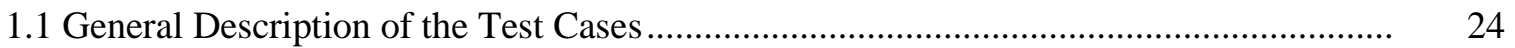

1.2 Accompanying Electronic Files Required for Running the Test Cases ........................... 24

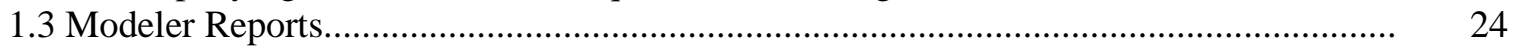

1.4 Comparing Tested Program Output to the Example Simulation Results......................... 24

2. Intentionally blank

3. Intentionally blank.

3.1 Intentionally blank

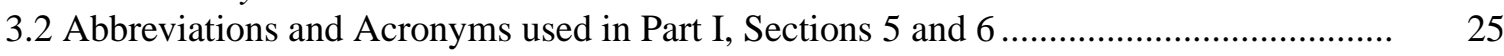

4. Intentionally blank....

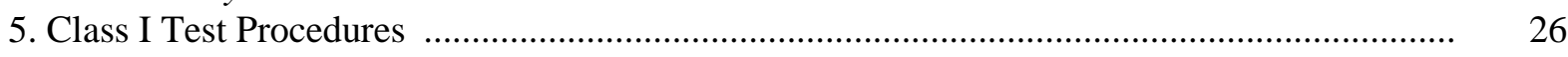

5.1 Modeling Approach ........................................................................................... 26

5.2 Input Specifications for Building Thermal Envelope and Fabric Load Test Cases .......... 27

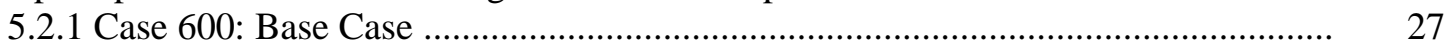

5.2.2 Basic Tests .................................................................................. 41

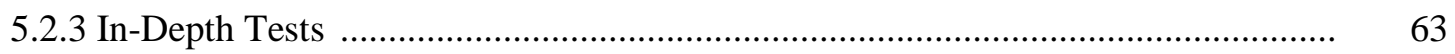

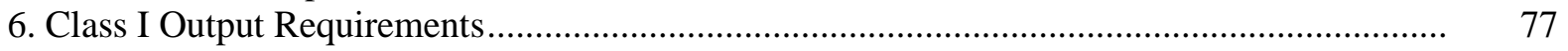

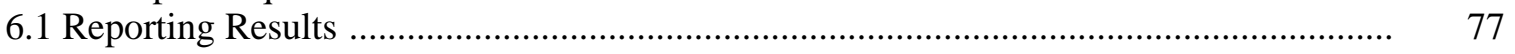

6.2 Intentionally blank, no proposed changes to Standard 140 for this section ................... 77

6.2.1 Output Requirements for Building Thermal Envelope and Fabric Load Tests of

Sections 5.2.1, 5.2.2, and 5.2.3 .......................................................................... 77

6.2.2 Intentionally blank; no proposed changes to Standard 140 for this section .......... 81

Normative Annexes

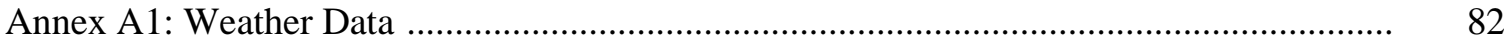

A1.1.1: Weather Data for Building Thermal Envelope and Fabric Load Tests of Sections

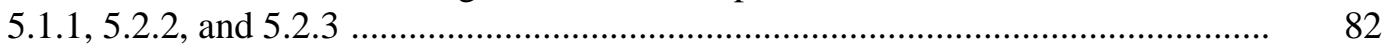

A1.8: TMY3 Weather Data Format ......................................................................... 84

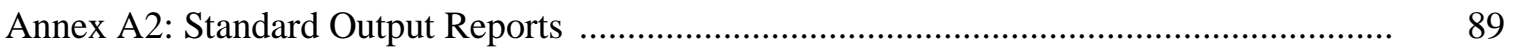

Informative Annexes

Annex B1: Tabular Summary of Test Cases ...................................................................... 92

Annex B2: About Typical Meteorological Year (TMY) Weather Data .............................. 97

Annex B3: Infiltration and Fan Adjustments for Altitude ................................................. 98

Annex B4: Alternative Constant Convective-Only and Combined Radiative and Convective Surface Coefficients ........................................................................................... 100

Annex B5: Infrared Portion of Film Coefficients ............................................................... 103

Annex B6: Window Thermal and Optical Property Calculations ........................................ 104

Annex B7: Detailed Calculation of Alternative Constant Interior Solar Distribution Fractions 114

Annex B11: Production of Example Results for Building Thermal Envelope and Fabric Load and Ground-coupled Slab-on-Grade Tests of Section 5.2 ........................................... 119 
Annex B24: Informative References ...................................................................... 120

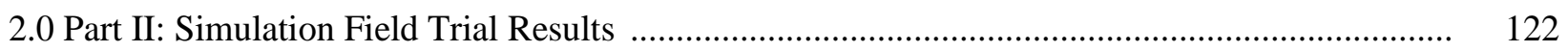

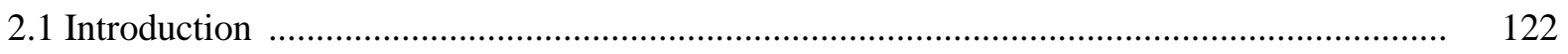

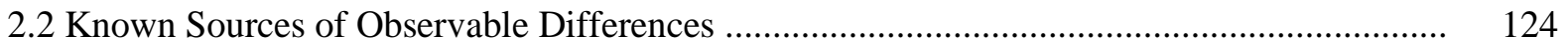

2.3 Abbreviations and Acronyms Used in Results Charts and Tables ..................................... 126

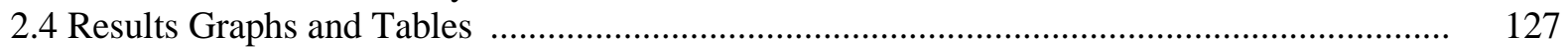

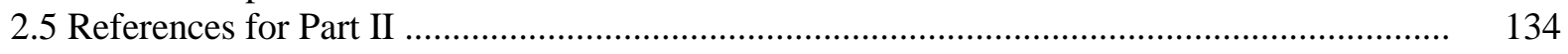

3.0 Part III: Production of Field-Trial Example Simulation Results ......................................... 135

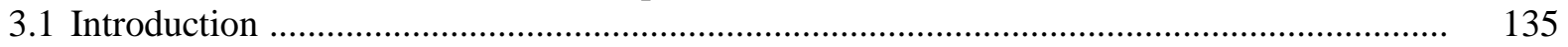

3.2 Selection of Simulation Programs and Modeling Rules for Simulations ........................... 136

3.3 Improvements to the Test Specification as a Result of the Field Trials ............................... 136

3.4 Improvements to Programs that Participated in the Simulation Trials ................................ 141

3.5 Interpretation of Results ............................................................................................ 143

3.5.1 Improvements to Ranges of Differences of Example Results Versus Original Example

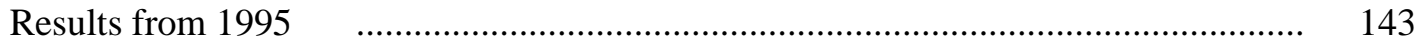

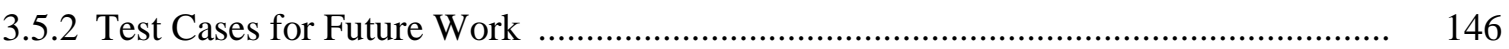

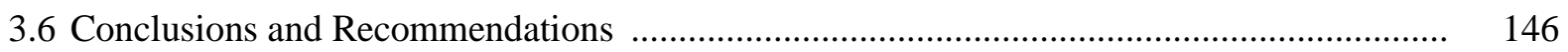

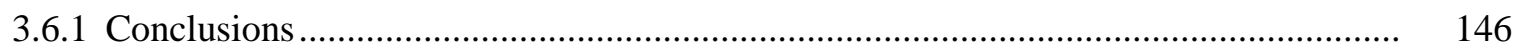

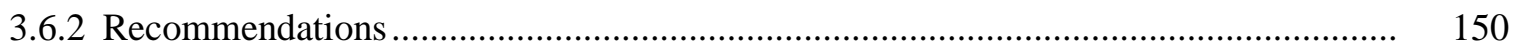

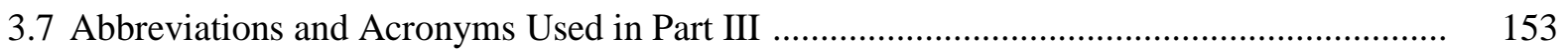

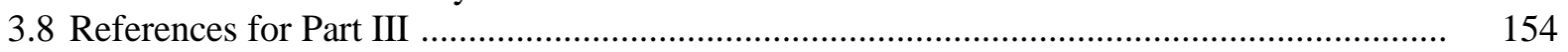

3.9 Appendix III: Simulation Modeler Reports Accompanying File ....................................... 157

4.0 Part IV: Other Supporting Material Appendices ................................................................ 158

4A Appendix A: Development of Alternative Constant Convective-Only and Combined Radiative and Convective Surface Coefficients of Standard 140, Informative Annex B4 .................. 158

4A.1 Introduction .............................................................................................. 158

4A.2 Methods for Calculating Alternative Constant Convective Heat Transfer Coefficients 158

4A.3 Calculation of Alternative Convective and Combined Surface Heat Transfer Coefficients Applying Verified Simulations ...................................................................... 162

4A.4 Archival Record of Work to Develop Alternative Constant Heat Transfer Coefficients

4A.5 Comparison of New Versus Standard-140-1027 Alternative Constant Surface Heat Transfer Coefficients and Effect on Heating and Cooling Loads

4B Appendix B: Development of Informative Sky Temperature Data of Annex A1, Section A1.1.1.2

4C Appendix C: Calculation of Alternative Constant Interior Solar Distribution Fractions of Annex B7

4D Appendix D: References for Part IV 


\section{Electronic Media Contents}

BESTEST Building Thermal Fabric Test Cases Update. These accompanying files are included in the following .zip-file link: Link to Accompanying Zipped Data Files (100 MB). This link is also on the title page.

- README-Thermal-Fabric-Update.docx: Electronic media contents.

ISec5-2AFilestNormative Materials subfolder

Files apply as they are called out in the test procedure.

- 725650TY.CSV: TMY3 weather data for Denver International Airport, Denver, Colorado - the weather data file to be used. The format of Typical Meteorological Year, version 3 (TMY3) data is described in Normative Annex A1.

- Sec5-2Aout.XLSX: Spreadsheet output report for entering simulation results. Instructions for the Standard Output Reports are included in Normative Annex A2. Workbook tabs apply as follows:

○ "A": Primary output template, see instructions beginning in Cell A6.

- "TMPBIN": Case 900FF bin frequency output post-processor as specified in Section 6.2.1.7.1.2, see instructions beginning in Cell B1.

- S140outNotes.TXT: Standard Output Report for entering modeling notes. Instructions for the Standard Output Reports are included in Normative Annex A2. See

S140outNotes_Examples.TXT (in the corresponding "Informative Materials" subfolder) for example modeling notes.

○ Informative Note: Changes to S140outNotes.TXT since the Standard 140-2017 version are indicated in Informative-S140outNotes-txt-edits-140-2017A.PDF.

ISec5-2AFiles\Informative Materials subfolder

- Case600-W7-DblPaneClr-ID23.TXT: Window 7 Glazing System output report for double-pane clear window (specified for Case 600)

- Case660-W7-DbIPaneLowE-ID36.TXT: Window 7 Glazing System output report for doublepane low-emissivity window (specified for Case 660)

- Case670-W7-SglPane-ID15.TXT: Window 7 Glazing System output report for single-pane window (specified for Case 670)

- S140outNotes_Examples.TXT: Example modeling notes.

○ Changes to S140outNotes_Examples.TXT since the Standard 140-2017 version are indicated in S140outNotes_Examples-txt-edits-140-2017A.PDF.

- Tsky-Informative.XLSX: Workbook containing supplementary calculated hourly sky temperature data for programs that may need it. See discussion included in the informative note with Annex A1, Section A1.1.1.2. Workbook tabs apply as follows:

○ "Informative-Tsky": Hourly sky temperature data are in column D; hourly weather file date and time are in columns A and B, respectively

○ “Supporting-Tsky-Calcs": Supporting calculations for the algorithm applied to develop the sky temperatures, along with comparison to two other algorithms; see calculation documentation beginning in Cell AK5.

- RESULTS5-2A-Update.PDF: File with the example results as described in Part II.

- RESULTS5-2A-Update.XLSX: Workbook containing the example results; see Part II. New results can be added to this file and will be automatically included in the summary tables and figures to facilitate comparison with the example results. 
InputFiles5-2A subfolder: (ASHRAE SSPC 140 Building Thermal Fabric Working Group participant simulation input files)

○ README-BEFORE-VIEWING-INPUT-FILES.DOCX: Review this file before opening the input files.

$\begin{array}{ll}\text { Subfolder } & \text { Simulation Program } \\ \text { IBSIMAC } & \text { BSIMAC, Version 9.0.74 } \\ \text { ICSE } & \text { California Simulation Engine, Version 0.861.1 } \\ \text { IDeST } & \text { DeST 2.0, Version 20190401 } \\ \text { IEnergyPlus } & \text { EnergyPlus, Version 9.0.1 } \\ \text { IESP-r } & \text { ESP-r, Version 13.3 } \\ \text { INewHASP } & \text { NewHASP/ACLD, Version20121213 } \\ \text { ITRNSYS } & \text { TRNSYS, Version 18.01.0001 }\end{array}$

\section{ISec5-2AFilesiSupplementary subfolder}

- 140-2017-Sec5_2-Update-TestSpec-EditTracked.DOCX: Edit-tracked test specification (Part I of this report) for 140 users familiar with the previous version that were not involved in the simulation trials and for use with ASHRAE staff for developing 140-2017 Addendum A.

- ChangesSummary-Sec5_2-Update.PDF: Documentation of changes to the test specification, organized sequentially by test spec section.

- ModelerReports-ThermalFabricUpdate.PDF: Appendix III (Part III, Section 3.9) simulation trial participant modeler reports. 


\section{Executive Summary}

\section{Project Description}

This report documents new work intended to update the current building thermal fabric software-tosoftware comparative test specifications and example results of ANSI/ASHRAE Standard 140-2017, ${ }^{1}$ Sections 5.2.1, 5.2.2, 5.2.3, and related supporting sections. The Building Energy Simulation Test and Diagnostic Method (BESTEST) test specification and example results that provide the basis for these Standard 140 sections were originally published in $1995 .^{2}$ The state of the art in building energy simulation modeling has advanced since then. Additionally, comments on the test specification over the years highlighted ambiguities, further necessitating the update to the original work.

This new work was conducted for the U.S. Department of Energy (DOE) by Argonne National Laboratory (Argonne) and National Renewable Energy Laboratory (NREL), in collaboration with a working group of international experts associated with the American Society of Heating, Refrigerating, and Air-Conditioning Engineers (ASHRAE) Standing Standard Project Committee (SSPC) 140. SSPC 140 is responsible for ANSI/ASHRAE Standard 140. The new work, presented in this report, defined the test cases and specifications such that building energy simulation programs with time steps of one hour or less can perform the tests. Revisions to the test specification and update of example results follow the vetting process of iterative field trials established for previous BESTEST work that has been adapted for ASHRAE Standard $140 .{ }^{2,3,4,5,6,7,8}$

\section{Background}

The development of practical procedures and data for tool evaluation and improvement is part of an overall validation methodology that has been under development for many years. The methodology combines empirical validation, analytical verification, and comparative analysis techniques. Details are discussed in the Background section of HVAC BESTEST Volume $1,{ }^{5}$ with the most recent updates, as of this writing, published in the 2017 ASHRAE Handbook of Fundamentals ${ }^{9}$ and elsewhere. ${ }^{10,11,12,13,14}$ NREL originally developed the BESTEST method in International Energy Agency (IEA) Solar Heating and Cooling Programme Task 12 to test building thermal fabric (envelope) models and to diagnose sources of predictive disagreements. ${ }^{2}$ This method of testing was adopted with some refinements by ASHRAE in accordance with procedures of ANSI, and now forms the basis for ANSI/ASHRAE Standard 140, Method of Test for the Evaluation of Building Energy Analysis Computer Programs. ${ }^{1,15,16,17,18,19}$

\section{The Updated Building Thermal Fabric Modeling Test Cases}

The updated building thermal fabric modeling test suite, described in Part I of this report, includes a set of 52 diagnostic test cases. The test cases are summarized in Tables B1-2 and B1-3 of Annex B1. These are software-to-software comparative tests, where simulation results are compared to each other. All simulation results are provided in Part II. A summary of the process of updating and improving the test specification is described in Part III, Section 3.3, along with a summary topical listing of the improvements.

J. Neymark \& Associates, under contracts with Argonne and NREL, led the collaborative effort to vet and extensively revise the test case specifications for external use as a standard method of test that can be integrated with the tests of ASHRAE Standard 140. The collaboration included a number of software developer members of SSPC 140 along with other international software developers and participants. The contribution of the SSPC 140 industry working group participants was particularly valuable because the expert software developer teams supplied continuous feedback throughout the field trial effort. 
A major enhancement to the test specification was to improve equivalent inputs for surface heat transfer. Equivalent inputs are important because they allow testing of a variety of programs with a variety of input schemes that may require different levels of input detail. Carefully defining surface heat transfer parameters is fundamental to modeling because 1) interior surface heat transfer interfaces the building interior surfaces and related thermal mass with the zone temperature and the thermostat, 2) interior surface radiative exchange interfaces interior surfaces with each other, and 3) exterior surface heat transfer interfaces the building with weather data, the surrounding environment, and other parts of the building (if the building has a concave geometry). Work related to these improvements to the test specification, and the substantial effect of those improvements, is described in detail in Part IV, Appendix A; also see the related summary paper. ${ }^{20}$

Another substantial improvement was replacing the Denver, Colorado, TMY data set applied for the original test cases with Denver TMY3 weather data for the new test cases. Although both data sets were taken within the same metropolitan area, the precise locations and time periods of the data are different, resulting in some differences: e.g., annual average temperature and global horizontal solar radiation are $9.7^{\circ} \mathrm{C}(\mathrm{TMY})$ versus $10.9^{\circ} \mathrm{C}(\mathrm{TMY} 3)$ and $1832 \mathrm{kWh} / \mathrm{m}^{2}$ (TMY) versus $1670 \mathrm{kWh} / \mathrm{m}^{2}$ (TMY3), respectively.

There were also a number of other specification improvements and clarifications, including revisions to window construction properties, super-insulated floor details, site altitude and terrain details, infiltration airflow rate adjustment for site altitude, internal mass, simulation initialization and pre-conditioning requirements, thermostat control, etc. (see Part III, Section 3.3).

\section{Results and Conclusions}

The updated building thermal fabric modeling test cases have been vetted via field trials with a number of detailed state-of-the-art whole-building energy simulation programs from around the world; see Table ES-1. The field-trial process was iterative in that executing the simulations led to refinement of the test cases, and the results of the tests led to improving and debugging the models. Improvements to simulation programs or simulation inputs made by participants must have a mathematical and a physical basis and must be applied consistently across tests. Arbitrary modification of a simulation program's input or internal code just for the purpose of more closely matching a given set of results is not allowed. All improvements were requested to be documented and justified in the modeler reports. Improvements to simulation models are summarized in Table 3.4-1 (see Part III, Section 3.4) and in the participant modeler reports of Part III, Section 3.9. 
Table ES-1 Building Thermal Fabric Test Cases Update, Participating Organizations and Models

\begin{tabular}{|l||l||l||l||}
\hline $\begin{array}{l}\text { Simulation } \\
\text { Program }\end{array}$ & Authoring Organization(s) & Implemented by & Abbreviation \\
\hline \hline BSIMAC 9.0.74 & $\begin{array}{l}\text { Alec Johannsen Consulting } \\
\text { Engineers, South Africa }\end{array}$ & $\begin{array}{l}\text { Alec Johannsen Consulting } \\
\text { Engineers, South Africa }\end{array}$ & BSIMAC \\
\hline $\begin{array}{l}\text { California } \\
\text { Simulation } \\
\text { Engine 0.861.1 }\end{array}$ & $\begin{array}{l}\text { J.R. Barnaby/C.S. Barnaby/Big } \\
\text { Ladder Software LLC/Wrightsoft } \\
\text { Corp., United States }\end{array}$ & $\begin{array}{l}\text { Big Ladder Software LLC, } \\
\text { United States }\end{array}$ & CSE \\
\hline $\begin{array}{l}\text { DeST 2.0 Version } \\
20190401\end{array}$ & $\begin{array}{l}\text { Tsinghua University, China } \\
\text { EnergyPlus 9.0.1 }\end{array}$ & $\begin{array}{l}\text { Southeast University, China } \\
\text { Tsinghua University, China }\end{array}$ & DeST \\
\hline Building Technologies Office, & $\begin{array}{l}\text { GARD Analytics, Inc., United } \\
\text { States }\end{array}$ & \multirow{2}{*}{ EnergyPlus } \\
\hline ESP-r 13.3 & $\begin{array}{l}\text { University of Strathclyde, United } \\
\text { Kingdom }\end{array}$ & $\begin{array}{l}\text { University of Strathclyde, United } \\
\text { Kingdom }\end{array}$ & ESP-r \\
\hline $\begin{array}{l}\text { NewHASP/ } \\
\text { ACLD 201213 }\end{array}$ & $\begin{array}{l}\text { Japan Building Mechanical and } \\
\text { Electrical Engineers Association, } \\
\text { Japan }\end{array}$ & $\begin{array}{l}\text { Kajima Technical Research } \\
\text { Institute, Japan }\end{array}$ & NewHASP \\
\hline $\begin{array}{l}\text { TRNSYS } \\
18.01 .0001\end{array}$ & $\begin{array}{l}\text { Transsolar Energietechnik GmbH, } \\
\text { Germany; Thermal Energy System } \\
\text { Specialists, United States }\end{array}$ & $\begin{array}{l}\text { Transsolar Energietechnik } \\
\text { GmbH, Germany }\end{array}$ & TRNSYS \\
\hline $\begin{array}{l}\text { TRNSYS } \\
17.02 .0005 \text { and } \\
18.00 .0017\end{array}$ & $\begin{array}{l}\text { Transsolar Energietechnik GmbH, } \\
\text { Germany; Thermal Energy System } \\
\text { Specialists, United States }\end{array}$ & $\begin{array}{l}\text { Ecole Polytechnique Montréal, } \\
\text { Canada,b }\end{array}$ & [n/a] \\
\hline \hline
\end{tabular}

${ }^{a}$ Ecole Polytechnique and GARD also worked on simulations for developing alternative constant interior and exterior surface coefficients, applying TRNSYS and EnergyPlus, respectively.

${ }^{b}$ Also checking input files versus the Transsolar participant's files and vice versa.

\section{Improvements to the Updated Ranges of Differences of Example Results Versus Original Example Results from 1995}

The range of difference has been reduced (improved) for the updated simulation results as compared to those in the 1995 BESTEST report. ${ }^{2}$ This reduction was due to making the test specification updates described above, applying a set of more up-to-date programs than was available in 1995, correcting software errors, and making other model input improvements using the diagnostic capabilities of the BESTEST procedures. The new simulation results are planned for inclusion with the update to Standard 140. Figures ES-1 and ES-2 compare ranges of differences of results for the set of programs that ran the updated test specification versus the set of programs that produced the 1995 BESTEST results. ${ }^{2}$ For this comparison, Figure ES-1 shows Case 600 (low mass) annual heating and cooling loads, while Figure ES-2 shows Case 900 (high mass) annual heating and cooling loads. In both figures, the range of 1995 and new results is represented by black and blue horizontal lines, respectively, with individual 1995 and new results shown with black-pattern and blue-pattern bars, respectively. These figures, and Table ES-2 discussed below, exclude the new results for the NewHASP program for reasons discussed in Part II, Section 2.2.1.

Table ES-2 quantifies ranges of differences of the new results set versus the 1995 results set for the Basic Tests of Part I, Section 5.2.2 (low-mass Cases 600 through 650 and similar high-mass Cases 900 through 950). Here, the range for each data set is assessed by (Max - Min $) /((\operatorname{Max}+\operatorname{Min}) / 2)$ expressed in percent. 
For this calculation, a smaller percent-difference indicates better agreement. Table ES-2 includes this comparison for annual total heating and cooling loads and annual peak heating and cooling loads.

The tabulation indicates that new results have substantially improved ranges of difference (narrower range implying better agreement) versus the 1995 results for annual heating and cooling loads and peak heating loads, where in many cases the range of difference is reduced by half or more. For peak cooling loads, the tabulation indicates similar improvement for the high-mass cases and for low-mass cases 620 and 630 . However, new peak cooling load results for low-mass Cases 600, 610, 640 and 650 have a mild percentrange increase versus the 1995 results, with both ranges $\leq 22 \%$. This level of percent-difference for the new peak-cooling load results appears to be consistent with the percent-difference for other new results in Table ES-2. In general, peak cooling load is considered more difficult to assess-because of timing of solar gains and mass and surface heat transfer interactions - than the other outputs shown in Table ES-1, and the ranges of differences for the new results support that. Another noteworthy result is the relatively small improvement (56\% to 47\%) in the difference for the new annual heating results for Case 940 (high mass with heating temperature setback). A possible cause for the continuing relatively high percent-difference for Case 940 is that the night setback reduces the annual heating load such that the results differences typically occurring throughout the 900 -series cases annual heating loads are magnified as a percentage when the signal (in this case annual heating load) has been reduced; see Table B8-1 and Figure B8-11 in Results5-2AUpdate.XLSX of the accompanying files.

Improvements to both the test specification and the state of the art of the programs, as well as the change of included software programs, likely contribute to the improved results agreement. Because sensitivity tests of these improvements were not made individually, and would have been very difficult to do if even possible, we cannot separate their effects. The programs in the new results set are either updated versions of previous programs or entirely new programs, while some programs in the 1995 results set are no longer supported and were therefore not applied for the new results set. Regarding improvements to the test specification, a major improvement to the BESTEST update is for surface heat transfer input equivalence. This is discussed in detail in Part IV, Appendix A, where Table 4A-4 shows up to a $28 \%$ effect on Case 600 heating load depending on selection of alternative constant coefficients for 1995 versus new values; also see the related summary paper. ${ }^{20}$ There were a number of other specification improvements, as listed in the preceding section.

The example program results from the final round of field trials that are provided with this report do not necessarily represent truth; they do represent the current state of the art in building energy simulation as established through a well-defined, repeatable process. The process is used in this report to gauge improvement in the state of the art since the thermal fabric test cases and accompanying simulation results were originally developed in 1995 . The process can also be used periodically in the future to identify further progress. 


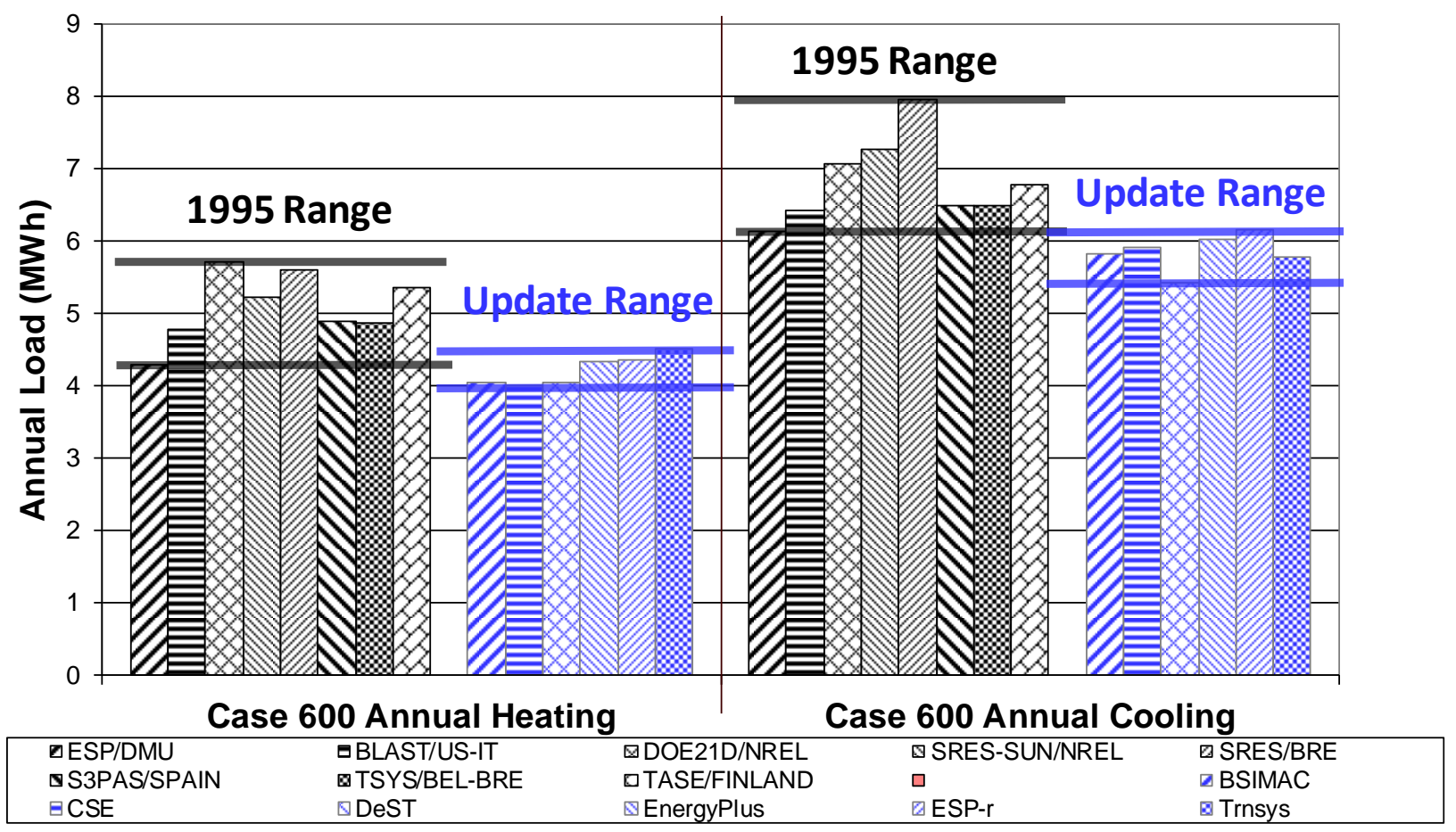

Figure ES-1: BESTEST Case 600 (Low Mass) Annual Heating and Cooling Loads, Improvement to Ranges of Differences: New Results (Blue-Pattern Bars) Versus 1995 Results (Black-Pattern Bars)

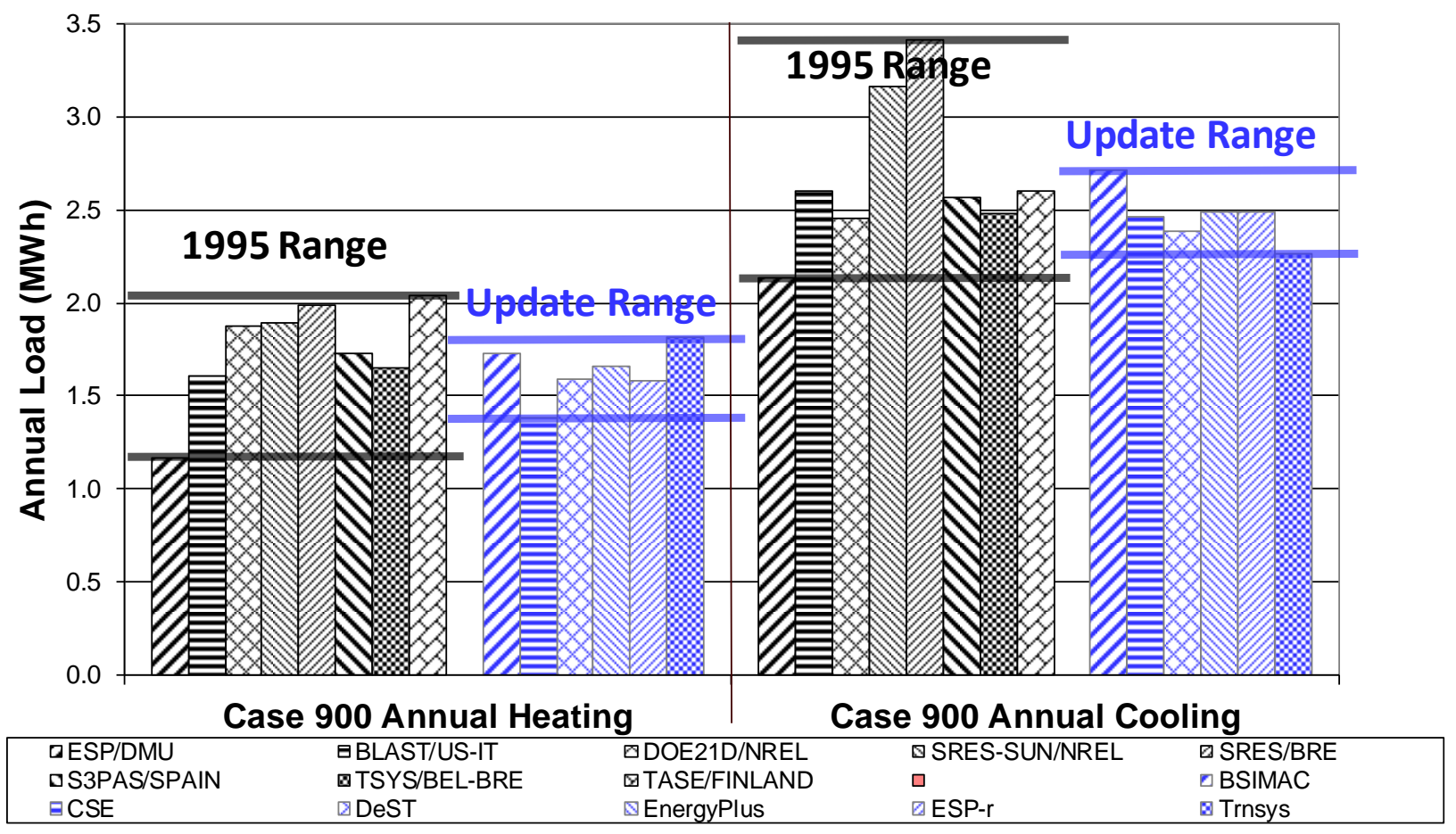

Figure ES-2: BESTEST Case 900 (High Mass) Annual Heating and Cooling Loads, Improvement to Ranges of Differences: New Results (Blue-Pattern Bars) Versus 1995 Results (Black-Pattern Bars) 
Table ES-2 Comparison of Ranges of Differences ${ }^{\mathrm{a}, \mathrm{b}}$ for New Results versus 1995 Results

\begin{tabular}{|c|c|c|c|c|c|c|c|c|}
\hline \multirow[b]{2}{*}{ Case Description } & \multicolumn{2}{|c|}{ Annual Heating } & \multicolumn{2}{|c|}{ Annual Cooling } & \multicolumn{2}{|c|}{ Peak Heating } & \multicolumn{2}{|c|}{ Peak Cooling } \\
\hline & 1995 & New & 1995 & New & 1995 & New & 1995 & New \\
\hline \multicolumn{9}{|l|}{ Low Mass } \\
\hline 600 South Windows & $28 \%$ & $12 \%$ & $26 \%$ & $13 \%$ & $24 \%$ & $11 \%$ & $13 \%$ & $18 \%$ \\
\hline 610 South Windows + Overhang & $28 \%$ & $12 \%$ & $38 \%$ & $6 \%$ & $24 \%$ & $11 \%$ & $12 \%$ & $19 \%$ \\
\hline 620 East \& West Windows & $25 \%$ & $14 \%$ & $38 \%$ & $14 \%$ & $20 \%$ & $11 \%$ & $33 \%$ & $19 \%$ \\
\hline 630 E\&W Windows + Overhang \& Fins & $25 \%$ & $16 \%$ & $54 \%$ & $18 \%$ & $17 \%$ & $11 \%$ & $29 \%$ & $18 \%$ \\
\hline 640 Case 600 with Htg Temp Setback & $32 \%$ & $11 \%$ & $27 \%$ & $12 \%$ & $28 \%$ & $14 \%$ & $14 \%$ & $18 \%$ \\
\hline 650 Case 600 with Night Ventilation & & & $30 \%$ & $17 \%$ & & & $14 \%$ & $22 \%$ \\
\hline \multicolumn{9}{|l|}{ High Mass } \\
\hline 900 South Windows & $54 \%$ & $27 \%$ & $46 \%$ & $18 \%$ & $28 \%$ & $13 \%$ & $29 \%$ & $28 \%$ \\
\hline 910 South Windows + Overhang & $37 \%$ & $27 \%$ & $78 \%$ & $22 \%$ & $28 \%$ & $13 \%$ & $53 \%$ & $27 \%$ \\
\hline 920 East \& West Windows & $26 \%$ & $20 \%$ & $51 \%$ & $20 \%$ & $20 \%$ & $14 \%$ & $38 \%$ & $25 \%$ \\
\hline $930 \mathrm{E} \& W$ Windows + Overhang \& Fins & $25 \%$ & $22 \%$ & $73 \%$ & $27 \%$ & $19 \%$ & $16 \%$ & $49 \%$ & $27 \%$ \\
\hline 940 Case 900 with Htg Temp Setback & $56 \%$ & $47 \%$ & $44 \%$ & $17 \%$ & $47 \%$ & $24 \%$ & $29 \%$ & $28 \%$ \\
\hline 950 Case 900 with Night Ventilation & & & $82 \%$ & $19 \%$ & & & $44 \%$ & $15 \%$ \\
\hline
\end{tabular}

${ }^{a}$ Smaller \%-range of difference indicates better agreement.

${ }^{\mathrm{b}}$ Results for NewHASP are excluded for reasons discussed in Part II, Section 2.2.1.

\section{Major Accomplishments}

The major accomplishments of this project were as follows:

- Update of the BESTEST procedures of Standard 140-2017, ${ }^{1}$ Sections 5.2.1, 5.2.2, and 5.2.3, which were developed before $1995^{2}$ and were the basis of the initial version of Standard 140 $(140-2001) .^{15}$

- This update reflects improvements to the modeling state of the art since the early $1990 \mathrm{~s}$ and addresses ambiguities in the test specification identified since 1995.

- Development of test specifications with improved clarity, and such that a variety of state-of-theart building simulation programs with a variety of input structures and modeling approaches can perform the tests.

- Improvement of, or identification of potential improvements for, all of the programs that participated in the simulation trials of the test cases.

- Development of a set of national and international field-trial example simulation results representative of the range of legitimate modeling differences for the current state of the art in whole-building energy simulation computer programs.

- Substantial improvement of ranges of differences (narrower range implying better agreement) for example results versus the previous set of example results for the 1995 test specification.

- Development of the test suite update such that it is suitable for easy adaptation for inclusion in Standard 140.

\section{Findings}

A number of important technology advances occurred as a result of running the test cases:

- The test suite improvements allowed diagnosis of errors and identification of potential areas for improvement that may have been missed with the previous version of the test suite.

- Of 30 identified program errors or potential improvements, 25 of those were diagnosed and fixed. Several of the identified errors affected some individual results by $>20 \%$. 
- Additionally, 61 sets of input errors and 16 sets of output reporting errors were found and corrected. These errors provided the basis for revealing a number of test specification ambiguities that were clarified as the simulation trials progressed, and underscore the importance of iterative simulation trials in vetting the test specifications before they are included in a standard method of test.

- Based on this work, there are a number of recommended areas for further investigation with respect to developing additional validation test cases for building thermal fabric modeling. These areas are described in Section 3.5.2.

The above findings show how the test procedure is used to diagnose and correct or improve algorithms in complex simulation programs. Diagnosis is enhanced by improvements to the test specification since 1995. Based on results after several simulation trial iterations and resulting model improvements, all but one of the tested programs (NewHASP) appear reliable for modeling the tested building thermal fabric physics under the conditions examined and for inclusion with the Standard 140 updated example results. This topic is further discussed in Part II, Section 2.2.1 and Part III, Section 3.6.1.2.

\section{Closing Remarks}

The work presented in this report and the work that has preceded it are important for two reasons:

- The methods have been successful at correcting software errors in advanced building energy simulation programs throughout the world.

- The methods are finding their way into industry by being adopted as the theoretical basis for formalized standard methods of test and software certification procedures; in this sense, the work may be thought of as pre-normative research.

ASHRAE Standard $140,{ }^{1}$ and the BESTEST reports that comprise the test suites contained therein, are being referenced and used worldwide by a growing number of code promulgation authorities. ASHRAE Standard 90.1, ${ }^{21}$ which is ASHRAE's consensus energy standard for commercial buildings and for nonlow-rise residential buildings, requires that software used for demonstrating performance compliance with Standard 90.1 be tested using the Class I test procedures of ASHRAE Standard 140-2014. ${ }^{19}$ Software used for calculating energy savings for purposes of the energy-efficient commercial building tax deductions in the United States ${ }^{22,23}$ must be tested with Standard 140-2014. ${ }^{19}$ As part of their building energy performance assessments under the European Community's Energy Performance of Buildings Directive ${ }^{24}$ several countries are using software tools that have been checked with BESTEST. Further details of international use of BESTEST, along with growing evidence that the BESTEST procedures are becoming part of software developers' normal in-house quality control efforts, are included elsewhere. ${ }^{11,25,26}$

The current set of BESTEST/Standard 140 test suites emphasize isolating the ability to perform specific modeling physics addressed in the tests. As standard methods of test, the BESTEST procedures provide test specifications including input and output requirements, along with vetted example results from iterative simulation trials. The outputs provide metrics for comparison of programs. The vetted example results, along with the diagnostic logic of the test cases, provide a means of diagnosing the sources of identifiable disagreements with the example results. Although the BESTEST procedures provide vetted example results, the procedures do not provide pass/fail or other qualification criteria. ${ }^{27}$ This is analogous, for example, to applying procedures to determine the efficiencies of HVAC equipment (e.g., Annual Fuel Utilization Efficiency [AFUE] for a gas-fired furnace), where a procedure exists that provides instructions on how to determine a metric or set of metrics, but it is up to a separate standard or authority-havingjurisdiction to set compliance requirements (e.g., minimum AFUE). Therefore, based solely on running the BESTEST cases - and independent of the requirements of other standards or authorities-having- 
jurisdiction - it is not appropriate to extrapolate (or otherwise claim) that a program has "passed" BESTEST or been validated in its entirety.

Computer scientists universally accept the merits of software testing. A well-known rule of thumb is that in a typical programming project, more than $50 \%$ of the total cost is expended in testing the program or system being developed. ${ }^{28}$ Of this, about $20 \%$ of development time goes toward system testing. ${ }^{29}$ Because new energy-related technologies are continually being introduced into the buildings market, there will always be a need for further development of simulation models, combined with a substantial program of testing and validation. Such an effort should contain all the elements of an overall validation methodology, ${ }^{9,10,11}$ including:

- Analytical verification

- Comparative testing and diagnostics

- Empirical validation.

Future work should therefore continue to:

- Produce analytical verification tests where possible

- Develop a set of diagnostic comparative tests that emphasize the modeling issues important in large commercial buildings, including more tests for heating, ventilating, and air-conditioning systems and other mechanical equipment, including on-site power generation equipment

- Develop a sequentially ordered series of high-quality diagnostic data sets for empirical validation.

The work described here represents continuing progress in the effort to develop carefully validated building energy simulation tools. Continued development and validation of whole-building energy simulation programs are two of the most important activities meriting the support of national energy research programs and are a beneficial area for international collaboration. The DOE should continue its support of this essential research area.

Finally, the authors wish to acknowledge that the expertise available through ASHRAE SSPC 140 and other international participants, and their dedication to the simulation trials, were essential to the success of this project. Over the five-year field-trial effort, there were several revisions to the test specifications and subsequent re-executions of the computer simulations. This iterative process led to the refining of the new BESTEST cases, and the results of the tests led to improving and debugging of the simulation models. This process underscores the importance of the software development industry participation in this project via the ASHRAE Standard 140 project committee (SSPC 140), and via our previous collaborations with International Energy Agency software testing and validation projects. Extensive field trials, and resulting enhancements to the tests, were much more comprehensive and cost effective with the participation of the national and international software-development industry experts. Their persistence throughout the project demonstrates their interest in, and the importance of, this work.

\title{
References for Executive Summary
}

\author{
${ }^{1}$ ANSI/ASHRAE Standard 140-2017 (2017). Standard Method of Test for the Evaluation of Building \\ Energy Analysis Computer Programs. Atlanta, Georgia, U.S.A.: American Society of Heating, \\ Refrigerating and Air-Conditioning Engineers. \\ ${ }^{2}$ Judkoff, R.; Neymark, J. (1995a). International Energy Agency Building Energy Simulation Test \\ (IEA BESTEST) and Diagnostic Method. NREL/TP-472-6231. Golden, Colorado, U.S.A.: National \\ Renewable Energy Laboratory. http://www.nrel.gov/docs/legosti/old/6231.pdf (PDF 13.8 MB).
}


${ }^{3}$ Judkoff, R.; Neymark, J. (1995b). Home Energy Rating System Building Energy Simulation Test (HERS BESTEST). NREL/TP-472-7332. Golden, Colorado, U.S.A.: National Renewable Energy Laboratory.

Volume 1: Tier 1 and Tier 2 Tests User's Manual, NREL/TP-472-7332a, http://www.nrel.gov/docs/legosti/fy96/7332a.pdf (PDF 5.6 MB);

Volume 2: Tier 1 and Tier 2 Tests Reference Results, NREL/TP-472-7332b, http://www.nrel.gov/docs/legosti/fy96/7332b.pdf (PDF 1.9 MB).

${ }^{4}$ Purdy, J.; Beausoleil-Morrison, I. (2003). Building Energy Simulation Test and Diagnostic Method for Heating, Ventilation, and Air-Conditioning Equipment Models (HVAC BESTEST): Fuel-Fired Furnace Test Cases. Ottawa, Ontario, Canada: CANMET Energy Technology Centre, Natural Resources Canada. www.iea-shc.org/task22/deliverables.htm.

${ }^{5}$ Neymark J.; Judkoff, R. (2002). International Energy Agency Building Energy Simulation Test and Diagnostic Method for Heating, Ventilating, and Air-Conditioning Equipment Models (HVAC BESTEST), Volume 1: Cases E100-E200. NREL/TP-550-30152. Golden, Colorado, U.S.A.: National Renewable Energy Laboratory. http://www.nrel.gov/docs/fy02osti/30152.pdf.

${ }^{6}$ Neymark, J.; Judkoff, R. (2004). International Energy Agency Building Energy Simulation Test and Diagnostic Method for Heating, Ventilating, and Air-Conditioning Equipment Models (HVAC BESTEST), Volume 2: Cases E300-E545. NREL/TP-550-36754. Golden, Colorado, U.S.A.: National Renewable Energy Laboratory. www.nrel.gov/docs/fy05osti/36754.pdf.

${ }^{7}$ Neymark, J.; Judkoff, R.; with Beausoleil-Morrison, I; Ben-Nakhi, A.; Crowley, M.; Deru, M.; Henninger, R.; Ribberink, H.; Thornton, J.; Wijsman, A.; Witte, M. (2008a). International Energy Agency Building Energy Simulation Test and Diagnostic Method (IEA BESTEST) In-Depth Diagnostic Cases for Ground Coupled Heat Transfer Related to Slab-On-Grade Construction. NREL/TP-550-43388. Golden, Colorado, U.S.A.: National Renewable Energy Laboratory.

${ }^{8}$ Neymark, J.; Kennedy, M.; Judkoff, R.; Gall, J.; Henninger, R.; Hong, T.; Knebel, D.; McDowell, T.; Witte, M.; Yan, D.; Zhou, X. (2016). Airside HVAC BESTEST: Adaptation of ASHRAE RP 865 Airside HVAC Equipment Modeling Test Cases for ASHRAE Standard 140, Volume 1: Cases AE101 - AE445. NREL/TP-5500-66000. Golden, Colorado, U.S.A.: National Renewable Energy Laboratory. www.nrel.gov/docs/fy16osti/66000.pdf.

${ }^{9}$ ASHRAE. (2017). 2017 Handbook of Fundamentals, Atlanta, Georgia, U.S.A.: American Society of Heating, Refrigerating and Air-Conditioning Engineers. See Chapter 19.

${ }^{10}$ ANSI/ASHRAE Standard 140-2017. (2017). Standard Method of Test for the Evaluation of Building Energy Analysis Computer Programs. Atlanta, Georgia, U.S.A.: American Society of Heating, Refrigerating and Air-Conditioning Engineers. See Annex B23.

${ }^{11}$ Judkoff, R.; Neymark, J. (2006). "Model Validation and Testing: The Methodological Foundation of ASHRAE Standard 140.” ASHRAE Transactions, 112 (2) 367-376. Atlanta, Georgia, U.S.A.: American Society of Heating, Refrigerating and Air-Conditioning Engineers.

${ }^{12}$ Judkoff, R. (1988). "Validation of Building Energy Analysis Simulation Programs at the Solar Energy Research Institute." Energy and Buildings, Vol. 10, No. 3, p. 235. Lausanne, Switzerland: Elsevier Sequoia.

${ }^{13}$ Judkoff, R.; Neymark, J. (2009). "What Did They Do in IEA 34/43? Or How to Diagnose and Repair Bugs in 500,000 Lines of Code." Proceedings of Building Simulation 2009. Glasgow, United 
Kingdom: International Building Performance Simulation Association. Preprint version, NREL Report CP-550-44978. Golden, Colorado, U.S.A.: National Renewable Energy Laboratory. http://www.nrel.gov/docs/fy09osti/44978.pdf.

${ }^{14}$ Judkoff, R.; Wortman, D.; O’Doherty, B.; Burch, J. (2008). A Methodology for Validating Building Energy Analysis Simulations. NREL/TP-550-42059. Golden, Colorado, U.S.A.: National Renewable Energy Laboratory. This is a formal publication of work that was brought to final draft in 1983 and referenced in a number of documents as SERI/TR-254-1508. The two reports are identical except for a few minor edits to complete the previous draft.

${ }^{15}$ ANSI/ASHRAE Standard 140-2001 (2001). Standard Method of Test for the Evaluation of Building Energy Analysis Computer Programs. Atlanta, Georgia, U.S.A.: American Society of Heating, Refrigerating and Air-Conditioning Engineers.

${ }^{16}$ ANSI/ASHRAE Standard 140-2004 (2004). Standard Method of Test for the Evaluation of Building Energy Analysis Computer Programs. Atlanta, Georgia, U.S.A.: American Society of Heating, Refrigerating and Air-Conditioning Engineers.

${ }^{17}$ ANSI/ASHRAE Standard 140-2007 (2007). Standard Method of Test for the Evaluation of Building Energy Analysis Computer Programs. Atlanta, Georgia, U.S.A.: American Society of Heating, Refrigerating and Air-Conditioning Engineers.

${ }^{18}$ ANSI/ASHRAE Standard 140-2011 (2011). Standard Method of Test for the Evaluation of Building Energy Analysis Computer Programs. Atlanta, Georgia, U.S.A.: American Society of Heating, Refrigerating and Air-Conditioning Engineers.

${ }^{19}$ ANSI/ASHRAE Standard 140-2014 (2014). Standard Method of Test for the Evaluation of Building Energy Analysis Computer Programs. Atlanta, Georgia, U.S.A.: American Society of Heating, Refrigerating and Air-Conditioning Engineers.

${ }^{20}$ Neymark, J., Kummert, M., and Judkoff, R. (2019). "Developing Equivalent Surface Heat Transfer Input Parameters for Updated Standard 140/BESTEST Thermal Fabric Test Cases." Proceedings of Building Simulation 2019. Rome, Italy. Sept. 2-4, 2019. International Building Performance Simulation Association.

${ }^{21}$ ANSI/ASHRAE/IESNA (2016). ANSI/ASHRAE/IESNA Standard 90.1-2016, Energy Standard for Buildings Except Low-Rise Residential Buildings. Atlanta, Georgia, U.S.A.: American Society of Heating, Refrigerating and Air-Conditioning Engineers.

${ }^{22}$ Internal Revenue Service (IRS) (2008). Amplification of Notice 2006-52, Deduction for Energy Efficient Commercial Buildings. IRS Notice 2008-40. Appears in Internal Revenue Bulletin (IRB) No. 2008-14, April 7, 2008. Washington, D.C., U.S.A.: United States Department of Treasury, Internal Revenue Service.

${ }^{23}$ U.S. DOE (2019). Qualified Software for Calculating Commercial Building Tax Deductions. Washington, D.C.: U.S. Department of Energy, Office of Energy Efficiency and Renewable Energy, Building Technologies Program. http://energy.gov/eere/buildings/qualified-software-calculatingcommercial-building-tax-deductions. Last accessed Aug. 11, 2019.

${ }^{24}$ European Union (2018). Directive (EU) 2018/844 of the European Parliament and of the Council of 30 May 2018 amending Directive 2010/31/EU on the energy performance of buildings and Directive 2012/27/EU on energy efficiency. Official Journal of the European Union, L 156/75, June 2018. 
https://eur-lex.europa.eu/legal-

content/EN/TXT/?toc=OJ\%3AL\%3A2018\%3A156\%3ATOC\&uri=uriserv\%3AOJ.L . 2018.156.01.0

075.01.ENG

${ }^{25}$ Judkoff, R.; Neymark, J. (2013). "Twenty Years On!: Updating the IEA BESTEST Building Thermal Fabric Test Cases for ASHRAE Standard 140." Proceedings of Building Simulation 2013. Chambéry, France. International Building Performance Simulation Association. Preprint version, NREL Report CP-5500-58487. Golden, Colorado, U.S.A.: National Renewable Energy Laboratory. http://www.nrel.gov/docs/fy13osti/58487.pdf .

${ }^{26}$ Neymark, J.; Judkoff, R.; with Beausoleil-Morrison, I; Ben-Nakhi, A.; Crowley, M.; Deru, M.; Henninger, R.; Ribberink, H.; Thornton, J.; Wijsman, A.; Witte, M. (2008a). International Energy Agency Building Energy Simulation Test and Diagnostic Method (IEA BESTEST) In-Depth Diagnostic Cases for Ground Coupled Heat Transfer Related to Slab-On-Grade Construction. NREL/TP-550-43388. Golden, Colorado, U.S.A.: National Renewable Energy Laboratory. See Section 2.6.2.2.

${ }^{27}$ ANSI/ASHRAE Standard 140-2017 (2017). Standard Method of Test for the Evaluation of Building Energy Analysis Computer Programs. Atlanta, Georgia, U.S.A.: American Society of Heating, Refrigerating and Air-Conditioning Engineers. See Section 4.4.1.

${ }^{28}$ Myers, G. (2004). The Art of Software Testing. Hoboken, New Jersey, U.S.A.: John Wiley \& Sons. See p. xiii.

${ }^{29}$ McConnell, S. (2004). Code Complete: A Practical Handbook of Software Construction. Microsoft Press, p. 502. 


\section{Introduction}

The Building Energy Simulation Test and Diagnostic Method (BESTEST) procedure for testing the ability of whole-building energy simulation software to model the building thermal fabric was originally published in 1995 (Judkoff and Neymark 1995a). This test suite was adapted for the initial version of American Society of Heating, Refrigerating, and Air-Conditioning Engineers (ASHRAE) Standard 140, Standard Method of Test for the Evaluation of Building Energy Analysis Computer Programs (ANSI/ASHRAE 2001) and has remained in all revisions of the standard through the current version as of this writing (ANSI/ASHRAE 2017). The state of the art in building energy simulation modeling has advanced since 1995. Additionally, comments on the test specification over the years highlighted ambiguities, further necessitating the update to the original work.

This report documents updates to the original building thermal fabric test suite by Argonne National Laboratory (Argonne) and National Renewable Energy Laboratory (NREL), in collaboration with the ASHRAE Standing Standard Project Committee 140 (SSPC 140). SSPC 140 is the committee responsible for ASHRAE Standard 140.

This project built on the initial version of the building thermal fabric BESTEST suite, with the intent to include the updated test cases in a future version of ASHRAE Standard 140. The original test suite provided the starting point for the test specifications. From this starting point, there was substantial effort to improve and field-test an updated test specification intended for continuing use by most state-of-the-art whole building energy software and suitable for Standard 140. The specification improvements addressed ambiguities discovered since the original field-trials before 1995 and included additional test cases and diagnostic outputs. J. Neymark \& Associates, under contracts with Argonne and NREL, led the collaborative effort to a) extensively revise and update the test specifications such that they would be unambiguous for the input structures of most whole-building energy simulation programs with time steps of one hour or less, and b) field-test the specifications with a variety of different simulation programs and associated software development groups around the world, to ensure their suitability as a standard method of test that can be integrated into ASHRAE Standard 140. The collaboration included a number of software developer members of SSPC 140 along with other international software developers and participants; see Executive Summary, Table ES-1 or Part II, Table 2-1.

\section{Advantages of BESTEST Methodology}

The BESTEST methodology for testing building energy simulation programs is described in the literature (ANSI/ASHRAE 2017, Informative Annex B23; ASHRAE 2017; Judkoff and Neymark 2006). The methodology describes an overall means for applying software-to-software comparative tests (comparing programs to each other), analytical verification tests (comparison of software to analytical solutions), and empirical validation tests (comparison of software to empirical data). In all these types of tests, the methodology emphasizes varying input parameters individually or in related small groups to enhance diagnostic capability.

An advantage of the BESTEST methodology is that a program is examined over a broad range of parametric interactions based on a variety of output types, minimizing the possibility of concealing problems by compensating errors. Performance of the tests resulted in quality improvements, or identification of potential improvements, to all of the building energy simulation models used in the field trials. Some of the bugs that were found may well have been present for many years. The fact that they have just now been uncovered shows the power of BESTEST and suggests the importance of continuing to develop formalized validation and diagnostic methods. This fact also underscores the need to update existing test suites periodically — as we have done here - as the modeling state of the art improves. Only after coding bugs and input ambiguities have been eliminated can the assumptions and approximations in the algorithms be evaluated. 
Checking a building energy simulation program for the first time with the thermal fabric test cases requires approximately one week for an experienced user, not including improvements to the software, if necessary. Subsequent program checks are faster because input files may be reused. Because the simulation programs have taken many years to produce, the updated BESTEST cases provide a costeffective way of testing them. As we continue to develop new test cases, we will adhere to the principle of parsimony so that the entire suite of BESTEST cases may be implemented by users with a reasonable time commitment. Many software developers have automated the tests, further reducing the time to rerun them as an internal quality control check after code modifications.

Software developers, architects, engineers, and researchers can use these new BESTEST cases in a number of ways, including the following:

- Comparing predictions from building energy simulation programs to the simulation results in this report, which, with the exception of one program, represent a reasonable range of differences for the current state of the art in simulation modeling.

- Comparing several building energy simulation programs to determine the degree of disagreement among them.

- Diagnosing the algorithmic sources of prediction differences.

- Checking a program against a previous version of itself after the internal code has been modified, to ensure that only the intended changes actually resulted.

- Checking a program against itself after a single algorithmic change to understand the sensitivity between algorithms.

- Providing a set of procedures to evaluate acceptability of software. Examples of referencing Standard 140 as of the date of publication of this report include IRS 179d; RESNET; ASHRAE 90.1, 90.2, 189.1; IECC; Florida Building Commission; European Energy Performance of Buildings Directive; and others. (IRS 2008; U.S. DOE 2019; RESNET 2013, 2019; ANSI/ASHRAE/IESNA 2016; ANSI/ASHRAE 2018; ANSI/ASHRAE/ICC/USGBC/IES 2017; ICC 2017; ICC 2018; European Union 2018.).

The current set of BESTEST/Standard 140 test suites emphasize isolating the ability to perform specific modeling physics addressed in the tests. As standard methods of test, the BESTEST procedures provide test specifications including input and output requirements, along with vetted example results from iterative simulation trials. The outputs provide metrics for comparison of programs. The vetted example results, along with the diagnostic logic of the test cases, provide a means of diagnosing the sources of identifiable disagreements with the example results. Although the BESTEST procedures provide vetted example results, the procedures do not provide pass/fail or other qualification criteria as discussed in Section 4.4.1 of Standard 140 (ANSI/ASHRAE 2017). This is analogous, for example, to applying procedures to determine the efficiencies of HVAC equipment (e.g., Annual Fuel Utilization Efficiency [AFUE] for a gas-fired furnace), where a procedure exists that provides instructions on how to determine a metric or set of metrics, but it is up to a separate standard or authority-having-jurisdiction (e.g., see last bullet of above paragraph) to set compliance requirements (e.g., minimum AFUE). Therefore, based solely on running the BESTEST cases - and independent of the requirements of other standards or authorities-having-jurisdiction - it is not appropriate to extrapolate (or otherwise claim) that a program has "passed" BESTEST or been validated in its entirety. 


\section{Other BESTEST Procedures}

As a BESTEST user, if you have not already tested your software with previously developed BESTEST procedures, we strongly recommend that you run all the building thermal fabric and mechanical equipment modeling cases currently included in ANSI/ASHRAE Standard 140-2017 (ANSI/ASHRAE 2017):

- Class I tests (detailed diagnostic tests for simulation software capable of hourly or sub-hourly simulation time steps)

○ International Energy Agency (IEA) BESTEST, building thermal fabric comparative tests (Judkoff and Neymark 1995a)

- IEA BESTEST, in-depth diagnostic ground-coupled slab-on-grade heat transfer analytical verification tests (Neymark et al. 2008a)

- HVAC BESTEST Volume 1, unitary cooling equipment analytical verification tests (Neymark and Judkoff 2002)

- HVAC BESTEST Volume 2, unitary cooling equipment comparative tests (Neymark and Judkoff 2004)

- HVAC BESTEST Fuel-Fired Furnace analytical verification and comparative tests (Purdy and Beausoleil-Morrison 2003)

- Airside HVAC BESTEST Volume 1, HVAC air-distribution system analytical verification tests (Neymark et al. 2016)

- Class II tests (for all types of building load calculation methods regardless of time-step granularity)

○ Home Energy Rating Systems (HERS) BESTEST, building thermal fabric comparative tests (Judkoff and Neymark 1995b). These test cases have a more realistic base building than the Class I building thermal fabric test cases; however, their ability to diagnose sources of differences among results is not as robust (Neymark and Judkoff 1997).

Other BESTEST procedures that we recommend include the following:

- IEA BESTEST multi-zone non-airflow in-depth diagnostic cases (Neymark et al. 2008b). These test cases are currently under consideration for inclusion in Standard 140.

- BESTEST-EX thermal fabric test cases for existing homes (Judkoff et al. 2010, 2011). These include building physics tests, some of which update HERS BESTEST and calibration tests included as a Residential Energy Services Network (RESNET) Standard Method of Test (ANSI/RESNET 2016; Judkoff et al. 2016).

\section{Report Structure}

This report is divided into four parts. Part I is a user's manual that furnishes instructions on how to apply this BESTEST procedure. Part II presents the simulation program example results in tables and graphs; these data can be used to compare results from other programs to the Part II results. Part III describes the development, field testing, and production of simulation results data for the procedure, along with conclusions regarding improvements to the test suite and recommendations for further work. Part IV provides additional supporting material for the Part I user's manual.

\section{References for Introduction}

ANSI/ASHRAE (2001). ANSI/ASHRAE Standard 140-2001. Standard Method of Test for the Evaluation of Building Energy Analysis Computer Programs. Atlanta, Georgia, U.S.A.: American Society of Heating, Refrigerating and Air-Conditioning Engineers. 
ANSI/ASHRAE (2017). ANSI/ASHRAE Standard 140-2017. Standard Method of Test for the Evaluation of Building Energy Analysis Computer Programs. Atlanta, Georgia, U.S.A.: American Society of Heating, Refrigerating and Air-Conditioning Engineers.

ANSI/ASHRAE (2018). ANSI/ASHRAE Standard 90.2-2018. Energy-Efficient Design of Low-Rise Residential Buildings. Atlanta, Georgia, U.S.A.: American Society of Heating, Refrigerating, and AirConditioning Engineers, Inc.

ANSI/ASHRAE/ICC/USGBC/IES (2017). Standard for the Design of High-Performance Green Buildings Except Low-Rise Residential Buildings. Atlanta, Georgia, U.S.A.: American Society of Heating, Refrigerating, and Air-Conditioning Engineers, Inc.

ANSI/ASHRAE/IESNA (2016). ANSI/ASHRAE/IESNA Standard 90.1-2016, Energy Standard for Buildings Except Low-Rise Residential Buildings. Atlanta, Georgia, U.S.A.: American Society of Heating, Refrigerating and Air-Conditioning Engineers.

ANSI/RESNET (2016). ANSI/RESNET Standard 1201-2016. Standard Method of Test for the Evaluation of Building Energy Analysis Model Calibration Methods. Oceanside, California, U.S.A.: Residential Energy Services Network.

ASHRAE (2017). Handbook of Fundamentals. Atlanta, Georgia, U.S.A.: American Society of Heating, Refrigerating, and Air-Conditioning Engineers, Inc. See Chapter 19.

European Union (2018). Directive (EU) 2018/844 of the European Parliament and of the Council of 30 May 2018 amending Directive 2010/31/EU on the energy performance of buildings and Directive 2012/27/EU on energy efficiency. Official Journal of the European Union, L 156/75, June 2018. https://eur-lex.europa.eu/legalcontent/EN/TXT/?toc=OJ\%3AL\%3A2018\%3A156\%3ATOC\&uri=uriserv\%3AOJ.L_.2018.156.01.0075. $\underline{01 . E N G}$

ICC (2017). 2017 Florida Building Code - Energy Conservation. $6^{\text {th }}$ Edition. Country Club Hills, Illinois, U.S.A.: International Code Council.

ICC (2018). 2018 International Energy Conservation Code (IECC). Country Club Hills, Illinois, U.S.A.: International Code Council.

IRS (2008). Amplification of Notice 2006-52, Deduction for Energy Efficient Commercial Buildings. IRS Notice 2008-40. Appears in Internal Revenue Bulletin (IRB) No. 2008-14, April 7, 2008. Washington, D.C., U.S.A.: United States Department of Treasury, Internal Revenue Service.

Judkoff, R.; Neymark, J. (1995a). International Energy Agency Building Energy Simulation Test (BESTEST) and Diagnostic Method. Golden, Colorado, U.S.A.: National Renewable Energy Laboratory, NREL/TP-472-6231, www.nrel.gov/docs/legosti/old/6231.pdf.

Judkoff, R.; Neymark, J. (1995b). Home Energy Rating System Building Energy Simulation Test (HERS BESTEST). Golden, Colorado, U.S.A.: National Renewable Energy Laboratory, NREL/TP-472-7332.

Volume 1: Tier 1 and Tier 2 Tests User's Manual, NREL/TP-472-7332a, www.nrel.gov/docs/legosti/fy96/7332a.pdf;

Volume 2: Tier 1 and Tier 2 Tests Reference Results, NREL/TP-472-7332b, www.nrel.gov/docs/legosti/fy96/7332b.pdf. 
Judkoff, R.; Neymark, J. (2006). "Model Validation and Testing: The Methodological Foundation of ASHRAE Standard 140." ASHRAE Transactions, 112 (2) 367-376. Atlanta, Georgia, U.S.A.: American Society of Heating, Refrigerating and Air-Conditioning Engineers.

www.nrel.gov/docs/fy06osti/40360.pdf.

Judkoff, R.; Polly, B.; Bianchi, M.; Neymark, J. (2010). Building Energy Simulation Test for Existing Homes (BESTEST-EX). NREL/CP-550-47427. Golden, Colorado, U.S.A.: National Renewable Energy Laboratory. www.nrel.gov/docs/fy10osti/47427.pdf.

Judkoff, R.; Polly, B.; Bianchi, M.; Neymark, J; Kennedy, M. (2011). Building Energy Simulation Test for Existing Homes (BESTEST-EX): Instructions for Implementing the Test Procedure, Calibration Test Reference Results, and Example Acceptance-Range Criteria. NREL/TP-5500-52414. Golden, Colorado, U.S.A.: National Renewable Energy Laboratory. www.nrel.gov/docs/fy11osti/52414.pdf.

Judkoff, R.; Polly, B.; Neymark, J. (2016). “A Method to Test Model Calibration Techniques.” Proc. 2016 ACEEE Summer Study on Energy Efficiency in Buildings. August 21-26, 2016, Pacific Grove, California. Washington, D.C.: American Council for an Energy-Efficient Economy. Also available as NREL preprint NREL/CP-5500-65981. Golden, Colorado, U.S.A.: National Renewable Energy Laboratory.

Neymark, J.; Judkoff, R. (1997). "A Comparative Validation Based Certification Test for Home Energy Rating System Software.” Proc. Building Simulation '97. September 8-10, Prague, Czech Republic. International Building Performance Simulation Association.

Neymark J.; Judkoff, R. (2002). International Energy Agency Building Energy Simulation Test and Diagnostic Method for Heating Ventilating and Air-Conditioning Equipment Models (HVAC BESTEST), Volume 1: Cases E100-E200. NREL/TP-550-30152. Golden, Colorado, U.S.A.: National Renewable Energy Laboratory. www.nrel.gov/docs/fy02osti/30152.pdf.

Neymark, J.; Judkoff, R. (2004). International Energy Agency Building Energy Simulation Test and Diagnostic Method for Heating, Ventilating, and Air-Conditioning Equipment Models (HVAC BESTEST), Vol. 2: Cases E300-E545. NREL/TP-550-36754. Golden, Colorado, U.S.A.: National Renewable Energy Laboratory. www.nrel.gov/docs/fy05osti/36754.pdf.

Neymark, J.; Judkoff, R.; Alexander, D.; Felsmann, C.; Strachan, P.; Wijsman, A. (2008b.) International Energy Agency Building Energy Simulation Test and Diagnostic Method (IEA BESTEST) Multi-Zone Non-Airflow In-Depth Diagnostic Cases: MZ320 - MZ360. NREL/TP-550-43827. Golden, Colorado, U.SA.: National Renewable Energy Laboratory. www.nrel.gov/docs/fy08osti/43827.pdf.

Neymark, J.; Judkoff, R.; Beausoleil-Morrison, I.; Ben-Nakhi, A.; Crowley, M.; Deru, M.; Henninger, R.; Ribberink, H.; Thornton, J.; Wijsman, A.; Witte, M. (2008a.) International Energy Agency Building Energy Simulation Test and Diagnostic Method (IEA BESTEST) In-Depth Diagnostic Cases for Ground Coupled Heat Transfer Related to Slab-on-Grade Construction, NREL/TP-550-43388. Golden, Colorado, U.S.A.: National Renewable Energy Laboratory. www.nrel.gov/docs/fy08osti/43388.pdf.

Neymark, J.; Kennedy, M.; Judkoff, R.; Gall, J.; Henninger, R.; Hong, T.; Knebel, D.; McDowell, T.; Witte, M.; Yan, D.; Zhou, X. (2016). Airside HVAC BESTEST: Adaptation of ASHRAE RP 865 Airside HVAC Equipment Modeling Test Cases for ASHRAE Standard 140, Volume 1: Cases AE101 - AE445. NREL/TP-5500-66000. Golden, Colorado, U.S.A.: National Renewable Energy Laboratory. www.nrel.gov/docs/fy16osti/66000.pdf. 
Purdy, J.; Beausoleil-Morrison, I. (2003). Building Energy Simulation Test and Diagnostic Method for Heating, Ventilating, and Air-Conditioning Equipment Models (HVAC BESTEST): Fuel-Fired Furnace Test Cases. Ottawa, Canada: Natural Resources Canada, CANMET Energy Technology Centre. www.ieashc.org/task22/deliverables.htm.

RESNET (2013). Mortgage Industry National Home Energy Rating System Standards. Oceanside, CA: RESNET.

RESNET (2019). RESNET Accredited Rating Software Tools. Oceanside, CA: RESNET. http://www.resnet.us/professional/programs/software.

U.S. DOE (2019). Qualified Software for Calculating Commercial Building Tax Deductions. Washington, D.C.: U.S. Department of Energy, Office of Energy Efficiency and Renewable Energy, Building Technologies Program. http://energy.gov/eere/buildings/qualified-software-calculating-commercialbuilding-tax-deductions. Last accessed Aug. 11, 2019. 


\section{Part I: User's Manual: Procedure and Test Specification}

[Note: Material in Part I, beginning with Section 3.2, includes both original material and existing material from ANSI/ASHRAE Standard 140-2017. Where existing Standard-140 material is used, it is @ASHRAE, www.ashrae.org. and is used in this report with permission from Standard 140-2017-Standard Method of Test for the Evaluation of Building Energy Analysis Computer Programs.]

\section{Introduction}

1.1 General Description of the Test Cases. Fifty-two test cases are summarized in Annex B1, Tables B1-2 and B13. Test case specifications and supporting material follow in the remainder of Part I. Example simulation results that were developed during field-trials of the test specification are provided in Part II.

1.2 Accompanying Electronic Files Required for Running the Test Cases. The following files included within the accompanying electronic media are required for running the test cases described in Part I.

- 725650TY.CSV: Typical Meteorological Year 3 (TMY3) format weather data file for Denver International Airport, Denver, Colorado, United States. A summary of site weather data parameters is provided in Annex A1, Section A1.1.1, Table A1-1.

- Sec5-2Aout.xlsx: output report template.

Accompanying files that support other parts of this report are described in the Electronic Media Contents listed with the front matter Table of Contents.

1.3 Modeler Reports. The ASHRAE SSPC 140 simulation-trial working group participants submitted modeler reports along with their simulation results (see Part III, Section 3.9). Users developing modeler reports may consider using the structure of any of those modeler reports as a template.

1.4 Comparing Tested Program Output to Example Simulation Results. An electronic version of the example results is provided in the accompanying file Results5-2A-Update.xlsx as described in Part II (within the accompanying files, see subfolder "Informative Materials"). For the convenience of users who wish to plot or tabulate their results along with these example results, instructions are provided in the "Read me" sheet (leftmost tab) of the file.

1.4.1 Criteria for Determining Agreement between Results. There are no formal criteria for when results agree or disagree. Determination of when results agree or disagree is left to the user. In making this determination, the user should consider the following:

- Magnitude of results for individual cases;

- Magnitude of difference in results between certain cases (e.g., Case 610 - Case 600);

- Same direction of sensitivity (positive or negative) for difference in results between certain cases (e.g., Case 610 - Case 600);

- Whether results are logically counterintuitive with respect to known or expected physical behavior; and

- Example simulation results do not represent a truth standard.

For any given case, a tested program may fall outside the range of example results without necessarily being incorrect. However, it is worthwhile to investigate the source of significant differences, as the collective experience of the authors is that such differences often indicate problems with the software or its use, including, but not limited to, the following:

- User input error, where the user misinterpreted or incorrectly entered one or more program inputs;

- A problem with a particular algorithm in the program or its documentation; and

- One or more program algorithms used outside their intended range.

Also, for any given case, a program that yields values in the middle of the range established by the example results should not be perceived as better or worse than a program that yields values at the borders of the range. 
1.4.2 Rules for Modifying Simulation Programs or Simulation Inputs. Modifications to simulation programs or simulation inputs shall have a mathematical, physical, or logical basis and shall be applied consistently across tests. Such improvements must be documented in modeler reports. Arbitrary modification of a simulation program's input or internal code just for the purpose of more closely matching a given set of results shall be prohibited.

[Note to Users: Sections 2, 3, and 3.1 are intentionally blank so that the following material matches the Standard 140 numbering scheme.]

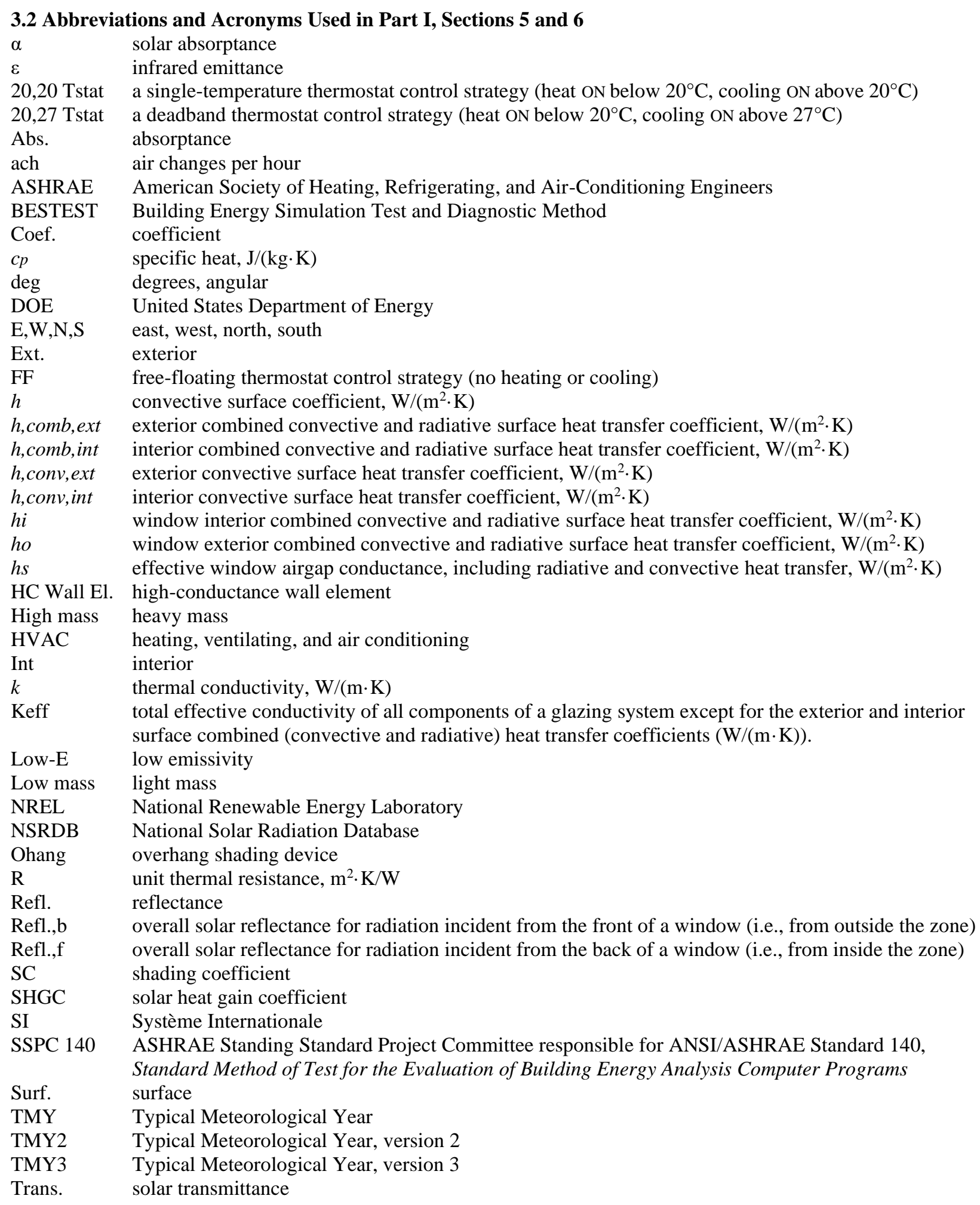


$\begin{array}{ll}\text { Tsky } & \text { sky temperature } \\ \text { Unit thermal conductance or overall heat transfer coefficient, } \mathrm{W} /\left(\mathrm{m}^{2} \cdot \mathrm{K}\right) \\ \text { UA } & \text { thermal conductance, W/K } \\ \text { WYEC2 } & \text { Weather Year for Energy Calculations } 2\end{array}$

[Note to Users: Section 4 is intentionally blank so that the remaining material matches Standard 140 numbering.]

\section{Class I Test Procedures}

[Note to Users: Where Sections 5.2.4, 5.3, 5.4, 5.5, 6.3, 6.4, 6.5, and A1.5 are cross-referenced in 5.1, they refer to ASHRAE Standard 140-2017 (ANSI/ASHRAE 2017); those sections do not apply to this thermal fabric test cases update.]

5.1 Modeling Approach. This modeling approach shall apply to all of the test cases presented in Section 5 . 5.1.1 Time Convention. All references to "time" in this specification are to local standard time and assume that hour 1 = the interval from midnight to 1 A.M. Daylight savings time or holidays shall not be used for scheduling. Informative Note: TMY weather data are in hourly bins corresponding to solar time as specified in Annex A1, Section A1.5. TMY2, TMY3, and WYEC2 data are in hourly bins corresponding to local standard time.

5.1.2 Geometry Convention. If the program being tested includes the thickness of walls in a three-dimensional (3D) definition of the building geometry, then wall, roof, and floor thicknesses shall be defined such that the interior air volume of the building model remains as specified. The thicknesses shall extend exterior to the currently defined internal volume.

Informative Note: For example, for the building thermal envelope and fabric load test cases of Sections 5.2.1, 5.2.2, and 5.2.3, interior air volume would be calculated as $6 \times 8 \times 2.7 \mathrm{~m}=129.6 \mathrm{~m}^{3}\left(19.7 \times 26.2 \times 8.9 \mathrm{ft}^{2}=4576.8 \mathrm{ft}^{3}\right)$.

5.1.3 Nonapplicable Inputs. If the specification includes input values that do not apply to the input structure of the program being tested, disregard the nonapplicable inputs and continue.

Informative Note: Selected equivalent inputs are included in the test specification for those programs that may need them.

5.1.4 Consistent Modeling Methods. Where options exist within a simulation program for modeling a specific thermal behavior, consistent modeling methods shall be used for all cases. The option that is used shall be documented in the Standard Output Report (as specified in Annex A2).

Informative Note: For example, if a program gives a choice of methods for modeling windows, the same window modeling method is to be applied for all cases.

5.1.5 Equivalent Modeling Methods. Where a program or specific model within a program does not allow direct input of specified values, or where input of specified values causes instabilities in a program's calculations, modelers shall develop equivalent inputs that match the intent of the test specification as nearly as the software being tested allows. Such equivalent inputs shall be developed based on the data provided in the test specification, and such equivalent inputs shall have a mathematical, physical, or logical basis and shall be applied consistently throughout the test cases. The modeler shall document the equivalent modeling method in the Standard Output Report (see Normative Annex A2).

5.1.6 Use of Nonspecified Inputs. Use of nonspecified inputs shall be permitted only for the following specified sections relating to the following topics:

- Alternative constant exterior convective or combined (radiative and convective) surface coefficients in Sections 5.2.1.9.3, 5.2.3.1.4.3, 5.2.3.3.2, and 5.3.1.8

- Alternative constant interior convective or combined (radiative and convective) surface coefficients in Sections 5.2.1.10.3, 5.2.3.1.4.4, 5.2.3.2.2, and 5.3.1.9

- Alternative constant interior solar distribution fractions in Sections 5.2.1.12, 5.2.2.1.2.2, 5.2.2.1.6.2, 5.2.2.1.7.2, 5.2.2.2.7.4, 5.2.3.9.3, 5.2.3.10.2, and 5.2.3.12.2

- Air density given at specific altitudes for the space cooling and space heating equipment cases in Sections 5.3.1.4.3, 5.3.3.4.3, and 5.4.1.4.3.

Use of nonspecified inputs shall be permitted only if there is a mathematical, physical, or logical basis for applying them. Where different values are used, they shall be applied consistently throughout the test cases. Use of nonspecified inputs shall be documented in the Standard Output Report specified in Normative Annex A2.

5.1.7 Simulation Initialization and Preconditioning.

5.1.7.1 For the test cases of Section 5.2.4 (ground-coupled slab-on-grade analytical verification tests), see Section 5.1.8.2 and skip Section 5.1.7.2. 
5.1.7.2 For test cases other than those of Section 5.2.4, if the program being tested allows for preconditioning (simulation of an initial time period before recording annual simulation results beginning January 1 hour 1), that capability shall be applied.

Informative Note: For the test cases of Sections 5.2.1, 5.2.2, and 5.2.3, initialization may most affect annual peak heating load results, and January monthly heating and peak heating load results.

5.1.8 Simulation Duration

5.1.8.1 Results for the tests of Sections 5.2.1, 5.2.2, 5.2.3, 5.3.3, and 5.3.4 shall be taken from full annual simulations.

5.1.8.2 For the tests of Section 5.2.4, if the program being tested allows multiyear simulations, models shall run for a number of years to satisfy the requirements of specific test cases. If the software being tested is not capable of simulation duration sufficient to satisfy the requirements of specific test cases, the simulation shall be run for the maximum duration allowed by the software being tested.

Informative Note: The duration to achieve requirements of specific test cases may vary among the test cases.

5.1.8.3 For the tests of Sections 5.3.1 and 5.3.2, the simulation shall be run for at least the first two months for which the weather data are provided. Provide output for the second month of the simulation (February) in accordance with Section 6.3.1.

Informative Note: The first month of the simulation period (January) serves as an initialization period.

5.1.8.4 For the tests of Section 5.4, the simulation shall be run for at least the first three months for which the weather data are provided. Provide output for the first three months of the year (January 1 through March 31) in accordance with Section 6.4.

5.1.8.5 For the tests of Section 5.5, the simulation shall be run until the final-hour output agrees with the previoushour output. Provide output in accordance with Section 6.5.

5.1.9 Rules for Modifying Simulation Programs or Simulation Inputs. Modifications to simulation programs or simulation inputs shall have a mathematical, physical, or logical basis and shall be applied consistently across tests. Arbitrary modification of a simulation program's input or internal code solely for the purpose of more closely matching a given set of results shall be prohibited.

If changes are made to the source code of the software for the purpose of performing tests, and these changes are not available in publicly released versions of the software, then the changes shall be documented in sufficient detail, using the modeler report template provided in Normative Annex A2, so that the implications of the changes are assessable.

\subsection{Input Specifications for Building Thermal Envelope and Fabric Load Tests}

5.2.1 Case 600: Base Case. Begin with Case 600. Case 600 shall be modeled as specified in this section and its subsections.

Informative Note: Informative Table 5-1 provides a summary listing of the test cases of Sections 5.2.1, 5.2.2, and 5.2.3, including the primary tested modeling features addressed by each test case. Further summary description regarding parameters that vary among these test cases is provided in Annex B1, Tables B1-2 and B1-3. Full input specification details are provided beginning in Section 5.2.1.1.

Informative Note: The bulk of the work for implementing the tests is assembling an accurate base-building model. It is recommended that base-building inputs be double checked and results disagreements be diagnosed before going on to the other cases.

Informative Note: For the convenience of users of previous versions of Standard 140 (editions 140-2017, 2014, 2011, 2007, 2004, and 2001), all revisions to the test cases of Sections 5.2.1, 5.2.2, and 5.2.3 of Standard 140-2017, Addendum $a$, are provided in the supplementary accompanying file "140-2017-Sec5_2-Update-TestSpec-

EditTracked.docx", indicated by edit tracking. 
Informative Table 5-1 Summary of Test Cases and Tested Features for Sections 5.2.1, 5.2.2, and 5.2.3

\begin{tabular}{|c|c|c|c|c|}
\hline \multirow[b]{2}{*}{ Primary Tested Feature } & \multicolumn{2}{|c|}{ Low Mass Building } & \multicolumn{2}{|c|}{ High Mass Building } \\
\hline & Test & Section & Test & Section \\
\hline \multicolumn{5}{|l|}{ Basic Tests with Windows (South unless East/West is Indicated) } \\
\hline $\begin{array}{l}\text { Base Case (South clear double-pane windows and "20,27" } \\
\text { Deadband Thermostat [Tstat]) }\end{array}$ & 600 & 5.2 .1 & 900 & 5.2.2.2.1 \\
\hline South Shading (overhang) & 610 & 5.2.2.1.1 & 910 & 5.2.2.2.2 \\
\hline East/West Windows & 620 & 5.2 .2 .1 .2 & 920 & 5.2 .2 .2 .3 \\
\hline East/West Windows with Shading (overhang + fins) & 630 & 5.2.2.1.3 & 930 & 5.2 .2 .2 .4 \\
\hline Tstat Setback & 640 & 5.2.2.1.4 & 940 & 5.2.2.2.5 \\
\hline Night Ventilation & 650 & 5.2.2.1.5 & 950 & 5.2.2.2.6 \\
\hline Low-Emissivity Windows & 660 & 5.2.2.1.6 & & \\
\hline Single-Pane Windows & 670 & 5.2.2.1.7 & & \\
\hline Sunspace & & & 960 & 5.2.2.2.7 \\
\hline Increased Wall and Roof Insulation & 680 & 5.2.2.1.8 & 980 & 5.2.2.2.8 \\
\hline “20,20” Tstat & 685 & 5.2.2.1.9 & 985 & 5.2.2.2.9 \\
\hline Increased Wall and Roof Insulation with " 20,20 ” Tstat & 695 & 5.2.2.1.10 & 995 & 5.2.2.2.10 \\
\hline \multicolumn{5}{|c|}{ Basic Tests without Mechanical Heating and Cooling (Free-Float [FF] Temperatures) } \\
\hline Base Case & 600FF & 5.2 .2 .3 .1 & 900FF & 5.2 .2 .3 .4 \\
\hline Night Ventilation & 650FF & 5.2 .2 .3 .2 & 950FF & 5.2 .2 .3 .5 \\
\hline Increased Wall and Roof Insulation & 680FF & 5.2.2.3.3 & 980FF & 5.2.2.3.6 \\
\hline \multicolumn{5}{|c|}{ In-Depth Tests with "20,20” Tstat, and High-Conductance Wall Elements or Solid Conduction } \\
\hline Base Case ( 0 internal heat gains, 0 infiltration) & 220 & 5.2.3.1 & & \\
\hline Interior Infrared Radiation Exchange & 210 & 5.2 .3 .2 & & \\
\hline Exterior Infrared Radiation Exchange & 215 & 5.2.3.3 & & \\
\hline Interior and Exterior Infrared Radiation Exchange & 200 & 5.2 .3 .4 & & \\
\hline Solid Conduction (no windows or high-cond. wall elements) & 195 & 5.2 .3 .5 & & \\
\hline Infiltration & 230 & 5.2.3.6 & & \\
\hline Internal Gains & 240 & 5.2.3.7 & & \\
\hline Exterior Solar Absorptance & 250 & 5.2.3.8 & & \\
\hline \multicolumn{5}{|c|}{ In-Depth Tests with “20,20" Tstat and Windows (South unless East/West is indicated) } \\
\hline South Solar Gains & 270 & 5.2.3.9 & & \\
\hline Cavity Albedo (interior solar absorptance) & 280 & 5.2 .3 .10 & & \\
\hline South Shading (overhang) & 290 & 5.2 .3 .11 & & \\
\hline East/West Windows & 300 & 5.2.3.12 & & \\
\hline East/West Windows with Shading (overhang + fins) & 310 & 5.2.3.13 & & \\
\hline “20,27” Deadband Tstat & 320 & 5.2 .3 .14 & & \\
\hline \multicolumn{5}{|c|}{ In-Depth Tests with "20,27” Deadband Tstat, and High-Conductance Wall Elements or Solid Conduction } \\
\hline Base Case (0 internal heat gains, 0 infiltration) & 400 & 5.2.3.15 & & \\
\hline Solid Conduction & 395 & 5.2.3.16 & & \\
\hline Infiltration & 410 & 5.2.3.17 & & \\
\hline Internal Gains & 420 & 5.2.3.18 & & \\
\hline Exterior Solar Absorptance & 430 & 5.2.3.19 & & \\
\hline Thermal Mass Without Solar Gains & & & 800 & 5.2.3.24 \\
\hline \multicolumn{5}{|l|}{ In-Depth Tests with “20,27” Deadband Tstat and South Windows } \\
\hline Cavity Albedo & 440 & 5.2 .3 .20 & 810 & 5.2.3.25 \\
\hline Constant Combined Interior and Exterior Surface Coefficients & 450 & 5.2 .3 .21 & & \\
\hline Constant Combined Interior Surface Coefficients & 460 & 5.2 .3 .22 & & \\
\hline Constant Combined Exterior Surface Coefficients & 470 & 5.2 .3 .23 & & \\
\hline
\end{tabular}




\subsubsection{Weather and Site Data}

5.2.1.1.1 Weather Data.

5.2.1.1.1.1 Normative Weather Data. The 725650TY.CSV weather data provided with the electronic files accompanying this standard shall be used for all cases in Sections 5.2.1, 5.2.2, and 5.2.3. These data are described in Normative Annex A1, Section A1.1.1.

5.2.1.1.1.2 Informative Sky Temperature Data. Informative Note: The specified weather data file does not include data for sky temperature $\left(\mathrm{T}_{\text {sky }}\right)$. For programs that do not automatically calculate $\mathrm{T}_{\text {sky }}$, and use $\mathrm{T}_{\text {sky }}$ as an input from the weather data file, calculated $\mathrm{T}_{\text {sky }}$ values are provided as informative material in the file "TskyInformative.xlsx", included with the electronic files accompanying this standard. That file and calculation of $\mathrm{T}_{\text {sky }}$ data are further described in the informative note with Annex A1, Informative Section A1.1.1.2.

\subsection{Site Data.}

5.2.1.1.2.1. The site latitude, longitude, altitude, and time zone provided in Normative Annex A1, Table A1-1 shall be used.

5.2.1.1.2.2. The site shall be located at the weather station, in open terrain with scattered obstructions having heights generally less than $9 \mathrm{~m}$, including flat open country typical of meteorological-station surroundings. There is no additional shielding of the building at the site.

Informative Note: The site location corresponds to Terrain Category 3, documented in 2017 ASHRAE Handbook of Fundamentals, p. 24.4, Table $1^{\mathrm{B}-101}$.

5.2.1.1.2.3. The height of the weather station tower (location of sensors) shall be assumed to be $10 \mathrm{~m}$.

5.2.1.1.2. The interior surface of the building floor shall be assumed to be $10 \mathrm{~m}$ below the top of the weather station.

5.2.1.1.2.5. The solar reflectance of the site ground surface $=0.2$.

Informative Note: Ground reflectance (albedo) included with the weather data is recommended to be ignored if the software being tested does not require use of those data. Ground reflectance in the provided weather data ranges from 0.19 to 0.22 with an average of 0.203 ; it is provided as hourly data, but only varies monthly.

5.2.1.2 Output Requirements. Case 600 requires the following output:

a. All non-free-float case output in accordance with Section 6.2.1.1.

b. Case 600 output in accordance with Section 6.2.1.2.

c. Daily hourly output as specified for Case 600 in Section 6.2.1.8.

d. General reporting requirements of Section 6.1 .

Informative Note: In this description the term "free-float cases" refers to cases designated with "FF" in the case description (i.e., 600FF, 650FF, 900FF, 950FF); non-free-float cases are all the other cases described in Sections 5.2.1, 5.2.2, and 5.2.3 (Informative Annex B1, Tables B1-2 and B1-3, include a summary listing of the cases of Sections 5.2.1, 5.2.2, and 5.2.3.).

5.2.1.3 Building Geometry. The base building plan shall be a $48-\mathrm{m}^{2}$-floor-area, single-story, low-mass building with rectangular-prism geometry and $12 \mathrm{~m}^{2}$ of south-facing windows as shown in Figure 5-1.

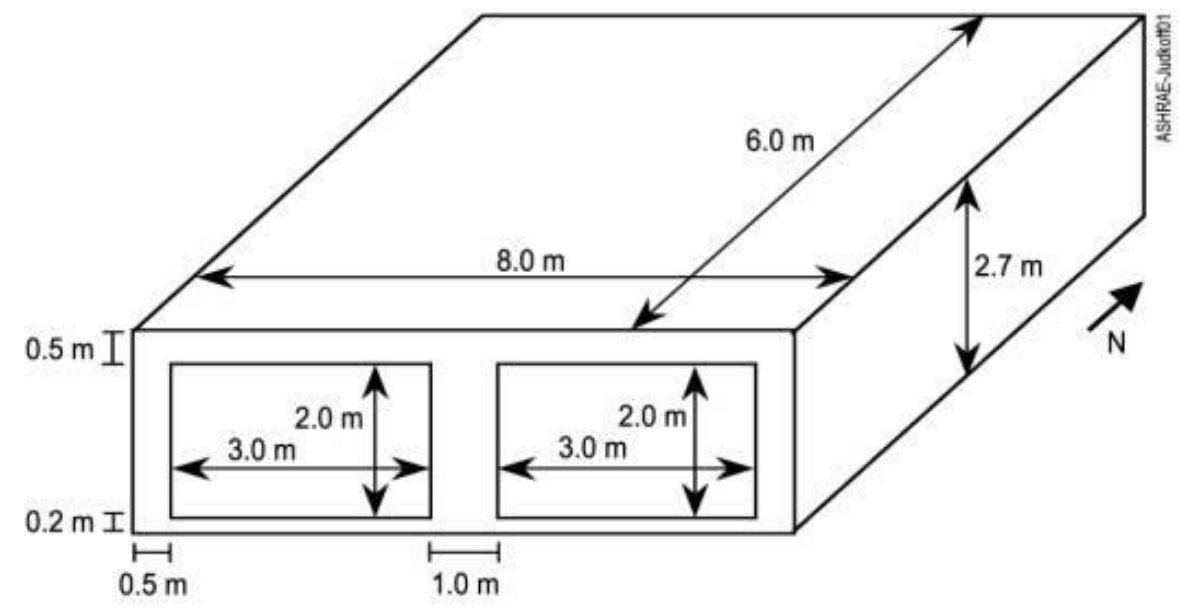

Figure 5-1 Isometric south windows-unshaded (Case 600). 
5.2.1.4 Material Properties. For the walls, floor, and roof, the fundamental thermal and material properties provided in Table 5-2 shall be applied.

Informative Note: Informative Table 5-3 includes summary calculated values derived from fundamental properties of normative Table 5-2 and alternative constant surface coefficients of Sections 5.2.1.9.3 and 5.2.1.10.3, for programs that may need this information. For programs that automatically calculate surface radiation or convection or both, or that allow more detailed constant surface coefficient inputs (e.g., for scheduling), variation of individual interior surface coefficient U-values, total U- and total UA-values, and heat capacities from Table 5-3 may be expected.

Table 5-2 Fundamental Material Thermal Property Specifications for Low-Mass Case

\begin{tabular}{|c|c|c|c|c|c|c|}
\hline Element & $\begin{array}{c}\mathbf{k}, \\
\mathbf{W} /(\mathbf{m} \cdot \mathbf{K})\end{array}$ & $\begin{array}{c}\text { Thickness, } \\
\text { m }\end{array}$ & $\begin{array}{c}\mathbf{U}, \\
\mathbf{W} /\left(\mathbf{m}^{2} \cdot \mathbf{K}\right)\end{array}$ & $\begin{array}{c}\mathbf{R}, \\
\mathbf{m}^{2} \cdot \mathbf{K} / \mathbf{W}\end{array}$ & $\begin{array}{c}\text { Density, } \\
\mathrm{kg} / \mathrm{m}^{3}\end{array}$ & $\begin{array}{c}\mathbf{c}_{\mathrm{p}} \\
\mathbf{J} /(\mathbf{k g} \cdot \mathbf{K})\end{array}$ \\
\hline \multicolumn{7}{|c|}{ Low-Mass Case: Exterior Wall (inside to outside) } \\
\hline Plasterboard & 0.16 & 0.012 & 13.333 & 0.075 & 950 & 840 \\
\hline Fiberglass quilt & 0.04 & 0.066 & 0.606 & 1.650 & 12 & 840 \\
\hline Wood siding & 0.14 & 0.009 & 15.556 & 0.064 & 530 & 900 \\
\hline \multicolumn{7}{|c|}{ Low-Mass Case: Raised Floor (inside to outside) } \\
\hline Timber flooring & 0.14 & 0.025 & 5.600 & 0.179 & 650 & 1200 \\
\hline Insulation & 0.04 & 1.003 & 0.040 & 25.075 & $0^{\mathrm{a}}$ & $0^{\mathrm{a}}$ \\
\hline \multicolumn{7}{|c|}{ Low-Mass Case: Roof (inside to outside) } \\
\hline Plasterboard & 0.16 & 0.010 & 16.000 & 0.063 & 950 & 840 \\
\hline Fiberglass quilt & 0.04 & 0.1118 & 0.358 & 2.794 & 12 & 840 \\
\hline Roofdeck & 0.14 & 0.019 & 7.368 & 0.136 & 530 & 900 \\
\hline
\end{tabular}

a. Underfloor insulation has the minimum density and specific heat the program being tested will allow, but not $<0$.

5.2.1.4.1 Internal Mass. There shall be no additional internal mass within the zone corresponding to furniture or other nonspecified elements. Informative Note: Programs should consider thermal capacitance of the zone based on the given zone construction details, zone air volume, and their determination of density of air within the zone. 


\section{Informative Table 5-3 Calculated Summary Thermal Conductances and Heat Capacities, Low-Mass}

Case $^{a}$

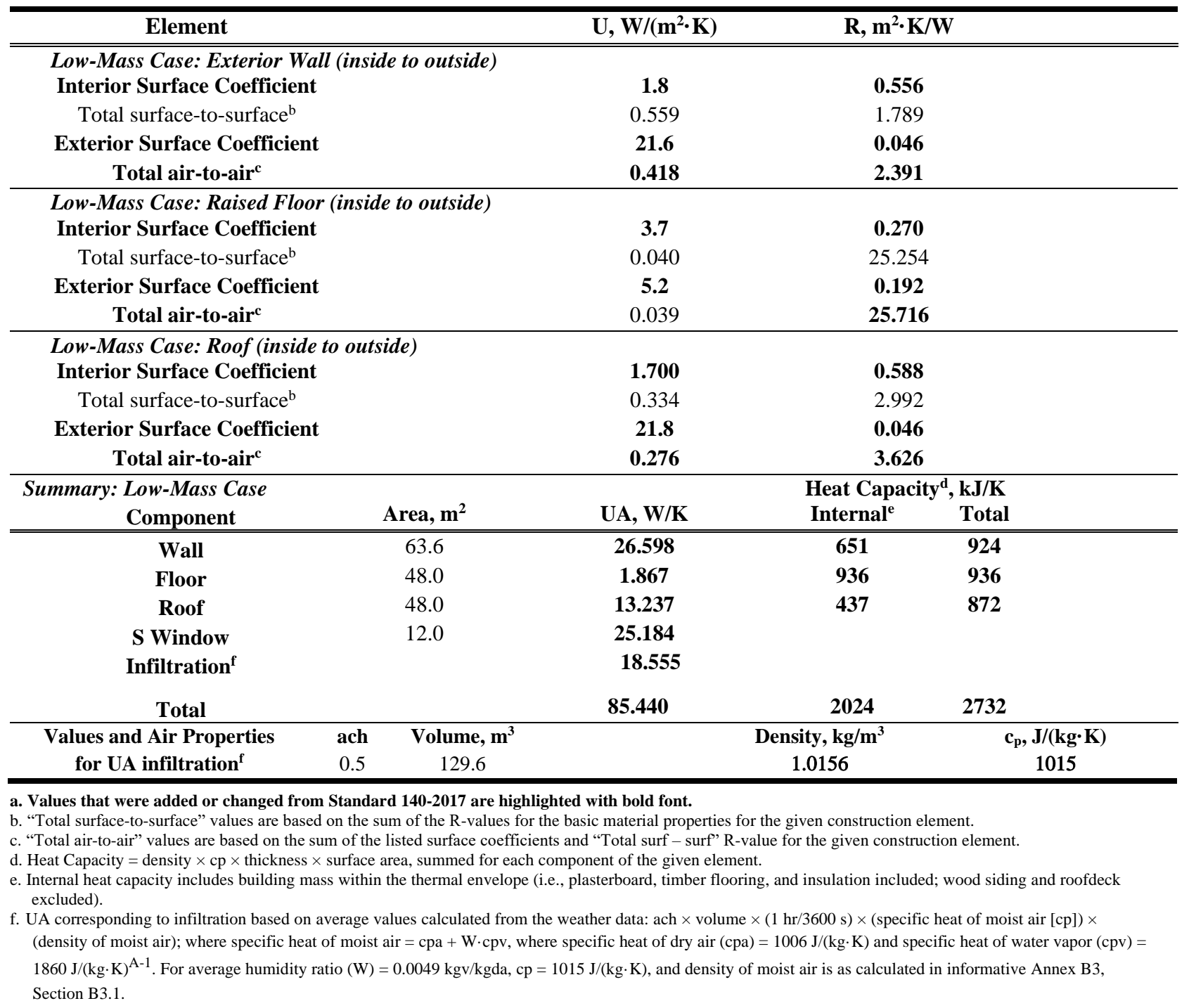

\subsubsection{Raised Floor Exposed to Air.}

Informative Note: To reduce uncertainty regarding testing of the other aspects of simulating the building envelope, the floor insulation described in Table 5-2 has been made very thick to effectively decouple the floor thermally from the ground, while not decoupling the floor mass from the zone. Application of a raised floor eliminates the need for modeling ground-coupled heat transfer.

5.2.1.5.1 The floor shall be modeled as follows:

- The air temperature below the raised floor shall be equal to the outdoor air temperature.

- The floor exterior surface (surface facing downward) shall receive no solar radiation.

- The underside of the conditioned-zone floor shall have zero wind speed. Informative Note: Instructions for modeling exterior surface heat transfer for all surfaces are provided in Section 5.2.1.9.

Informative Note: The assumption that the air temperature below the raised floor is equal to ambient temperature may be approximated either by modeling a building that hovers above the ground (raised floor on stilts, for example) or by modeling a highly ventilated crawl space. The zero wind speed approximation is applicable because the interior floor surface location relative to the weather-tower sensors is as described in Sections 5.2.1.1.2.3 and 5.2.1.1.2.4. The zero solar-radiation-to-exterior-floor assumption can be modeled by assigning the highest solar reflectance allowed by the software being tested to the underside of the floor and/or defining shading planes where walls would be if the raised floor were modeled as a crawl space. For programs that do not apply constant combined 
film coefficients, infrared radiative exchange between the floor exterior surface and the ground surface may be modeled as typical for the program being tested.

5.2.1.5.2 The underfloor insulation shall have the minimum density and specific heat that the program being tested allows.

5.2.1.6 Infiltration. The infiltration rate shall be $0.5 \mathrm{ach}$, continuously ( 24 hours per day for the full year). The infiltration rate shall be independent of wind speed, indoor/outdoor temperature difference, and other variables. 5.2.1.6.1 The weather data file represents a high-altitude site with an elevation of $1650 \mathrm{~m}$ above sea level. If the program being tested does not use barometric pressure from the weather data or otherwise automatically correct for the change in air density due to altitude, then the specified infiltration rates shall be adjusted to yield mass flows equivalent to those occurring at $1650 \mathrm{~m}$ altitude, as shown in Table 5-4.

Informative Note: Air density at $1650 \mathrm{~m}$ altitude is roughly $80 \%$ of that at sea level. The calculation technique used to develop Table 5-4 is provided as background information in Informative Annex B3, Section B3.1.

Informative Note: Alternatively, the given infiltration rate may be input as a constant ventilation rate.

Table 5-4 Infiltration Rates Depending on the Presence of Automatic Altitude Adjustment ${ }^{\mathrm{a}}$

\begin{tabular}{lcc}
\hline Altitude Adjustment Algorithm & $\begin{array}{c}\text { Input Air Changes per } \\
\text { Hour, ach }\end{array}$ & $\begin{array}{c}\text { Adjustment } \\
\text { Factor }\end{array}$ \\
\hline \hline $\begin{array}{l}\text { Programs with automatic altitude adjustment; set altitude } \\
\text { to } 1650 \mathrm{~m} \text { above sea level }\end{array}$ & 0.5 & 1.0 \\
$\begin{array}{l}\text { Programs with fixed assumption that site is at sea level } \\
\text { (no automatic adjustment) }\end{array}$ & $\mathbf{0 . 4 1 4}^{\mathbf{b}}$ & $\mathbf{0 . 8 2 9}^{\mathrm{b}}$ \\
\hline $\begin{array}{l}\text { anformative Note: } \text { Values that were changed from Standard 140-2017 are highlighted with bold font. } \\
\text { b. (Specified Rate) } \times(\mathbf{1 . 0 1 5 6 / . 2 2 5 5})=(\text { altitude adjusted rate) }\end{array}$ &
\end{tabular}

5.2.1.7 Internally Generated Sensible Heat. The following internal heat gains shall be used:

- Internal gains shall be $200 \mathrm{~W}$, continuously ( 24 hours per day for the full year).

- Internal gains shall be $100 \%$ sensible, $0 \%$ latent.

- Sensible internal gains shall be $60 \%$ radiative, $40 \%$ convective.

Informative Note: These are internally generated sources of heat (from equipment, lights, people, etc.) that are not related to heating, ventilating, and air conditioning (HVAC). The convective portion of internal gains may be reasonably assumed to be distributed evenly throughout the zone air. The radiative portion may be reasonably assumed to be distributed uniformly among the zone interior surfaces (area weighted distribution), assuming an effective infrared transmittance of approximately one for air within the zone.

\subsubsection{Opaque Surface Radiative Properties.}

5.2.1.8.1 Absorptances and Emittances.

a. The interior and exterior opaque surfaces solar (visible and ultraviolet wavelengths) absorptances and infrared emittances shall be applied to all opaque surfaces, except for the raised floor, as specified in Table 5-5.

b. For the raised floor:

- Interior surface solar absorptance and infrared emittance, and exterior surface infrared emittance, shall be applied as specified in Table 5-5.

- The exterior surface shall be modeled as receiving no solar radiation (see Section 5.2.1.5.1). 
Table 5-5 Opaque Surface Radiative Properties, Case 600

\begin{tabular}{lcc}
\hline & Interior Surface & Exterior Surface \\
\hline \hline Solar absorptance & 0.6 & 0.6 \\
\hline Infrared emittance & 0.9 & 0.9 \\
\hline
\end{tabular}

5.2.1.8.2 Surrounding Ground Surface Temperature for Exterior Infrared Radiation Exchange. If the program being tested does not automatically calculate a separate component of exterior surface infrared radiation exchange with the surrounding ground, skip the remaining instructions and proceed to Section 5.2.1.9.

5.2.1.8.2.1 If the program being tested calculates this exchange component and the program automatically calculates surrounding ground surface temperature, then the program's calculated surrounding ground surface temperature shall be applied. If this instruction is applied, skip the remaining instructions and proceed to Section 5.2.1.9. 5.2.1.8.2.2 If the program being tested calculates this exchange component and does not automatically calculate surrounding ground surface temperature, the instructions of Section 5.2.1.8.2.2.1 or 5.2.1.8.2.2.2 shall be applied. 5.2.1.8.2. 2.1 The surrounding ground surface temperature shall be equal to, and shall vary with, the ambient air temperature from the provided weather data (see Section 5.2.1.1.1) for each hour of the simulation.

5.2.1.8.2.2.2 If the program being tested calculates an ambient air temperature for each time step of the simulation based on the given weather data, the surrounding ground surface temperature for each time step shall be equal to, and shall vary with, the calculated ambient air temperature for each time step.

\subsubsection{Exterior Surface Heat Transfer.}

5.2.1.9.1 Terrain Category. For programs that allow variation of wind speed with height above ground, local site terrain data provided in Section 5.2.1.1.2 shall be applied.

5.2.1.9.2 Exterior Surface Texture. For programs that allow variation of exterior surface convection with surface texture, exterior surface texture shall be as indicated in Table 5-6.

Table 5-6 Exterior Surface Texture, Case 600

\begin{tabular}{|c|c|}
\hline Surface Type & Surface Texture ${ }^{a}$ \\
\hline Walls & Rough $^{b}$ \\
\hline Roof & Rough $^{b}$ \\
\hline Raised Floor & Rough $^{b}$ \\
\hline Windows (glass) & Very Smooth \\
\hline
\end{tabular}

5.2.1.9.3 Alternative Constant Convective and Combined (Radiative and Convective) Surface Coefficients. a. If the program being tested calculates exterior surface convective coefficients and infrared radiative exchange varying with time step:

- Those calculations shall be applied.

- Skip the remaining instructions in this section and proceed to Section 5.2.1.10.

b. If the program being tested does not calculate time-step-varying exterior surface convective coefficients or infrared radiative exchange, then the information provided in Table 5-7 shall be applied. In applying Table 5-7:

- Programs that calculate time-step varying exterior surface infrared radiative exchange, but not convective coefficients, shall apply the listed exterior convective surface coefficients (h,conv,ext) for each surface type.

- Programs that do not calculate time-step varying exterior surface convective coefficients and infrared radiative exchange shall apply the listed exterior combined surface coefficients (h,comb,ext) for each surface type.

- Use of different (nonspecified) values shall not be prohibited if there is a mathematical, physical, or logical basis for applying them. Where different values are used, they shall be applied consistently throughout the test 
cases. Use of nonspecified values shall be documented in the Standard Output Report specified in Normative Annex A2.

Informative Note: The constant values of Table 5-7 are provided for programs that require this input, i.e., that have no time-step-varying exterior surface convective coefficient or infrared radiative heat transfer calculation method, or no other constant exterior surface heat transfer coefficients explicit to their internal coding. Programs (or models within those programs, where a program allows a variety of modeling methods) that calculate time-step-varying surface convective coefficients and infrared radiative heat transfer should not be adjusted to match the constant values provided here.

Informative Note: Example constant surface coefficients presented here apply only to the test cases, and were calculated using a verified simulation process (see Part IV, Appendix A, Section 4A.3) only for test cases with south-facing windows or south-facing high-conductance wall elements. They should not be assumed to apply beyond this test suite. Supporting information about the development of Table 5-7 is provided in Informative Annex B4.

\section{Table 5-7 Alternative Constant Exterior Convective and Combined Surface Coefficients for Each Surface Type, Case 600a,b}

\begin{tabular}{lcc}
\hline Surface Type & $\begin{array}{c}\text { Exterior Convective Surface } \\
\text { Coefficient (h,conv,ext), } \\
\mathrm{W} /\left(\mathbf{m}^{2} \cdot \mathbf{K}\right)\end{array}$ & $\begin{array}{c}\text { Exterior Combined Surface } \\
\text { Coefficient }(\mathbf{h}, \text { comb,ext), } \\
\mathrm{W} /\left(\mathbf{m}^{2} \cdot \mathbf{K}\right)\end{array}$ \\
\hline \hline Walls & 11.9 & 21.6 \\
Roof & 14.4 & 21.8 \\
Raised Floor & 0.8 & 5.2 \\
Windows & 8.0 & 17.8 \\
\hline
\end{tabular}

a. Informative Note: Changes to Standard 140-2017 are highlighted with bold font.

b. Informative Note: Informative Annex B4 includes supporting information.

c. Informative Note: Calculated for wind speed $=0$ as described in Section 5.2.1.9; also see Part IV, Appendix A, Section 4A.2.1.1.

\subsubsection{Interior Surface Heat Transfer.}

5.2.1.10.1 Zone Air Flow Regime. For programs that allow variation of zone air flow regime, buoyancy (nonmechanically)-driven airflow shall be applied. Operation of the specified ideal mechanical system (see Section 5.2.1.13) shall have no effect on the interior surface convective heat transfer flow regime.

5.2.1.10.2 Interior Surface Texture. For programs that allow variation of interior surface convection with surface texture, interior surface texture shall be as indicated in Table 5-8.

Table 5-8 Interior Surface Texture, Case 600

\begin{tabular}{lc}
\hline Surface Type & Surface Texture $^{\mathbf{a}}$ \\
\hline \hline Walls & Smooth $^{\mathbf{b}}$ \\
Roof & Smooth $^{\mathbf{b}}$ \\
Raised Floor & Smooth $^{\mathbf{b}}$ \\
Windows (glass) & Very Smooth \\
\hline
\end{tabular}

a. Informative Note: Surface texture designations correspond with the following: 2009 ASHRAE Handbook Fundamentals, p. 26.2 ${ }^{\mathrm{B}-10}$; Walton (1983), Section III.I.1 ${ }^{\mathrm{B}-20}$; and DOE (2018), Section 3.5.5.1 ${ }^{\mathrm{A}-2}$. Also see Part IV, Appendix A, Section 4A.2.1.

b. Informative Note: The "Smooth" surface corresponds to smooth plaster. Uniform interior surface texture is specified for the Case 600 opaque interior surfaces to simplify input. 
5.2.1.10.3 Alternative Constant Convective and Combined (Radiative and Convective) Surface Coefficients. a. If the program being tested calculates interior surface convective coefficients and infrared radiative exchange varying with time step:

- Those calculations shall be applied.

- Skip the remaining instructions in this section and proceed to Section 5.2.1.11.

b. If the program being tested does not calculate time-step-varying interior surface convective coefficients or infrared radiative exchange, then the information provided in Table 5-9 shall be applied. In applying Table 5-9:

- Programs that calculate time-step-varying interior surface infrared radiative exchange, but not convective coefficients, shall apply the listed interior convective surface coefficients (h,conv,int) for each surface type.

- Programs that do not calculate time-step-varying interior surface convective coefficients and infrared radiative exchange shall apply the listed interior combined surface coefficients (h,comb,int) for each surface type.

- Use of different (nonspecified) values shall not be prohibited if there is a mathematical, physical, or logical basis for applying them. Where different values are used, they shall be applied consistently throughout the test cases. Use of nonspecified values shall be documented in the Standard Output Report specified in Normative Annex A2.

Informative Note: The constant values of Table 5-9 are provided for programs that require this input, i.e., that have no time-step-varying interior surface convective coefficient or infrared radiative heat transfer calculation method or no other constant interior surface heat transfer coefficients explicit to their internal coding. Programs (or models within those programs, where a program allows a variety of modeling methods) that calculate time-step-varying surface convective coefficients and infrared radiative heat transfer should not be adjusted to match the constant values provided here.

Informative Note: Example constant surface coefficients presented here apply only to the test cases, and were calculated using a verified simulation process (see Part IV, Appendix A, Section 4A.3) only for test cases with south-facing windows or south-facing high-conductance wall elements. They should not be assumed to apply beyond this test suite. Example constant interior surface coefficients assume buoyancy regime heat transfer only (see Part IV, Appendix A, Section 4A.2.2). Supporting information about the development of Table 5-9 is provided in Informative Annex B4.

\section{Table 5-9 Alternative Constant Interior Convective and Combined Surface Coefficients for Each Surface Type, Case $600^{\mathrm{a}, \mathrm{b}}$}

\begin{tabular}{|c|c|c|}
\hline Surface Type & $\begin{array}{c}\text { Interior Convective Surface } \\
\text { Coefficient (h,conv,int), } \\
\mathrm{W} /\left(\mathbf{m}^{2} \cdot \mathbf{K}\right)\end{array}$ & $\begin{array}{c}\text { Interior Combined Surface } \\
\text { Coefficient (h,comb,int), } \\
\qquad \mathrm{W} /\left(\mathbf{m}^{2} \cdot \mathbf{K}\right)\end{array}$ \\
\hline Walls & 2.2 & $1.8^{\mathrm{c}}$ \\
\hline Ceiling & 1.8 & $1.7^{\mathrm{c}}$ \\
\hline Raised Floor & 2.2 & 3.7 \\
\hline Windows & 2.4 & 4.5 \\
\hline
\end{tabular}




\subsubsection{Transparent Window}

Informative Note: Use of different algorithms to calculate window thermal and optical performance requires different inputs. Extensive information about the window properties has therefore been provided so that equivalent input for the window will be possible for many programs. As stated in Section 5.1.3 (Nonapplicable Inputs), use only the information that is relevant to the program being tested.

5.2.1.11.1 Geometry. The windows shall have no sash area. The rough openings shown in Figure 5-1 shall contain only the double-pane glass specified in Table 5-10.

5.2.1.11.2 Window Properties. The properties of the window provided in Table 5-10 shall be applied. All glass pane surfaces are clean; there is no dirt or fouling.

Informative Note, Calculated Properties of Informative Table 5-11: Informative Table 5-11 includes calculated values derived from fundamental properties of normative Table 5-10 and alternative constant surface coefficients of Sections 5.2.1.9.3 and 5.2.1.10.3, for programs that may need this information.

Informative Note, Variation of Listed Surface Coefficients and Overall U-Values from Values of Informative Table 5-11: For programs that calculate time-step-varying surface infrared radiative exchange or convective coefficients or both, or that allow more detailed constant surface coefficient inputs (e.g., for scheduling), variation of the following from the values given in Table 5-11 may be expected: individual surface coefficient U-values, air gap effective conductance, and overall U-value.

Informative Note, Variation of Air Gap Conductance from Values of Informative Table 5-11: For programs that automatically calculate heat transfer within an air space or empty cavity, variation of the following from the values given in Table 5-11 may be expected: effective air gap conductance and overall U-value.

\subsection{Alternative Incidence-Angle-Dependent Optical Properties.}

a. If the program being tested automatically calculates incidence-angle-dependent optical properties based on inputs from Table 5-10, or if the program does not allow direct user input of angle-dependent optical properties, then skip the instructions in this section and proceed to Section 5.2.1.12.

b. For programs that apply incidence-angle-dependent optical properties as direct inputs, the values given in Table 5-12 shall be applied.

- For programs that need transmittance or reflectance at other angles of incidence, the user shall be permitted to interpolate between the values in Table 5-12 using the cosine of the incident angle as the basis for interpolation.

- Where unspecified equivalent inputs are needed, values that are consistent with those specified shall be applied according to the instructions of Section 5.1.5, "Equivalent Modeling Methods."

Informative Note: Supporting information regarding window thermal and optical properties is provided in Informative Annex B6. This includes the output report from the WINDOW 7 software $^{\mathrm{A}-3}$ that was applied to generate values in Table 5-12, and selected values in informative Table 5-11, as described in the notes with those tables. This informative data file is included with the accompanying electronic media and may be used by simulation programs that can read it directly. 
Table 5-10 Fundamental Properties of Clear Double-Pane Glazing System ${ }^{a}$

\begin{tabular}{|c|c|}
\hline Property & Value \\
\hline \multicolumn{2}{|l|}{ Fundamental Construction Properties } \\
\hline Height, individual rough opening & $2 \mathrm{~m}$ \\
\hline Width, individual rough opening & $3 \mathrm{~m}$ \\
\hline Area, individual gross window (also center of glass area) & $6 \mathrm{~m}^{2}$ \\
\hline Number of panes & 2 \\
\hline Pane thickness ${ }^{b}$ & $3.048 \mathrm{~mm}$ \\
\hline Thickness of space between panes ${ }^{c}$ & $12.0 \mathrm{~mm}$ \\
\hline Fill gas (in space between panes) & Air \\
\hline $\begin{array}{l}\text { Curtains, blinds, frames, spacers, mullions, obstructions } \\
\text { inside the window }\end{array}$ & None \\
\hline \multicolumn{2}{|l|}{ Basic Material Properties } \\
\hline Thermal conductivity of glass ${ }^{b}$ & $1.00 \mathrm{~W} /(\mathrm{m} \cdot \mathrm{K})$ \\
\hline Density of glass ${ }^{d}$ & $2470 \mathrm{~kg} / \mathrm{m}^{3}$ \\
\hline Specific heat of glass ${ }^{\mathrm{d}}$ & $750 \mathrm{~J} /(\mathrm{kg} \cdot \mathrm{K})$ \\
\hline Air: conductivity $(k)^{\mathrm{e}, \mathrm{f}}$ & $\begin{array}{l}0.024069 \mathrm{~W} /(\mathrm{m} \cdot \mathrm{K}) \text {, shall be allowed to vary with } \\
\text { temperature and pressure }\end{array}$ \\
\hline Air: specific heat $\left(c_{p}\right)^{e, f}$ & $\begin{array}{l}1006.103271 \mathrm{~J} /(\mathrm{kg} \cdot \mathrm{K}) \text {, shall be allowed to vary } \\
\text { with temperature and pressure }\end{array}$ \\
\hline Air: density $(\rho)^{\mathrm{e}, \mathrm{f}}$ & $\begin{array}{l}1.292498 \mathrm{~kg} / \mathrm{m}^{3} \text {, shall be allowed to vary with } \\
\text { temperature and pressure }\end{array}$ \\
\hline Air: viscosity $(\mu)^{e, f}$ & $\begin{array}{l}0.000017 \mathrm{~kg} /(\mathrm{m} \cdot \mathrm{s}), \text { shall be allowed to vary with } \\
\text { temperature and pressure }\end{array}$ \\
\hline Air: Prandtl number $(\mathbf{P r})^{\mathrm{e}, \mathrm{f}}$ & $\begin{array}{l}0.7197 \text { (dimensionless), shall be allowed to vary } \\
\text { with temperature and pressure }\end{array}$ \\
\hline Air: molecular weight ${ }^{\mathrm{e}}$ & $28.970 \mathrm{~g} / \mathrm{mol}$ \\
\hline Hemispherical infrared emittance of glass ${ }^{b}$ & 0.840 \\
\hline Infrared transmittance of glass ${ }^{b}$ & 0.000 \\
\hline $\begin{array}{l}\text { Direct-beam transmittance through } \\
\text { each pane }{ }^{b}\end{array}$ & $\mathbf{0 . 8 3 4}$, at normal incidence \\
\hline Direct-beam reflectance for each pane ${ }^{b}$ & $\mathbf{0 . 0 7 5}$, at normal incidence \\
\hline
\end{tabular}


Informative Table 5-11 Calculated Properties of Clear Double-Pane Glazing System ${ }^{\mathrm{a}}$

\begin{tabular}{|c|c|c|}
\hline Property & Value & \\
\hline $\begin{array}{l}\text { Effective conductance of air gap, including } \\
\text { radiative and convective heat transfer } \\
\left(h_{s}\right)^{\text {b }}\end{array}$ & $5.208 \mathrm{~W} /\left(\mathrm{m}^{2} \cdot \mathrm{K}\right)$ & {$\left[\mathbf{R}-\mathbf{0 . 1 9 2 0 0} \mathrm{m}^{2} \cdot \mathrm{K} / \mathrm{W}\right]$} \\
\hline Conductance of each glass pane ${ }^{c}$ & $328 \mathrm{~W} /\left(\mathrm{m}^{2} \cdot \mathrm{K}\right)$ & {$\left[\mathbf{R - 0 . 0 0 3 0 5} \mathrm{m}^{2} \cdot \mathrm{K} / \mathrm{W}\right]$} \\
\hline Exterior combined surface coefficient $\left(h_{o}\right)^{\mathrm{d}}$ & $17.8 \mathrm{~W} /\left(\mathrm{m}^{2} \cdot \mathrm{K}\right)$ & {$\left[\mathbf{R}-\mathbf{0 . 0 5 6 1 8} \mathrm{m}^{2} \cdot \mathrm{K} / \mathrm{W}\right]$} \\
\hline Interior combined surface coefficient $\left(h_{i}\right)^{\mathrm{d}}$ & $4.5 \mathrm{~W} /\left(\mathrm{m}^{2} \cdot \mathrm{K}\right)$ & {$\left[\mathbf{R}-\mathbf{0 . 2 2 2 2 2} \mathrm{m}^{2} \cdot \mathrm{K} / \mathrm{W}\right]$} \\
\hline U-Value from interior air to ambient air ${ }^{\mathrm{e}}$ & $2.10 \mathrm{~W} /\left(\mathrm{m}^{2} \cdot \mathrm{K}\right)$ & {$\left[\mathbf{R}-\mathbf{0 . 4 7 6 5 0} \mathrm{m}^{2} \cdot \mathrm{K} / \mathrm{W}\right]$} \\
\hline Double-pane solar heat gain coefficient $\left(\right.$ SHGC) ${ }^{\mathrm{f}}$ & \multicolumn{2}{|c|}{ 0.769, at normal incidence ${ }^{\mathrm{g}}$} \\
\hline Double-pane shading coefficient $(\mathrm{SC})^{\mathrm{h}}$ & \multicolumn{2}{|c|}{$\mathbf{0 . 8 8 3}$, at normal incidence } \\
\hline Index of refraction ${ }^{i}$ & \multicolumn{2}{|l|}{1.493} \\
\hline Extinction coefficient ${ }^{\mathrm{i}}$ & \multicolumn{2}{|l|}{$0.0337 / \mathrm{mm}$} \\
\hline
\end{tabular}

a. Updates to Standard 140-2017 are highlighted with bold font.

b. Calculated: (air gap conductance $)=($ Keff $) /($ air gap thickness $)$, where Keff $=0.0625 \mathrm{~W} /(\mathrm{m} \cdot \mathrm{K})$ from Window 7 on-screen output; R-Value = $1 /$ ( conductance).

c. Calculated: (pane conductance) $=$ (pane conductivity) / (pane thickness); R-Value $=1 /$ (conductance).

d. Value from Annex B4, Section B4.1.

e. Calculated: $(\mathrm{R}$ value, total $)=1 /\left(\mathrm{h}_{\mathrm{s}}\right)+2 *($ pane $\mathrm{R}$ value $)+1 / \mathrm{h}_{\mathrm{i}}+1 / \mathrm{h}_{\mathrm{o}} ;(\mathrm{U}$ Value $)=1 /(\mathrm{R}$ value $)$. This value agrees with

WINDOW 7 output of $\mathrm{U}=2.10 \mathrm{~W} /(\mathrm{m} \cdot \mathrm{K})$, applying constant combined coefficients in the environmental conditions.

f. Calculated by WINDOW 7, see Informative Annex B6, Section B6.1. This matches, within rounding tolerance, SHGC from Equations 13, 14, and 16 (pp. 15.19-20) of ASHRAE 2017 Fundamentals $^{\mathrm{B}-101}$.

g. Table 5-12 includes angle-dependent optical properties calculated by WINDOW 7.

h. WINDOW 7 on-screen value. This matches within rounding tolerance SC = SHGC/0.87 per Eqn. 91 (p. 31.39) of ASHRAE 2005 Fundamentals ${ }^{\mathrm{B}-32}$.

i. Calculated, based on Informative Annex B6, Section B6.2. 
Table 5-12 Alternative Angular-Dependent Optical Properties of the Double-Pane Windowa,b,c

\begin{tabular}{ccccccc}
\hline $\begin{array}{c}\text { Angle of } \\
\text { Incidence, deg }\end{array}$ & Trans. & Refl.,f & Refl.,b & $\begin{array}{c}\text { Abs. } \\
\text { Outer Pane }\end{array}$ & $\begin{array}{c}\text { Abs. } \\
\text { Inner Pane }\end{array}$ & SHGC $^{\text {d }}$ \\
\hline \hline 0 & $\mathbf{0 . 7 0 3}$ & $\mathbf{0 . 1 2 8}$ & $\mathbf{0 . 1 2 8}$ & $\mathbf{0 . 0 9 6}$ & $\mathbf{0 . 0 7 2}$ & $\mathbf{0 . 7 6 9}$ \\
10 & $\mathbf{0 . 7 0 2}$ & $\mathbf{0 . 1 2 8}$ & $\mathbf{0 . 1 2 8}$ & $\mathbf{0 . 0 9 7}$ & $\mathbf{0 . 0 7 3}$ & $\mathbf{0 . 7 6 8}$ \\
20 & $\mathbf{0 . 6 9 9}$ & $\mathbf{0 . 1 2 8}$ & $\mathbf{0 . 1 2 8}$ & $\mathbf{0 . 0 9 9}$ & $\mathbf{0 . 0 7 4}$ & $\mathbf{0 . 7 6 6}$ \\
30 & $\mathbf{0 . 6 9 2}$ & $\mathbf{0 . 1 3 0}$ & $\mathbf{0 . 1 3 0}$ & $\mathbf{0 . 1 0 2}$ & $\mathbf{0 . 0 7 5}$ & $\mathbf{0 . 7 6 1}$ \\
40 & $\mathbf{0 . 6 7 8}$ & $\mathbf{0 . 1 3 9}$ & $\mathbf{0 . 1 3 9}$ & $\mathbf{0 . 1 0 6}$ & $\mathbf{0 . 0 7 7}$ & $\mathbf{0 . 7 4 8}$ \\
50 & $\mathbf{0 . 6 4 6}$ & $\mathbf{0 . 1 6 4}$ & $\mathbf{0 . 1 6 4}$ & $\mathbf{0 . 1 1 2}$ & $\mathbf{0 . 0 7 8}$ & $\mathbf{0 . 7 1 8}$ \\
60 & $\mathbf{0 . 5 7 7}$ & $\mathbf{0 . 2 2 7}$ & $\mathbf{0 . 2 2 7}$ & $\mathbf{0 . 1 1 9}$ & $\mathbf{0 . 0 7 7}$ & $\mathbf{0 . 6 5 1}$ \\
70 & $\mathbf{0 . 4 3 8}$ & $\mathbf{0 . 3 6 5}$ & $\mathbf{0 . 3 6 5}$ & $\mathbf{0 . 1 2 7}$ & $\mathbf{0 . 0 7 0}$ & $\mathbf{0 . 5 0 9}$ \\
80 & $\mathbf{0 . 2 0 8}$ & $\mathbf{0 . 6 1 2}$ & $\mathbf{0 . 6 1 2}$ & $\mathbf{0 . 1 3 0}$ & $\mathbf{0 . 0 5 0}$ & $\mathbf{0 . 2 6 7}$ \\
90 & 0.000 & 1.000 & 1.000 & 0.000 & 0.000 & 0.000 \\
Hemis. & $\mathbf{0 . 6 0 1}$ & $\mathbf{0 . 2 0 6}$ & $\mathbf{0 . 2 0 6}$ & $\mathbf{0 . 1 1 0}$ & $\mathbf{0 . 0 7 3}$ & $\mathbf{0 . 6 7 0}$ \\
\hline
\end{tabular}

a. "deg" = degrees; "Trans." = transmittance; "Refl.,f" = overall solar reflectance for radiation incident from the front (i.e., from the outside);

"Refl.,b" = overall solar reflectance for radiation incident from the back (i.e., from inside the zone); "Abs." = absorptance; SHGC = solar heat gain coefficient; "Hemis." = hemispherically integrated. "Refl.,f" = "Refl.,b", for this glazing system.

b. Informative Note: Changes to Standard 140-2017 are highlighted with bold font.

c. Informative Note: Properties evaluated using WINDOW $7^{\mathrm{A}-3}$; see Annex B6, Section B6.1.

d. Informative Note: This matches, within rounding tolerance, SHGC from Equations 13, 14, and 16 (pp. 15.19-20) of ASHRAE 2017 Fundamentals ${ }^{\mathrm{B}-101}$.

\subsubsection{Interior Solar Distribution.}

5.2.1.12.1 This is the fractional distribution among interior surfaces of solar radiation transmitted through the windows that is absorbed by each given surface after all reflections off of interior surfaces and accounting for solar lost (transmitted solar radiation reflected by interior opaque surfaces and retransmitted back out the windows). For programs that calculate interior solar distribution internally (via ray tracing or other means based on interior solar absorptance given in Table 5-5), and do not require a separate input for interior solar distribution fraction, ignore Section 5.2.1.12.2 and skip to Section 5.2.1.13.

5.2.1.12.2 If the program being tested does not calculate interior solar distribution internally but requires distribution fractions from the user, then the use of Table 5-13 shall be permitted. Use of different (nonspecified) values shall not be prohibited if there is a mathematical, physical, or logical basis for applying them. Where different values are used, they shall be applied consistently throughout the test cases. The use of nonspecified values shall be documented in the Standard Output Report (Normative Annex A2).

Informative Note: Table 5-13 presents an approximate calculation of solar distribution fractions by assuming that $100 \%$ of the incoming radiation strikes the floor first and that all reflections are diffuse. Fractional values for the walls with windows (i.e., the south wall) include the portion of the solar radiation absorbed by the glass (as it passes back out the window) and conducted back into the zone. Solar radiation absorbed by the glass (and conducted inward) as it initially passes into the building is not included in the values in Table 5-13. Informative Annex B7 gives background information regarding the calculation technique used for developing these solar fractions. 
Table 5-13 Alternative Constant Interior Solar Distribution Fractions by Surface, Case $600^{a}$

\begin{tabular}{cccccccc}
\hline Surface & Floor & Ceiling & $\begin{array}{c}\text { East } \\
\text { Wall }\end{array}$ & $\begin{array}{c}\text { West } \\
\text { Wall }\end{array}$ & $\begin{array}{c}\text { North } \\
\text { Wall }\end{array}$ & $\begin{array}{c}\text { South } \\
\text { Wall }\end{array}$ & $\begin{array}{c}\text { Solar Lost } \\
\text { through } \\
\text { Windows }\end{array}$ \\
\hline \hline Solar Fraction & 0.642 & $\mathbf{0 . 1 6 7}$ & 0.038 & 0.038 & 0.053 & $\mathbf{0 . 0 2 7}$ & 0.035 \\
\hline
\end{tabular}

a. Informative Note: Values that were changed from Standard 140-2017 are highlighted with bold font.

5.2.1.13 Mechanical System. All equipment shall be $100 \%$ efficient with no duct losses and no capacity limitations. The mechanical system shall be modeled with the following features as specified below and in Sections 5.2.1.13.1 and 5.2.1.13.2:

a. $100 \%$ convective air system.

b. The thermostat senses only the air temperature.

c. Nonproportional-type thermostat (as specified in Section 5.2.1.13.1).

d. No latent heat extraction.

Informative Note: The intent of the mechanical system is to produce only pure heating load and sensible cooling load outputs.

\subsection{Thermostat Control Strategy}

5.2.1.13.1.1 The following thermostat control strategy shall be used:

- Heat $=\mathrm{ON}$ if temperature $<20^{\circ} \mathrm{C}$; otherwise, Heat $=$ OFF

- $\mathrm{Cool}=\mathrm{ON}$ if temperature $>27^{\circ} \mathrm{C}$; otherwise, $\mathrm{Cool}=$ OFF.

Informative Note: "Temperature" refers to conditioned-zone air temperature.

5.2.1.13.1.2 The thermostat is nonproportional.

Informative Note: A nonproportional thermostat operates such that when the conditioned-zone air temperature exceeds the thermostat cooling set point, the heat extraction rate is adjusted to maintain the zone air temperature exactly at the cooling set point. Likewise, when the conditioned-zone air temperature drops below the thermostat heating set point, the heat addition rate is adjusted to maintain the zone air temperature exactly at the heating set point. A proportional thermostat throttles the heat addition rate (or extraction rate) in proportion to the difference between the zone set point temperature and the actual zone temperature. A proportional thermostat model can be made to approximate a nonproportional thermostat model by setting a very small throttling range (the minimum allowed by the program being tested).

5.2.1.13.2 Equipment Characteristics. The following inputs shall be used:

- Heating capacity $=1000 \mathrm{~kW}$ (effectively infinite).

- Effective efficiency $=100 \%$.

- Cooling capacity $=1000 \mathrm{~kW}$ (effectively infinite).

- Effective efficiency $=100 \%$.

- Sensible cooling only; no latent heat load calculation.

- Waste heat from fan $=0$.

Equipment efficiency shall always be $100 \%$ independent of part loading, indoor dry-bulb temperature and humidity ratio, outdoor dry-bulb temperature and humidity ratio, and/or other conditions. 
5.2.2 Basic Tests. The basic tests shall be modeled as specified in this section and its subsections. The basic tests include Cases 610 through 995 and 600FF through 980FF.

Informative Note: For convenience to users, the base cases for developing the various basic tests are as shown in Informative Table 5-14 and Informative Figure 5-2. In Informative Table 5-14, "Secondary Base Case" indicates additional cases from which selected input specifications for the given test case are applied.

Informative Note: It is recommended to double check the Case 600 base building inputs and to diagnose Case 600 results disagreements before going on to the other cases.

Informative Table 5-14 Base Cases for Basic Tests of Section 5.2.2

\begin{tabular}{|c|c|c|c|c|c|c|}
\hline \multirow[b]{2}{*}{ Primary Tested Feature } & \multicolumn{3}{|c|}{ Low-Mass Building } & \multicolumn{3}{|c|}{ High-Mass Building } \\
\hline & Case & $\begin{array}{c}\text { Primary } \\
\text { Base } \\
\text { Case }\end{array}$ & $\begin{array}{l}\text { Secondary } \\
\text { Base Case }\end{array}$ & Case & $\begin{array}{l}\text { Primary } \\
\text { Base } \\
\text { Case }\end{array}$ & $\begin{array}{l}\text { Secondary } \\
\text { Base Case }\end{array}$ \\
\hline South Windows Base Case & 600 & --- & --- & 900 & 600 & --- \\
\hline South Shade (overhang) & 610 & 600 & --- & 910 & 610 & 900 \\
\hline East/West Windows & 620 & 600 & --- & 920 & 620 & 900 \\
\hline East/West Shade (ohang + fins) & 630 & 620 & 610 & 930 & 630 & 900 \\
\hline Thermostat Setback & 640 & 600 & --- & 940 & 640 & 900 \\
\hline Night Ventilation & 650 & 600 & --- & 950 & 650 & 900 \\
\hline Low-Emissivity Windows & 660 & 600 & --- & & & \\
\hline Single-Pane Windows & 670 & 600 & --- & & & \\
\hline Sunspace & & & & 960 & 600 & 900 \\
\hline Increased Insulation & 680 & 600 & --- & 980 & 900 & --- \\
\hline “20,20” Thermostat (Tstat) & 685 & 600 & --- & 985 & 900 & 685 \\
\hline $\begin{array}{l}\text { Increased Insulation + “20,20” } \\
\text { Tstat }\end{array}$ & 695 & 680 & 685 & 995 & 980 & 685 \\
\hline $\begin{array}{l}\text { Free Float, Base Case } \\
\text { (S. windows) }\end{array}$ & $600 \mathrm{FF}$ & 600 & --- & $900 \mathrm{FF}$ & 900 & $600 \mathrm{FF}$ \\
\hline Free Float, Night Ventilation & $650 \mathrm{FF}$ & 650 & $600 \mathrm{FF}$ & $950 \mathrm{FF}$ & 950 & $650 \mathrm{FF}$ \\
\hline Free Float, Increased Insulation & $680 \mathrm{FF}$ & 680 & $600 \mathrm{FF}$ & $980 \mathrm{FF}$ & 980 & $600 \mathrm{FF}$ \\
\hline
\end{tabular}




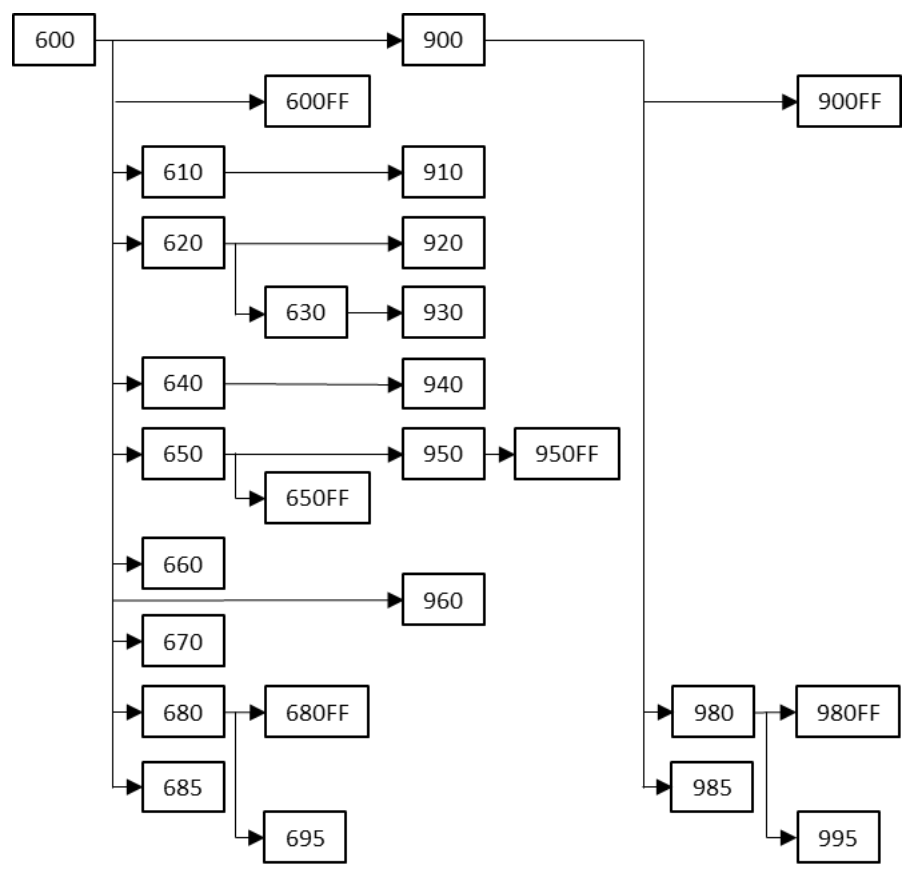

Informative Figure 5-2 Primary base cases for basic cases of Section 5.2.2.

5.2.2.1 Low-Mass Tests. The low-mass basic tests shall be modeled as specified in this section and its subsections. The low-mass basic tests include cases 600 through 695. Once an accurate input description for Case 600 has been developed, the remaining low-mass basic cases shall be input by modifying Case 600, except for the following cases:

- Case 630 shall be input by modifying Case 620 .

- Case 695 shall be input by modifying Case 680.

5.2.2.1.1 Case 610: South Shading. Case 610 shall be modeled exactly the same as Case 600 except for changes specified in the subsections below.

5.2.2.1.1.1 South Overhang Geometry. The overhang specified in Figure 5-3 shall be added. The horizontal overhang for south-facing windows shall extend across the entire length of the south wall.

5.2.2.1.1.2 Overhang Construction.

5.2.2.1.1.2.1 Properties. The following properties shall be applied to both sides of the shading device as nearly as the program being tested allows:

a. Solar absorptance $=1($ reflectance $=0$, transmittance $=0)$, independent of incidence angle.

b. Infrared emittance $=0$.

c. All heat from solar radiation absorbed by the shading device is dissipated to the ambient environment via convection.

d. Both sides of the shading device actively shade the building.

Informative Note: For properties with values of 0 , apply the lowest value allowed by the program being tested for stable simulation (e.g., 0.0001).

5.2.2.1.1.2.2 Thickness. If the program requires an input for thickness of shading devices, the smallest allowable value shall be applied (e.g., $0.001 \mathrm{~m}$ ).

5.2.2.1.1.3 Output Requirements. Case 610 requires the following output:

a. All non-free-float-case output in accordance with Section 6.2.1.1.

b. Additional output in accordance with Section 6.2.1.3.

c. General reporting requirements of Section 6.1. 


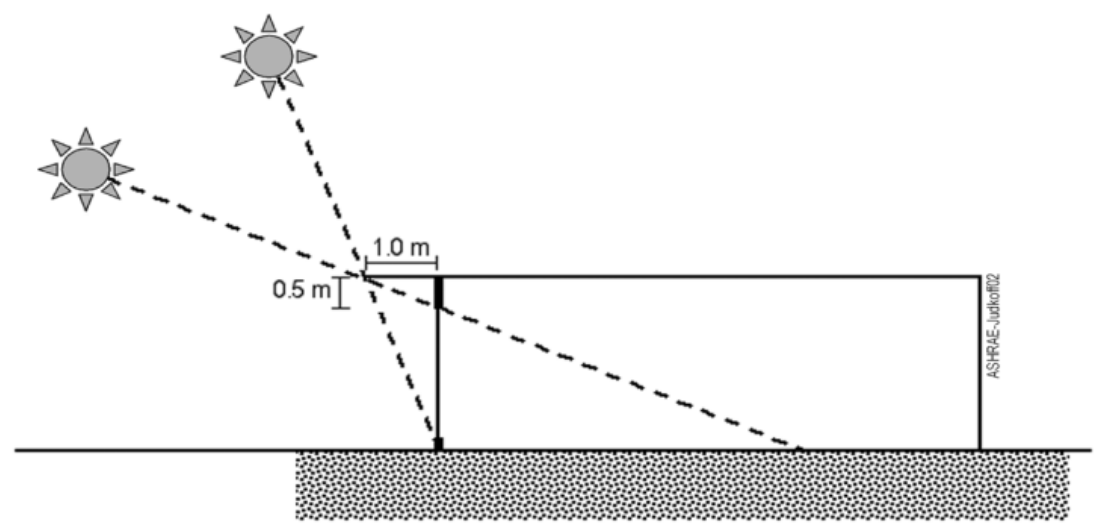

Figure 5-3 Section of south window overhang (Case 610).

\subsection{Case 620: East/West Window Orientation.}

Case 620 shall be modeled exactly the same as Case 600 except for changes specified in the subsections below. 5.2.2.1.2.1 Window Orientation. The window orientation shall be modified, as specified in Figure 5-4, such that there shall be $6 \mathrm{~m}^{2}$ of window area facing east, $6 \mathrm{~m}^{2}$ of window area facing west, and no other windows. Other than the change in orientation, the windows shall be exactly as in Case 600 .

\subsection{Interior Solar Distribution.}

5.2.2.1.2.2.1 This is the fractional distribution among interior surfaces of solar radiation transmitted through the windows that is absorbed by each given surface after all reflections off of interior surfaces and accounting for solar lost (transmitted solar radiation reflected by interior opaque surfaces and retransmitted back out the windows). For programs that calculate interior solar distribution internally (via ray tracing or other means based on interior solar absorptance given in Table 5-5), and do not require a separate input for interior solar distribution fraction, ignore the following Section 5.2.2.1.2.2.2 and skip to Section 5.2.2.1.2.3.

5.2.2.1.2.2.2 If the program being tested does not calculate interior solar distribution internally but requires distribution fractions from the user, then the use of Table 5-15 shall be permitted. Use of different (nonspecified) values shall not be prohibited if there is a mathematical, physical, or logical basis for applying them. Where different values are used, they shall be applied consistently throughout the test cases. The use of nonspecified values shall be documented in the Standard Output Report (see Normative Annex A2).

Informative Note: Table 5-15 presents an approximate calculation of solar distribution fractions adjusted for the geometry of Case 620 by assuming that $100 \%$ of the incoming radiation strikes the floor first and that all reflections are diffuse. Fractional values for the walls with windows (i.e., the east and west walls) include the portion of the solar radiation absorbed by the glass (as it passes back out the window) and conducted back into the zone. Solar radiation absorbed by the glass (and conducted inward) as it initially passes into the building is not included in the values in Table 5-15. Informative Annex B7 gives background information regarding the calculation technique used for developing these solar fractions.

5.2.2.1.2.3 Output Requirements. Case 620 requires the following output:

a. All non-free-float case output in accordance with Section 6.2.1.1.

b. Additional output in accordance with Section 6.2.1.4.

c. General reporting requirements of Section 6.1. 

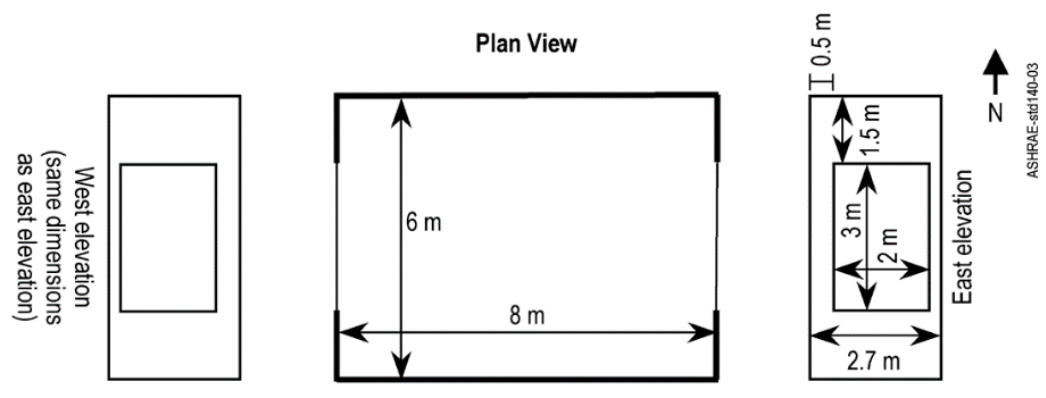

Figure 5-4 East and west window (Case 620).

Table 5-15 Alternative Constant Interior Solar Distribution Fractions by Surface, Case $620^{\mathrm{a}}$

\begin{tabular}{cccccccc}
\hline Surface & Floor & Ceiling & $\begin{array}{c}\text { East } \\
\text { Wall }\end{array}$ & $\begin{array}{c}\text { West } \\
\text { Wall }\end{array}$ & $\begin{array}{c}\text { North } \\
\text { Wall }\end{array}$ & $\begin{array}{c}\text { South } \\
\text { Wall }\end{array}$ & $\begin{array}{c}\text { Solar Lost } \\
\text { Through } \\
\text { Windows }\end{array}$ \\
\hline \hline Solar Fraction & 0.642 & 0.167 & 0.025 & 0.025 & $\mathbf{0 . 0 5 3}$ & $\mathbf{0 . 0 5 3}$ & 0.035 \\
\hline a. Informative Note: Values that were changed from Standard 140-2017 are highlighted with bold font.
\end{tabular}

5.2.2.1.3 Case 630: East/West Shading. Case 630 shall be modeled exactly the same as Case 620 except for changes specified in the subsections below.

\subsection{East/West Overhang and Fin Geometry.}

Shading devices shall be added to the east and west windows as specified in Figures 5-5 and 5-6.

5.2.2.1.3.2 Overhang and Fin Construction. Shading device construction shall be applied as specified in Sections 5.2.2.1.1.2.1 and 5.2.2.1.1.2.2 (Case 610).

5.2.2.1.3.3 Output Requirements. Case 630 requires the following output:

a. All non-free-float case output in accordance with Section 6.2.1.1.

b. Additional output in accordance with Section 6.2.1.5.

c. General reporting requirements of Section 6.1.

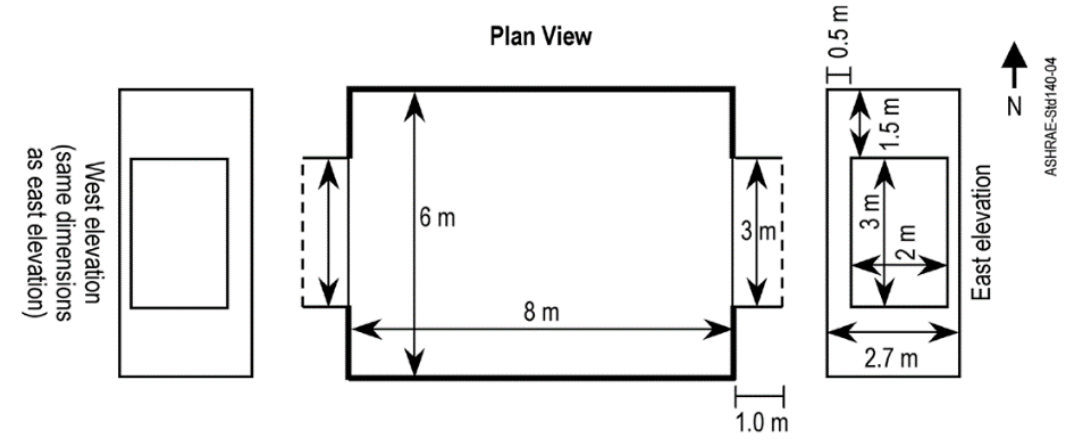

Figure 5-5 East and west window shading (Case 630). 


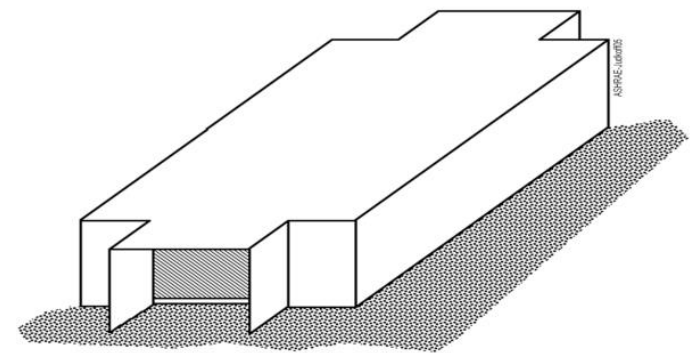

Figure 5-6 Isometric east and west window shading (Case 630).

5.2.2.1.4 Case 640: Thermostat Setback. Case 640 shall be modeled exactly the same as Case 600 except for changes specified in the subsections below.

\subsection{Thermostat Control Strategy}

5.2.2.1.4.1.1 The thermostat set point control shall be scheduled as follows:

a. From 0800 hours to 2300 hours, Heat $=$ ON IF Temperature $<20^{\circ} \mathrm{C}$

b. From 2300 hours to 0700 hours, Heat $=$ ON IF Temperature $<10^{\circ} \mathrm{C}$

$\circ$ The $10^{\circ} \mathrm{C}$ setting beginning immediately after 2300 hours shall be an instantaneous step-down from the $20^{\circ} \mathrm{C}$ setting ending at 2300 hours, as shown in Figure 5-7.

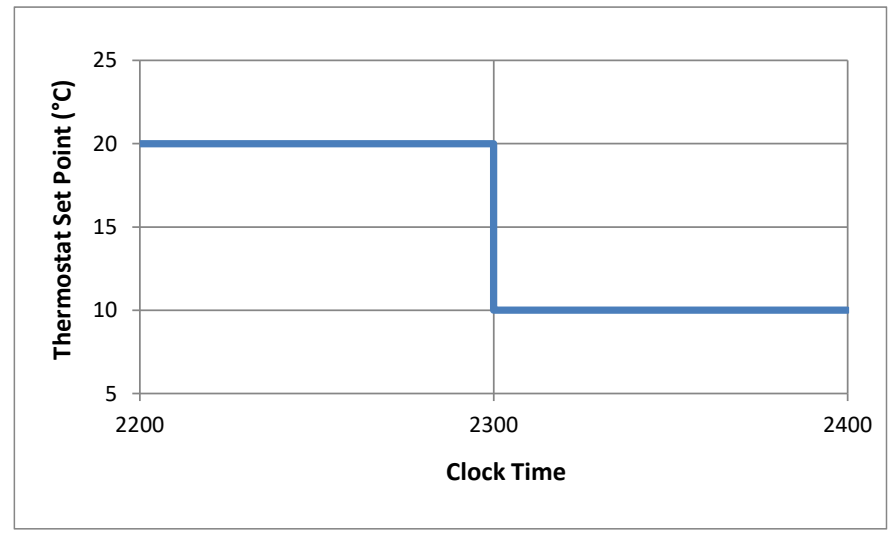

Figure 5-7 Thermostat instantaneous step-down at clock time $=2300$ from $20^{\circ} \mathrm{C}$ to $10^{\circ} \mathrm{C}($ Case 640$)$.

c. From 0700 hours to 0800 hours, the thermostat set point shall vary linearly with time from $10^{\circ} \mathrm{C}$ to $20^{\circ} \mathrm{C}$ as shown in Figure 5-8. If the program runs with sub-hourly time steps, the instructions in the following Section 5.2.2.1.4.1(c.1) shall be applied; then skip Section 5.2.2.1.4.1(c.2) and continue with Section 5.2.2.1.4.1(d). If the program runs with hourly time steps, the instructions of Section 5.2.2.1.4.1(c.2) (below) shall be applied.

c. 1 For programs with sub-hourly time steps, during the hour 0700-0800, if the zone temperature is less than the thermostat set point for a sub-hourly time step, heat shall be added to the zone such that the zone temperature at the end of each sub-hourly time step shall correspond to the thermostat set point that occurs at the end of each sub-hourly time step (see Figure 5-8), and such that zone temperature $=20^{\circ} \mathrm{C}$ at 0800 .

Informative Note: For example, incremental linear ramp-up implies that for a 15-minute time step, the set point ramps up as $12.5^{\circ} \mathrm{C}, 15^{\circ} \mathrm{C}, 17.5^{\circ} \mathrm{C}$, and $20^{\circ} \mathrm{C}$ within the hour $(0700-0800)$.

c. 2 For programs with hourly time steps, during the hour $0700-0800$, if zone temperature $<20^{\circ} \mathrm{C}$ at 0700 , heat shall be added to the zone during the hour such that zone temperature $=20^{\circ} \mathrm{C}$ at 0800 . 


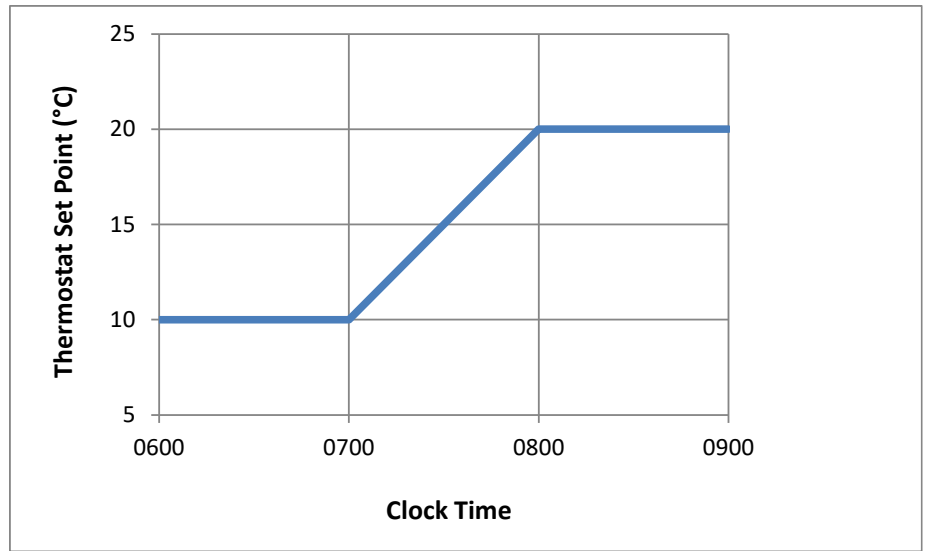

Figure 5-8 Thermostat linear variation from $10^{\circ} \mathrm{C}$ to $20^{\circ} \mathrm{C}$ for clock time $=0700$ to 0800 (Case 640 ).

d. All hours, Cool $=$ ON IF Temperature $>27^{\circ} \mathrm{C}$.

e. Otherwise, mechanical equipment is OFF.

Informative Note: "Temperature" refers to the conditioned-zone air temperature.

5.2.2.1.4.1.2 A nonproportional thermostat as specified in Section 5.2.1.13.1.2 (Case 600) shall be used.

5.2.2.1.4.2 Output Requirements. Case 640 requires the following output:

a. All non-free-float case output in accordance with Section 6.2.1.1.

b. Daily hourly output as specified for Case 640 in Section 6.2.1.8.

c. General reporting requirements of Section 6.1 .

5.2.2.1.5 Case 650: Night Ventilation. Case 650 shall be modeled exactly the same as Case 600 except for changes specified in the subsections below.

5.2.2.1.5.1 Thermostat and Ventilation Fan Control Strategy.

5.2.2.1.5.1.1 The following configuration schedule shall be applied:

- From 1800 hours to 0700 hours, Vent fan $=$ ON.

(1800 to 0700 is the same as Hour 19 through Hour 7 per the time convention of Section 5.1.1.)

- From 0700 hours to 1800 hours, Vent fan = OFF.

(0700 to 1800 is the same as Hour 8 through Hour 18 per the time convention of Section 5.1.1.)

- Heating = always OFF.

- From 1800 hours to 0700 hours, Cool = OFF.

- From 0700 hours to 1800 hours, $\mathrm{Cool}=\mathrm{ON} \mathrm{IF}$ Temperature $>27^{\circ} \mathrm{C}$; otherwise, $\mathrm{Cool}=\mathrm{OFF}$.

Informative Note: "Temperature" refers to the conditioned-zone air temperature.

5.2.2.1.5.1.2 A nonproportional thermostat as specified in Section 5.2.1.13.1.2 (Case 600) shall be used.

5.2.2.1.5.2 Ventilation Fan Characteristics

a. Vent fan capacity $=1700$ standard $\mathrm{m}^{3} / \mathrm{h}$ (in addition to specified infiltration rate of Section 5.2.1.6 [Case 600]).

b. Waste heat from fan $=0$.

c. If the program being tested does not automatically correct for the reduced density of air at altitude, inputs for the fan capacity shall be adjusted as shown in Table 5-16.

Informative Note: The calculation technique used to develop Table 5-16 is provided as background information in Informative Annex B3, Section B3.1. 
Table 5-16 Vent Fan Airflow Rate Depending on the Presence of Automatic Altitude Adjustment ${ }^{\mathrm{a}}$

\begin{tabular}{lcc} 
Vent Fan Volumetric Airflow Rate & $\mathbf{m}^{\mathbf{3} / \mathbf{h}}$ & $\begin{array}{c}\text { Air Changes per } \\
\text { Hour, ach }\end{array}$ \\
\hline \hline $\begin{array}{l}\text { Input for programs that automatically correct vent fan mass flow for } \\
\text { altitude; set altitude to } \mathbf{1 6 5 0} \mathrm{m} \text { above sea level. }\end{array}$ & $\mathbf{1 7 0 0}$ & $\mathbf{1 3 . 1 2}$ \\
\hline $\begin{array}{l}\text { Input for programs with fixed assumption that site is at sea level } \\
\text { (no automatic correction of fan mass flow). }\end{array}$ & $\mathbf{1 4 0 9}$ & $\mathbf{1 0 . 8 7}$ \\
\hline
\end{tabular}

a. Informative Note: Changes to Standard 140-2017 are highlighted with bold font.

b. $($ Specified Rate $) \times(1.0156 / 1.2255)=($ altitude adjusted rate $)$

5.2.2.1.5.3 Output Requirements. Case 650 requires the following output:

a. All non-free-float case output in accordance with Section 6.2.1.1.

b. General reporting requirements of Section 6.1.

5.2.2.1.6 Case 660: Low-Emissivity Windows with Argon Gas.

Case 660 shall be modeled exactly the same as Case 600 except for changes specified in the subsections below.

\subsection{Transparent Window.}

Informative Note: Use of different algorithms to calculate window thermal and optical performance requires different inputs. Extensive information about the window properties has therefore been provided so that equivalent input for the window will be possible for many programs. As stated in Section 5.1.3 (Nonapplicable Inputs), use only the information that is relevant to the program being tested.

5.2.2.1.6.1.1 Geometry. The windows shall have no sash area; the rough openings shown in Figure 5-1 (see Section 5.2.1.11.1 [Case 600]) shall contain only the low-e argon-filled window specified in Table 5-17.

5.2.2.1.6.1.2 Window Properties. The properties of the window provided in Table 5-17 shall be applied. All glass pane surfaces are clean; there is no dirt or fouling.

Informative Note, Calculated Properties of Informative Table 5-18: Informative Table 5-18 includes calculated values derived from fundamental properties of normative Table 5-17 and alternative constant surface coefficients of Sections 5.2.1.9.3 and 5.2.1.10.3 (Case 600), for programs that may need this information.

Informative Note, Corresponding Overall UA Values: For programs that may need this information, corresponding calculated values for south window UA and total building UA are as follows:

- South Window UA = $14.239 \mathrm{~W} / \mathrm{K}$.

- Total Building UA $=74.495 \mathrm{~W} / \mathrm{K}$.

These values for Case 660 (low-e window) are analogous to those UA values listed in Informative Table 5-3 (see informative note with Section 5.2.1.4 [Case 600]) for the clear double-pane window of Case 600.

Informative Note, Variation of Listed Surface Coefficients and Overall U-Values from Values of Informative Table 5-18. For programs that calculate time-step-varying surface infrared radiative exchange or convective coefficients or both, or that allow more detailed constant surface coefficient inputs (e.g., for scheduling), variation of the following from values given in Table 5-18 may be expected: individual surface coefficient U-values, effective conductance of the space between window panes, and overall U-value.

Informative Note, Variation of Conductance of the Space Between Window Panes from Values of Informative Table 5-18: For programs that automatically calculate heat transfer within a space between window panes or empty cavity, variation of the following from values given in Table 5-18 may be expected: effective conductance of the space between window panes and overall U-value. 
Table 5-17 Fundamental Properties of Low-Emissivity Argon-Filled Glazing System

\begin{tabular}{|c|c|}
\hline Property & Value \\
\hline \multicolumn{2}{|l|}{ Fundamental Construction Properties } \\
\hline Height, individual rough opening & $2 \mathrm{~m}$ \\
\hline Width, individual rough opening & $3 \mathrm{~m}$ \\
\hline Area, individual gross window (also center of glass area) & $6 \mathrm{~m}^{2}$ \\
\hline Number of panes & 2 \\
\hline Outer (low-e) pane thickness ${ }^{\mathrm{a}}$ & $3.180 \mathrm{~mm}$ \\
\hline Inner (clear) pane thickness ${ }^{b}$ & $3.048 \mathrm{~mm}$ \\
\hline Thickness of space between panes ${ }^{c}$ & $12.0 \mathrm{~mm}$ \\
\hline Fill gas (in space between panes) & Argon \\
\hline $\begin{array}{l}\text { Curtains, blinds, frames, spacers, mullions, obstructions } \\
\text { inside the window }\end{array}$ & None \\
\hline \multicolumn{2}{|l|}{ Basic Material Properties } \\
\hline Thermal conductivity of glass ${ }^{\mathrm{a}, \mathrm{b}}$ & $1.00 \mathrm{~W} /(\mathrm{m} \cdot \mathrm{K})$ \\
\hline Density of glass ${ }^{\mathrm{d}}$ & $2470 \mathrm{~kg} / \mathrm{m}^{3}$ \\
\hline Specific heat of glass ${ }^{\mathrm{d}}$ & $750 \mathrm{~J} /(\mathrm{kg} \cdot \mathrm{K})$ \\
\hline Argon: conductivity $(\mathrm{k})^{\mathrm{e}, \mathrm{f}}$ & $\begin{array}{l}0.016349 \mathrm{~W} /(\mathrm{m} \cdot \mathrm{K}), \text { shall be allowed to vary } \\
\text { with temperature and pressure }\end{array}$ \\
\hline Argon: specific heat $\left(c_{p}\right)^{e, f}$ & $\begin{array}{l}521.928528 \mathrm{~J} /(\mathrm{kg} \cdot \mathrm{K}) \text {, shall be allowed to vary } \\
\text { with temperature and pressure }\end{array}$ \\
\hline Argon: density $(\rho)^{\mathrm{e}, \mathrm{f}}$ & $\begin{array}{l}1.782282 \mathrm{~kg} / \mathrm{m}^{3}, \text { shall be allowed to vary with } \\
\text { temperature and pressure }\end{array}$ \\
\hline Argon: viscosity $(\mu)^{e, f}$ & $\begin{array}{l}0.000021 \mathrm{~kg} /(\mathrm{m} \cdot \mathrm{s}) \text {, shall be allowed to vary } \\
\text { with temperature and pressure }\end{array}$ \\
\hline Argon: Prandtl number $(\operatorname{Pr})^{\mathrm{e}, \mathrm{f}}$ & $\begin{array}{c}0.6704 \text { (dimensionless), shall be allowed to } \\
\text { vary with temperature and pressure }\end{array}$ \\
\hline Argon: molecular weight ${ }^{\mathrm{e}}$ & $39.948 \mathrm{~g} / \mathrm{mol}$ \\
\hline Hemispherical infrared emittance of glass ${ }^{\mathrm{a}, \mathrm{b}}$ & 0.840 , except outer pane inside facing surface \\
\hline Outer-pane inside facing surface infrared emittance ${ }^{a}$ & 0.047 \\
\hline Infrared transmittance of glass ${ }^{\mathrm{a}, \mathrm{b}}$ & 0.000 \\
\hline Outer-pane direct-beam transmittance ${ }^{\mathrm{a}}$ & 0.452 , at normal incidence \\
\hline Outer-pane direct-beam refl., outside facing surface ${ }^{a}$ & 0.359 , at normal incidence \\
\hline Outer-pane direct-beam reflectance, inside facing surface ${ }^{a}$ & 0.397 , at normal incidence \\
\hline Inner-pane direct-beam transmittance ${ }^{b}$ & 0.834 , at normal incidence \\
\hline Inner-pane direct-beam reflectance (same value both sides) ${ }^{b}$ & 0.075 , at normal incidence \\
\hline
\end{tabular}

a. Informative Note: Value from WINDOW 7 glass library, "CSR42_3.afg"; this pane is the same as the outer pane of the double-pane low-e window for WINDOW 7 glazing system ID 3 (basic low-e example).

b. Informative Note: Value from WINDOW 7 glass library, "CLEAR_3.DAT"; this is the same as the Case 600 pane.

c. Informative Note: Value same as the Case 600 glazing system.

d. Informative Note: Value for soda-lime glass from 2017 ASHRAE Fundamentals (SI version) ${ }^{\mathrm{B}-101}$, p. 33.3.

e. Informative Note: Value from WINDOW 7 gas library, "Argon".

f. Informative Note: In WINDOW 7 this value is reported at $0^{\circ} \mathrm{C}, 101.325 \mathrm{kPa}$. 
Informative Table 5-18 Calculated Properties of Low-Emissivity Argon-Filled Glazing System

Effective conductance of argon gap, including radiative and convective heat transfer $\left(h_{s}\right)^{\mathrm{a}}$

Conductance of outer pane ${ }^{b}$

Conductance of inner pane ${ }^{b}$

Exterior combined surface coefficient $\left(h_{o}\right)^{\mathrm{c}}$

Interior combined surface coefficient $\left(h_{i}\right)^{\mathrm{c}}$

$\mathrm{U}$-Value from interior air to ambient air ${ }^{\mathrm{d}}$

Double-pane solar heat gain coefficient $\left(\right.$ SHGC) ${ }^{\mathrm{e}}$

$1.792 \mathrm{~W} /\left(\mathrm{m}^{2} \cdot \mathrm{K}\right) \quad\left[\mathrm{R}-0.55814 \mathrm{~m}^{2} \cdot \mathrm{K} / \mathrm{W}\right]$

Double-pane shading coefficient (SC) ${ }^{\mathrm{g}}$

$314 \mathrm{~W} /\left(\mathrm{m}^{2} \cdot \mathrm{K}\right) \quad\left[\mathrm{R}-0.00318 \mathrm{~m}^{2} \cdot \mathrm{K} / \mathrm{W}\right]$

Index of refraction, inner pane ${ }^{\mathrm{h}}$

$328 \mathrm{~W} /\left(\mathrm{m}^{2} \cdot \mathrm{K}\right) \quad\left[\mathrm{R}-0.00305 \mathrm{~m}^{2} \cdot \mathrm{K} / \mathrm{W}\right]$

Extinction coefficient, inner pane ${ }^{\mathrm{h}}$

$17.8 \mathrm{~W} /\left(\mathrm{m}^{2} \cdot \mathrm{K}\right) \quad\left[\mathrm{R}-0.05618 \mathrm{~m}^{2} \cdot \mathrm{K} / \mathrm{W}\right]$

Index of refraction, outer pane

$4.5 \mathrm{~W} /\left(\mathrm{m}^{2} \cdot \mathrm{K}\right) \quad\left[\mathrm{R}-0.22222 \mathrm{~m}^{2} \cdot \mathrm{K} / \mathrm{W}\right]$

$1.19 \mathrm{~W} /\left(\mathrm{m}^{2} \cdot \mathrm{K}\right) \quad\left[\mathrm{R}-0.84277 \mathrm{~m}^{2} \cdot \mathrm{K} / \mathrm{W}\right]$

0.440 , at normal incidence ${ }^{\mathrm{f}}$

0.506 , at normal incidence

$0.0337 / \mathrm{mm}$

Extinction coefficient, outer pane

Not calculated ${ }^{\mathrm{i}}$

Not calculated ${ }^{\mathrm{i}}$

a. Calculated: (argon gap conductance $)=($ Keff $) /($ thickness of space between panes $)$, where Keff $=0.0215 \mathrm{~W} /(\mathrm{m} \cdot \mathrm{K}) \mathrm{from}$

Window 7 on-screen output; R-Value $=1 /$ (conductance).

b. Calculated: $($ pane conductance $)=($ pane conductivity $) /($ pane thickness $) ; \mathrm{R}-$ Value $=1 /$ (conductance $)$.

c. Value from Annex B4, Section B4.1.

d. Calculated: $(\mathrm{R}$ value, total $)=1 /\left(\mathrm{h}_{\mathrm{s}}\right)+($ outer pane $\mathrm{R}$ value $)+($ inner pane $\mathrm{R}$ value $)+1 / \mathrm{h}_{\mathrm{i}}+1 / \mathrm{h}_{\mathrm{o}}$; $(\mathrm{U}$ Value $)=1 /(\mathrm{R}$ value $)$. This value agrees with WINDOW 7 output of $\mathrm{U}=1.19 \mathrm{~W} /(\mathrm{m} \cdot \mathrm{K})$, applying constant combined coefficients in the environmental conditions.

e. Calculated by WINDOW 7, see Informative Annex B6, Section B6.1. This matches, within rounding tolerance, SHGC from Equations 13, 14, and 16 (pp. 15.19-20) of ASHRAE 2017 Fundamentals $^{\mathrm{B}-101}$.

f. Table 5-19 includes angle-dependent optical properties calculated by WINDOW 7.

g. WINDOW 7 on-screen value. This matches, within rounding tolerance, SC $=$ SHGC/0.87 per Eqn. 91 (p. 31.39 ) of ASHRAE 2005 Fundamentals ${ }^{\mathrm{B}-32}$.

h. Calculated, based on Informative Annex B6, Section B6.2.

i. Single values of index of refraction and extinction coefficient do not adequately describe the optical properties of coated glass.

\subsection{3 Alternative Incidence-Angle-Dependent Optical Properties.}

a. If the program being tested automatically calculates incidence-angle-dependent optical properties based on inputs from Table 5-17, or if the program does not allow direct user input of angle-dependent optical properties, then skip the instructions in this section and proceed to Section 5.2.2.1.6.2.

b. For programs that apply incidence-angle-dependent optical properties as direct inputs, the values given in Table 519 shall be applied.

- For programs that need transmittance or reflectance at other angles of incidence, the user shall be permitted to interpolate between the values in Table 5-19 using the cosine of the incident angle as the basis for interpolation.

- Where unspecified equivalent inputs are needed, values that are consistent with those specified shall be applied according to the instructions of Section 5.1.5, "Equivalent Modeling Methods."

Informative Note: Supporting information regarding window thermal and optical properties is provided in Informative Annex B6. This includes the output report from the WINDOW 7 software $^{\mathrm{A}-3}$ that was applied to generate values in Table 5-19 and selected values in informative Table 5-18, as described in the notes with those tables. This informative data file is included with the accompanying electronic media and may be used by simulation programs that can read it directly. 
Table 5-19 Alternative Angular-Dependent Optical Properties for the Low-Emissivity Windowa,b

\begin{tabular}{ccccccc}
\hline $\begin{array}{c}\text { Angle of } \\
\text { Incidence, deg }\end{array}$ & Trans. & Refl.,f & Refl.,b & $\begin{array}{c}\text { Abs. } \\
\text { Outer Pane }\end{array}$ & $\begin{array}{c}\text { Abs. } \\
\text { Inner Pane }\end{array}$ & SHGC $^{\text {C }}$ \\
\hline \hline 0 & 0.394 & 0.380 & 0.349 & 0.195 & 0.031 & 0.440 \\
10 & 0.397 & 0.375 & 0.344 & 0.197 & 0.031 & 0.443 \\
20 & 0.391 & 0.374 & 0.342 & 0.204 & 0.031 & 0.438 \\
30 & 0.383 & 0.376 & 0.342 & 0.209 & 0.032 & 0.432 \\
40 & 0.373 & 0.384 & 0.347 & 0.211 & 0.032 & 0.422 \\
50 & 0.353 & 0.398 & 0.360 & 0.215 & 0.033 & 0.403 \\
60 & 0.310 & 0.427 & 0.393 & 0.230 & 0.032 & 0.361 \\
70 & 0.228 & 0.496 & 0.476 & 0.247 & 0.029 & 0.278 \\
80 & 0.108 & 0.658 & 0.652 & 0.213 & 0.021 & 0.148 \\
90 & 0.000 & 0.999 & 1.000 & 0.001 & 0.000 & 0.000 \\
Hemis. & 0.329 & 0.415 & 0.384 & 0.215 & 0.031 & 0.377 \\
\hline
\end{tabular}

a. "deg" = degrees; "Trans." = transmittance; "Refl.,f" = overall solar reflectance for radiation incident from the front (i.e., from the outside); "Refl.,b" = overall solar reflectance for radiation incident from the back (i.e., from inside the zone); "Abs." = absorptance; SHGC = solar heat gain coefficient; "Hemis." = hemispherically integrated.

b. Informative Note: Properties are evaluated using WINDOW $7^{\mathrm{A}-3}$; see Annex B6, Section B6.1.

c. Informative Note: This matches, within rounding tolerance, SHGC from Equations 13, 14, and 16 (pp. 15.19-20) of ASHRAE 2017 Fundamentals ${ }^{\mathrm{B}-101}$.

\subsection{Interior Solar Distribution.}

5.2.2.1.6.2.1 This is the fractional distribution among interior surfaces of solar radiation transmitted through the windows that is absorbed by each given surface after all reflections off of interior surfaces and accounting for solar lost (transmitted solar radiation reflected by interior opaque surfaces and retransmitted back out the windows). For programs that calculate interior solar distribution internally (via ray tracing or other means based on interior solar absorptance given in Table 5-5), and do not require a separate input for interior solar distribution fraction, ignore the following Section 5.2.2.1.6.2.2 and skip to Section 5.2.2.1.6.3.

5.2.2.1.6.2.2 If the program being tested does not calculate interior solar distribution internally but requires distribution fractions from the user, then the use of Table 5-20 shall be permitted. Use of different (nonspecified) values shall not be prohibited if there is a mathematical, physical, or logical basis for applying them. Where different values are used, they shall be applied consistently throughout the test cases. The use of nonspecified values shall be documented in the Standard Output Report (Normative Annex A2).

Informative Note: Table 5-20 presents an approximate calculation of solar distribution fractions by assuming that $100 \%$ of the incoming radiation strikes the floor first and that all reflections are diffuse. Fractional values for the walls with windows (i.e., the south wall) include the portion of the solar radiation absorbed by the glass (as it passes back out the window) and conducted back into the zone. Solar radiation absorbed by the glass (and conducted inward) as it initially passes into the building is not included in the values in Table 5-20. Informative Annex B7 gives background information regarding the calculation technique used for developing these solar fractions.

Table 5-20 Alternative Constant Interior Solar Distribution Fractions by Surface, Case 660

\begin{tabular}{cccccccc}
\hline & Floor & Ceiling & Wall & $\begin{array}{c}\text { West } \\
\text { Wall }\end{array}$ & $\begin{array}{c}\text { North } \\
\text { Wall }\end{array}$ & $\begin{array}{c}\text { South } \\
\text { Wall }\end{array}$ & $\begin{array}{c}\text { Solar Lost } \\
\text { through } \\
\text { Windows }\end{array}$ \\
\hline \hline Solar Fraction & 0.645 & 0.170 & 0.039 & 0.039 & 0.054 & 0.026 & 0.027 \\
\hline
\end{tabular}


5.2.2.1.6.3 Output Requirements. Case 660 requires the following output:

a. All non-free-float case output in accordance with Section 6.2.1.1.

b. Additional output in accordance with Section 6.2.1.2.2.

c. Daily hourly output as specified for Case 660 in Section 6.2.1.8.

d. General reporting requirements of Section 6.1.

\subsection{Case 670: Single Pane Windows.}

Case 670 shall be modeled exactly the same as Case 600 except for changes specified in the subsections below.

\subsection{Transparent Window.}

Informative Note: Use of different algorithms to calculate window thermal and optical performance requires different inputs. Extensive information about the window properties has therefore been provided so that equivalent input for the window will be possible for many programs. As stated in Section 5.1.3 (Nonapplicable Inputs), use only the information that is relevant to the program being tested.

5.2. 2.1.7.1.1 Geometry. The windows shall have no sash area; the rough openings shown in Figure 5-1 (see Section 5.2.1.11.1 [Case 600]) shall contain only the single-pane window specified in Table 5-21.

5.2.2.1.7.1.2 Window Properties. The properties of the window provided in Table 5-21 shall be applied. All glass pane surfaces are clean; there is no dirt or fouling.

Informative Note, Calculated Properties of Informative Table 5-22: Informative Table 5-22 includes calculated values derived from fundamental properties of normative Table 5-21 and alternative constant surface coefficients of Sections 5.2.1.9.3 and 5.2.1.10.3 (Case 600), for programs that may need this information.

Informative Note, Corresponding Overall UA Values: For programs that may need this information, corresponding calculated values for south window UA and total building UA are as follows:

- South Window UA $=61.935 \mathrm{~W} / \mathrm{K}$.

- Total Building UA = $122.191 \mathrm{~W} / \mathrm{K}$.

These values for Case 670 (single-pane window) are analogous to those UA values listed in Informative Table 5-3 (see informative note with Section 5.2.1.4 [Case 600]) for the clear double-pane window of Case 600.

Informative Note, Variation of Listed Surface Coefficients and Overall U-Values from Values of Informative

Table 5-22. For programs that calculate time-step-varying surface infrared radiative exchange or convective coefficients or both, or that allow more detailed constant surface coefficient inputs (e.g., for scheduling), variation of the following from values given in Table 5-22 may be expected: individual surface coefficient U-values and overall U-value.

\subsection{3 Alternative Incidence-Angle-Dependent Optical Properties.}

a. If the program being tested automatically calculates incidence-angle-dependent optical properties based on inputs from Table 5-21, or if the program does not allow direct user input of angle-dependent optical properties, then skip the instructions in this section and proceed to Section 5.2.2.1.7.2.

b. For programs that apply incidence-angle-dependent optical properties as direct inputs, the values given in Table 5-23 shall be applied.

- For programs that need transmittance or reflectance at other angles of incidence, the user shall be permitted to interpolate between the values in Table 5-23 using the cosine of the incident angle as the basis for interpolation.

- Where unspecified equivalent inputs are needed, values that are consistent with those specified shall be applied according to the instructions of Section 5.1.5, "Equivalent Modeling Methods."

Informative Note: Supporting information regarding window thermal and optical properties is provided in Informative Annex B6. This includes the output report from the WINDOW 7 software $^{\mathrm{A}-4}$ that was applied to generate values in Table 5-23 and selected values in informative Table 5-22, as described in the notes with those tables. This informative data file is included with the accompanying electronic media and may be used by simulation programs that can read it directly. 
Table 5-21 Fundamental Properties of Clear Single-Pane Glazing System

\begin{tabular}{|c|c|}
\hline Property & Value \\
\hline \multicolumn{2}{|l|}{ Fundamental Construction Properties } \\
\hline Height, individual rough opening & $2 \mathrm{~m}$ \\
\hline Width, individual rough opening & $3 \mathrm{~m}$ \\
\hline Area, individual gross window (also center of glass area) & $6 \mathrm{~m}^{2}$ \\
\hline Number of panes & 1 \\
\hline Pane thickness ${ }^{\mathrm{a}}$ & $3.048 \mathrm{~mm}$ \\
\hline $\begin{array}{l}\text { Curtains, blinds, frames, spacers, mullions, obstructions } \\
\text { inside the window }\end{array}$ & None \\
\hline \multicolumn{2}{|l|}{ Basic Material Properties } \\
\hline Thermal conductivity of glass ${ }^{\mathrm{a}}$ & $1.00 \mathrm{~W} /(\mathrm{m} \cdot \mathrm{K})$ \\
\hline Density of glass ${ }^{\mathrm{b}}$ & $2470 \mathrm{~kg} / \mathrm{m}^{3}$ \\
\hline Specific heat of glass ${ }^{\mathrm{b}}$ & $750 \mathrm{~J} /(\mathrm{kg} \cdot \mathrm{K})$ \\
\hline Hemispherical infrared emittance of glass ${ }^{\mathrm{a}}$ & 0.840 \\
\hline Infrared transmittance of glass ${ }^{\mathrm{a}}$ & 0.000 \\
\hline Pane direct-beam transmittance ${ }^{a}$ & 0.834 , at normal incidence \\
\hline Pane direct-beam reflectance (same value on both sides) ${ }^{\mathrm{a}}$ & 0.075 , at normal incidence \\
\hline
\end{tabular}

a. Informative Note: Value from WINDOW 7 glass library, "CLEAR_3.DAT"; this is the same as the Case 600 pane.

b. Informative Note: Value for soda-lime glass from 2017 ASHRAE Fundamentals (SI version) ${ }^{\mathrm{B}-101}$, p. 33.3.

Informative Table 5-22 Calculated Properties of Clear Single-Pane Glazing System

\begin{tabular}{|c|c|}
\hline Pane conductance ${ }^{\mathrm{a}}$ & {$\left[\mathrm{R}-0.00305 \mathrm{~m}^{2} \cdot \mathrm{K} / \mathrm{W}\right]$} \\
\hline Exterior combined surface coefficient $\left(h_{o}\right)^{\mathrm{b}}$ & $16.0 \mathrm{~W} /\left(\mathrm{m}^{2} \cdot \mathrm{K}\right) \quad\left[\mathrm{R}-0.06250 \mathrm{~m}^{2} \cdot \mathrm{K} / \mathrm{W}\right]$ \\
\hline Interior combined surface coefficient $\left(h_{i}\right)^{\mathrm{b}}$ & {$\left[\mathrm{R}-0.12821 \mathrm{~m}^{2} \cdot \mathrm{K} / \mathrm{W}\right]$} \\
\hline U-Value from interior air to ambient airc & $5.16 \mathrm{~W} /\left(\mathrm{m}^{2} \cdot \mathrm{K}\right) \quad\left[\mathrm{R}-0.19376 \mathrm{~m}^{2} \cdot \mathrm{K} / \mathrm{W}\right]$ \\
\hline Solar heat gain coefficient $\left(\right.$ SHGC) ${ }^{d}$ & 0.864 , at normal incidence ${ }^{\mathrm{e}}$ \\
\hline Shading coefficient $(S C)^{f}$ & 0.993, at normal incidence \\
\hline Index of refraction ${ }^{\mathrm{g}}$ & 1.493 \\
\hline Extinction coefficient ${ }^{\mathrm{g}}$ & $0.0337 / \mathrm{mm}$ \\
\hline \multicolumn{2}{|c|}{ 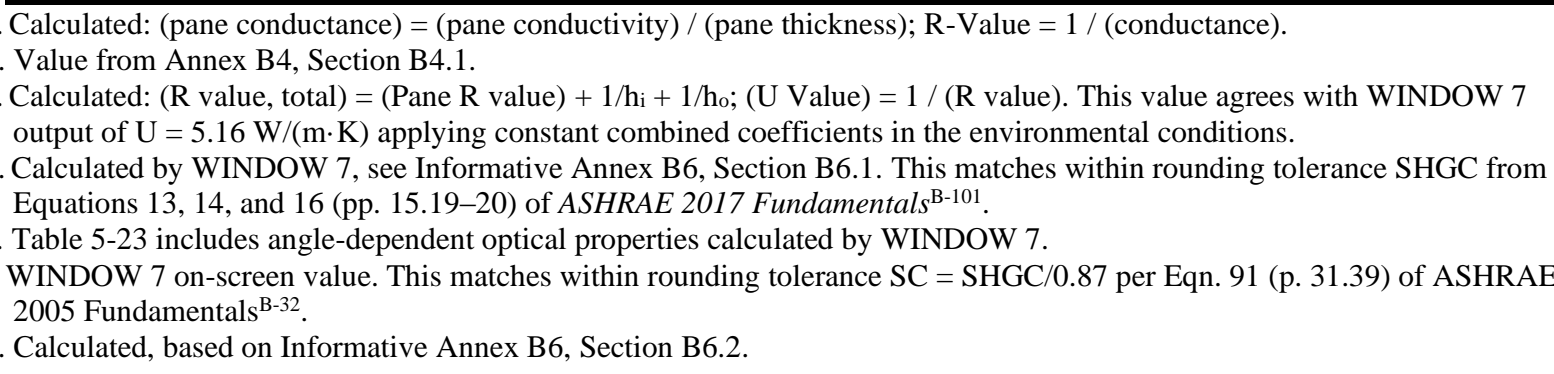 } \\
\hline
\end{tabular}


Table 5-23 Alternative Angular-Dependent Optical Properties for the Single-Pane Window ${ }^{\mathrm{a}, \mathrm{b}}$

\begin{tabular}{cccccc}
\hline $\begin{array}{c}\text { Angle of } \\
\text { Incidence, deg }\end{array}$ & Trans. & Refl.,f & Refl.,b & Abs. & SHGC $^{\mathbf{c}}$ \\
\hline \hline 0 & 0.834 & 0.075 & 0.075 & 0.091 & 0.864 \\
10 & 0.833 & 0.075 & 0.075 & 0.092 & 0.864 \\
20 & 0.831 & 0.075 & 0.075 & 0.094 & 0.862 \\
30 & 0.827 & 0.077 & 0.077 & 0.096 & 0.859 \\
40 & 0.818 & 0.082 & 0.082 & 0.100 & 0.851 \\
50 & 0.797 & 0.099 & 0.099 & 0.104 & 0.831 \\
60 & 0.749 & 0.143 & 0.143 & 0.108 & 0.785 \\
70 & 0.637 & 0.253 & 0.253 & 0.110 & 0.673 \\
80 & 0.389 & 0.506 & 0.506 & 0.105 & 0.424 \\
90 & 0.000 & 1.000 & 1.000 & 0.000 & 0.000 \\
Hemis. & 0.753 & 0.136 & 0.136 & 0.101 & 0.787 \\
\hline
\end{tabular}

a. "deg" = degrees; "Trans." = transmittance; "Refl.,f" = overall solar reflectance for radiation incident from the front (i.e., from the outside); "Refl.,b" = overall solar reflectance for radiation incident from the back (i.e., from inside the zone); "Abs." = absorptance; SHGC = solar heat gain coefficient; "Hemis." = hemispherically integrated. "Refl.,f" = "Refl.,b", for this glazing system.

b. Informative Note: Properties evaluated using WINDOW $7^{\mathrm{A}-4}$; see Annex B6, Section B6.1.

c. Informative Note: This matches, within rounding tolerance, SHGC from Equations 13, 14, and 16 (pp. 15.19-20) of ASHRAE 2017 Fundamentals $^{\mathrm{B}-101}$.

\subsection{Interior Solar Distribution.}

5.2.2.1.7.2.1 This is the fractional distribution among interior surfaces of solar radiation transmitted through the windows that is absorbed by each given surface after all reflections off of interior surfaces and accounting for solar lost (transmitted solar radiation reflected by interior opaque surfaces and retransmitted back out the windows). For programs that calculate interior solar distribution internally (via ray tracing or other means based on interior solar absorptance given in Table 5-5), and do not require a separate input for interior solar distribution fraction, ignore the following Section 5.2.2.1.7.2.2 and skip to Section 5.2.2.1.7.3.

5.2.2.1.7.2.2 If the program being tested does not calculate interior solar distribution internally but requires distribution fractions from the user, then the use of Table 5-24 shall be permitted. Use of different (nonspecified) values shall not be prohibited if there is a mathematical, physical, or logical basis for applying them. Where different values are used, they shall be applied consistently throughout the test cases. The use of nonspecified values shall be documented in the Standard Output Report (Normative Annex A2).

Informative Note: Table 5-24 presents an approximate calculation of solar distribution fractions by assuming that $100 \%$ of the incoming radiation strikes the floor first and that all reflections are diffuse. Fractional values for the walls with windows (i.e., the south wall) include the portion of the solar radiation absorbed by the glass (as it passes back out the window) and conducted back into the zone. Solar radiation absorbed by the glass (and conducted inward) as it initially passes into the building is not included in the values in Table 5-24. Informative Annex B7 gives background information regarding the calculation technique used for developing these solar fractions.

Table 5-24 Alternative Constant Interior Solar Distribution Fractions by Surface, Case 670

\begin{tabular}{cccccccc}
\hline Surface & Floor & Ceiling & Wall & Wall & $\begin{array}{c}\text { North } \\
\text { Wall }\end{array}$ & $\begin{array}{c}\text { South } \\
\text { Wall }\end{array}$ & $\begin{array}{c}\text { Solar Lost } \\
\text { through } \\
\text { Windows }\end{array}$ \\
\hline \hline Solar Fraction & 0.641 & 0.166 & 0.038 & 0.038 & 0.052 & 0.025 & 0.040 \\
\hline
\end{tabular}


5.2.2.1.7.3 Output Requirements. Case 670 requires the following output:

a. All non-free-float case output in accordance with Section 6.2.1.1.

b. Additional output in accordance with Section 6.2.1.2.2.

c. Daily hourly output as specified for Case 670 in Section 6.2.1.8.

d. Case-670-only output in accordance with Section 6.2.1.10.

e. General reporting requirements of Section 6.1.

5.2.2.1.8 Case 680: Increased Exterior Wall and Roof Insulation. Case 680 shall be modeled exactly the same as Case 600, except for changes specified in the subsections below.

5.2.2.1.8.1 Material Properties. For the walls and floor, the fundamental materials specifications of Table 5-25 shall be applied in place of the materials specifications of Table 5-2 (see Section 5.2.1.4 [Case 600]). The following changes shall be applied as indicated with bold font in Table 5-25:

- Exterior wall insulation material is changed to foam insulation and thickness is increased; this change is applied to all four exterior walls.

- Roof fiberglass quilt thickness is increased.

- The floor is unchanged from Case 600.

Informative Note: Informative Table 5-26 includes summary calculated values derived from fundamental properties of normative Table 5-25 and alternative constant surface coefficients of Sections 5.2.1.9.3 and 5.2.1.10.3 (Case 600 ), for programs that may need this information. Changes indicated in Informative Table 5-26 versus Informative Table 5-3 (see Section 5.2.1.4 [Case 600]) are highlighted with bold font. For programs that automatically calculate surface radiation or convection or both, or that allow more detailed constant surface coefficient inputs (e.g., for scheduling), variation of individual interior surface coefficient $U$-values, total $U$ and total $U A$ values, and heat capacities from Table 5-26 may be expected.

5.2.2.1.8.2 Output Requirements. Case 680 requires the following output:

a. All non-free-float case output in accordance with Section 6.2.1.1.

b. Additional output specified for Case 680 in Section 6.2.1.8.

c. General reporting requirements of Section 6.1.

Table 5-25 Fundamental Material Thermal Property Specifications, Increased Exterior Wall and Roof Insulation, Low-Mass Case ${ }^{a}$

\begin{tabular}{|c|c|c|c|c|c|c|}
\hline Element & $\begin{array}{c}\mathbf{k}, \\
\mathbf{W} /(\mathbf{m} \cdot \mathbf{K}) \\
\end{array}$ & $\begin{array}{c}\text { Thickness, } \\
\text { m } \\
\end{array}$ & $\begin{array}{c}\mathbf{U}, \\
\mathbf{W} /\left(\mathbf{m}^{2} \cdot \mathbf{K}\right) \\
\end{array}$ & $\mathbf{R}, \mathbf{m}^{2} \cdot \mathbf{K} / \mathbf{W}$ & $\begin{array}{c}\text { Density, } \\
\mathrm{kg}^{3} \mathrm{~m}^{3}\end{array}$ & $\begin{array}{c}\mathbf{c}_{\mathrm{p}} \\
\mathrm{J} /(\mathbf{k g} \cdot \mathbf{K}) \\
\end{array}$ \\
\hline \multicolumn{7}{|c|}{ Low-Mass Case: Exterior Wall (inside to outside) } \\
\hline Plasterboard & 0.16 & 0.012 & 13.333 & 0.075 & 950 & 840 \\
\hline Foam Insulation & 0.04 & 0.250 & 0.160 & 6.250 & 10 & 1400 \\
\hline Wood Siding & 0.14 & 0.009 & 15.556 & 0.064 & 530 & 900 \\
\hline \multicolumn{7}{|c|}{ Low-Mass Case: Raised Floor (inside to outside) ${ }^{b}$} \\
\hline Timber flooring & 0.14 & 0.025 & 5.600 & 0.179 & 650 & 1200 \\
\hline Insulation & 0.04 & 1.003 & 0.040 & 25.075 & $0^{c}$ & $0^{c}$ \\
\hline \multicolumn{7}{|c|}{ Low-Mass Case: Roof (inside to outside) } \\
\hline Plasterboard & 0.16 & 0.010 & 16.000 & 0.063 & 950 & 840 \\
\hline Fiberglass quilt & 0.04 & 0.400 & 0.100 & 10.000 & 12 & 840 \\
\hline Roofdeck & 0.14 & 0.019 & 7.368 & 0.136 & 530 & 900 \\
\hline
\end{tabular}

a. Changes to Case 600 are highlighted with bold font, except headers are always bold. All other properties remain as in Case 600 .

b. The Case 680 floor is the same as the Case 600 floor.

c. Underfloor insulation has the minimum density and specific heat the program being tested will allow, but not $<0$. 
Informative Table 5-26 Calculated Summary Thermal Conductances and Heat Capacities, Increased Exterior Wall and Roof Insulation, Low-Mass Case ${ }^{a}$

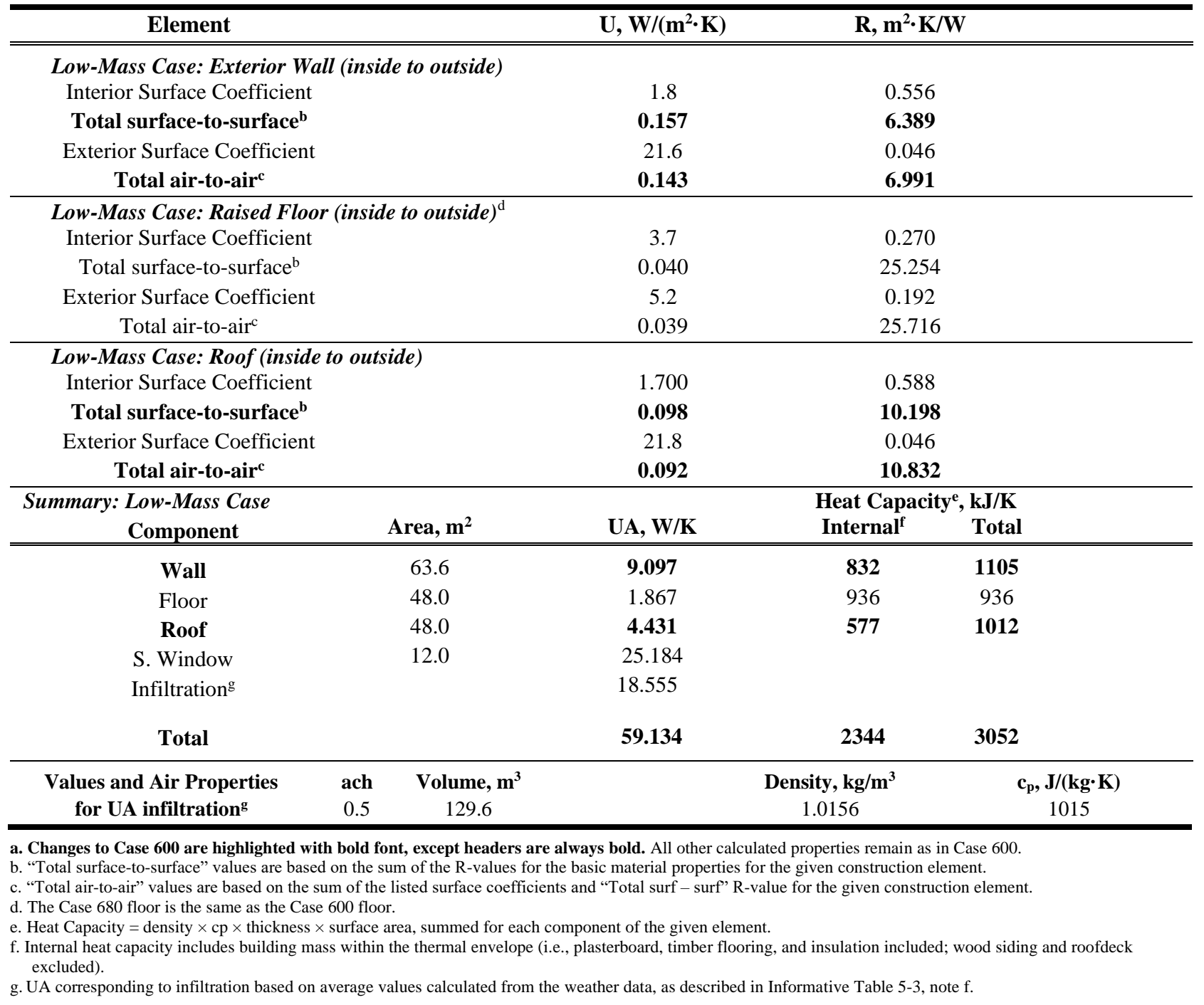

5.2.2.1.9 Case 685: Base Case with "20,20" Thermostat. Case 685 shall be modeled exactly the same as Case 600, except for changes specified in the subsections below.

5.2.2.1.9.1 Thermostat Control

5.2.2.1.9.1.1 The following " 20,20 " thermostat control configuration shall be used:

- Heat $=$ ON if temperature $<20^{\circ} \mathrm{C}$.

- $\mathrm{Cool}=\mathrm{ON}$ if temperature $>20^{\circ} \mathrm{C}$.

Informative Note: "Temperature" refers to the conditioned-zone air temperature.

5.2.2.1.9.1.2 The thermostat shall be nonproportional as specified in Section 5.2.1.13.1.2 (Case 600).

5.2.2.1.9.2 Output Requirements. Case 685 requires the following output:

a. All non-free-float case output in accordance with Section 6.2.1.1.

b. Additional output specified for Case 685 in Section 6.2.1.8.

c. General reporting requirements of Section 6.1.

5.2.2.1.10 Case 695: Increased Exterior Wall and Roof Insulation with "20,20" Thermostat. Case 695 shall be modeled exactly the same as Case 680 (increased exterior wall and roof insulation), except for changes specified in the subsections below.

\subsection{Thermostat Control}

5.2.2.1.10.1.1 The following " 20,20 " thermostat control configuration shall be used (as in Case 685):

- Heat $=$ ON if temperature $<20^{\circ} \mathrm{C}$.

- $\mathrm{Cool}=\mathrm{ON}$ if temperature $>20^{\circ} \mathrm{C}$. 
Informative Note: "Temperature" refers to the conditioned-zone air temperature.

5.2.2.1.10.1.2 The thermostat shall be nonproportional as specified in Section 5.2.1.13.1.2 (Case 600).

5.2.2.1.10.2 Output Requirements. Case 695 requires the following output:

a. All non-free-float case output in accordance with Section 6.2.1.1.

b. Additional output specified for Case 695 in Section 6.2.1.8.

c. General reporting requirements of Section 6.1.

5.2.2.2 High-Mass Basic Tests. The high-mass basic tests shall be modeled as specified in this section and its subsections. These tests include cases 900 through 995. The first case shall be Case 900. Once an accurate input description for Case 900 has been developed, the remaining high-mass cases shall be input by modifying each corresponding 600-series case as indicated case-by-case below, except for the following cases:

- Case 960 (sunspace) shall be based on Case 600 and shall integrate aspects of Case 900 as specified in Section 5.2.2.2.7.

- Case 995 shall be input by modifying Case 980 as specified in Section 5.2.2.2.10.

Informative Note: For Cases 900 through 950 and 985, the high-mass cases are the same as the corresponding lowmass 600-series cases, except that material properties are taken from Table 5-27 rather than Table 5-2 so that the wall and floor properties are more massive; the roof properties and all surface textures are unchanged. For Cases 980 and 995, where wall and roof insulation properties are varied, the high-mass cases are the same as the corresponding low-mass 600-series cases (Cases 680 and 695) except that material properties are taken from Table 5-31 rather than Table 5-25.

5.2.2.2.1 Case 900: High-Mass Base Building. Case 900 shall be modeled exactly the same as Case 600, except for changes specified in the subsections below.

5.2.2.2.1.1 Material Properties. For the walls and floor, the fundamental materials specifications of Table 5-27 shall be applied in place of the materials specifications of Table 5-2 (see Section 5.2.1.4 [Case 600]). The roof materials shall not change for any of the 900-series cases. The surface textures of Sections 5.2.1.9.2 and 5.2.1.10.2 (Case 600) shall continue to apply. Informative Note: Informative Table 5-28 includes summary calculated values derived from fundamental properties of normative Table 5-27 and alternative constant surface coefficients of Sections 5.2.1.9.3 and 5.2.1.10.3 (Case 600), for programs that may need this information. For programs that automatically calculate surface radiation or convection or both, or that allow more detailed constant surface coefficient inputs (e.g., for scheduling), variation of individual interior surface coefficient $\mathrm{U}$-values, total $\mathrm{U}$ and total UA values, and heat capacities from Table 5-28 may be expected.

Table 5-27 Fundamental Material Thermal Property Specifications for High-Mass Case

\begin{tabular}{|c|c|c|c|c|c|c|}
\hline Element & $\begin{array}{c}\mathbf{k}, \\
\mathbf{W} /(\mathbf{m} \cdot \mathbf{K})\end{array}$ & $\begin{array}{c}\text { Thickness, } \\
\text { m }\end{array}$ & $\mathbf{U}, \mathbf{W} /\left(\mathbf{m}^{2} \cdot \mathbf{K}\right)$ & $\begin{array}{c}\mathbf{R}, \\
\mathbf{m}^{2} \cdot \mathbf{K} / \mathbf{W}\end{array}$ & $\begin{array}{c}\text { Density, } \\
\mathrm{kg} / \mathrm{m}^{3}\end{array}$ & $\begin{array}{c}\mathbf{c}_{\mathrm{p}}, \\
\mathrm{J} /(\mathrm{kg} \cdot \mathrm{K})\end{array}$ \\
\hline \multicolumn{7}{|c|}{ "High-Mass Case: Exterior Wall (inside to outside) } \\
\hline Concrete Block & 0.51 & 0.100 & 5.100 & 0.196 & 1400 & 1000 \\
\hline Foam Insulation & 0.04 & 0.0615 & 0.651 & 1.537 & 10 & 1400 \\
\hline Wood Siding & 0.14 & 0.009 & 15.556 & 0.064 & 530 & 900 \\
\hline \multicolumn{7}{|c|}{ High-Mass Case: Raised Floor (inside to outside) } \\
\hline Concrete Slab & 1.13 & 0.080 & 14.125 & 0.071 & 1400 & 1000 \\
\hline Insulation & 0.04 & $1.007^{\mathrm{a}}$ & 0.040 & 25.175 & $0^{\mathrm{b}}$ & $0^{\mathrm{b}}$ \\
\hline \multicolumn{7}{|c|}{ High-Mass Case: Roof (inside to outside) ${ }^{c}$} \\
\hline Plasterboard & 0.16 & 0.010 & 16.000 & 0.063 & 950 & 840 \\
\hline Fiberglass quilt & 0.04 & 0.1118 & 0.358 & 2.794 & 12 & 840 \\
\hline Roofdeck & 0.14 & 0.019 & 7.368 & 0.136 & 530 & 900 \\
\hline
\end{tabular}

a. Informative Note: Because the R-value of the concrete slab material layer in Case 900 varies slightly from the R-value of the timber floor layer in Case 600 , the floor insulation thickness varies slightly from Case 600 so that the total floor R-values match better for both cases.

b. Underfloor insulation has the minimum density and specific heat the program being tested will allow, but not $<0$.

c. Informative Note: The high-mass-case roof is the same as the low-mass-case roof. 
Informative Table 5-28 Calculated Summary Thermal Conductances and Heat Capacities, HighMass Case ${ }^{a}$

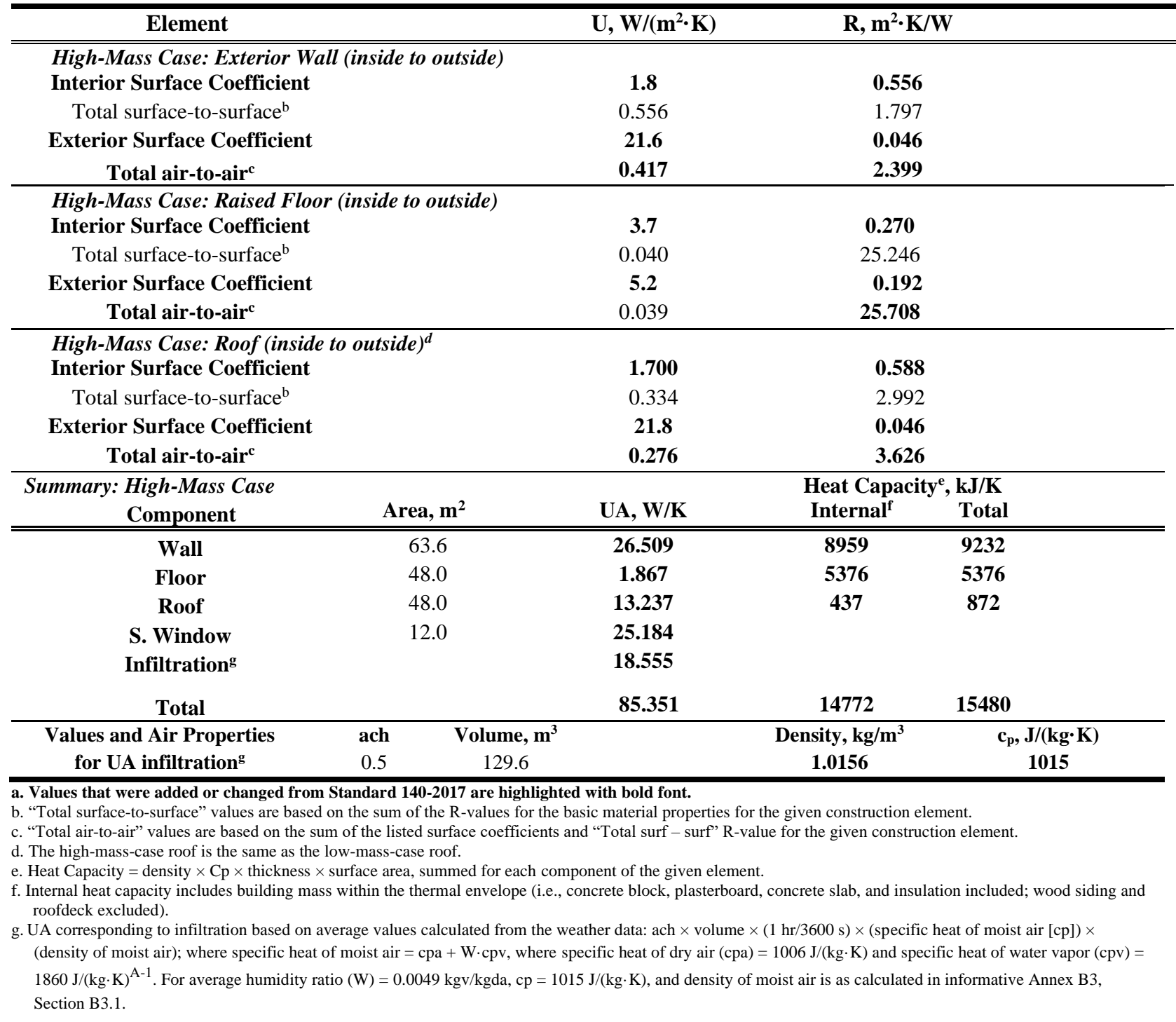

5.2.2.2.1.2 Output Requirements. Case 900 requires the following output:

a. All non-free-float case output in accordance with Section 6.2.1.1.

b. Monthly conditioned-zone load output specified in Section 6.2.1.2.5.

c. Additional output specified for Case 900 in Section 6.2.1.8.

d. General reporting requirements of Section 6.1.

5.2.2.2.2 Case 910: High-Mass South Shading. Case 910 shall be modeled exactly the same as Case 610 except for changes specified in the subsections below.

5.2.2.2.2.1 Material Properties. See the requirements of Section 5.2.2.2.1.1 (Case 900).

5.2.2.2.2.2 Output Requirements. Case 910 requires the following output:

a. All non-free-float case output in accordance with Section 6.2.1.1.

b. General reporting requirements of Section 6.1.

5.2.2.2.3 Case 920: High-Mass East/West Window Orientation. Case 920 shall be modeled exactly the same as Case 620 except for changes specified in the subsections below.

5.2.2.2.3.1 Material Properties. See the requirements of Section 5.2.2.2.1.1 (Case 900).

5.2.2.2.3.2 Output Requirements. Case 920 requires the following output:

a. All non-free-float case output in accordance with Section 6.2.1.1.

b. General reporting requirements of Section 6.1. 
5.2.2.2.4 Case 930: High-Mass East/West Shading. Case 930 shall be modeled exactly the same as Case 630 except for changes specified in the subsections below.

5.2.2.2.4.1 Material Properties. See the requirements of Section 5.2.2.2.1.1 (Case 900).

5.2.2.2.4.2 Output Requirements. Case 930 requires the following output:

a. All non-free float case output in accordance with Section 6.2.1.1.

b. General reporting requirements of Section 6.1.

5.2.2.2.5 Case 940: High-Mass Thermostat Setback.

Case 940 shall be modeled exactly the same as Case 640 except that the exterior wall and floor materials specifications of Table 5-27 shall be applied in place of the materials specifications of Table 5-2.

5.2.2.2.6 Case 950: High-Mass Night Ventilation.

Case 950 shall be modeled exactly the same as Case 650 except that the exterior walls and floor materials specifications of Table 5-27 shall be applied in place of the materials specifications of Table 5-2.

5.2.2.2.7 Case 960: Sunspace. Case 960 shall consist of two zones (back zone and sun zone) separated by a common wall (as specified in Figure 5-9). The back zone shall be of lightweight construction, and the sun zone shall be of heavyweight construction.

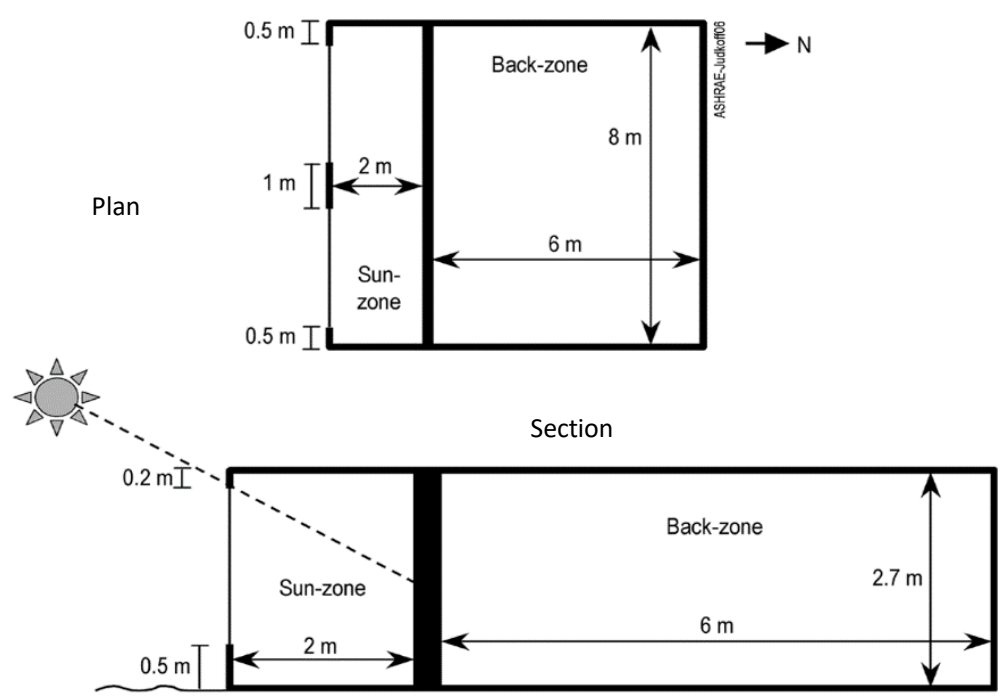

Figure 5-9 Sunspace plan and section (Case 960).

Informative Note: In Figure 5-9, plan and section diagrams have different scales.

\subsection{Back Zone}

a. The geometric and thermal properties of the back zone shall be exactly the same as for Case 600 except that the south wall and windows are replaced with the common wall.

b. Infiltration in the back zone $=0.5$ ach. This is exchange of back-zone air and ambient air only; there is no interzonal air exchange between the sun zone and the back zone. If the program being tested does not use barometric pressure from weather data or otherwise automatically correct for the change in air density due to altitude, then follow the requirements of Section 5.2.1.6.1 (Case 600).

c. Internal heat generation in the back zone shall be as specified in Section 5.2.1.7 (Case 600).

\subsection{Sun-Zone/Back-Zone Common Wall.}

Material properties of the sun-zone/back-zone common wall specified in Table 5-29 shall be used. In Table 5-29, Uand R-values are surface-to-surface conductance and resistance, excluding interior surface heat transfer coefficients. If the program being tested does not calculate interior surface convective coefficients and infrared radiative exchange varying with time step, then the instructions of Section 5.2.1.10 (Case 600) shall apply. 
Table 5-29 Thermal and Physical Properties of the Sun-Zone/Back-Zone Common Wall (Case 960)

\begin{tabular}{cccccccc}
\hline $\mathbf{k}, \mathbf{W} /(\mathbf{m} \cdot \mathbf{K})$ & $\begin{array}{c}\text { Thickness, } \\
\mathbf{m}\end{array}$ & $\begin{array}{c}\mathbf{U}, \\
\mathbf{W} /\left(\mathbf{m}^{\mathbf{2}} \cdot \mathbf{K}\right)\end{array}$ & $\begin{array}{c}\mathbf{R}, \\
\mathbf{m}^{\mathbf{2}} \mathbf{K} / \mathbf{W}\end{array}$ & $\begin{array}{c}\text { Density, } \\
\mathbf{k g} / \mathbf{m}^{\mathbf{3}}\end{array}$ & $\begin{array}{c}\boldsymbol{c}_{\boldsymbol{p}}, \\
\mathbf{J} /(\mathbf{k g} \cdot \mathbf{K})\end{array}$ & $\begin{array}{c}\text { Shortwave } \\
\text { Absorptance }\end{array}$ & $\begin{array}{c}\text { Infrared } \\
\text { Emittance }\end{array}$ \\
\hline \hline 0.510 & 0.20 & 2.55 & 0.392 & 1400 & 1000 & 0.6 & 0.9 \\
\hline
\end{tabular}

5.2.2.2.7.3 Sun Zone. The sun zone shall be $2 \mathrm{~m}$ deep by $8 \mathrm{~m}$ wide by $2.7 \mathrm{~m}$ high. The back (north) wall of the sun zone shall be the common wall. The south wall of the sun zone shall contain two $6-\mathrm{m}^{2}$ windows that shall be the same as the windows in Case 900 except that they are raised $0.3 \mathrm{~m}$ higher on the south wall than in Case 900 (as specified in Figure 5-9). The thermal and physical properties of the sun zone shall be the same as Case 900 with the following exceptions:

a. Zone depth shall be $2 \mathrm{~m}$.

b. The north wall shall be replaced by the common wall.

c. The south wall shall have two $3 \times 2-\mathrm{m}$ windows raised $0.3 \mathrm{~m}$ higher on the south wall than in Case 900 . These windows shall be double-pane and have the same properties as the windows in Case 900.

$\mathrm{d}$. The areas of the east and west walls of the sun zone (end walls) shall be $5.4 \mathrm{~m}^{2}$ each.

e. The air volume of the sun zone shall be $43.2 \mathrm{~m}^{2}$.

f. Infiltration in the sun zone shall be $0.5 \mathrm{ach}$. This is exchange of sun-zone air and ambient air only; there is no inter-zonal air exchange between the sun zone and the back zone. If the program being tested does not use barometric pressure from weather data or otherwise automatically correct for the change in air density due to altitude, then the infiltration rate shall be adjusted according to Section 5.2.1.6.1 (Case 600).

g. Internal heat gains in the sun zone $=0 \mathrm{~W}$.

h. The exact geometric details shall be as shown in Figure 5-9.

5.2.2.2.7.4 Interior Solar Distribution in Sun Zone.

5.2.2. 2. 4.1 This is the fractional distribution among interior surfaces of solar radiation transmitted through the windows that is absorbed by each given surface after all reflections off of interior surfaces, and accounting for solar lost (transmitted solar radiation reflected by interior opaque surfaces and retransmitted back out the windows). For programs that calculate interior solar distribution internally (via ray tracing or other means based on interior solar absorptance given in Table 5-5), and do not require a separate input for interior solar distribution fraction, ignore the following Section 5.2.2.2.7.4.2 and skip to Section 5.2.2.2.7.5.

5.2.2.2.7.4.2 If the program being tested does not calculate interior solar distribution internally but requires distribution fractions from the user, the use of Table 5-30 shall be permitted. Use of different (nonspecified) values shall not be prohibited if there is a mathematical, physical, or logical basis for applying them. Where different values are used, they shall be applied consistently throughout the test cases. The use of nonspecified values shall be documented in the Standard Output Report (Normative Annex A2).

Table 5-30 Alternative Constant Interior Solar Distribution Fractions by Surface, Case 960, Sun Zone $^{\mathrm{a}}$

\begin{tabular}{cccccccc}
\hline Surface & Floor & Ceiling & $\begin{array}{c}\text { East } \\
\text { Wall }\end{array}$ & $\begin{array}{c}\text { West } \\
\text { Wall }\end{array}$ & $\begin{array}{c}\text { North } \\
\text { Wall }\end{array}$ & $\begin{array}{c}\text { South } \\
\text { Wall }\end{array}$ & $\begin{array}{c}\text { Solar Lost Through } \\
\text { Windows }\end{array}$ \\
\hline \hline Solar Fraction & 0.6 & $\mathbf{0 . 0 5}$ & 0.02 & 0.02 & 0.2 & 0.03 & $\mathbf{0 . 0 8}$ \\
\hline
\end{tabular}

a. Informative Note: Values that were changed from Standard 140-2017 are highlighted with bold font.

Informative Note: Table 5-30 presents an approximate calculation of solar distribution fractions adjusted for the geometry of the Case 960 sun zone by assuming that $100 \%$ of the incoming radiation strikes the floor first and that all reflections are diffuse. Fractional values for the walls with windows (i.e., the sun-zone south wall) include the portion of the solar radiation absorbed by the glass (as it passes back out the window) and conducted back into the zone. Solar radiation absorbed by the glass (and conducted inward) as it initially passes into the building is not included in the values in Table 5-30. Informative Annex B7 gives background information regarding the calculation technique used for developing these solar fractions.

\subsection{Heating and Cooling Control Strategies}

a. The sun zone shall not have a space-conditioning system, and the sun-zone air temperature shall be allowed to free-float.

b. The back zone shall be controlled the same as for Case 600 . 
5.2.2.2.7.6 Interzone Mass Transfer. There shall be no mechanically-driven or natural interzone air exchange. 5.2.2.2.7.7 Output Requirements. Case 960 requires the following output:

a. Back zone only, all non-free-float case outputs in accordance with Section 6.2.1.1.

b. Sun zone only, all free-float case outputs in accordance with Section 6.2.1.6.

c. General reporting requirements of Section 6.1.

5.2.2.2.8 Case 980: High-Mass Increased Exterior Wall and Roof Insulation. Case 980 shall be modeled exactly the same as Case 900, except for changes specified in the subsections below.

5.2.2.2.8.1 Material Properties. For the walls and floor, the fundamental materials specifications of Table 5-31 shall be applied in place of the materials specifications of Table 5-27 (see Section 5.2.2.2.1.1 [Case 900]). The following changes shall be applied as indicated with bold font in Table 5-31:

- Exterior wall insulation thickness is increased; this change is applied to all four exterior walls.

- Roof fiberglass quilt thickness is increased.

- The floor is unchanged from Case 900.

Informative Note: Informative Table 5-32 includes summary calculated values derived from fundamental properties of normative Table 5-31 and alternative constant surface coefficients of Sections 5.2.1.9.3 and 5.2.1.10.3 (Case 600, also applied for Case 900), for programs that may need this information. Changes indicated in Informative Table 532 versus Informative Table 5-28 (see Section 5.2.2.2.1.1 [Case 900]) are highlighted with bold font. For programs that automatically calculate surface radiation or convection or both, or that allow more detailed constant surface coefficient inputs (e.g., for scheduling), variation of individual interior surface coefficient $U$-values, total $U$ and total UA values, and heat capacities from Table 5-32 may be expected.

5.2.2.2.8.2 Output Requirements. Case 980 requires the following output:

a. All non-free-float case output in accordance with Section 6.2.1.1.

b. Additional output specified for Case 980 in Section 6.2.1.8.

c. General reporting requirements of Section 6.1.

Table 5-31 Fundamental Material Thermal Property Specifications, Increased Exterior Wall and Roof Insulation, High-Mass Case ${ }^{a}$

\begin{tabular}{|c|c|c|c|c|c|c|}
\hline Element & $\begin{array}{c}\mathbf{k}, \\
\mathbf{W} /(\mathbf{m} \cdot \mathbf{K})\end{array}$ & $\begin{array}{c}\text { Thickness, } \\
\text { m }\end{array}$ & $\mathbf{U}, \mathbf{W} /\left(\mathbf{m}^{2} \cdot \mathbf{K}\right)$ & $\begin{array}{c}\mathbf{R}, \\
\mathbf{m}^{2} \cdot \mathbf{K} / \mathbf{W}\end{array}$ & $\begin{array}{c}\text { Density, } \\
\mathrm{kg} / \mathrm{m}^{3}\end{array}$ & $\begin{array}{c}\mathbf{c}_{\mathrm{p}}, \\
\mathrm{J} /(\mathbf{k g} \cdot \mathbf{K})\end{array}$ \\
\hline \multicolumn{7}{|c|}{ High-Mass Case: Exterior Wall (inside to outside) } \\
\hline Concrete Block & 0.51 & 0.100 & 5.100 & 0.196 & 1400 & 1000 \\
\hline Foam Insulation & 0.04 & 0.2452 & 0.163 & 6.130 & 10 & 1400 \\
\hline Wood Siding & 0.14 & 0.009 & 15.556 & 0.064 & 530 & 900 \\
\hline \multicolumn{7}{|c|}{ High-Mass Case: Raised Floor (inside to outside) ${ }^{\mathrm{b}}$} \\
\hline Concrete Slab & 1.13 & 0.080 & 14.125 & 0.071 & 1400 & 1000 \\
\hline Insulation & 0.04 & $1.007^{\mathrm{c}}$ & 0.040 & 25.175 & $0^{\mathrm{d}}$ & $0^{\mathrm{d}}$ \\
\hline \multicolumn{7}{|c|}{ High-Mass Case: Roof (inside to outside) ${ }^{\mathrm{e}}$} \\
\hline Plasterboard & 0.16 & 0.010 & 16.000 & 0.063 & 950 & 840 \\
\hline Fiberglass quilt & 0.04 & 0.4 & 0.100 & 10.000 & 12 & 840 \\
\hline Roofdeck & 0.14 & 0.019 & 7.368 & 0.136 & 530 & 900 \\
\hline
\end{tabular}

a. Changes to Case 900 are highlighted with bold font, except headers are always bold. All other calculated properties remain as in Case 900.

b. The Case 980 floor is the same as the Case 900 floor.

c. Informative Note: Because the R-value of the concrete slab material layer in Case 900 (and Case 980) varies slightly from the R-value of the timber floor layer in

Case 600 (and Case 680), the floor insulation thickness varies slightly from Case 600 so that the total floor R-values match better for the cases.

d. Underfloor insulation has the minimum density and specific heat the program being tested will allow, but not $<0$.

e. Informative Note: The Case 980 roof is the same as the Low-Mass-Case 680 roof. 
Informative Table 5-32 Calculated Summary Thermal Conductances and Heat Capacities, Increased Exterior Wall and Roof Insulation, High-Mass Case ${ }^{a}$

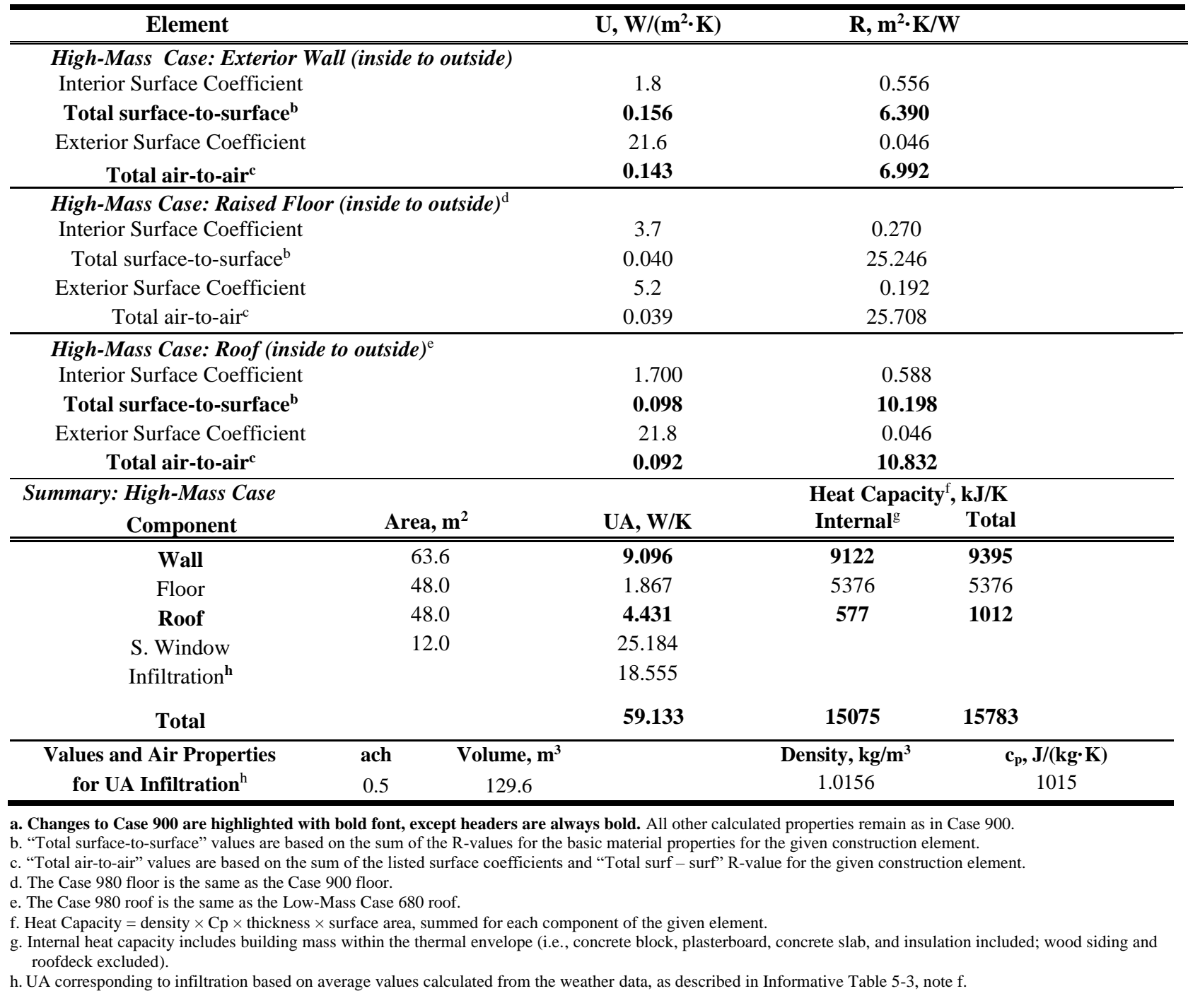

5.2.2.2.9 Case 985: High Mass with "20,20" Thermostat. Case 985 shall be modeled exactly the same as Case 900, except for changes specified in the subsections below.

\subsection{Thermostat Control}

5.2.2. 9.1 .1 The following " 20,20 " thermostat control configuration shall be used (as in Case 685):

- Heat $=$ ON IF Temperature $<20^{\circ} \mathrm{C}$.

- $\mathrm{Cool}=\mathrm{ON}$ IF Temperature $>20^{\circ} \mathrm{C}$.

Informative Note: "Temperature" refers to the conditioned-zone air temperature.

5.2.2. 2.1.2 The thermostat shall be nonproportional as specified in Section 5.2.1.13.1.2 (Case 600, also applied in Case 685).

5.2.2.2.9.2 Output Requirements. Case 985 requires the following output:

a. All non-free-float case output in accordance with Section 6.2.1.1.

b. Additional output specified for Case 985 in Section 6.2.1.8.

c. General reporting requirements of Section 6.1 .

5.2.2.2.10 Case 995: High-Mass Increased Exterior Wall and Roof Insulation with “20,20" Thermostat. Case 995 shall be modeled exactly the same as Case 980 (high-mass increased exterior wall and roof insulation), except for changes specified in the subsections below. 


\subsection{Thermostat Control}

5.2.2.2.10.1.1 The following " 20,20 " thermostat control configuration shall be used (as in Case 685):

- Heat $=$ ON IF Temperature $<20^{\circ} \mathrm{C}$.

- Cool $=$ ON IF Temperature $>20^{\circ} \mathrm{C}$.

Informative Note: "Temperature" refers to the conditioned-zone air temperature.

5.2.2.2.10.1.2 The thermostat shall be nonproportional as specified in Section 5.2.1.13.1.2 (Case 600, also applied in Case 685).

5.2.2.2.10.2 Output Requirements. Case 995 requires the following output:

a. All non-free-float case output in accordance with Section 6.2.1.1.

b. Additional output specified for Case 995 in Section 6.2.1.8.

c. General reporting requirements of Section 6.1.

5.2.2.3 Free-Float Cases: Cases 600FF, 650FF, 680FF, 900FF 950FF, and 980FF. If the program being tested has the ability to calculate and output hourly zone air temperatures, the six free-floating cases shall be modeled as specified in this section and its subsections.

Informative Note: The free-float cases are based on their corresponding non-free-float cases. For all cases where free-float zone air temperature output is required, the free-float zone air temperature is for the zone air only, assuming well-mixed air with no radiant effects (i.e., equivalent to what would be obtained from a hypothetical aspirated temperature sensor perfectly shielded from solar and infrared radiation).

5.2.2.3.1 Case 600FF: Free-Float Low Mass. Case 600FF shall be modeled exactly the same as Case 600 except for changes specified in the subsections below.

5.2.2.3.1.1 Mechanical System. There is no mechanical heating or cooling of the building.

5.2.2.3.1.2 Output Requirements. Case $600 \mathrm{FF}$ requires the following output:

a. All free-float case output in accordance with Section 6.2.1.6

b. Daily hourly output specified for Case 600FF in Section 6.2.1.8

c. General reporting requirements of Section 6.1.

5.2.2.3.2 Case 650FF: Free-Float Night Ventilation. Case 650FF shall be modeled exactly the same as Case 650 except for changes specified in the subsections below.

5.2.2.3.2.1 Mechanical System.

a. There is no mechanical heating or cooling of the building (as in Case 600FF).

b. The mechanical venting schedule shall remain as follows:

- From 1800 hours to 0700 hours, vent fan $=$ ON

(1800 to 0700 is the same as Hour 19 through Hour 7 per the time convention of Section 5.1.1).

- From 0700 hours to 1800 hours, vent fan $=$ OFF

(0700 to 1800 is the same as Hour 8 through Hour 18 per the time convention of Section 5.1.1).

c. Ventilation fan characteristics shall remain as follows:

- Vent fan capacity $=1700$ standard $\mathrm{m}^{3} / \mathrm{h}$ (in addition to specified infiltration rate of Section 5.2.1.6 [Case 600,

also applied in Case 650]).

- Waste heat from fan $=0$.

d. If the program being tested does not automatically correct for the reduced density of air at altitude, then the inputs for the fan capacity shall be adjusted as specified in Table 5-16 (see Section 5.2.2.1.5.2 [Case 650]).

5.2.2.3.2.2 Output Requirements. Case $650 \mathrm{FF}$ requires the following output:

a. All free-float case output in accordance with Section 6.2.1.6.

b. Daily hourly output specified for Case 650FF in accordance with Section 6.2.1.8.

c. General reporting requirements of Section 6.1.

5.2.2.3.3 Case 680FF: Free-Float Increased Exterior Wall and Roof Insulation. Case 680FF shall be modeled exactly the same as Case 680 except for changes specified in the subsections below.

5.2.2.3.3.1 Mechanical System. There is no mechanical heating or cooling of the building (as in Case 600FF).

5.2.2.3.3.2 Output Requirements. Case $680 \mathrm{FF}$ requires the following output:

a. All free-float case output in accordance with Section 6.2.1.6.

b. Daily hourly output specified for Case 680FF in Section 6.2.1.8.

c. General reporting requirements of Section 6.1. 
5.2.2.3.4 Case 900FF: Free-Float High Mass. Case 900FF shall be modeled exactly the same as Case 900 except for changes specified in the subsections below.

5.2.2.3.4.1 Mechanical System. There is no mechanical heating or cooling of the building (as in Case 600FF).

5.2.2.3.4.2 Output Requirements. Case $900 \mathrm{FF}$ requires the following output:

a. All free-float case output in accordance with Section 6.2.1.6.

b. Case 900FF only output in accordance with Section 6.2.1.7.

c. Daily hourly output specified for Case 900FF in Section 6.2.1.8.

d. General reporting requirements of Section 6.1.

5.2.2.3.5 Case 950FF: Free-Float High-Mass Night Ventilation. Case 950FF shall be modeled exactly the same as Case 950 except for changes specified in the subsections below.

5.2.2.3.5.1 Mechanical System. See Section 5.2.2.3.2.1 (Case 650FF) for requirements.

5.2.2.3.5.2 Output Requirements. Case $950 \mathrm{FF}$ requires the following output:

a. All free-float case output in accordance with Section 6.2.1.6.

b. Daily hourly output specified for Case 950FF in Section 6.2.1.8.

c. General reporting requirements of Section 6.1.

5.2.2.3.6 Case 980FF: Free-Float High-Mass Increased Exterior Wall and Roof Insulation. Case 980FF shall be modeled exactly the same as Case 980 except for changes specified in the subsections below.

5.2.2.3.6.1 Mechanical System. There is no mechanical heating or cooling of the building (as in Case 600FF).

5.2.2.3.6.2 Output Requirements. Case $980 \mathrm{FF}$ requires the following output:

a. All free-float case output in accordance with Section 6.2.1.6.

b. Daily hourly output specified for Case 980FF in Section 6.2.1.8.

c. General reporting requirements of Section 6.1.

\subsubsection{In-Depth Tests.}

a. The in-depth tests shall be modeled as specified in this section and the following subsections. The in-depth tests include Cases 195 through 320, 395 through 470, 800, and 810.

b. Except for Case 200, the in-depth series tests require only non-free-float case output and general reporting requirements in accordance with Sections 6.2.1.1 and 6.1, respectively.

Informative Note: For convenience to users, the base cases for developing the various in-depth tests are as shown in Informative Table 5-33 and Informative Figure 5-10. In Informative Table 5-33 "Secondary Base Case" indicates additional cases from which selected input specifications for the given case are applied. 
Informative Table 5-33 Base Cases for In-Depth Cases of Section 5.2.3

\begin{tabular}{|c|c|c|c|c|c|c|}
\hline \multirow[t]{2}{*}{ Primary Tested Feature } & \multicolumn{3}{|c|}{ Cases with "20,20" Tstat } & \multicolumn{3}{|c|}{ Cases with "20,27" Tstat } \\
\hline & Case & $\begin{array}{c}\text { Primary } \\
\text { Base } \\
\text { Case }\end{array}$ & $\begin{array}{l}\text { Secondary } \\
\text { Base Case }\end{array}$ & Case & $\begin{array}{c}\text { Primary } \\
\text { Base } \\
\text { Case }\end{array}$ & $\begin{array}{l}\text { Secondary } \\
\text { Base Case }\end{array}$ \\
\hline \multicolumn{7}{|c|}{ Low-Mass Cases with High-Conductance Wall Elements or Solid Conduction } \\
\hline High-Cond. Wall Elements Base Case & 220 & 600 & 685 & & & \\
\hline Interior IR Radiation Exchange & 210 & 220 & --- & & & \\
\hline Exterior IR Radiation Exchange & 215 & 220 & --- & & & \\
\hline Int. \& Ext. IR Radiation Exchange & 200 & 210 & 215 & & & \\
\hline Surface Heat Transfer with " 20,27 ” Tstat & & & & 400 & 600 & 220 \\
\hline $\begin{array}{l}\text { Solid Conduction (no windows or high- } \\
\text { cond. wall elements) }\end{array}$ & 195 & 200 & 600 & 395 & 400 & 195 \\
\hline Infiltration & 230 & 220 & --- & 410 & 400 & 600 \\
\hline Internal Gains & 240 & 220 & --- & 420 & 410 & 600 \\
\hline Exterior Solar Absorptance & 250 & 220 & 600 & 430 & 420 & 600 \\
\hline \multicolumn{7}{|c|}{ Low-Mass Cases with Windows (South-Facing unless East/West is Indicated) } \\
\hline South Solar Gains (add South windows) & 270 & 220 & 600 & & & \\
\hline Cavity Albedo (interior solar absorptance) & 280 & 270 & --- & 440 & 600 & 280 \\
\hline South Shading (overhang) & 290 & 270 & 610 & & & \\
\hline East/West Windows & 300 & 270 & 620 & & & \\
\hline East/West Shading (overhang + fins) & 310 & 300 & 630 & & & \\
\hline “20,27” Thermostat with South Windows & 320 & 270 & 600 & & & \\
\hline $\begin{array}{l}\text { Constant Combined Int. \& Ext. Surf. } \\
\text { Coefs. }\end{array}$ & & & & 450 & 600 & --- \\
\hline Constant Combined Interior Surf. Coefs. & & & & 460 & 600 & 450 \\
\hline Constant Combined Exterior Surf. Coefs. & & & & 470 & 600 & 450 \\
\hline \multicolumn{7}{|l|}{ High-Mass Cases } \\
\hline Thermal Mass Without Solar Gains & & & & 800 & 430 & 900 \\
\hline Cavity Albedo with South Windows & & & & 810 & 900 & 280 \\
\hline
\end{tabular}




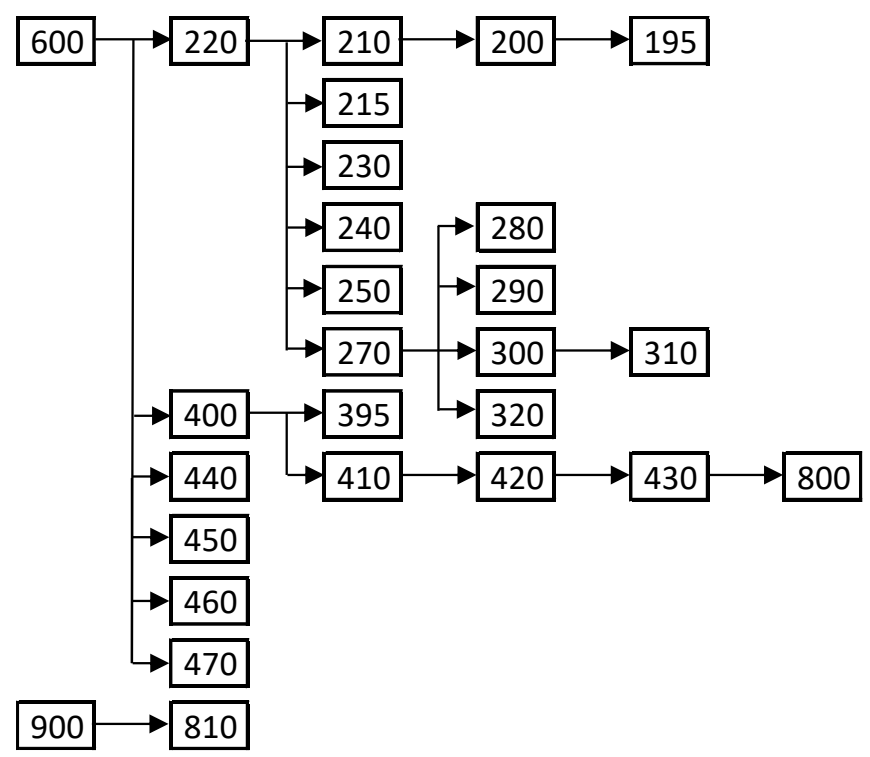

Informative Figure 5-10 Primary base cases for in-depth cases of Section 5.2.3.

5.2.3.1 Case 220: In-Depth Series Base Case. Case 220 shall be modeled exactly the same as Case 600 except for the changes specified in the following subsections.

5.2.3.1.1 Infiltration. Infiltration rate $=0$ ach, continuously ( 24 hours per day for the full year).

5.2.3.1.2 Internal Gains. Internal gains $=0 \mathrm{~W}$, continuously ( 24 hours per day for the full year).

5.2.3.1.3 Opaque Surface Radiative Properties.

a. Interior and exterior opaque surface solar (visible and ultraviolet wavelengths) absorptances and infrared emittances shall be applied to all opaque surfaces, except for the raised floor, as specified in Table 5-34. b. For the raised floor:

- Interior surface solar absorptance and infrared emittance, and exterior surface infrared emittance, shall be applied as specified in Table 5-34.

- The exterior surface shall continue to be modeled as receiving no solar radiation (see Section 5.2.1.5.1

[Case 600]).

c. Opaque surface radiative properties shall also be applied to the high-conductance wall elements as specified in Section 5.2.3.1.4.2 (below).

Informative Note: Where variations to opaque surface radiative properties are specified for other test cases of Section 5.2.3, these variations apply to all interior only, exterior only, or interior and exterior opaque surfaces, as specified for a given test case.

Informative Note: Listed infrared emittances are unchanged from Case 600.

Table 5-34 Opaque Surface Radiative Properties, Case 220

\begin{tabular}{ccc}
\hline & Interior Surface & Exterior Surface \\
\hline \hline Solar absorptance & $0.6^{\mathrm{a}}$ & 0.1 \\
Infrared emittance & 0.9 & 0.9 \\
\hline
\end{tabular}

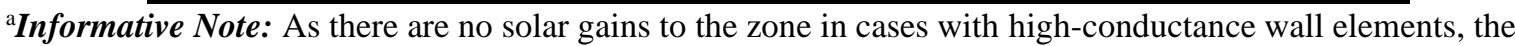
value input for interior solar absorptance should not affect the simulation results.

\subsection{High-Conductance Wall Element.}

5.2.3.1.4.1 High-conductance wall elements shall replace the $12 \mathrm{~m}^{2}$ of transparent windows on the south wall.

5.2.3.1.4.2 The properties of the high-conductance wall elements shall be as follows:

a. Shortwave transmittance $=0$.

b. Infrared emittances and solar absorptances provided in Table 5-34 shall be applied.

c. The surface texture for the high-conductance wall elements shall be very smooth, the same as the window glass; see Tables 5-6 and 5-8 of Sections 5.2.1.9 and 5.2.1.10 (Case 600), respectively. 
d. Other construction geometry and material thermal properties shall be applied as specified in Tables 5-35 and 5-36, respectively.

Informative Note, Calculated Properties of Informative Table 5-37: Informative Table 5-37 includes calculated values derived from the fundamental material thermal properties of normative Table 5-36 and alternative constant surface coefficients of Sections 5.2.3.1.4.3 and 5.2.3.1.4.4, for programs that may need this information.

Informative Note, Variation of Listed Surface Coefficients and Overall U-Values from Values of Informative Table 5-37: For programs that calculate time-step varying surface infrared radiative exchange or convective coefficients or both, or that allow more detailed constant surface coefficient inputs (e.g., for scheduling), variation of the following from the values given in Table 5-37 may be expected: individual surface coefficient $\mathrm{U}$-values and overall U-value.

Informative Note: Values listed in Tables 5-35, 5-36, and 5-37 are excerpted from those for the Case 600 transparent window listed in Tables 5-10 and 5-11.

Table 5-35 High-Conductance Wall Element Geometry and Construction Properties

\begin{tabular}{lc}
\hline Property & Value \\
\hline \hline Height, individual unit & $2 \mathrm{~m}$ \\
Width, individual unit & $3 \mathrm{~m}$ \\
Area, individual unit & $6 \mathrm{~m}^{2}$ \\
Number of individual units & 2 \\
\hline
\end{tabular}

Table 5-36 Fundamental Material Thermal Properties of High-Conductance Wall Elements $\mathbf{s}^{\mathrm{a}, \mathrm{b}}$

\begin{tabular}{ccccccc}
\hline Element & $\begin{array}{c}\mathbf{k}, \\
\mathrm{W} /(\mathbf{m} \cdot \mathbf{K})\end{array}$ & $\begin{array}{c}\text { Thickness, } \\
\mathbf{m m}\end{array}$ & $\begin{array}{c}\mathbf{U}, \\
\mathbf{W} /\left(\mathbf{m}^{2} \cdot \mathbf{K}\right)\end{array}$ & $\begin{array}{c}\mathbf{R}, \\
\mathbf{m}^{2} \cdot \mathbf{K} / \mathbf{W}\end{array}$ & $\begin{array}{c}\text { Density, } \\
\mathbf{k g} / \mathbf{m}^{\mathbf{3}}\end{array}$ & $\begin{array}{c}\boldsymbol{c}_{p}, \\
\mathbf{J} /(\mathbf{k g} \cdot \mathbf{K})\end{array}$ \\
\hline \hline Opaque panel & $\mathbf{1 . 0 0}$ & $\mathbf{3 . 0 4 8}$ & $\mathbf{3 2 8}$ & $\mathbf{0 . 0 0 3 0 5}$ & $\mathbf{2 4 7 0}$ & 750 \\
Air gap $^{\mathbf{c}}$ & $\mathbf{0 . 0 6 2 5}$ & $\mathbf{1 2 . 0}$ & $\mathbf{5 . 2 0 8}$ & $\mathbf{0 . 1 9 2 0 0}$ & $\mathbf{1 . 2 9 2 4 9 8}$ & $\mathbf{1 0 0 6 . 1 0 3 2 7 1}$ \\
Opaque panel & $\mathbf{1 . 0 0}$ & $\mathbf{3 . 0 4 8}$ & $\mathbf{3 2 8}$ & $\mathbf{0 . 0 0 3 0 5}$ & $\mathbf{2 4 7 0}$ & 750 \\
\hline
\end{tabular}

a. Informative Note: Updates to Standard 140-2017 are highlighted with bold font.

b. Informative Note: Values listed here are from Tables 5-10 and 5-11 (see Section 5.2.1.11 [Case 600]), except where noted. c. For the high-conductance wall element, air-gap properties are constant (not allowed to vary with temperature and pressure). d. Informative Note: Air-gap conductivity from $\mathrm{k}=\mathrm{U} \times$ (Thickness); this is the effective constant air-gap conductivity, including the effect of natural convection, as calculated by WINDOW 7 for the Case 600 clear double-pane window of Table 5-10.

Informative Table 5-37 Calculated Properties of High-Conductance Wall Elements ${ }^{a}$

\begin{tabular}{ccc}
\hline Element & $\mathrm{U}, \mathrm{W} /\left(\mathrm{m}^{2} \cdot \mathrm{K}\right)$ & $\mathrm{R}, \mathbf{m}^{2} \cdot \mathrm{K} / \mathrm{W}$ \\
\hline \hline${\text { Interior combined surface coefficient }\left(\mathrm{h}_{\mathrm{i}}\right)^{\mathrm{b}}}_{\text {Total surface-to-surface }}^{\mathrm{c}}$ & 4.5 & $\mathbf{0 . 2 2 2 2 2}$ \\
${\text { Exterior combined surface coefficient }\left(\mathrm{h}_{\mathbf{o}}\right)^{\mathrm{b}}}_{\text {Total air-to-air }^{\mathrm{d}}}$ & 5.048 & $\mathbf{0 . 1 9 8 1 0}$ \\
\hline
\end{tabular}

a. Updates to Standard 140-2017 are highlighted with bold font.

b. U-values listed here are combined surface coefficient values (h,comb) from Tables 5-38 and 5-39 (see Sections 5.2.3.1.4.3 and

5.2.3.1.4.4, respectively); (R Value) = 1 / (U value); these match values of Table 5-11 (see Section 5.2.1.11 [Case 600]).

c. Calculated from values of Table 5-36: $(\mathrm{R}$ value, total surface to surface $)=(\mathrm{R}$ air gap $)+2 \times($ opaque panel $\mathrm{R}$ value $)$;

$(\mathrm{U}$ Value $)=1 /(\mathrm{R}$ value $)$.

d. Calculated: $(\mathrm{R}$ value, total air to air $)=(\mathrm{R}$ value, total surface to surface $)+1 / \mathrm{h}_{\mathrm{i}}+1 / \mathrm{h}_{\mathrm{o}}$; $(\mathrm{U}$ Value $)=1 /(\mathrm{R}$ value $)$; these match values of Table 5-11 (see Section 5.2.1.11 [Case 600]). 


\subsection{Alternative Constant Exterior Convective and Combined (Radiative and Convective) Surface}

Coefficients.

a. If the program being tested calculates exterior surface convective coefficients and infrared radiative exchange varying with time step:

- Those calculations shall be applied.

- Skip the remaining instructions in this section and proceed to Section 5.2.3.1.4.4.

b. If the program being tested does not calculate time-step-varying exterior surface convective coefficients or infrared radiative exchange, then the information provided in Table 5-38 shall be applied. In applying Table 5-38:

- Programs that calculate time-step-varying exterior surface infrared radiative exchange, but not convective coefficients, shall apply the listed exterior convective surface coefficient (h,conv,ext) for the high-conductance wall elements.

- Programs that do not calculate time-step-varying exterior surface convective coefficients and infrared radiative exchange shall apply the listed exterior combined surface coefficient (h,comb,ext) for the high-conductance wall elements.

- Use of different (nonspecified) values shall not be prohibited if there is a mathematical, physical, or logical basis for applying them. Where different values are used, they shall be applied consistently throughout the test cases. Use of nonspecified values shall be documented in the Standard Output Report specified in Normative Annex A2.

Informative Note: The constant values of Table 5-38 are provided for programs that require this input, i.e., that have no time-step-varying exterior surface convective coefficient or infrared radiative heat transfer calculation method or no other constant exterior surface heat transfer coefficients explicit to their internal coding. Programs (or models within those programs, where a program allows a variety of modeling methods) that calculate time-step-varying surface convective coefficients and infrared radiative heat transfer should not be adjusted to match the constant values provided here.

Informative Note: Supporting information about development of alternative constant surface coefficients is provided in Informative Annex B4.

\section{Table 5-38 Alternative Constant Exterior Convective and Combined Surface Coefficients for High-} Conductance Wall Elements, Case 220

\begin{tabular}{lcc}
\hline Surface Type & $\begin{array}{c}\text { Exterior Convective Surface } \\
\text { Coefficient }(\mathbf{h}, \mathrm{conv}, \mathrm{ext}), \\
\mathrm{W} /\left(\mathbf{m}^{2} \cdot \mathbf{K}\right)\end{array}$ & $\begin{array}{c}\text { Exterior Combined Surface } \\
\text { Coefficient }(\mathbf{h}, \mathrm{comb}, \mathrm{ext}), \\
\mathrm{W} /\left(\mathbf{m}^{2} \cdot \mathbf{K}\right)\end{array}$ \\
\hline $\begin{array}{l}\text { High-Conductance Wall } \\
\text { Element }\end{array}$ & 8.0 & 17.8 \\
\hline
\end{tabular}

a. Informative Note: Changes to Standard 140-2017 are highlighted with bold font.

b. Informative Note: Informative Annex B4 includes supporting information.

\subsection{Alternative Constant Interior Convective and Combined (Radiative and Convective) Surface} Coefficients.

a. If the program being tested calculates interior surface convective coefficients and infrared radiative exchange varying with time step:

- Those calculations shall be applied.

- Skip the remaining instructions in this section and proceed to Section 5.2.3.1.5.

b. If the program being tested does not calculate time-step-varying interior surface convective coefficients or infrared radiative exchange, then the information provided in Table 5-39 shall be applied. In applying Table 5-39:

- Programs that calculate time-step-varying interior surface infrared radiative exchange, but not convective coefficients, shall apply the listed interior convective surface coefficient (h,conv,int) for the high-conductance wall elements.

- Programs that do not calculate time-step-varying interior surface convective coefficients and infrared radiative exchange shall apply the listed interior combined surface coefficient (h,comb,int) for the high-conductance wall elements.

- Use of different (nonspecified) values shall not be prohibited if there is a mathematical, physical, or logical basis for applying them. Where different values are used, they shall be applied consistently throughout the test 
cases. Use of nonspecified values shall be documented in the Standard Output Report specified in Normative Annex A2.

Informative Note: The constant values of Table 5-39 are provided for programs that require this input, i.e., that have no time-step-varying interior surface convective coefficient or infrared radiative heat transfer calculation method or no other constant interior surface heat transfer coefficients explicit to their internal coding. Programs (or models within those programs, where a program allows a variety of modeling methods) that calculate time-step-varying surface convective coefficients and infrared radiative heat transfer should not be adjusted to match the constant value provided here.

Informative Note: Supporting information about development of alternative constant surface coefficients is provided in Informative Annex B4.

Table 5-39 Alternative Constant Interior Convective and Combined Surface Coefficients for HighConductance Wall Elements, Case 220 $0^{\mathrm{a}, \mathrm{b}}$

\begin{tabular}{lcc}
\hline Surface Type & $\begin{array}{c}\text { Interior Convective Surface } \\
\text { Coefficient (h,conv,int) } \\
\mathrm{W} /\left(\mathrm{m}^{2} \cdot \mathbf{K}\right)\end{array}$ & $\begin{array}{c}\text { Interior Combined Surface } \\
\text { Coefficient }(\mathbf{h}, \mathrm{comb}, \mathrm{int}), \\
\mathrm{W} /\left(\mathbf{m}^{2} \cdot \mathbf{K}\right)\end{array}$ \\
\hline $\begin{array}{l}\text { High-Conductance Wall } \\
\text { Element }\end{array}$ & 2.4 & 4.5 \\
\hline
\end{tabular}

a. Informative Note: Changes to Standard 140-2017 are highlighted with bold font.

b. Informative Note: Informative Annex B4 includes supporting information.

\subsection{Thermostat Control}

5.2.3.1.5.1 The following " $20,20 "$ thermostat control configuration shall be used (as in Case 685):

- Heat $=$ ON IF Temperature $<20^{\circ} \mathrm{C}$.

- $\mathrm{Cool}=$ ON IF Temperature $>20^{\circ} \mathrm{C}$.

Informative Note: "Temperature" refers to the conditioned-zone air temperature.

5.2.3.1.5.2 The thermostat shall be nonproportional, as specified in Section 5.2.1.13.1.2 (Case 600).

5.2.3.1.6 Output Requirements. Case 220 requires the following output:

a. Non-free-float case output in accordance with Section 6.2.1.1.

b. General reporting requirements of Section 6.1 .

5.2.3.2 Case 210: Interior Infrared Radiation. Case 210 shall be modeled exactly the same as Case 220 except for changes specified in the following subsections.

5.2.3.2.1 Opaque Surface Radiative Properties. Interior infrared emittance $=0.1$. This value shall be applied to only the interior side of all opaque surfaces, including the high-conductance wall elements (see Section 5.2.3.1.4 [Case 220]).

5.2.3.2.2 Alternative Constant Interior Convective and Combined (Radiative and Convective) Surface Coefficients.

a. If the program being tested calculates interior surface convective coefficients and infrared radiative exchange varying with time step:

- $\quad$ Those calculations shall be applied.

- $\quad$ Skip the remaining instructions in this section and proceed to Section 5.2.3.3 (Case 215).

b. If the program being tested does not calculate time-step-varying interior convective surface coefficients or infrared radiative exchange, the information provided in Table 5-40 shall be applied. In applying Table 5-40:

- Programs that calculate time-step-varying interior surface infrared radiative exchange, but not convective coefficients, shall apply the listed interior convective surface coefficients (h,conv,int) for each surface type.

- Programs that do not calculate time-step-varying interior surface convective coefficients and infrared radiative exchange shall apply the listed interior combined surface coefficients (h,comb,int) for each surface type.

- Use of different (nonspecified) values shall not be prohibited if there is a mathematical, physical, or logical basis for applying them. Where different values are used, they shall be applied consistently throughout the test cases. Use of nonspecified values shall be documented in the Standard Output Report specified in Normative Annex A2. 
Informative Note: The constant values of Table 5-40 are provided for programs that require this input, i.e., that have no time-step-varying interior surface convective coefficient or infrared radiative heat transfer calculation method or no other constant interior surface heat transfer coefficients explicit to their internal coding. Programs (or models within those programs, where a program allows a variety of modeling methods) that calculate time-step-varying surface convective coefficients and infrared radiative heat transfer should not be adjusted to match the constant values provided here.

Informative Note: Supporting information about the development of Table 5-40 is provided in Informative Annex B4.

\section{Table 5-40 Alternative Constant Interior Convective and Combined Surface Coefficients for Each Surface Type, Case 210,b}

\begin{tabular}{|c|c|c|}
\hline Surface Type & $\begin{array}{c}\text { Interior Convective Surface } \\
\text { Coefficient (h,conv,int), } \\
\qquad \mathrm{W} /\left(\mathbf{m}^{\mathbf{2}} \cdot \mathbf{K}\right)\end{array}$ & $\begin{array}{c}\text { Interior Combined Surface } \\
\text { Coefficient (h,comb,int), } \\
\qquad \mathbf{W} /\left(\mathbf{m}^{2} \cdot \mathbf{K}\right)\end{array}$ \\
\hline Walls & 1.9 & 2.1 \\
\hline Ceiling & 1.9 & $1.9^{c}$ \\
\hline Raised Floor & 1.0 & $0.4^{\mathrm{c}}$ \\
\hline $\begin{array}{l}\text { High-Conductance Wall } \\
\text { Elements }\end{array}$ & 2.6 & 3.1 \\
\hline
\end{tabular}

a. Informative Note: Changes to Standard 140-2017 are highlighted with bold font.

b. Informative Note: Informative Annex B4 includes supporting information.

c. Informative Note: h,comb, int $\leq \mathrm{h}$,conv, int is possible here because convective and radiative heat flows may be in opposite directions for a given surface for a sufficient number of time steps.

5.2.3.3 Case 215: Exterior Infrared Radiation. Case 215 shall be modeled exactly the same as Case 220 except for changes specified in the following subsections.

5.2.3.3.1 Opaque Surface Radiative Properties. Exterior infrared emittance $=0.1$. This value shall be applied to only the exterior side of all opaque surfaces, including the high-conductance wall elements (see Section 5.2.3.1.4 [Case 220]).

\subsection{Alternative Constant Exterior Convective and Combined (Radiative and Convective) Surface}

\section{Coefficients.}

a. If the program being tested calculates exterior surface convective coefficients and infrared radiative exchange varying with time step:

- Those calculations shall be applied.

- Skip the remaining instructions in this section and proceed to Section 5.2.3.4 (Case 200).

b. If the program being tested does not calculate time-step-varying exterior surface coefficients or infrared radiative exchange, the information provided in Table 5-41 shall be applied. In applying Table 5-41:

- Programs that calculate time-step-varying exterior surface infrared radiative exchange, but not convective coefficients, shall apply the listed exterior convective surface coefficients (h,conv,ext) for each surface type.

- Programs that do not calculate time-step-varying exterior surface convective coefficients and infrared radiative exchange shall apply the listed exterior combined surface coefficients (h,comb,ext) for each surface type.

- Use of different (nonspecified) values shall not be prohibited if there is a mathematical, physical, or logical basis for applying them. Where different values are used, they shall be applied consistently throughout the test cases. Use of nonspecified values shall be documented in the Standard Output Report specified in Normative Annex A2.

Informative Note: The constant values of Table 5-41 are provided for programs that require this input, i.e., that have no time-step-varying exterior surface convective coefficient or infrared radiative heat transfer calculation method or no other constant exterior surface heat transfer coefficients explicit to their internal coding. Programs (or models within those programs, where a program allows a variety of modeling methods) that calculate surface convective coefficients and infrared radiative heat transfer should not be adjusted to match the constant values provided here. Informative Note: Supporting information about the development of Table 5-41 is provided in Informative Annex B4. 
Table 5-41 Alternative Constant Exterior Convective and Combined Surface Coefficients for Each Surface Type, Case 215

\begin{tabular}{lcc}
\hline Surface Type & $\begin{array}{c}\text { Exterior Convective Surface } \\
\text { Coefficient (h,conv,ext), } \\
\mathrm{W} /\left(\mathbf{m}^{2} \cdot \mathbf{K}\right)\end{array}$ & $\begin{array}{c}\text { Exterior Combined Surface } \\
\text { Coefficient }(\mathbf{h}, \text { comb,ext), } \\
\mathrm{W} /\left(\mathbf{m}^{2} \cdot \mathbf{K}\right)\end{array}$ \\
\hline \hline Walls & 11.8 & 12.8 \\
Roof & 14.4 & 17.4 \\
Raised Floor & 0.9 & 1.3 \\
High-Conductance Wall & 7.9 & 8.1 \\
Elements & & \\
\hline
\end{tabular}

a. Informative Note: Changes to Standard 140-2017 are highlighted with bold font.

b. Informative Note: Informative Annex B4 includes supporting information.

\subsubsection{Case 200 Infrared Radiation.}

Case 200 shall be modeled exactly the same as Case 210 except for changes specified in the following subsections. 5.2.3.4.1 Opaque Surface Radiative Properties. Exterior infrared emittance $=0.1$. This value shall be applied to only the exterior side of all opaque surfaces, including the high-conductance wall elements.

5.2.3.4.2 Alternative Constant Exterior Convective and Combined (Radiative and Convective) Surface Coefficients. See Section 5.2.3.3.2 (Case 215) for requirements.

5.2.3.4.3 Output Requirements. Case 200 requires the following output:

a. Non-free-float case output in accordance with Section 6.2.1.1.

b. Case-200-only output in accordance with Section 6.2.1.9.

c. General reporting requirements of Section 6.1.

5.2.3.5 Case 195: Solid Conduction Test. Case 195 shall be modeled exactly the same as Case 200, except the 12 $\mathrm{m}^{2}$ of high-conductance wall elements shall be replaced with the lightweight exterior walls with thermal and material properties as specified in Table 5-2 (see Section 5.2.1.4 [Case 600]). These walls shall have:

- A rough exterior surface and smooth interior surface; see Tables 5-6 and 5-8 of Sections 5.2.1.9 and 5.2.1.10 (Case 600), respectively.

- Surface radiative properties and associated surface heat transfer characteristics as specified for the lightweight exterior walls of Case 200.

5.2.3.5.1 Output Requirements. Case 195 requires the following output:

a. Non-free-float case output in accordance with Section 6.2.1.1.

b. General reporting requirements of Section 6.1.

5.2.3.6 Case 230: Infiltration. Case 230 shall be modeled exactly the same as Case 220 except that the infiltration rate shall be 1.0 ach, continuously ( 24 hours per day for the full year). The infiltration rate shall be independent of wind speed, indoor/outdoor temperature difference, or other variables.

The weather data file represents a high-altitude site with an elevation of $1650 \mathrm{~m}$ above sea level. If the program being tested does not use barometric pressure from the weather data or otherwise automatically correct for the change in air density due to altitude, then the specified infiltration rates shall be adjusted to yield mass flows equivalent to those occurring at the specified altitude as shown in Table 5-42.

Informative Note: Air density at $1650 \mathrm{~m}$ altitude is roughly $80 \%$ of that at sea level. The calculation technique used to develop Table 5-42 is provided as background information in Informative Annex B3, Section B3.1.

Informative Note: Alternatively, the given infiltration rate may be input as a constant ventilation rate. 
Table 5-42 Infiltration Rates Depending on the Presence of Automatic Altitude Adjustment, Case 230 ${ }^{\mathrm{a}}$

\begin{tabular}{lcc}
\hline \multicolumn{1}{c}{ Altitude Adjustment Algorithm } & $\begin{array}{c}\text { Input Air Changes per } \\
\text { Hour (ach) }\end{array}$ & $\begin{array}{c}\text { Adjustment } \\
\text { Factor }\end{array}$ \\
\hline \hline $\begin{array}{l}\text { Programs with automatic altitude adjustment; set altitude } \\
\text { to } 1650 \mathrm{~m} \text { above sea level } \\
\begin{array}{l}\text { Programs with fixed assumption that site is at sea level } \\
\text { (no automatic adjustment) }\end{array}\end{array}$ & 1.0 \\
\hline \\
$\begin{array}{l}\text { Informative Note: } \text { Values that were changed from Standard 140-2017 are highlighted with bold font. } \\
\text { b. (Specified Rate) } \times(1.0156 / 1.2255)=(\text { Altitude adjusted rate) }\end{array}$
\end{tabular}

5.2.3.7 Case 240: Internal Gains. Case 240 shall be modeled exactly the same as Case 220 except for the following changes to internal gains:

- Internal gains $=200 \mathrm{~W}$, continuously ( 24 hours per day for the full year).

- Internal gains are $100 \%$ sensible, $0 \%$ latent.

- Sensible internal gains are $60 \%$ radiative, $40 \%$ convective.

Informative Note: These are internally generated sources of heat (from equipment, lights, people, etc.) that are not related to heating, ventilating, and air conditioning (HVAC). The convective portion of internal gains may be reasonably assumed to be distributed evenly throughout the zone air. The radiative portion may be reasonably assumed to be distributed uniformly among the zone interior surfaces (area weighted distribution), assuming an effective infrared transmittance of approximately one for air within the zone.

5.2.3.8 Case 250: Exterior Shortwave Absorptance.

a. Case 250 shall be modeled exactly the same as Case 220 except that exterior shortwave (solar) absorptance $=0.9$.

b. Except for the raised floor, this value shall be applied to only the exterior side of all opaque surfaces, including the high-conductance wall elements (see Section 5.2.3.1.4 [Case 220]).

c. For the raised floor, the exterior surface shall continue to be modeled as receiving no solar radiation (see Section 5.2.1.5.1 [Case 600]).

5.2.3.9 Case 270: South Solar Gains. Case 270 shall be modeled exactly the same as Case 220 except for the changes specified in the following subsections.

5.2.3.9.1 Opaque Surface Radiative Properties. Interior shortwave absorptance $=0.9$. This value shall be applied to only the interior side of all opaque surfaces.

5.2.3.9.2 Transparent Window. The $12 \mathrm{~m}^{2}$ of high-conductance wall elements on the south walls shall be replaced by transparent windows as in Case 600. Window geometry shall be as shown in Figure 5-1 (Section 5.2.1.3 [Case 600]), and window thermal and optical properties shall be as shown in Section 5.2.1.11 (Case 600). Exterior and interior surface radiation and convection for windows are as specified in Sections 5.2.1.9 and 5.2.1.10 (Case 600), respectively.

\subsection{Interior Solar Distribution.}

5.2.3.9.3.1 This is the fractional distribution among interior surfaces of solar radiation transmitted through windows that is absorbed by each given surface after all reflections off of interior surfaces and accounting for solar lost (transmitted solar radiation reflected by interior opaque surfaces and retransmitted back out the windows). For programs that calculate interior solar distribution internally (via ray tracing or other means based on interior solar absorptance given in Section 5.2.3.9.1 [above]), and do not require a separate input for interior solar distribution fraction, ignore the following Section 5.2.3.9.3.2 and skip to Section 5.2.3.10 (Case 280).

5.2.3.9.3.2 If the program being tested does not calculate interior solar distribution internally but requires distribution fractions from the user, the use of Table 5-43 shall be permitted. Use of different (nonspecified) values shall not be prohibited if there is a mathematical, physical, or logical basis for applying them. Where different values are used, they shall be applied consistently throughout the test cases. The use of nonspecified values shall be documented in the Standard Output Report (Normative Annex A2).

Informative Note: Table 5-43 presents an approximate calculation of solar distribution fractions corresponding to the interior solar absorptance for Case 270 by assuming that $100 \%$ of the incoming radiation strikes the floor first and that all reflections are diffuse. Fractional values for the walls with windows (i.e., the south wall) include the portion of the solar radiation absorbed by the glass (as it passes back out the window) and conducted back into the zone. Solar radiation absorbed by the glass (and conducted inward) as it initially passes into the building is not included in the values in Table 5-43. Informative Annex B7 gives background information regarding the calculation technique used for developing these solar fractions. 
Table 5-43 Alternative Constant Interior Solar Distribution Fractions by Surface, Case $270^{\mathrm{a}}$

\begin{tabular}{lccccccc}
\hline \multicolumn{1}{c}{ Surface } & Floor & Ceiling & $\begin{array}{c}\text { East } \\
\text { Wall }\end{array}$ & $\begin{array}{c}\text { West } \\
\text { Wall }\end{array}$ & $\begin{array}{c}\text { North } \\
\text { Wall }\end{array}$ & $\begin{array}{c}\text { South } \\
\text { Wall }\end{array}$ & $\begin{array}{c}\text { Solar Lost } \\
\text { through Windows }\end{array}$ \\
\hline \hline $\begin{array}{l}\text { Solar } \\
\text { Fraction }\end{array}$ & 0.903 & $\mathbf{0 . 0 5 0}$ & $\mathbf{0 . 0 1 0}$ & $\mathbf{0 . 0 1 0}$ & $\mathbf{0 . 0 1 4}$ & $\mathbf{0 . 0 0 7}$ & 0.006 \\
\hline
\end{tabular}

a. Informative Note: Values that were changed from Standard 140-2017 are highlighted with bold font.

5.2.3.10 Case 280: Cavity Albedo. Case 280 shall be modeled exactly the same as Case 270 except for changes specified in the following subsections.

5.2.3.10.1 Opaque Surface Radiative Properties. Interior shortwave absorptance $=0.1$. This value shall be applied to only the interior side of all opaque surfaces.

\subsection{Interior Solar Distribution.}

5.2.3.10.2.1 This is the fractional distribution among interior surfaces of solar radiation transmitted through windows that is absorbed by each given surface after all reflections off of interior surfaces and accounting for solar lost (transmitted solar radiation reflected by interior opaque surfaces and retransmitted back out the windows). For programs that calculate interior solar distribution internally (via ray tracing or other means based on interior solar absorptance given in Section 5.2.3.10.1 [above]), and do not require a separate input for interior solar distribution fraction, ignore the following Section 5.2.3.10.2.2 and skip to Section 5.2.3.11 (Case 290).

5.2.3.10.2.2 If the program being tested does not calculate interior solar distribution internally but requires distribution fractions from the user, then the use of Table 5-44 shall be permitted. Use of different (nonspecified) values shall not be prohibited if there is a mathematical, physical, or logical basis for applying them. Where different values are used, they shall be applied consistently throughout the test cases. The use of nonspecified values shall be documented in the Standard Output Report (Normative Annex A2).

Informative Note: Table 5-44 presents an approximate calculation of solar distribution fractions corresponding to the interior solar absorptance of Case 280 by assuming that $100 \%$ of the incoming radiation strikes the floor first and that all reflections are diffuse. Fractional values for the walls with windows (i.e., the south wall) include the portion of the solar radiation absorbed by the glass (as it passes back out the window) and conducted back into the zone. Solar radiation absorbed by the glass (and conducted inward) as it initially passes into the building is not included in the values in Table 5-44. Informative Annex B7 gives background information regarding the calculation technique used for developing these solar fractions.

Table 5-44 Alternative Constant Interior Solar Distribution Fractions by Surface, Case $280^{\mathrm{a}}$

\begin{tabular}{lccccccc}
\hline \multicolumn{1}{c}{ Surface } & Floor & Ceiling & $\begin{array}{c}\text { East } \\
\text { Wall }\end{array}$ & $\begin{array}{c}\text { West } \\
\text { Wall }\end{array}$ & $\begin{array}{c}\text { North } \\
\text { Wall }\end{array}$ & $\begin{array}{c}\text { South } \\
\text { Wall }\end{array}$ & $\begin{array}{c}\text { Solar Lost } \\
\text { through Windows }\end{array}$ \\
\hline \hline $\begin{array}{l}\text { Solar } \\
\text { Fraction }\end{array}$ & $\mathbf{0 . 2 4 3}$ & 0.191 & 0.057 & 0.057 & $\mathbf{0 . 0 7 7}$ & $\mathbf{0 . 0 6 3}$ & $\mathbf{0 . 3 1 2}$ \\
\hline
\end{tabular}

a. Informative Note: Values that were changed from Standard 140-2017 are highlighted with bold font.

5.2.3.11 Case 290: South Shading. Case 290 shall be modeled exactly the same as Case 270 except that the overhang specified in Sections 5.2.2.1.1.1 and 5.2.2.1.1.2 (Case 610) is added. The horizontal overhang for southfacing windows shall extend across the entire length of the south wall.

5.2.3.12 Case 300: East/West Window Orientation. Case 300 shall be modeled exactly the same as Case 270 except for changes specified in the following subsections.

5.2.3.12.1 Window Orientation. The window orientation shall be modified as detailed in Figure 5-4 (Section 5.2.2.1.2.1 [Case 620]) such that $6 \mathrm{~m}^{2}$ of window area face east and $6 \mathrm{~m}^{2}$ of window area face west and there are no other windows. Other than the change in orientation, the windows shall be exactly as in Case 270.

\subsection{Interior Solar Distribution.}

5.2.3.12.2.1 This is the fractional distribution among interior surfaces of solar radiation transmitted through windows that is absorbed by each given surface after all reflections off of interior surfaces and accounting for solar lost (transmitted solar radiation reflected by interior opaque surfaces and retransmitted back out the windows). For programs that calculate interior solar distribution internally (via ray tracing or other means based on interior solar absorptance given in Section 5.2.3.9.1 [Case 270]), and do not require a separate input for interior solar distribution fraction, ignore the following Section 5.2.3.12.2.2 and skip to Section 5.2.3.13 (Case 310). 
5.2.3.12.2.2 If the program being tested does not calculate interior solar distribution internally but requires distribution fractions from the user, the use of Table 5-45 shall be permitted. Use of different (nonspecified) values shall not be prohibited if there is a mathematical, physical, or logical basis for applying them. Where different values are used, they shall be applied consistently throughout the test cases. The use of nonspecified values shall be documented in the Standard Output Report (Normative Annex A2).

Informative Note: Table 5-45 presents an approximate calculation of solar distribution fractions adjusted for the geometry of Case 300 by assuming that $100 \%$ of the incoming radiation strikes the floor first and that all reflections are diffuse. Fractional values for the walls with windows (i.e., the east and west walls) include the portion of the solar radiation absorbed by the glass (as it passes back out the window) and conducted back into the zone. Solar radiation absorbed by the glass (and conducted inward) as it initially passes into the building is not included in the values in Table 5-45. Informative Annex B7 gives background information regarding the calculation technique used for developing these solar fractions.

Table 5-45 Alternative Constant Interior Solar Distribution Fractions by Surface, Case $300^{\text {a }}$

\begin{tabular}{lccccccc}
\hline \multicolumn{1}{c}{ Surface } & Floor & Ceiling & $\begin{array}{c}\text { East } \\
\text { Wall }\end{array}$ & $\begin{array}{l}\text { West } \\
\text { Wall }\end{array}$ & $\begin{array}{c}\text { North } \\
\text { Wall }\end{array}$ & $\begin{array}{c}\text { South } \\
\text { Wall }\end{array}$ & $\begin{array}{c}\text { Solar Lost } \\
\text { through Windows }\end{array}$ \\
\hline \hline $\begin{array}{l}\text { Solar } \\
\text { Fraction }\end{array}$ & 0.903 & $\mathbf{0 . 0 5 0}$ & $\mathbf{0 . 0 0 6 5}$ & $\mathbf{0 . 0 0 6 5}$ & $\mathbf{0 . 0 1 4}$ & $\mathbf{0 . 0 1 4}$ & 0.006 \\
\hline
\end{tabular}

a. Informative Note: Values that were changed from Standard 140-2017 are highlighted with bold font.

5.2.3.13 Case 310: East/West Shading. Case 310 shall be modeled exactly the same as Case 300 except that shading devices are added to the east and west windows as specified in Sections 5.2.2.1.3.1 and 5.2.2.1.3.2 (Case $630)$.

5.2.3.14 Case 320: Thermostat. Case 320 shall be modeled exactly the same as Case 270 except for the changes specified in the following subsections.

5.2.3.14.1 The thermostat shall have the following 20,27 deadband configuration (as in Case 600):

- Heat $=$ ON IF Temperature $<20^{\circ} \mathrm{C}$; otherwise, Heat $=$ OFF.

- $\mathrm{Cool}=\mathrm{ON}$ IF Temperature $>27^{\circ} \mathrm{C}$; otherwise, $\mathrm{Cool}=\mathrm{OFF}$.

Informative Note: "Temperature" refers to the conditioned-zone air temperature.

5.2.3.14.2 The thermostat shall be nonproportional as specified in Section 5.2.1.13.1.2 (Case 600).

5.2.3.15 Case 400: High-Conductance Wall Elements with Deadband Thermostat. Case 400 shall be modeled exactly the same as Case 600 except for the changes specified in the following subsections.

5.2.3.15.1 Infiltration. Infiltration rate $=0$ ach, continuously ( 24 hours per day for the entire year).

5.2.3.15.2 Internal Gains. Internal gains $=0 \mathrm{~W}$, continuously ( 24 hours per day for the entire year).

5.2.3.15.3 Opaque Surface Radiative Properties.

a. Exterior solar absorptance $=0.1$.

b. Except for the raised floor, this value shall be applied to only the exterior side of all opaque surfaces, including the high-conductance wall elements of Section 5.2.3.15.4 (below).

c. For the raised floor, the exterior surface shall continue to be modeled as receiving no solar radiation (see Section

5.2.1.5.1 [Case 600]).

5.2.3.15.4 High-Conductance Wall Element. High-conductance wall elements shall replace the $12 \mathrm{~m}^{2}$ of transparent windows on the south wall, as follows:

a. The properties of the high-conductance wall elements shall be as specified in Section 5.2.3.1.4 (Case 220) and its subsections.

b. Exterior solar absorptance $=0.1$.

5.2.3.15.5 Output Requirements. Case 400 requires the following output:

a. Non-free-float case output in accordance with Section 6.2.1.1.

b. General reporting requirements of Section 6.1. 
5.2.3.16 Case 395: Solid Conduction Test. Case 395 shall be modeled exactly the same as Case 400 except that the $12 \mathrm{~m}^{2}$ of high-conductance wall elements shall be replaced with the lightweight exterior walls that shall have thermal and material properties specified in Table 5-2 (see Section 5.2.1.4 [Case 600]), as in Case 195. These walls shall have:

- A rough exterior surface and smooth interior surface; see Tables 5-6 and 5-8 of Sections 5.2.1.9 and 5.2.1.10 (Case 600), respectively.

- Surface radiative properties and associated surface heat transfer characteristics as specified for the lightweight exterior walls of Case 400.

5.2.3.17 Case 410: Infiltration. Case 410 shall be modeled exactly the same as Case 400 except that infiltration rate $=0.5$ ach, continuously ( 24 hours per day for the full year). If the program being tested does not use barometric pressure from weather data or otherwise automatically correct for the change in air density due to altitude, the infiltration rate shall be adjusted as specified in Section 5.2.1.6.1 (Case 600).

5.2.3.18 Case 420: Internal Gains. Case 420 shall be modeled exactly the same as Case 410 except for the following changes to internal gains (as in Case 600):

- Internal gains $=200 \mathrm{~W}$, continuously (24 hours per day for the full year).

- Internal gains are $100 \%$ sensible, $0 \%$ latent.

- Sensible internal gains are $60 \%$ radiative, $40 \%$ convective.

Informative Note: These are internally generated sources of heat (from equipment, lights, people, etc.) that are not related to heating, ventilating, and air conditioning (HVAC). The convective portion of internal gains may be reasonably assumed to be distributed evenly throughout the zone air. The radiative portion may be reasonably assumed to be distributed uniformly among the zone interior surfaces (area weighted distribution), assuming an effective infrared transmittance of approximately one for air within the zone.

5.2.3.19 Case 430: Exterior Shortwave Absorptance.

a. Case 430 shall be modeled exactly the same as Case 420 except that exterior shortwave (solar) absorptance $=0.6$ (as in Case 600).

b. Except for the raised floor, this value shall be applied to only the exterior side of all opaque surfaces, including the high-conductance wall elements.

c. For the raised floor, the exterior surface shall continue to be modeled as receiving no solar radiation (see Section 5.2.1.5.1 [Case 600]).

5.2.3.20 Case 440: Cavity Albedo. Case 440 shall be modeled exactly the same as Case 600 except for changes specified in the following subsections.

5.2.3.20.1 Opaque Surface Radiative Properties. Interior shortwave absorptance $=0.1$ (as in Case 280). This value shall be applied to only the interior side of all opaque surfaces.

5.2.3.20.2 Interior Solar Distribution. Interior solar distribution shall be as specified in Section 5.2.3.10.2 (Case 280).

5.2.3.20.3 Output Requirements. Case 440 requires the following output:

a. Non-free-float case output in accordance with Section 6.2.1.1.

b. General reporting requirements of Section 6.1.

5.2.3.21 Case 450: Constant Combined Interior and Exterior Surface Coefficients. Case 450 shall be modeled exactly the same as Case 600 except for changes specified in the following subsections.

Informative Note: The purpose of Case 450 is to isolate differences associated with varying surface interior and exterior surface convective heat transfer and radiative exchange models by comparing results of this case to Cases 600,460 , and 470 .

5.2.3.21.1 Interior Combined Radiative and Convective Surface Coefficients. The constant interior combined surface coefficients (h,comb,int) provided in Table 5-46 shall be applied. Time-step-varying calculation of interior surface heat transfer coefficients is prohibited. Use of constant values other than those of Table 5-46 is prohibited. Informative Note: For programs that allow direct input of constant convective surface coefficients, but not direct input of constant combined (radiative and convective) surface coefficients, input may be entered as follows: enter the appropriate values given for interior surfaces in Table 5-46 as convective coefficients, and set respective interior surface emittances to 0 (or as low as the program being tested allows). Informative Note: These are the same values as for h,comb,int in Table 5-9 (Section 5.2.1.10 [Case 600]). Constant surface coefficients presented here apply only to the test cases, and were calculated only for test cases with south-facing windows or south-facing highconductance wall elements; they should not be assumed to apply beyond this test suite. Supporting information about the development of Table 5-46 is provided in Informative Annex B4. 
5.2.3.21.2 Exterior Combined Radiative and Convective Surface Coefficients. The constant exterior combined surface coefficients (h,comb,ext) provided in Table 5-46 shall be applied. Time-step-varying calculation of exterior surface heat transfer coefficients is prohibited. Use of constant values other than those of Table 5-46 is prohibited. Informative Note: For programs that allow direct input of constant convective surface coefficients, but not direct input of constant combined (radiative and convective) surface coefficients, input may be entered as follows: enter the appropriate values given for exterior surfaces in Table 5-46 as convective coefficients, and set respective exterior surface emittances to 0 (or as low as the program being tested allows).

Informative Note: These are the same values as for h,comb,ext in Table 5-7 (Section 5.2.1.9 [Case 600]). Constant surface coefficients presented here apply only to the test cases, and were calculated only for test cases with southfacing windows or south-facing high-conductance wall elements; they should not be assumed to apply beyond this test suite. Supporting information about the development of Table 5-46 is provided in Informative Annex B4.

5.2.3.21.3 Output Requirements. Case 450 requires the following output:

a. Non-free-float case output in accordance with Section 6.2.1.1.

b. General reporting requirements of Section 6.1.

Table 5-46 Interior and Exterior Combined Surface Coefficients for Each Surface Type, Case 450a

\begin{tabular}{|c|c|c|}
\hline Surface Type & $\begin{array}{c}\text { Interior Combined Surface } \\
\text { Coefficient }(\mathbf{h}, \text { comb,int }) \text {, } \\
\qquad W /\left(\mathbf{m}^{2} \cdot \mathbf{K}\right)\end{array}$ & $\begin{array}{c}\text { Exterior Combined Surface } \\
\text { Coefficient }(\mathbf{h}, \mathrm{comb}, \mathrm{ext}), \\
\qquad \mathrm{W} /\left(\mathbf{m}^{\mathbf{2}} \cdot \mathbf{K}\right)\end{array}$ \\
\hline Walls & 1.8 & 21.6 \\
\hline Roof & 1.7 & 21.8 \\
\hline Raised Floor & 3.7 & 5.2 \\
\hline Windows & 4.5 & 17.8 \\
\hline
\end{tabular}

a. Informative Note: Informative Annex B4 includes supporting information.

5.2.3.22 Case 460: Constant Combined Interior Surface Coefficients. Case 460 shall be modeled exactly the same as Case 600 except for changes specified in the following subsections.

Informative Note: The purpose of Case 460 is to isolate differences associated with varying interior surface convective heat transfer and radiative exchange models by comparing results of this case to Cases 600 and 450 .

5.2.3.22.1 Interior Combined Radiative and Convective Surface Coefficients. The constant interior combined surface coefficients (h,comb,int) provided in Table 5-46 (see Section 5.2.3.21 [Case 450]) shall be applied. Timestep-varying calculation of interior surface heat transfer coefficients is prohibited. Use of constant values other than those of Table 5-46 is prohibited.

Informative Note: For programs that allow direct input of constant convective surface coefficients, but not direct input of constant combined (radiative and convective) surface coefficients, input may be entered as follows: enter the appropriate values given for interior surfaces in Table 5-46 as convective coefficients, and set respective interior surface emittances to 0 (or as low as the program being tested allows).

Informative Note: These are the same values as for h,comb,int in Table 5-9 (Section 5.2.1.10 [Case 600]). Constant surface coefficients presented here apply only to the test cases, and were calculated only for test cases with southfacing windows or south-facing high-conductance wall elements; they should not be assumed to apply beyond this test suite. Supporting information about the development of Table 5-46 is provided in Informative Annex B4.

Informative Note: Exterior surface heat transfer remains as in Section 5.2.1.9 (Case 600).

5.2.3.22.2 Output Requirements. Case 460 requires the following output:

a. Non-free-float case output in accordance with Section 6.2.1.1.

b. General reporting requirements of Section 6.1.

5.2.3.23 Case 470: Constant Combined Exterior Surface Coefficients. Case 470 shall be modeled exactly the same as Case 600 except for changes specified in the following subsections.

Informative Note: The purpose of Case 470 is to isolate differences associated with varying exterior surface convective heat transfer and radiative exchange models by comparing results of this case to Cases 600 and 450 . 
5.2.3.23.1 Exterior Combined Radiative and Convective Surface Coefficients. The constant exterior combined surface coefficients (h,comb, ext) provided in Table 5-46 (see Section 5.2.3.21 [Case 450]) shall be applied. Timestep-varying calculation of exterior surface heat transfer coefficients is prohibited. Use of constant values other than those of Table 5-46 is prohibited. Informative Note: For programs that allow direct input of constant convective surface coefficients, but not direct input of constant combined (radiative and convective) surface coefficients, input may be entered as follows: enter the appropriate values given for exterior surfaces in Table 5-46 as convective coefficients, and set respective exterior surface emittances to 0 (or as low as the program being tested allows).

Informative Note: These are the same values as for h,comb,ext in Table 5-7 (Section 5.2.1.9 [Case 600]). Constant surface coefficients presented here apply only to the test cases, and were calculated only for test cases with southfacing windows or south-facing high-conductance wall elements; they should not be assumed to apply beyond this test suite. Supporting information about the development of Table 5-46 is provided in Informative Annex B4.

Informative Note: Interior surface heat transfer remains as in Section 5.2.1.10 (Case 600).

5.2.3.23.2 Output Requirements. Case 470 requires the following output:

a. Non-free-float case output in accordance with Section 6.2.1.1.

b. General reporting requirements of Section 6.1.

5.2.3.24 Case 800: High Mass without Solar Gains. Case 800 shall be modeled exactly the same as Case 430 except as follows. The exterior wall and floor materials specifications of Table 5-27 (Section 5.2.2.2.1.1 [Case 900]) shall be applied in place of the materials specifications of Table 5-2 (Section 5.2.1.4 [Case 600]). The roof materials shall not change, and the high-conductance wall elements shall also remain as in Case 430.

Informative Note: Informative Table 5-28 (Section 5.2.2.2.1.1 [Case 900]) includes summary calculated values derived from fundamental properties of normative Table 5-27 and alternative constant surface coefficients of Sections 5.2.1.9.3 and 5.2.1.10.3 (Case 600), for programs that may need this information. For programs that automatically calculate surface radiation or convection or both, or that allow more detailed constant surface coefficient inputs (e.g., for scheduling), variation of individual interior surface coefficient $\mathrm{U}$-values, total $\mathrm{U}$ and total UA values, and heat capacities from Table 5-28 may be expected.

5.2.3.25 Case 810: High-Mass Cavity Albedo. Case 810 shall be modeled exactly the same as Case 900 except for changes specified in the following subsections.

5.2.3.25.1 Opaque Surface Radiative Properties. Interior shortwave absorptance $=0.1$ (as in Case 280). This value shall be applied to only the interior side of all opaque surfaces.

5.2.3.25.2 Interior Solar Distribution. Interior solar distribution shall be as specified in Section 5.2.3.10.2 (Case 280).

5.2.3.25.3 Output Requirements. Case 810 requires the following output:

a. Non-free-float case output in accordance with Section 6.2.1.1.

b. General reporting requirements of Section 6.1. 


\section{Class I Output Requirements}

Class I output requirements listed in Section 6 shall be applied as specified in Section 5.

\subsection{Reporting Results}

6.1.1 Standard Output Reports. The standard output reports included on the accompanying electronic media shall be used. Instructions regarding these reports are included in Normative Annex A2. Information required for this report includes the following:

a. Software name and version number.

b. Modeling documentation using "S140outNotes.TXT" on the accompanying electronic media for the following:

1. Software identifying information and operating requirements.

2. Modeling methods used when alternative methods are available in the software (as specified in Section

5.1.4).

3. Equivalent modeling methods used when the software does not allow direct input of specified values (as specified in Section 5.1.5).

4. Nonspecified inputs (as specified in Section 5.1.6).

5. Changes to source code for the purpose of running the tests, where such changes are not available in publicly released versions of the software (as specified in Section 5.1.9).

6. Omitted test cases and results (as specified in Section 6.1.3).

7. Anomalous results (as specified in Section 6.1.4).

c. Results for simulated cases using the following files on the accompanying electronic media:

1. Sec5-2Aout.XLSX for the building thermal envelope and fabric load tests of Sections 5.2.1, 5.2.2, and 5.2.3.

[Note to Users: Remainder of Section 6.1.1(c) excluded; it refers to other test suites.]

6.1.2 Simulation Input Files. All supporting data required for generating results with the tested software shall be saved, including the following:

- Input files.

- Processed weather data.

- Intermediate files containing calculations used for developing inputs.

- A "Readme-softwarename-yymmdd.pdf" file that briefly describes the contents of the above files according to their file type (i.e., their ".xyz" file extension).

6.1.3 Omitted Test Cases. If a program being tested omits a test case, the modeler shall provide an explanation of the omission using the modeler report template provided in Normative Annex A2.

6.1.4 Discussion of Anomalous Results. Explanation of anomalous test results using the modeler report template provided in Normative Annex A2 shall be permitted but is not required.

\subsection{Intentionally blank, no proposed changes to Standard 140 for 6.2 header and introduction.}

6.2.1 Output Requirements for Building Thermal Envelope and Fabric Load Tests of Sections 5.2.1, 5.2.2, and 5.2.3

6.2.1.1 All Non-Free-Float Cases. Required outputs for the non-free-float cases shall be as designated in Sections 6.2.1.1.1 through 6.2.1.1.5.

Informative Note: In this description, the term "free-float cases" refers to cases designated with "FF" in the case description (i.e., 600FF, 650FF, 680FF, 900FF, 950FF, 980FF); non-free-float cases are all the other cases described in Sections 5.2.1, 5.2.2, and 5.2.3 (Tables B1-2 and B1-3 of Informative Annex B1 include an informative summary listing of the cases of Sections 5.2.1, 5.2.2, and 5.2.3).

6.2.1.1.1 Annual heating load (MWh).

6.2.1.1.2 Annual sensible cooling load (MWh).

6.2.1.1.3 Annual hourly integrated peak heating load $(\mathrm{kW})$ with month, day, and hour of occurrence, applying month abbreviations specified in Sec5-2Aout.xlsx, tab 'A', cells C17 to C30.

6.2.1.1.4 Annual hourly integrated peak sensible cooling load $(\mathrm{kW})$ with month, day, and hour of occurrence, applying month abbreviations specified in Sec5-2Aout.xlsx, tab 'A', cells C17 to C30.

6.2.1.1.5 All heating and cooling loads listed in Sections 6.2.1.1.1 through 6.2.1.1.4 shall be entered into the appropriate standard output report (as specified in Normative Annex A2) as positive values $(\geq 0)$.

6.2.1.2 Case 600 (and other cases where indicated)

6.2.1.2.1 Annual incident unshaded total solar radiation (diffuse and direct-beam) on horizontal, north, east, south, and west surfaces $\left(\mathrm{kWh} / \mathrm{m}^{2}\right)$. 
6.2.1.2.2 (also for Cases 660 and 670) Unshaded annual transmitted total solar radiation (diffuse and direct-beam) through south windows $\left(\mathrm{kWh} / \mathrm{m}^{2}\right)$. This quantity does not include radiation that is absorbed in the glass and conducted inward as heat.

Informative Note: This quantity may be taken as the optically transmitted solar radiation through a window that is backed by a perfectly absorbing black cavity.

6.2.1.2.3 Exterior and interior convective surface coefficients $\left(\mathrm{W} /\left(\mathrm{m}^{2} \mathrm{~K}\right)\right)$, as follows, for the roof; north, east, west, and south walls; and a south window:

6.2.1.2.3.1 (also for Case 670 single-pane window and Case 200) Annual load-weighted average of hourly integrated absolute values, as follows:

6.2.1.2.3.1.1 For exterior surface convective coefficients $\left(h_{\text {conv,ext,lwa }}\right.$ in $\left.W / m^{2} K\right)$, apply the following for a full-year simulation (8760 hours):

$$
\mathrm{h}_{\text {conv,ext,lwa }}=\frac{\Sigma\left(\left|\mathrm{h}_{\text {conv,ext,hour }}\right| *\left|\mathrm{q}_{\text {zone,hour }}\right|\right)}{\left(\left|\mathrm{q}_{\text {zone,htg,ann }}\right|+\left|\mathrm{q}_{\text {zone,clg,ann }}\right|\right)}
$$

where,

$$
\begin{aligned}
& \mathrm{h}_{\text {conv,ext,hour }}=\text { hourly exterior convective coefficient for given surface, } \mathrm{W} / \mathrm{m}^{2} \mathrm{~K} \\
& \mathrm{q}_{\text {zone,hour }}=\text { hourly zone load, } \mathrm{kWh} \\
& \mathrm{q}_{\text {zone,htg,ann }}=\text { annual zone heating load, } \mathrm{kWh} \\
& \mathrm{q}_{\text {zone,clg,ann }}=\text { annual zone sensible cooling load, } \mathrm{kWh}
\end{aligned}
$$

Informative Note: Equation 6-1 allows direct comparison with alternative constant convection coefficients of Table 5-7 (for Case 600 results) and Table 5-41 (for Case 200 results); also see Annex B4, Table B4-1.

6.2.1.2.3.1.2 For interior surface convective coefficients $\left(h_{\text {conv,int,lwa }}\right.$ in $\left.W / m^{2} K\right)$, apply the following for a full-year simulation (8760 hours):

$$
\mathrm{h}_{\text {conv,int,lwa }}=\frac{\Sigma\left(\left|\mathrm{h}_{\text {conv,int,hour }}\right| *\left|\mathrm{q}_{\text {zone,hour }}\right|\right)}{\left(\left|\mathrm{q}_{\text {zone,htg,ann }}\right|+\left|\mathrm{q}_{\text {zone,clg,ann }}\right|\right)}
$$

where,

$\mathrm{h}_{\text {conv,int,hour }}=$ hourly interior convective coefficient for given surface, $\mathrm{W} / \mathrm{m}^{2} \mathrm{~K}$

$\mathrm{q}_{\mathrm{zone}, \text { hour, }} \mathrm{q}_{\mathrm{zone}, \text { htg,ann, and }} \mathrm{q}_{\mathrm{zone}, \mathrm{clg}, \text { ann }}$ are the same as for the exterior surface convective coefficients (see Section 6.2.1.2.3.1.1)

Informative Note: Equation 6-2 allows direct comparison with alternative constant convection coefficients of Table 5-9 (for Case 600 results) and Table 5-40 (for Case 200 results); also see Annex B4, Table B4-1.

6.2.1.2.3.2 Annual hourly integrated maximum absolute value with month, day, and hour of occurrence, applying month abbreviations specified in Sec5-2Aout.xlsx, tab 'A', cells C17 to C30.

6.2.1.2.3.3 Annual hourly integrated minimum absolute value with month, day, and hour of occurrence, applying month abbreviations specified in Sec5-2Aout.xlsx, tab 'A', cells C17 to C30.

6.2.1.2.3.4 (also for Case 670 single-pane window and Case 200) For programs that do not directly output convective surface coefficients, they shall be calculated as described in Sections 6.2.1.2.3.4.1 through 6.2.1.2.3.4.3. 6.2.1.2.3.4.1 For hourly integrated exterior convective surface coefficients:

$$
\mathrm{h}_{\mathrm{conv}, \text { ext,hour }}=\mathrm{ABS}\left(\mathrm{q}_{\text {surf,conv,ext,hour }} /\left(\mathrm{T}_{\text {surf,ext,hour }}-\mathrm{T}_{\text {amb,hour }}\right)\right)
$$

where,

$\mathrm{h}_{\mathrm{conv}, \mathrm{ext} \text {,hour }}=$ hourly integrated exterior convective surface coefficient, $\mathrm{W} /\left(\mathrm{m}^{2} \mathrm{~K}\right)$

$\operatorname{ABS}()=$ absolute value of the calculated value

$\mathrm{q}_{\text {surf,conv,ext,hour }}=$ hourly integrated convective heat flux at the exterior surface, $\mathrm{W} / \mathrm{m}^{2}$

$\mathrm{T}_{\text {surf,ext,hour }}=$ hourly integrated exterior surface temperature, ${ }^{\circ} \mathrm{C}$

$\mathrm{T}_{\text {amb,hour }}=$ hourly integrated ambient temperature, ${ }^{\circ} \mathrm{C}$ 
For determining annual hourly load-weighted average of hourly integrated values, this determination of $\mathrm{h}_{\text {conv,ext,hour }}$ shall be substituted for $\mathrm{h}_{\text {conv,ext,hour in Equation 6-1. }}$.

6.2.1.2.3.4.2 For hourly integrated interior convective surface coefficients:

$\mathrm{h}_{\text {conv,int,hour }}=\operatorname{ABS}\left(\mathrm{q}_{\text {surf,conv,int,hour }} /\left(\mathrm{T}_{\text {surf,int,hour }}-\mathrm{T}_{\text {zone,hour }}\right)\right)$

where,

$\mathrm{h}_{\mathrm{conv}, \text { int,hour }}=$ hourly integrated interior convective surface coefficient, $\mathrm{W} /\left(\mathrm{m}^{2} \mathrm{~K}\right)$

$\operatorname{ABS}()=$ absolute value of the calculated value

$\mathrm{q}_{\text {surf,conv,int,hour }}=$ hourly integrated convective heat flux at the interior surface, $\mathrm{W} / \mathrm{m}^{2}$

$\mathrm{T}_{\text {surf,int,hour }}=$ hourly integrated interior surface temperature, ${ }^{\circ} \mathrm{C}$

$\mathrm{T}_{\text {zone,hour }}=$ hourly integrated zone temperature, ${ }^{\circ} \mathrm{C}$

For determining the annual hourly load-weighted average of hourly integrated values, this determination of $\mathrm{h}_{\text {conv,int,hour }}$ shall be substituted for $\mathrm{h}_{\text {conv,int,hour in Equation 6-2. }}$.

6.2.1.2.3.4.3 For programs that subdivide the given surfaces into sub-surfaces, surface heat fluxes and temperatures are the spatially integrated average value for the surface.

6.2.1.2.4 If the program applies sky temperature, report sky temperature output as follows.

Informative Note: This is the temperature that the program applies for the portion of infrared radiation exchange between an exterior surface and the deep sky, including adjustment for the presence of clouds.

6.2.1.2.4.1 Annual mean sky temperature $\left({ }^{\circ} \mathrm{C}\right)$.

6.2.1.2.4.2 Annual hourly integrated minimum sky temperature $\left({ }^{\circ} \mathrm{C}\right)$ with month, day, and hour of occurrence, applying month abbreviations specified in Sec5-2Aout.xlsx, tab 'A', cells C17 to C30.

6.2.1.2.4.3 Annual hourly integrated maximum sky temperature $\left({ }^{\circ} \mathrm{C}\right)$ with month, day, and hour of occurrence, applying month abbreviations specified in Sec5-2Aout.xlsx, tab 'A', cells C17 to C30.

6.2.1.2.5 (also for Case 900) Monthly conditioned-zone loads shall be as designated in Sections 6.2.1.2.5.1 through 6.2.1.2.5.5.

6.2.1.2.5.1 Monthly heating load for each month of the year (kWh).

6.2.1.2.5.2 Monthly cooling load for each month of the year $(\mathrm{kWh})$.

6.2.1.2.5.3 Monthly hourly integrated peak heating load $(\mathrm{kW})$ for each month of the year, with day and hour of occurrence.

6.2.1.2.5.4 Monthly hourly integrated peak sensible cooling load $(\mathrm{kW})$ for each month of the year, with day and hour of occurrence.

6.2.1.2.5.5 All heating and cooling loads listed in Sections 6.2.1.2.5.1 through 6.2.1.2.5.4 shall be entered into the appropriate standard output report (as specified in Normative Annex A2) as positive values $(\geq 0)$.

\subsubsection{Case 610 Only}

6.2.1.3.1 Annual transmitted solar radiation (diffuse and direct-beam) through the shaded south window with a horizontal overhang $\left(\mathrm{kWh} / \mathrm{m}^{2}\right)$. This quantity does not include radiation that is absorbed in the glass and conducted inward as heat.

Informative Note: This quantity may be taken as the optically transmitted solar radiation through a window that is backed by a perfectly absorbing black cavity.

\subsubsection{Case 620 Only}

6.2.1.4.1 Unshaded annual transmitted solar radiation (diffuse and direct-beam) through the west window $\left(\mathrm{kWh} / \mathrm{m}^{2}\right)$. This quantity does not include radiation that is absorbed in the glass and conducted inward as heat.

Informative Note: This quantity may be taken as the optically transmitted solar radiation through a window that is backed by a perfectly absorbing black cavity.

\subsubsection{Case 630 Only}

6.2.1.5.1 Annual transmitted solar radiation (diffuse and direct-beam) through the shaded west window with horizontal overhang and vertical fins $\left(\mathrm{kWh} / \mathrm{m}^{2}\right)$. This quantity does not include radiation that is absorbed in the glass and conducted inward as heat.

Informative Note: This quantity may be taken as the optically transmitted solar radiation through a window that is backed by a perfectly absorbing black cavity. 
6.2.1.6 All Free-Float Cases. Required outputs for the free-float cases shall be as designated in Sections 6.2.1.6.1 through 6.2.1.6.3.

Informative Note: In this description, the term "free-float cases" refers to cases designated with "FF" in the case description (i.e., 600FF, 650FF, 680FF, 900FF, 950FF, 980FF, and for just the sun zone in Case 960).

6.2.1.6.1 Annual mean zone air temperature $\left({ }^{\circ} \mathrm{C}\right)$.

6.2.1.6.2 Annual hourly integrated minimum zone air temperature $\left({ }^{\circ} \mathrm{C}\right)$ with month, day, and hour of occurrence, applying month abbreviations specified in Sec5-2Aout.xlsx, tab 'A', cells C17 to C30.

6.2.1.6.3 Annual hourly integrated maximum zone air temperature $\left({ }^{\circ} \mathrm{C}\right)$ with month, day, and hour of occurrence, applying month abbreviations specified in Sec5-2Aout.xlsx, tab 'A', cells C17 to C30.

Informative Note: For all cases where free-float zone air temperature output is required, the free-float zone air temperature is for the zone air only, assuming well-mixed air with no radiant effects (i.e., equivalent to what would be obtained from an aspirated temperature sensor perfectly shielded from solar and infrared radiation).

\subsubsection{Case 900FF Only}

6.2.1.7.1 Annual hourly integrated $1{ }^{\circ} \mathrm{C}$ zone air temperature bin frequencies from $-50^{\circ} \mathrm{C}$ to $98^{\circ} \mathrm{C}$, where "bin frequency" is the number of hours a given zone air temperature has values within given bins $\left(1^{\circ} \mathrm{C}\right.$ bin width) during the annual simulation.

6.2.1.7.1.1 Zone air temperature bins are defined by an integer value of temperature as the lower bound (inclusive) of the range, the upper bound of the range being less than the next highest integer value.

Informative Note: For example, the zone air temperature $T$ bin defined by $20^{\circ} \mathrm{C}$ is $20^{\circ} \mathrm{C} \leq T<21^{\circ} \mathrm{C}$; similarly, the bin defined by $-2^{\circ} \mathrm{C}$ is $-2^{\circ} \mathrm{C} \leq T<-1^{\circ} \mathrm{C}$.

Output Example: Output from an annual simulation (8760 hours) might indicate 400 hours when the zone air temperature $(T)$ is $25^{\circ} \mathrm{C}\left(25^{\circ} \mathrm{C} \leq T<26^{\circ} \mathrm{C}\right)$, and 430 hours when the zone air temperature is $28^{\circ} \mathrm{C}\left(28^{\circ} \mathrm{C} \leq T<\right.$ $29^{\circ} \mathrm{C}$ ), with temperatures for remaining hours distributed among other bins as appropriate.

6.2.1.7.1.2 To process bin frequencies, the post-processor included with sheet tab 'TMPBIN' with the normative output file (Sec5-2Aout.xls) shall be used. To apply the post-processor, the 8760 hours of annual hourly zone temperature data shall be sequential hourly values compatible with entry into an xls or xlsx file, and shall be entered into a single data column.

Informative Note: Post-processor data entry instructions and data flow description are included with Sec52Aout.xls, sheet tab 'TMPBIN', beginning in cell C1.

6.2.1.8 Daily Hourly Output for Building Thermal Envelope and Fabric Load Tests of Sections 5.2.1 and 5.2.2. If the program being tested is capable of producing hourly outputs, the following hourly values for the specified days shall be provided. To produce this output, the simulation period shall be a typical annual run, as specified in Sections 5.1.7 and 5.1.8.1. Running the simulation for only the required days specified in the output requirements shall be prohibited, because the results could contain temperature history errors. Required outputs shall be as listed for specific cases in Table 6-1.

6.2.1.9 Case 200 only. Annual hourly load-weighted average exterior and interior convective surface coefficients for the roof; north, east, west, and south walls; and a high-conductance wall element as described in Sections 6.2.1.2.3.1 and 6.2.1.2.3.4.

6.2.1.10 Case 670 only. Annual hourly load-weighted average exterior and interior convective surface coefficients for the single-pane window only, as described in Sections 6.2.1.2.3.1 and 6.2.1.2.3.4. 
Table 6-1 Daily Hourly Output Requirements for Building Thermal Envelope and Fabric Load Tests of Sections 5.2.1 and 5.2.2

\begin{tabular}{|c|c|c|}
\hline Case(s) & Hourly Output Type ${ }^{a}$ & $\operatorname{Day}(\mathbf{s})^{\mathbf{b}}$ \\
\hline 600 & $\begin{array}{l}\text { Hourly integrated incident unshaded total solar radiation (direct } \\
\text { and diffuse) on horizontal, south, and west surfaces }\left(\mathrm{Wh} / \mathrm{m}^{2}\right)\end{array}$ & May 4, Jul 14 \\
\hline 600 & Hourly integrated sky temperature $\left({ }^{\circ} \mathrm{C}\right)^{\mathrm{c}}$ & Feb 1, May 4, Jul 14 \\
\hline $600,660,670$ & $\begin{array}{l}\text { Hourly integrated transmitted total solar radiation (direct and } \\
\text { diffuse) through south windows }\left(\mathrm{Wh} / \mathrm{m}^{2}\right)^{\mathrm{d}}\end{array}$ & Feb 1, May 4, Jul 14 \\
\hline $\begin{array}{c}600,660,670,680 \\
685,695,900,980 \\
985,995\end{array}$ & $\begin{array}{l}\text { Hourly integrated heating }(+) \text { and sensible cooling }(-) \text { loads } \\
(\mathrm{kWh} \text {; designate cooling with a }[-] \text { sign })\end{array}$ & Feb 1, Jul 14 \\
\hline 640,940 & $\begin{array}{l}\text { Hourly integrated heating }(+) \text { and sensible cooling }(-) \text { loads } \\
(\mathrm{kWh} \text {; designate cooling with a }[-] \text { sign })\end{array}$ & Feb 1 \\
\hline 640,940 & Hourly integrated conditioned-zone air temperature $\left({ }^{\circ} \mathrm{C}\right)$ & Feb 1 \\
\hline $\begin{array}{l}\text { 600FF, 680FF, } \\
900 \mathrm{FF}, 980 \mathrm{FF}\end{array}$ & Hourly integrated free-float zone air temperature $\left({ }^{\circ} \mathrm{C}\right)$ & Feb 1 \\
\hline $650 \mathrm{FF}, 950 \mathrm{FF}$ & Hourly integrated free-float zone air temperature $\left({ }^{\circ} \mathrm{C}\right)$ & Jul 14 \\
\hline
\end{tabular}

${ }^{\text {a }}$ Hourly data to consist of 24 hourly integrated values for each day. The first hour (hour 1 ) is defined to run from 0000 to 0100 hours.

b Month abbreviations: "Feb" = "February", "May"= May, "Jul" = July.

${ }^{\mathrm{c}}$ Informative Note: This is the temperature that the program applies for the portion of infrared radiation exchange between an exterior surface and the deep sky, including adjustment for the presence of clouds.

${ }^{\mathrm{d}}$ Informative Note: These outputs may be taken as the hourly integrated total transmitted solar radiation, divided by the total window area.

6.2.2 Intentionally blank, no proposed changes to Standard 140 for this section. 
[Note to Users: Only selected portions of Standard 140-2017 Annex A1 relevant to the thermal fabric test cases are included here.]

\section{NORMATIVE ANNEX A1 WEATHER DATA}

\section{A1.1 Weather Data}

A1.1.1 Weather Data for Building Thermal Envelope and Fabric Load Tests of Sections 5.2.1, 5.2.2, and 5.2.3. A1.1.1.1 Normative Weather Data. The full-year weather data 725650TY.CSV (Denver International Airport TMY3 data) provided with the accompanying electronic media shall be used for performing the tests called out in Sections 5.2.1, 5.2.2, and 5.2.3. Site and weather characteristics are summarized in Table A1-1. See Section A1.8 for details about the TMY3 weather data file format.

A1.1.1.2 Informative Sky Temperature Data. Informative Note: The specified weather data file does not include data for sky temperature $\left(\mathrm{T}_{\text {sky }}\right)$. For programs that do not automatically calculate $\mathrm{T}_{\text {sky }}$, and use $\mathrm{T}_{\text {sky }}$ as an input from the weather data file, calculated $\mathrm{T}_{\text {sky }}$ values are provided as informative material in the file "Tsky-Informative.xlsx" (see tab "Informative-Tsky"), included with the electronic files accompanying this standard. Calculation of $\mathrm{T}_{\text {sky }}$ is provided in Part IV, Appendix B (Section 4B). 
Table A1-1 Site and Weather Summary for 725650TY.CSV Weather Data Used with Building Thermal Envelope and Fabric Load Tests ${ }^{a}$

\begin{tabular}{|c|c|}
\hline Property & Value \\
\hline Weather type & Cold clear winters/hot dry summers \\
\hline Weather format & Typical Meteorological Year 3 (TMY3) \\
\hline Latitude & $\mathbf{3 9 . 8 3 3}^{\circ}$ North \\
\hline Longitude & $104.650^{\circ}$ West \\
\hline Altitude & $1650 \mathrm{~m}$ \\
\hline Time zone & 7 \\
\hline Ground reflectance & $0.2^{\mathrm{b}}$ \\
\hline Site & $\begin{array}{l}\text { Open terrain with scattered obstructions having } \\
\text { heights generally less than } 9 \mathrm{~m}^{\mathrm{c}}\end{array}$ \\
\hline Anemometer height & $10 \mathrm{~m}^{\mathrm{d}}$ \\
\hline Mean annual wind speed & $3.9 \mathrm{~m} / \mathrm{s}$ \\
\hline Maximum annual wind speed & $20.6 \mathrm{~m} / \mathrm{s}$ \\
\hline Mean annual ambient dry-bulb temperature & $10.9^{\circ} \mathrm{C}$ \\
\hline Minimum annual dry-bulb temperature & $-19.4^{\circ} \mathrm{C}$ \\
\hline Maximum annual dry-bulb temperature & $40.0^{\circ} \mathrm{C}$ \\
\hline Heating degree-days (base $18^{\circ} \mathrm{C}$ ) & $3129^{\circ} \mathrm{C}$-days \\
\hline Cooling degree-days (base $18^{\circ} \mathrm{C}$ ) & $529^{\circ} \mathrm{C}$-days \\
\hline Mean annual dew-point temperature & $-1.1^{\circ} \mathrm{C}$ \\
\hline Mean annual relative humidity & $50 \%$ \\
\hline Mean annual humidity ratio & $0.0049^{\mathrm{e}}$ \\
\hline Mean annual opaque cloud cover & 0.44, fraction of covered sky \\
\hline Global horizontal solar radiation annual total & $1670 \mathrm{kwh} /\left(\mathrm{m}^{2} \cdot \mathrm{y}\right)$ \\
\hline Direct normal solar radiation annual total & $1978 \mathrm{kWh} /\left(\mathrm{m}^{2} \cdot \mathrm{y}\right)$ \\
\hline Diffuse horizontal solar radiation & $556 \mathrm{kWh} /\left(\mathrm{m}^{2} \cdot \mathrm{y}\right)$ \\
\hline
\end{tabular}

a. Informative Note: Updates to Standard 140-2017 are highlighted with bold font.

b. Informative Note: See informative note with Section 5.2.1.1.2.5 regarding use of ground reflectance data.

c. Informative Note: The site location corresponds to Terrain Category 3, documented in 2017 ASHRAE Handbook of Fundamentals, p. 24.4, Table $1^{\text {B-101. }}$

d. Informative Note: Assumed typical anemometer location height.

e. Informative Note: Approximation calculated from ODB, RH and Patm based on ideal-gas equations.

[Note to Users: A1.2 through A1.7 are intentionally blank so remaining material matches Standard 140 numbering; those sections do not apply to the thermal fabric test cases update.] 
A1.8 TMY3 Weather Data Format. TMY3 weather data are provided in comma-separated value (CSV)

file format. The TMY3 data format has two file headers followed by 8,760 lines of data, each with 68 data fields, as described below.

Informative Note: This information is provided for those programs that do not have Typical Meteorological Year 3 (TMY3) weather processors. If this summary is insufficient, the complete documentation on TMY3 weather data ${ }^{\mathrm{A}-5}$ can be obtained at http://www.nrel.gov/docs/fy08osti/43156.pdf.

A1.8.1 File Headers. The first row of each file is the file header that describes the station. This row contains the WBAN number, city/location, state, time zone, latitude, longitude, and elevation. The field positions and definitions of these header elements are given in Table A1-19. The second row of data includes the data field name and its units for each data field; see Table A1-20.

A1.8.2 Hourly Records. Following the file headers, 8,760 rows of hourly data records provide one year of solar radiation, illuminance, and meteorological data, along with their source and uncertainty flags, as described in Table A1-21. Tables A1-22 through A1-24 include source and uncertainty flag definitions as called out in Table A1-21. Informative Note: For solar radiation and illuminance elements, the data values represent the energy received during the 60 minutes preceding the hour indicated (60-minute period ending at the time stamp), as described in Table A1-21. For meteorological elements (with some exceptions), observations or measurements were made at the hour indicated as described in Table A1-21. Some of the meteorological elements had observations, measurements, or estimates made at other intervals.

Table A1-19. TMY3 data header (line 1)

\begin{tabular}{cll}
\hline Field & Element & Unit or Description \\
\hline \hline 1 & Site identifier code & USAF number \\
\hline 2 & Station name & Quote delimited \\
\hline 3 & Station state & Two-letter U.S. Postal abbreviation \\
\hline 4 & Site time zone & Hours from Greenwich, negative west \\
\hline 5 & Site latitude & Decimal degree \\
\hline 6 & Site longitude & Decimal degree \\
\hline 7 & Site elevation & Meter \\
\hline
\end{tabular}

Table A1-20. TMY3 data header (line 2)

\begin{tabular}{ll}
\hline Field & Element \\
\hline \hline $1-68$ & Data field name and units (abbreviation or mnemonic) \\
\hline
\end{tabular}


Table A1-21. TMY3 data fields (lines 3-8762)

\begin{tabular}{|c|c|c|c|c|}
\hline Field & Element & Unit or Range & Resolution & Description \\
\hline 1 & Date & "MM/DD/YYYY & 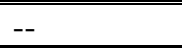 & Date of data record \\
\hline 2 & Time & HH:MM & -- & Time of data record (local standard time) \\
\hline 3 & $\begin{array}{l}\text { Hourly } \\
\text { extraterrestrial } \\
\text { radiation on a } \\
\text { horizontal surface }\end{array}$ & $\begin{array}{l}\text { Watt-hour per } \\
\text { square meter }\end{array}$ & $1 \mathrm{Wh} / \mathrm{m}^{2}$ & $\begin{array}{l}\text { Amount of solar radiation received on a horizontal } \\
\text { surface at the top of the atmosphere during the } 60 \text { - } \\
\text { minute period ending at the timestamp }\end{array}$ \\
\hline 4 & $\begin{array}{l}\text { Hourly } \\
\text { extraterrestrial } \\
\text { radiation normal to } \\
\text { the sun }\end{array}$ & $\begin{array}{l}\text { Watt-hour per } \\
\text { square meter }\end{array}$ & $1 \mathrm{Wh} / \mathrm{m}^{2}$ & $\begin{array}{l}\text { Amount of solar radiation received on a surface normal } \\
\text { to the sun at the top of the atmosphere during the } 60- \\
\text { minute period ending at the timestamp }\end{array}$ \\
\hline 5 & $\begin{array}{l}\text { Global horizontal } \\
\text { irradiance }\end{array}$ & $\begin{array}{l}\text { Watt-hour per } \\
\text { square meter }\end{array}$ & $1 \mathrm{Wh} / \mathrm{m}^{2}$ & $\begin{array}{l}\text { Total amount of direct and diffuse solar radiation } \\
\text { received on a horizontal surface during the } 60 \text {-minute } \\
\text { period ending at the timestamp }\end{array}$ \\
\hline 6 & $\begin{array}{l}\text { Global horizontal } \\
\text { irradiance source } \\
\text { flag }\end{array}$ & $1-2$ & -- & See Table A1-22 \\
\hline 7 & $\begin{array}{l}\text { Global horizontal } \\
\text { irradiance } \\
\text { uncertainty }\end{array}$ & Percent & $1 \%$ & $\begin{array}{l}\text { Uncertainty based on random and bias error estimates. } \\
\text { Informative Note: } \text { For more information, see NSRDB } \\
\text { User's Manual }{ }^{\mathrm{A}-6} \text {. }\end{array}$ \\
\hline 8 & $\begin{array}{l}\text { Direct normal } \\
\text { irradiance }\end{array}$ & $\begin{array}{l}\text { Watt-hour per } \\
\text { square meter }\end{array}$ & $1 \mathrm{Wh} / \mathrm{m}^{2}$ & $\begin{array}{l}\text { Amount of solar radiation (modeled) received in a } \\
\text { collimated beam on a surface normal to the sun during } \\
\text { the } 60 \text {-minute period ending at the timestamp }\end{array}$ \\
\hline 9 & $\begin{array}{l}\text { Direct normal } \\
\text { irradiance source } \\
\text { flag }\end{array}$ & $1-2$ & -- & See Table A1-22 \\
\hline 10 & $\begin{array}{l}\text { Direct normal } \\
\text { irradiance } \\
\text { uncertainty }\end{array}$ & Percent & $1 \%$ & $\begin{array}{l}\text { Uncertainty based on random and bias error estimates. } \\
\text { Informative Note: } \text { For more information, see NSRDB } \\
\text { User's Manual }{ }^{\mathrm{A}-6} \text {. }\end{array}$ \\
\hline 11 & $\begin{array}{l}\text { Diffuse horizontal } \\
\text { irradiance }\end{array}$ & $\begin{array}{l}\text { Watt-hour per } \\
\text { square meter }\end{array}$ & $1 \mathrm{Wh} / \mathrm{m}^{2}$ & $\begin{array}{l}\text { Amount of solar radiation received from the sky } \\
\text { (excluding the solar disk) on a horizontal surface during } \\
\text { the } 60 \text {-minute period ending at the timestamp }\end{array}$ \\
\hline 12 & $\begin{array}{l}\text { Diffuse horizontal } \\
\text { irradiance source } \\
\text { flag }\end{array}$ & $1-2$ & -- & See Table A1-22 \\
\hline 13 & $\begin{array}{l}\text { Diffuse horizontal } \\
\text { irradiance } \\
\text { uncertainty }\end{array}$ & Percent & $1 \%$ & $\begin{array}{l}\text { Uncertainty based on random and bias error estimates. } \\
\text { Informative Note: } \text { For more information, see NSRDB } \\
\text { User's Manual }{ }^{\mathrm{A}-6} \text {. }\end{array}$ \\
\hline 14 & $\begin{array}{l}\text { Global horizontal } \\
\text { illuminance }\end{array}$ & Lux & $1001 \mathrm{x}$ & $\begin{array}{l}\text { Average total amount of direct and diffuse illuminance } \\
\text { received on a horizontal surface during the } 60 \text {-minute } \\
\text { period ending at the timestamp }\end{array}$ \\
\hline 15 & $\begin{array}{l}\text { Global horizontal } \\
\text { illuminance source } \\
\text { flag }\end{array}$ & $1-2$ & -- & See Table A1-22 \\
\hline 16 & $\begin{array}{l}\text { Global horizontal } \\
\text { illuminance } \\
\text { uncertainty }\end{array}$ & Percent & $1 \%$ & $\begin{array}{l}\text { Uncertainty based on random and bias error estimates. } \\
\text { Informative Note: } \text { For more information, see Users } \\
\text { Manual for TMY3 Data Sets }{ }^{\mathrm{A}-5} \text {, section } 2.10 \text {. }\end{array}$ \\
\hline 17 & $\begin{array}{l}\text { Direct normal } \\
\text { illuminance }\end{array}$ & Lux & $100 \mathrm{~lx}$ & $\begin{array}{l}\text { Average amount of direct normal illuminance received } \\
\text { within a } 5.7^{\circ} \text { field of view centered on the sun during } \\
\text { the } 60 \text {-minute period ending at the timestamp }\end{array}$ \\
\hline 18 & $\begin{array}{l}\text { Direct normal } \\
\text { illuminance source } \\
\text { flag }\end{array}$ & $1-2$ & -- & See Table A1-22 \\
\hline
\end{tabular}




\begin{tabular}{|c|c|c|c|c|}
\hline Field & Element & Unit or Range & Resolution & Description \\
\hline 19 & $\begin{array}{l}\text { Direct normal } \\
\text { illuminance } \\
\text { uncertainty }\end{array}$ & Percent & $1 \%$ & $\begin{array}{l}\text { Uncertainty based on random and bias error estimates. } \\
\text { Informative Note: For more information. see Users } \\
\text { Manual for TMY3 Data Sets }{ }^{\mathrm{A}-5} \text {, section } 2.10 \text {. }\end{array}$ \\
\hline 20 & $\begin{array}{l}\text { Diffuse horizontal } \\
\text { illuminance }\end{array}$ & Lux & $1001 \mathrm{x}$ & $\begin{array}{l}\text { Average amount of illuminance received from the sky } \\
\text { (excluding the solar disk) on a horizontal surface } \\
\text { during the } 60 \text {-minute period ending at the timestamp }\end{array}$ \\
\hline 21 & $\begin{array}{l}\text { Diffuse horizontal } \\
\text { illuminance source } \\
\text { flag }\end{array}$ & $1-2$ & $\begin{array}{ll}- \\
-\end{array}$ & See Table A1-22 \\
\hline 22 & $\begin{array}{l}\text { Diffuse horizontal } \\
\text { illuminance } \\
\text { uncertainty }\end{array}$ & Percent & $1 \%$ & $\begin{array}{l}\text { Uncertainty based on random and bias error estimates. } \\
\text { Informative Note: For more information, see Users } \\
\text { Manual for TMY3 Data Sets }{ }^{\mathrm{A}-5} \text {, section } 2.10 \text {. }\end{array}$ \\
\hline 23 & Zenith luminance & $\begin{array}{l}\text { Candela per } \\
\text { square meter }\end{array}$ & $10 \mathrm{~cd} / \mathrm{m}^{2}$ & $\begin{array}{l}\text { Average amount of luminance at the sky's zenith } \\
\text { during the } 60 \text {-minute period ending at the timestamp }\end{array}$ \\
\hline 24 & $\begin{array}{l}\text { Zenith luminance } \\
\text { source flag }\end{array}$ & $1-2$ & -- & See Table A1-22 \\
\hline 25 & $\begin{array}{l}\text { Zenith luminance } \\
\text { uncertainty }\end{array}$ & Percent & $1 \%$ & $\begin{array}{l}\text { Uncertainty based on random and bias error estimates. } \\
\text { Informative Note: For more information, see Users } \\
\text { Manual for TMY3 Data Sets }{ }^{\mathrm{A}-5} \text {, section } 2.10 \text {. }\end{array}$ \\
\hline 26 & Total sky cover & Tenths of sky & 1 tenth & $\begin{array}{l}\text { Amount of sky dome covered by clouds or obscuring } \\
\text { phenomena at the time indicated }\end{array}$ \\
\hline 27 & \multicolumn{3}{|c|}{ Total sky cover flag (source) } & See Table A1-23 \\
\hline 28 & \multicolumn{3}{|c|}{ Total sky cover flag (uncertainty) } & See Table A1-24 \\
\hline 29 & Opaque sky cover & Tenths of sky & 1 tenth & $\begin{array}{l}\text { Amount of sky dome covered by clouds or obscuring } \\
\text { phenomena that prevent observing the sky or higher } \\
\text { cloud layers at the time indicated }\end{array}$ \\
\hline 30 & \multicolumn{3}{|c|}{ Opaque sky cover flag (source) } & See Table A1-23 \\
\hline 31 & \multicolumn{3}{|c|}{ Opaque sky cover flag (uncertainty) } & See Table A1-24 \\
\hline 32 & $\begin{array}{l}\text { Dry-bulb } \\
\text { temperature }\end{array}$ & Degree C & $0.1^{\circ}$ & Dry-bulb temperature at the time indicated \\
\hline 33 & \multicolumn{3}{|c|}{ Dry-bulb temperature flag (source) } & See Table A1-23 \\
\hline 34 & \multicolumn{3}{|c|}{ Dry-bulb temperature flag (uncertainty) } & See Table A1-24 \\
\hline 35 & $\begin{array}{l}\text { Dew-point } \\
\text { temperature }\end{array}$ & Degree C & $0.1^{\circ}$ & Dew-point temperature at the time indicated \\
\hline 36 & \multicolumn{3}{|c|}{ Dew-point temperature flag (source) } & See Table A1-23 \\
\hline 37 & \multicolumn{3}{|c|}{ Dew-point temperature flag (uncertainty) } & See Table A1-24 \\
\hline 38 & Relative humidity & Percent & $1 \%$ & Relative humidity at the time indicated \\
\hline 39 & \multicolumn{3}{|c|}{ Relative humidity flag (source) } & See Table A1-23 \\
\hline 40 & \multicolumn{3}{|c|}{ Relative humidity flag (uncertainty) } & See Table A1-24 \\
\hline 41 & Station pressure & Millibar & $1 \mathrm{mbar}$ & Station pressure at the time indicated \\
\hline 42 & \multicolumn{3}{|c|}{ Station pressure flag (source) } & See Table A1-23 \\
\hline 43 & \multicolumn{3}{|c|}{ Station pressure flag (uncertainty) } & See Table A1-24 \\
\hline 44 & Wind direction & \begin{tabular}{|l|} 
Degrees from \\
north $\left(360^{\circ}=\right.$ \\
north; $0^{\circ}=$ \\
undefined, calm $)$ \\
\end{tabular} & $10^{\circ}$ & Wind direction at the time indicated \\
\hline 45 & \multicolumn{3}{|c|}{ Wind direction flag (source) } & See Table A1-23 \\
\hline 46 & \multicolumn{3}{|c|}{ Wind direction flag (uncertainty) } & See Table A1-24 \\
\hline 47 & Wind speed & Meter/second & $0.1 \mathrm{~m} / \mathrm{s}$ & Wind speed at the time indicated \\
\hline 48 & \multicolumn{3}{|c|}{ Wind speed flag (source) } & See Table A1-23 \\
\hline 49 & \multicolumn{3}{|c|}{ Wind speed flag (uncertainty) } & See Table A1-24 \\
\hline
\end{tabular}




\begin{tabular}{|c|c|c|c|c|}
\hline Field & Element & Unit or Range & Resolution & Description \\
\hline$\overline{50}$ & $\begin{array}{l}\text { Horizontal } \\
\text { visibility }\end{array}$ & Meter* & $1 \mathrm{~m}$ & $\begin{array}{l}\text { Distance to discernible remote objects at the time } \\
\text { indicated }(7777=\text { unlimited) }\end{array}$ \\
\hline 51 & \multicolumn{3}{|c|}{ Horizontal visibility flag (source) } & See Table A1-23 \\
\hline 52 & \multicolumn{3}{|c|}{ Horizontal visibility flag (uncertainty) } & See Table A1-24 \\
\hline 53 & Ceiling height & Meter* & $1 \mathrm{~m}$ & $\begin{array}{l}\text { Height of the cloud base above local terrain }(77777= \\
\text { unlimited) }\end{array}$ \\
\hline 54 & \multicolumn{3}{|c|}{ Ceiling height flag (source) } & See Table A1-23 \\
\hline 55 & \multicolumn{3}{|c|}{ Ceiling height flag (uncertainty) } & See Table A1-24 \\
\hline 56 & Precipitable water & Centimeter & $0.1 \mathrm{~cm}$ & $\begin{array}{l}\text { The total precipitable water contained in a column of } \\
\text { unit cross section extending from the earth's surface to } \\
\text { the top of the atmosphere }\end{array}$ \\
\hline 57 & \multicolumn{3}{|c|}{ Precipitable water flag (source) } & See Table A1-23 \\
\hline 58 & \multicolumn{3}{|c|}{ Precipitable water flag (uncertainty) } & See Table A1-24 \\
\hline 59 & $\begin{array}{l}\text { Aerosol optical } \\
\text { depth, broadband }\end{array}$ & [unitless] & 0.001 & $\begin{array}{l}\text { The broadband aerosol optical depth per unit of air } \\
\text { mass due to extinction by the aerosol component of the } \\
\text { atmosphere }\end{array}$ \\
\hline 60 & \multicolumn{3}{|c|}{ Aerosol optical depth, broadband flag (source) } & See Table A1-23 \\
\hline 61 & \multicolumn{3}{|c|}{ Aerosol optical depth, broadband flag (uncertainty) } & See Table A1-24 \\
\hline 62 & Albedo & [unitless] & 0.01 & $\begin{array}{l}\text { The ratio of reflected solar irradiance to global } \\
\text { horizontal irradiance }\end{array}$ \\
\hline 63 & \multicolumn{3}{|l|}{ Albedo flag (source) } & See Table A1-23 \\
\hline 64 & \multicolumn{3}{|c|}{ Albedo flag (uncertainty) } & See Table A1-24 \\
\hline 65 & $\begin{array}{l}\text { Liquid } \\
\text { precipitation depth }\end{array}$ & Millimeter* & $1 \mathrm{~mm}$ & $\begin{array}{l}\text { The amount of liquid precipitation observed at the } \\
\text { indicated time for the period indicated in the liquid } \\
\text { precipitation quantity field }\end{array}$ \\
\hline 66 & $\begin{array}{l}\text { Liquid } \\
\text { precipitation } \\
\text { quantity }\end{array}$ & Hour* & $1 \mathrm{hr}$ & $\begin{array}{l}\text { The period of accumulation for the liquid precipitation } \\
\text { depth field }\end{array}$ \\
\hline 67 & \multicolumn{3}{|c|}{ Liquid precipitation depth flag (source) } & See Table A1-23 \\
\hline 68 & \multicolumn{3}{|c|}{ Liquid precipitation depth flag (uncertainty) } & See Table A1-24 \\
\hline
\end{tabular}

* Value of -9900 indicates the measurement is missing. 
Table A1-22. Solar radiation and illuminance source flags

\begin{tabular}{ll}
\hline Flag & Definition \\
\hline \hline 1 & Data modeled using METSTAT or from 1961-1990 NSRDB solar fields \\
2 & Data modeled using SUNY Satellite model (time shifted) \\
\hline
\end{tabular}

Table A1-23. Meteorological source flags

\begin{tabular}{|c|c|}
\hline Flag & Definition \\
\hline A & Data as received from NCDC, converted to SI units \\
\hline B & Linearly interpolated \\
\hline $\mathrm{C}$ & Non-linearly interpolated to fill data gaps from 6 to 47 hours in length \\
\hline $\mathrm{D}$ & Not used \\
\hline $\mathrm{E}$ & $\begin{array}{l}\text { Modeled or estimated, except: precipitable water, calculated from radiosonde data; dew point } \\
\text { temperature calculated from dry-bulb temperature and relative humidity; and relative humidity } \\
\text { calculated from dry-bulb temperature and dew-point temperature }\end{array}$ \\
\hline $\mathrm{F}$ & $\begin{array}{l}\text { Precipitable water, calculated from surface vapor pressure; aerosol optical depth, estimated from } \\
\text { geographic correlation }\end{array}$ \\
\hline ? & Source does not fit any of the above. Used mostly for missing data \\
\hline
\end{tabular}

Table A1-24. Meteorological uncertainty flags

\begin{tabular}{ll}
\hline Flag & Definition \\
\hline \hline $1-6$ & Not used \\
7 & $\begin{array}{l}\text { Uncertainty consistent with NWS practices and the instrument or observation used to } \\
\text { obtain the data }\end{array}$ \\
8 & $\begin{array}{l}\text { Greater uncertainty than } 7 \text { because values were interpolated or estimated } \\
9\end{array}$ \\
0 & Greater uncertainty than 8 or unknown \\
\hline
\end{tabular}


[Note to Users: Only selected portions of Standard 140-2017 Annex A2 relevant to the thermal fabric test cases are included here.]

\section{NORMATIVE ANNEX A2 \\ STANDARD OUTPUT REPORTS}

The standard output reports, consisting of the following seven forms provided with the electronic media accompanying this standard, shall be used:

a. Output results for cases of Sections 5.2.1, 5.2.2, and 5.2.3 (Sec5-2Aout.XLSX, spreadsheet file)

$[\ldots$.

h. Modeling notes (S140outNotes.TXT, text file reprinted as Attachment A2.7)

$[\ldots$.

Informative Note: For entering modeling notes into S140outNotes.TXT, the format of the examples applying S140outNotes_Examples.TXT given in Informative Attachment A2.8 within this section is recommended. Changes to S140outNotes.TXT and S140outNotes_Examples.TXT since 140-2017 are indicated, respectively, in

"Informative-S140outNotes-txt-edits-140-2017A.PDF" and "S140outNotes_Examples-txt-edits-140-2017A.PDF".

\section{Attachment A2.1-Instructions for Entering Results into Sec5-2Aout.XLSX}

STANDARD 140 OUTPUT FORM-RESULTS

Sec5-2Aout.XLSX, Sheet 'A'

INSTRUCTIONS:

1. Use specified units.

2. All radiation data are for sum of direct and diffuse solar radiation.

3. Output terminology is defined in Section 6.2.1.

4. Format dates using the appropriate three-character month code, one- or two-digit day, and two-digit hour code (24-hour clock) as shown below:

$\begin{array}{cc}\text { MONTH } & \text { CODE } \\ \text { January } & \text { Jan } \\ \text { February } & \text { Feb } \\ \text { March } & \text { Mar } \\ \text { April } & \text { Apr } \\ \text { May } & \text { May } \\ \text { June } & \text { Jun } \\ \text { July } & \text { Jul } \\ \text { August } & \text { Aug } \\ \text { September } & \text { Sep } \\ \text { October } & \text { Oct } \\ \text { November } & \text { Nov } \\ \text { December } & \text { Dec }\end{array}$


For example, a peak occurring on January 4 during the 8th hour interval (0700-0800), shall be input as follows:

$\begin{array}{ccc}\text { MONTH } & \text { DAY } & \text { HOUR } \\ \text { Jan } & 4 & 8\end{array}$

5. Data entry is restricted to the following ranges:
C61...C63: Software Name, Version, and Date of Results
C70...L115: Conditioned-Zone Loads (Non-Free-Float Test Cases)
C130...K136: Free-Float Case Zone Temperatures
C155...C171: Solar Radiation, as specified
C178...K178: Sky Temperature
C190_..R201: Monthly Conditioned-Zone Loads (Cases 600 and 900)
C230...T253: Specific-Day Hourly Output: incident and transmitted solar radiation and sky temperatures
C262...Z285: Specific-Day Hourly Output: zone loads (selected cases) and conditioned-zone temperatures (Cases 640 and 940)
C294...H317: Specific-Day Hourly Output: free-float temperatures
C330...C478: Case 900FF Zone Temperature Bin Data, enter 8760 hours of zone temperature data in Sheet 'TMPBIN' (of Sec5-2Aout.xlsx), as described in Cell E1 there. Bin data will flow to C330 - C478 on Sheet 'A' (of Sec5-2Aout.xlsx).
C501...F557: Case 600 Convective Surface Coefficients; data entry is restricted to Columns C,D,E,F.
J501...J537: Case 200 Convective Surface Coefficients; data entry is restricted to Cells J501 - J507 and J531 - J537.
M501, M531: Case 670 Convective Surface Coefficients, window only; data entry is restricted to Cells M501 and M531.

[Note to Users: Attachments A2.2 through A2.6 are intentionally blank so remaining material matches Standard 140 numbering; these attachments do not relate to the thermal fabric test cases update.]

\section{Attachment A2.7-Standard 140 Output Form-Modeling Notes (S140outNotes.TXT)}

[Note to Users: See S140outNotes.TXT in accompanying electronic media for the full form. Only Report Block D is shown here, as that is the only report block that has changes. Report blocks $A, B$, and $C$ are intentionally blank here so remaining material matches Standard 140 numbering.]

[Note to Users: Where Sections 5.3 and 5.4 are cross-referenced in Attachments A2.7 and A2.8, they refer to ASHRAE Standard 140-2017 (ANSI/ASHRAE 2017); Sections 5.3 and 5.4 do not relate to the thermal fabric test cases update.]

\section{REPORT BLOCK FOR USE OF NONSPECIFIED INPUTS}

CONTENT: This section shall describe nonspecified inputs used to perform the tests. Use of nonspecified inputs shall be permitted only for the following specified sections relating to the following topics:

- Alternative constant exterior surface coefficients in Sections 5.2.1.9.3, 5.2.3.1.4.3, 5.2.3.3.2, and 5.3.1.8

- Alternative constant interior surface coefficients in Sections 5.2.1.10.3, 5.2.3.1.4.4, 5.2.3.2.2, and 5.3.1.9

- Alternative constant interior solar distribution fractions in Sections 5.2.1.12, 5.2.2.1.2.2, 5.2.2.1.6.2, 5.2.2.1.7.2, 5.2.2.2.7.4, 5.2.3.9.3, 5.2.3.10.2, and 5.2.3.12.2

- Air density given at specific altitudes for the space-cooling and space-heating equipment cases in Sections 5.3.1.4.3, 5.3.3.4.3, and 5.4.1.4.3. 
INSTRUCTIONS: If nonspecified inputs are applied, a separate note for each use of nonspecified inputs shall be provided. The standard format shown below and a separate number and title for each note shall be applied. If nonspecified inputs are not applied, specify "NONE" in place of the information below.

NOTE $1-<$ Title $>$

1.1 Describe the Effect Being Simulated:

1.2 Section(s) of the Standard where Relevant Inputs are Specified:

1.3 Nonspecified Input(s) Used:

1.4 Physical, Mathematical, or Logical Justification for Use of the Nonspecified Input(s)—provide supporting calculations if relevant:

\section{INFORMATIVE ATTACHMENT A2.8-EXAMPLES OF MODELING NOTES}

(S140outNotes_Examples.TXT)

$[\ldots$.

See S140outNotes_Examples.TXT provided with the accompanying electronic media within the "Informative Materials" subfolder [....] [Note to users: Remainder of Annex A2 is not relevant to the thermal fabric test cases.] 


\section{INFORMATIVE ANNEX B1: TABULAR SUMMARY OF TEST CASES}

Table B1-1 summarizes the content of the test-case tabular summary tables, including relevant sections of the standard for each suite of tests.

[Note to Users: Standard 140-2017 Tables B1-1 (cited above) and B1-4 through B1-18 (cited below) are not included; these do not apply to the thermal fabric test cases update.]

\section{Nomenclature}

Abbreviations and symbols used in Tables B1-2, B1-3, and B1-6 through B1-17 are listed below. Abbreviations used for Tables B1-4, B1-5, and B1-18 are listed with those tables.

$1.0 \mathrm{mH}$ horizontal overhang projecting $1 \mathrm{~m}$ perpendicular to window surface as in Figure 5-3 (Section 5.2.2.1.1.1)

$1.0 \mathrm{mHV}$ horizontal overhang and vertical fins projecting 1 meter perpendicular to window surface as in Figures 5-5 and 5-6 (Section 5.2.2.1.3.1)

1-pane single-pane window

20,20 a single-temperature thermostat control strategy (heat $\mathrm{ON}$ below $20^{\circ} \mathrm{C}$, cooling $\mathrm{ON}$ above $20^{\circ} \mathrm{C}$ )

20,27 a deadband thermostat control strategy (heat on below $20^{\circ} \mathrm{C}$, cooling $\mathrm{ON}$ above $27^{\circ} \mathrm{C}$ )

$27, \mathrm{~V}$ a thermostat and ventilation control strategy with cooling (ON above $27^{\circ} \mathrm{C}$, daytime only) and nighttimeonly ventilation; no heating anytime

Absorpt. absorptance

ach air changes per hour

Apr. April

AHRI Air-Conditioning, Heating and Refrigeration Institute

COP coefficient of performance

DB dry-bulb temperature

DBT dry-bulb temperature

DP dew-point temperature

E,W east and west

EDB entering dry-bulb temperature

Emit. emittance

Ext. exterior

FF free-floating thermostat control strategy (no heating or cooling)

$\mathrm{H} \quad$ heavy mass

$\mathrm{H}, \mathrm{C}, \mathrm{V}$ heating, cooling, ventilation

high greater loads relative to "mid"

high2 greater loads relative to "mid2"

Infil. infiltration (natural ventilation)

Int. interior

Intgen. internally generated sensible heat gains

IR infrared radiation

L light mass

Low-e low emissivity window

mid internal gains schedules are relatively high daytime and low nighttime periodically/seasonally adjusted values

mid2 similar to "mid" but with cooler-month internal gains $=0$ for 0 cooling at $\mathrm{ODB}<55^{\circ} \mathrm{F}$ for $0 \mathrm{OA}$

NA not applicable

Num. zone number (1 or 2$)$

OA outdoor air

Oct. October

ODB outdoor dry-bulb temperature

Orient. orientation

PLR part-load ratio for cooling

PLR $f \quad$ part-load ratio for furnace

S south

Shade window shading device: horizontal overhang and/or vertical fins 
SHR sensible heat ratio

SS sunspace

SW shortwave (solar spectrum) radiation

Temp. temperature

tstat thermostat

$\mathrm{V}$ forced ventilation cooling 
Table B1-2 Section 5.2.3 Case Descriptions, Low-Mass In-Depth

\begin{tabular}{|c|c|c|c|c|c|c|c|c|c|c|c|c|}
\hline \multirow[b]{2}{*}{ Case \# } & \multicolumn{2}{|l|}{$\underline{\text { Setpoints }}$} & \multirow[b]{2}{*}{$\begin{array}{l}\text { Intgen., } \\
\text { W }\end{array}$} & \multirow[b]{2}{*}{$\begin{array}{l}\text { Infil., } \\
\text { ach }\end{array}$} & \multicolumn{3}{|c|}{ Opaque Surface } & \multirow[b]{2}{*}{$\begin{array}{l}\text { Ext. SW } \\
\text { Absorpt. }\end{array}$} & \multirow[b]{2}{*}{$\begin{array}{c}\text { Glass, } \\
\mathbf{m}^{2}\end{array}$} & \multirow[b]{2}{*}{ Orient. } & \multirow[b]{2}{*}{ Shade } & \multirow[b]{2}{*}{ Comments } \\
\hline & $\underset{ }{\mathbf{H}, \mathbf{C}, \mathbf{V}}$ & Mass & & & $\begin{array}{l}\text { Int. IR } \\
\text { Emit. }\end{array}$ & $\begin{array}{l}\text { Ext. IR } \\
\text { Emit. }\end{array}$ & $\begin{array}{l}\text { Int. SW } \\
\text { Absorpt. }\end{array}$ & & & & & \\
\hline 195 & 20,20 & $\mathrm{~L}$ & 0 & 0 & 0.1 & 0.1 & $\begin{array}{c}\text { NA } \\
\text { see Note } 1 \\
\end{array}$ & 0.1 & $\begin{array}{c}\text { See } \\
\text { Note } 2 \\
\end{array}$ & $\mathrm{~S}$ & No & Case 195 tests solid conduction. \\
\hline 200 & 20,20 & $\mathrm{~L}$ & 0 & 0 & 0.1 & 0.1 & NA & 0.1 & $\begin{array}{c}0 \\
\text { (See } \\
\text { Note } \\
3 \text { ) }\end{array}$ & $\mathrm{S}$ & No & $\begin{array}{l}\text { Run cases } 200 \text { through } 215 \text { only if you can } \\
\text { explicitly adjust infrared emittance in your } \\
\text { code. Cases } 200,195 \text { test film convection } \\
\text { algorithms. The major portion of the change } \\
\text { in results between Cases } 200 \text { and } 195 \text { will be } \\
\text { from the high-conductance wall elements. } \\
\text { Increased differences between codes will be } \\
\text { from the different film algorithms. }\end{array}$ \\
\hline 210 & 20,20 & $\mathrm{~L}$ & 0 & 0 & 0.1 & 0.9 & NA & 0.1 & 0 & S & No & $\begin{array}{l}\text { Cases 220, } 210 \text { test Int. IR with Ext. IR oN. } \\
\text { Cases 210, } 200 \text { test Ext. IR with Int. IR OFF. }\end{array}$ \\
\hline 215 & 20,20 & $\mathrm{~L}$ & 0 & 0 & 0.9 & 0.1 & NA & 0.1 & 0 & S & No & $\begin{array}{l}\text { Cases 220, } 215 \text { test Ext. IR with Int. IR oN. } \\
\text { Cases 215, } 200 \text { test Int. IR with Ext. IR OFF. }\end{array}$ \\
\hline 220 & 20,20 & $\mathrm{~L}$ & 0 & 0 & 0.9 & 0.9 & NA & 0.1 & 0 & S & No & $\begin{array}{l}\text { Cases } 220,210 \text { test Int. IR with Ext. IR oN. } \\
\text { Case } 220 \text { is the base for Cases 230-270. }\end{array}$ \\
\hline 230 & 20,20 & $\mathrm{~L}$ & 0 & 1 & 0.9 & 0.9 & NA & 0.1 & 0 & $\mathrm{~S}$ & No & Cases 230, 220 test infiltration. \\
\hline 240 & 20,20 & $\mathrm{~L}$ & 200 & 0 & 0.9 & 0.9 & NA & 0.1 & 0 & $\mathrm{~S}$ & No & Cases 240, 220 test internal gains. \\
\hline 250 & 20,20 & $\mathrm{~L}$ & 0 & 0 & 0.9 & 0.9 & NA & 0.9 & 0 & S & No & $\begin{array}{l}\text { Cases } 250,220 \text { test exterior solar absorp- } \\
\text { tance/incident solar. }\end{array}$ \\
\hline 270 & 20,20 & $\mathrm{~L}$ & 0 & 0 & 0.9 & 0.9 & 0.9 & 0.1 & 12 & S & No & $\begin{array}{l}\text { Cases } 270,220 \text { test south solar transmit- } \\
\text { tance/incident solar. }\end{array}$ \\
\hline 280 & 20,20 & $\mathrm{~L}$ & 0 & 0 & 0.9 & 0.9 & 0.1 & 0.1 & 12 & $\mathrm{~S}$ & No & Cases 280,270 test cavity albedo. \\
\hline 290 & 20,20 & $\mathrm{~L}$ & 0 & 0 & 0.9 & 0.9 & 0.9 & 0.1 & 12 & $\mathrm{~S}$ & $1.0 \mathrm{mH}$ & $\begin{array}{l}\text { Cases 290, } 270 \text { test south } \\
\text { horizontal overhang. }\end{array}$ \\
\hline 300 & 20,20 & $\mathrm{~L}$ & 0 & 0 & 0.9 & 0.9 & 0.9 & 0.1 & 6,6 & $\mathrm{E}, \mathrm{W}$ & No & $\begin{array}{l}\text { Cases } 300,270 \text { test east and west solar } \\
\text { transmittance and incidence. }\end{array}$ \\
\hline 310 & 20,20 & $\mathrm{~L}$ & 0 & 0 & 0.9 & 0.9 & 0.9 & 0.1 & 6,6 & $\mathrm{E}, \mathrm{W}$ & $\begin{array}{l}1.0 \mathrm{~m} \\
\mathrm{HV}\end{array}$ & $\begin{array}{l}\text { Cases } 310,300 \text { test east and west } \\
\text { overhang and fins. }\end{array}$ \\
\hline 320 & 20,27 & $\mathrm{~L}$ & 0 & 0 & 0.9 & 0.9 & 0.9 & 0.1 & 12 & $S$ & No & Cases 320, 270 test thermostat deadband. \\
\hline
\end{tabular}

Note 1: Interior shortwave absorptance doesn't matter when glass area is zero.

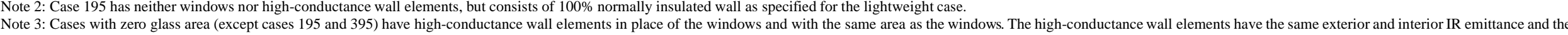
same solar absorptance as specified for the normal wall in each case. The high-conductance wall element surface texture is very smooth (like glass) 
Table B1-3 Sections 5.2.1, 5.2.2 and 5.2.3 Case Descriptions, Basic and In-Depth Cases

\begin{tabular}{|c|c|c|c|c|c|c|c|c|c|c|c|c|}
\hline \multirow{2}{*}{ Case \# } & \multirow{2}{*}{$\frac{\text { Setpoints }}{\underset{\mathrm{H}, \mathrm{C}, \mathrm{V}}{{ }^{\circ} \mathrm{C}}}$} & \multirow[b]{2}{*}{ Mass } & \multirow[b]{2}{*}{$\begin{array}{l}\text { Intgen., } \\
\text { W }\end{array}$} & \multirow[b]{2}{*}{$\begin{array}{l}\text { Infil., } \\
\text { ach }\end{array}$} & \multicolumn{4}{|c|}{ Opaque Surface } & \multirow[b]{2}{*}{$\begin{array}{l}\text { Glass, } \\
\mathbf{m}^{2}\end{array}$} & \multirow[b]{2}{*}{ Orient. } & \multirow[b]{2}{*}{ Shade } & \multirow[b]{2}{*}{ Comments } \\
\hline & & & & & $\begin{array}{l}\text { Int. IR } \\
\text { Emit. }\end{array}$ & $\begin{array}{l}\text { Ext. IR } \\
\text { Emit. }\end{array}$ & $\begin{array}{l}\text { Int. SW } \\
\text { Absorpt. }\end{array}$ & $\begin{array}{l}\text { Ext. SW } \\
\text { Absorpt. }\end{array}$ & & & & \\
\hline 395 & 20,27 & 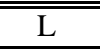 & 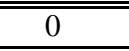 & 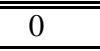 & 0.9 & 0.9 & NA & 0.1 & see Note 1 & $\overline{\mathrm{S}}$ & No & Case 395 tests solid conduction. \\
\hline 400 & 20,27 & $\mathrm{~L}$ & 0 & 0 & 0.9 & 0.9 & NA & 0.1 & 0 & $S$ & No & $\begin{array}{l}\text { Cases } 400,395 \text { test surface convection and IR. } \\
\text { (See Note 2.) }\end{array}$ \\
\hline 410 & 20,27 & $\mathrm{~L}$ & 0 & 0.5 & 0.9 & 0.9 & NA & 0.1 & 0 & $\mathrm{~S}$ & No & Cases 410,400 test infiltration. \\
\hline 420 & 20,27 & $\mathrm{~L}$ & 200 & 0.5 & 0.9 & 0.9 & NA & 0.1 & 0 & $\bar{S}$ & No & Cases 420,410 test internal heat generation. \\
\hline 430 & 20,27 & $\mathrm{~L}$ & 200 & 0.5 & 0.9 & 0.9 & NA & 0.6 & 0 & $\mathrm{~S}$ & No & $\begin{array}{l}\text { Cases } 430,420 \text { test exterior solar absorptance } \\
\text { and incident solar. }\end{array}$ \\
\hline 440 & 20,27 & $\mathrm{~L}$ & 200 & 0.5 & 0.9 & 0.9 & 0.1 & 0.6 & 12 & $S$ & No & $\begin{array}{l}\text { Cases } 440,600 \text { test interior solar absorptance } \\
\text { and cavity albedo. }\end{array}$ \\
\hline 450 & \multicolumn{11}{|c|}{ This case is the same as Case 600 except constant combined interior and exterior suface coefficients are applied. } & $\begin{array}{l}\text { Cases } 450,460,470,600 \text { test interior and exterior } \\
\text { surface convective and IR heat transfer. }\end{array}$ \\
\hline 460 & \multicolumn{11}{|c|}{ This case is the same as Case 600 except constant combined interior suface coefficients are applied. } & $\begin{array}{l}\text { Cases } 460,450,600 \text { test interior convective } \\
\text { and IR heat transfer. }\end{array}$ \\
\hline 470 & \multicolumn{11}{|c|}{ This case is the same as Case 600 except constant combined exterior suface coefficients are applied. } & $\begin{array}{l}\text { Cases } 470,450,600 \text { test exterior surface } \\
\text { convective and IR heat transfer. }\end{array}$ \\
\hline 600 & 20,27 & $\mathrm{~L}$ & 200 & 0.5 & 0.9 & 0.9 & 0.6 & 0.6 & 12 & $\bar{S}$ & No & Cases 600,430 test south solar transmission. \\
\hline 610 & 20,27 & $\mathrm{~L}$ & 200 & 0.5 & 0.9 & 0.9 & 0.6 & 0.6 & 12 & $\mathrm{~S}$ & $1.0 \mathrm{mH}$ & Case 610,600 test south overhang. \\
\hline 620 & 20,27 & $\mathrm{~L}$ & 200 & 0.5 & 0.9 & 0.9 & 0.6 & 0.6 & 6,6 & $\mathrm{E}, \mathrm{W}$ & No & $\begin{array}{l}\text { Cases 620, } 600 \text { test east and west } \\
\text { solar transmittance/incidence. }\end{array}$ \\
\hline 630 & 20,27 & $\mathrm{~L}$ & 200 & 0.5 & 0.9 & 0.9 & 0.6 & 0.6 & 6,6 & $\mathrm{E}, \mathrm{W}$ & $\begin{array}{c}1.0 \mathrm{~m} \\
\mathrm{HV}\end{array}$ & Cases 630,620 test east and west overhangs and fins. \\
\hline 640 & SETBACK & $\mathrm{L}$ & 200 & 0.5 & 0.9 & 0.9 & 0.6 & 0.6 & 12 & $\mathrm{~S}$ & No & Cases 640,600 test night setback. \\
\hline 650 & $27, \mathrm{~V}$ & $\mathrm{~L}$ & 200 & 0.5 & 0.9 & 0.9 & 0.6 & 0.6 & 12 & $\mathrm{~S}$ & No & Cases 650,600 test venting. \\
\hline 660 & 20,27 & $\mathrm{~L}$ & 200 & 0.5 & 0.9 & 0.9 & 0.6 & 0.6 & 12, Low-e & $\mathrm{S}$ & No & Cases 660, 600 test low-emissivity window \\
\hline 670 & 20,27 & $\mathrm{~L}$ & 200 & 0.5 & 0.9 & 0.9 & 0.6 & 0.6 & 12,1-pane & $\mathrm{S}$ & No & Cases 670, 600 test single-pane window \\
\hline 680 & 20,27 & $\mathrm{~L}$ & This ca & is the $\mathrm{s}$ & e as Case & 00 except & creased wall & nd roof insul & ation are appli & lied. & & Cases 680,600 test increased insulation; 20,27 tstat. \\
\hline 685 & 20,20 & $\mathrm{~L}$ & 200 & 0.5 & 0.9 & 0.9 & 0.6 & 0.6 & 12 & $\mathrm{~S}$ & No & Cases 685,600 test thermostat deadband. \\
\hline 695 & 20,20 & $\mathrm{~L}$ & This & s the & as $\mathrm{Ca}$ & 5 excep & reased wa & roof ins & tion are appl & lied. & & Cases 695,685 test increased insulation; 20,20 tstat. \\
\hline
\end{tabular}

Note 1: Case 395 has neither a window nor high-conductance wall elements. It consists of 100\% normally insulated wall as specified for the lightweight case.

Note 2: Cases 400, 395 test surface convection and IR radiation. The major portion of the change in results will be from high-conductance wall elements. Increased differences between codes will be from the different film convection and

IR algorithms. 
Table B1-3 Sections 5.2.1, 5.2.2 and 5.2.3 Case Descriptions, Basic and In-Depth Cases (Continued)

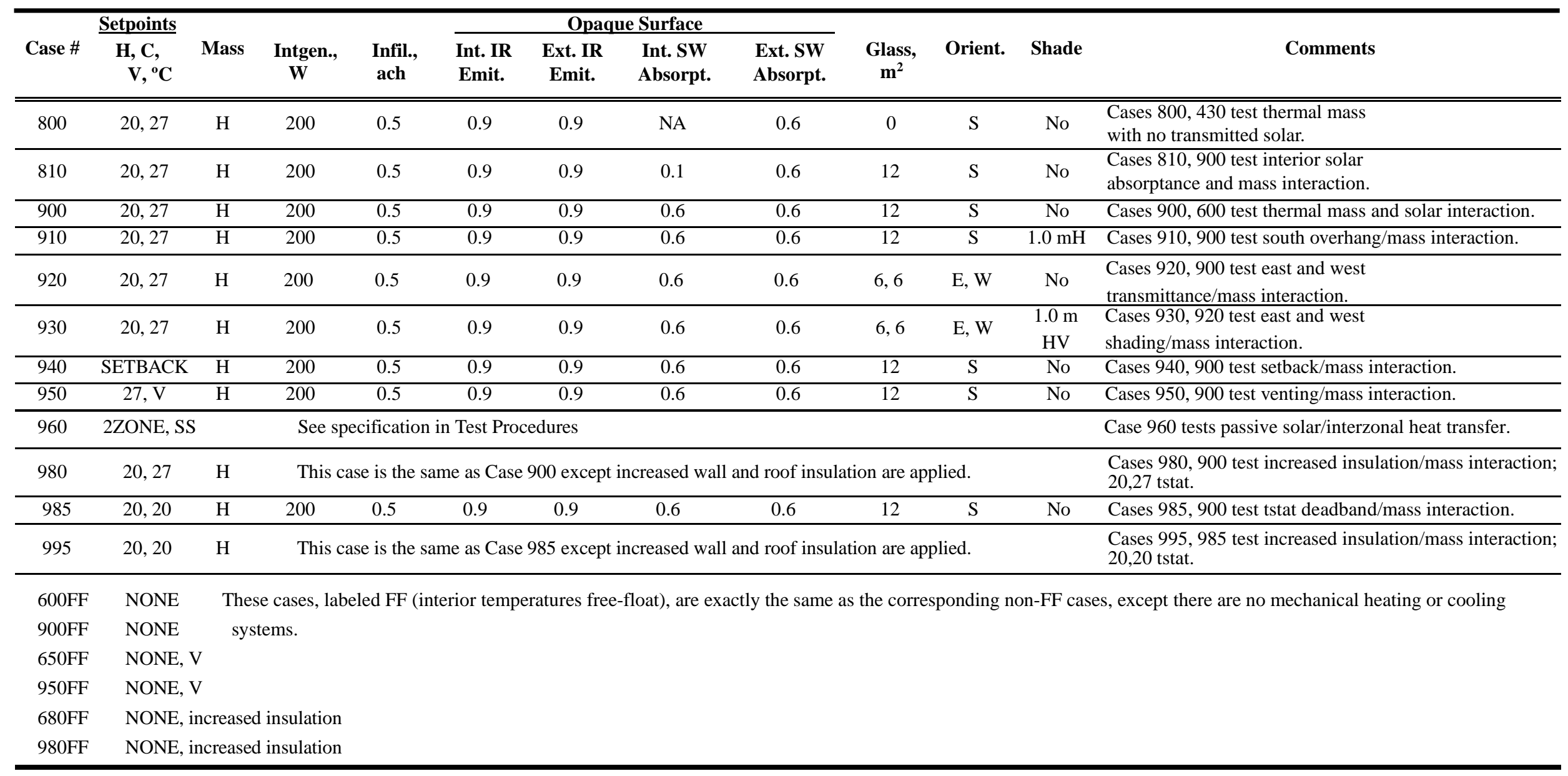


[Note to Users: Annex B2 is no longer referenced by the Section 5.2 test cases; including it here documents revisions to Standard 140 needed for consistency with that.]

\section{INFORMATIVE ANNEX B2: ABOUT TYPICAL METEOROLOGICAL YEAR (TMY) WEATHER DATA}

The original research for Section 7.2, HERS BESTEST, was performed by NREL in collaboration with the U.S.

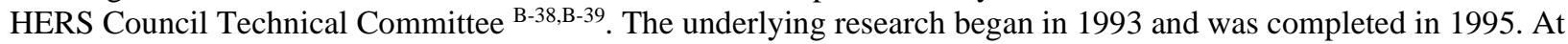
that time, TMY data represented the state of the art for hourly weather data. TMY2 data were just becoming available toward the end of the project, but the work was too far along to switch weather data files, which would have required adjusting test specifications. For example, the specified equivalent convective portion of annual average exterior combined surface coefficients - provided for those programs that do not calculate exterior convection hourly - are related to the average annual wind speed from the original weather data file. Such changes to the test specification would also require rerunning the programs that provided example results.

For Sections 5.3.1 and 5.3.2, either TMY-format data or TMY2-format data may be used as described in Normative Annex A1, Section A1.2.1.

For convenience, we have reprinted the following discussion from the documentation for the DOE2.1A Reference Manual (p. VIII-31) ${ }^{\mathrm{B}-40}$.

Solar radiation and surface meteorological data recorded on an hourly basis are maintained at the National Climatic Data Center (NCDC). These data cover recording periods from January 1953 through December 1975 for 26 data rehabilitation stations, although the recording periods for some stations may differ. The data are available in blocked (compressed) form on magnetic tape (SOLMET) for the entire recording period for the station of interest. Note: Hourly readings for meteorological data are available through 1964; subsequent readings are on a three-hour basis.

Contractors desiring to use a database for simulation or system studies for a particular geographic area require a database that is more tractable than these and also one that is representative of the area. Sandia National Laboratory has used statistical techniques to develop a method for producing a typical meteorological year for each of the 26 rehabilitation stations. This section describes the use of these magnetic tapes.

The TMY tapes comprise specific calendar months selected from the entire recorded span for a given station as the most representative, or typical, for that station and month. For example, a single January is chosen from the 23 Januaries for which data are recorded from 1953 through 1975 on the basis of its being most nearly like the composite of all 23 Januaries. Thus, for a given station, January of 1967 might be selected as the typical meteorological month (TMM) after a statistical comparison with all of the other 22 Januaries. This process is pursued for each of the other calendar months, and the twelve months chosen then constitute the TMY.

Although the data have been rehabilitated by NCDC, some recording gaps do occur in the SOLMET tapes. Moreover, there are data gaps because of the change from one-hour to three-hour meteorological data recording in 1965. Consequently, as TMY tapes were being constituted from the SOLMET data, the variables data for barometric pressure, temperature, and wind velocity and direction were scanned on a month-by-month basis, and missing data were replaced by linear interpolation. Missing data in the leading and trailing positions of each monthly segment are replaced with the earliest/latest legitimate observation.

Also, since the TMMs were selected from different calendar years, discontinuities occurred at the month interfaces for the above continuous variables. Hence, after the monthly segments were rearranged in calendar order, the discontinuities at the month interfaces were ameliorated by cubic spline smoothing covering the six-hourly points on either side of the interface. 


\section{INFORMATIVE ANNEX B3: INFILTRATION AND FAN ADJUSTMENTS FOR ALTITUDE}

\section{B3.1 Adjustments for Test Cases of Sections 5.2.1, 5.2.2, and 5.2.3.}

For sea-level standard temperature and pressure conditions of $15^{\circ} \mathrm{C}$ and $101.325 \mathrm{kPa}$ (ASHRAE 2017 ${ }^{\mathrm{B}-101}$, p. 1.1), air density $=1.2255 \mathrm{~kg} / \mathrm{m}^{3}(\text { ASHRAE 2012) })^{\mathrm{A}-7}$.

For the current weather data file, with data from an altitude of $1650 \mathrm{~m}$, annual average air density of $1.0156 \mathrm{~kg} / \mathrm{m}^{3}$ was calculated. This was based on an hourly air density calculation, applying ASHRAE (2017) ${ }^{\mathrm{B}-101}$, Chapter 1, Equation 26-where atmospheric pressure and dry-bulb temperatures are taken directly from the weather file (with simple unit conversions as needed), and humidity ratio is calculated from weather file hourly dry-bulb temperature, relative humidity, and atmospheric pressure based on ASHRAE (2017) ${ }^{\mathrm{B}-101}$, Chapter 1, Equation 20 and related equations. The resulting annual average humidity ratio using this calculation was $0.0049 \mathrm{kgw} / \mathrm{kgda}$. For programs that do not allow variation of air density, corrections to the infiltration and ventilation rates specified for various test cases are calculated as follows:

For programs assuming standard air density, the corrected infiltration rate $=($ specified rate $) \times(1.0156 / 1.2255)$. For example, 0.5 ach becomes 0.414 ach, and 1 ach becomes 0.829 ach.

Similarly, for cases with vent fan $(650,950,650 \mathrm{FF}, 950 \mathrm{FF})$, the corrected vent-fan capacity $=($ specified capacity $)$ $\times(1.0156 / 1.2255)$. For example, $1700 \mathrm{~m}^{3} / \mathrm{h}$ becomes $1409 \mathrm{~m}^{3} / \mathrm{h}$.

[Note to Users: Sections B3.2 and B3.3 are not referenced by the Section 5.2 test cases; including them here documents revisions to Standard 140 needed for consistency with revisions to Section B3.1.]

B3.2 Adjustments for Section 7.2 Test Cases. The decline in air density with altitude may be expressed according to the following exponential curve fit:

$$
\rho_{\mathrm{air}, \mathrm{u}}=\rho_{\mathrm{air}, 0} \times e^{(a)(e l e v)}
$$

For HERS BESTEST ${ }^{\mathrm{B}-38}$, parameters of Equation B3-1 are as follows:

$\rho_{\text {air }, \mathrm{u}}=$ air density at specified elevation

$\rho_{\text {air }, 0}=$ air density at sea level $=0.075 \mathrm{lb} / \mathrm{ft}^{3}$ (approximate value)

e $\quad=$ inverse $\mathrm{Ln}$

a $=-3.71781196 \times 10^{-5} / \mathrm{ft}$

elev = elevation, $\mathrm{ft}$

This calculation results in the following:

Air density at $6145 \mathrm{ft}=0.05968 \mathrm{lb} / \mathrm{ft}^{3}$

Air density at $2178 \mathrm{ft}=0.06917 \mathrm{lb} / \mathrm{ft}^{3}$

If the software being tested does not allow variation of air density, the specified infiltration rate is adjusted as follows:

Corrected infiltration rate for $6145 \mathrm{ft}$ altitude $=($ Specified rate $) \times(0.05968 / 0.075)$

Corrected infiltration rate for $2178 \mathrm{ft}$ altitude $=($ Specified rate $) \times(0.06917 / 0.075)$

[Note to Users: The remainder of Standard 140-2017, Section B3.2 is excluded; there are no changes and Section B3.3 does not reference the excluded material.]

B3.3 Comparison of Section B3.2 with ASHRAE Handbook-Fundamentals. The altitude correction in Section B3.2 was created by fitting an exponential curve to data in the 1993 ASHRAE Handbook-Fundamentals, chapter 6, Table $1^{\mathrm{B}-26}$. Beginning in 2001, ASHRAE Handbook-Fundamentals ${ }^{\mathrm{B}-30}$ included an equation for calculating altitude corrections in addition to the tabular data (see Equation B3-2 below). This equation gives results slightly different from those described in Section B3.2, with a maximum difference of $0.2 \%$. 
The decline in atmospheric pressure with altitude is presented in the 2017 ASHRAE Handbook-Fundamentals, p. 1.1, Equation $3^{\mathrm{B}-101}$, as follows:

$$
p=101.325\left(1-2.25577 \times 10^{-5} \mathrm{Z}\right)^{5.2559}
$$

where

$$
\begin{aligned}
& p=\text { atmospheric pressure at elevation, bar } \\
& Z=\text { elevation, } \mathrm{m}
\end{aligned}
$$

A dimensionless altitude correction factor for pressure or density (these are directly proportional, assuming air is an ideal gas) can be expressed as follows:

$$
c f=\left(1-2.25577 \times 10^{-5} \mathrm{Z}\right)^{5.2559}
$$

For example, infiltration of 1 ach at an elevation of $6145 \mathrm{ft}(1873 \mathrm{~m})$ is equivalent to 0.7957 ach at sea level using Equation B3-1 versus 0.7970 ach at sea level using Equation B3-2. 


\section{INFORMATIVE ANNEX B4: ALTERNATIVE CONSTANT CONVECTIVE-ONLY AND COMBINED RADIATIVE-AND-CONVECTIVE SURFACE COEFFICIENTS}

Alternative constant values for exterior and interior surface coefficients are provided for programs that require these inputs, i.e., that have no automated (time-step-varying) exterior or interior surface convective coefficient or infrared radiative heat transfer calculation method, or no other constant exterior or interior surface heat transfer coefficients explicit to their internal coding. Programs (or models within those programs, where a program allows a variety of modeling methods) that calculate time-step-varying surface convective coefficients and infrared radiative heat transfer should not be adjusted to match the constant values provided here. Additionally, the calculation methods provided here should be perceived as examples only. Other methods may also be reasonably applied.

Further information on alternative constant surface coefficients derived for the test cases of Sections 5.2.1, 5.2.2, and 5.2.3 is included in Section B4.1. Further information on alternative surface coefficients for the test cases of Section 7.2 is included in Section B4.3 and Informative Annex B5. (Section B4.2 is intentionally blank.)

\section{B4.1 Alternative Constant Convective and Combined (Convective and Radiative) Surface Heat Transfer Coefficients for Test Cases of Sections 5.2.1, 5.2.2, and 5.2.3.}

Alternative constant convective and combined (convective and radiative) surface heat transfer coefficients are provided in Tables B4-1 and B4-2, respectively. Each table provides coefficients for interior and exterior surfaces, disaggregated for surfaces with $\varepsilon=0.9$ and $\varepsilon=0.1$, where $\varepsilon$ is surface infrared emittance. Values for highconductance wall elements with $\varepsilon=0.9$, where they occur (e.g., Case 220), are the same as for the transparent windows. Table B4-2 further includes alternative combined surface coefficients for the Case 670 single-pane windows; these have a significant impact on results versus applying the Case 600 double-pane window combined coefficients (see Part IV, Appendix A, Section 4A.3.3.2 for more details). For the walls, ceiling and floor, Case 670 applies the same alternative coefficients as Case 600. The following abbreviations are applied in the tables:

- h,conv,int: interior convective surface coefficient

- h,conv,ext: exterior convective surface coefficient

- h,comb,int: interior combined surface coefficient

- h,comb,ext: exterior combined surface coefficient

Table B4-1. Interior and Exterior Surface Convective Heat Transfer Coefficients for Test Cases of Sections 5.2.1, 5.2.2, and 5.2.3

\begin{tabular}{|c|c|c|c|c|}
\hline Surface Type & $\begin{array}{c}\text { Windows or } \\
\text { High-Conductance } \\
\text { Wall Elements } \\
\end{array}$ & Walls & Ceiling & Floor \\
\hline \multicolumn{5}{|l|}{$\varepsilon=0.9$, Interior } \\
\hline$h$, conv,int $\left(W /\left(m^{2} \cdot K\right)\right)$ & 2.4 & 2.2 & 1.8 & 2.2 \\
\hline \multicolumn{5}{|l|}{$\varepsilon=0.9$, Exterior } \\
\hline $\mathrm{h}, \mathrm{conv}$,ext $\left(\mathrm{W} /\left(\mathrm{m}^{2} \cdot \mathrm{K}\right)\right)$ & 8.0 & 11.9 & 14.4 & 0.8 \\
\hline \multicolumn{5}{|l|}{$\varepsilon=0.1$, Interior } \\
\hline$h$, conv,int $\left(W /\left(m^{2} \cdot K\right)\right)$ & 2.6 & 1.9 & 1.9 & 1.0 \\
\hline \multicolumn{5}{|l|}{$\varepsilon=0.1$, Exterior } \\
\hline$h$, conv, ext $\left(W /\left(m^{2} \cdot K\right)\right)$ & 7.9 & 11.8 & 14.4 & 0.9 \\
\hline
\end{tabular}

SurfCoeffAnalysis...032718.xIsx; AllCoeffs600+...!P81+ 
Table B4-2. Interior and Exterior Surface Combined (Convective and Radiative) Heat Transfer Coefficients for Test Cases of Sections 5.2.1, 5.2.2, and 5.2.3

\begin{tabular}{|c|c|c|c|c|c|}
\hline Surface Type & $\begin{array}{l}\text { Windows or } \\
\text { High-Conductance } \\
\text { Wall Elements }\end{array}$ & Walls & Ceiling & Floor & $\begin{array}{c}\text { Case } 670 \\
\text { Single-Pane } \\
\text { Windows }\end{array}$ \\
\hline \multicolumn{6}{|l|}{$\varepsilon=0.9$, Interior } \\
\hline$h$, comb,int $\left(W /\left(m^{2} \cdot K\right)\right)$ & 4.5 & 1.8 & 1.7 & 3.7 & 7.8 \\
\hline \multicolumn{6}{|l|}{$\varepsilon=0.9$, Exterior } \\
\hline$h, c o m b, e x t\left(W /\left(m^{2} \cdot k\right)\right)$ & 17.8 & 21.6 & 21.8 & 5.2 & 16.0 \\
\hline \multicolumn{6}{|l|}{$\varepsilon=0.1$, Interior } \\
\hline$h$, comb,int $\left(W /\left(m^{2} \cdot K\right)\right)$ & 3.1 & 2.1 & 1.9 & 0.4 & \\
\hline \multicolumn{6}{|l|}{$\varepsilon=0.1$, Exterior } \\
\hline$h, c o m b$,ext $\left(W /\left(m^{2} \cdot k\right)\right)$ & 8.1 & 12.8 & 17.4 & 1.3 & \\
\hline
\end{tabular}

SurfCoeffAnalysis...080318.xlsx; AllCoeffs600+...!P94+

Example constant surface coefficients presented here apply only to the test cases, and were calculated using a verified simulation process (see Part IV, Appendix A, Section 4A.3) only for test cases with south-facing windows or south-facing high-conductance wall elements. They should not be assumed to apply beyond this test suite.

Example constant interior surface coefficients assume buoyancy regime heat transfer only (see Part IV, Appendix A, Section 4A.2.2).

$\mathrm{h}_{\text {comb }}<\mathrm{h}_{\text {conv }}$ is possible here because convective and radiative heat flows may be in opposite directions for a given surface for a sufficient number of time steps.

Equations underlying the provided derived constant convective coefficients $\left(\mathrm{h}_{\text {conv }}\right.$ ) for various surface configurations are described in Part IV, Appendix A, Section 4A.2. Application of these equations for development of equivalent constant $h_{\text {conv }}$ values, along with development of example constant combined coefficients, $\left(h_{\text {comb }}\right)$, are described in Part IV, Appendix A, Section 4A.3. The content of Part IV is summarized by Neymark et al. (2019). ${ }^{\mathrm{A}-8}$

\section{B4.2 Intentionally Blank.}

[Note to Users: Section B4.3 is not referenced by the Section 5.2 cases; including it here documents revisions to Standard 140 needed for consistency with revisions to Section B4.1.]

B4.3 Alternative Constant Exterior Surface Coefficients for Section 7.2 Test Cases. Some simulation programs (e.g., EnergyPlus, using its option for simple outside surface conductance ${ }^{\mathrm{A}-2, \mathrm{~B}-20}$ ) allow calculation of the exterior combined radiative and convective surface coefficient as a second-order polynomial in wind speed of the form

$h=a_{1}+a_{2} V+a_{3} V^{2}$,

where the units of $h$ are $\mathrm{W} /\left(\mathrm{m}^{2} \cdot \mathrm{K}\right)$, and the $a$ coefficients are dependent on the surface texture. From HERS BESTEST $^{\mathrm{B}-38}$, the $a$ coefficients that apply for Equation B4-1 (using I-P units) are listed in Table B4-3.

Assuming a surface texture of brick or rough plaster, and a mean annual wind speed of $10.7 \mathrm{mph}$ (9.304 knots), then

Exterior combined surface coefficient for all walls and roofs $=5.748 \mathrm{Btu} /\left(\mathrm{h} \cdot \mathrm{ft}^{2} \cdot{ }^{\circ} \mathrm{F}\right)$.

For programs requiring a method for disaggregation of infrared and convective surface coefficients from combined surface coefficients, see Informative Annex B5. 
Table B4-3 Polynomial Coefficients for Describing Exterior Surface Coefficient as a Function of Wind Speed (I-P Units)

\begin{tabular}{cccc}
\hline Material & $\boldsymbol{a}_{\mathbf{1}}$ & $\boldsymbol{a}_{\mathbf{2}}$ & $\boldsymbol{a}_{\mathbf{3}}$ \\
\hline \hline Stucco & 2.04 & 0.535 & 0.0 \\
Brick/rough plaster & 2.20 & 0.369 & 0.001329 \\
Concrete & 1.90 & 0.380 & 0.0 \\
Clear pine & 1.45 & 0.363 & -0.002658 \\
Smooth plaster & 1.80 & 0.281 & 0.0 \\
Glass & 1.45 & 0.302 & -0.001661 \\
\hline
\end{tabular}




\section{INFORMATIVE ANNEX B5: INFRARED PORTION OF FILM COEFFICIENTS}

[Note to Users: Annex B5 is no longer referenced by the Section 5 test cases. It is included in this report to document Annex $B 5$ revisions for consistency with related Annex B4 revisions.]

B5.1 General Equation. The infrared portion of film coefficients is based on the linearized gray-body radiation equation $^{\mathrm{B}-97}$ :

$h_{i}=4 \varepsilon \sigma T^{3}$,

\section{B5.2 Intentionally blank.}

[Note to Users: Section B5.3 is not referenced by the Section 5.2 cases; including it here documents revisions to Standard 140 needed for consistency with other proposed revisions to Annex B5.]

\section{B5.3 Tabulation for Section 7.2 Test Cases}

For the test cases of Section 7.2, the parameters of Equation B5-1 are as follows:

$\varepsilon=$ infrared emittance

$\sigma=0.1718 \times 10^{-8} \mathrm{Btu} /\left(\mathrm{h} \cdot \mathrm{ft}^{2} \cdot{ }^{\circ} \mathrm{R}^{4}\right)($ Stefan/Boltzmann constant $)$

$T=$ average temperature of surrounding surfaces (assumed to be $50^{\circ} \mathrm{F}\left[510^{\circ} \mathrm{R}\right]$ for outside, $68^{\circ} \mathrm{F}\left[528^{\circ} \mathrm{R}\right]$ for inside)

$\mathrm{R}=$ Rankine (absolute zero $=0^{\circ} \mathrm{R}=-459.67^{\circ} \mathrm{F}$ )

$h_{i}=$ infrared radiation portion of surface coefficient.

Other nomenclature used for Tables B5-1 and B5-2 is as follows:

$h_{c}=$ convective portion of surface coefficient

$h_{s}=$ total combined interior surface coefficient

$h_{o}=$ total combined outside surface coefficient.

Tables B5-1 and B5-2 show convective and infrared radiative portions of film coefficients for the various orientations and surfaces of HERS BESTEST ${ }^{\mathrm{B}-38}$. In Table B5-1, combined exterior surface coefficients are evaluated using the algorithm of Informative Annex B4, Section B4.3; combined interior surface coefficients are based on ASHRAE data (see 1993 ASHRAE Handbook-Fundamentals, p. 22.1 ${ }^{\mathrm{B}-26}$ ). In Table B5-2, combined interior and exterior surface coefficients are based on the output of WINDOW $4.1^{\mathrm{B}-25}$.

[Note to Users: Tables B5-1 and B5-2 are not included; they are for the Section 7.2 tests and only have changes to their Table numbers.]

Table B5-1 Disaggregated Film Coefficients for Opaque Surfaces for Section 7.2 Tests (I-P Units) Table B5-2 Disaggregated Film Coefficients for Windows and Window Frames for Section 7.2 Tests (I-P Units) 


\section{INFORMATIVE ANNEX B6: WINDOW THERMAL AND OPTICAL PROPERTY CALCULATIONS}

\section{B6.1 Window Modeling with WINDOW 7}

WINDOW 7.4.8 $8^{\mathrm{A}-3, \mathrm{~A}-9}$ was applied for calculating thermal and optical properties shown in the following tables:

- Tables 5-11 and 5-12 for the clear double-pane window (Case 600 and most other cases).

- Tables 5-18 and 5-19 for the low-e window (Case 660).

WINDOW 7.6.4 ${ }^{\mathrm{A}-4}$ was applied for calculating thermal and optical properties shown in Tables 5-22 and 5-23 for the single-pane window (Case 670), as this work was done after new combined surface coefficients were developed for Case 670.

The calculations in WINDOW 7 are based on ISO $15099^{\mathrm{A}-10}$. For the windows of Cases 600 and 660 , there were no differences in results for version 7.6.04 (the latest version as of this writing) versus version 7.4.8, so the version 7.4.8 results remain here for those windows.

Tables B6-1, B6-2, and B6-3 include the WINDOW 7 listing of outputs and inputs for the updated BESTEST Case 600 (base case) double-pane window, Case 660 low-e argon window, and Case 670 single-pane window, respectively. Abbreviations used in these tables are described in Section B6.1.1. The following inputs applied in the analysis are not listed in the tables:

- "NFRC" calculation mode is applied.

- Environmental conditions match "NFRC 100-2014"A-11, except:

○ For Cases 600 and 660:

- $\quad$ Fixed combined interior surface coefficient $=4.5 \mathrm{~W} /\left(\mathrm{m}^{2} \mathrm{~K}\right)$.

- $\quad$ Fixed combined exterior surface coefficient $=17.8 \mathrm{~W} /\left(\mathrm{m}^{2} \mathrm{~K}\right)$.

○ For Case 670:

- $\quad$ Fixed combined interior surface coefficient $=7.8 \mathrm{~W} /\left(\mathrm{m}^{2} \mathrm{~K}\right)$.

- $\quad$ Fixed combined exterior surface coefficient $=16.0 \mathrm{~W} /\left(\mathrm{m}^{2} \mathrm{~K}\right)$.

The tables only include the WINDOW 7 Glazing System report; no frames, spacers, mullions, etc., are included for these idealized windows, so the full Window report is not applied. The Glazing System report does not include the constant surface coefficient values provided above. Presumably, the listed wind speeds are not applied when constant surface coefficients are specified; in any case, the reported "Uvalue" matches the manually calculated total U-values (see Table 5-11, note "e"; Table 5-18, note "d"; and Table 5-22, note "c").

The low-e (outer) window pane for Case 660 was selected from the WINDOW 7 glazing system library, ID 3 (basic low-e example); this pane-along with the clear pane applied for the low-e, clear double-pane, and clear single-pane windows - are taken from the International Glazing Database ${ }^{\mathrm{A}-12}$. The selected low-e glazing pane happens to be somewhat similar to that applied in Case L130A of Section 7.2.2.3 (also see HERS BESTEST ${ }^{\mathrm{B}-38}$ and BESTEST-EX ${ }^{\mathrm{A}-}$ ${ }^{13}$ ), but also includes spectral data embedded in the WINDOW 7 library.

For programs that may read WINDOW 7 output directly, the following "Glazing System Thermal and Optical Properties" report output is included with the accompanying electronic media as informative material (see README-Thermal-Fabric-Update.DOCX, provided with the accompanying electronic media):

- $\quad$ Case600-W7-DblPaneClr-ID23.txt

- Case660-W7-DblPaneLowE-ID36.txt

- Case670-W7-SglPaneClr-ID15.txt. 


\section{Table B6-1 WINDOW 7 Input/Output Tabulation, Clear Double-Pane Window}

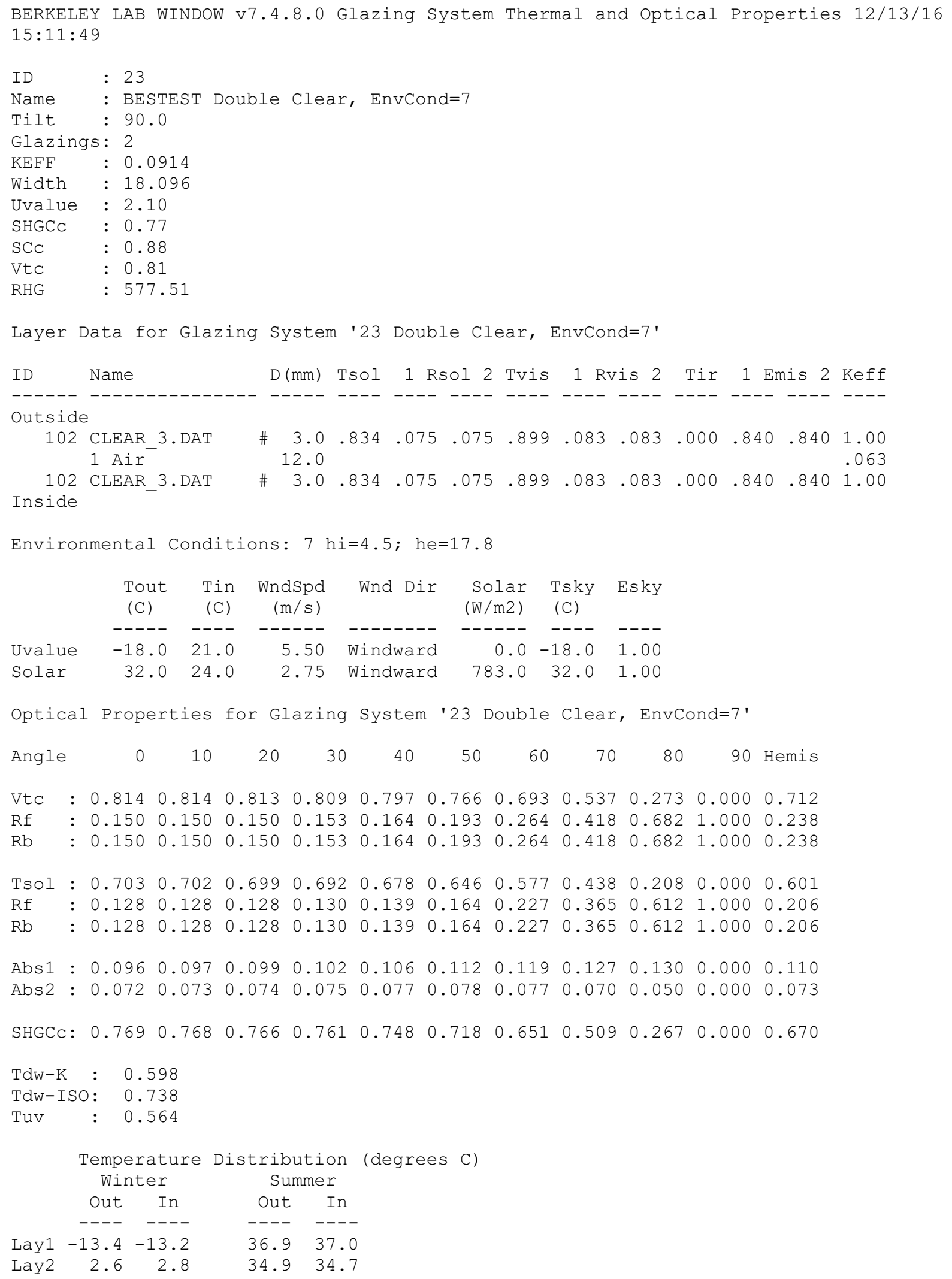


Gas Data (from Window 7 gas data library)

\begin{tabular}{|c|c|c|c|c|c|c|}
\hline Name & Type & $\begin{array}{l}\text { Conductivity } \\
\mathrm{W} / \mathrm{m}-\mathrm{K}\end{array}$ & $\begin{array}{l}\mathrm{Viscosity} \\
\mathrm{kg} / \mathrm{m}-\mathrm{s}\end{array}$ & $\begin{array}{l}\mathrm{Cp} \\
\mathrm{J} / \mathrm{kg}-\mathrm{K}\end{array}$ & $\begin{array}{l}\text { Density } \\
\mathrm{kg} / \mathrm{m} 3\end{array}$ & Prandt \\
\hline Air & Pure & 0.024069 & 0.000017 & 1006.103271 & 1.292498 & 0.7197 \\
\hline
\end{tabular}

Note: Window 7 does not tabulate constant surface coefficients in an output report. 


\section{Table B6-2 WINDOW 7 Input/Output Tabulation, Double-Pane Low-E Window}

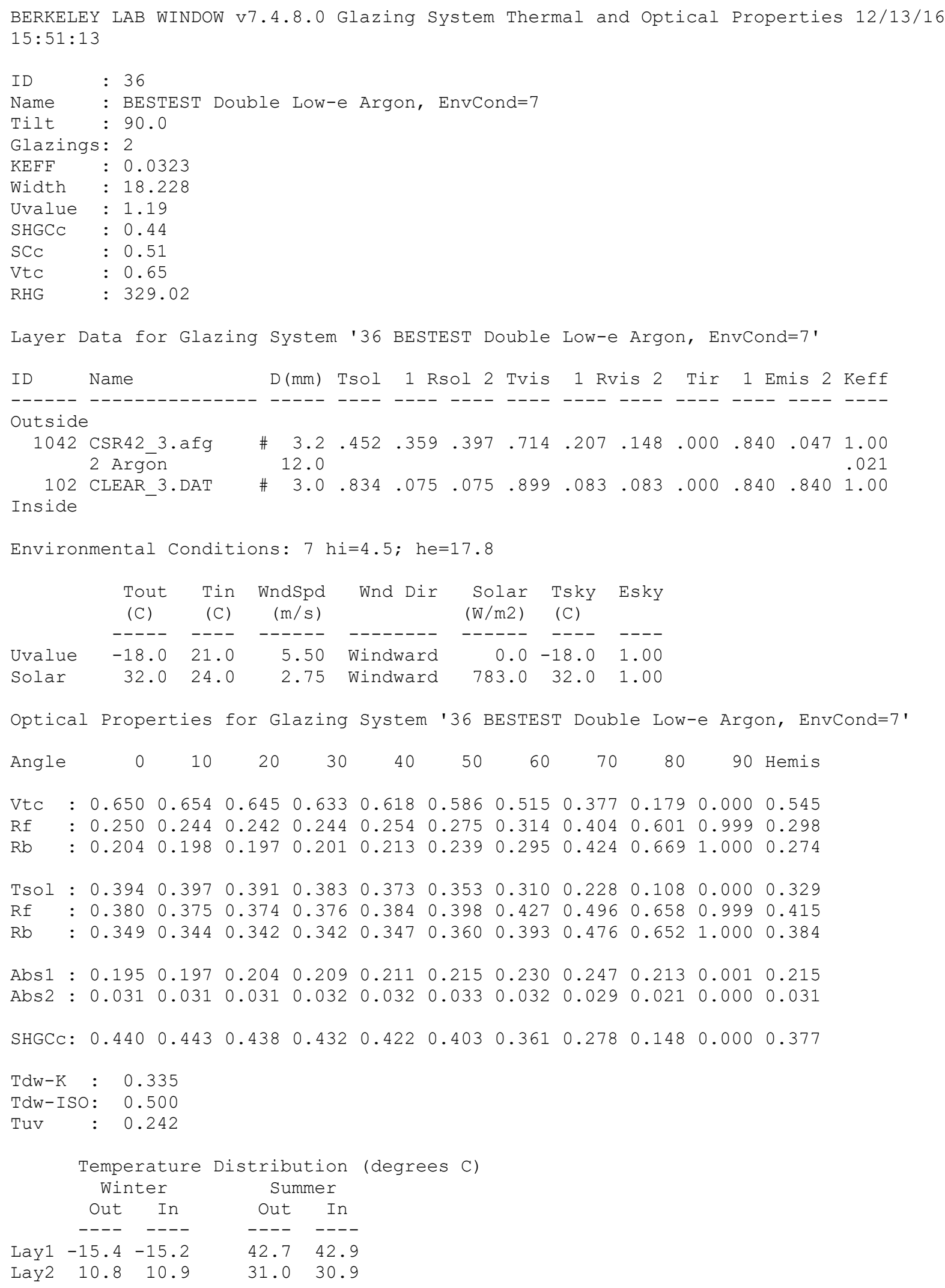


Gas Data (from Window 7 gas data library)

\begin{tabular}{|c|c|c|c|c|c|c|}
\hline Name & Type & $\begin{array}{l}\text { Conductivity } \\
\mathrm{W} / \mathrm{m}-\mathrm{K}\end{array}$ & $\begin{array}{l}\mathrm{Viscosity} \\
\mathrm{kg} / \mathrm{m}-\mathrm{s}\end{array}$ & $\begin{array}{l}\mathrm{Cp} \\
\mathrm{J} / \mathrm{kg}-\mathrm{K}\end{array}$ & $\begin{array}{l}\text { Density } \\
\mathrm{kg} / \mathrm{m} 3\end{array}$ & Prandtl \\
\hline Argon & Pure & 0.016349 & 0.000021 & 521.928528 & 1.782282 & .6704 \\
\hline
\end{tabular}

Note: Window 7 does not tabulate constant surface coefficients in an output report. 


\section{Table B6-3 WINDOW 7 Input/Output Tabulation, Clear Single-Pane Window}

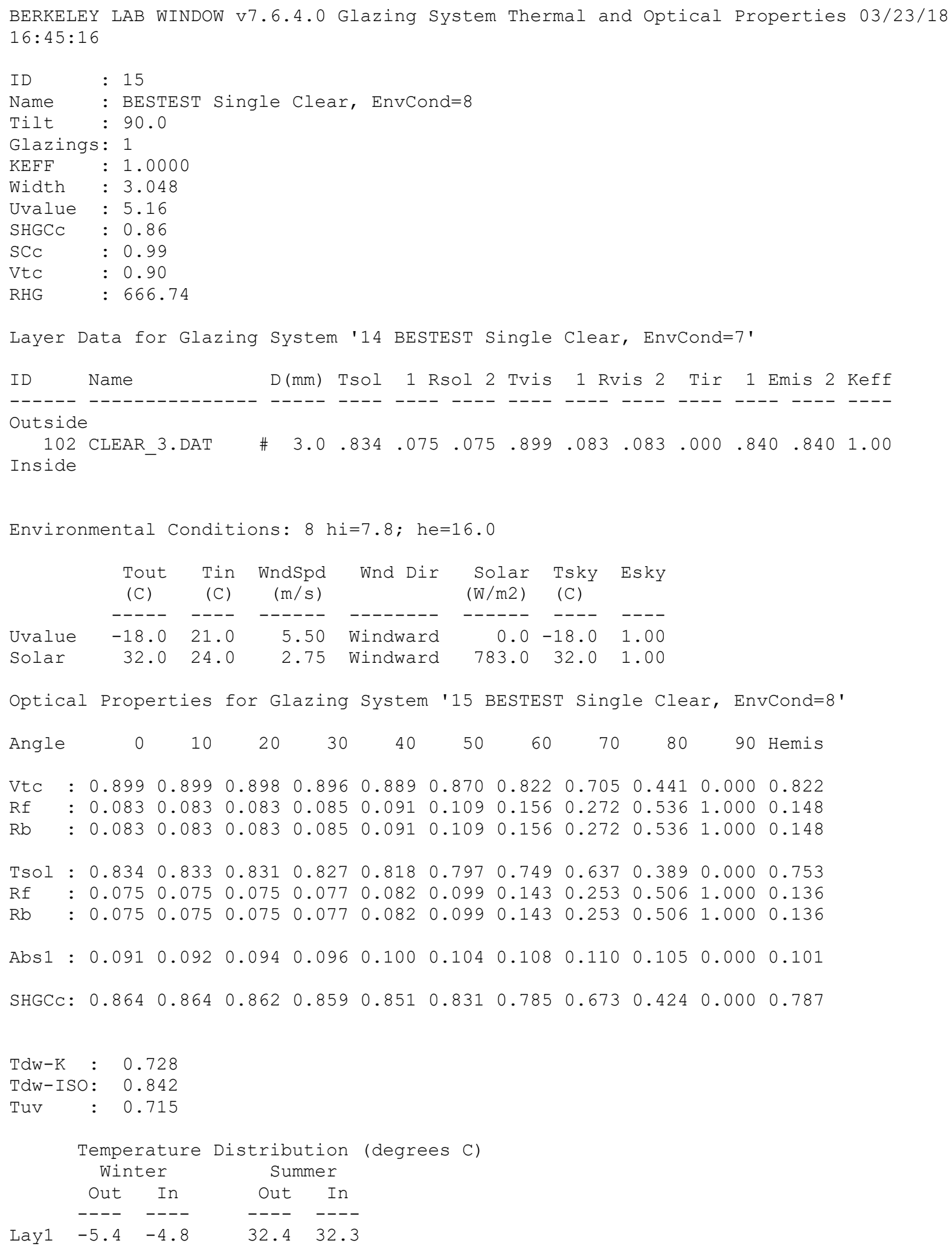

Note: Window 7 does not tabulate constant surface coefficients in an output report. 


\section{B6.1.1 Abbreviations for Tables B6-1, B6-2, and B6-3}

Abbreviations used in Tables B6-1, B6-2, and B6-3 are primarily excerpted from the WINDOW 4.1 user's manual ${ }^{\mathrm{B}-}$ ${ }^{25}$. The definition documentation does not appear to be updated for WINDOW $6^{\mathrm{A}-9}$, or WINDOW $7^{\mathrm{A}-4}$ (which references the WINDOW 6 documentation). Further detail is provided by Finlayson et al. ${ }^{\mathrm{A}-14}$.

- Abs: solar absorptance for a pane of a glazing system (exterior-facing surface is 1, and interior-facing surface is 2).

- Angle: solar incidence angle with respect to vertical surface, " 0 " is normal to vertical.

- $\quad$ D: glazing layer thickness (mm), input from glass library.

- $\quad$ Emis: infrared emittance of a glazing layer (exterior-facing surface is 1, and interior-facing surface is 2), input from the glass library.

- $\quad$ Esky: effective sky emittance for calculating radiation exchange between the exterior glazing surface and the sky, input from environmental conditions.

- $\quad$ Glazings: number of glazing panes.

- $\quad$ Hemis: hemispherically integrated property.

- ID: Window 7 library identification number for given system or component.

- Keff: conductivity or effective conductivity of a window component (glass, gap, etc.), input from the glass library or as calculated for the gap between panes $(\mathrm{W} /(\mathrm{mK}))$.

- $\quad$ KEFF: total effective conductivity of all components of a glazing system except for the exterior and interior surface combined (convective and radiative) heat transfer coefficients $(\mathrm{W} /(\mathrm{mK}))$.

- $\quad$ Lay: glass layer (exterior layer is 1, interior layer is 2).

- $\mathrm{Rb}$ : the back (exterior) surface reflectance of a glazing system.

- $\quad$ Rf: the front (interior) surface reflectance of a glazing system.

- $\quad$ RHG: relative heat gain through the glazing system equal to Uc*(Ti-To)+SC*(Incident Solar Radiation); see WINDOW $4.1^{\mathrm{B}-25}$ and Finlayson et $\mathrm{al}^{\mathrm{A}-14}$ for more detail.

- $\quad$ Rsol: solar reflectance of the glazing layer (exterior-facing surface is 1 , and interior-facing surface is 2), input from the glass library.

- $\quad$ Rvis: visible reflectance of the glazing layer (exterior-facing surface is 1, and interior-facing surface is 2), input from the glass library.

- $\quad$ SCc: the shading coefficient of the glazing system (center-of-glass).

- $\quad$ SHGCc: the solar heat gain coefficient of the glazing system (center-of-glass) only.

- Solar: incident solar radiation from environmental conditions for which SC and SHGC are calculated, input from environmental conditions.

- $\quad$ Tdw: the damage-weighted transmittance, which includes the effects of damage from the ultraviolet and visible portions of the solar spectrum.

- $\quad$ Tin: inside surface temperature, input from environmental conditions $\left({ }^{\circ} \mathrm{C}\right)$.

- $\quad$ Tir: thermal infrared transmittance of a glazing layer, input from the glass library.

- $\quad$ Tilt: tilt angle of the window, where $90^{\circ}$ is vertical.

- $\quad$ Tsky: effective sky temperature for calculating infrared radiation heat transfer between the exterior glass surface and the sky, input from environmental conditions.

- $\quad$ Tout: outside temperature, input from environmental conditions $\left({ }^{\circ} \mathrm{C}\right)$.

- Tsol: solar transmittance of the glazing layer input from the glass library, or as calculated for the glazing system.

- $\quad$ Tuv: the unweighted transmittance between wavelengths of 0.30 and 0.38 microns.

- $\quad$ Tvis: visible transmittance of the glazing layer input from the glass library, or as calculated for the glazing system.

- Uvalue: the total air-to-air heat transfer coefficient for the window system, including exterior and interior surface combined (convective and radiative) heat transfer coefficients $\left(\mathrm{W} /\left(\mathrm{m}^{2} \mathrm{~K}\right)\right.$ ).

- Vtc: visible transmittance of the glazing system (center-of-glass) only.

- Width: total thickness of the glazing system (mm).

- Wnd Dir: wind direction, input from environmental conditions (windward or leeward).

- WndSpd: wind speed, input from environmental conditions $(\mathrm{m} / \mathrm{s})$. 


\title{
B6.2 Alternate Calculation of Optical Properties Based on Index of Refraction and Extinction Coefficient.
}

Table B6-4 provides clear-glazing optical property calculations applying calculated transmittances due to reflectance and absorptance losses ( $\mathrm{Tr}$ and Tabs respectively; see nomenclature below). These calculations were applied for developing optical properties in the original BESTEST suite ${ }^{\mathrm{B}-29}$, and are also useful for comparing with WINDOW 7 output (see Section B6.3).

For developing Table B6-4, values of index of refraction and extinction coefficient were adjusted for singlepane glass to match the normal-incident reflectance and transmittance indicated by WINDOW 7 for the layer of clear glass from the WINDOW 7 glass library that was selected for developing glazing system properties described in Section B6.1. Resulting normal-incident absorptance has greater disagreement versus that of Table B6-1 than the resulting transmittance and reflectance, but is less of a concern because some absorbed solar radiation is conducted back out to ambient conditions. The resulting clear single-pane glazing index of refraction and extinction coefficient were then applied to the double-pane glazing system calculation, yielding the values shown in Table B6-4.

Index of refraction and extinction coefficient were not calculated for the low-e glazing system (Case 660) because single values for each of these parameters do not adequately describe the optical properties of coated glass.

Nomenclature and associated equations for calculating the angle-dependent solar transmittance of glass in air listed in Table B6-4 are provided below.

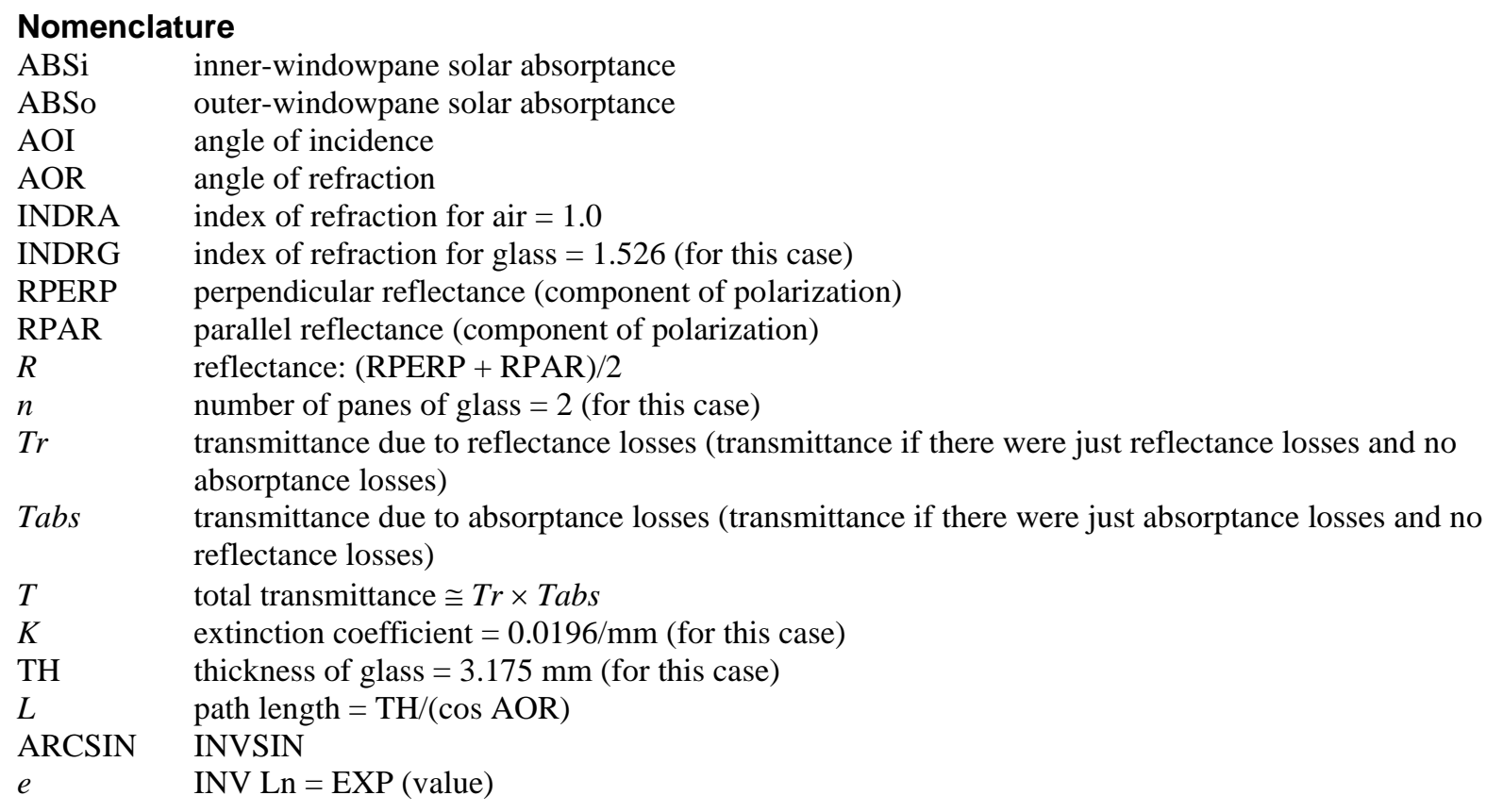

\author{
Snell's Law \\ INDRA/INDRG $=\sin$ AOR/sin AOI \\ $\mathrm{AOR}=\mathrm{ARCSIN}[(\sin \mathrm{AOI}) / \mathrm{INDRG}]$ \\ Fresnel Equations (Reflectance at an individual air-to-glass interface) \\ $\mathrm{RPERP}=\left[\sin ^{2}(\mathrm{AOR}-\mathrm{AOI})\right] /\left[\sin ^{2}(\mathrm{AOR}+\mathrm{AOI})\right]$ \\ $\mathrm{RPAR}=\left[\tan ^{2}(\mathrm{AOR}-\mathrm{AOI})\right] /\left[\tan ^{2}(\mathrm{AOR}+\mathrm{AOI})\right]$ \\ $\mathrm{R}=(\mathrm{RPERP}+\mathrm{RPAR}) / 2$
}

Fresnel Equations (Transmittance due to reflectance with several panes)

$\operatorname{Tr}, n=0.5\{[(1-\mathrm{RPERP}) /(1+(2 n-1) \mathrm{RPERP})]+$

$[(1-\mathrm{RPAR}) /(1+(2 n-1) \mathrm{RPAR})]\}$

Bouguer's Law (Transmittance due to absorptance)

Tabs $=e^{[n(-\mathrm{KL})]}$

$T \cong T r \times T a b s$ 
Table B6-4 Glazing Properties as a Function of Incidence Angle

\begin{tabular}{|c|c|c|c|c|c|c|c|}
\hline INPUTS & \multicolumn{3}{|c|}{ DOUBLE GLAZING } & \multicolumn{4}{|c|}{ (deg=degrees $\mathrm{rad}=$ radians) } \\
\hline $\mathrm{AOI}(\mathrm{deg})$ & INDRA & INDRG & $\mathrm{n}$ & $\mathrm{K}(/ \mathrm{mm})$ & $\mathrm{TH}(\mathrm{mm})$ & $\mathrm{AOI}(\mathrm{rad})$ & $\mathrm{AOR}(\mathrm{rad})$ \\
\hline 0 & 1 & 1.493 & 2 & 0.0337 & 3.048 & 0.0000 & 0.0000 \\
\hline 10 & 1 & 1.493 & 2 & 0.0337 & 3.048 & 0.1745 & 0.1166 \\
\hline 20 & 1 & 1.493 & 2 & 0.0337 & 3.048 & 0.3491 & 0.2311 \\
\hline 30 & 1 & 1.493 & 2 & 0.0337 & 3.048 & 0.5236 & 0.3415 \\
\hline 40 & 1 & 1.493 & 2 & 0.0337 & 3.048 & 0.6981 & 0.4451 \\
\hline 45 & 1 & 1.493 & 2 & 0.0337 & 3.048 & 0.7854 & 0.4934 \\
\hline 50 & 1 & 1.493 & 2 & 0.0337 & 3.048 & 0.8727 & 0.5388 \\
\hline 60 & 1 & 1.493 & 2 & 0.0337 & 3.048 & 1.0472 & 0.6188 \\
\hline 70 & 1 & 1.493 & 2 & 0.0337 & 3.048 & 1.2217 & 0.6808 \\
\hline 80 & 1 & 1.493 & 2 & 0.0337 & 3.048 & 1.3963 & 0.7203 \\
\hline OUTPUTS & \multicolumn{3}{|c|}{ DOUBLE GLAZING } & & & & \\
\hline $\mathrm{AOI}(\mathrm{deg})$ & AOR(deg) & RPERP & RPAR & $\mathrm{R}$ & $\operatorname{Tr}$ & Tabs & $\mathrm{T}$ \\
\hline 0 & 0.0000 & 0.0391 & 0.0391 & 0.0391 & 0.8600 & 0.8143 & 0.7003 \\
\hline 10 & 6.6791 & 0.0407 & 0.0375 & 0.0391 & 0.8600 & 0.8132 & 0.6993 \\
\hline 20 & 13.2431 & 0.0461 & 0.0327 & 0.0394 & 0.8595 & 0.8097 & 0.6960 \\
\hline 30 & 19.5662 & 0.0566 & 0.0246 & 0.0406 & 0.8574 & 0.8041 & 0.6894 \\
\hline 40 & 25.5015 & 0.0757 & 0.0139 & 0.0448 & 0.8500 & 0.7964 & 0.6769 \\
\hline 45 & 28.2692 & 0.0904 & 0.0082 & 0.0493 & 0.8419 & 0.7920 & 0.6667 \\
\hline 50 & 30.8699 & 0.1102 & 0.0031 & 0.0566 & 0.8282 & 0.7871 & 0.6519 \\
\hline 60 & 35.4546 & 0.1741 & 0.0019 & 0.0880 & 0.7674 & 0.7771 & 0.5964 \\
\hline 70 & 39.0058 & 0.2966 & 0.0428 & 0.1697 & 0.6102 & 0.7677 & 0.4684 \\
\hline 80 & 41.2706 & 0.5358 & 0.2372 & 0.3865 & 0.3118 & 0.7608 & 0.2373 \\
\hline INPUTS & & VGLE GL & & & & & \\
\hline AOI & $\overline{I I N D R A}$ & IINDRG & $\bar{n}$ & $\bar{K}$ & $\overline{\mathrm{TTH}}$ & AOI RAD & $\begin{array}{l}\text { AOR RAD } \\
\end{array}$ \\
\hline 0 & 1 & 1.493 & 1 & 0.0337 & 3.048 & 0.0000 & 0.0000 \\
\hline 10 & 1 & 1.493 & 1 & 0.0337 & 3.048 & 0.1745 & 0.1166 \\
\hline 20 & 1 & 1.493 & 1 & 0.0337 & 3.048 & 0.3491 & 0.2311 \\
\hline 30 & 1 & 1.493 & 1 & 0.0337 & 3.048 & 0.5236 & 0.3415 \\
\hline 40 & 1 & 1.493 & 1 & 0.0337 & 3.048 & 0.6981 & 0.4451 \\
\hline 45 & 1 & 1.493 & 1 & 0.0337 & 3.048 & 0.7854 & 0.4934 \\
\hline 50 & 1 & 1.493 & 1 & 0.0337 & 3.048 & 0.8727 & 0.5388 \\
\hline 60 & 1 & 1.493 & 1 & 0.0337 & 3.048 & 1.0472 & 0.6188 \\
\hline 70 & 1 & 1.493 & 1 & 0.0337 & 3.048 & 1.2217 & 0.6808 \\
\hline 80 & 1 & 1.493 & 1 & 0.0337 & 3.048 & 1.3963 & 0.7203 \\
\hline OUTPUTS & & GLE GL & & & & & \\
\hline $\mathrm{AOI}$ & AOR & RPERP & RPAR & $\mathrm{R}$ & $\operatorname{Tr}$ & Tabs & $\mathrm{T}$ \\
\hline 0 & 0.0000 & 0.0391 & 0.0391 & 0.0391 & 0.92473 & 0.90238 & 0.83446 \\
\hline 10 & 6.6791 & 0.0407 & 0.0375 & 0.0391 & 0.92471 & 0.90175 & 0.83385 \\
\hline 20 & 13.2431 & 0.0461 & 0.0327 & 0.0394 & 0.92432 & 0.89985 & 0.83175 \\
\hline 30 & 19.5662 & 0.0566 & 0.0246 & 0.0406 & 0.92240 & 0.89672 & 0.82713 \\
\hline 40 & 25.5015 & 0.0757 & 0.0139 & 0.0448 & 0.91594 & 0.89243 & 0.81741 \\
\hline 45 & 28.2692 & 0.0904 & 0.0082 & 0.0493 & 0.90903 & 0.88992 & 0.80896 \\
\hline 50 & 30.8699 & 0.1102 & 0.0031 & 0.0566 & 0.89766 & 0.88721 & 0.79642 \\
\hline 60 & 35.4546 & 0.1741 & 0.0019 & 0.0880 & 0.84979 & 0.88153 & 0.74911 \\
\hline 70 & 39.0058 & 0.2966 & 0.0428 & 0.1697 & 0.73017 & 0.87618 & 0.63976 \\
\hline 80 & 41.2706 & 0.5358 & 0.2372 & 0.3865 & 0.45939 & 0.87226 & 0.40071 \\
\hline
\end{tabular}




\section{B6.3 Comparison of Two Algorithms for Calculating Window Transmittance.}

Table B6-5 compares angle-dependent solar transmittance calculated using the equations of Section B6.2 to the same properties calculated by WINDOW 7 (see Section B6.1) for the clear double-pane window of Case 600 .

Table B6-5 shows that at higher incidence angles, there is an increasing difference between the transmittance calculated by the two algorithms. This difference occurs because of a simplification associated with the algorithm of Section B6.2. The error caused by the simplification is magnified at the higher incidence angles but is still small in the context of solar heat gains. The resulting difference in solar heat gains to the building is minimized for two reasons:

a. As incidence angle increases, the intensity of solar radiation incident on a given surface decreases with the cosine of the incidence angle.

b. As incidence angle increases, the solar transmittance of glass decreases as a cosine-like function of the incidence angle.

Table B6-5 Angular Dependence of Transmittance of Clear Double-Pane Glazing System

\begin{tabular}{|c|c|c|}
\hline $\begin{array}{c}\text { Incidence } \\
\text { Angle (deg) }\end{array}$ & $\begin{array}{c}\text { Section B6.1 } \\
(\text { Window 7) } \\
\text { Solar } \\
\text { Transmittance }\end{array}$ & $\begin{array}{c}\text { Section B6.2 } \\
\text { (BESTEST 1995) }^{\mathrm{B}-29} \\
\text { Solar } \\
\text { Transmittance }\end{array}$ \\
\hline 0 & 0.703 & 0.700 \\
\hline 10 & 0.702 & 0.699 \\
\hline 20 & 0.699 & 0.696 \\
\hline 30 & 0.692 & 0.689 \\
\hline 40 & 0.678 & 0.677 \\
\hline 50 & 0.646 & 0.652 \\
\hline 60 & 0.577 & 0.596 \\
\hline 70 & 0.438 & 0.468 \\
\hline 80 & 0.208 & 0.237 \\
\hline
\end{tabular}




\section{INFORMATIVE ANNEX B7: DETAILED CALCULATION OF ALTERNATIVE CONSTANT INTERIOR SOLAR DISTRIBUTION FRACTIONS}

For double-pane glazing, solar fraction approximations are calculated from the following:

$$
\mathrm{SF}_{n}=\mathrm{B} 1_{n}+\mathrm{B} 2_{n}+\mathrm{B} 3_{n}+\mathrm{BR}_{n}
$$

where

$n=$ a particular surface

$\mathrm{SF}=$ total solar fraction

B1 describes the first bounce of incident shortwave radiation, assuming all of it initially hits the floor.

$\mathrm{B} 1_{\text {floor }}=\alpha$

$\mathrm{B} 1_{\text {all other }}=0$

$\alpha=$ interior shortwave absorptance of opaque surfaces (all interior surfaces have the same absorptance except for the transparent window absorptance, which is indicated as $\alpha_{w}$ ).

B2 describes the second bounce such that shortwave radiation diffusely reflected by the floor is distributed over other surfaces in proportion to their view factor-absorptance product.

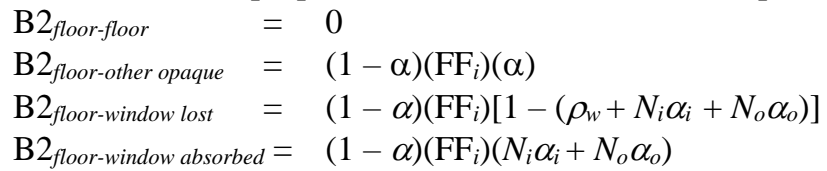

where

$i=$ particular surface the floor "sees" according to the view factor (see "FF" below). View factors for windows are based on the view factor for the wall where the windows are located, multiplied by the fraction of the area of that wall occupied by the windows. View factors for the opaque portion of walls with windows are adjusted similarly. To simplify calculation of solar lost, all windows are assumed located on the south wall as in Case 600 (Section 5.2.1) and Case L150A (Section 7.2).

$\rho_{w}=$ reflectance for specific glazing, hemispherically integrated (diffuse radiation).

$\alpha_{i}=$ inner-pane absorptance for specific glazing, hemispherically integrated (diffuse radiation).

$\alpha_{o}=$ outer-pane absorptance for specific glazing, hemispherically integrated (diffuse radiation).

$N_{i}=$ inward-conducted fraction of cavity-reflected absorbed solar radiation for inner pane.

$N_{o}=$ inward-conducted fraction of cavity-reflected absorbed solar radiation for outer pane.

For double-pane glazing, $N_{i}$ and $N_{o}$ are the ratio of total R-value of the components on the exterior side of the inner and outer pane, respectively, to the total air-air center-of-glass R-value of the double-pane unit including gap between panes, window panes, and interior and exterior surface combined (convective and radiative) heat transfer coefficients.

$\mathrm{FF}=$ view factor from Figures B7-1 and B7-2, which are equivalent to the equations below.

Equation for Figure B7-1:

$$
F_{1-2}=\frac{1}{\pi Y}\left(\begin{array}{l}
Y \tan ^{-1}\left(\frac{1}{Y}\right)+Z \tan ^{-1}\left(\frac{1}{Z}\right)-\sqrt{Z^{2}+Y^{2}} \tan ^{-1}\left(\frac{1}{\sqrt{Z^{2}+Y^{2}}}\right) \\
+\frac{1}{4} \ln \left\{\frac{\left(1+Y^{2}\right)\left(1+Z^{2}\right)}{\left(1+Y^{2}+Z^{2}\right)}\left[\frac{Y^{2}\left(1+Y^{2}+Z^{2}\right)}{\left(1+Y^{2}\right)\left(Y^{2}+Z^{2}\right)}\right]^{Y^{2}}\left[\frac{Z^{2}\left(1+Z^{2}+Y^{2}\right)}{\left(1+Z^{2}\right)\left(Z^{2}+Y^{2}\right)}\right]^{Z^{2}}\right.
\end{array}\right)
$$


where

$Y=y / x, Z=z / x$ for $x, y$, and $z$ as defined in Figure B7-1.

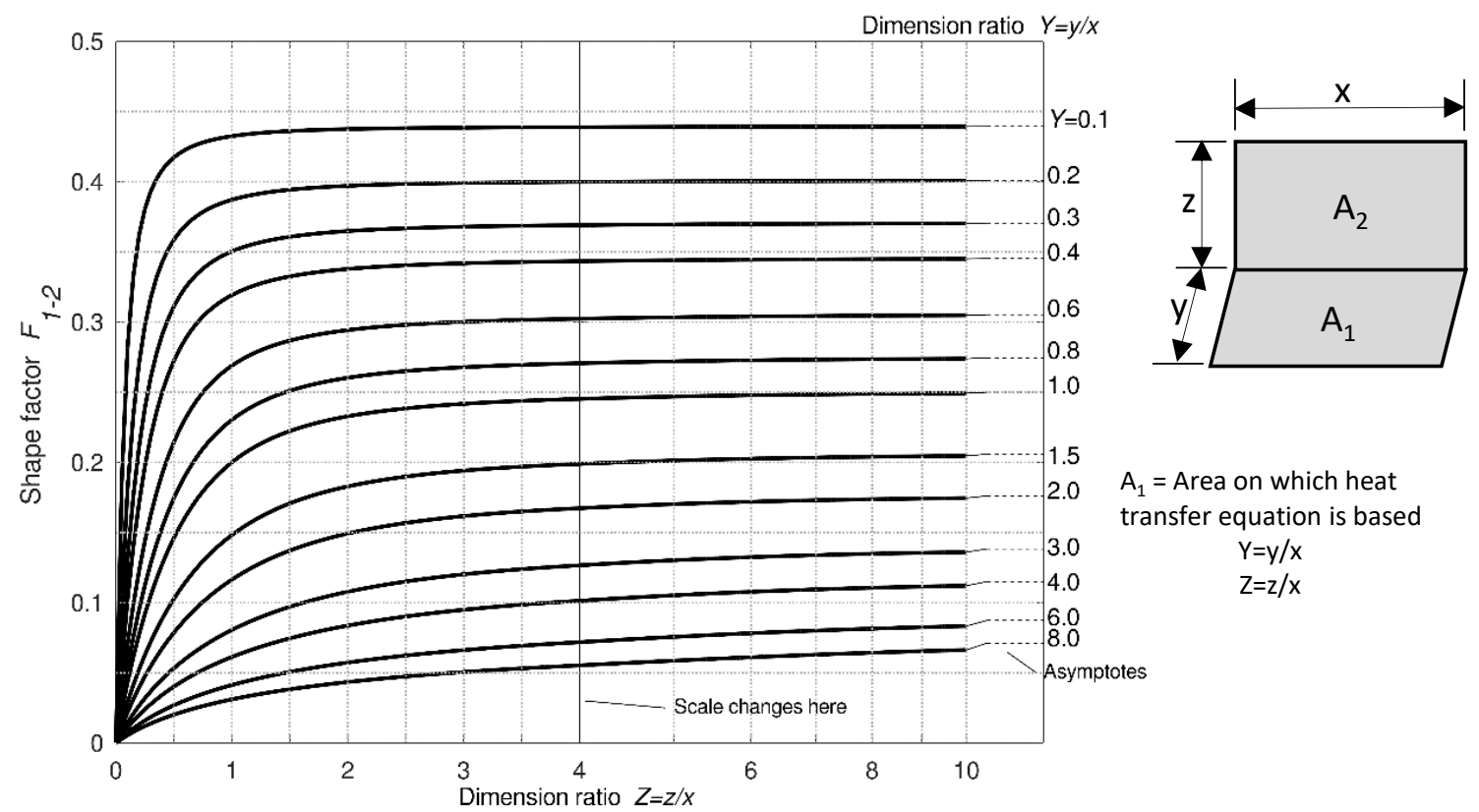

Figure B7-1 Shape factor for adjacent rectangles in perpendicular planes sharing a common edge.

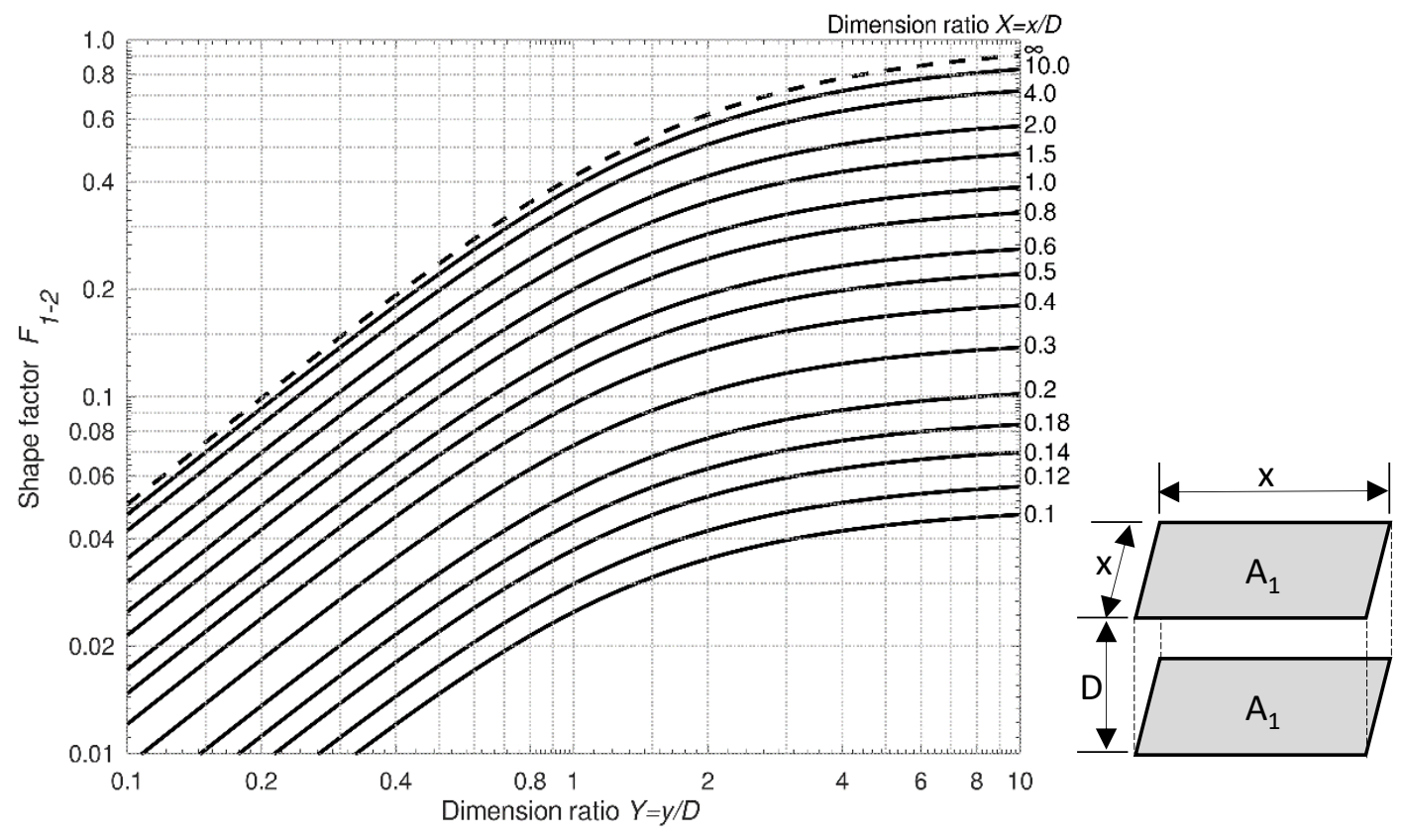

Figure B7-2 Shape factor for directly opposed rectangles. 
The equation for Figure B7-2 is as follows:

$$
F_{1-2}=\frac{2}{\pi X Y}\left(\begin{array}{l}
\ln \left[\frac{\left(1+X^{2}\right)\left(1+Y^{2}\right)}{\left(1+X^{2}+Y^{2}\right)}\right]^{1 / 2}+X \sqrt{1+Y^{2}} \tan ^{-1}\left(\frac{X}{\sqrt{1+Y^{2}}}\right) \\
+Y \sqrt{1+X^{2}} \tan ^{-1}\left(\frac{Y}{\sqrt{1+X^{2}}}\right)-X \tan ^{-1} X-Y \tan ^{-1} Y
\end{array}\right)
$$

where $X=x / D, Y=y / D$ for $x, y$, and $D$ as defined in Figure B7-2.

B3 describes the third bounce such that the remaining nonabsorbed shortwave radiation is distributed over each surface in proportion to its area-absorptance product.

$\mathrm{B}_{\text {opaque-opaque }}=\left[1-\alpha-\sum\left(\mathrm{B} 2_{n}\right)\right]\left(A_{n} / A_{\text {total }}\right)(\alpha)$

$\mathrm{B}_{\text {opaque-window lost }}=\left[1-\alpha-\sum\left(\mathrm{B} 2_{n}\right)\right]\left(A_{n} / A_{\text {total }}\right)\left[1-\left(\rho_{w}+N_{i} \alpha_{i}+N_{o} \alpha_{o}\right)\right]$

$\mathrm{B} 3_{\text {opaque-window absorbed }}=\left[1-\alpha-\sum\left(\mathrm{B} 2_{n}\right)\right]\left(A_{n} / A_{\text {total }}\right)\left(N_{i} \alpha_{i}+N_{o} \alpha_{o}\right)$

where

$A_{n} \quad=$ area of surface $n$

$A_{\text {total }}=$ total area of all surfaces

BR describes the distribution of all remaining bounces based on distribution fractions from calculations for $\mathrm{B} 3_{n}$ above.

$\mathrm{BR}_{n}=\left[1-\alpha-\sum\left(\mathrm{B} 2_{n}\right)-\sum\left(\mathrm{B} 3_{n}\right)\right]\left[\mathrm{B} 3_{n} / \sum\left(\mathrm{B} 3_{n}\right)\right]$

For single-pane glazing, the solar lost calculation is the same as for double-pane glazing, except for the following differences:

$\mathrm{B} 2_{\text {floor-window lost }}=(1-\alpha)\left(\mathrm{FF}_{i}\right)\left\{1-\left[\rho_{w}+(N)\left(\alpha_{w}\right)\right]\right\}$

$\mathrm{B} 2_{\text {floor-window absorbed }}=(1-\alpha)\left(\mathrm{FF}_{i}\right)(N)\left(\alpha_{w}\right)$

$\mathrm{B} 3_{\text {opaque-window lost }}=\left[1-\alpha-\sum\left(\mathrm{B} 2_{n}\right)\right]\left(A_{n} / A_{\text {total }}\right)\left\{1-\left[\rho_{w}+(N)\left(\alpha_{w}\right)\right]\right\}$

$\mathrm{B} 3_{\text {opaque-window absorbed }}=\left[1-\alpha-\sum\left(\mathrm{B} 2_{n}\right)\right]\left(A_{\mathrm{n}} / A_{\text {total }}\right)(N)\left(\alpha_{w}\right)$

where

$\alpha_{\mathrm{w}}=$ absorptance for specific glazing, hemispherically integrated (diffuse radiation)

$N=$ inward-conducted fraction of cavity-reflected absorbed solar radiation. For single-pane glass, $N$ is the ratio of the exterior combined (convective and radiative) surface heat transfer coefficient R-value to the total airair center-of-glass R-value.

No transmitted solar radiation is assumed to be directly absorbed by the zone air at any time during this analysis.

B7.1 Resulting Alternative Constant Solar Distribution Fractions for the Cases of Sections 5.2.1, 5.2.2, and 5.2.3.

Table B7-1 summarizes the interior solar distribution fractions, using the above formulation, for the various window configurations and interior surface absorptances that arise in the test cases of Sections 5.2.1, 5.2.2 and 5.2.3. Where needed, minor rounding adjustments were made to the values for the ceiling or east/west walls as indicated in the table, so that the sum of listed rounded values in Table B7-1 for all cases is 1.000 .

Fractional values for the walls with windows include the portion of the internally reflected solar radiation absorbed by the glass (as the radiation passes back out the window) that is conducted back into the zone. Solar radiation 
absorbed by the glass (and conducted inward) as it initially passes into the building is treated separately by most programs in their window optical algorithms; therefore, it is not included in the values in Table B7-1.

In the cases with windows oriented east and west, solar fractions are assumed to be the same as for the southoriented cases with similar interior solar absorptance, except that the fractions are adjusted in proportion to the change in the opaque areas of the east, west, and south walls caused by moving the windows.

For Case 960 (sunspace), solar lost was calculated using the same assumptions as for the south-window orientation cases, with some adjustments because the sun-zone south wall (containing the windows) and common wall are only $2 \mathrm{~m}$ apart. The tabulated values assume a solar fraction of 0.6 for the floor and 0.2 for the common wall. The solarlost fraction was adjusted based on increased ratio of window area to opaque surface area for the sunspace versus Case 600, and rounded to 0.07 . The remaining solar fractions were distributed in proportion to the area-absorptance products of the remaining surfaces.

Calculations applying the preceding algorithm are documented in Part IV, Appendix C (Section 4C).

Table B7-1 Alternative Constant Interior Solar Distribution Fractions Versus Window Orientation and Interior Solar Absorptance for Tests of Sections 5.2.1, 5.2.2, and 5.2.3 ${ }^{\mathrm{a}, \mathrm{b}}$

\begin{tabular}{|c|c|c|c|c|c|c|c|c|}
\hline Surface & $\begin{array}{c}\text { South } \\
\text { Window } \\
\text { Cases, } \\
\alpha=\mathbf{0 . 6}\end{array}$ & $\begin{array}{c}\text { East/West } \\
\text { Window } \\
\text { Cases, } \\
\alpha=0.6\end{array}$ & $\begin{array}{c}\text { Low-E } \\
\text { S. Win. } \\
\text { Case, } \\
\alpha=\mathbf{0 . 6}^{\text {f }}\end{array}$ & $\begin{array}{c}\text { 1-Pane } \\
\text { S. Win. } \\
\text { Case, } \\
\alpha=0^{6}\end{array}$ & $\begin{array}{c}\text { South } \\
\text { Window } \\
\text { Cases, } \\
\alpha=0.9\end{array}$ & $\begin{array}{c}\text { East/West } \\
\text { Window } \\
\text { Cases, } \\
\alpha=0.9\end{array}$ & $\begin{array}{c}\text { South } \\
\text { Window } \\
\text { Cases, } \\
\alpha=0.1\end{array}$ & $\begin{array}{c}\text { Sunspace } \\
\text { Case }\end{array}$ \\
\hline Floor & 0.642 & 0.642 & 0.645 & 0.641 & 0.903 & 0.903 & 0.243 & 0.6 \\
\hline Ceiling & 0.167 & 0.167 & 0.170 & 0.166 & 0.050 & 0.050 & $0.191^{\mathrm{d}}$ & 0.05 \\
\hline East wall & 0.038 & $0.025^{\mathrm{c}}$ & 0.039 & 0.038 & 0.010 & $0.0065^{\mathrm{e}}$ & 0.057 & 0.02 \\
\hline West wall & 0.038 & $0.025^{\mathrm{c}}$ & 0.039 & 0.038 & 0.010 & $0.0065^{e}$ & 0.057 & 0.02 \\
\hline North wall & 0.053 & 0.053 & 0.054 & 0.052 & 0.014 & 0.014 & 0.077 & 0.2 \\
\hline South wall & 0.027 & 0.053 & 0.026 & 0.025 & 0.007 & 0.014 & 0.063 & 0.03 \\
\hline $\begin{array}{l}\text { Solar lost through } \\
\text { windows }\end{array}$ & 0.035 & 0.035 & 0.027 & 0.040 & 0.006 & 0.006 & 0.312 & 0.08 \\
\hline
\end{tabular}

a. Interior solar absorptance indicated as $\alpha$.

b. Changes to Standard 140-2017 are highlighted with bold font.

c. Value rounded down (by $\mathbf{0 . 0 0 0 2}$ ) so that sum of all indicated values is $\mathbf{1 . 0 0 0}$.

d. Value rounded up (by 0.0004 ) so that sum of all indicated values is $\mathbf{1 . 0 0 0 .}$

e. Value rounded up (by $\mathbf{0 . 0 0 0 1}$ ) so that sum of all indicated values is $\mathbf{1 . 0 0 0}$.

f. The Low-E south window and the Single (1)-Pane south window columns are new. 
[Note to Users: Section B7.2 is not referenced by the Section 5.2 cases; including it here documents revisions to Standard 140 needed for consistency with other proposed revisions to Annex B7.]

B7.2 Solar Fraction Approximation Algorithm for Section 7.2 Test Cases. The method used to determine solar lost for the Section 7.2 tests is described in the introductory text of this Annex. The assumptions there are useful for the calculation of solar lost, but would result in different inside solar fractions for various opaque surfaces compared to the area weighting shown in Section 7.2 tables that contain solar fractions (e.g., Table 7-3). A spreadsheet tabulation of the calculation process for the Section 7.2 tests is provided in Table B7-2. Interior walls have been excluded to simplify the calculation of solar lost. Also, as shown in Table B7-2, solar radiative exchange between opaque surfaces for the third bounce and the remaining bounces (B3 and BR, respectively) can be aggregated.

[Note to Users: Table B7-2 not included; it is for the Section 7.2 tests and only has changes to Table number.]

Table B7-2 Calculations of Solar Lost (Cavity Albedo) for Section 7.2 Tests 
INFORMATIVE ANNEX B11: PRODUCTION OF EXAMPLE RESULTS FOR BUILDING THERMAL ENVELOPE AND FABRIC LOAD AND GROUND-COUPLED SLAB-ON-GRADE TESTS OF SECTION

\section{2}

[Note to Users: Standard 140, Annex B11 will be updated to include the following.]

B11.1.n Non-Application of Interior Surface Texture. For the example results of Informative Annex B8, Section B8.1, none of the models apply interior surface texture to evaluate interior surface heat transfer, so that inputs from Table 5-8 (see Section 5.2.1.10.2) do not affect results for any of the programs that provided example results for Informative Annex B8, Section B8.1. However, many of these models apply direct input of exterior surface texture (see Table 5-6 of Section 5.2.1.9.2) to evaluate exterior surface heat transfer and are sensitive to that input. 


\section{INFORMATIVE ANNEX B24: INFORMATIVE REFERENCES}

[Note to Users: References new to Standard 140 begin with " $A$-” and are listed below sequentially in the order in which they are first referenced in the preceding text. References beginning with " $B$-" are already cited elsewhere in Standard 140-2017; where those references apply in the preceding text, they are cited as listed further below using the reference numbering of Standard 140-2017.]

${ }^{\mathrm{A}-1}$ McQuiston, F., and J. Parker (1994). HVAC Analysis and Design, Fourth Edition, pp. 66, 707, 709. New York: John Wiley \& Sons.

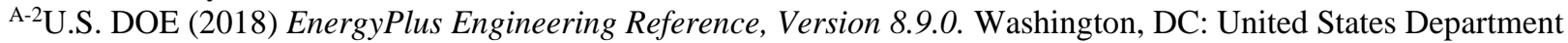
of Energy; Urbana, IL: University of Illinois; Berkeley, CA: University of California and Lawrence Berkeley National Laboratory. March 2018. https://energyplus.net/sites/all/modules/custom/nrel_custom/pdfs/pdfs_v8.9.0/EngineeringReference.pdf. Last accessed Feb 27, 2019.

${ }^{\mathrm{A}-3}$ WINDOW 7 (2016). Berkeley Lab WINDOW 7.4. Berkeley, CA: Lawrence Berkeley National Laboratory. https://windows.lbl.gov/software/window/. Last accessed October 25, 2016. Note: WINDOW 6 is the relevant user's manual $^{\mathrm{A}-9}$.

${ }^{\mathrm{A}-4}$ WINDOW 7 (2017). Berkeley Lab WINDOW 7.6. Berkeley, CA: Lawrence Berkeley National Laboratory. https://windows.lbl.gov/tools/window/software-download. Last accessed Mar 23, 2018. Note: WINDOW 6 is the relevant user's manual ${ }^{\mathrm{A}-9}$.

${ }^{A-5}$ Wilcox, S., W. Marion (2008). Users Manual for TMY3 Data Sets. NREL/TP-581-43156. Golden, Colorado, U.S.A.: National Renewable Energy Laboratory. http://www.nrel.gov/docs/fy08osti/43156.pdf

${ }^{A-6}$ Wilcox, S. (2007). National Solar Radiation Database 1991-2005 Update: User's Manual. 472 pp.; NREL/TP581-41364. Golden, Colorado, U.S.A.: National Renewable Energy Laboratory. http://www.nrel.gov/docs/fy07osti/41364.pdf

${ }^{A-7}$ ASHRAE (2012). Psychrometric Analysis, Version 7. Atlanta: ASHRAE.

${ }^{A-8}$ Neymark, J., Kummert, M., and Judkoff, R. (2019). "Developing Equivalent Surface Heat Transfer Input Parameters for Updated Standard 140/BESTEST Thermal Fabric Test Cases.” Proceedings of Building Simulation 2019. Rome, Italy. Sep 2-4, 2019. International Building Performance Simulation Association. http://www.ibpsa.org/proceedings/BS2019/BS2019 210588.pdf

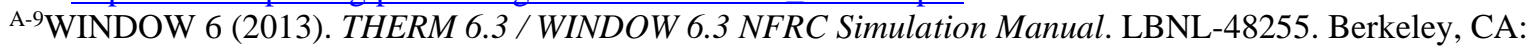
Lawrence Berkeley National Laboratory.

${ }^{\text {A-10} I S O} 15099$ (2003). Thermal Performance of Windows, Doors, and Shading Devices - Detailed Calculations. Geneva, Switzerland: International Organization for Standardization.

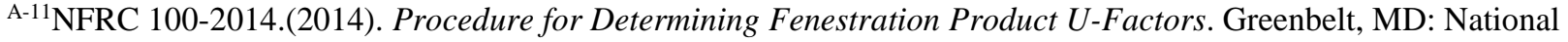
Fenestration Rating Council.

${ }^{\text {A-12} I G D B ~(2016) ~ I n t e r n a t i o n a l ~ G l a z i n g ~ D a t a b a s e . ~ B e r k e l e y, ~ C A: ~ L a w r e n c e ~ B e r k e l e y ~ N a t i o n a l ~ L a b o r a t o r y . ~}$ http://windowoptics.lbl.gov/data/igdb. Last accessed Oct. 21, 2016.

A-13Judkoff, R., Polly, B., Bianchi, M., and J. Neymark (2010). Building Energy Simulation Test for Existing Homes (BESTEST-EX) Phase 1 Test Procedure: Building Thermal Fabric Cases. NREL/TP-550-47427. Golden, Colorado, U.S.A.: National Renewable Energy Laboratory. http://www.nrel.gov/docs/fy10osti/47427.pdf.

${ }^{\text {A-14} F i n l a y s o n, ~ E . ; ~ A r a s t e h, ~ D . ; ~ H u i z e n g a, ~ C . ; ~ R u b i n, ~ M . ; ~ R e i l l y, ~ M . ~(1993) . ~ W I N D O W ~ 4.0: ~ D o c u m e n t a t i o n ~ o f ~}$ Calculation Procedures. LBL-33943. Berkeley, CA: Lawrence Berkeley National Laboratory.

B-10ASHRAE (2009). ASHRAE Handbook-2009 Fundamentals. Atlanta, GA: ASHRAE.

${ }^{\text {B-20} W a l t o n, ~ G . ~(1983) . ~ T h e r m a l ~ A n a l y s i s ~ R e s e a r c h ~ P r o g r a m ~ R e f e r e n c e ~ M a n u a l ~(T A R P) . ~ N B S I R ~ 83-2655 . ~}$ Washington, D.C.: National Bureau of Standards (now called National Institute of Standards and Technology).

${ }^{\mathrm{B}-25}$ WINDOW 4.1 (1994). LBL-35298. Berkeley, CA: Lawrence Berkeley Laboratory

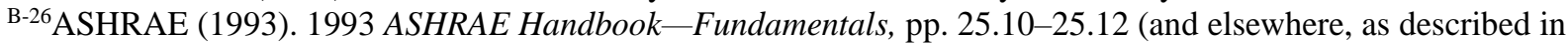
the text). Atlanta, GA: ASHRAE.

B-29Judkoff, R., and J. Neymark (1995). International Energy Agency Building Energy Simulation Test (BESTEST) and Diagnostic Method. NREL/TP-472-6231. Golden, Colorado, U.S.A.: National Renewable Energy Laboratory. www.nrel.gov/docs/legosti/old/6231.pdf.

${ }^{\mathrm{B}-30}$ ASHRAE (2001). 2001 ASHRAE Handbook-Fundamentals. Atlanta, GA: ASHRAE.

B-32 ASHRAE (2005). 2005 ASHRAE Handbook-Fundamentals. Atlanta, GA: ASHRAE. 
B-38Judkoff, R., and J. Neymark (1995). Home Energy Rating System Building Energy Simulation Test (HERS BESTEST), Volume 1: Tier 1 and Tier 2 Tests User's Manual. NREL/TP-472-7332a. Golden, Colorado, U.S.A.: National Renewable Energy Laboratory. www.nrel.gov/docs/legosti/fy96/7332a.pdf

B-39Judkoff, R., and J. Neymark (1995). Home Energy Rating System Building Energy Simulation Test (HERS BESTEST), Volume 2: Tier 1 and Tier 2 Tests Reference Results. NREL/TP-472-7332b. Golden, Colorado, U.S.A.: National Renewable Energy Laboratory. www.nrel.gov/docs/legosti/fy96/7332b.pdf.

B-40 York, D., and C. Cappiello, eds. DOE-2 Reference Manual (Version 2.1A) Part 1. (May 1981). Los Alamos, NM: Los Alamos Scientific Laboratory; Berkeley, CA: Lawrence Berkeley Laboratory.

B-97Duffie, J.A., and W.A. Beckman (1974). Solar Energy Thermal Processes. New York: John Wiley \& Sons. B-101 ASHRAE (2017). 2017 ASHRAE Handbook-Fundamentals. Atlanta, GA: ASHRAE. 


\subsection{Part II: Simulation Field Trial Results}

\subsection{Introduction}

Material from Part II is intended to update Standard 140-2017, Informative Annexes B8, B10, and B11. These annexes include, respectively, the Standard 140 example results, instructions for using the workbook that contains the results, and discussion of how the results were produced.

An electronic version of the simulation field trial results tables and charts is included with accompanying files Results5-2A-Update.xlsx and Results5-2A-Update.pdf (see subfolder Sec5-2AFiles\nformative Materials), with navigation instructions included in the "Read Me" tab of the workbook file. See Section 2.4 for further description. Definitions of the abbreviations and acronyms used in these charts and tables are provided in Section 2.3. Case descriptions are summarized in Part I, Annex B1, Tables B1-2 and B13.

These are results after numerous iterations to incorporate clarifications to the test specification, simulation input corrections, and simulation software improvements as described in Part III. Where improvements to simulation programs or simulation inputs were made as a result of running the tests, such improvements must have had mathematical and physical bases and must have been applied consistently across tests. Also, all improvements were required to be documented in modeler reports (Part III, Section 3.9). Arbitrary modification of a simulation program's input or internal code just for the purpose of more closely matching a given set of results was not allowed. Known sources of observable differences among the simulation-trial results are described in the following Section 2.2.

Table 2-1 summarizes the following information for the seven models, which were implemented by the eight organizations that participated in this project: model authoring organization, model testing organization ("Implemented by"), and abbreviation labels used in the results graphs and tables. 
Table 2-1 Building Thermal Fabric Test Cases Update, Participating Organizations and Models

\begin{tabular}{|c|c|c|c|}
\hline Simulation Program & Authoring Organization(s) & Implemented by & Abbreviation \\
\hline $\begin{array}{l}\text { BSIMAC, Version } \\
\text { 9.0.74 }\end{array}$ & $\begin{array}{l}\text { Alec Johannsen Consulting } \\
\text { Engineers, South Africa }\end{array}$ & $\begin{array}{l}\text { Alec Johannsen Consulting } \\
\text { Engineers, South Africa }\end{array}$ & BSIMAC \\
\hline $\begin{array}{l}\text { California Simulation } \\
\text { Engine, Version } \\
0.861 .1 \\
\end{array}$ & $\begin{array}{l}\text { J.R. Barnaby/C.S. Barnaby/Big } \\
\text { Ladder Software LLC/Wrightsoft } \\
\text { Corp., United States }\end{array}$ & $\begin{array}{l}\text { Big Ladder Software LLC, } \\
\text { United States }\end{array}$ & CSE \\
\hline $\begin{array}{l}\text { DeST 2.0, Version } \\
20190401\end{array}$ & Tsinghua University, China & $\begin{array}{l}\text { Southeast University, China } \\
\text { Tsinghua University, China }\end{array}$ & DeST \\
\hline $\begin{array}{l}\text { EnergyPlus, Version } \\
9.0 .1\end{array}$ & $\begin{array}{l}\text { U.S. Department of Energy, } \\
\text { Building Technologies Office, } \\
\text { United States }\end{array}$ & $\begin{array}{l}\text { GARD Analytics, Inc., } \\
\text { United States }^{\mathrm{d}}\end{array}$ & EnergyPlus \\
\hline ESP-r, Version 13.3 & $\begin{array}{l}\text { University of Strathclyde, United } \\
\text { Kingdom }\end{array}$ & $\begin{array}{l}\text { University of Strathclyde, } \\
\text { United Kingdom }\end{array}$ & ESP-r \\
\hline $\begin{array}{l}\text { NewHASP/ ACLD, } \\
\text { Version } 201213\end{array}$ & $\begin{array}{l}\text { Japan Building Mechanical and } \\
\text { Electrical Engineers Association, } \\
\text { Japan }\end{array}$ & $\begin{array}{l}\text { Kajima Technical Research } \\
\text { Institute, Japan }\end{array}$ & NewHASP \\
\hline $\begin{array}{l}\text { TRNSYS, Version } \\
18.01 .0001\end{array}$ & $\begin{array}{l}\text { Transsolar Energietechnik GmbH, } \\
\text { Germany; Thermal Energy System } \\
\text { Specialists, United States }\end{array}$ & $\begin{array}{l}\text { Transsolar Energietechnik } \\
\text { GmbH, Germany }\end{array}$ & TRNSYS \\
\hline $\begin{array}{l}\text { TRNSYS, Versions } \\
17.02 .0005 \text { and } \\
18.00 .0017\end{array}$ & $\begin{array}{l}\text { Transsolar Energietechnik GmbH, } \\
\text { Germany; Thermal Energy System } \\
\text { Specialists, United States }\end{array}$ & $\begin{array}{l}\text { Ecole Polytechnique } \\
\text { Montréal, Canada }{ }^{\mathrm{a}, \mathrm{b}}\end{array}$ & {$[\mathrm{n} / \mathrm{a}]$} \\
\hline
\end{tabular}

${ }^{\text {a }}$ Ecole Polytechnique and GARD also worked on simulations for developing alternative constant interior and exterior surface coefficients; these organizations applied TRNSYS and EnergyPlus, respectively.

${ }^{b}$ Also checking input files versus the Transsolar participant's files and vice versa.

Note: Results for "TestSpec-Alt" are shown in Tables B8-16 and B8-hc1 through B8-hc6 and in Figures B8-6, B8-H10, B8-H11, and B8-hc1through B8-hc6; contents of tables and figures are further described in Tables 2.4-2 and 2.4-3 below. "TestSpec-Alt" results are alternative values resulting from optional alternative inputs for sky temperature and surface convective heat transfer coefficients provided in the test specification (see Part I). 


\subsection{Known Sources of Observable Differences}

Modeling methods are summarized in the modeler reports of Part III, Section 3.9, especially in each participant's pro-forma modeler report included there. Program results based on inputs that clearly deviate from the test specification are discussed in Section 2.2.1. The remaining range of disagreement represents legitimate modeling differences further described in Section 2.2.2.

\subsubsection{Model Deviations from Test Specification}

The following results were identified, per the participants' modeler reports, as having inputs that deviate from the test specification:

- NewHASP/ACLD: This program does not allow variation of constant convective coefficients for opaque surfaces; this aspect of the model is fixed within the NewHASP code. Furthermore, since the program is no longer maintained, the fixed portion of their code could not be adjusted to match the test specification for the purpose of running the tests. This input disagreement affects all of their case results. NewHASP also has the greatest occurrence and magnitude of outlying results, which may be attributed to this issue, though that can only be shown by revising the fixed surface coefficients within the program.

- $\quad$ BSIMAC: This program does not allow variation of interior solar absorptance $(\alpha$,int), because it applies the Radiant Time Series method as described in the modeler report. The code author/modeler excluded results for cases with $\alpha$,int $=0.1$ that specifically test cavity albedo. However, the code author included results for cases with $\alpha$,int $=0.9$ (Cases 270, 290, 300, 310, 320) because those cases include in-depth thermostat, orientation, and shading sensitivity diagnostics where the 20/20 thermostat, 0 internal gains, and $0 \mathrm{ACH}$ infiltration are applied throughout; these cases were of value to the code author.

Because of these known input deviations, all results for HASP and the BSIMAC results for cases 270, 290, 300, 310, and 320 are planned to be excluded from the Standard 140 example results set. These results are included with this report. The value of including these results within this report, especially where they have outlying results, is to show there is better agreement among programs that abide by the test specification. That reasons for disagreement can be discerned also underscores the diagnostic value of the test suite.

\subsubsection{Legitimate Modeling Differences}

We define legitimate modeling differences or disagreement by the following criteria:

1. The program's test case inputs conform to the test specification.

2. Reviewers have not identified a disqualifying algorithmic deficiency as the cause of disagreement.

Criterion 1 is directly determinable from the simulation-trial participant modeler reports (see Part III, Section 3.9). Regarding criterion 2, the determination of "legitimate" or "disqualifying" is a judgment decision on the part of the simulation-trial modeler-report author, the Standard 140 Committee, and/or other reviewer(s).

Two points relevant to the second criterion were initially articulated at the January 2019 Building Thermal Fabric Working Group meeting (ASHRAE SSPC 140, 2019) and are further developed here: 
- Some algorithms are difficult to measure empirically (e.g., sky temperature, surface heat transfer) and some may depend on correlations for which there is no overall agreement on which correlation is best. Differences among such algorithms are generally legitimate modeling differences.

- A program is a set of many algorithms, where some individual aspects of a given model may be stronger than those of other models. For example, varying surface coefficients are clearly better than annual-constant coefficients. However, when a program may have some better or weaker individual aspects, but is not obviously better or weaker overall, then use of simplifications in that program can be legitimate.

Based on these two points, and where Criterion 1 is satisfied, we should conclude that characterization of a difference would default to "legitimate" when 1) there is not a clear set of measurements to show which individual algorithm (as applied in a program with many algorithms) is better OR 2) when it is not clear that a more detailed composite model is obviously better.

For the current results set, six of the programs have good agreement for most outputs, with legitimate modeling differences noted in their modeler reports (see Part III, Section 3.9), where previous disagreements were corrected with logical justifications (also discussed in the modeler reports). The remaining disagreements, especially for annual and monthly peaks and hourly results, are attributed to legitimate modeling differences. These differences were identified for each program in the modeler reports as follows:

- BSIMAC: The main areas of disagreement are mass sensitivity effects in hourly zone temperatures and loads, and resulting floor convective surface coefficients.

○ The program author attributes differences to use of the ASHRAE RTS (Radiant Time Series) method for "spreading" the instantaneous heat gains over time using factors dependent on thermal capacity category, \% glass, etc.: "BSIMAC does not consider solar distribution between the different surfaces within the zone, so it cannot quantify the specific effects of each surface, such as the heavily insulated floor. The other programs may be capable of determining these effects for each surface and this is likely to affect the mass sensitivity and the hourly profiles of zone temperatures and loads."

- The reasons for the disagreeing calculated interior convective surface coefficients for the floor are likely to be the same as those discussed just above.

- CSE: Legitimate differences may be attributable to the program's adjustment of convective surface coefficients (for each time step) as a function of air density at local elevation; the Denver weather data for these test cases is for $1650 \mathrm{~m}$ elevation.

- DeST:

- Inputs for interior and exterior surface coefficients are constant values, per the test specification. The DeST participants further state in their modeler report, “... it seems that it leads to the thermal inertia of the envelope a little different to other participants' results, which leads to a lower peaking load in many results, and also some disagreeing hours in hourly load plot[s]."

- For Case 660, the low-e window model is a simplified model, which could be improved in the future.

- EnergyPlus:

○ Sky infrared radiation exchange is modeled with the method of Clark and Allen (1978), while many of the other programs are based on the method of Martin and Berdahl (1984). A recent paper on sky temperature estimation (Zhang et al. 2017) indicates, "Further work should aim at developing more accurate regressions and implement them in BPS [building performance simulation] tools.” 
- Revise the definition of leeward wind incidence for the MoWitt algorithm (U.S. DOE 2019) to $>90^{\circ}$ (from $\leq 100^{\circ}$ ), though this change seems minor.

- ESP-r

○ The method of Alamdari and Hammond (1983) is applied for interior surface convection.

- The method of Clarke (2001) is applied for exterior surface convection.

$\circ$ Combined overhang and fin shading factors are under review by the developer.

- TRNSYS: None specifically noted.

From the pro forma modeler reports provided in Part III, Section 3.9, we also observe common variations among models such as the modeling of thermal diffusion, transmitted solar radiation, and internal radiation exchange. See the pro forma modeler reports for more details.

\subsubsection{Possible Program Improvements Identified by Modelers}

All programs except EnergyPlus and NewHASP implemented improvements to their programs that were directly related to the simulation trials; see Part III, Section 3.4, and the modeler reports of Section 3.9. Remaining possible improvements, as indicated by the program authors, are summarized by program as follows:

- BSIMAC: None reported

- CSE:

- Allow reporting of per-window solar gains.

- Apply more flexible aggregation of sub-hourly outputs into longer-period outputs, to reduce large output file length.

- DeST: Update existing low-e window model.

- EnergyPlus:

o Sky IR exchange: switch to the Martin-Berdahl (1984) method from the Clark-Allen (1978) method.

- Revise definition of leeward for MoWiTT algorithm to $>90^{\circ}$ (from $\left.\leq 100^{\circ}\right)$ [probably a minor improvement].

- ESP-r: May further check shading calculations.

- NewHASP: Would revise constant surface coefficients for opaque surfaces, but the program is no longer being maintained.

- TRNSYS: None reported.

\subsection{Abbreviations and Acronyms Used in Results Charts and Tables}

Abbreviations for example results identifiers used in the chart legends and tables are in listed in Table 2-1; additional abbreviations used in the charts and tables are listed below. Also see Part I, Section 3.2.

$\begin{array}{ll}\text { Abs.: } & \text { absorptance } \\ \text { Apr: } & \text { April } \\ \text { Ann.: } & \text { annual } \\ \text { Aug: } & \text { August } \\ \text { BESTEST: } & \text { Building Energy Simulation Test and Diagnostic Method } \\ \text { Coefs: } & \text { coefficients } \\ \text { Cond. } & \text { conductance } \\ \text { Const } & \text { constant } \\ \text { Conv.: } & \text { convection } \\ \text { Dec: } & \text { December }\end{array}$




$\begin{array}{ll}\text { E.: } & \text { East } \\ \text { El.: } & \text { element } \\ \text { Ext: } & \text { exterior } \\ \text { E\&W: } & \text { East and West } \\ \text { Feb: } & \text { February } \\ \text { HC Wall: } & \text { high-conductance wall element } \\ \text { Himass: } & \text { high mass } \\ \text { Hr: } & \text { hour } \\ \text { Htg } & \text { heating } \\ \text { Int: } & \text { interior } \\ \text { IR: } & \text { infrared (radiation exchange) } \\ \text { Jan: } & \text { January } \\ \text { Jul: } & \text { July } \\ \text { Jun: } & \text { June } \\ \text { Low E: } & \text { low emissivity }(\text { window) } \\ \text { Mar: } & \text { March } \\ \text { Max: } & \text { maximum } \\ \text { May: } & \text { May } \\ \text { Min: } & \text { minimum } \\ \text { Mo.: } & \text { month } \\ \text { N.: } & \text { North } \\ \text { Nov: } & \text { November } \\ \text { Oct: } & \text { October } \\ \text { Or.: } & \text { orientation } \\ \text { Orient. } & \text { orientation } \\ \text { Prg: } & \text { program } \\ \text { S.: } & \text { South } \\ \text { Sep: } & \text { September } \\ \text { Shd.: } & \text { Shading } \\ \text { Sol.: } & \text { solar } \\ \text { Surf. } & \text { surface } \\ \text { T: } & \text { temperature } \\ \text { Temp.: } & \text { temperature } \\ \text { Transf: } & \text { transfer } \\ \text { Tstat: } & \text { thermostat } \\ \text { Vent: } & \text { ventilation } \\ \text { W.: } & \text { West } \\ \text { Win.: } & \text { window } \\ \text { w/ } & \text { with } \\ \text { 20/20: } & \text { thermostat setpoint } 20^{\circ} \mathrm{C} \text { heating } / 20^{\circ} \mathrm{C} \text { cooling } \\ \text { 20/27: } & \text { thermostat setpoint } 20^{\circ} \mathrm{C} \text { heating } / 27^{\circ} \mathrm{C} \text { cooling } \\ \text { > Ins.: } & \text { greater insulation } \\ & \end{array}$

\subsection{Results Graphs and Tables}

[Note: Tables in this section and accompanying file Results5-2A-Update.XLSX include new content applying some of the format from Results5-2A.XLSX of ANSI/ASHRAE Standard 140-2017. Where existing Standard-140 material is used, it is $\bigcirc A S H R A E$, www.ashrae.org. and is used in this report with permission from Standard 140-2017Standard Method of Test for the Evaluation of Building Energy Analysis Computer Programs.]

Example results are included in the file RESULTS5-2A-Update.PDF in the accompanying electronic media. The accompanying file RESULTS5-2A-Update.XLSX is included for convenience of users who 
wish to plot or tabulate their results along with the example results. A sheet tab guide for RESULTS5-2AUpdate.XLSX is included with the file (see its "Read Me" tab) and is printed in Table 2.4-1. Listings of the contents of the example-results tables and figures are provided in the sheets labeled "Table List" and "Figure List," respectively, and are printed here as Tables 2.4-2 and 2.4-3. In Tables 2.4-2 and 2.4-3, the "Sheet Tab" and "Cell Range" columns are only applicable to the RESULTS5-2A-Update.XLSX file. The RESULTS5-2A-Update.PDF file presents the tables and figures sequentially.

New results can be imported to the "YourData" sheet of RESULTS5-2A-Update.XLSX and will automatically appear in all tables and in the graphic figures. The "YourData" sheet has been designed with the same data structure (data units, format, and position) as the Standard Output Report spreadsheet Sec5-2Aout.XLS file so that new results can be copied directly. Import data so that Cell B66 of Sec52Aout.XLS is in B66 of the "YourData" sheet. Check that the first value (Annual Heating Load for Case 600 ) is in YourData!C70. The "Adding Results" sheet has instructions for accomplishing this. New results data will appear in the rightmost column of each table and in all figures. To print example results, or example results with new user-generated results, go to the "Title Page" sheet and follow the instructions starting in Cell B5.

Within the tables and figures, results are grouped by case numbers; e.g., "395" is Case 395 (Section 5.2.3.16). Sensitivity results are listed using two case numbers separated by a minus sign; e.g., " 610 600 " is the difference between Case 610 (Section 5.2.2.1.1) and Case 600 (Section 5.2.1). For this project report, tables and figures are numbered consistently with the numbering in Standard 140, informative Annex B8, i.e., the "B8-" prefix is applied to each table and figure number. Nomenclature used in the tables and figures is defined in Section 2.3 above. 
Table 2.4-1 Index of Sheets in RESULTS5-2A-Update.XLSX

\begin{tabular}{|c|c|}
\hline Sheet & Description \\
\hline "Read Me" & General directions for using this workbook. \\
\hline "Adding Results" & Instructions for adding new results. \\
\hline "YourData" & $\begin{array}{l}\text { For inputting new simulation test results; see sheet "Adding Results" for } \\
\text { instructions. Data input to this sheet will pass through into all tables and charts. }\end{array}$ \\
\hline "Title Page" & $\begin{array}{l}\text { Title Page for printed informative example or new comparison results. Sets } \\
\text { headers for tables and charts. See instructions on page. }\end{array}$ \\
\hline "Program List" & List of simulation programs and organizations producing example results. \\
\hline "Table List" & Listing of Part II tables with sheet tab locations. \\
\hline "Figure List" & Listing of Part II figures with sheet tab labels. \\
\hline $\begin{array}{l}\text { "Tables 1" to "Tables 7", } \\
\text { "Tables M1" to "Tables M3", } \\
\text { "Tables hconv1", "Tables } \\
\text { hconv2" (12 sheets) }\end{array}$ & $\begin{array}{l}\text { Formatted summary results tables including example simulation results and } \\
\text { statistics. See Table 2.4-2 below or the "Table List" sheet in RESULTS5-2A- } \\
\text { Update.XLSX for a list of all tables with sheet tab and cell range location. New } \\
\text { results (entered in sheet "YourData") automatically appear on the right side of } \\
\text { each table. }\end{array}$ \\
\hline $\begin{array}{l}\text { "Fig B8-1" to "Fig B8-59", } \\
\text { "Fig B8-M1" to "Fig B8- } \\
\text { M12", "Fig B8-H1" to "Fig } \\
\text { B8-H38", "Fig B8-hc1" to } \\
\text { "B8-hc6" (115 sheets) }\end{array}$ & $\begin{array}{l}115 \text { summary charts (one per sheet). See Table } 2.4-3 \text { below or the "Figure List" } \\
\text { sheet in RESULTS5-2A-Update.XLSX for a list of all figures with sheet tab } \\
\text { location. }\end{array}$ \\
\hline "DATA for charts" & $\begin{array}{l}\text { Unformatted data for use by the } 115 \text { charts. New results (entered in sheet } \\
\text { "YourData") automatically appear on the right side of each data table. }\end{array}$ \\
\hline $\begin{array}{l}\text { "BSIMAC" to "TRNSYS" } \\
\text { (7 sheets) }\end{array}$ & Results sheets from each simulation program used to produce example results. \\
\hline "TestSpecAlt" & $\begin{array}{l}\text { Tsky and h,conv alternative values from the test specification (Part I). Data from } \\
\text { this sheet only apply to: } \\
\text { - For Tsky: Table B8-16 and Figures B8-6, B8-H10, B8-H11. } \\
\text { - For h,conv: Tables B8-hc1 to B8-hc6 and Figures B8-hc1 to B8-hc6. }\end{array}$ \\
\hline K & Spare data entry sheet. \\
\hline
\end{tabular}


Table 2.4-2 RESULTS5-2A-Update.XLSX Tables

\begin{tabular}{|c|c|c|c|}
\hline Table & Description & Sheet Tab & Cell Range \\
\hline B8-1 & Annual Heating Loads & \multirow[t]{2}{*}{ Tables 1} & B7-O57 \\
\hline B8-2 & Annual Sensible Cooling Loads & & B59-0109 \\
\hline B8-3 & Annual Hourly Integrated Peak Heating Loads & \multirow[t]{3}{*}{ Tables 2} & B7-AM57 \\
\hline B8-4 & Annual Hourly Integrated Peak Sensible Cooling Loads & & B59-AM109 \\
\hline B8-5 & Free-Float Temperature Output & & B111-AM145 \\
\hline B8-6 & Low Mass Basic Sensitivity Tests & \multirow{2}{*}{ Tables 3} & B7-076 \\
\hline B8-7 & High Mass Basic Sensitivity Tests & & B61-0112 \\
\hline B8-8 & Low Mass In-Depth (Cases 195 thru 320) Sensitivity Tests & Tables 4 & $\mathrm{~B} 7-\mathrm{O} 76$ \\
\hline B8-9 & Low Mass In-Depth (Cases 395 thru 470) Sensitivity Tests & \multirow{2}{*}{ Tables 5} & B7-064 \\
\hline B8-10 & High Mass Basic and In-Depth Sensitivity Tests & & B67-O122 \\
\hline B8-11 & Annual Transmissivity Coefficient of Windows & \multirow[t]{5}{*}{ Tables 6} & $\mathrm{~B} 7-\mathrm{O} 16$ \\
\hline B8-12 & $\begin{array}{l}\text { Annual Shading Coefficient of Window Shading Devices: Overhangs } \\
\text { \& Fins }\end{array}$ & & $\mathrm{B} 18-\mathrm{O} 25$ \\
\hline B8-13 & Case 600 Annual Incident Solar Radiation $\left(\mathrm{kWh} / \mathrm{m}^{2}\right)$ & & $\mathrm{B} 27-\mathrm{O} 36$ \\
\hline B8-14 & Case 600 Annual Transmitted Solar Radiation - Unshaded $\left(\mathrm{kWh} / \mathrm{m}^{2}\right)$ & & $\mathrm{B} 38-\mathrm{O} 46$ \\
\hline B8-15 & Case 600 Annual Transmitted Solar Radiation - Shaded $\left(\mathrm{kWh} / \mathrm{m}^{2}\right)$ & & B48-O54 \\
\hline $\mathrm{B} 8-16$ & Sky Temperature Output, Case 600 & Tables 7 & B7-AM15 \\
\hline B8-M1 & Monthly Heating Loads & \multirow[t]{2}{*}{ Tables M1 } & $\mathrm{B} 7-\mathrm{O} 36$ \\
\hline B8-M2 & Monthly Sensible Cooling Loads & & B38-067 \\
\hline B8-M3 & Monthly Hourly Integrated Peak Heating Loads & \multirow[t]{2}{*}{ Tables M2 } & B7-AE36 \\
\hline B8-M4 & Monthly Hourly Integrated Peak Sensible Cooling Loads & & B38-AE67 \\
\hline B8-M5 & Monthly Load 600-900 Sensitivity Tests & Tables M3 & B7-O68 \\
\hline B8-hc1 & Exterior Convective Surface Coefficient, Annual Average $\left(\mathrm{W} / \mathrm{m}^{2} \mathrm{~K}\right)$ & \multirow{2}{*}{$\begin{array}{l}\text { Tables } \\
\text { hconv1 }\end{array}$} & B7-O29 \\
\hline B8-hc2 & Interior Convective Surface Coefficient, Annual Average $\left(\mathrm{W} / \mathrm{m}^{2} \mathrm{~K}\right)$ & & $\mathrm{B} 31-\mathrm{O} 54$ \\
\hline B8-hc3 & $\begin{array}{l}\text { Exterior Convective Surface Coefficient, Annual Hourly Integrated } \\
\text { Maximum }\left(\mathrm{W} / \mathrm{m}^{2} \mathrm{~K}\right)\end{array}$ & \multirow[t]{4}{*}{$\begin{array}{l}\text { Tables } \\
\text { hconv2 }\end{array}$} & B7-AN19 \\
\hline B8-hc4 & $\begin{array}{l}\text { Exterior Convective Surface Coefficient, Annual Hourly Integrated } \\
\text { Minimum }\left(\mathrm{W} / \mathrm{m}^{2} \mathrm{~K}\right)\end{array}$ & & B21-AN33 \\
\hline B8-hc5 & $\begin{array}{l}\text { Interior Convective Surface Coefficient, Annual Hourly Integrated } \\
\text { Maximum }\left(\mathrm{W} / \mathrm{m}^{2} \mathrm{~K}\right)\end{array}$ & & B35-AN47 \\
\hline B8-hc6 & $\begin{array}{l}\text { Interior Convective Surface Coefficient, Annual Hourly Integrated } \\
\text { Minimum }\left(\mathrm{W} / \mathrm{m}^{2} \mathrm{~K}\right)\end{array}$ & & B49-AN61 \\
\hline
\end{tabular}

Table 2.4-3 RESULTS5-2A-Update.XLSX Figures

\begin{tabular}{|l|l|l|}
\hline Figure & Title & Sheet Tab \\
\hline B8-1 & Annual Incident Solar Radiation & Fig B8-1 Ann Incident Solar \\
\hline B8-2 & Annual Transmitted Solar Radiation Unshaded & Fig B8-2 Ann SolRad Unshaded \\
\hline B8-3 & Annual Transmitted Solar Radiation Shaded & Fig B8-3 Ann SolRad Shaded \\
\hline B8-4 & $\begin{array}{l}\text { Annual Transmissivity Coefficient of Windows } \\
\text { Unshaded Transmitted)/(Incident Solar Radiation) }\end{array}$ & Fig B8-4 Trans Coeff \\
\hline B8-5 & $\begin{array}{l}\text { Annual Overhang and Fin Shading Coefficients } \\
\text { (1-(Shaded)/(Unshaded)) Transmitted Solar Radiation }\end{array}$ & Fig B8-5 OH\&Fin Shade Coeff \\
\hline B8-6 & Average, Minimum and Maximum Sky Temperature, Case 600 & Fig B8-6 Sky Temp \\
\hline B8-7 & Basic: Low Mass Annual Heating & Fig B8-7 Lomass Ann Heat \\
\hline B8-8 & Basic: Low Mass Annual Sensible Cooling & Fig B8-8 Lomass Ann Cool \\
\hline B8-9 & Basic: Low Mass Peak Heating & Fig B8-9 Lomass Peak Heat \\
\hline B8-10 & Basic: Low Mass Peak Sensible Cooling & Fig B8-10 Lomass Peak Cool \\
\hline B8-11 & Basic: High Mass Annual Heating & Fig B8-11 Himass Ann Heat \\
\hline B8-12 & Basic: High Mass Annual Sensible Cooling & Fig B8-12 Himass Ann Cool \\
\hline B8-13 & Basic: High Mass Peak Heating & Fig B8-13 Himass Peak Heat \\
\hline B8-14 & Basic: High Mass Peak Sensible Cooling & Fig B8-14 Himass Peak Cool \\
\hline
\end{tabular}




\begin{tabular}{|c|c|c|}
\hline B8-15 & $\begin{array}{l}\text { Basic and In-Depth: South Window (Delta), } \\
\text { Annual Heating and Sensible Cooling }\end{array}$ & Fig B8-15 Delta-S Win-Ann \\
\hline B8-16 & $\begin{array}{l}\text { Basic and In-Depth: South Window (Delta), } \\
\text { Peak Heating and Sensible Cooling }\end{array}$ & Fig B8-16 Delta-S Win-Peak \\
\hline B8-17 & $\begin{array}{l}\text { Basic: Window Shading and Orientation (Delta), } \\
\text { Annual Heating and Sensible Cooling }\end{array}$ & Fig B8-17 Delta-ShadeOrient-Load \\
\hline B8-18 & $\begin{array}{l}\text { Basic: Window Shading and Orientation (Delta), } \\
\text { Peak Heating and Sensible Cooling }\end{array}$ & Fig B8-18 Delta-ShadeOrient-Peak \\
\hline B8-19 & $\begin{array}{l}\text { Basic: Thermostat Setback, Vent Cooling, and Sunspace } \\
\text { (Delta), Annual Heating and Sensible Cooling }\end{array}$ & Fig B8-19 Delta-640650960-Load \\
\hline B8-20 & $\begin{array}{l}\text { Basic: Thermostat Setback, Vent Cooling, and Sunspace } \\
\text { (Delta), Peak Heating and Sensible Cooling }\end{array}$ & Fig B8-20 Delta-640650960-Peak \\
\hline B8-21 & $\begin{array}{l}\text { Basic and In-Depth: Mass Effect (Delta), } \\
\text { Annual Heating and Sensible Cooling }\end{array}$ & Fig B8-21 Delta-Mass Effect-Ann \\
\hline B8-22 & $\begin{array}{l}\text { Basic and In-Depth: Mass Effect (Delta), } \\
\text { Peak Heating and Sensible Cooling }\end{array}$ & Fig B8-22 Delta-Mass Effect-Pk \\
\hline B8-23 & Basic: Cases 660 to 695 and 980 to 995 Annual Heating & Fig B8-23 660+ Ann Heat \\
\hline B8-24 & Basic: Cases 660 to 695 and 980 to 995 Annual Cooling & Fig B8-24 660+ Ann Cool \\
\hline B8-25 & Basic: Cases 660 to 695 and 980 to 995 Peak Heating & Fig B8-25 660+ Peak Heat \\
\hline B8-26 & Basic: Cases 660 to 695 and 980 to 995 Peak Cooling & Fig B8-26 660+ Peak Cool \\
\hline B8-27 & Basic: Window Types (Delta), Annual Heating and Sensible Cooling & Fig B8-27 Delta-Windows-Load \\
\hline B8-28 & Basic: Window Types (Delta), Peak Heating and Sensible Cooling & Fig B8-28 Delta-Windows-Peak \\
\hline B8-29 & Basic: Insulation (Delta), Annual Heating and Sensible Cooling & Fig B8-29 Delta-Insul-Load \\
\hline B8-30 & Basic: Insulation (Delta), Peak Heating and Sensible Cooling & Fig B8-30 Delta-Insul-Peak \\
\hline B8-31 & $\begin{array}{l}\text { Basic: Insulation, Mass Effect (Delta), } \\
\text { Annual Heating and Sensible Cooling }\end{array}$ & Fig B8-31 Del-Mass-Ins-Load \\
\hline B8-32 & $\begin{array}{l}\text { Basic: Insulation, Mass Effect (Delta), } \\
\text { Peak Heating and Sensible Cooling }\end{array}$ & Fig B8-32 Del-Mass-Ins-Peak \\
\hline B8-33 & Basic: Average Hourly Annual Temperature Free-Float Cases & Fig B8-33 FF Average Temp \\
\hline B8-34 & Basic: Maximum Hourly Annual Temperature Free-Float Cases & Fig B8-34 FF Maximum Temp \\
\hline B8-35 & Basic: Minimum Hourly Annual Temperature Free-Float Cases & Fig B8-35 FF Minimum Temp \\
\hline B8-36 & In-Depth: Low Mass Cases 195 to 250 Annual Heating & Fig B8-36 195to250 Ann Heat \\
\hline B8-37 & In-Depth: Low Mass Cases 195 to 250 Annual Sensible Cooling & Fig B8-37 195to250 Ann Cool \\
\hline B8-38 & In-Depth: Low Mass Cases 195 to 250 Peak Heating & Fig B8-38 195to250 Peak Heat \\
\hline B8-39 & In-Depth: Low Mass Cases 195 to 250 Peak Sensible Cooling & Fig B8-39 195to250 Peak Cool \\
\hline B8-40 & In-Depth: Low Mass Cases 270 to 320 Annual Heating & Fig B8-40 270to320 Ann Heat \\
\hline B8-41 & In-Depth: Low Mass Cases 270 to 320 Annual Sensible Cooling & Fig B8-41 270to320 Ann Cool \\
\hline B8-42 & In-Depth: Low Mass Cases 270 to 320 Peak Heating & Fig B8-42 270to320 Peak Heat \\
\hline B8-43 & In-Depth: Low Mass Cases 270 to 320 Peak Sensible Cooling & Fig B8-43 270to320 Peak Cool \\
\hline B8-44 & $\begin{array}{l}\text { In-Depth: Cases } 195 \text { to } 220 \text { (Delta), } \\
\text { Annual Heating and Sensible Cooling }\end{array}$ & Fig B8-44 Delta 195to220 Load \\
\hline B8-45 & $\begin{array}{l}\text { In-Depth: Cases } 195 \text { to } 220 \text { (Delta), } \\
\text { Peak Heating and Sensible Cooling }\end{array}$ & Fig B8-45 Delta 195to220 Peak \\
\hline B8-46 & $\begin{array}{l}\text { In-Depth: Cases } 220 \text { to } 270 \text { (Delta), } \\
\text { Annual Heating and Sensible Cooling }\end{array}$ & Fig B8-46 Delta 220to270 Load \\
\hline B8-47 & $\begin{array}{l}\text { In-Depth: Cases } 220 \text { to } 270 \text { (Delta), } \\
\text { Peak Heating and Sensible Cooling }\end{array}$ & Fig B8-47 Delta 220to270 Peak \\
\hline B8-48 & $\begin{array}{l}\text { In-Depth: Cases } 270 \text { to } 320 \text { (Delta), } \\
\text { Annual Heating and Sensible Cooling }\end{array}$ & Fig B8-48 Delta 270to320 Load \\
\hline B8-49 & $\begin{array}{l}\text { In-Depth: Cases } 270 \text { to } 320 \text { (Delta), } \\
\text { Peak Sensible Cooling }\end{array}$ & Fig B8-49 Delta 270to320 Peak \\
\hline B8-50 & In-Depth: Cases 395 to $440,800,810$ Annual Heating & Fig B8-50 395to440,8n0 Ann Heat \\
\hline B8-51 & In-Depth: Cases 395 to $440,800,810$ Annual Sensible Cooling & Fig B8-51 395to440,8n0 Ann Cool \\
\hline B8-52 & In-Depth: Cases 395 to $440,800,810$ Peak Heating & Fig B8-52 395to440,8n0 Pk Heat \\
\hline B8-53 & In-Depth: Cases 395 to 440, 800, 810 Peak Sensible Cooling & Fig B8-53 395to440,8n0 Pk Cool \\
\hline B8-54 & $\begin{array}{l}\text { In-Depth: Cases } 395 \text { to } 600,810 \text { to } 900 \text { (Delta), } \\
\text { Annual Heating and Sensible Cooling }\end{array}$ & Fig B8-54 Del 395-600,810,900 Ld \\
\hline B8-55 & $\begin{array}{l}\text { In-Depth: Cases } 395 \text { to } 600,810 \text { to } 900 \text { (Delta), } \\
\text { Peak Heating and Sensible Cooling }\end{array}$ & Fig B8-55 Del 395-600,810,900 Pk \\
\hline
\end{tabular}




\begin{tabular}{|c|c|c|}
\hline B8-56 & $\begin{array}{l}\text { In-Depth: Surface Heat Transfer Cases 600, 450, 460, 470, } \\
\text { Annual Heating and Sensible Cooling }\end{array}$ & Fig B8-56 SurfCoefs-Load \\
\hline B8-57 & $\begin{array}{l}\text { In-Depth: Surface Heat Transfer Cases 600, 450, 460, 470, } \\
\text { Peak Heating and Sensible Cooling }\end{array}$ & Fig B8-57 SurfCoefs-Peak \\
\hline B8-58 & $\begin{array}{l}\text { In-Depth: Surface Heat Transfer Cases } 450 \text { to } 600 \text { (Delta), } \\
\text { Annual Heating and Sensible Cooling }\end{array}$ & Fig B8-58 SurfHT Delta-Load \\
\hline B8-59 & $\begin{array}{l}\text { In-Depth: Surface Heat Transfer Cases } 450 \text { to } 600 \text { (Delta), } \\
\text { Peak Heating and Sensible Cooling }\end{array}$ & Fig B8-59 SurfHT Delta-Peak \\
\hline B8-M1 & Monthly Heating, Case 600 & Fig B8-M1 MthlyHtg-600 \\
\hline $\mathrm{B} 8-\mathrm{M} 2$ & Monthly Sensible Cooling, Case 600 & Fig B8-M2 MthlyClg-600 \\
\hline B8-M3 & Monthly Peak Heating, Case 600 & Fig B8-M3 MthlyPkHtg-600 \\
\hline B8-M4 & Monthly Peak Sensible Cooling, Case 600 & Fig B8-M4 MthlyPkClg-600 \\
\hline B8-M5 & Monthly Heating, Case 900 & Fig B8-M5 MthlyHtg-900 \\
\hline B8-M6 & Monthly Sensible Cooling, Case 900 & Fig B8-M6 MthlyClg-900 \\
\hline B8-M7 & Monthly Peak Heating, Case 900 & Fig B8-M7 MthlyPkHtg-900 \\
\hline B8-M8 & Monthly Peak Sensible Cooling, Case 900 & Fig B8-M8 MthlyPkClg-900 \\
\hline B8-M9 & Monthly Heating Sensitivity (Delta), Case 600-900 & Fig B8-M9 Del-MthlyHtg 600-900 \\
\hline B8-M10 & Monthly Cooling Sensitivity (Delta), Case 600-900 & $\begin{array}{l}\text { Fig B8-M10 Del-MthlyClg 600- } \\
900\end{array}$ \\
\hline B8-M11 & Monthly Peak Heating Sensitivity (Delta), Case 600-900 & $\begin{array}{l}\text { Fig B8-M11 Del-MthlyPkH 600- } \\
900\end{array}$ \\
\hline B8-M12 & Monthly Peak Cooling Sensitivity (Delta), Case 600-900 & $\begin{array}{l}\text { Fig B8-M12 Del-MthlyPkC 600- } \\
900\end{array}$ \\
\hline B8-H1 & Case 900FF Annual Hourly Temperature Frequency & Fig B8-H1 Hrly-Temp Freq \\
\hline B8-H2 & $\begin{array}{l}\text { Case } 600 \text { Cloudy \& Clear Day Hourly Incident Solar, } \\
\text { Horizontal (Upward) Facing Surface }\end{array}$ & Fig B8-H2 Hrly-IncSol-Horz \\
\hline B8-H3 & $\begin{array}{l}\text { Case } 600 \text { Cloudy \& Clear Day Hourly Incident Solar, } \\
\text { South Facing Surface }\end{array}$ & Fig B8-H3 Hrly-IncidentSol-S \\
\hline B8-H4 & $\begin{array}{l}\text { Case } 600 \text { Cloudy \& Clear Day Hourly Incident Solar, } \\
\text { West Facing Surface }\end{array}$ & Fig B8-H4 Hrly-IncidentSol-W \\
\hline B8-H5 & $\begin{array}{l}\text { Cases 600, 660, } 670 \text { Hourly Transmitted Solar, Clear/Cold Day } \\
\text { (Feb 1), Double-Pane, Low-E, Single-Pane Windows }\end{array}$ & Fig B8-H5 Hrly-TransSol-Feb1 \\
\hline B8-H6 & $\begin{array}{l}\text { Case } 600 \text { Hourly Transmitted Solar, Cloudy Day (May 4), } \\
\text { Double-Pane Windows }\end{array}$ & Fig B8-H6 Hrly-Trans-May4-600 \\
\hline B8-H7 & $\begin{array}{l}\text { Cases 660, } 670 \text { Hourly Transmitted Solar, Cloudy Day (May 4), } \\
\text { Low-E and Single-Pane Windows }\end{array}$ & Fig B8-H7 Hrly-Trans-May4-6670 \\
\hline B8-H8 & $\begin{array}{l}\text { Case } 600 \text { Hourly Transmitted Solar, Clear/Hot Day (Jul 14), } \\
\text { Double-Pane Windows }\end{array}$ & Fig B8-H8 Hrly-Trans-Jul14-600 \\
\hline B8-H9 & $\begin{array}{l}\text { Cases 660, } 670 \text { Hourly Transmitted Solar, Clear/Hot Day (Jul } \\
\text { 14), Low-E and Single-Pane Windows }\end{array}$ & Fig B8-H9 Hrl-Trans-Jul14-6670 \\
\hline B8-H10 & $\begin{array}{l}\text { Hourly Sky Temperatures, Case 600: } \\
\text { Clear/Cold, Cloudy Days }\end{array}$ & Fig B8-H10 Hrly-Tsky-ClearCloud \\
\hline B8-H11 & $\begin{array}{l}\text { Hourly Sky Temperatures, Case 600: } \\
\text { Clear/Cold, Clear/Hot Days }\end{array}$ & Fig B8-H11 Hrly-Tsky-ColdHot \\
\hline B8-H12 & $\begin{array}{l}\text { Hourly Free-Float Temperatures, } \\
\text { Clear Cold Day (Feb 1), Cases 600FF and 900FF }\end{array}$ & $\begin{array}{l}\text { Fig B8-H12 Hrly-FF Temp- } \\
\text { ColdDay }\end{array}$ \\
\hline B8-H13 & $\begin{array}{l}\text { Hourly Free-Float Temperatures, } \\
\text { Clear Hot Day (Jul 14), Cases 650FF and 950FF }\end{array}$ & $\begin{array}{l}\text { Fig B8-H13 Hrly-FF Temp- } \\
\text { HotDay }\end{array}$ \\
\hline B8-H14 & $\begin{array}{l}\text { Hourly Free-Float Temperatures, } \\
\text { Clear Cold Day (Feb 1), Cases 680FF and 980FF }\end{array}$ & $\begin{array}{l}\text { Fig B8-H14 Hr-6980FF T- } \\
\text { ColdDay }\end{array}$ \\
\hline B8-H15 & $\begin{array}{l}\text { Hourly Loads: Clear Cold Day, Case } 600 \\
\text { (Low Mass, Double-Clear Window) Heating (+), Sensible Cooling (-) }\end{array}$ & Fig B8-H15 Hrly-600Loads-Cold \\
\hline B8-H16 & $\begin{array}{l}\text { Hourly Loads: Clear Hot Day, Case } 600 \\
\text { (Low Mass, Double-Clear Window) Heating (+), Sensible Cooling (-) }\end{array}$ & Fig B8-H16 Hrly-600Loads-Hot \\
\hline B8-H17 & $\begin{array}{l}\text { Hourly Loads: Clear Cold Day, Case } 640 \text { (Low Mass, } \\
\text { Night Setback), Heating (+), Sensible Cooling (-) }\end{array}$ & Fig B8-H17 Hrly-640Loads-Cold \\
\hline B8-H18 & $\begin{array}{l}\text { Hourly Conditioned Zone Temperatures, Clear Cold Day, Case } \\
640 \text {, Heating }(+) \text {, Sensible Cooling }(-)\end{array}$ & Fig B8-H18 Hrly-640Tzone-Cold \\
\hline
\end{tabular}




\begin{tabular}{|c|c|c|}
\hline B8-H19 & $\begin{array}{l}\text { Hourly Loads: Clear Cold Day, Case } 940 \text { (High Mass, } \\
\text { Night Setback), Heating (+), Sensible Cooling (-) }\end{array}$ & Fig B8-H19 Hrly-940Loads-Cold \\
\hline B8-H20 & $\begin{array}{l}\text { Hourly Conditioned Zone Temperatures, Clear Cold Day, Case } \\
940, \text { Heating }(+) \text {, Sensible Cooling }(-)\end{array}$ & Fig B8-H20 Hrly-940Tzone-Cold \\
\hline $\mathrm{B} 8-\mathrm{H} 21$ & $\begin{array}{l}\text { Hourly Loads: Clear Cold Day, Case } 660 \text { (Low-E Window), } \\
\text { Heating (+), Sensible Cooling (-) }\end{array}$ & Fig B8-H21 Hrly-660Loads-Cold \\
\hline B8-H22 & $\begin{array}{l}\text { Hourly Loads: Clear Hot Day, Case } 660 \text { (Low-E Window), } \\
\text { Heating (+), Sensible Cooling (-) }\end{array}$ & Fig B8-H22 Hrly-660Loads-Hot \\
\hline B8-H23 & $\begin{array}{l}\text { Hourly Loads: Clear Cold Day, Case } 670 \text { (Single-Pane } \\
\text { Window), Heating (+), Sensible Cooling (-) }\end{array}$ & Fig B8-H23 Hrly-670Loads-Cold \\
\hline B8-H24 & $\begin{array}{l}\text { Hourly Loads: Clear Hot Day, Case } 670 \text { (Single-Pane } \\
\text { Window), Heating (+), Sensible Cooling (-) }\end{array}$ & Fig B8-H24 Hrly-670Loads-Hot \\
\hline B8-H25 & $\begin{array}{l}\text { Hourly Loads: Clear Cold Day, Case } 680 \text { (Insulation), } \\
\text { Heating (+), Sensible Cooling (-) }\end{array}$ & Fig B8-H25 Hrly-680Loads-Cold \\
\hline B8-H26 & $\begin{array}{l}\text { Hourly Loads: Clear Hot Day, Case } 680 \text { (Insulation), } \\
\text { Heating (+), Sensible Cooling (-) }\end{array}$ & Fig B8-H26 Hrly-680Loads-Hot \\
\hline B8-H27 & $\begin{array}{l}\text { Hourly Loads: Clear Cold Day, Case } 685 \text { (20/20 Tstat), } \\
\text { Heating (+), Sensible Cooling (-) }\end{array}$ & Fig B8-H27 Hrly-685Loads-Cold \\
\hline B8-H28 & $\begin{array}{l}\text { Hourly Loads: Clear Hot Day, Case } 685 \text { (20/20 Tstat), } \\
\text { Heating (+), Sensible Cooling (-) }\end{array}$ & Fig B8-H28 Hrly-685Loads-Hot \\
\hline B8-H29 & $\begin{array}{l}\text { Hourly Loads: Clear Cold Day, Case } 695 \text { (20/20, } \\
\text { Insulation), Heating (+), Sensible Cooling (-) }\end{array}$ & Fig B8-H29 Hrly-695Loads-Cold \\
\hline B8-H30 & $\begin{array}{l}\text { Hourly Loads: Clear Hot Day, Case } 695 \text { (20/20, Insulation), } \\
\text { Heating (+), Sensible Cooling (-) }\end{array}$ & Fig B8-H30 Hrly-695Loads-Hot \\
\hline B8-H31 & $\begin{array}{l}\text { Hourly Loads: Clear Cold Day, Case } 900 \text { (High Mass), } \\
\text { Heating (+), Sensible Cooling (-) }\end{array}$ & Fig B8-H31 Hrly-900Loads-Cold \\
\hline B8-H32 & $\begin{array}{l}\text { Hourly Loads: Clear Hot Day, Case } 900 \text { (High Mass), } \\
\text { Heating (+), Sensible Cooling (-) }\end{array}$ & Fig B8-H32 Hrly-900Loads-Hot \\
\hline B8-H33 & $\begin{array}{l}\text { Hourly Loads: Clear Cold Day, Case } 980 \text { (High Mass, } \\
\text { Insulation), Heating (+), Sensible Cooling (-) }\end{array}$ & Fig B8-H33 Hrly-980Loads-Cold \\
\hline B8-H34 & $\begin{array}{l}\text { Hourly Loads: Clear Hot Day, Case } 980 \text { (High Mass, } \\
\text { Insulation), Heating (+), Sensible Cooling (-) }\end{array}$ & Fig B8-H34 Hrly-980Loads-Hot \\
\hline B8-H35 & $\begin{array}{l}\text { Hourly Loads: Clear Cold Day, Case } 985 \text { (High Mass, } \\
\text { 20/20 Tstat), Heating (+), Sensible Cooling (-) }\end{array}$ & Fig B8-H35 Hrly-985Loads-Cold \\
\hline B8-H36 & $\begin{array}{l}\text { Hourly Loads: Clear Hot Day, Case } 985 \text { (High Mass, 20/20 } \\
\text { Tstat), Heating (+), Sensible Cooling (-) }\end{array}$ & Fig B8-H36 Hrly-985Loads-Hot \\
\hline B8-H37 & $\begin{array}{l}\text { Hourly Loads: Clear Cold Day, Case } 995 \\
\text { (High Mass, 20/20, Insulation), Heating (+), Sensible Cooling (-) }\end{array}$ & Fig B8-H37 Hrly-995Loads-Cold \\
\hline B8-H38 & $\begin{array}{l}\text { Hourly Loads: Clear Hot Day, Case } 995 \\
\text { (High Mass, 20/20, Insulation), Heating (+), Sensible Cooling (-) }\end{array}$ & Fig B8-H38 Hrly-995Loads-Hot \\
\hline B8-hc1 & $\begin{array}{l}\text { Annual Load-Weighted Average Exterior Surf. Convection } \\
\text { Coefficients Cases 600, } 670 \text { (window only), and } 200\end{array}$ & Fig B8-hc1 hext,avg \\
\hline B8-hc2 & Annual Maximum Exterior Surface Convection Coefficients, Case 600 & Fig B8-hc2 hext,max \\
\hline B8-hc3 & Annual Minimum Exterior Surface Convection Coefficients, Case 600 & Fig B8-hc3 hext,min \\
\hline B8-hc4 & $\begin{array}{l}\text { Annual Load-Weighted Average Interior Surf. Convection } \\
\text { Coefficients Cases } 600,670 \text { (window only), and } 200\end{array}$ & Fig B8-hc4 hint,avg \\
\hline B8-hc5 & Annual Maximum Interior Surface Convection Coefficients, Case 600 & Fig B8-hc5 hint,max \\
\hline B8-hc6 & Annual Minimum Interior Surface Convection Coefficients, Case 600 & Fig B8-hc6 hint,min \\
\hline
\end{tabular}




\subsubsection{Test Cases and Other Outputs Excluded from the Results Sets (by Program)}

Some programs excluded cases or specific results, which are left as blank in the results compilation. Reasons for exclusions are discussed in the modeler reports of Section 3.9. A summary listing for excluded results follows:

- BSIMAC

○ Cases: 960, 280, 440, 810.

○ Other output: Annual sky temperature (average, minimum, and maximum); hourly sky temperatures were included.

- CSE

- Cases: None excluded.

- Other output: West window transmitted solar radiation.

- DeST: None excluded.

- EnergyPlus: None excluded.

- ESP-r: None excluded.

- NewHASP

○ Cases: 640, 940, 195, 200, 210, 270, 280, 290, 300, 310, 320, 440, 450, 460, 470, 810.

- Other output: Incident and transmitted solar radiation, sky temperature, convective surface coefficients.

- TRNSYS: None excluded.

\subsubsection{Non-Application of Interior Surface Texture in the Models}

For the example results of Part II, none of the models apply interior surface texture to evaluate interior surface heat transfer, so that inputs from Part I, Table 5-8 (see Part I, Section 5.2.1.10.2) do not affect results for any of the programs that provided example results. However, many of these models apply direct input of exterior surface texture (see Table 5-6 of Part I, Section 5.2.1.9.2) to evaluate exterior surface heat transfer and are sensitive to that input.

\subsection{References for Part II}

Alamdari, F., and G.P. Hammond (1983). "Improved Data Correlations for Buoyancy-Driven Convection in Rooms.” Building Services Engineering Research \& Technology. Vol. 4, No. 3.

ASHRAE SSPC 140 (2019). ASHRAE SSPC 140 Building Thermal Fabric Working Group Minutes, January 14, 2019, Atlanta, GA.

Clark, G., and C. Allen (1978). "The Estimation of Atmospheric Radiation for Clear and Cloudy Skies."

Proceedings of the 2nd National Passive Solar Conference. AS/ISES, pp. 675-678.

Clarke, J. A. (2001). Energy Simulation in Building Design. 2nd Edition. London: Butterworth-Heinemann, ISBN 0 750650826.

Martin, M., and P. Berdahl (1984). "Characteristics of Infrared Sky Radiation in the United States." Solar Energy, Vol. 33, No. 3/4, pp. 321-336. Oxford, U.K.: Pergamon Press Ltd.

U.S. DOE (2019). EnergyPlus Engineering Reference. Washington, DC: United States Department of Energy; Urbana, IL: University of Illinois; Berkeley, CA: University of California and Lawrence Berkeley National Laboratory. https://energyplus.net/sites/all/modules/custom/nrel_custom/pdfs/pdfs_v9.1.0/EngineeringReference.pdf

Zhang, K., McDowell, T., and Kummert, M. (2017). "Sky Temperature Estimation and Measurement for Longwave Radiation Calculation.” Proceedings Building Simulation 2017, San Francisco, California, U.S.A., Aug 7-9. International Building Performance Simulation Association. http://www.ibpsa.org/proceedings/BS2017/BS2017_569.pdf 


\subsection{Part III: Production of Field-Trial Example Simulation Results}

\subsection{Introduction}

In this section, we describe what the working group members did to produce example results with several detailed programs that were considered to represent the state of the art for building energy simulation in the United States, China, Japan, South Africa, and the United Kingdom. The objectives of developing the simulation results were as follows:

- To demonstrate the general applicability and usefulness of the test suite for a variety of stateof-the-art building energy simulation programs with a variety of input structures and modeling approaches.

- To improve the test procedure through field trials.

- To eliminate input errors and internal modeling bugs in the participating computer programs such that the set of example results (see Part II) is representative of the current range of legitimate modeling differences in today's state-of-the-art building energy simulation software.

- To investigate whether the range of differences among example results for the building thermal fabric test cases of Sections 5.2.1, 5.2.2, and 5.2.3 would improve in conjunction with improvements to the test specification and improvements to the state of the art in building energy simulation programs, since the test cases and example results were first published in 1995 (Judkoff and Neymark 1995a).

The field trial effort took about 5 years and involved several revisions to the test specifications and subsequent re-execution of the computer simulations. The process was iterative in that executing the simulations led to the refinement of the test suite, and the results of the tests led to the improvement and debugging of the models. This process underscores the importance of the software development industry's participation in this project via the ASHRAE Standard 140 Project Committee (SSPC 140), and via previous collaborations with International Energy Agency (IEA) software testing and validation projects (e.g., Judkoff and Neymark 2009). Extensive field trials and the resulting enhancements to the tests were much more comprehensive and cost-effective with the participation of the national and international software-development industry experts.

Table 2-1 (see Part II, Section 2.1) describes the programs used to generate the simulation results. Appendix III (Section 3.9) presents reports written by the modelers for each simulation program.

The tables and graphs in Part II present the final results from all the simulation programs used in this study. The primary purpose of including simulation results for the test cases is to allow simulationists to compare their relative agreement (or disagreement) with those results.

Abbreviations and acronyms used in Sections 3.1 through 3.6 are given in Section 3.7. References cited in Section 3.1 through 3.6 are given in Section 3.8. 


\subsection{Selection of Simulation Programs and Modeling Rules for Simulations}

The industry working group participating in this project made the initial selections of the simulation programs used in this study. The selection criteria required that:

- A program be a true simulation based on hourly weather data and calculation time increments of 1 hour or less.

- A program be representative of the state of the art in whole-building energy simulation as defined by the working group participants making the selection.

The modeling rules were somewhat different (more stringent) for the simulation programs used for Part II example results from those for a given program to be normally tested with this procedure (see Part I, Section 5.1, Modeling Rules). For the Part II simulation results, we allowed a variety of modeling approaches that complied with the test specification input requirements. However, we required that these cases be modeled in the most detailed way possible for each simulation program within the limits of the test specification - for example, the test specification assumes that solid-material properties (e.g., thermal conductivity of plasterboard) of the walls, roof, and floor do not vary with temperature or humidity.

To minimize the potential for user error, we encouraged more than one modeler to develop input files for each program; this occurred for four of the participating programs (DeST, EnergyPlus, ESP-r and TRNSYS). We also encouraged participants to check their results versus other participants' simulation program results. We also distributed documentation of noteworthy isolated results differences and the probable diagnosis to each program participant during the simulation trials.

Where improvements to simulation programs or simulation inputs were made as a result of running the tests, such improvements had to have a mathematical and physical basis and had to be applied consistently across tests. In addition, all improvements were requested to be documented in modeler reports. Arbitrary modification of a simulation program's input or internal code just for the purpose of more closely matching a given set of results was not allowed. The diagnostic process of improving simulation models discussed in Section 3.4 also isolated input errors that were corrected, as noted there and in the modeler reports (Section 3.9).

\subsection{Improvements to the Test Specification as a Result of the Field Trials}

Based on comments by the ASHRAE SSPC 140 industry working group participants during the field trials and from reviewing submitted results and modeler reports, we made improvements and revisions to the test specification. Although researching the comments and communicating specification revisions to the field trial participants was very time-consuming, the importance of the accuracy and clarity of the test specification for this type of work cannot be overstated. This is the only method to our knowledge that can produce a test specification that is unambiguous for a variety of state-of-the-art simulation programs with a variety of input structures and modeling approaches.

The contribution of the SSPC 140 industry working group participants was particularly valuable because the expert software developer teams supplied continuous feedback throughout the field trial effort. Their feedback resulted in several iterations of revisions to the test specifications and subsequent re-execution of the computer simulations. This iterative process led to refinement of the test suite, and the results of the tests led to the improvement and debugging of the programs.

The full cumulative set of revisions to the Standard 140-2017 test specification that resulted from all the simulation trials is provided with edit-tracking in the accompanying file, "140-2017-Sec5_2-Update- 
TestSpec-EditTracked.docx"; this file is intended for submission to ASHRAE for developing the addendum to Standard 140 that is the intended outcome of this project. A cumulative-summary topical listing of these revisions, which was useful during the simulation trials, is included as the accompanying file "ChangesSummary-Sec5_2-Update.PDF." The following subsections summarize details of the improvements to the test specification over the course of the simulation trials.

The test specification language revisions are compatible with ANSI/ASHRAE mandatory language requirements.

\subsubsection{Development of the Initial Draft Test Specification (Simulation Trial \#1)}

The initial draft updated test specification was distributed on July 22, 2014. The test specification was initially based on ASHRAE Standard 140-2011 (ANSI/ASHRAE 2011), Sections 5.2.1, 5.2.2, and 5.2.3 (also see Judkoff and Neymark 1995a, Part I). There are no substantive differences in Sections 5.2.1, 5.2.2, and 5.2.3 and related material within Standard 140 going from 140-2011 to 140-2014 to 140-2017. Initial revisions are summarized as follows (these generally apply to all test cases except where specific test cases are noted):

- $\quad$ Updated to Denver TMY3 (725650TY.csv) weather data:

○ TMY3 data are more recent than TMY data and TMY3 data apply typical standard-time convention in place of the solar-time convention of TMY data.

- Site details (terrain type, weather-tower height, etc.) clarified.

- Material properties tables reorganized as fundamental properties and calculated values based on the fundamental properties.

- Original floor in contact with ground changed to raised floor exposed to air, as in HERS BESTEST and BESTEST-EX (Judkoff and Neymark 1995b; Judkoff et al. 2010).

- Infiltration airflow f(altitude) adjustment updated.

- Uniform distribution of internally generated heat clarified.

- Alternative constant values for interior and exterior surface heat transfer coefficients updated, along with supporting documentation in Informative Annex B4, and following clarifications:

- Interior surface convection is buoyancy-driven.

- More work was done to define alternative constant surface coefficients for subsequent simulation trials (see Sections 3.3.2 and 3.3.3 below).

- Double-pane window construction and thermal and optical properties updated for consistency with LBNL WINDOW 6 (2013) libraries and results, and updated supporting documentation in Informative Annex B6:

- Reorganized window properties tables as normative fundamental properties and informative calculated values based on the fundamental properties.

- Alternative constant interior solar distribution fractions updated for consistency with revisions to windows and alternative constant interior surface coefficients

- Thermostat operation clarified as: "adjusted to maintain the zone air temperature exactly at the [cooling/heating] set point."

- Setback thermostat control specification clarified (Cases 640 and 940).

- Ventilation fan airflow f(altitude) adjustment updated, consistent with infiltration update (Cases 650, 650FF and 950).

- Sunspace common-wall U- and R- values clarified as surface-to-surface values (Case 960).

- High-Conductance wall (replaces windows in some diagnostic cases) updated for consistency with revised transparent double-pane windows.

- Hourly outputs clarified as "hourly integrated" output. 
- Output for integrated interior and exterior convective surface coefficients added (Cases 600, 220, and 200): average of annual hourly integrated absolute values and annual maximum and minimum absolute values, for all surfaces.

- Other related editorial revisions made.

\subsubsection{Revisions for the Second-Draft Test Specification (Simulation Trial \#2)}

The second-round draft test specification was distributed on March 13, 2017. As a prerequisite for this round, the simulation trial participants ran the previously published multi-zone shading cases (Neymark et al. 2008a) and were asked to correct any software issues that may have been identified for those cases. Additionally, there were a number of comments from the first-round simulation trial that led to a large number of changes and additions of new test cases. These changes included a substantial effort to improve specification of equivalent inputs related to interior and exterior surface heat transfer, including further development of new constant convective and combined (convective and radiative) surface heat transfer coefficients for programs that may need them. The second-round revisions are summarized as follows (these generally apply to all test cases, except where specific test cases are noted):

- Simulation initialization and pre-conditioning instructions clarified.

- Sky temperature data based on Martin and Berdahl (1984) included as informative supplement to weather data, along with supporting xlsx file.

- Ground reflectance in weather data to be ignored, use specified constant value.

- Material properties tables:

- Original tables disaggregated as normative fundamental properties and informative calculated values (based on fundamental properties).

- Informative calculated-values table further provided:

- Internal and total heat capacities accounting for walls, roof and floor.

- Equivalent UA value of infiltration applying moist-air density and specific heat based on annual average weather conditions.

- Raised-floor exterior surface clarified as exposed to zero windspeed.

- Infiltration airflow rate $\mathrm{f}$ (altitude) further revised as calculated from moist-air density based on annual average weather conditions.

- Instructions added regarding applicable ground-surface temperature for calculating infrared radiation exchange.

- Alternative constant values for interior and exterior surface heat transfer coefficients further updated, along with supporting Informative Annex B4, and following clarifications:

- Clarified language regarding application of the alternative constant values.

- Given alternative constant values are appropriate only to the test specification.

- Other tables with calculated values updated for new calculated combined coefficients where needed (e.g., for calculated opaque-surface and window total conductances, and alternative constant solar distribution fractions).

- Detailed discussion of the work on developing alternative constant surface coefficients is included in Part I, Annex B4 and Part IV, Appendix A of this report.

- Informative Annex B5 revised as not applying to the Section 5 test cases; it now only applies to the Standard 140 Section 7 tests.

- Double-pane window properties clarified:

- Clean surfaces without dirt or fouling.

- Thermal and optical properties updated for consistency with LBNL WINDOW 7 (2016) libraries and results, and supporting documentation in Informative Annex B6 updated.

- Minor revisions to glass density (to match 2013 ASHRAE Fundamentals [ASHRAE 2013]) and air properties (to match WINDOW 7). 
○ Angle-dependent optical properties indicated as alternative values for programs that require this input.

- Alternative constant interior solar distribution calculation technique revised to match algorithm applied for the Standard 140 Section 7 test cases; supporting material in Informative Annex B7 also revised, and includes calculations for new cases with low-e and single-pane windows (see below).

- Shading-device (overhang and fins) optical properties specified.

- Setback thermostat control specification further clarified (Cases 640 and 940).

- Ventilation fan airflow f(altitude) adjustment further updated, consistent with infiltration update (Cases 650, 650FF and 950).

- Sunspace Case 960 clarification: no interzonal air exchange between sun zone and back zone.

- High-Conductance wall (replaces windows in some diagnostic cases) further updated for consistency with revised transparent double-pane windows.

- For cases where surface emittances are varied, application to interior and/or exterior surfaces, as appropriate, clarified.

- Solar radiation output clarified as sum of direct-beam and diffuse radiation.

- Output for average of annual hourly integrated absolute values for interior and exterior convective surface coefficients revised as load-weighted average (Cases 600 and 200).

- Output requirements added for:

○ Calculated sky temperature: annual mean, maximum and minimum (Case 600).

- Monthly conditioned-zone total heating and cooling loads and monthly peak heating and cooling loads (Cases 600 and 900).

- Days for specifying hourly output updated to be optimal for new weather data of Round 1.

- Bin temperature output post-processor moved to main Sec5-2Aout.xlsx output template; original TMPBIN.exe and its supporting Informative Annex B12 deleted.

- Output requirement for Case 220 convective surface coefficients deleted; this output is sufficient for Cases 600 and 200 only.

- Output requirement for Case 200 interior and exterior convective surface coefficient maxima and minima deleted; this output is sufficient for Case 600 only.

- New test cases added for window types:

○ Low-Emissivity windows with Argon Gas (Case 660)

- Single-pane windows (Case 670)

- For new Cases 660 and 670, the following were also included:

- Window construction, thermal and optical properties specified for consistency with LBNL WINDOW 7 libraries and results, and supporting documentation added in Informative Annex B6

- Transmitted solar radiation output requirements added, consistent with those for Case 600, along with typical output requirements for each test case.

- New low-mass cases added for increased exterior wall and roof insulation:

○ Increased insulation with 20/27 dead band thermostat settings (Case 680).

○ 20/20 "bang-bang" thermostat settings (Case 685).

- Increased insulation with 20/20 thermostat settings (Case 695).

- Increased insulation with thermostat off, floating zone temperature (Case 680FF).

- New high-mass cases added for increased exterior wall and roof insulation:

- Increased insulation with 20/27 dead band thermostat settings (Case 980).

○ 20/20 "bang-bang" thermostat settings (Case 985).

○ Increased insulation with 20/20 thermostat settings (Case 995).

- Increased insulation with thermostat off, floating zone temperature (Case 980FF).

- New test cases added with specified constant combined surface coefficients, for isolating effects of simultaneous surface convective heat transfer and IR exchange: 
○ Constant combined interior and exterior coefficients (Case 450).

- Constant combined interior coefficients (Case 460).

- Constant combined exterior coefficients (Case 470).

- Pro forma modeler report queries updated/expanded.

- Other related editorial revisions made.

\subsubsection{Further Revisions to the Draft Test Specification (Simulation Trials \#3, \#4, and \#5)}

Subsequent, less extensive revisions during the final phase of simulation trials are summarized below. These revisions addressed SSPC 140 working group comments as the work further progressed. Some test specification issues were only recognizable via some of the remaining results disagreements after previous issues - which also caused some observable results disagreements - were identified and fixed. These revisions generally apply to all test cases, except where specific test cases are noted.

\subsubsection{Third Round of Revisions (Simulation Trial \#3)}

- $\quad$ Test spec distributed on Sep 13, 2017.

- Simulation initialization and pre-conditioning instructions further clarified.

- Absorptance and emittance properties application to raised floor clarified.

- Exterior and interior surface textures included.

- Typo corrected for the calculated value of double-pane glass "U-value from interior air to ambient air"

- "Interior solar distribution fraction" definition clarified.

- Hourly load and zone temperature output for clear/cold day added for thermostat setback Cases 640 and 940.

- Note added affirming that Case 900 floor insulation thickness is slightly different from Case 600 floor thickness.

- Sunspace-common-wall surfaces clarified as applying interior surface heat transfer coefficients on both sides, for programs that input this (Case 960).

- Mechanical ventilation schedule clarified in the free-float version of cases that have this (Cases $650 \mathrm{FF}$ and 950FF).

- Opaque-surface interior solar absorptance clarified for cases with high-conductance wall elements.

- High-conductance wall element specification further clarified (for cases that have these).

- Deleted erroneous reference to high-conductance wall elements in two cases that have transparent windows (Cases 270 and 280).

- Pro forma modeler report queries further updated/expanded.

- Other related editorial revisions made.

\subsubsection{Fourth Round of Revisions (Simulation Trial \#4)}

- Test spec distributed on Apr 24, 2018.

- Application of alternative constant interior solar distribution fractions further clarified.

- Separate alternative constant interior and exterior combined surface coefficients developed and included for single-pane windows (Case 670); documentation is included in Part I, Annex B4 and Part IV, Appendix A. This change relates to calculated window properties and alternative constant interior solar distribution fractions; see Part I, Annexes B6 and B7 of this report.

- Output requirement of hourly-integrated annual load-weighted average interior and exterior convective surface coefficients for single-pane window added (Case 670).

- High-conductance wall element geometry and construction properties further clarified: 
- Air gap specified as having constant thermal properties, not varying as a function of buoyancy-driven natural convection.

- Further updated alternative constant values for $h$,comb, int and $h$,comb, ext for $\varepsilon=0.1$, for cases where $\varepsilon=0.1$ occurs; also see Part I, Informative Annex B4.

- Tables specifying high-conductance wall element properties reorganized.

- Term "opaque window" deleted in favor of "high-conductance wall element".

- Informative note to be added to Informative Annex B11 (production of example results) indicating that none of the current models applied in the simulation trials consider interior surface texture in their calculations.

- Other related editorial clarifications made.

\subsubsection{Fifth/Final Round of Revisions (Simulation Trial \#5)}

- $\quad$ Test spec distributed Sep 10, 2018.

- Clarification: no additional internal mass within the zone corresponding to furniture or other nonspecified elements.

- Language related to infiltration airflow rate clarified, based on external Standard 140-2017 user comment not related to the field trials.

- Setback thermostat control specification further clarified with new figures (Cases 640 and 940).

- Mechanical ventilation schedule further clarified (Cases 650 and 950).

- Informative test case characterization tabulations and text revisions:

- Primary tested modeling features summarized for each test case, along with navigational overview.

- Primary and secondary base cases summarized for each test case.

- Case numbers included with section cross-references where appropriate.

- Other related editorial clarifications made.

\subsection{Improvements to Programs that Participated in the Simulation Trials}

Simulations were performed for each test case with the participating computer programs. At each stage of the exercise, output data from the simulations were compared to each other, and the comparisons and probable diagnosis of disagreements were distributed to the simulation trial participants. Participants discussed selected comparisons and resulting improvements in their modeler reports (see Section 3.9).

The test diagnostics revealed bugs, faulty algorithms, potential program improvements, input errors, or some combination of those in all of the tested models. Table 3.6-1 (see Section 3.6.1.2) enumerates software issues, input errors, and reporting errors that were found and fixed during the simulation trials.

Table 3.4-1 (below) summarizes the nature of 30 software issues found among the 7 participating programs using the test cases during the simulation trials. The table also indicates where programs were corrected or improved, shows the effect of improvements on load calculations, and provides crossreferencing to appropriate sections of each participant modeler report of Section 3.9. Abbreviations used in the table are provided in Section 3.7.

As discussed in Section 3.2, improvements to simulation programs or simulation inputs made by participants were required to have a mathematical and a physical basis, and to be applied consistently throughout the test cases; all improvements were requested to be documented in modeler reports. For most of the improvements to the tested programs, illustration of how the test procedure was used to isolate and correct errors is sufficiently discussed in the modeler reports of Section 3.9. 
Table 3.4-1. Summary of Software Issues Found Using the Test Cases

\begin{tabular}{|c|c|c|c|c|}
\hline Model $^{\text {a }}$ & Issue/Error Description $^{\text {a }}$ & $\begin{array}{l}\text { Modeler } \\
\text { Report Ref. }\end{array}$ & $\begin{array}{l}\text { \% Load } \\
\text { Effect }^{\mathrm{a}, \mathrm{c}}\end{array}$ & $\begin{array}{l}\text { Out- } \\
\text { come }^{\text {a }}\end{array}$ \\
\hline BSIMAC & Upgrade calculation of interior- and exterior surface coeffs & A, 5 & $\begin{array}{l}9 \% \operatorname{clg} 200 \\
3 \% \text { htg } 220\end{array}$ & Fixed \\
\hline BSIMAC & Include surface emittance in exterior radiative exchange calc & A, 5.2 & $10 \% \mathrm{htg}$ & Fixed \\
\hline BSIMAC & Diffuse solar shading for overhang bypassed for solar report & A, 5.4.1 & None $^{\mathrm{d}}$ & Fixed \\
\hline BSIMAC & $\begin{array}{l}\text { Diffuse solar shading for fins bypassed for solar report and load } \\
\text { calc }\end{array}$ & A, 5.4.2 & Unknown ${ }^{\mathrm{e}}$ & Fixed \\
\hline BSIMAC & Load-weighted average $\mathrm{h}$,conv summations incorrect & A, 5.4 .3 & None $^{\mathrm{d}}$ & Fixed \\
\hline BSIMAC & Unshaded annual transmitted solar report & A, 5.8.1 & None $^{\mathrm{d}}$ & Fixed \\
\hline BSIMAC & Horizontal or inclined h,conv & A, 5.9.1 & Unknown $^{\mathrm{e}}$ & Fixed \\
\hline BSIMAC & Interior radiative exchange & A, 5.9.2 & Unknown $^{\mathrm{e}}$ & Fixed \\
\hline BSIMAC & Upgrade glazing transmittance calculations & $\mathrm{A}, 5.11$ & Unknown $^{\mathrm{e}}$ & Fixed \\
\hline BSIMAC & Add "Medium-Heavy" mass category for high-mass cases & A5.14,16 & \multirow{2}{*}{$7 \% \operatorname{clg} 900$} & Fixed \\
\hline BSIMAC & Increase number of Loads-T loop iterations for mass $>$ Light & A5.15,16 & & Fixed \\
\hline BSIMAC & Upgrade to single-pane glazing transmittance calc was missed & A, 5.19 & $11 \% \operatorname{clg} 670$ & Fixed \\
\hline CSE & Berdahl-Martin Sky Temperature corrected & $\mathrm{B}, 5$ & Unknown $^{\mathrm{e}}$ & Fixed \\
\hline CSE & Sub-hourly thermostat ramping & $\mathrm{B}, 5$ & $\begin{array}{c}30 \% \text { pk htg } \\
640,940\end{array}$ & Fixed \\
\hline CSE & Added EnergyPlus "DOE2" and "TARP" ext and int h,conv & $\mathrm{B}, 5$ & $\mathrm{n} / \mathrm{a}^{\mathrm{f}}$ & Fixed \\
\hline CSE & Revise cloudy-day sky temperature correction & $\mathrm{B}, 5$ & $3 \%$ htg & Fixed \\
\hline CSE & Allow reporting of per-window solar gains & $\mathrm{B}, 8$ & None $^{\mathrm{d}}$ & Noted $^{\mathrm{h}}$ \\
\hline DeST & $\begin{array}{l}\text { Solar lost (reflected from interior back through window) not } \\
\text { accounted for }\end{array}$ & $\mathrm{C}, 5$ & Unknown $^{\mathrm{e}}$ & Fixed \\
\hline DeST & Overlapping shadows of overhangs and fins: $630,930,310$ & $\mathrm{C}, 5$ & Unknown $^{\mathrm{e}}$ & Fixed \\
\hline DeST & Sky background infrared radiation & $\mathrm{C}, 5$ & Unknown $^{\mathrm{e}}$ & Fixed \\
\hline DeST & $\begin{array}{l}\text { Sky diffuse shading factors applied to ground-reflected } \\
\text { radiation }\end{array}$ & $\mathrm{C}, 5$ & Unknown $^{\mathrm{e}}$ & Fixed \\
\hline DeST & Low-e window model could be improved & $\mathrm{C}, 6.1$ & Unknown $^{\mathrm{g}}$ & Noted $^{\mathrm{h}}$ \\
\hline EnergyPlus & Sky IR exchange from Clark-Allen to Martin-Berdahl? & None ${ }^{\mathrm{i}}$ & $\begin{array}{c}1 \%-4 \% \text { htg \& } \\
\text { clg loads? }\end{array}$ & Noted $^{\mathrm{k}}$ \\
\hline EnergyPlus & Define leeward for MoWitt h,conv,ext to $>90^{\circ}$ from $\leq 100^{\circ}$ & None $^{1}$ & Unknown $^{\mathrm{m}}$ & Fixed \\
\hline ESP-r & Improvements to climate database & E, 5 & Unknown $^{\mathrm{e}}$ & Fixed \\
\hline ESP-r & $\begin{array}{l}\text { Use measured instead of estimated cloud-cover data within } \\
\text { Berdahl-Martin algorithm for long-wave sky radiation }\end{array}$ & $\mathrm{E}, 5$ & $2 \% \mathrm{htg}$ & Fixed \\
\hline ESP-r & $\begin{array}{l}\text { Sky diffuse shading factors incorrectly applied to ground- } \\
\text { reflected radiation }\end{array}$ & $\mathrm{E}, 5$ & $\begin{array}{l}20 \% \text { clg Case } \\
630 \\
\end{array}$ & Fixed \\
\hline ESP-r & Further shading model corrections? & None $^{n}$ & Unknown $^{\mathrm{g}}$ & Noted $^{\mathrm{h}}$ \\
\hline NewHASP & Constant h,conv within code do not match spec & $\mathrm{F}, 2$ & Unknown $^{\mathrm{g}}$ & Noted $^{\text {h }}$ \\
\hline TRNSYS & Shading of circumsolar radiation: shading cases & $\mathrm{G}, 5$ & $<1 \%$ loads & Fixed \\
\hline
\end{tabular}

a Acronyms and abbreviations used in this column are defined in Section 3.7.

b All sections refer to Appendix III (Section 3.9); for example, "A, 5.4.1" is "Appendix III-A, Section 5.4.1".

c Specific or example cases relevant to the described effects are listed. For disagreements indicated as "Fixed", listed percentage values are the effect of the change for new results versus previous results for a given model.

d No loads effect; the fix to the program corrected reporting of specific output, but the named item was calculated correctly for loads analysis.

e Not isolated in submitted results.

f Not applicable; these algorithms were not used in the CSE final results.

$\mathrm{g}$ Not possible to ascertain without revising the software.

h Authors notified.

i See Part II, Section 2.4, Figure B8-H11.

jee Part IV, Appendix B, Table 4B-1.

k Per email from M. Witte to J. Neymark, August 25, 2019: DOE/LBNL will be doing additional research on sky infrared radiation exchange.

1 Observed in EnergyPlus documentation by J. Neymark during alternative constant surface coeff analysis (see Part IV).

m Per email from M. Witte to J. Neymark, August 25, 2019: Change made for EnergyPlus v9.2.0 due late September 2019. Before-andafter sensitivity runs have not been done for this fix using the thermal fabric test cases.

n Per email from P. Strachan to J. Neymark, Apr 30, 2019. 


\subsection{Interpretation of Results}

\subsubsection{Improvements to the Updated Ranges of Differences of Example Results Versus Original Example Results from 1995}

Figures 3.5-1 and 3.5-2 compare ranges of differences of results for the set of programs that ran the updated test specification versus the set of programs that produced the 1995 BESTEST results (Judkoff and Neymark 1995a). For this comparison, Figure 3.5-1 shows Case 600 (low mass) annual heating and cooling loads, while Figure 3.5-2 shows Case 900 (high mass) annual heating and cooling loads. In both figures the range of 1995 and new results is represented by black and blue horizontal lines, respectively, with individual 1995 and new results shown with black-pattern and blue-pattern bars, respectively. These figures, and Table 3.5-1 discussed below, exclude the new results for the NewHASP program for reasons discussed in Part II, Section 2.2.1.

Table 3.5-1 quantifies ranges of differences of the new results set versus the 1995 results set for the Basic Tests of Part I, Section 5.2.2 (low-mass Cases 600 through 650 and similar high-mass Cases 900 through $950)$. Here, the range for each data set is assessed by $(\operatorname{Max}-\operatorname{Min}) /((\operatorname{Max}+\operatorname{Min}) / 2)$ expressed in percent. For this calculation, a smaller percent-difference indicates better agreement. Table 3.5-1 includes this comparison for annual total heating and cooling loads and annual peak heating and cooling loads.

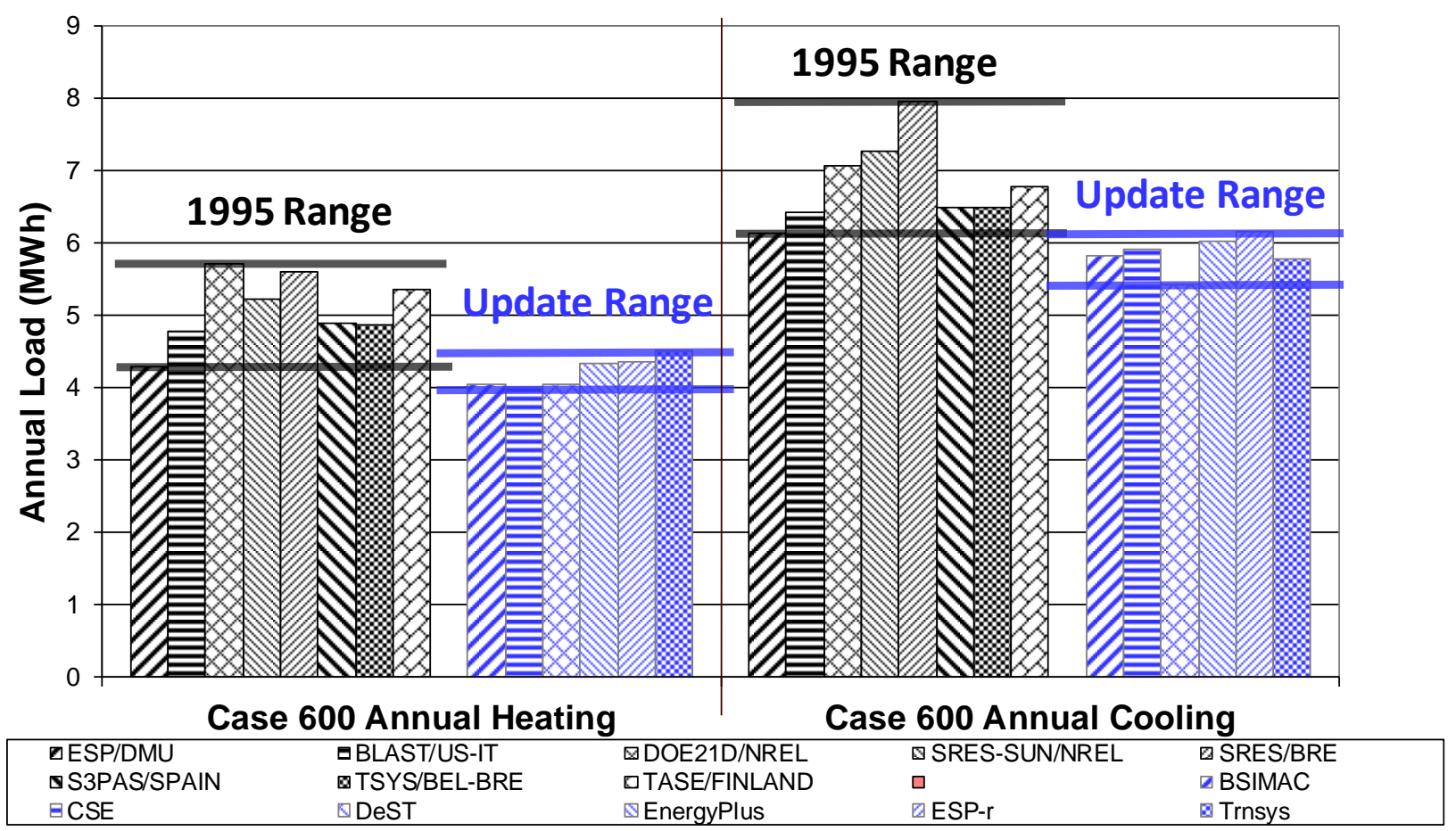

Figure 3.5-1: BESTEST Case 600 (Low Mass) Annual Heating and Cooling Loads, Improvement to Ranges of Differences: New Results (Blue-Pattern Bars) Versus 1995 Results (Black-Pattern Bars) 


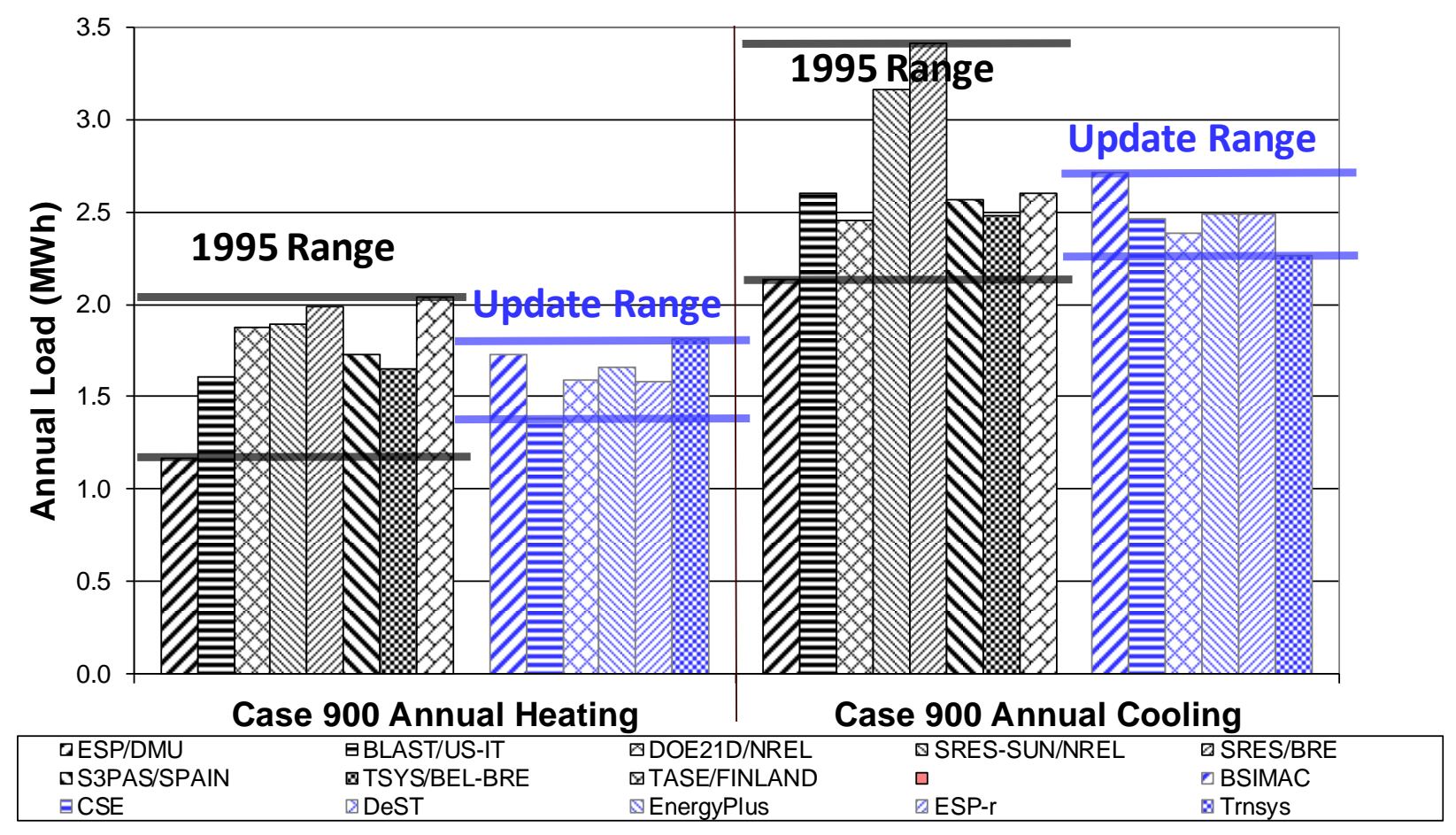

Figure 3.5-2: BESTEST Case 900 (High Mass) Annual Heating and Cooling Loads, Improvement to Ranges of Differences: New Results (Blue-Pattern Bars) Versus 1995 Results (Black-Pattern Bars)

Table 3.5-1 Comparison of Ranges of Differences ${ }^{\mathrm{a}, \mathrm{b}}$ for New Results versus 1995 Results

\begin{tabular}{|c|c|c|c|c|c|c|c|c|}
\hline \multirow{2}{*}{ Case Description } & \multicolumn{2}{|c|}{ Annual Heating } & \multicolumn{2}{|c|}{ Annual Cooling } & \multicolumn{2}{|c|}{ Peak Heating } & \multicolumn{2}{|c|}{ Peak Cooling } \\
\hline & 1995 & New & 1995 & New & 1995 & New & 1995 & New \\
\hline Low Mass & & & & & & & & \\
\hline 600 South Windows & $28 \%$ & $12 \%$ & $26 \%$ & $13 \%$ & $24 \%$ & $11 \%$ & $13 \%$ & $18 \%$ \\
\hline 610 South Windows + Overhang & $28 \%$ & $12 \%$ & $38 \%$ & $6 \%$ & $24 \%$ & $11 \%$ & $12 \%$ & $19 \%$ \\
\hline 620 East \& West Windows & $25 \%$ & $14 \%$ & $38 \%$ & $14 \%$ & $20 \%$ & $11 \%$ & $33 \%$ & $19 \%$ \\
\hline $630 \mathrm{E} \& W$ Windows + Overhang \& Fins & $25 \%$ & $16 \%$ & $54 \%$ & $18 \%$ & $17 \%$ & $11 \%$ & $29 \%$ & $18 \%$ \\
\hline 640 Case 600 with Htg Temp Setback & $32 \%$ & $11 \%$ & $27 \%$ & $12 \%$ & $28 \%$ & $14 \%$ & $14 \%$ & $18 \%$ \\
\hline 650 Case 600 with Night Ventilation & & & $30 \%$ & $17 \%$ & & & $14 \%$ & $22 \%$ \\
\hline High Mass & & & & & & & & \\
\hline 900 South Windows & $54 \%$ & $27 \%$ & $46 \%$ & $18 \%$ & $28 \%$ & $13 \%$ & $29 \%$ & $28 \%$ \\
\hline 910 South Windows + Overhang & $37 \%$ & $27 \%$ & $78 \%$ & $22 \%$ & $28 \%$ & $13 \%$ & $53 \%$ & $27 \%$ \\
\hline 920 East \& West Windows & $26 \%$ & $20 \%$ & $51 \%$ & $20 \%$ & $20 \%$ & $14 \%$ & $38 \%$ & $25 \%$ \\
\hline $930 \mathrm{E} \& W$ Windows + Overhang \& Fins & $25 \%$ & $22 \%$ & $73 \%$ & $27 \%$ & $19 \%$ & $16 \%$ & $49 \%$ & $27 \%$ \\
\hline 940 Case 900 with Htg Temp Setback & $56 \%$ & $47 \%$ & $44 \%$ & $17 \%$ & $47 \%$ & $24 \%$ & $29 \%$ & $28 \%$ \\
\hline 950 Case 900 with Night Ventilation & & & $82 \%$ & $19 \%$ & & & $44 \%$ & $15 \%$ \\
\hline
\end{tabular}

${ }^{a}$ Smaller \%-range of difference indicates better agreement

${ }^{\mathrm{b}}$ Results for NewHASP are excluded for reasons discussed in Part II, Section 2.2.1.

The tabulation indicates that new results have substantially improved the range of difference (narrower range implying better agreement) versus the 1995 results for annual heating and cooling loads and peak heating loads, where in many cases the range of difference is reduced by half or more. For peak cooling 
loads, the tabulation indicates similar improvement for the high-mass cases and for low-mass Cases 620 and 630. However, new peak cooling load results for low-mass Cases 600, 610, 640 and 650 have a mild percent-range increase versus the 1995 results, with both ranges $\leq 22 \%$. This level of percent-difference for the new peak-cooling load results appears to be consistent with the percent-difference for other new results in Table 3.5-1. In general, peak cooling load is considered more difficult to assess-because of timing of solar gains and mass and surface heat transfer interactions - than the other outputs shown in Table 3.5-1, and the ranges of differences for the new results support that. Another noteworthy result is the relatively small improvement (56\% to 47\%) in the difference for the new annual heating results for Case 940 (high mass with heating temperature setback). A possible cause for the continuing relatively high percentdifference for Case 940 is that the night setback reduces the annual heating load such that the results differences typically occurring throughout the 900-series cases' annual heating loads are magnified as a percentage when the signal (in this case, annual heating load) has been reduced; see Table B8-1 and Figure B8-11 within the accompanying file RESULTS5-2A-Update.XLSX.

Improvements to both the test specification and in the state of the art of the programs, as well as the change of included software programs, likely contribute to the improved results agreement. Because sensitivity tests of these improvements were not performed individually, and would have been very difficult to do if even possible, we cannot separate their effects. The programs in the new results set are either updated versions of previous programs or entirely new programs, while some programs in the 1995 results set are no longer supported and were therefore not applied for the new results set. Regarding improvements to the test specification, a major improvement to the base cases (600 and 900) for the BESTEST update is for surface heat transfer input equivalence. This improvement is discussed in detail in Part IV, Appendix A, where Table 4A-4 shows up to a $28 \%$ effect on Case 600 heating load depending on selection of alternative constant coefficients for 1995 versus new values; also see the related summary paper (Neymark et al. 2019). Greatest effects occur where interior alternative constant combined (convective and radiative) coefficients are applied; similarly, selection of interior constant convective-only coefficients has an effect of up to $10 \%$ on the Case 600 heating load. There were a number of other specification improvements and clarifications, including revisions to window construction properties, super-insulated floor details, site altitude and terrain details, infiltration airflow rate for site altitude, internal mass, simulation and pre-conditioning requirements, thermostat control, etc. (see Section 3.3). Also, although the TMY3 weather data for the new test cases are for a similar location (Denver, Colorado) to that of the TMY data for 1995, there are some differences: e.g., annual average temperature and global horizontal solar radiation are $9.7^{\circ} \mathrm{C}(\mathrm{TMY})$ versus $10.9^{\circ} \mathrm{C}(\mathrm{TMY} 3)$ and $1832 \mathrm{kWh} / \mathrm{m}^{2}$ (TMY) versus $1670 \mathrm{kWh} / \mathrm{m}^{2}$ (TMY3), respectively. Along with the general improvement in results agreement, these test specification revisions could cause an overall shift in the amplitude of the results-e.g., observable in Figure 3.5-1.

The example program results from the final round of field trials that are provided with this report do not necessarily represent truth; they do represent the current state of the art in building energy simulation as established through a well-defined, repeatable process. The process is used in this report to gauge improvement in the state of the art since the thermal fabric test cases and accompanying simulation results were originally developed in 1995 . The process can also be used periodically in the future to identify further progress. 


\subsubsection{Test Cases for Future Work}

\subsubsection{Additional Building Thermal Fabric Test Cases}

During this project, participants discussed a number of important test case configurations that could not be included with the current comparative test cases because of resource and project completion timing constraints. These test cases include:

- Weather-driven infiltration and natural ventilation.

- Weather driver fundamental tests.

- Thermal bridging, including 2- and 3-dimensional conduction.

Prioritization of new test cases should have the goals of addressing fundamental and commonly applied modeling physics not addressed in the current cases, and of balancing realism versus the ability to diagnose results differences.

\subsubsection{Standard 140 Test Suite Prioritization Roadmap}

Additional building thermal fabric and mechanical equipment model test cases for consideration to be developed in the future are summarized and prioritized in Standard 140 Test Suite Prioritization Roadmap, June 24, 2019 (ASHRAE SSPC 140, 2019), which also includes empirical validation test cases. See Section 3.6.2.1 for further discussion.

\subsection{Conclusions and Recommendations}

\subsubsection{Conclusions}

This work is intended to update the current test specifications and example results of ANSI/ASHRAE Standard 140-2017 (ANSI/ASHRAE 2017), Sections 5.2.1, 5.2.2, 5.2.3; Informative Annex B8, Section B8.1; and other related Standard 140 annexes. Revisions to the test specification and update of example results follow the vetting process of iterative field trials established for previous BESTEST work that has been adapted for ASHRAE Standard 140 (Judkoff and Neymark 1995a, 1995b; Purdy and BeausoleilMorrison 2003; Neymark and Judkoff 2002, 2004; Neymark et al. 2008b; Neymark et al 2016).

\subsubsection{Major Accomplishments}

The major accomplishments of this project were as follows:

- Update of the BESTEST procedures of Standard 140-2017, Sections 5.2.1, 5.2.2, and 5.2.3 (ANSI/ASHRAE 2017) that were developed before 1995 (Judkoff and Neymark 1995a) and were the basis of the initial version of Standard 140 (140-2001):

- This update reflects improvements to the modeling state of the art since the early 1990s and addresses ambiguities in the test specification identified since 1995.

- A major improvement is the specification of surface heat transfer along with how the related physics is characterized in the models.

- A comprehensive listing of test specification revisions is provided in Section 3.3.

- Development of test specifications with improved clarity, and such that a variety of state-of-theart building simulation programs with a variety of input structures and modeling approaches can perform the tests.

- Improvements, or identification of potential improvements, for all of the programs that participated in the simulation trials of the test cases: 
○ 25 program errors or improvements were diagnosed and fixed or implemented.

- Development of a set of national and international field-trial example simulation results representative of the range of legitimate modeling differences for the current state of the art in whole-building energy simulation computer programs.

- Substantial improvement of ranges of differences (narrower range implying better agreement) for example results versus the previous set of example results for the 1995 test specification:

$\circ$ See Section 3.5.1, Table 3.5-1 and Figures 3.5-1 and 3.5-2 for details.

- Improvements in both the test specification and the state of the art of the programs, as well as the change of included software programs, likely contribute to the improved results agreement.

- Development of the test suite update such that it is suitable for easy adaptation for inclusion in Standard 140.

\subsubsection{Summary of Findings}

This project built on the initial version of the building thermal fabric BESTEST suite (Judkoff and Neymark 1995a; ANSI/ASHRAE 2001, 2017) with the intent to include the updated test cases in a future version of ASHRAE Standard 140 (current version is ANSI/ASHRAE 2017). The original research provided a technically sound conceptual starting point for the test specifications. However, from this starting point there was substantial effort to improve and field-test an updated test specification intended to be usable by most state-of-the-art whole building energy software and suitable for Standard 140. The specification improvements addressed ambiguities discovered since the original field-trials before 1995 and included additional test cases and diagnostic outputs.

The test specifications were field-tested with a number of building energy simulation programs from around the world. This method has proven effective at vetting test specifications and isolating the sources of predictive differences among simulation programs. The diagnostic procedures revealed bugs, faulty algorithms, limitations, input errors, and/or potential improvements for all of the programs tested in this study. These programs include the following models that ran the test cases: BSIMAC, CSE, DeST, EnergyPlus, ESP-r, NewHASP, and TRNSYS. Some important technology advances occurred as a result of running the test cases:

- The test suite improvements allowed diagnosis of errors and identification of potential areas for improvement that may have been missed with the previous version of the test suite.

- Of 30 identified program errors or potential improvements, 25 of those were diagnosed and fixed. Table 3.4-1 summarizes the identified issues (error trapping); supporting details are summarized in Section 3.4 and discussed with greater detail in the modeler reports (see Section 3.9).

- Additionally, 61 sets of input errors and 16 sets of output reporting errors were found and corrected as enumerated in Table 3.6-1; these are also discussed in greater detail in the modeler reports of Section 3.9. These errors, especially the input errors, provided the basis for revealing a number of test specification ambiguities that were clarified as the simulation trials progressed. 
Table 3.6-1. Number of Issues Addressed for Thermal Fabric Cases

\begin{tabular}{||l|c|c|c|c||}
\hline Model $^{\mathbf{a}}$ & $\begin{array}{l}\text { Software Fixes or } \\
\text { Improvements }^{-}\end{array}$ & Input Corrections $^{\mathbf{b}}$ & Reporting Errors $^{\mathbf{b}}$ & Modeler Report $^{\text {(n) }}$ \\
\hline BSIMAC & 12 & 11 & 6 & III-A \\
\hline CSE & 4 & 4 & 6 & III-B \\
\hline DeST & 4 & 37 & III-C $^{\text {d }}$ & III-D \\
\hline EnergyPlus & $1^{\mathrm{c}}$ & 4 & 1 & III-E \\
\hline ESP-r & 3 & 1 & 0 & III-F \\
\hline NewHASP & $0^{\mathrm{e}}$ & 3 & 0 & III-G \\
\hline TRNSYS & 1 & 1 & $\mathbf{7 6}$ & \\
\hline Total & $\mathbf{2 5}$ & $\mathbf{6 1}$ & & \\
\hline
\end{tabular}

a Acronyms and abbreviations used in this column are defined in Section 3.7.

b Here, an individual input correction or reporting error as enumerated may have applied to all cases, a subset of the cases, or only one case; for any of those situations, it is only counted as one correction for the purpose of this table.

c EnergyPlus also had one minor software fix related to surface heat transfer during the time of test suite development that was not found as a result of these tests.

d Modeler report indicates "Errors in the output spreadsheet found in Round 2 were corrected."

e The program is no longer maintained. Convective surface coefficients fixed within the program could not be varied to match the test specification.

Many of the program improvements listed in Table 3.4-1 were significant, with some having greater than a $20 \%$ effect on annual total or peak loads. For individual programs that applied the test cases, some errors had relatively minor $(<1 \%)$ effect on loads. Where a program had multiple errors of smaller magnitude, such errors did not necessarily compensate each other and may have been cumulative. Therefore, correcting the minor as well as the major errors is important.

The number of input errors listed in Table 3.6-1 and the resulting test specification clarifications indicate the importance of iterative field trials for vetting a test suite before it is promulgated for wider use as a standard method of test.

After updating the test specification, applying a set of more up-to-date programs than was available in 1995, correcting software errors, and making other model input improvements using the diagnostic capabilities of the BESTEST procedures, the range of differences has been reduced (i.e., agreement has improved) for updated simulation results that are planned for inclusion with the update to Section 5.2 of Standard 140. This is exemplified in Table 3.5-1, which indicates that for the updated results and test specification versus that from 1995, the ranges of differences are about half or less for annual heating and cooling and peak heating loads for many of the low- and high-mass basic tests (Cases 600 through 650 and 900 through 950, respectively). This is also true for the high-mass peak cooling loads. However, new peak cooling load results for low-mass Cases 600, 610, 640 and 650 have a mild range-of-difference increase versus the 1995 results, though the level of percent-difference for the new peak load results appears to be consistent with that for other new results in Table 3.5-1. The collective results provided in Part II are a good representation of the modeling state of the art.

The above findings show how the test procedure is used to diagnose and correct or improve algorithms in complex simulation programs. Diagnosis is enhanced by improvements to the test specification since 1995. Based on results after several simulation trial iterations and resulting model improvements, all but one of the tested programs (NewHASP) appear reliable for modeling the tested building thermal fabric physics under the conditions examined and for inclusion with the Standard 140 updated example results. NewHASP could not be judged as reliable relative to the other programs because the modelers were not able to match the test specification (see Part II, Section 2.2.1) and were not able to make related 
recommended improvements to the program. Similarly, the 1995 results set (Judkoff and Neymark 1995a) had final-project-report results that were excluded from Standard 140, as documented in Standard 140, Informative Annex B11, Section B11.1.2; e.g., see ANSI/ASHRAE (2001, 2017). The value of including the NewHASP results with the final report, especially where they include outlying results, is to show the better agreement among other programs that abide by the test specification. It was also useful to have their thorough review of the test suite. That reasons for differences can be discerned also underscores the diagnostic value of the test suite.

Based on this work, there are a number of recommended areas for further investigation with respect to developing additional validation test cases for building thermal fabric modeling; these are listed in Section 3.5.2.1. For the longer term, we hope to develop test cases that emphasize additional modeling aspects and physics associated with weather data, the building thermal fabric, and HVAC systems; see Section 3.6.2.1.

\subsubsection{Advantages of BESTEST Methodology}

The BESTEST methodology for testing building energy simulation programs is described in the literature (ANSI/ASHRAE 2017, Informative Annex B23; ASHRAE 2017, Chapter 19; Judkoff and Neymark 2006). The methodology describes an overall means for applying software-to-software comparative tests (comparing programs to each other), analytical verification tests (comparison of software to analytical solutions), and empirical validation tests (comparison of software to empirical data). In all these types of tests, the methodology emphasizes varying input parameters individually or in related small groups to enhance diagnostic capability.

Like previous test suites that applied the BESTEST method, these new cases have a variety of uses, including the following:

- Comparing predictions from building energy simulation programs to the simulation results in this report, which, with the exception of one program, represent a reasonable range of differences for the current state of the art in simulation modeling.

- Comparing several building energy simulation programs to determine the degree of disagreement among them.

- Diagnosing the algorithmic sources of prediction differences.

- Checking a program against a previous version of itself after the internal code has been modified, to ensure that only the intended changes actually resulted.

- Checking a program against itself after a single algorithmic change to understand the sensitivity between algorithms.

- Providing a set of procedures to evaluate the acceptability of software. Examples of referencing Standard 140 as of the date of publication of this report include IRS 179d; RESNET; ASHRAE 90.1, 90.2, 189.1; IECC; Florida Building Commission; European Energy Performance of Buildings Directive; and others. (IRS 2008; U.S. DOE 2019; RESNET 2013, 2019; ANSI/ASHRAE/IESNA 2016; ANSI/ASHRAE 2018; ANSI/ASHRAE/ICC/USGBC/IES 2017; ICC 2017; ICC 2018; European Union 2018.)

An advantage of the BESTEST methodology is that a program is examined over a broad range of parametric interactions based on a variety of output types, minimizing the possibility of concealing problems by compensating errors. Performance of the tests resulted in quality improvements, or identification of potential improvements, to all of the building energy simulation models used in the field trials. Some of the bugs that were found may well have been present for many years. The fact that they have just now been uncovered shows the power of BESTEST and suggests the importance of continuing 
to develop formalized validation and diagnostic methods. This fact also underscores the need to update existing test suites periodically - as we have done here - as the modeling state of the art improves. Only after coding bugs and input ambiguities have been eliminated can the assumptions and approximations in the algorithms be evaluated.

Checking a building energy simulation program for the first time with the thermal fabric test cases requires approximately one week for an experienced user, not including improvements to the software, if necessary. Subsequent program checks are faster because input files may be reused. Because the simulation programs have taken many years to produce, the updated BESTEST cases provide a cost-effective way of testing them. As we continue to develop new test cases, we will adhere to the principle of parsimony so the entire suite of BESTEST cases may be implemented by users with a reasonable time commitment. Many software developers have automated the tests, further reducing the time to rerun them as an internal quality control check after code modifications.

\subsubsection{Recommendations}

\subsubsection{Adaptation of Test Procedures for ANSI/ASHRAE Standard 140}

The work presented in this report and the work that has preceded it (discussed below) are important for two reasons:

- The methods have been successful at correcting software errors in advanced building energy simulation programs throughout the world.

- The methods are finding their way into industry by being adopted as the theoretical basis for formalized standard methods of test and software certification procedures; in this sense, the work may be thought of as pre-normative research.

The overall validation methodology (Judkoff 1988; Judkoff and Neymark 2006, 2009; Judkoff et al. 2008) is included in the ASHRAE Handbook of Fundamentals (ASHRAE 2017) and informative Annex B23 of Standard 140 (ANSI/ASHRAE 2017). The following test suites, all but two of which were developed in conjunction with the International Energy Agency (IEA), have been code-language adapted and formally approved as a standard method of test, per ANSI/ASHRAE Standard 140-2017, Standard Method of Test for the Evaluation of Building Energy Analysis Computer Programs (ANSI/ASHRAE 2017):

- Class I tests (detailed diagnostic tests for simulation software capable of hourly or subhourly simulation time steps):

- IEA BESTEST, building thermal fabric comparative tests (Judkoff and Neymark 1995a).

- IEA BESTEST, in-depth diagnostic ground-coupled slab-on-grade heat transfer analytical verification tests (Neymark et al. 2008b).

- HVAC BESTEST Volume 1, unitary cooling equipment analytical verification tests (Neymark and Judkoff 2002).

- HVAC BESTEST Volume 2, unitary cooling equipment comparative tests (Neymark and Judkoff 2004).

- HVAC BESTEST fuel-fired furnace analytical verification and comparative tests (Purdy and Beausoleil-Morrison 2003).

- HVAC BESTEST air-distribution system equipment analytical verification tests (Neymark et al. 2016).

- Class II tests (for all types of building load calculation methods regardless of time-step granularity):

- HERS BESTEST, building thermal fabric comparative tests (Judkoff and Neymark 1995b). 
Within the BESTEST/Standard 140 structure, there is room to add new test cases. BESTEST is better developed in areas related to energy flows and energy storage in the architectural fabric of the building. BESTEST work related to mechanical equipment is still in its early phases, in that there are many kinds and configurations of mechanical systems to test.

The updated building thermal fabric modeling test cases described in this report are planned for inclusion in Standard 140. Additional test cases either currently being adapted for inclusion in Standard 140 or prioritized for future inclusion are described in Standard 140 Test Suite Prioritization Roadmap, June 24, 2019 (ASHRAE SSPC 140, 2019). Within the roadmap, the current highest-priority test suites have been identified as follows:

- $\quad$ Airside HVAC BESTEST Volume 2 (follow-on cases to Standard 140, Section 5.5).

- Update HVAC BESTEST Performance Maps with Empirical Data (updates Standard 140, Section 5.3).

- Weather-Driven Infiltration and Natural Ventilation.

- Weather Drivers.

The above test suites are all analytical verification and/or comparative tests, except that the second suite includes empirically determined performance data.

Additional analytical verification and comparative tests within the roadmap include the following:

- Analytical Building Fabric Tests - ASHRAE 1052 RP.

- Domestic Hot Water.

- Ground Coupling (expansion of Standard 140, Section 5.2.4).

- Multi-Zone Non-Airflow Test Cases (from IEA Task 34/43).

- Standard 205 Performance Map Tests.

- Thermal Bridging (2- and 3-dimensional conduction).

Additional empirical validation tests within the roadmap include the following:

- Empirical Test Sets from LBNL Flexlab and ORNL-FRP.

- Empirical Test Set from NREL Indoor/Outdoor Modular Apartment.

- ETNA BESTEST Empirical Validation.

The roadmap is intended to be a "living" document and will be updated periodically by SSPC 140 as inprogress test procedures are completed, new topics are proposed, and/or priorities shift.

\subsubsection{Closing Remarks}

ASHRAE Standard 140 (ANSI/ASHRAE 2017) and the BESTEST reports that comprise the test suites contained therein are being referenced and used worldwide by a growing number of code promulagation authorities. ASHRAE Standard 90.1 (ANSI/ASHRAE/IESNA 2016), which is ASHRAE's consensus energy standard for commercial buildings and for non-low-rise residential buildings, requires that software used for demonstrating performance compliance with Standard 90.1 be tested using the Class I test procedures of ASHRAE Standard 140-2014 (ANSI/ASHRAE 2014). Software used for calculating energy savings for purposes of the energy-efficient commercial building tax deductions in the United States (IRS 2008, U.S. DOE 2019) must be tested with Standard 140-2014 (ANSI/ASHRAE 2014). As part of their building energy performance assessments under the European Community's Energy Performance of Buildings Directive (European Union 2018), several countries are using software tools that have been 
checked with BESTEST. Further details of international use of BESTEST, along with growing evidence that the BESTEST procedures are becoming part of software developers' normal in-house quality control efforts, are included elsewhere (Judkoff and Neymark 2006, 2013; Neymark et al. 2008b, Section 2.6.2.2).

The current set of BESTEST/Standard 140 test suites emphasize isolating the ability to perform specific modeling physics addressed in the tests. As standard methods of test, the BESTEST procedures provide test specifications including input and output requirements, along with vetted example results from iterative simulation trials. The outputs provide metrics for comparison of programs. The vetted example results, along with the diagnostic logic of the test cases, provide a means of diagnosing the sources of identifiable disagreements with the example results. Although the BESTEST procedures provide vetted example results, the procedures do not provide pass/fail or other qualification criteria as discussed in Section 4.4.1 of Standard 140 (ANSI/ASHRAE 2017). This is analogous, for example, to applying procedures to determine the efficiencies of HVAC equipment (e.g., Annual Fuel Utilization Efficiency [AFUE] for a gas-fired furnace), where a procedure exists that provides instructions on how to determine a metric or set of metrics, but it is up to a separate standard or authority-having-jurisdiction to set compliance requirements (e.g., minimum AFUE). Therefore, based solely on running the BESTEST cases - and independent of the requirements of other standards or authorities-having-jurisdiction - it is not appropriate to extrapolate (or otherwise claim) that a program has "passed" BESTEST or been validated in its entirety.

Computer scientists universally accept the merits of software testing. A well-known rule of thumb is that in a typical programming project, more than $50 \%$ of the total cost is expended in testing the program or system being developed (Myers 2004). Of this, about 20\% of development time goes toward system testing (McConnell 2004). Because new energy-related technologies are continually being introduced into the buildings market, there will always be a need for further development of simulation models, combined with a substantial program of testing and validation. Such an effort should contain all the elements of an overall validation methodology (ANSI/ASHRAE 2017, Informative Annex B23; ASHRAE 2017, Ch. 19; Judkoff and Neymark 2006), including:

- Analytical verification

- Comparative testing and diagnostics

- Empirical validation.

Future work should therefore continue to:

- Produce analytical verification tests where possible

- Develop a set of diagnostic comparative tests that emphasize the modeling issues important in large commercial buildings, including more tests for heating, ventilating, and air-conditioning systems and other mechanical equipment, including on-site power generation equipment

- Develop a sequentially ordered series of high-quality diagnostic data sets for empirical validation.

The work described here represents continuing progress in the effort to develop carefully validated building energy simulation tools. Continued development and validation of whole-building energy simulation programs are two of the most important activities meriting the support of national energy research programs, and are a beneficial area for international collaboration. The U.S. Department of Energy should continue its support of this essential research area.

Finally, the authors wish to acknowledge that the expertise available through ASHRAE SSPC 140 and other international participants, and their dedication to the simulation trials, were essential to the success of this project. Over the five-year field-trial effort, there were several revisions to the test specifications and subsequent re-executions of the computer simulations. This iterative process led to the refining of the 
new BESTEST cases, and the results of the tests led to improving and debugging of the simulation models. This process underscores the importance of the software development industry participation in this project via the ASHRAE Standard 140 project committee (SSPC 140), and via our previous collaborations with IEA software testing and validation projects. Extensive field trials and resulting enhancements to the tests were much more comprehensive and cost-effective with the participation of the national and international software-development industry experts. Their persistence throughout the project demonstrates their interest in, and the importance of, this work.

\subsection{Abbreviations and Acronyms Used in Part III}

These abbreviations and acronyms are used in Sections 3.1 through 3.6.

$\begin{array}{ll}\text { ANSI } & \text { American National Standards Institute } \\ \text { ASHRAE } & \text { American Society of Heating, Refrigerating and Air-Conditioning Engineers } \\ \text { BESTEST } & \text { Building Energy Simulation Test and Diagnostic Method } \\ \text { BSIMAC } & \text { simulation program; see Part II, Table 2-1 } \\ \text { Calc } & \text { calculation } \\ \text { clg } & \text { cooling } \\ \text { coeffs } & \text { coefficients } \\ \text { CSE } & \text { simulation program; see Part II, Table 2-1 } \\ \text { DeST } & \text { simulation program; see Part II, Table 2-1 } \\ \text { DOE } & \text { United States Department of Energy } \\ \text { EnergyPlus } & \text { simulation program; see Part II, Table 2-1 } \\ \text { ESP-r } & \text { simulation program; see Part II, Table 2-1 } \\ \text { ETNA } & \text { Essais Thermiques en climat Naturel et Artificiel (Thermal Studies in Natural and } \\ & \text { Artificial Climate) } \\ \text { ext } & \text { exterior } \\ \text { E\&W } & \text { East and West } \\ \text { h,conv } & \text { convective heat transfer coefficient } \\ \text { htg } & \text { heating } \\ \text { HVAC } & \text { heating, ventilating, and air conditioning } \\ \text { IEA } & \text { International Energy Agency } \\ \text { IESNA } & \text { Illuminating Engineering Society of North America } \\ \text { int } & \text { interior } \\ \text { LBNL } & \text { Lawrence Berkeley National Laboratory } \\ \text { n/a } & \text { not applicable } \\ \text { NewHASP } & \text { simulation program; see Part II, Table 2-1 } \\ \text { NREL } & \text { National Renewable Energy Laboratory } \\ \text { ORNL-FRP } & \text { Oak Ridge National Laboratory - Flexible Research Platforms } \\ \text { RP 1052 } & \text { Spitler et al. (2001) } \\ \text { SSPC 140 } & \text { ASHRAE Standing Standard Project Committee 140, responsible for } \\ & \text { ANSI/ASHRAE Standard 140 Standard Method of Test for the Evaluation of } \\ \text { T } & \text { Building Energy Analysis Computer Programs } \\ \text { Task 34/43 } & \text { temperature } \\ \text { IEA research task: Solar Heating and Cooling Programme Task 34 / Energy } \\ \text { TMY } & \text { Conservation in Buildings and Community Systems Task 43 } \\ \text { TMY3 } & \text { Typical Meteorological Year (weather data) } \\ \text { TRNSYS } & \text { Typical Meteorological Year, version 3 (weather data) } \\ \text { simulation program; see Part II, Table 2-1 } \\ \end{array}$




\subsection{References for Part III}

ANSI/ASHRAE Standard 140-2001 (2001). Standard Method of Test for the Evaluation of Building Energy Analysis Computer Programs. Atlanta, Georgia, U.S.A.: American Society of Heating, Refrigerating, and AirConditioning Engineers, Inc.

ANSI/ASHRAE Standard 140-2011 (2011). Standard Method of Test for the Evaluation of Building Energy Simulation Computer Programs. Atlanta, Georgia, U.S.A.: American Society of Heating, Refrigerating and AirConditioning Engineers.

ANSI/ASHRAE Standard 140-2014 (2014). Standard Method of Test for the Evaluation of Building Energy Simulation Computer Programs. Atlanta, Georgia, U.S.A.: American Society of Heating, Refrigerating and AirConditioning Engineers.

ANSI/ASHRAE Standard 140-2017 (2017). Standard Method of Test for the Evaluation of Building Energy Analysis Computer Programs. Atlanta, Georgia, U.S.A.: American Society of Heating, Refrigerating, and AirConditioning Engineers, Inc.

ANSI/ASHRAE Standard 90.2-2018 (2018). Energy-Efficient Design of Low-Rise Residential Buildings. Atlanta, Georgia, U.S.A.: American Society of Heating, Refrigerating, and Air-Conditioning Engineers, Inc.

ANSI/ASHRAE/ICC/USGBC/IES (2017). Standard for the Design of High-Performance Green Buildings Except Low-Rise Residential Buildings. Atlanta, Georgia, U.S.A.: American Society of Heating, Refrigerating, and Air-Conditioning Engineers, Inc.

ANSI/ASHRAE/IESNA (2016) ANSI/ASHRAE/IESNA Standard 90.1-2016, Energy Standard for Buildings Except Low-Rise Residential Buildings. Atlanta, Georgia, U.S.A.: American Society of Heating, Refrigerating and AirConditioning Engineers.

ASHRAE (2013). Handbook of Fundamentals. Atlanta, Georgia, U.S.A.: American Society of Heating, Refrigerating, and Air-Conditioning Engineers, Inc.

ASHRAE (2017). Handbook of Fundamentals. Atlanta, Georgia, U.S.A.: American Society of Heating, Refrigerating, and Air-Conditioning Engineers, Inc.

ASHRAE SSPC 140 (2019). Standard 140 Test Suite Prioritization Roadmap, June 24, 2019. Standing Standard Project Committee working document. Atlanta, Georgia, U.S.A.: American Society of Heating, Refrigerating, and Air-Conditioning Engineers, Inc. Posted on ASHRAE SSPC 140 Basecamp site, limited access, available on request, contact SSPC 140 Chair, J. Neymark, at neymarkj@msn.com.

European Union (2018). Directive (EU) 2018/844 of the European Parliament and of the Council of 30 May 2018 amending Directive 2010/31/EU on the energy performance of buildings and Directive 2012/27/EU on energy efficiency. Official Journal of the European Union, L 156/75, June 2018. https://eur-lex.europa.eu/legalcontent/EN/TXT/?toc=OJ\%3AL\%3A2018\%3A156\%3ATOC\&uri=uriserv\%3AOJ.L_.2018.156.01.0075.01.ENG

ICC. (2017) 2017 Florida Building Code - Energy Conservation. $6^{\text {th }}$ Edition. Country Club Hills, Illinois, U.S.A.: International Code Council.

ICC (2018). 2018 International Energy Conservation Code (IECC). Country Club Hills, IL: International Code Council.

Internal Revenue Service (IRS) (2008). Amplification of Notice 2006-52, Deduction for Energy Efficient Commercial Buildings. IRS Notice 2008-40. Appears in Internal Revenue Bulletin (IRB) No. 2008-14, April 7, 2008. Washington, D.C., U.S.A.: United States Department of Treasury, Internal Revenue Service.

Judkoff, R. (1988). "Validation of Building Energy Analysis Simulation Programs at the Solar Energy Research Institute." Energy and Buildings, 10 (3) 235. Lausanne, Switzerland: Elsevier Sequoia.

Judkoff, R., and J. Neymark (1995a). International Energy Agency Building Energy Simulation Test (BESTEST) and Diagnostic Method. NREL/TP-472-6231, Golden, Colorado: National Renewable Energy Laboratory.

https://www.nrel.gov/docs/legosti/old/6231.pdf. 
Judkoff, R., and J. Neymark (1995b). Home Energy Rating System Building Energy Simulation Test (HERS BESTEST), Volume 1: Tier 1 and Tier 2 Tests User's Manual. NREL/TP-472-7332a. Golden, Colorado, U.S.A.: National Renewable Energy Laboratory. www.nrel.gov/docs/legosti/fy96/7332a.pdf.

Judkoff, R.; Neymark, J. (2006). "Model Validation and Testing: The Methodological Foundation of ASHRAE Standard 140." ASHRAE Transactions, 112 (2) 367-376. Atlanta, Georgia, U.S.A.: American Society of Heating, Refrigerating and Air-Conditioning Engineers. http://www.nrel.gov/docs/fy06osti/40360.pdf.

Judkoff, R., and J. Neymark (2009). "What did they do in IEA 34/43? Or how to diagnose and repair bugs in 500,000 lines of code". Proceedings Building Simulation 2009, Glasgow, U.K., July 27-30, 2009. International Building Performance Simulation Association. Also see the preprinted version, NREL/CP-550-44978. Golden, Colorado, U.S.A.: National Renewable Energy Laboratory www.nrel.gov/docs/fy09osti/44978.pdf.

Judkoff, R., Polly, B., Bianchi, M., and J. Neymark (2010). Building Energy Simulation Test for Existing Homes (BESTEST-EX) Phase 1 Test Procedure: Building Thermal Fabric Cases. NREL/TP-550-47427. Golden, Colorado, U.S.A.: National Renewable Energy Laboratory. http://www.nrel.gov/docs/fy10osti/47427.pdf.

Judkoff, R.; Neymark, J. (2013). “Twenty Years On!: Updating the IEA BESTEST Building Thermal Fabric Test Cases for ASHRAE Standard 140.” Proceedings of Building Simulation 2013. Chambéry, France. International Building Performance Simulation Association. Preprint version, NREL/CP-5500-58487. Golden, Colorado, U.S.A.: National Renewable Energy Laboratory. http://www.nrel.gov/docs/fy13osti/58487.pdf .

Judkoff, R.; Wortman, D.; O'Doherty, B.; Burch, J. (2008). A Methodology for Validating Building Energy Analysis Simulations. NREL/TP-550-42059. Golden, Colorado, U.S.A.: National Renewable Energy Laboratory. Based on unpublished report of 1983 with same authors and title, previously referenced as SERI/TR-254-1508. http://www.nrel.gov/docs/fy08osti/42059.pdf

Martin, M., and P. Berdahl (1984). Characteristics of Infrared Sky Radiation in the United States. Solar Energy, Vol. 33. No. 3/4, pp. 321-336. Oxford, U.K.: Pergamon Press Ltd.

McConnell, S. (2004). Code Complete: A Practical Handbook of Software Construction. Microsoft Press, p. 502.

Myers, G. (2004). The Art of Software Testing. Hoboken, New Jersey, U.S.A.: John Wiley \& Sons, p. xiii.

Neymark, J., and R. Judkoff (2002). International Energy Agency Building Energy Simulation Test and Diagnostic Method for Heating, Ventilating, and Air-Conditioning Equipment Models (HVAC BESTEST) Volume 1: Cases E100-E200. NREL/TP-550-30152. Golden, Colorado, U.S.A.: National Renewable Energy Laboratory. www.nrel.gov/docs/fy02osti/30152.pdf.

Neymark, J., and R. Judkoff (2004). International Energy Agency Building Energy Simulation Test and Diagnostic Method for Heating, Ventilating, and Air-Conditioning Equipment Models (HVAC BESTEST), Volume 2: Cases E300-E545. NREL/TP-550-36754. Golden, Colorado, U.S.A.: National Renewable Energy Laboratory. Available from www.nrel.gov/docs/fy05osti/36754.pdf.

Neymark, J., R. Judkoff, D. Alexander, D., C. Felsmann, P. Strachan, and A. Wijsman (2008a). International Energy Agency Building Energy Simulation Test and Diagnostic Method (IEA BESTEST) Multi-Zone Non-Airflow In-Depth Diagnostic Cases: MZ320-MZ360. NREL/TP-550-43827. Golden, Colorado, U.S.A.: National Renewable Energy Laboratory. www.nrel.gov/docs/fy08osti/43827.pdf

Neymark, J., R. Judkoff, I. Beausoleil-Morrison, A. Ben-Nakhi, M. Crowley, M. Deru, R. Henninger, H. Ribberink, J. Thornton, A. Wijsman, and M. Witte (2008b). International Energy Agency Building Energy Simulation Test and Diagnostic Method (IEA BESTEST) In-Depth Diagnostic Cases for Ground Coupled Heat Transfer Related to Slabon-Grade Construction. NREL/TP-550-43388. Golden, Colorado, U.S.A.: National Renewable Energy Laboratory, in collaboration with International Energy Agency Solar Heating and Cooling Program Task 34 and Energy Conservation in Buildings and Community Systems Annex 43. www.nrel.gov/docs/fy08osti/43388.pdf.

Neymark, J.; Kennedy, M.; Judkoff, R.; Gall, J.; Henninger, R.; Hong, T.; Knebel, D.; McDowell, T.; Witte, M.; Yan, D.; and Zhou, X. (2016). Airside HVAC BESTEST: Adaptation of ASHRAE RP 865 Airside HVAC Equipment Modeling Test Cases for ASHRAE Standard 140, Volume 1: Cases AE101-AE445. NREL/TP-5500-66000. Golden, Colorado, U.S.A.: National Renewable Energy Laboratory. www.nrel.gov/docs/fy16osti/66000.pdf. 
Neymark, J., Kummert, M., and Judkoff, R. (2019). “Developing Equivalent Surface Heat Transfer Input Parameters for Updated Standard 140/BESTEST Thermal Fabric Test Cases." Proceedings of Building Simulation 2019. Rome, Italy. Sep 2-4. International Building Performance Simulation Association.

Purdy, J., and I. Beausoleil-Morrison (2003). Building Energy Simulation Test for Heating, Ventilating, and AirConditioning Equipment Models (HVAC BESTEST), IEA Fuel-Fired Furnace. Ottawa, ON: CANMET Energy

Technology Centre, Natural Resources Canada. www.ieashc.org/data/sites/1/publications/Furnace\%20HVAC\%20BESTEST\%20Report.pdf.

RESNET (2013). Mortgage Industry National Home Energy Rating System Standards. Oceanside, CA: RESNET.

RESNET (2019). RESNET Accredited Rating Software Tools. Oceanside, CA: RESNET. http://www.resnet.us/professional/programs/software.

Spitler, J.D., S.J. Rees, and D. Xiao (2001). Development of an Analytical Verification Test Suite for Whole Building Energy Simulation Programs - Building Fabric. Final Report for ASHRAE 1052-RP. Atlanta, Georgia, U.S.A.: ASHRAE.

U.S. DOE (2019). Qualified Software for Calculating Commercial Building Tax Deductions. Washington, D.C.: U.S. Department of Energy, Office of Energy Efficiency and Renewable Energy, Building Technologies Program. http://energy.gov/eere/buildings/qualified-software-calculating-commercial-building-tax-deductions. Last accessed Aug 11, 2019.

WINDOW 6 (2013). THERM 6.3 / WINDOW 6.3 NFRC Simulation Manual. LBNL-48255. Berkeley, California, U.S.A.: Lawrence Berkeley National Laboratory. https://windows.lbl.gov/software/NFRC/SimMan/NFRCSim6.32013-07-Manual.pdf.

WINDOW 7 (2016). Berkeley Lab WINDOW 7.4. Berkeley, California, U.S.A.: Lawrence Berkeley National Laboratory. https://windows.lbl.gov/software/window/7/index_7_4_8.html. Last accessed October 25, 2016. Note: WINDOW 6 (2013) is the relevant user's manual. LBNL Window 7 (2016) 


\subsection{Appendix III: Simulation Modeler Reports Accompanying File}

Here we include reports written by the modelers for each simulation program. The modeler reports are provided in the accompanying file "ModelerReports-ThermalFabricUpdate.pdf"; see folder "ISec52AISupplementary”.

The modelers were asked to document the following:

- Modeling assumptions (required inputs not explicitly described in the test specification).

- Modeling options (alternative modeling techniques).

- Difficulties experienced in developing input files for the test cases with their programs.

- Bugs, faulty algorithms, documentation problems, and input errors uncovered during the field trials.

- Source code or input modifications made because of the diagnostic results.

- Comments on agreement or disagreement of results compared to the quasi-analytical solution and other simulation results.

- Any odd results obtained with their programs.

- Sensitivity studies conducted to further understand the sources of differences between their programs and the others.

- Conclusions and recommendations about their simulation models, the test specification, or both.

Modelers also filled out a pro forma description that defines inputs for the test cases and submitted S140outNotes forms; the submitted pro forma description and S140outNotes forms are provided at the end of each individual modeler report. The modeler reports appear as submitted, with minimal reformatting and editing.

Some discussion in the modeler reports applies to early versions of the test specification (see Part I). For example, table, figure, and section numbering may have changed, and much of the discussion of Informative Annex B4 has been moved to Part IV, Appendix A, for this final report. We apologize for any confusion in this regard.

\section{Contents of this appendix (within the accompanying .pdf file)}

Appendix III-A: BSIMAC, Alec Johannsen Consulting Engineers, South Africa ................................... 2

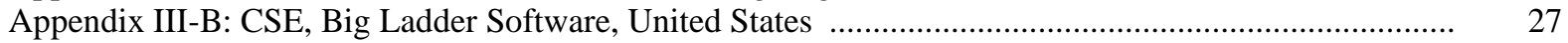

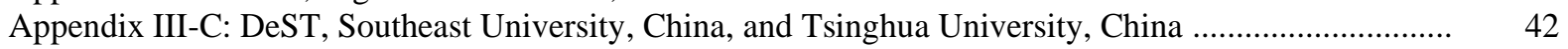

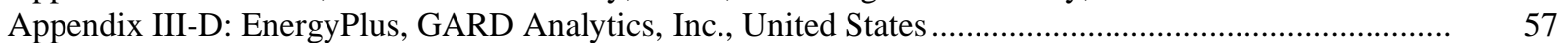

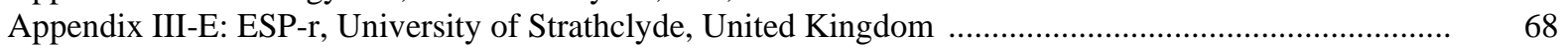

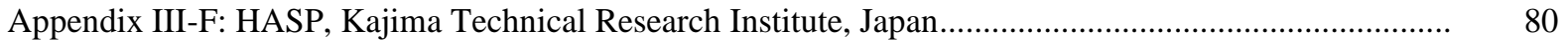

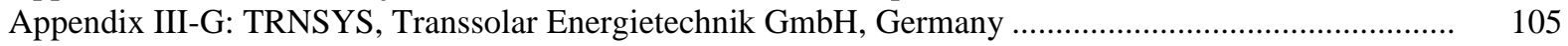




\subsection{Part IV: Other Supporting-Material Appendices}

\section{A Appendix A: Development of Alternative Constant Convective-Only and Combined Radiative-and- Convective Surface Coefficients of Standard 140, Informative Annex B4.}

\section{A.1 Introduction}

Appendix A provides the following material:

- Methods for calculating alternative constant convective heat transfer coefficients; see Section 4A.2.

- Calculation of alternative convective and combined (radiative and convective) surface heat transfer coefficients applying verified simulations; see Section 4A.3.

- Archive of preliminary work to develop alternative constant heat transfer coefficients; see Section 4A.4.

- Comparison of new versus Standard 140-2017 (originally published in 1995) alternative constant heat transfer coefficients; see Section 4A.5.

The aim of this work is to improve (narrow) the range of differences among the example simulation results for the BESTEST/Standard 140 building thermal fabric test suite, by better defining the original test specification related to surface heat transfer modeling. This approach also enhances the diagnostic power of the test suite to find other sources of disagreement. A summary of this work is provided by Neymark et al. (2019).

\section{A.2 Methods for Calculating Alternative Constant Convective Heat Transfer Coefficients}

4A.2.1 Exterior surface convective heat transfer coefficients $\left(h_{\text {conv,ext }}\right)$. The convective heat transfer calculation applies an algorithm combining wind- and buoyancy-driven convection. The algorithm is based on measured data for glass surfaces from Lawrence Berkeley National Laboratory's Mobile Window Thermal Test (MoWiTT) facility (Yazdanian and Klems 1994). This algorithm was selected over the previous algorithm for combined convective and radiative coefficients published in ASHRAE Standard 140-2017 (ANSI/ASHRAE 2017; Judkoff and Neymark 1995; Walton 1983; Rowley et al. 1930), because the MoWiTT coefficients were developed from measurements on building-scale-sized surfaces applying measurement methods that have advanced since 1930 (see Section 4A.2.1.2 below). The recorded uncertainty of the MoWiTT measurements is about $\pm 2.5 \%$ for windward and $\pm 5 \%$ for leeward data at a weather-tower wind speed of $3 \mathrm{~m} / \mathrm{s}$.

For application here, the original MoWiTT algorithm is modified for local-height wind speed (Booten et al. 2012). The modified algorithm also accounts for surface orientation (Walton 1983; ASHRAE 1981, 2001) and surface roughness (Walton 1983; Rowley et al. 1930), as applied in the EnergyPlus "DOE-2 Model" (U.S. DOE 2018). The resulting model is formulated as

$$
\mathrm{h}_{\text {conv,ext }}=\mathrm{h}_{\mathrm{n}}+\mathrm{R}_{\mathrm{f}}\left(\mathrm{h}_{\mathrm{c}, \text { glass }}-\mathrm{h}_{\mathrm{n}}\right), \mathrm{W} /\left(\mathrm{m}^{2} \mathrm{~K}\right)
$$

where:

$$
\begin{aligned}
& \mathrm{h}_{\mathrm{n}}=\mathrm{a}\left|\Delta \mathrm{T}_{\mathrm{ext}}\right|{ }^{1 / 3}, \mathrm{~W} /\left(\mathrm{m}^{2} \mathrm{~K}\right) \\
& \text { where: } \mathrm{a}=1.31 \text { (vertical), } 0.76 \text { (stable horizontal), } 1.51 \text { (unstable horizontal); }{ }^{1} \\
& \text { "vertical" and "horizontal" refer to surface orientation, "stable" refers to retarded convection for } \\
& \text { rising warmer air or falling cooler air driven towards a surface, and "unstable" refers to enhanced } \\
& \text { convection for rising warmer air or falling cooler air moving away from a surface; } \\
& \text { and } \Delta \mathrm{T}_{\text {ext }} \text { is the temperature difference between the exterior surface and ambient dry-bulb } \\
& \text { temperature. } \\
& \mathrm{R}_{\mathrm{f}}=1.67 \text { (Rough), } 1.00 \text { (Very Smooth); more roughness coefficients are listed elsewhere (U.S. DOE 2018; } \\
& \text { Walton 1983). }
\end{aligned}
$$

\footnotetext{
${ }^{1}$ In these test cases, all surfaces are either vertical or horizontal. In the generalized algorithm (U.S. DOE 2018), the "a" coefficient varies from (between) the given values as a function of surface tilt angle.
} 


$$
\mathrm{h}_{\mathrm{c}, \text { glass }}=\left(\mathrm{h}_{\mathrm{n}}^{2}+\left(\mathrm{cV}_{\mathrm{z}}^{\mathrm{d}}\right)^{2}\right)^{(1 / 2)}, \mathrm{W} /\left(\mathrm{m}^{2} \mathrm{~K}\right)
$$

where: $h_{n}$ is the buoyancy-driven flow component described above, and $V_{z}$ is the local wind speed calculated at the height above ground of the surface centroid (see Section 4A.2.1.1);

and coefficients $\mathrm{c}$ and $\mathrm{d}$ vary with wind direction relative to the surface as follows: windward: $\mathrm{c}=$ 3.260, $d=0.890$; leeward: $c=3.550, d=0.617$ (Booten et al. 2012; U.S. DOE 2018). Regarding definition of leeward: Yazdanian and Klems (1994, p.4) indicate their data tabulations correspond to "windward and leeward hemispheres", interpretable as leeward being definable as $>90$ degrees from normal wind incidence. The roof is always windward, consistent with EnergyPlus documentation of its "adaptive convection algorithm" options for roof exterior surface heat transfer coefficient models. (U.S. DOE 2018, Table 3.11)

Other methods for calculating the convective portions of combined coefficients are documented elsewhere. (e.g., U.S. DOE 2018)

4A.2.1.1 Wind Speed at Local Height. The verified simulation calculations apply wind speed from the hourly weather data modified for the height of the respective surface centroids using the following equation.

$$
V=V_{m e t}\left(\frac{\delta_{m e t}}{z_{m e t}}\right)^{a m e t}\left(\frac{z}{\delta}\right)^{a}, \mathrm{~m} / \mathrm{s}
$$

where $V$ is the local wind speed, $V_{m e t}$ is the wind speed at the weather station, $z_{m e t}$ is the height of the wind speed measurement (assumed to be $10 \mathrm{~m}$ ), and $z$ is the height of the surface centroid. $\delta$ and $a$ are terrain-dependent coefficients found in ASHRAE 2013, p. 24.3, Table 1. Both the weather measurement and the building site are assumed to be in Terrain Category " 3 " ( $\delta$ met $=\delta=$ $\left.270 \mathrm{~m}, a_{m e t}=a=0.14\right)$. ASHRAE's description for this terrain condition is: "Open terrain with scattered obstruction having heights generally less than $9 \mathrm{~m}$, including flat open country typical of meteorological station surroundings."

The exterior surface of the floor sees 0 wind speed, as indicated in Section 5.2.1.5.1.

4A.2.1.1.1 Use of Approximate Centroid. Given the approximate nature of the convective surface coefficient calculation, locating the centroid for vertical surfaces at half the building height $(1.35 \mathrm{~m})$ is deemed sufficient. Actual centroid height of windows is $1.20 \mathrm{~m}$, which would result in about a $1 \%$ change to the convective portion of the total combined surface coefficient for the very smooth window (or high-conductance wall element) surface. This surface is most relevant here because the exterior surface coefficient matters most for the windows (or highconductance wall elements) versus other types of surfaces, with respect to total air-to-air conductance. The difference in $\mathrm{h}_{\text {conv,ext }}$ is less than the recorded uncertainty of the MoWiTT measurements, which is about $\pm 2.5 \%$ for windward and $\pm 5 \%$ for leeward data at a weather-tower wind speed of $3 \mathrm{~m} / \mathrm{s}$. Consistently implementing multiple centroids for vertical walls with windows would also require evaluating separate constant surface coefficient values for south, east, and west walls for a variety of surface geometries specified in the test suite, which is not justified by the uncertainty in the source measurement data.

4A.2.1.2 Surface Roughness Coefficients, History. The surface roughness coefficients of the TARP "Detailed" algorithm (Walton 1983) are based on ratios of surface conductances from previous measured data published by ASHRAE (1981, p. 23.2, Fig. 1 [as cited by Walton (1983)]). A plot of these conductances most recently appears in ASHRAE 2009 (p. 26.2, Fig 1), but was excluded from the 2013 edition. The original source of this work is Rowley et al (1930), which is also the original source of the previously applied simple combined coefficient based on a polynomial correlation of wind speed, previously applied in ASHRAE Standard 140-2017 (ANSI/ASHRAE 2017). Rowley et al. measured combined coefficients by locating a 12-inch square guarded hot plate surface in a cut-out portion of a long duct/wind tunnel (for fully developed tangential refrigerated/cold air flow) with the duct inside surface painted gray for uniform radiative exchange. They applied thermocouples to the surface of the hot plate, and used an unshielded thermocouple 1 inch from the hot plate surface for measuring air temperature in their duct. [Note: In this configuration, the unshielded air temperature thermocouple can receive radiation from the hot plate 
surface, resulting in a temperature measurement greater than the actual cold-air temperature, and the ultimate result may be an elevated combined heat transfer coefficient (recall, $h=q / \Delta T$ ).]

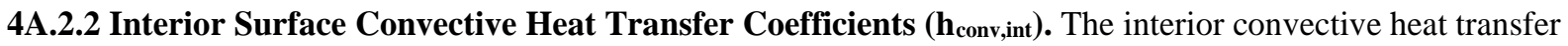
calculation applies an algorithm, see Equation 4A-5 below, for buoyancy-driven convection as a function of surfaceto-zone-air temperature difference and surface orientation (Walton 1983). Surface roughness is not considered in this algorithm. The algorithm is based on measured data (ASHRAE 1981, p. 2.12, Table 5 [also see ASHRAE 2001, p. 3.12, Table 5.]). The algorithm is the same as the natural convection portion of the $h_{\text {convext }}$ calculation (see Section 4A.2.1, equation 4A-2), but with different variable subscripts, as follows:

$$
\mathrm{h}_{\mathrm{conv}, \text { int }}=\mathrm{a}\left|\Delta \mathrm{T}_{\text {int }}\right|^{1 / 3}, \mathrm{~W} /\left(\mathrm{m}^{2} \mathrm{~K}\right)
$$

where: $\mathrm{a}=1.31$ (vertical), 0.76 (stable horizontal), 1.52 (unstable horizontal);

"vertical" and "horizontal" refer to surface orientation, "stable" refers to retarded convection for rising warmer air or falling cooler air driven towards a surface, and "unstable" refers to enhanced convection for rising warmer air or falling cooler air moving away from a surface;

and $\Delta \mathrm{T}_{\text {int }}$ is the temperature difference between the interior surface and zone air.

The algorithm of Equation 4A-5 was selected over the previous listing of convective coefficients published in ASHRAE Standard 140-2017 (ANSI/ASHRAE 2017; Judkoff and Neymark 1995; ASHRAE 1981, p. 23.12, Table 1); also see ASHRAE (2013), p. 26.20, which lists combined (convective and radiative) coefficients; the original source of these coefficients is not obviously cited in ASHRAE (1981) or (2013).

Table 4A-1 provides comparisons of buoyancy-driven convective coefficients calculated with Equation 4A-5 versus other buoyancy-driven calculation methods; the values that were calculated by applying Equation 4A-5 are labeled as "TARP 1983" in the table. Many of these methods, including the TARP method, are model options for EnergyPlus (U.S. DOE 2018) for buoyancy-driven surface airflow. The "J/N 1995" constant values and the "C/G 1995" method are not EnergyPlus options. The TARP method is also an option in TRNSYS (Klein et al. 2018a). So, "TARP 1983" is deemed appropriate for use with building energy modeling. Compared with other methods listed in Table 1, "TARP 1983" appears to have mostly better agreement with other methods than use of the "J/N1995" constant values, Specifically, for vertical surfaces, results for the algorithm of Equation 4A-5 appear to have good agreement with correlations based on other measured data (Fohanno and Polidori 2006; Alamdari and Hammond 1983), all of which produce lower values for convective coefficients than those based on the earlier ASHRAE combined coefficients (after the radiative portion is subtracted out of the ASHRAE combined coefficients [see the "J/N 1995" values in Table 4A-1]). There is some disagreement with Curcija and Goss (1995) and ISO 15099 (2003): the correlations from these sources are based on the same data sets, which applied empirical data using water rather than air as the convective transport medium. For horizontal surfaces, the correlations of Equation 4A-5, Alamdari and Hammond (1983), and Curcija and Goss (1995) produce lower convective coefficients than those based on the ASHRAE combined coefficients, albeit with better agreement for enhanced (unstable) convection than for retarded (stable) convection. Table 4A-17 (see Section 4A.4.2) indicates that floor convection tends to be enhanced while ceiling convection tends to be stable.

Other methods for calculating the convective portions of combined coefficients are documented elsewhere (e.g., U.S. DOE 2018). 
Table 4A-1. Example Convective Surface Coefficients from a Variety of Calculation Methods

\begin{tabular}{|c|c|c|c|c|c|c|}
\hline Method & Units & h,conv & h,conv & h,conv & h,conv & h,conv \\
\hline$\Delta T$ & $\left({ }^{\circ} \mathrm{C}\right)$ & 0.5 & 1 & 5 & 10 & 15 \\
\hline \multicolumn{7}{|l|}{ Vertical } \\
\hline J/N 1995 & $\mathrm{~W} /\left(\mathrm{m}^{2} \mathrm{~K}\right)$ & 3.16 & 3.16 & 3.16 & 3.16 & 3.16 \\
\hline A/H 1983 & $\mathrm{~W} /\left(\mathrm{m}^{2} \mathrm{~K}\right)$ & 1.15 & 1.40 & 2.26 & 2.79 & 3.17 \\
\hline F/P 2006 & $\mathrm{~W} /\left(\mathrm{m}^{2} \mathrm{~K}\right)$ & 1.09 & 1.36 & 2.25 & 2.81 & 3.19 \\
\hline TARP 1983 & $W /\left(m^{2} K\right)$ & 1.04 & 1.31 & 2.24 & 2.82 & 3.23 \\
\hline C/G 1995 & $\mathrm{~W} /\left(\mathrm{m}^{2} \mathrm{~K}\right)$ & 1.03 & 1.23 & 1.84 & 2.18 & 2.42 \\
\hline ISO 2003 & $\mathrm{~W} /\left(\mathrm{m}^{2} \mathrm{~K}\right)$ & 0.96 & 1.14 & 1.70 & 2.02 & 2.23 \\
\hline \multicolumn{7}{|c|}{ Horizontal Stable } \\
\hline J/N 1995 & $\mathrm{~W} /\left(\mathrm{m}^{2} \mathrm{~K}\right)$ & 1.00 & 1.00 & 1.00 & 1.00 & 1.00 \\
\hline A/H 1983 & $\mathrm{~W} /\left(\mathrm{m}^{2} \mathrm{~K}\right)$ & 0.24 & 0.28 & 0.38 & 0.44 & 0.48 \\
\hline C/G 1995 & $\mathrm{~W} /\left(\mathrm{m}^{2} \mathrm{~K}\right)$ & 0.34 & 0.40 & 0.55 & 0.63 & 0.68 \\
\hline TARP 1983 & $W /\left(m^{2} K\right)$ & 0.60 & 0.76 & 1.30 & 1.64 & 1.87 \\
\hline \multicolumn{7}{|c|}{ Horizontal Unstable } \\
\hline J/N 1995 & $\mathrm{~W} /\left(\mathrm{m}^{2} \mathrm{~K}\right)$ & 4.13 & 4.13 & 4.13 & 4.13 & 4.13 \\
\hline A/H 1983 & $\mathrm{~W} /\left(\mathrm{m}^{2} \mathrm{~K}\right)$ & 1.15 & 1.40 & 2.26 & 2.79 & 3.17 \\
\hline C/G 1995 & $\mathrm{~W} /\left(\mathrm{m}^{2} \mathrm{~K}\right)$ & 1.26 & 1.59 & 2.72 & 3.43 & 3.92 \\
\hline TARP 1983 & $W /\left(m^{2} K\right)$ & 1.20 & 1.51 & 2.58 & 3.25 & 3.72 \\
\hline
\end{tabular}

Notes:

IntSurfCoeffAnalysis-062315+122318.xlsx; AlgCompare!v36+

J/N 1995. Judkoff and Neymark (1995). Based on ASHRAE (1981, Table 1, p. 23.12) combined coefficients with radiative portion subtracted out. These are the values previously provided (in Standard 140-2017) for programs that do not automatically calculate surface heat transfer. A/H 1983. Alamdari and Hammond (1983). Correlations based on 9 data sets ( 8 for air, 1 for water) collected by various authors from 1922 to 1982, applying building-scale and smaller surfaces. Vertical surface calculation here applies height $=2 \mathrm{~m}$ (the window height); horizontal surface calculation applies hydraulic diameter $=4 \mathrm{x}$ (floor area) $/$ (floor perimeter length) $=6.86 \mathrm{~m}$ for $8 \mathrm{~m} \times 6 \mathrm{~m}$ zone floor dimensions.

F/P 2006. Fohanno and Polidori (2006). Results are within $\leq 10 \%$ of three relatively recent, full-scale, measured data sets, all for air collected by various authors from 1987 to 1999 . Calculation here applies mixed laminar and turbulent convection, and a height of $2 \mathrm{~m}$ (the window height),

TARP 1983. Walton (1983), for large surfaces, citing ASHRAE (1981, p. 2.12, Table 5). Per Curcija and Goss (1995), this approach is based on McAdams' (1954) method for data taken with relatively high film temperatures (about $100^{\circ} \mathrm{C}$ ).

C/G 1995. Curcija and Goss (1995). Cites data published in 1972 using electrically heated flat plates immersed in water; this is one of the data sets cited by Alamdari and Hammond (1983). These data were also applied for developing ISO 15099 (2003), however, C/G 1995 applies more simplified formulae than ISO 2003. Per Neymark et al (1989), there can be transport fluid behavior [e.g., f(Prandtl Number)] issues when trying to emulate air behavior in water (e.g., on the order of $25 \%$ lower Nusselt number in water than air for natural convection through apertures within an enclosure). Booten et al. (2012) indicates that C/G 1995 has better agreement with ISO 2003 than shown here; air density at altitude may be the reason, as agreement improves for sea-level density $=1.2 \mathrm{~kg} / \mathrm{m}^{3}$, while density $=1.04 \mathrm{~kg} / \mathrm{m}^{3}$ is applied here. (Density = $1.04 \mathrm{~kg} / \mathrm{m} 3$ is calculated from Patm at altitude, applying rough average of Patm values coincident with occurrence of $23.3^{\circ} \mathrm{C}$ dry-bulb temperature). For vertical surface calculation here, a height of $2 \mathrm{~m}$ (the window height) is applied, and for stable horizontal surfaces a characteristic length of $8 \mathrm{~m}$ (floor length) is applied; unstable horizontal convection is independent of length in this calculation.

ISO 2003. ISO 15099 (2003). Discussed in note "C/G 1995" just above. The calculation here applies the following assumptions: vertical surface height $=2 \mathrm{~m}$ (the window height), environment temperature $=23.5^{\circ} \mathrm{C}$ (average of zone temperature setpoints used for developing thermal properties), air density $=1.04 \mathrm{~kg} / \mathrm{m} 3$ (see note "C/G 1995" just above). 


\section{A.3 Calculation of Alternative Convective and Combined Surface Heat Transfer Coefficients Applying Verified Simulations}

Values provided in Part I, Annex B4, Table B4-1 are load-weighted average values based on the average of outputs from the following two programs:

- EnergyPlus Version 8.3.0 (U.S. DOE 2015), November 2016 simulations by J. Neymark applying input files originally developed by a separate modeler team (Henninger and Witte 2016)

- $\quad$ TRNSYS 17.2.5 (Klein et al. 2015), simulations by M. Kummert (2017).

Both models apply the convective interior and exterior surface coefficient algorithms of Equations 4A-1 through 4A-5 (see Section 4A.2) to all surfaces, including windows. Both programs apply the load-weighted averaging process for developing convective and combined coefficients as defined in Sections 4A.3.1 and 4A.3.2). Resulting surface coefficient values were verified by comparing outputs from the programs with each other as described in Section 4A.3.3. The verification process has uncertainty introduced by differences in the programs and user application of the programs. Development of values using comparisons among simulation tools was agreed to by ASHRAE SSPC $140(2015,2016)$.

\section{A.3.1 Load-Weighted Average Convective Coefficients.}

4A.3.1.1 Interior Surface Convective Coefficients. The following procedure for developing annual hourly-loadweighted average convection coefficients ( $\mathrm{h}_{\text {conv,int,lwa) }}$ ) for each interior surface applies:

$\mathrm{h}_{\text {conv,int,lwa }}=\frac{\sum\left(\left|\mathrm{h}_{\text {conv,int,hour }}\right| *\left|\mathrm{q}_{\text {zone,hour }}\right|\right)}{\left(\left|\mathrm{q}_{\text {zone,htg,ann }}\right|+\left|\mathrm{q}_{\text {zone,clg,ann }}\right|\right)}$

where

$\mathrm{h}_{\text {conv,int,hour }}=$ hourly interior convective coefficient for a given surface applying the algorithm of Equation 4A-5 (see Section 4A.2.2).

$\mathrm{q}_{\text {zone,hour }}=$ hourly zone load.

$\mathrm{q}_{\text {zone,htg,ann }}=$ annual zone heating load.

$\mathrm{q}_{\mathrm{zone}, \mathrm{clg}, \mathrm{ann}}=$ annual zone sensible cooling load.

4A.3.1.2 Exterior Surface Convective Coefficients. The following procedure for developing annual hourly-load-

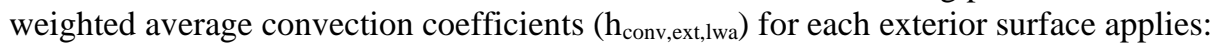

$\mathrm{h}_{\text {conv,ext,lwa }}=\frac{\Sigma\left(\left|\mathrm{h}_{\text {conv,ext,hour }}\right| *\left|\mathrm{q}_{\text {zone,hour }}\right|\right)}{\left(\left|\mathrm{q}_{\text {zone,ht, ann }}\right|+\left|\mathrm{q}_{\text {zone,clg,ann }}\right|\right)}$

where

$\mathrm{h}_{\text {conv, ext,hour }}=$ hourly exterior convective coefficient for a given surface applying the algorithm of Equations $4 \mathrm{~A}-1$ through 4A-4 (see Section 4A.2.1).

$\mathrm{q}_{\mathrm{zone}, \text { hour }}, \mathrm{q}_{\mathrm{zone}, \mathrm{htg}, \text { ann }}$, and $\mathrm{q}_{\mathrm{zone}, \mathrm{clg}, \text { ann }}$ are the same as for the interior surface convective coefficients (see Section 4A.3.1.1).

4A.3.2 Load-Weighted Average Combined Coefficients. For developing equivalent simplified constant combined surface coefficients, Standard 140-2017, Annex B5, Table B5-1 indicates that for $\varepsilon=0.9$, the approximate radiative component of combined interior and exterior surface coefficients is about $60 \%$ and $15 \%$, respectively, of the equivalent constant combined coefficient for each surface type. However, in general, and specifically for this test suite, radiative coefficients based on individual interior-surface-to-zone-air and exterior-surface-to-ambient-air temperature differences do not emulate radiative exchange as well as convective coefficients based on similar temperature differences because: 
- For interior surfaces:

- Air is infrared-transparent over short distances, so that direct radiative exchange occurs between other surfaces in the zone and generally does not occur directly with zone air.

- Many surfaces have similar surface temperatures much of the time; the windows and floor tend to have more surface temperature variation because of relatively low $\mathrm{U}$-value and higher distribution factor for transmitted solar radiation, respectively.

- Exterior surfaces radiate to the ground, neighboring surfaces including the horizon, and the sky to varying degrees, depending on their orientation. While the ground surface and neighboring surfaces including the horizon are at temperatures that may be approximated by the ambient air temperature, the sky temperature is substantially colder, especially when the sky is clear (relatively cloudless).

Additionally, representing combined coefficients by summing individual convective and radiative coefficients, where all values are positive, is not mathematically correct because convective and radiative fluxes can be opposing. Therefore, we applied direct calculation of combined surface coefficients.

4A.3.2.1 Interior Surface Combined Coefficients. Two ideas seem reasonable for developing simplified loadweighted average combined coefficients based on surface-to-zone-air temperature differences, as follows:

\section{A.3.2.1.1 Idea \#1:}

Conceptual basis is $\mathrm{h}_{\text {comb }}=\mathrm{q}_{\mathrm{comb}} /\left(\mathrm{T}_{\text {surf }}-\mathrm{T}_{\text {zone }}\right)$, calculated for a full year with hourly-load-weighted averaging, as:

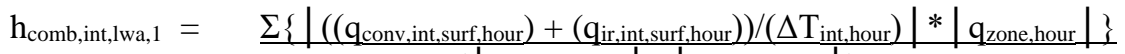

$$
\left(\left|q_{\text {zone,htg,ann }}\right|+\left|q_{\text {zone,clg,ann }}\right|\right)
$$

where

$\mathrm{q}_{\mathrm{conv}, \text { int,surf,hour }}=$ hourly convective heat flux for given interior surface.

$\mathrm{q}_{\mathrm{ir}, \text { int,surf,hour }}=$ hourly net radiative heat flux for given interior surface.

$\Delta \mathrm{T}_{\text {int,hour }}=$ hourly temperature difference of given interior surface and zone-air dry-bulb temperature $\left(\mathrm{T}_{\text {surf }}-\right.$

$\mathrm{T}_{\text {zone }}$ ); surface-to-zone dry-bulb temperature difference is the reference for constant interior surface coefficients.

$\mathrm{q}_{\text {zone,hour }}=$ hourly zone load.

$\mathrm{q}_{\mathrm{zone}, \mathrm{htg}, \text { ann }}=$ annual zone heating load.

$\mathrm{q}_{\text {zone,clg,ann }}=$ annual zone sensible cooling load.

For a given surface, $q_{c o n v, \text { int,surf,hour }}$ and $q_{i r, \text { int,surf,hour }}$ may flow in the same or opposite directions. Therefore, we are taking the absolute value of the sum of the components, where the sign of the individual components (which may be positive or negative) is based on the convention for surface heat flow as applied in the simulation tool doing the calculation (i.e., the signs of $\mathrm{q}_{\mathrm{conv}, \text { int,surf,hour }}$ and $\mathrm{q}_{\mathrm{ir}, \text { int,surf,hour }}$ may be different for any hour). This could yield the result that $\mathrm{h}_{\text {comb }}<\mathrm{h}_{\text {conv }}$ for some surfaces, which is reasonable based on the physics, and underscores limits to the ability of constant combined coefficients to model surface heat transfer physics.

\section{Advantage}

- Idea $\# 1$ is based on the equivalent $\mathrm{h}_{\text {,comb,int }}$ calculated for each hour, a true hourly-load-weighted average.

\section{Disadvantage}

- $\Delta \mathrm{T}_{\text {int,hour }}$ in the denominator of the numerator could cause some very high surface coefficients for some hours that may not be sufficiently compensated by low net surface flux and/or "unweighted" by low zone load. 


\section{A.3.2.1.2 Idea \#2 (variation on Idea \#1):}

$\mathrm{h}_{\text {comb,int,lwa,2 }}=\left(\mathrm{q}_{\text {comb,int,lwa }}\right) /\left(\Delta \mathrm{T}_{\text {int,lwa }}\right)$

where

$$
\begin{aligned}
& \mathrm{q}_{\text {comb,int,lwa }}=\Sigma\left(\left|\left(\mathrm{q}_{\text {conv,int,surf,hour }}\right)+\left(\mathrm{q}_{\text {ir,int,surf,hour }}\right)\right| *\left|\mathrm{q}_{\text {zone,hour }}\right|\right) \\
& \text { ( } \left.\left|\mathrm{q}_{\text {zone,htg,ann }}\right|+\left|\mathrm{q}_{\text {zone,clg,ann }}\right|\right) \\
& \Delta \mathrm{T}_{\text {int,lwa }}=\frac{\sum\left(\left|\Delta \mathrm{T}_{\text {int,hour }}\right| *\left|\mathrm{q}_{\text {zone,hour }}\right|\right)}{\left(\left|\mathrm{q}_{\text {zone,htg,ann }}\right|+\left|\mathrm{q}_{\text {zone,clg,ann }}\right|\right)}
\end{aligned}
$$

and where $\mathrm{q}_{\mathrm{conv}, \text { int,surf,hour }}$; $\mathrm{q}_{\mathrm{ir}, \text { int,surf,hour }}, \mathrm{q}_{\mathrm{zone}, \text { hour }}, \mathrm{q}_{\mathrm{zone}, \mathrm{htg}, \text { ann }}, \mathrm{q}_{\mathrm{zone}, \mathrm{clg}, \text { ann }}$, and $\Delta \mathrm{T}_{\text {int,hour }}$ are the same as defined in Idea \#1 (see Section 4A.3.2.1.1)

\section{Advantages}

- Idea \#2 is based on $\mathrm{q}_{\mathrm{comb}}$,int calculated for each hour.

- Idea \#2 resolves the issue of $\Delta \mathrm{T}_{\text {int,hour }}$ in the denominator of the numerator (Idea \#1), which may cause some anomalous hourly $\mathrm{h}_{\text {comb }}$ values for small $\Delta \mathrm{T}$.

\section{Disadvantage}

- Equivalent $\mathrm{h}_{\text {comb,int }}$ is not independently calculated for each hour; nevertheless, Idea \#2 is worth comparing with Idea \#1.

In previous work similarly evaluating IR radiative exchange coefficients separately, Idea \#1 ultimately proved difficult to implement because $\Delta \mathrm{T}_{\text {hour }}$ in the denominator of the numerator caused very high surface coefficients for some hours. It was possible to eliminate anomalous hours, but the criteria for doing that were arbitrary. Incremental elimination of anomalous (beginning with the most anomalous) hours generally indicated results for Idea \#1 approaching those for Idea \#2. We therefore applied Idea \#2 for generating constant combined coefficients.

4A.3.2.2 Exterior Surface Combined Coefficients. The following procedure for developing annual hourly-load-

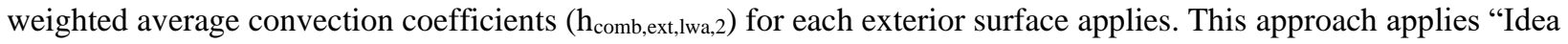
\#2" (see Section 4A.3.2.1.2) adapted for exterior surfaces.

$\mathrm{h}_{\text {comb,ext,lwa, } 2}=\quad\left(\mathrm{q}_{\text {comb,ext,lwa }}\right) /\left(\Delta \mathrm{T}_{\text {ext,lwa }}\right)$

where

$$
\begin{array}{ll}
\mathrm{q}_{\text {comb,ext,lwa }}= & \frac{\Sigma\left(\left|\left(\mathrm{q}_{\text {conv,ext,surf,hour }}\right)+\left(\mathrm{q}_{\text {ir,eext,surf,hour }}\right)\right| *\left|\mathrm{q}_{\text {zone,hour }}\right|\right)}{\left(\left|\mathrm{q}_{\text {zone,htg,ann }}\right|+\left|\mathrm{q}_{\text {zone,clg,ann }}\right|\right)} \\
\Delta \mathrm{T}_{\text {ext,lwa }}= & \frac{\Sigma\left(\left|\Delta \mathrm{T}_{\text {ext,hour }}\right| *\left|\mathrm{q}_{\text {zone,hour }}\right|\right)}{\left(\left|\mathrm{q}_{\text {zone,htg,ann }}\right|+\left|\mathrm{q}_{\text {zone,clg,ann }}\right|\right)}
\end{array}
$$

and where

$\mathrm{q}_{\mathrm{conv}, \mathrm{ext} \text {,surf,hour }}=$ hourly convective heat flux for a given exterior surface.

$\mathrm{q}_{\mathrm{ir}, \mathrm{xt} \text {,surf,hour }}=$ hourly net radiative heat flux for a given exterior surface.

$\Delta \mathrm{T}_{\text {ext,hour }}=$ hourly temperature difference between a given exterior surface and ambient conditions $\left(\mathrm{T}_{\text {surf }}-\right.$ $\mathrm{T}_{\text {ambient }}$ ); surface-to-ambient dry-bulb temperature difference is the reference for constant exterior surface coefficients

$\mathrm{q}_{\mathrm{zone}, \text { hour }}, \mathrm{q}_{\mathrm{zone}, \mathrm{htg}, \text { ann }}$, and $\mathrm{q}_{\mathrm{zone}, \mathrm{clg}, \text { ann }}$ are the same as before (see Section 4A.3.1.1).

Similarly to the interior surfaces, for a given exterior surface, $q_{\text {conv, ext,surf,hour }}$ and $q_{\text {ir, ext,surf,hour }}$ may flow in the same or opposite directions. Therefore, we are taking the absolute value of the sum of the components, where 
the sign of the individual components (which may be positive or negative) is based on the convention for surface heat flow as applied in the simulation tool doing the calculation (i.e., the signs of $\mathrm{q}_{\text {conv,ext,surf,hour }}$ and $\mathrm{q}_{\mathrm{ir}, \text { ext, surf,hour }}$ may be different for any hour). This could yield the result that $\mathrm{h}_{\text {comb,ext,lwa, } 2}<\mathrm{h}_{\text {conv,ext,lwa }}$ for some surfaces, which is reasonable based on the physics, and underscores limits to the ability of constant combined coefficients to model surface heat transfer physics.

\section{Advantages}

- This approach is based on $\mathrm{q}_{\mathrm{comb}, \mathrm{ext}}$ calculated for each hour

- It resolves the issue of interior surface coefficients of " $\Delta \mathrm{T}_{\text {hour }}$ " in the denominator of the numerator (Idea

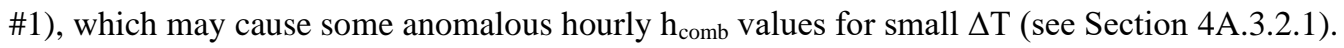

\section{Disadvantage}

- Equivalent hcomb,ext is not independently calculated for each hour; however, work with interior surface coefficients indicates that having $\Delta \mathrm{T}$ in the denominator causes some very large or infinite values for some hours.

\section{A.3.3 Results.}

4A.3.3.1 Cases 600 and 200. The results for interior and exterior constant convective surface coefficients (applying the calculation process of Section 4A.3.1), and constant combined surface coefficients (applying Section 4A.3.2), for two sets of simulations by separate modelers using separate programs are provided in Table 4A-2.

Nomenclature for Table 4A-2 is as follows:

- Row labels are variable names:

- $\mathrm{h}$,conv,lwa is $\mathrm{h}_{\text {conv,int,lwa }}$ and $\mathrm{h}_{\text {conv,ext,lwa }}$ for interior and exterior convective surface coefficients, respectively, as defined in Section 4A.3.1.

- $\mathrm{h}$, comb,lwa is $\mathrm{h}_{\text {comb,int,lwa,2 }}$ and $\mathrm{h}_{\text {comb,ext,lwa,2 }}$ for interior and exterior combined surface coefficients, respectively, as defined in Sections 4A.3.2.

- Modeler descriptions are:

○ "Kummert (TRNSYS)": runs by M. Kummert (2017), applying TRNSYS version 17.2.5.

○ "Neymark/GARD (EnergyPlus): runs by J. Neymark of November 2016, based on input files provided by R. Henninger and M. Witte (February 2016), applying EnergyPlus version 8.3.0. The EnergyPlus Case 200 runs were updated during April 2018 to correct an input error for the highconductance wall air gap R-value.

Other aspects of surface coefficient evaluation include:

- Floor and ceiling values are taken from post-processing of the simulation results by the modelers. This approach applies mixed natural convection, which is a mixture of stable and unstable convection components, applying the stable or unstable regime for each time step as automatically determined from the direction of heat flow in the detailed simulations, where "stable" refers to retarded convection for rising warmer air or falling cooler air driven towards a surface, and "unstable" refers to enhanced convection for rising warmer air or falling cooler air moving away from a surface.

- Wind-driven convection is also included for all exterior surfaces, except the floor (which is specified to see 0 wind speed).

- All other surface coefficient values (for windows and walls) are also taken from direct post-processing of the simulation results by the modelers. Values for the walls are area-weighted average values for the four walls at the different orientations (north, south, east, west [subscripts n, s, e, w, respectively]), taken as:

$h_{\text {conv,awa }}=\left(h_{n} A_{n}+h_{w} A_{w}+h_{e} A_{e}+h_{s} A_{s}\right) /\left(A_{n}+A_{w}+A_{e}+A_{s}\right)$

where

$\circ \mathrm{h}_{\text {conv,awa }}=$ area-weighted average convection coefficient for vertical surfaces with rough exterior texture (walls)

- $h_{n}, h_{w}, h_{e}$, and $h_{s}$ are the calculated coefficients for each wall.

○ $A_{n}=21.6 \mathrm{~m}^{2}, A_{w}=16.2 \mathrm{~m}^{2}, A_{e}=16.2 \mathrm{~m}^{2}, A_{s}=9.6 \mathrm{~m}^{2}$. 
And similarly for the area-weighted average combined coefficient $\left(\mathrm{h}_{\text {comb,awa }}\right)$ for vertical surfaces with rough exterior texture.

The following test cases were applied for developing the simplified constant coefficients ${ }^{2}$ :

- $\quad$ Case 600: low-mass base case with $\varepsilon=0.9$.

- Case 200: $\varepsilon=0.1$ and high-conductance wall elements.

In the TRNSYS model applying equations of Section 4A.2, to facilitate calculation convergence, hourly values of convective coefficients $h_{\text {conv,int,hour }}$ and $h_{\text {conv,ext,hour }}<1 \mathrm{~W} / \mathrm{m}^{2} \mathrm{~K}$ are not allowed (minimum value of 1 for such hours) (Kummert 2017). The EnergyPlus runs apply a minimum allowed value of $0.1 \mathrm{~W} / \mathrm{m}^{2} \mathrm{~K}$ for the interior surface convective coefficients, and do not apply a minimum allowed valued for the exterior surface convective coefficients (Witte 2016). Additionally, centroid heights for each surface are inputs in TRNSYS and are automatically calculated in EnergyPlus.

Table 4A-2 indicates that convective coefficients have good agreement ( $<2 \%$ difference), except for the floor. The floor has larger \%-differences because differences are applied to smaller basis values, and because the EnergyPlus coefficient values can be $<1 \mathrm{~W} / \mathrm{m}^{2} \mathrm{~K}$ (below TRNSYS' limit). The resulting overall heat transfer difference caused by floor exterior surface coefficient differences is small because the floor is highly insulated. Resulting combined coefficients generally exhibit greater disagreement, which may be caused by differences in evaluation of interior and exterior radiation exchange. In both programs, the exterior surface long-wave radiation is calculated in detail using separate components: to sky (applying sky temperature), and to air and ground (applying air temperature). The TRNSYS pro forma modeler report indicates that these are non-linear calculations (see Part III, Section 3.9, Appendix III-G of accompanying file "ModelerReports-ThermalFabricUpdate.pdf). The EnergyPlus documentation (U.S. DOE 2018, Sec 3.5.2) indicates that separate linearizations occur. Larger combined coefficient differences for windows may also be attributable to different window modeling algorithms applied by the two programs.

\footnotetext{
${ }^{2}$ Based on preliminary work analyzing constant coefficients for a variety of cases (see Section 4A.4), we concluded that developing constant coefficients for all other cases based on only these two cases is sufficient.
} 
Table 4A-2. Load-weighted average interior and exterior surface convective and combined coefficients developed from verified simulations, Cases 600 and $200^{\circ}$

\begin{tabular}{|c|c|c|c|c|c|c|c|c|}
\hline \multirow[b]{2}{*}{ Kummert (TRNSYS) } & \multicolumn{4}{|c|}{ INTERIOR COEFFICIENTS } & \multicolumn{4}{|c|}{ EXTERIOR COEFFICIENTS } \\
\hline & Windows ${ }^{b}$ & Walls & Ceiling & Floor & Windows $^{\mathrm{b}}$ & Walls & Ceiling & Floor \\
\hline \multicolumn{9}{|l|}{ Case 600 ( $\varepsilon=0.9$, low mass $)$} \\
\hline $\mathrm{h}, \mathrm{conv}, \mathrm{Iwa}\left(\mathrm{W} /\left(\mathrm{m}^{2} \cdot \mathrm{K}\right)\right)$ & 2.4 & 2.2 & 1.8 & 2.2 & 8.0 & 11.8 & 14.4 & 1.0 \\
\hline $\mathrm{h}, \mathrm{comb}, \mathrm{Iwa}, 2\left(\mathrm{~W} /\left(\mathrm{m}^{2} \cdot \mathrm{K}\right)\right)$ & 4.6 & 1.8 & 1.8 & 3.6 & 19.8 & 22.2 & 22.1 & 5.5 \\
\hline \multicolumn{9}{|l|}{ Case 200 ( $\varepsilon=0.1$, low mass) } \\
\hline h,conv,Iwa $\left(\mathrm{W} /\left(\mathrm{m}^{2} \cdot \mathrm{K}\right)\right)$ & 2.6 & 1.9 & 1.9 & 1.0 & 7.9 & 11.7 & 14.4 & 1.0 \\
\hline h,comb,lwa,2 (W/(m².K)) & 3.1 & 2.1 & 1.9 & 0.4 & 8.3 & 13.6 & 17.5 & 1.5 \\
\hline Neymark/GARD (EnergyPlus) & Windows $^{\mathrm{b}}$ & Walls & Ceiling & Floor & Windows $^{\mathrm{b}}$ & Walls & Ceiling & Floor \\
\hline \multicolumn{9}{|l|}{ Case 600 ( $\varepsilon=0.9$, low mass) } \\
\hline $\mathrm{h}, \mathrm{conv}, \mathrm{Iwa}\left(\mathrm{W} /\left(\mathrm{m}^{2} \cdot \mathrm{K}\right)\right)$ & 2.4 & 2.2 & 1.8 & 2.2 & 8.0 & 12.0 & 14.4 & 0.6 \\
\hline $\mathrm{h}, \mathrm{comb}, \mathrm{Iwa}, 2\left(\mathrm{~W} /\left(\mathrm{m}^{2} \cdot \mathrm{K}\right)\right)$ & 4.3 & 1.8 & 1.7 & 3.8 & 15.8 & 20.9 & 21.5 & 4.9 \\
\hline \multicolumn{9}{|l|}{ Case 200 ( $\varepsilon=0.1$, low mass $)$} \\
\hline h,conv, Iwa $\left(\mathrm{W} /\left(\mathrm{m}^{2} \cdot \mathrm{K}\right)\right)$ & 2.6 & 1.9 & 1.9 & 0.9 & 7.9 & 11.9 & 14.4 & 0.7 \\
\hline h,comb,Iwa,2 (W/(m².K)) & 3.1 & 2.1 & 1.9 & 0.4 & 8.0 & 11.9 & 17.4 & 1.1 \\
\hline \multicolumn{9}{|c|}{ \% Difference ((Neymark - Kummert)/Average) } \\
\hline & Windows $^{b}$ & Walls & Ceiling & Floor & Windows $^{b}$ & Walls & Ceiling & Floor \\
\hline \multicolumn{9}{|l|}{ Case 600 ( $\varepsilon=0.9$, low mass) } \\
\hline $\mathrm{h}, \mathrm{conv}$,Iwa $\left(\mathrm{W} /\left(\mathrm{m}^{2} \cdot \mathrm{K}\right)\right)$ & $0.2 \%$ & $-1.1 \%$ & $0.1 \%$ & $0.4 \%$ & $0.0 \%$ & $1.7 \%$ & $0.0 \%$ & $-50.0 \%$ \\
\hline h,comb,Iwa,2 (W/(m².K)) & $-7.5 \%$ & $-1.9 \%$ & $-4.1 \%$ & $4.7 \%$ & $-22.5 \%$ & $-6.0 \%$ & $-2.8 \%$ & $-11.5 \%$ \\
\hline \multicolumn{9}{|l|}{ Case 200 ( $\varepsilon=0.1$, low mass) } \\
\hline $\mathrm{h}, \mathrm{conv}$,Iwa $\left(\mathrm{W} /\left(\mathrm{m}^{2} \cdot \mathrm{K}\right)\right)$ & $-0.8 \%$ & $-0.4 \%$ & $-1.0 \%$ & $-12.1 \%$ & $0.4 \%$ & $1.5 \%$ & $-0.1 \%$ & $-41.5 \%$ \\
\hline h,comb,lwa,2 (W/(m².K)) & $-1.0 \%$ & $-0.5 \%$ & $-0.3 \%$ & $-6.4 \%$ & $-3.9 \%$ & $-13.0 \%$ & $-0.8 \%$ & $-28.6 \%$ \\
\hline \multicolumn{9}{|c|}{ Average ((Kummert + Neymark)/2) } \\
\hline & Windows $^{b}$ & Walls & Ceiling & Floor & Windows $^{b}$ & Walls & Ceiling & Floor \\
\hline \multicolumn{9}{|l|}{ Case 600 ( $\varepsilon=0.9$, low mass) } \\
\hline h,conv,Iwa $\left(\mathrm{W} /\left(\mathrm{m}^{2} \cdot \mathrm{K}\right)\right)$ & 2.4 & 2.2 & 1.8 & 2.2 & 8.0 & 11.9 & 14.4 & 0.8 \\
\hline h,comb,lwa,2 (W/(m².K)) & 4.5 & 1.8 & 1.7 & 3.7 & 17.8 & 21.6 & 21.8 & 5.2 \\
\hline \multicolumn{9}{|l|}{ Case 200 ( $\varepsilon=0.1$, low mass) } \\
\hline $\mathrm{h}$,conv,Iwa $\left(\mathrm{W} /\left(\mathrm{m}^{2} \cdot \mathrm{K}\right)\right)$ & 2.6 & 1.9 & 1.9 & 1.0 & 7.9 & 11.8 & 14.4 & 0.9 \\
\hline h,comb,Iwa,2 (W/(m².K)) & 3.1 & 2.1 & 1.9 & 0.4 & 8.1 & 12.8 & 17.4 & 1.3 \\
\hline
\end{tabular}

SurfCoeffAnalysis...080318.xlsx; AllCoeffs600+200...!B27+

${ }^{\mathrm{a}} \mathrm{h}, \mathrm{comb} \leq \mathrm{h}, \mathrm{conv}$ is possible here because convective and radiative heat flows may be in opposite directions for a given surface for a sufficient number of time steps.

${ }^{\mathrm{b}}$ Windows include values for Case 200 high-conductance wall elements. 
To analyze the effect of applying the derived constant coefficients of Table 4A-2 versus more detailed modeling, results were compared for detailed simulations versus simulations applying constant values developed by the modelers, applying the parametric sensitivity test scheme shown in Table 4A-3. Output for this test scheme is provided in Table 4A-4. The run designations for the case inputs in the column headers of Tables 4A-3 and 4A-4 are defined as follows:

- h0: Base case (the benchmark for comparison of other constant coefficient runs described below) run with:

- Automated detailed convection calculations applying Equation 4A-5 for interior surface convective heat transfer, and Equations 4A-1 through 4A-4 for exterior surface convective heat transfer, for each time step.

- Automated detailed interior surface-to-surface and exterior surface-to-outdoor-surroundingenvironment radiative exchange modeling.

- h1i:

- Constant interior convective coefficients (h,conv,int,lwa).

- Automated interior surface-to-surface radiative exchange.

- Automated exterior surface convection and radiation exchange.

- h1e:

- Constant exterior convective coefficients ( $h$,conv, ext,lwa).

- Automated exterior surface-to-outdoor-surrounding-environment radiative exchange.

- Automated interior surface convection and radiation exchange.

- h1ie:

- Constant interior and exterior convective coefficients ( $h$,conv, int,lwa and h,conv, ext,lwa).

- Automated interior surface-to-surface and exterior surface-to-outdoor-surrounding-environment radiative exchange.

- h2i:

- Constant interior combined coefficients (h,comb,int,lwa,2).

- Automated interior surface convection and radiative exchange modeling disabled or minimized (e.g., by setting interior surface $\varepsilon=0.0000001$ ).

- Automated exterior surface convection and radiation exchange.

- h2e:

- Constant exterior combined coefficients (h,comb,ext,lwa,2).

- Automated exterior surface convection and radiative exchange modeling disabled or minimized (e.g., by setting exterior surface $\varepsilon=0.0000001$ ).

$\circ$ Automated interior surface convection and radiation exchange.

- h2ie:

- Constant interior and exterior combined coefficients (h,comb,int,lwa,2 and h,comb,ext,lwa,2).

- Automated interior and exterior surface convection and radiative exchange modeling disabled or minimized (e.g., by setting all surface $\varepsilon=0.0000001$ ).

- "95" suffix to above (h1i95, h1 e95, h1ie95, h2i95, h2e95, h2ie95): Inclusion of the "95" suffix in the run designations indicates the same scheme as above, except the "Previous 1995" alternative constant coefficients (see following description and Table 4A-3) are applied where appropriate in place of the new alternative constant coefficients of Table 4A-2.

The model and modeler designations in Tables 4A-3 and 4A-4 are the same as for Table 4A-2, and also include "Previous 1995" to identify results applying the coefficients of ANSI/ASHRAE Standard 140-2017 originally published elsewhere (Judkoff and Neymark 1995). 
Table 4A-3. Input Settings for Constant Coefficient Sensitivity Tests, Cases 600 and 200

\begin{tabular}{|c|c|c|c|c|c|c|c|c|c|c|c|}
\hline \multirow{3}{*}{\multicolumn{2}{|c|}{ Kummert (TRNSYS) }} & \multicolumn{5}{|c|}{ Case 600 ( $\varepsilon=0.9 ; \varepsilon=0.84$ windows $)$} & \multicolumn{5}{|c|}{ Case 200 (low mass, $\varepsilon=0.1$ ) } \\
\hline & & \multirow[b]{2}{*}{ ho } & \multicolumn{2}{|c|}{ Interior } & \multicolumn{2}{|c|}{ Exterior } & \multirow[b]{2}{*}{ ho } & \multicolumn{2}{|c|}{ Interior } & \multicolumn{2}{|c|}{ Exterior } \\
\hline & & & h1i & h2i & h1e & h2e & & h1i & h2i & h1e & h2e \\
\hline \multicolumn{12}{|l|}{ Windows $^{b}$} \\
\hline \multicolumn{2}{|c|}{ IR exchange } & Auto & Auto & $\mathrm{N} / \mathrm{A}$ & Auto & $\mathrm{N} / \mathrm{A}$ & Auto & Auto & $\mathrm{N} / \mathrm{A}$ & Auto & N/A \\
\hline h,conv & $\mathrm{W} /\left(\mathrm{m}^{2} \cdot \mathrm{K}\right)$ & Auto & 2.4 & $\mathrm{~N} / \mathrm{A}$ & 8.0 & $\mathrm{~N} / \mathrm{A}$ & Auto & 2.6 & $\mathrm{~N} / \mathrm{A}$ & 7.9 & $\mathrm{~N} / \mathrm{A}$ \\
\hline h,comb & $\mathrm{W} /\left(\mathrm{m}^{2} \cdot \mathrm{K}\right)$ & $N / A$ & $\mathrm{~N} / \mathrm{A}$ & 4.6 & $\mathrm{~N} / \mathrm{A}$ & 19.8 & $\mathrm{~N} / \mathrm{A}$ & $\mathrm{N} / \mathrm{A}$ & 3.1 & $\mathrm{~N} / \mathrm{A}$ & 8.3 \\
\hline \multicolumn{12}{|c|}{ Insulated Walls, Vertical } \\
\hline \multicolumn{2}{|c|}{ IR exchange } & Auto & Auto & $\mathrm{N} / \mathrm{A}$ & Auto & $\mathrm{N} / \mathrm{A}$ & Auto & Auto & $\mathrm{N} / \mathrm{A}$ & Auto & $\mathrm{N} / \mathrm{A}$ \\
\hline h,conv & $\mathrm{W} /\left(\mathrm{m}^{2} \cdot \mathrm{K}\right)$ & Auto & 2.2 & $\mathrm{~N} / \mathrm{A}$ & 11.8 & $\mathrm{~N} / \mathrm{A}$ & Auto & 1.9 & $\mathrm{~N} / \mathrm{A}$ & 11.7 & $\mathrm{~N} / \mathrm{A}$ \\
\hline h,comb & $\mathrm{W} /\left(\mathrm{m}^{2} \cdot \mathrm{K}\right)$ & $N / A$ & $\mathrm{~N} / \mathrm{A}$ & 1.8 & $\mathrm{~N} / \mathrm{A}$ & 22.2 & $\mathrm{~N} / \mathrm{A}$ & $\mathrm{N} / \mathrm{A}$ & 2.1 & $\mathrm{~N} / \mathrm{A}$ & 13.6 \\
\hline \multicolumn{12}{|l|}{ Ceiling } \\
\hline \multicolumn{2}{|c|}{ IR exchange } & Auto & Auto & $\mathrm{N} / \mathrm{A}$ & Auto & $N / A$ & Auto & Auto & $\mathrm{N} / \mathrm{A}$ & Auto & N/A \\
\hline h,conv & $\mathrm{W} /\left(\mathrm{m}^{2} \cdot \mathrm{K}\right)$ & Auto & 1.8 & $\mathrm{~N} / \mathrm{A}$ & 14.4 & $\mathrm{~N} / \mathrm{A}$ & Auto & 1.9 & $\mathrm{~N} / \mathrm{A}$ & 14.4 & $\mathrm{~N} / \mathrm{A}$ \\
\hline h,comb & $\mathrm{W} /\left(\mathrm{m}^{2} \cdot \mathrm{K}\right)$ & $\mathrm{N} / \mathrm{A}$ & $\mathrm{N} / \mathrm{A}$ & 1.8 & $\mathrm{~N} / \mathrm{A}$ & 22.1 & $\mathrm{~N} / \mathrm{A}$ & $\mathrm{N} / \mathrm{A}$ & 1.9 & $\mathrm{~N} / \mathrm{A}$ & 17.5 \\
\hline \multicolumn{12}{|l|}{ Floor } \\
\hline IR exch & ge & Auto & Auto & $\mathrm{N} / \mathrm{A}$ & Auto & $\mathrm{N} / \mathrm{A}$ & Auto & Auto & $\mathrm{N} / \mathrm{A}$ & Auto & $\mathrm{N} / \mathrm{A}$ \\
\hline $\mathrm{h}, \mathrm{conv}$ & $\mathrm{W} /\left(\mathrm{m}^{2} \cdot \mathrm{K}\right)$ & Auto & 2.2 & $\mathrm{~N} / \mathrm{A}$ & 1.0 & $\mathrm{~N} / \mathrm{A}$ & Auto & 1.0 & $\mathrm{~N} / \mathrm{A}$ & 1.0 & $\mathrm{~N} / \mathrm{A}$ \\
\hline h,comb & $\mathrm{W} /\left(\mathrm{m}^{2} \cdot \mathrm{K}\right)$ & $\mathrm{N} / \mathrm{A}$ & $\mathrm{N} / \mathrm{A}$ & 3.6 & $\mathrm{~N} / \mathrm{A}$ & 5.5 & $\mathrm{~N} / \mathrm{A}$ & $\mathrm{N} / \mathrm{A}$ & 0.4 & $\mathrm{~N} / \mathrm{A}$ & 1.5 \\
\hline Neymark/ & ARD (Ener & & Inte & & Exte & & & Inte & & Exte & ior \\
\hline & & ho & h1i & h2i & h1e & h2e & ho & h1i & h2i & h1e & h2e \\
\hline Windows $^{b}$ & & & & & & & & & & & \\
\hline IR exch & & Auto & Auto & $\mathrm{N} / \mathrm{A}$ & Auto & $\mathrm{N} / \mathrm{A}$ & Auto & Auto & $\mathrm{N} / \mathrm{A}$ & Auto & $\mathrm{N} / \mathrm{A}$ \\
\hline h,conv & $\mathrm{W} /\left(\mathrm{m}^{2} \cdot \mathrm{K}\right)$ & Auto & 2.4 & $\mathrm{~N} / \mathrm{A}$ & 8.0 & $\mathrm{~N} / \mathrm{A}$ & Auto & 2.6 & $\mathrm{~N} / \mathrm{A}$ & 7.9 & N/A \\
\hline h,comb & $\mathrm{W} /\left(\mathrm{m}^{2} \cdot \mathrm{K}\right)$ & $N / A$ & $\mathrm{~N} / \mathrm{A}$ & 4.3 & $\mathrm{~N} / \mathrm{A}$ & 15.8 & $\mathrm{~N} / \mathrm{A}$ & $\mathrm{N} / \mathrm{A}$ & 3.1 & $\mathrm{~N} / \mathrm{A}$ & 8.0 \\
\hline Insulated & Ialls, Vertica & & & & & & & & & & \\
\hline IR exch & & Auto & Auto & $\mathrm{N} / \mathrm{A}$ & Auto & $\mathrm{N} / \mathrm{A}$ & Auto & Auto & $\mathrm{N} / \mathrm{A}$ & Auto & $\mathrm{N} / \mathrm{A}$ \\
\hline $\mathrm{h}, \mathrm{conv}$ & $\mathrm{W} /\left(\mathrm{m}^{2} \cdot \mathrm{K}\right)$ & Auto & 2.2 & $\mathrm{~N} / \mathrm{A}$ & 12.0 & $\mathrm{~N} / \mathrm{A}$ & Auto & 1.9 & $\mathrm{~N} / \mathrm{A}$ & 11.9 & $\mathrm{~N} / \mathrm{A}$ \\
\hline h,comb & $\mathrm{W} /\left(\mathrm{m}^{2} \cdot \mathrm{K}\right)$ & $\mathrm{N} / \mathrm{A}$ & $\mathrm{N} / \mathrm{A}$ & 1.8 & $\mathrm{~N} / \mathrm{A}$ & 20.9 & $\mathrm{~N} / \mathrm{A}$ & $\mathrm{N} / \mathrm{A}$ & 2.1 & $\mathrm{~N} / \mathrm{A}$ & 11.9 \\
\hline Ceiling & & & & & & & & & & & \\
\hline IR exch & & Auto & Auto & $\mathrm{N} / \mathrm{A}$ & Auto & $\mathrm{N} / \mathrm{A}$ & Auto & Auto & $\mathrm{N} / \mathrm{A}$ & Auto & $\mathrm{N} / \mathrm{A}$ \\
\hline $\mathrm{h}, \mathrm{conv}$ & $\mathrm{W} /\left(\mathrm{m}^{2} \cdot \mathrm{K}\right)$ & Auto & 1.8 & $\mathrm{~N} / \mathrm{A}$ & 14.4 & $\mathrm{~N} / \mathrm{A}$ & Auto & 1.9 & $\mathrm{~N} / \mathrm{A}$ & 14.4 & $N / A$ \\
\hline h,comb & $\mathrm{W} /\left(\mathrm{m}^{2} \cdot \mathrm{K}\right)$ & $\mathrm{N} / \mathrm{A}$ & N/A & 1.7 & $\mathrm{~N} / \mathrm{A}$ & 21.5 & $\mathrm{~N} / \mathrm{A}$ & $\mathrm{N} / \mathrm{A}$ & 1.9 & $\mathrm{~N} / \mathrm{A}$ & 17.4 \\
\hline Floor & & & & & & & & & & & \\
\hline IR exch & & Auto & Auto & $\mathrm{N} / \mathrm{A}$ & Auto & $\mathrm{N} / \mathrm{A}$ & Auto & Auto & $\mathrm{N} / \mathrm{A}$ & Auto & $\mathrm{N} / \mathrm{A}$ \\
\hline $\mathrm{h}, \mathrm{conv}$ & $\mathrm{W} /\left(\mathrm{m}^{2} \cdot \mathrm{K}\right)$ & Auto & 2.2 & $\mathrm{~N} / \mathrm{A}$ & 0.6 & $\mathrm{~N} / \mathrm{A}$ & Auto & 0.9 & $\mathrm{~N} / \mathrm{A}$ & 0.7 & $\mathrm{~N} / \mathrm{A}$ \\
\hline h,comb & $\mathrm{W} /\left(\mathrm{m}^{2} \cdot \mathrm{K}\right)$ & $\mathrm{N} / \mathrm{A}$ & $\mathrm{N} / \mathrm{A}$ & 3.8 & $\mathrm{~N} / \mathrm{A}$ & 4.9 & $\mathrm{~N} / \mathrm{A}$ & $\mathrm{N} / \mathrm{A}$ & 0.4 & $\mathrm{~N} / \mathrm{A}$ & 1.1 \\
\hline Previous & 995 & & Inte & & Exte & & & Inte & & Exte & ior \\
\hline & & ho & h1i95 & h2i95 & h1e95 & h2e95 & ho & h1i95 & h2i95 & h1e95 & h2e95 \\
\hline Windows $^{b}$ & & & & & & & & & & & \\
\hline IR exch & & Auto & Auto & $\mathrm{N} / \mathrm{A}$ & Auto & $\mathrm{N} / \mathrm{A}$ & Auto & Auto & $\mathrm{N} / \mathrm{A}$ & Auto & $\mathrm{N} / \mathrm{A}$ \\
\hline $\mathrm{h}, \mathrm{conv}$ & $\mathrm{W} /\left(\mathrm{m}^{2} \cdot \mathrm{K}\right)$ & Auto & 3.2 & $\mathrm{~N} / \mathrm{A}$ & 16.4 & $\mathrm{~N} / \mathrm{A}$ & Auto & 3.2 & $\mathrm{~N} / \mathrm{A}$ & 16.4 & $N / A$ \\
\hline h,comb & $\mathrm{W} /\left(\mathrm{m}^{2} \cdot \mathrm{K}\right)$ & $\mathrm{N} / \mathrm{A}$ & $\mathrm{N} / \mathrm{A}$ & 8.0 & N/A & 21.0 & $\mathrm{~N} / \mathrm{A}$ & $\mathrm{N} / \mathrm{A}$ & 3.7 & $\mathrm{~N} / \mathrm{A}$ & 16.9 \\
\hline Insulated & alls, Vertica & & & & & & & & & & \\
\hline IR exch & & Auto & Auto & $N / A$ & Auto & $\mathrm{N} / \mathrm{A}$ & Auto & Auto & $\mathrm{N} / \mathrm{A}$ & Auto & $\mathrm{N} / \mathrm{A}$ \\
\hline $\mathrm{h}, \mathrm{conv}$ & $\mathrm{W} /\left(\mathrm{m}^{2} \cdot \mathrm{K}\right)$ & Auto & 3.2 & $\mathrm{~N} / \mathrm{A}$ & 24.7 & $\mathrm{~N} / \mathrm{A}$ & Auto & 3.2 & $\mathrm{~N} / \mathrm{A}$ & 24.7 & $N / A$ \\
\hline h,comb & $\mathrm{W} /\left(\mathrm{m}^{2} \cdot \mathrm{K}\right)$ & $\mathrm{N} / \mathrm{A}$ & $\mathrm{N} / \mathrm{A}$ & 8.3 & $\mathrm{~N} / \mathrm{A}$ & 29.3 & $\mathrm{~N} / \mathrm{A}$ & $\mathrm{N} / \mathrm{A}$ & 3.7 & $\mathrm{~N} / \mathrm{A}$ & 25.2 \\
\hline Ceiling & & & & & & & & & & & \\
\hline IR exch & & Auto & Auto & $N / A$ & Auto & $\mathrm{N} / \mathrm{A}$ & Auto & Auto & $N / A$ & Auto & $\mathrm{N} / \mathrm{A}$ \\
\hline $\mathrm{h}, \mathrm{conv}$ & $\mathrm{W} /(\mathrm{m}$ & Auto & 3.2 & $\mathrm{~N} / \mathrm{A}$ & 24.7 & $\mathrm{~N} / \mathrm{A}$ & Auto & 3.2 & $\mathrm{~N} / \mathrm{A}$ & 24.7 & $\mathrm{~N} / \mathrm{A}$ \\
\hline h,comb & $\mathrm{W} /\left(\mathrm{m}^{2} \cdot \mathrm{K}\right)$ & $N / A$ & N/A & 8.3 & $\mathrm{~N} / \mathrm{A}$ & 29.3 & $\mathrm{~N} / \mathrm{A}$ & $N / A$ & 3.7 & $N / A$ & 25.2 \\
\hline Floor & & & & & & & & & & & \\
\hline IR exch & & Auto & Auto & $\mathrm{N} / \mathrm{A}$ & Auto & $\mathrm{N} / \mathrm{A}$ & Auto & Auto & $\mathrm{N} / \mathrm{A}$ & Auto & $\mathrm{N} / \mathrm{A}$ \\
\hline $\mathrm{h}, \mathrm{conv}$ & $\mathrm{W} /\left(\mathrm{m}^{2} \cdot \mathrm{K}\right)$ & Auto & 3.2 & $\mathrm{~N} / \mathrm{A}$ & 24.7 & $\mathrm{~N} / \mathrm{A}$ & Auto & 3.2 & $\mathrm{~N} / \mathrm{A}$ & 24.7 & $N / A$ \\
\hline h,comb & $\mathrm{W} /\left(\mathrm{m}^{2} \cdot \mathrm{K}\right)$ & $\mathrm{N} / \mathrm{A}$ & $\mathrm{N} / \mathrm{A}$ & 8.3 & N/A & 29.3 & $\mathrm{~N} / \mathrm{A}$ & $\mathrm{N} / \mathrm{A}$ & 3.7 & N/A & 25.2 \\
\hline
\end{tabular}

${ }^{a}$ Abbreviations

Auto: Automatically calculated for each time step by the program.

N/A: Not applied or that capability disabled.

${ }^{\mathrm{b}}$ Windows include values for Case 200 high-conductance wall elements. 
Table 4A-4. Comparison of simulations applying automated heat transfer and derived alternative equivalent constant surface coefficients, Cases 600 and 200

Loads Applying 2016 (New) Coefficients

Loads Applying 1995 (Original/140-2001to2014) Coefficients

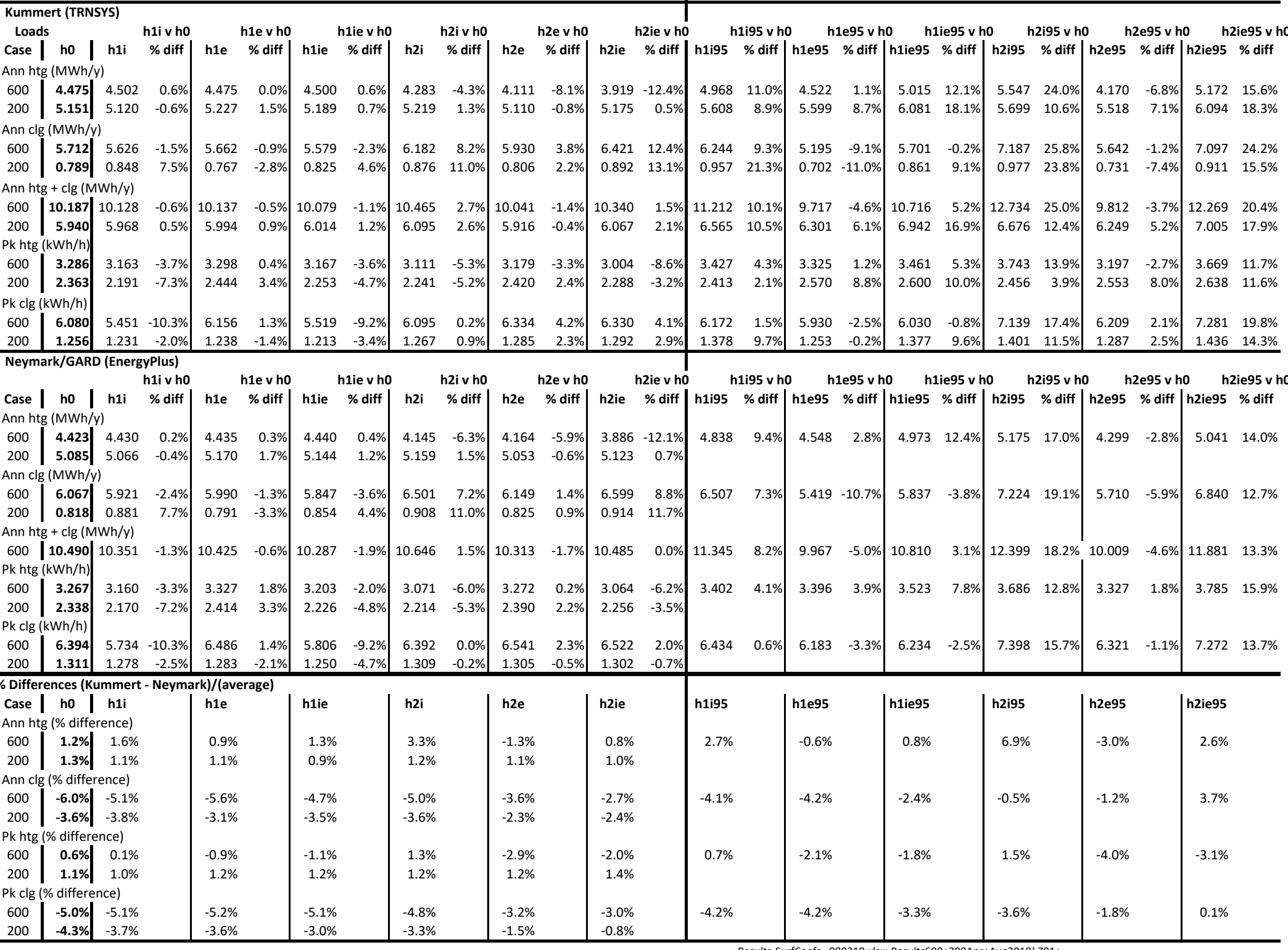


Table 4A-4 summarizes the load outputs and selected load differences (sensitivities) separately for the EnergyPlus runs and the TRNSYS runs (e.g., as "hli v. h0"). Differences between results for EnergyPlus and TRNSYS are included at the bottom of the table (see "\% Differences..."). All \%-differences between the EnergyPlus and TRNSYS results are $<7 \%$, with most differences substantially less than that; the differences are attributable to differences among the overall programs and models applied by the users. This is good agreement, thus verifying the evaluated alternative constant values within the approximate range of difference, given the algorithms applied (see Equations 4A-1 through 4A-5).

Other observations from these results follow.

- The results for the "h1" (constant convective coefficient) input settings indicate the following:

$\circ$ Use of the derived constant interior and/or exterior convective coefficients has relatively low impact on annual heating and cooling loads versus the "h0" runs (<1\% to $3 \%)$, except for Case 200 annual cooling loads, where the larger differences (up to $8 \%$ ) occur for reasonable variations among relatively small basis loads.

- The results for peak heating and cooling loads have larger disagreements versus " $h 0$ " (up to $10 \%$ ), as expected when using constant surface coefficients, because the constant coefficients are developed on the basis of annualized load-weighted averaging for each hour. This implies the results agreement for specific hours (including the peak load hours) using constant coefficients versus fully automated (h0) runs may not necessarily be as good as the agreement of a similar comparison for annual load results.

- All of the "h1i" and "hle" annual heating and cooling results have better agreement with "h0" than those applying the "1995" coefficients.

- The results for the " $\mathrm{h} 2$ " (constant combined coefficient) input settings indicate the following:

- Use of the derived interior constant combined coefficients has a mostly greater effect on annual heating and cooling loads versus the " $\mathrm{h} 0$ " runs than that for the derived interior convective coefficients. This result was expected because radiative heat transfer is difficult to represent with constant coefficients, as discussed in Section 4A.3.2.

- Use of the derived exterior combined coefficients has a greater effect on the Case 600 annual heating results than use of exterior convective coefficients, but does not have a consistently greater effect on the Case 600 annual cooling and Case 200 annual heating and cooling results (perhaps because of compensating effects).

- The " $\mathrm{h} 2 \mathrm{i}$ " interior constant combined coefficient results have better agreement with " $\mathrm{h} 0$ " than those applying the "1995" coefficients.

- For the summed annual heating + cooling loads, the "h2e" exterior constant combined coefficients also have better agreement with "h0" than those applying the "h2e95" coefficients. However, and while the variations are small, for disaggregated Case 600 annual heating loads (for both programs) and the annual cooling loads (for TRNSYS only), the " $\mathrm{h} 2 \mathrm{e} 95$ " coefficients have less disagreement versus the "h0" results than the "h2e" coefficients. This is possible because the loadweighted averaging scheme minimizes the error on the total combined heating and cooling loads occurring during an annual simulation.

The above observations indicate that for the purpose of developing alternative constant surface heat transfer coefficients for models that require them, and to compare such models with models applying contemporary detailed surface heat transfer algorithms as applied in these test cases, the alternative constant interior and exterior convective and combined coefficients derived here represent a satisfactory improvement over the alternative constant coefficients originally published in 1995.

Based on the above observations, we applied the following values of derived constant coefficients in summary Part I, Annex B4, Table B4-1:

- Apply values from the "h1" runs for Cases 600 and 200 for setting equivalent constant convective surface coefficient $\left(\mathrm{h}_{\text {conv }}\right)$ values for all cases with interior $\varepsilon=0.9$ and $\varepsilon=0.1$, respectively.

- Apply values from the " $\mathrm{h} 2$ " runs for Cases 600 and 200 for setting equivalent constant combined surface coefficient $\left(\mathrm{h}_{\text {comb }}\right.$ ) values for all cases with interior $\varepsilon=0.9$ and $\varepsilon=0.1$, respectively.

- Apply these as individual averages of the respective EnergyPlus and TRNSYS values as indicated in Table 4A-2 (see values in the bottom portion of the table identified as "Average...."). 
4A.3.3.2 Cases 670 and 660. Work on new Cases 670 (single-pane windows) and 660 (low-e windows), which came after work on Cases 600 and 200, is documented separately here. The results for interior and exterior constant convective surface coefficients (applying the calculation process of Section 4A.3.1), and constant combined surface coefficients (applying Section 4A.3.2), for two sets of simulations by separate modelers using separate programs are provided in Table 4A-5.

Nomenclature for Table 4A-5 is as follows:

- Row labels are variable names, the same as described for Table 4A-2 (see Section 4A.3.3.1).

- Modeler descriptions are:

○ "Kummert (TRNSYS)": runs by M. Kummert (2018), applying TRNSYS version 18.0.17 (Klein et al., 2018b).

- "Neymark/GARD (EnergyPlus)": runs by J. Neymark of March 2018, based on input files provided by J. Glazer, R. Henninger, and M. Witte (Glazer 2018), applying EnergyPlus version 8.8 (U.S. DOE, 2017).

Differences in software versions relevant to surface heat transfer analysis applied for Cases 600 and 200 (see Section 4A.3.3.1) versus for Cases 670 and 660 are minor. For EnergyPlus version 8.8 versus version 8.3, the maximum differences for Case 600 are $0.1 \%$ for loads and $0.9 \%$ for derived load-weighted average surface coefficients. For TRNSYS version 18.0.7 versus version 17.2.5, the maximum differences for Case 600 are $1.2 \%$ for loads and 1.9\% for derived load-weighted average surface coefficients; the TRNSYS difference also considers the full year of data for identifying peak load results - previously, the first week of data was ignored for this purpose.

Aspects of surface coefficient evaluation are the same as described in Section 4A.3.3.1.

The following test cases were applied for evaluating possible additional simplified constant coefficients:

- Case 670: single-pane windows.

- Case 660: low-e windows.

In the TRNSYS model applying equations of Section 4A.2, to facilitate calculation convergence, hourly values of convective coefficients $h_{\text {conv,int,hour and }} h_{\text {conv,ext,hour }}<1 \mathrm{~W} / \mathrm{m}^{2} \mathrm{~K}$ are not allowed (minimum value is 1 for such hours) (Kummert 2017). The EnergyPlus runs apply a minimum allowed value of $0.1 \mathrm{~W} / \mathrm{m}^{2} \mathrm{~K}$ for the interior surface convective coefficients, and do not apply a minimum allowed valued for the exterior surface convective coefficients (Witte 2016). Additionally, centroid heights for each surface are inputs in TRNSYS and are automatically calculated in EnergyPlus.

Table 4A-5 indicates that convective coefficients have good agreement ( $<3 \%$ difference), except for the floor. The floor has larger \%-differences because differences are applied to smaller basis values, and because the EnergyPlus coefficient values can be $<1 \mathrm{~W} / \mathrm{m}^{2} \mathrm{~K}$ (below TRNSYS's limit). The resulting overall heat transfer difference caused by floor exterior surface coefficient differences is small because the floor is highly insulated. Resulting combined coefficients generally exhibit greater disagreement, which may be caused by differences in evaluation of interior and exterior radiation exchange. In both programs, the exterior surface long-wave radiation is calculated in detail using separate components: to sky (applying sky temperature), and to air and ground (applying air temperature). The TRNSYS pro forma modeler report indicates that these are non-linear calculations (see Part III, Section 3.9, Appendix III-G of accompanying file "ModelerReports-ThermalFabricUpdate.pdf). The EnergyPlus documentation (U.S. DOE, 2018, Sec 3.5.2) indicates that separate linearizations occur. Larger combined coefficient differences for windows may also be attributable to different window modeling algorithms applied by the two programs. 
Table 4A-5. Load-weighted average interior and exterior surface convective and combined coefficients developed from verified simulations, Cases 670 and $660^{*}$

\begin{tabular}{|c|c|c|c|c|c|c|c|c|}
\hline \multirow[b]{2}{*}{ Kummert (TRNSYS) } & \multicolumn{4}{|c|}{ INTERIOR COEFFICIENTS } & \multicolumn{4}{|c|}{ EXTERIOR COEFFICIENTS } \\
\hline & Windows & Walls & Ceiling & Floor & Windows & Walls & Ceiling & Floor \\
\hline \multicolumn{9}{|c|}{ Case 670 (single-pane windows) } \\
\hline $\mathrm{h}$, conv,lwa $\left(\mathrm{W} /\left(\mathrm{m}^{2} \cdot \mathrm{K}\right)\right)$ & 2.585 & 2.276 & 1.903 & 2.178 & 8.032 & 11.718 & 14.306 & 1.000 \\
\hline h,comb,Iwa,2 (W/(m².K)) & 7.878 & 1.925 & 1.874 & 3.838 & 17.243 & 21.643 & 21.353 & 5.391 \\
\hline \multicolumn{9}{|l|}{ Case 660 (low-e windows) } \\
\hline h,conv,lwa $\left(\mathrm{W} /\left(\mathrm{m}^{2} \cdot \mathrm{K}\right)\right)$ & 2.214 & 2.010 & 1.762 & 1.736 & 7.777 & 11.549 & 14.088 & 1.000 \\
\hline h,comb,lwa,2 (W/(m².K)) & 3.678 & 2.051 & 1.801 & 2.326 & 19.136 & 21.036 & 20.593 & 5.248 \\
\hline Neymark/GARD (EnergyPlus & Windows & Walls & Ceiling & Floor & Windows & Walls & Ceiling & Floor \\
\hline \multicolumn{9}{|c|}{ Case 670 (single-pane windows) } \\
\hline h,conv, Iwa $\left(\mathrm{W} /\left(\mathrm{m}^{2} \cdot \mathrm{K}\right)\right)$ & 2.532 & 2.290 & 1.890 & 2.237 & 8.035 & 11.959 & 14.373 & 0.555 \\
\hline h,comb,Iwa,2 (W/(m².K)) & 7.775 & 1.873 & 1.799 & 4.075 & 14.686 & 20.659 & 21.027 & 4.894 \\
\hline \multicolumn{9}{|l|}{ Case 660 (low-e windows) } \\
\hline h,conv, Iwa $\left(\mathrm{W} /\left(\mathrm{m}^{2} \cdot \mathrm{K}\right)\right)$ & 2.260 & 2.021 & 1.745 & 1.776 & 7.778 & 11.808 & 14.176 & 0.557 \\
\hline h,comb,lwa,2 $\left(\mathrm{W} /\left(\mathrm{m}^{2} \cdot \mathrm{K}\right)\right)$ & 3.718 & 1.977 & 1.745 & 2.471 & 16.686 & 21.028 & 20.671 & 4.746 \\
\hline \multicolumn{9}{|c|}{ \% Difference ((Neymark - Kummert)/Average) } \\
\hline & Windows & Walls & Ceiling & Floor & Windows & Walls & Ceiling & Floor \\
\hline \multicolumn{9}{|c|}{ Case 670 (single-pane windows) } \\
\hline h,conv, Iwa $\left(\mathrm{W} /\left(\mathrm{m}^{2} \cdot \mathrm{K}\right)\right)$ & $-2.1 \%$ & $0.6 \%$ & $-0.7 \%$ & $2.7 \%$ & $0.0 \%$ & $2.0 \%$ & $0.5 \%$ & $-57.2 \%$ \\
\hline h,comb,Iwa,2 (W/(m².K)) & $-1.3 \%$ & $-2.7 \%$ & $-4.1 \%$ & $6.0 \%$ & $-16.0 \%$ & $-4.7 \%$ & $-1.5 \%$ & $-9.7 \%$ \\
\hline \multicolumn{9}{|l|}{ Case 660 (low-e windows) } \\
\hline $\mathrm{h}$,conv, Iwa $\left(\mathrm{W} /\left(\mathrm{m}^{2} \cdot \mathrm{K}\right)\right)$ & $2.1 \%$ & $0.5 \%$ & $-0.9 \%$ & $2.3 \%$ & $0.0 \%$ & $2.2 \%$ & $0.6 \%$ & $-56.9 \%$ \\
\hline h,comb,Iwa,2 (W/(m².K)) & $1.1 \%$ & $-3.7 \%$ & $-3.1 \%$ & $6.0 \%$ & $-13.7 \%$ & $0.0 \%$ & $0.4 \%$ & $-10.1 \%$ \\
\hline \multicolumn{9}{|c|}{ Average ((Kummert + Neymark)/2) } \\
\hline & Windows & Walls & Ceiling & Floor & Windows & Walls & Ceiling & Floor \\
\hline \multicolumn{9}{|c|}{ Case 670 (single-pane windows) } \\
\hline h,conv, Iwa $\left(\mathrm{W} /\left(\mathrm{m}^{2} \cdot \mathrm{K}\right)\right)$ & 2.6 & 2.3 & 1.9 & 2.2 & 8.0 & 11.8 & 14.3 & 0.8 \\
\hline h,comb,lwa,2 (W/(m².K)) & 7.8 & 1.9 & 1.8 & 4.0 & 16.0 & 21.2 & 21.2 & 5.1 \\
\hline \multicolumn{9}{|l|}{ Case 660 (low-e windows) } \\
\hline $\mathrm{h}, \mathrm{conv}$,Iwa $\left(\mathrm{W} /\left(\mathrm{m}^{2} \cdot \mathrm{K}\right)\right)$ & 2.2 & 2.0 & 1.8 & 1.8 & 7.8 & 11.7 & 14.1 & 0.8 \\
\hline h,comb,lwa,2 $\left(\mathrm{W} /\left(\mathrm{m}^{2} \cdot \mathrm{K}\right)\right)$ & 3.7 & 2.0 & 1.8 & 2.4 & 17.9 & 21.0 & 20.6 & 5.0 \\
\hline
\end{tabular}

SurfCoeffAnalysis...032318.xlsx; AllCoeffs670+660!B21+

$* \mathrm{~h}, \mathrm{comb} \leq \mathrm{h}, \mathrm{conv}$ is possible here because convective and radiative heat flows may be in opposite directions for a given surface for a sufficient number of time steps.

To analyze the effect of applying the derived constant coefficients of Table 4A-5 versus more detailed modeling, results were compared for detailed simulations versus simulations applying constant values developed by the modelers, applying the parametric sensitivity test scheme shown in Table 4A-6.

The run designations for the case inputs in the column headers of Table 4A-6 are defined as follows:

- h0, h1i, h1e, h1ie, h2i, h2e, h2ie: Same as in Section 4A.3.3.1.

- "17" suffix to h1i17, h1e17, h1ie17, h2i17, h2e17, h2ie17: Where the "17" suffix is included in the run designations, this indicates the same scheme as h1i, h1e, etc., except the "Previous 2017 (from Case 600)" alternative constant surface coefficients (see following description and Table 4A-6) are applied where appropriate in place of the new "Kummert (TRNSYS)" and "Neymark/GARD (EnergyPlus)" alternative constant coefficients. 
The model and modeler designations in Table 4A-6 are the same as for Table 4A-5, and include "Previous 2017 (from Case 600)" to identify results applying the Case 600 alternative constant coefficients of the March 2017 and September 2017 test specifications (for the second- and third-round simulation trials, respectively).

Tables 4A-7 through 4A-9 summarize the load outputs and selected load differences (sensitivities) separately for the EnergyPlus runs and the TRNSYS runs (e.g., as "h1i v. h0"); abbreviations in these tables are the same as for Table 4A-6 as described above, except in Tables 4A-8 and 4A-9 the following applies:

- "W" suffix to h1iW, h1eW, h1ieW, h2iW, h2eW, h2ieW: Where the "W" suffix is included in the run designations, this indicates the same scheme as h1i17, h1e17, etc., except the window surface coefficients corresponding to the new "Kummert (TRNSYS)" and "Neymark/GARD (EnergyPlus)" alternative constant coefficients of Table 4A-6 are applied only to the windows, as appropriate to the model.

These tables provide comparisons of annual and peak heating and cooling loads for three scenarios, as follows:

- Table 4A-7: All surfaces apply new "Kummert (TRNSYS)" and "Neymark/GARD (EnergyPlus)" surface coefficients for Cases 670 and 660 versus the "Previous 2017 (from Case 600)" surface coefficients, where these coefficients are given in Table 4A-6.

- Table 4A-8: Only the window surfaces apply new "Kummert (TRNSYS)" and "Neymark/GARD (EnergyPlus)" surface coefficients for Cases 670 and 660 versus the "Previous 2017 (from Case 600)" surface coefficients applied to all surfaces, where these coefficients are given in Table 4A-6 (i.e., the only change for the new TRNSYS and EnergyPlus simulations are the window interior and exterior surface coefficients; the other surfaces apply the "Previous 2017 (from Case 600)" coefficients).

- Table 4A-9: Compares results of the new "Kummert (TRNSYS)" and "Neymark/GARD (EnergyPlus)" simulations for updating all surface coefficients versus updating only the window surface coefficients.

In Tables 4A-7 and 4A-8, differences between EnergyPlus and TRNSYS results are included at the bottom of the tables (see "\% Differences..."). All differences between EnergyPlus and TRNSYS results are < 10\%, with most differences substantially smaller; the differences are attributable to differences among the overall programs and models applied by the users. This is good agreement, thus verifying the evaluated alternative constant values within the approximate range of difference, given the algorithms applied (see Equations 4A-1 through 4A-5). In Table 4A9, \%-differences included at the bottom of the table are as follows:

1. The "\% Diff h0" column indicates the difference between EnergyPlus and TRNSYS results as in Tables 4A-7 and 4A-8; this is a general indicator of potential legitimate model disagreement.

2. "Average ABS \% Differences Versus h0" is the average of the absolute values of the EnergyPlus and TRNSYS loads-result \%-differences for a given constant coefficient run scenario versus the automated runs for a given test case (e.g., Case 670 "h1i v h0").

3. "Max ABS \% Differences, Windows Only vs All Surfs" is the maximum of the absolute values of the EnergyPlus and TRNSYS loads-result \%-differences for: a given windows-only-updated constant coefficient run scenario versus a given all-surfaces-updated constant coefficient run scenario for a given test case (e.g., Case 670 "hliW v h1i")

Comparison of the second and third items indicates that for Case 670, the differences between applying constant updated surface coefficients to windows only versus to all surfaces is substantially smaller than the differences between applying constant surface coefficients versus automated (h0) runs. For Case 660, this is also generally true except for the annual heating and cooling loads for the h1i and h1ie runs. The importance of these observations is further developed with the analysis of Tables 4A-10 thru 4A-13. 
Table 4A-6. Input Settings for Sensitivity Tests of Constant Coefficients Versus Automated Heat Transfer, Cases 670 and $660^{*}$

\begin{tabular}{|c|c|c|c|c|c|c|c|c|c|c|c|}
\hline & & Case & 70 (sing & -pane & indows & & Case & 50 (low & windo & & \\
\hline Kummert & TRNSYS) & & & ior & Exte & ior & & Int & ior & Exte & ior \\
\hline & & ho & h1i & h2i & h1e & h2e & ho & h1i & h2i & h1e & h2e \\
\hline Windows & & & & & & & & & & & \\
\hline IR excha & ge & Auto & Auto & $\mathrm{N} / \mathrm{A}$ & Auto & $\mathrm{N} / \mathrm{A}$ & Auto & Auto & $\mathrm{N} / \mathrm{A}$ & Auto & $\mathrm{N} / \mathrm{A}$ \\
\hline h,conv & $\mathrm{W} /\left(\mathrm{m}^{2} \cdot \mathrm{K}\right)$ & Auto & 2.6 & $\mathrm{~N} / \mathrm{A}$ & 8.0 & $\mathrm{~N} / \mathrm{A}$ & Auto & 2.2 & $\mathrm{~N} / \mathrm{A}$ & 7.8 & $\mathrm{~N} / \mathrm{A}$ \\
\hline $\mathrm{h}, \mathrm{comb}$ & $\mathrm{W} /\left(\mathrm{m}^{2} \cdot \mathrm{K}\right)$ & $N / A$ & N/A & 7.9 & $\mathrm{~N} / \mathrm{A}$ & 17.2 & $\mathrm{~N} / \mathrm{A}$ & $\mathrm{N} / \mathrm{A}$ & 3.7 & $\mathrm{~N} / \mathrm{A}$ & 19.1 \\
\hline Insulated & alls, Vertica & & & & & & & & & & \\
\hline IR excha & ge & Auto & Auto & $\mathrm{N} / \mathrm{A}$ & Auto & $\mathrm{N} / \mathrm{A}$ & Auto & Auto & $\mathrm{N} / \mathrm{A}$ & Auto & $\mathrm{N} / \mathrm{A}$ \\
\hline $\mathrm{h}, \mathrm{conv}$ & $\mathrm{W} /\left(\mathrm{m}^{2} \cdot \mathrm{K}\right)$ & Auto & 2.3 & $\mathrm{~N} / \mathrm{A}$ & 11.7 & $\mathrm{~N} / \mathrm{A}$ & Auto & 2.0 & N/A & 11.5 & $\mathrm{~N} / \mathrm{A}$ \\
\hline h,comb & $\mathrm{W} /\left(\mathrm{m}^{2} \cdot \mathrm{K}\right)$ & $N / A$ & N/A & 1.9 & $\mathrm{~N} / \mathrm{A}$ & 21.6 & $\mathrm{~N} / \mathrm{A}$ & $\mathrm{N} / \mathrm{A}$ & 2.1 & $\mathrm{~N} / \mathrm{A}$ & 21.0 \\
\hline Ceiling & & & & & & & & & & & \\
\hline IR excha & ge & Auto & Auto & $\mathrm{N} / \mathrm{A}$ & Auto & $\mathrm{N} / \mathrm{A}$ & Auto & Auto & $\mathrm{N} / \mathrm{A}$ & Auto & $\mathrm{N} / \mathrm{A}$ \\
\hline h,conv & $\mathrm{W} /\left(\mathrm{m}^{2} \cdot \mathrm{K}\right)$ & Auto & 1.9 & $\mathrm{~N} / \mathrm{A}$ & 14.3 & $\mathrm{~N} / \mathrm{A}$ & Auto & 1.8 & N/A & 14.1 & N/A \\
\hline h,comb & $\mathrm{W} /\left(\mathrm{m}^{2} \cdot \mathrm{K}\right)$ & $\mathrm{N} / \mathrm{A}$ & N/A & 1.9 & $\mathrm{~N} / \mathrm{A}$ & 21.4 & $\mathrm{~N} / \mathrm{A}$ & $\mathrm{N} / \mathrm{A}$ & 1.8 & $\mathrm{~N} / \mathrm{A}$ & 20.6 \\
\hline Floor & & & & & & & & & & & \\
\hline IR excha & ge & Auto & Auto & $\mathrm{N} / \mathrm{A}$ & Auto & $\mathrm{N} / \mathrm{A}$ & Auto & Auto & N/A & Auto & $N / A$ \\
\hline $\mathrm{h}, \mathrm{conv}$ & $\mathrm{W} /\left(\mathrm{m}^{2} \cdot \mathrm{K}\right)$ & Auto & 2.2 & $\mathrm{~N} / \mathrm{A}$ & 1.0 & $\mathrm{~N} / \mathrm{A}$ & Auto & 1.7 & N/A & 1.0 & $\mathrm{~N} / \mathrm{A}$ \\
\hline h,comb & $\mathrm{W} /\left(\mathrm{m}^{2} \cdot \mathrm{K}\right)$ & $\mathrm{N} / \mathrm{A}$ & $\mathrm{N} / \mathrm{A}$ & 3.8 & $\mathrm{~N} / \mathrm{A}$ & 5.4 & $\mathrm{~N} / \mathrm{A}$ & $\mathrm{N} / \mathrm{A}$ & 2.3 & $\mathrm{~N} / \mathrm{A}$ & 5.2 \\
\hline Neymark/ & ARD (Ener & & Int & & Exte & ior & & Inte & & Ext $\epsilon$ & ior \\
\hline & & ho & h1i & h2i & h1e & h2e & ho & h1i & h2i & h1e & h2e \\
\hline Windows & & & & & & & & & & & \\
\hline IR excha & & Auto & Auto & $\mathrm{N} / \mathrm{A}$ & Auto & $\mathrm{N} / \mathrm{A}$ & Auto & Auto & N/A & Auto & $\mathrm{N} / \mathrm{A}$ \\
\hline h,conv & $\mathrm{W} /\left(\mathrm{m}^{2} \cdot \mathrm{K}\right)$ & Auto & 2.5 & $\mathrm{~N} / \mathrm{A}$ & 8.0 & $\mathrm{~N} / \mathrm{A}$ & Auto & 2.3 & N/A & 7.8 & $\mathrm{~N} / \mathrm{A}$ \\
\hline $\mathrm{h}, \mathrm{comb}$ & $\mathrm{W} /\left(\mathrm{m}^{2} \cdot \mathrm{K}\right)$ & $\mathrm{N} / \mathrm{A}$ & N/A & 7.8 & $\mathrm{~N} / \mathrm{A}$ & 14.7 & $\mathrm{~N} / \mathrm{A}$ & $\mathrm{N} / \mathrm{A}$ & 3.7 & $\mathrm{~N} / \mathrm{A}$ & 16.7 \\
\hline Insulated & alls, Vertica & & & & & & & & & & \\
\hline IR excha & & Auto & Auto & $\mathrm{N} / \mathrm{A}$ & Auto & $\mathrm{N} / \mathrm{A}$ & Auto & Auto & $\mathrm{N} / \mathrm{A}$ & Auto & $\mathrm{N} / \mathrm{A}$ \\
\hline $\mathrm{h}, \mathrm{conv}$ & $\mathrm{W} /\left(\mathrm{m}^{2} \cdot \mathrm{K}\right)$ & Auto & 2.3 & $\mathrm{~N} / \mathrm{A}$ & 12.0 & $\mathrm{~N} / \mathrm{A}$ & Auto & 2.0 & $\mathrm{~N} / \mathrm{A}$ & 11.8 & $\mathrm{~N} / \mathrm{A}$ \\
\hline h,comb & $\mathrm{W} /\left(\mathrm{m}^{2} \cdot \mathrm{K}\right)$ & $N / A$ & $\mathrm{~N} / \mathrm{A}$ & 1.9 & $\mathrm{~N} / \mathrm{A}$ & 20.7 & $\mathrm{~N} / \mathrm{A}$ & $\mathrm{N} / \mathrm{A}$ & 2.0 & $\mathrm{~N} / \mathrm{A}$ & 21.0 \\
\hline Ceiling & & & & & & & & & & & \\
\hline IR excha & & Auto & Auto & $\mathrm{N} / \mathrm{A}$ & Auto & $\mathrm{N} / \mathrm{A}$ & Auto & Auto & $\mathrm{N} / \mathrm{A}$ & Auto & $\mathrm{N} / \mathrm{A}$ \\
\hline h,conv & $\mathrm{W} /\left(\mathrm{m}^{2} \cdot \mathrm{K}\right)$ & Auto & 1.9 & $\mathrm{~N} / \mathrm{A}$ & 14.4 & $\mathrm{~N} / \mathrm{A}$ & Auto & 1.7 & N/A & 14.2 & $\mathrm{~N} / \mathrm{A}$ \\
\hline h,comb & $\mathrm{W} /\left(\mathrm{m}^{2} \cdot \mathrm{K}\right)$ & $\mathrm{N} / \mathrm{A}$ & $N / A$ & 1.8 & $\mathrm{~N} / \mathrm{A}$ & 21.0 & $\mathrm{~N} / \mathrm{A}$ & $\mathrm{N} / \mathrm{A}$ & 1.7 & $\mathrm{~N} / \mathrm{A}$ & 20.7 \\
\hline Floor & & & & & & & & & & & \\
\hline IR excha & & Auto & Auto & $\mathrm{N} / \mathrm{A}$ & Auto & $\mathrm{N} / \mathrm{A}$ & Auto & Auto & N/A & Auto & $N / A$ \\
\hline h,conv & $\mathrm{W} /\left(\mathrm{m}^{2} \cdot \mathrm{K}\right)$ & Auto & 2.2 & $N / A$ & 0.6 & $\mathrm{~N} / \mathrm{A}$ & Auto & 1.8 & $\mathrm{~N} / \mathrm{A}$ & 0.6 & $N / A$ \\
\hline $\mathrm{h}, \mathrm{comb}$ & $\mathrm{W} /\left(\mathrm{m}^{2} \cdot \mathrm{K}\right)$ & $\mathrm{N} / \mathrm{A}$ & $\mathrm{N} / \mathrm{A}$ & 4.1 & $\mathrm{~N} / \mathrm{A}$ & 4.9 & $\mathrm{~N} / \mathrm{A}$ & $\mathrm{N} / \mathrm{A}$ & 2.5 & $\mathrm{~N} / \mathrm{A}$ & 4.7 \\
\hline Previous & 017 (from C & & Inte & & Exte & ior & & Inte & & $\overline{E x t \epsilon}$ & \\
\hline & & ho & h1i17 & h2i17 & h1e17 & h2e17 & ho & h1i17 & h2i17 & h1e17 & h2e17 \\
\hline Windows & & & & & & & & & & & \\
\hline $\begin{array}{l}\text { IR excha } \\
\text { h,conv }\end{array}$ & $\begin{array}{l}\text { ge } \\
W /\left(m^{2} \cdot K\right)\end{array}$ & $\begin{array}{l}\text { Auto } \\
\text { Auto }\end{array}$ & $\begin{array}{c}\text { Auto } \\
2.4\end{array}$ & $\begin{array}{l}N / A \\
N / A\end{array}$ & $\begin{array}{c}\text { Auto } \\
8.0\end{array}$ & $\begin{array}{l}\text { N/A } \\
\text { N/A }\end{array}$ & $\begin{array}{l}\text { Auto } \\
\text { Auto }\end{array}$ & $\begin{array}{c}\text { Auto } \\
2.4\end{array}$ & $\begin{array}{l}\text { N/A } \\
\text { N/A }\end{array}$ & $\begin{array}{c}\text { Auto } \\
8.0\end{array}$ & $\begin{array}{l}\text { N/A } \\
\text { N/A }\end{array}$ \\
\hline h,comb & $\mathrm{W} /\left(\mathrm{m}^{2} \cdot \mathrm{K}\right)$ & $\mathrm{N} / \mathrm{A}$ & $\mathrm{N} / \mathrm{A}$ & 4.5 & $\mathrm{~N} / \mathrm{A}$ & 17.8 & $\mathrm{~N} / \mathrm{A}$ & $\mathrm{N} / \mathrm{A}$ & 4.5 & $\mathrm{~N} / \mathrm{A}$ & 17.8 \\
\hline Insulated & alls, Vertica & & & & & & & & & & \\
\hline IR excha & & Auto & Auto & $N / A$ & Auto & $\mathrm{N} / \mathrm{A}$ & Auto & Auto & N/A & Auto & N/A \\
\hline h,conv & $\mathrm{W} /\left(\mathrm{m}^{2} \cdot \mathrm{K}\right)$ & Auto & 2.2 & $\mathrm{~N} / \mathrm{A}$ & 11.9 & $\mathrm{~N} / \mathrm{A}$ & Auto & 2.2 & $N / A$ & 11.9 & $\mathrm{~N} / \mathrm{A}$ \\
\hline $\mathrm{h}, \mathrm{comb}$ & $\mathrm{W} /\left(\mathrm{m}^{2} \cdot \mathrm{K}\right)$ & $\mathrm{N} / \mathrm{A}$ & $\mathrm{N} / \mathrm{A}$ & 1.8 & $\mathrm{~N} / \mathrm{A}$ & 21.6 & $\mathrm{~N} / \mathrm{A}$ & $\mathrm{N} / \mathrm{A}$ & 1.8 & $\mathrm{~N} / \mathrm{A}$ & 21.6 \\
\hline Ceiling & & & & & & & & & & & \\
\hline IR excha & ge & Auto & Auto & $\mathrm{N} / \mathrm{A}$ & Auto & $\mathrm{N} / \mathrm{A}$ & Auto & Auto & $\mathrm{N} / \mathrm{A}$ & Auto & $\mathrm{N} / \mathrm{A}$ \\
\hline h,conv & $\mathrm{W} /\left(\mathrm{m}^{2} \cdot \mathrm{K}\right)$ & Auto & 1.8 & $\mathrm{~N} / \mathrm{A}$ & 14.4 & $\mathrm{~N} / \mathrm{A}$ & Auto & 1.8 & N/A & 14.4 & $\mathrm{~N} / \mathrm{A}$ \\
\hline h,comb & $\mathrm{W} /\left(\mathrm{m}^{2} \cdot \mathrm{K}\right)$ & $N / A$ & $\mathrm{~N} / \mathrm{A}$ & 1.7 & $\mathrm{~N} / \mathrm{A}$ & 21.8 & $\mathrm{~N} / \mathrm{A}$ & $\mathrm{N} / \mathrm{A}$ & 1.7 & $\mathrm{~N} / \mathrm{A}$ & 21.8 \\
\hline Floor & & & & & & & & & & & \\
\hline IR excha & & Auto & Auto & $\mathrm{N} / \mathrm{A}$ & Auto & $\mathrm{N} / \mathrm{A}$ & Auto & Auto & N/A & Auto & $\mathrm{N} / \mathrm{A}$ \\
\hline h,conv & $\mathrm{W} /\left(\mathrm{m}^{2} \cdot \mathrm{K}\right)$ & Auto & 2.2 & $\mathrm{~N} / \mathrm{A}$ & 0.8 & $\mathrm{~N} / \mathrm{A}$ & Auto & 2.2 & N/A & 0.8 & $N / A$ \\
\hline h,comb & $\mathrm{W} /\left(\mathrm{m}^{2} \cdot \mathrm{K}\right)$ & $\mathrm{N} / \mathrm{A}$ & $\mathrm{N} / \mathrm{A}$ & 3.7 & $\mathrm{~N} / \mathrm{A}$ & 5.2 & $\mathrm{~N} / \mathrm{A}$ & $\mathrm{N} / \mathrm{A}$ & 3.7 & $\mathrm{~N} / \mathrm{A}$ & 5.2 \\
\hline
\end{tabular}

* Abbreviations

Auto: Automatically calculated for each time step by the program.

N/A: Not applied or that capability disabled. 
Table 4A-7. Comparison of simulations applying derived alternative constant surface coefficients, varying all surface coefficients, versus automated heat transfer, Cases 670 and 660

\begin{tabular}{|c|c|c|c|c|c|c|c|c|c|c|c|c|c|c|c|c|c|c|c|c|c|c|c|c|c|}
\hline \multicolumn{14}{|c|}{ Loads Applying 2018 (New for Case } & \multicolumn{12}{|c|}{ Ids Applying 2017 (Case 600) Coefficients to All Surfaces } \\
\hline \multicolumn{14}{|c|}{ Kummert (TRNSYS) } & & & & & & & & & & & & \\
\hline Load & & & h1iv ho & & h1e v ho & & 1ie v ho & & h2i v ho & & h2e v h0 & & 2ie v ho & \multicolumn{2}{|c|}{ h1i17 v h0 } & \multicolumn{2}{|c|}{ h1e17 v h0 } & \multicolumn{2}{|c|}{ h1ie17 v ho } & \multicolumn{2}{|c|}{ h2i17 v h0 } & \multicolumn{2}{|c|}{ h2e17 v h0 } & \multicolumn{2}{|c|}{ h2ie17 v hc } \\
\hline Case I & ho I & $\mathbf{h} 1 \mathbf{i}$ & $\%$ diff & h1e & $\%$ diff & h1ie & $\%$ diff & h2i & $\%$ diff & h2e & $\%$ diff & h2ie & $\%$ diff & h1i17 & $\%$ diff & | h1e17 & $\%$ diff & | h1ie17 & $\%$ diff & | h2i17 & $\%$ diff & h2e17 & $\%$ diff & | h2ie17 & $\%$ diff \\
\hline \multicolumn{26}{|c|}{ Ann htg (MWh/y) } \\
\hline 670 & 6.134 & 6.016 & $1.9 \%$ & 6.173 & $0.6 \%$ & 6.044 & $-1.5 \%$ & 6.778 & $10.5 \%$ & 5.805 & $5-5.4 \%$ & 6.478 & $5.6 \%$ & 5.889 & $-4.0 \%$ & 6.171 & $0.6 \%$ & 5.914 & $-3.6 \%$ & 5.301 & $\mid-13.6 \%$ & 5.849 & $-4.6 \%$ & 4.917 & $-19.8 \%$ \\
\hline 660 & 3.791 & 3.803 & $0.3 \%$ & 3.773 & $-0.5 \%$ & 3.785 & $-0.2 \%$ & 3.658 & $-3.5 \%$ & 3.370 & $-11.1 \%$ & 3.249 & $-14.3 \%$ & 3.890 & $2.6 \%$ & 3.772 & $-0.5 \%$ & 3.871 & $2.1 \%$ & 3.736 & $5-1.5 \%$ & 3.372 & $-11.1 \%$ & 3.328 & $-12.2 \%$ \\
\hline \multicolumn{26}{|c|}{ Ann clg $(\mathrm{MWh} / \mathrm{y})$} \\
\hline 670 & 6.202 & 6.066 & $.2 \%$ & 6.159 & $-0.7 \%$ & 6.023 & $-2.9 \%$ & 6.862 & $10.6 \%$ & 6.530 & $5.3 \%$ & 7.284 & $17.4 \%$ & 6.019 & $-3.0 \%$ & 6.151 & $-0.8 \%$ & 5.970 & $-3.7 \%$ & 7.187 & $15.9 \%$ & 6.490 & $4.6 \%$ & 7.544 & $21.6 \%$ \\
\hline 660 & 2.967 & 2.935 & $-1.1 \%$ & 2.931 & $-1.2 \%$ & 2.900 & $-2.3 \%$ & 3.132 & $5.6 \%$ & 3.208 & $8.1 \%$ & 3.375 & $13.8 \%$ & 3.043 & $2.6 \%$ & 2.913 & $-1.8 \%$ & 2.990 & $0.8 \%$ & 3.226 & $58.7 \%$ & 3.178 & $7.1 \%$ & 3.435 & $15.8 \%$ \\
\hline Ann htg & $\mathrm{s}+\mathrm{clg}(\mathrm{M}$ & hWh/y) & & & & & & & & & & & & & & & & & & & & & & & \\
\hline 670 & 12.336 & | 12.082 & $-2.1 \%$ & 12.332 & $0.0 \%$ & 12.067 & $-2.2 \%$ & 13.640 & $10.6 \%$ & 12.335 & $0.0 \%$ & 13.762 & $11.6 \%$ & 11.908 & $-3.5 \%$ & 12.322 & $-0.1 \%$ & 11.884 & $-3.7 \%$ & 12.488 & $1.2 \%$ & 12.339 & $0.0 \%$ & 12.461 & $1.0 \%$ \\
\hline 660 & 6.758 & 6.738 & $-0.3 \%$ & 6.704 & $-0.8 \%$ & 6.685 & $-1.1 \%$ & 6.790 & $0.5 \%$ & 6.578 & $\begin{array}{ll}B & -2.7 \%\end{array}$ & 6.624 & $-2.0 \%$ & 6.933 & $2.6 \%$ & 6.685 & $-1.1 \%$ & 6.861 & $1.5 \%$ & 6.962 & $3.0 \%$ & 6.550 & $-3.1 \%$ & 6.763 & $0.1 \%$ \\
\hline Pk htg & $(\mathrm{kWh} / \mathrm{h})$ & & & & & & & & & & & & & & & & & & & & & & & & \\
\hline 670 & 4.216 & 3.886 & $-7.8 \%$ & 4.334 & $2.8 \%$ & 3.999 & $-5.1 \%$ & 4.431 & $5.1 \%$ & 4.363 & $3.5 \%$ & 4.577 & $8.6 \%$ & 3.818 & $-9.4 \%$ & 4.333 & $2.8 \%$ & 3.929 & $-6.8 \%$ & 3.656 & $-13.3 \%$ & 4.387 & $4.1 \%$ & 3.722 & $-11.7 \%$ \\
\hline 660 & 2.956 & 2.836 & $-4.1 \%$ & 2.887 & $-2.3 \%$ & 2.776 & $-6.1 \%$ & 2.812 & $-4.9 \%$ & 2.738 & $\begin{array}{ll}3 & -7.4 \%\end{array}$ & 2.611 & $-11.7 \%$ & 2.891 & $-2.2 \%$ & 2.886 & $-2.4 \%$ & 2.830 & $-4.3 \%$ & 2.826 & ; $-4.4 \%$ & 2.735 & $-7.5 \%$ & 2.634 & $-10.9 \%$ \\
\hline Pk clg ( & $\mathrm{kWh} / \mathrm{h})$ & & & & & & & & & & & & & & & & & & & & & & & & \\
\hline 670 & 6.403 & 5.858 & $-8.5 \%$ & 6.487 & $1.3 \%$ & 5.775 & $-9.8 \%$ & 6.686 & $4.4 \%$ & 6.704 & $4.7 \%$ & 7.027 & $9.7 \%$ & 5.794 & $-9.5 \%$ & 6.485 & $1.3 \%$ & 5.711 & $-10.8 \%$ & 6.757 & $5.5 \%$ & 6.684 & $4.4 \%$ & 7.059 & $10.2 \%$ \\
\hline 660 & 3.458 & 3.121 & $-9.7 \%$ & 3.375 & $-2.4 \%$ & 3.094 & $-10.5 \%$ & 3.294 & $-4.7 \%$ & 3.508 & $1.4 \%$ & 3.342 & $-3.4 \%$ & 3.256 & $-5.8 \%$ & 3.364 & $-2.7 \%$ & 3.200 & $-7.5 \%$ & 3.466 & $0.2 \%$ & 3.497 & $1.1 \%$ & 3.505 & $1.4 \%$ \\
\hline Neyn & ark/GARD & $\mathrm{D}$ (Energ) & gyPlus) & & & & & & & & & & & & & & & & & & & & & & \\
\hline & & & h1iv h0 & & h1ev ho & & 1 ie v ho & & h2i v h0 & & h2e v h0 & & 2ie v ho & & i17 v h0 & h1e & 17 v h0 & h1ie & 17 v h0 & & $2 i 17$ v h0 & & e17 v h0 & h2ie & e17 v ho \\
\hline $\begin{array}{l}\text { Case I } \\
\text { Ann hts }\end{array}$ & $\begin{array}{c}\text { ho } \\
\text { (MWh/y }\end{array}$ & h1) & \% diff & h1e & $\%$ diff & h1ie & $\%$ diff & h2i & $\%$ diff & h2e & $\%$ diff & h2ie & $\%$ diff & h1i17 & $\%$ diff & h1e17 & $\%$ diff & h1ie17 & $\%$ diff & h2i17 & $\%$ diff & h2e17 & $\%$ diff & h2ie17 & $\%$ diff \\
\hline 670 & 5.965 & 5.805 & $-2.7 \%$ & 6.020 & $0.9 \%$ & 5.850 & $-1.9 \%$ & 6.521 & $9.3 \%$ & 5.752 & $2-3.6 \%$ & 6.327 & $6.1 \%$ & 5.728 & $-4.0 \%$ & 6.020 & $0.9 \%$ & 5.771 & $-3.3 \%$ & 5.151 & $-13.6 \%$ & 6.004 & $0.7 \%$ & 5.029 & $-15.7 \%$ \\
\hline 660 & 3.730 & 3.725 & $-0.1 \%$ & 3.724 & $-0.2 \%$ & 3.720 & $-0.3 \%$ & 3.563 & $-4.5 \%$ & 3.460 & $-7.2 \%$ & 3.302 & $-11.5 \%$ & 3.800 & $1.9 \%$ & 3.725 & $-0.1 \%$ & 3.795 & $1.7 \%$ & 3.643 & $-2.3 \%$ & 3.473 & $-6.9 \%$ & 3.393 & $-9.0 \%$ \\
\hline Ann clg & (MWh/y & & & & & & & & & & & & & & & & & & & & & & & & \\
\hline 670 & 6.593 & 6.398 & $-3.0 \%$ & 6.523 & $-1.1 \%$ & 6.331 & $-4.0 \%$ & 7.280 & $10.4 \%$ & 6.757 & $2.5 \%$ & 7.498 & $13.7 \%$ & 6.345 & $-3.8 \%$ & 6.526 & $-1.0 \%$ & 6.281 & $-4.7 \%$ & 7.535 & $14.3 \%$ & 6.540 & $-0.8 \%$ & 7.583 & $15.0 \%$ \\
\hline 660 & 3.258 & 3.189 & $-2.1 \%$ & 3.200 & $-1.8 \%$ & 3.133 & $-3.8 \%$ & 3.385 & $3.9 \%$ & 3.325 & $2.1 \%$ & 3.461 & $6.2 \%$ & 3.289 & $1.0 \%$ & 3.190 & $-2.1 \%$ & 3.222 & $-1.1 \%$ & 3.478 & $6.8 \%$ & 3.268 & $0.3 \%$ & 3.496 & $7.3 \%$ \\
\hline Ann $\mathrm{h}$ & $g+\operatorname{clg}(M$ & hW/y) & & & & & & & & & & & & & & & & & & & & & & & \\
\hline 670 & 12.558 & 12.203 & $-2.8 \%$ & 12.543 & $-0.1 \%$ & 12.181 & $-3.0 \%$ & 13.801 & $9.9 \%$ & 12.509 & 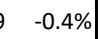 & 13.825 & $10.1 \%$ & 12.073 & $-3.9 \%$ & 12.546 & $-0.1 \%$ & 12.052 & $-4.0 \%$ & 12.686 & $1.0 \%$ & 12.544 & $-0.1 \%$ & 12.612 & $0.4 \%$ \\
\hline 660 & 6.988 & 6.914 & $-1.1 \%$ & 6.924 & $-0.9 \%$ & 6.853 & $-1.9 \%$ & 6.948 & $-0.6 \%$ & 6.785 & $5-2.9 \%$ & 6.763 & $-3.2 \%$ & 7.089 & $1.4 \%$ & 6.915 & $-1.0 \%$ & 7.017 & $0.4 \%$ & 7.121 & $1.9 \%$ & 6.741 & $-3.5 \%$ & 6.889 & $-1.4 \%$ \\
\hline Pk htg & $(k W h / h)$ & & & & & & & & & & & & & & & & & & & & & & & & \\
\hline 670 & 4.125 & 3.798 & $-7.9 \%$ & 4.265 & $3.4 \%$ & 3.924 & $-4.9 \%$ & 4.338 & $5.2 \%$ & 4.298 & $\begin{array}{l}8.2 \% \\
\end{array}$ & 4.499 & $9.1 \%$ & 3.755 & $-9.0 \%$ & 4.265 & $3.4 \%$ & 3.879 & $-6.0 \%$ & 3.614 & $-12.4 \%$ & 4.439 & $7.6 \%$ & 3.783 & $-8.3 \%$ \\
\hline 660 & 2.855 & 2.754 & $-3.5 \%$ & 2.861 & $0.2 \%$ & 2.758 & $-3.4 \%$ & 2.717 & $-4.8 \%$ & 2.784 & $\begin{array}{l}4-2.5 \% \\
\end{array}$ & 2.653 & $-7.1 \%$ & 2.805 & $-1.8 \%$ & 2.862 & $0.2 \%$ & 2.810 & $-1.6 \%$ & 2.751 & $-3.6 \%$ & 2.789 & $-2.3 \%$ & 2.695 & $-5.6 \%$ \\
\hline $\mathrm{Pk} \mathrm{clg}$ & $\mathrm{kWh} / \mathrm{h})$ & & & & & & & & & & & & & & & & & & & & & & & & \\
\hline 670 & 6.828 & 6.248 & $-8.5 \%$ & 6.913 & $1.2 \%$ & 6.172 & $-9.6 \%$ & 7.174 & $5.1 \%$ & 7.008 & $2.6 \%$ & 7.384 & $8.1 \%$ & 6.185 & $-9.4 \%$ & 6.915 & $1.3 \%$ & 6.109 & $-10.5 \%$ & 7.158 & $4.8 \%$ & 6.890 & $0.9 \%$ & 7.271 & $6.5 \%$ \\
\hline 660 & 3.796 & 3.401 & $-10.4 \%$ & 3.629 & $-4.4 \%$ & 3.276 & $-13.7 \%$ & 3.586 & $-5.5 \%$ & 3.683 & $\begin{array}{ll}3 & -3.0 \%\end{array}$ & 3.491 & $-8.0 \%$ & 3.543 & $-6.7 \%$ & 3.623 & $-4.6 \%$ & 3.398 & $-10.5 \%$ & 3.754 & $-1.1 \%$ & 3.653 & $-3.8 \%$ & 3.632 & $-4.3 \%$ \\
\hline \% Diff & ences ( & ummer & i- & $\mathrm{rk}) /(\mathrm{av}$ & rage) & & & & & & & & & & & & & & & & & & & & \\
\hline Case | & ho & h1i & & h1e & & h1ie & & h2i & & h2e & & h2ie & & h1i17 & & | h1e17 & & | h1ie17 & & | h2i17 & & h2e17 & & | h2ie17 & \\
\hline Ann hts & (MWh/y & & & & & & & & & & & & & & & & & & & & & & & & \\
\hline 670 & $2.8 \%$ & $3.6 \%$ & & $2.5 \%$ & & $3.3 \%$ & & $3.9 \%$ & & 0.9 & & $2.4 \%$ & & $2.8 \%$ & & $2.5 \%$ & & $2.4 \%$ & & $2.9 \%$ & & $-2.6 \%$ & & $-2.3 \%$ & \\
\hline 660 & $1.6 \%$ & $2.1 \%$ & & $1.3 \%$ & & $1.7 \%$ & & $2.6 \%$ & & $-2.6 \%$ & & $-1.6 \%$ & & $2.3 \%$ & & $1.3 \%$ & & $2.0 \%$ & & $2.5 \%$ & & $-3.0 \%$ & & $-1.9 \%$ & \\
\hline Ann clg & $(\mathrm{MWh} / \mathrm{y}$ & & & & & & & & & & & & & & & & & & & & & & & & \\
\hline 670 & $-6.1 \%$ & $-5.3 \%$ & & $-5.7 \%$ & & $-5.0 \%$ & & $-5.9 \%$ & & $-3.4 \%$ & & $-2.9 \%$ & & $-5.3 \%$ & & $-5.9 \%$ & & $-5.1 \%$ & & $-4.7 \%$ & & $-0.8 \%$ & & $-0.5 \%$ & \\
\hline 660 & $-9.3 \%$ & $-8.3 \%$ & & $-8.8 \%$ & & $-7.7 \%$ & & $-7.8 \%$ & & $-3.6 \%$ & & $-2.5 \%$ & & $-7.8 \%$ & & $-9.1 \%$ & & $-7.5 \%$ & & $-7.5 \%$ & & $-2.8 \%$ & & $-1.8 \%$ & \\
\hline Pk htg & $(\mathrm{kWh} / \mathrm{h})$ & & & & & & & & & & & & & & & & & & & & & & & & \\
\hline 670 & $2.2 \%$ & $2.3 \%$ & & $1.6 \%$ & & $1.9 \%$ & & $2.1 \%$ & & $1.5 \%$ & & $1.7 \%$ & & $1.7 \%$ & & $1.6 \%$ & & $1.3 \%$ & & $1.2 \%$ & & $-1.2 \%$ & & $-1.6 \%$ & \\
\hline 660 & $3.5 \%$ & $2.9 \%$ & & $0.9 \%$ & & $0.7 \%$ & & $3.4 \%$ & & $-1.7 \%$ & & $-1.6 \%$ & & $3.0 \%$ & & $0.8 \%$ & & $0.7 \%$ & & $2.7 \%$ & & $-2.0 \%$ & & $-2.3 \%$ & \\
\hline Pk clg ( & $\mathrm{kWh} / \mathrm{h})$ & & & & & & & & & & & & & & & & & & & & & & & & \\
\hline 670 & $-6.4 \%$ & $-6.4 \%$ & & $-6.4 \%$ & & $-6.6 \%$ & & $-7.0 \%$ & & $-4.4 \%$ & & $-5.0 \%$ & & $-6.5 \%$ & & $-6.4 \%$ & & $-6.7 \%$ & & $-5.8 \%$ & & $-3.0 \%$ & & $-3.0 \%$ & \\
\hline 660 & $-9.3 \%$ & $-8.6 \%$ & & $-7.3 \%$ & & $-5.7 \%$ & & $-8.5 \%$ & & $-4.9 \%$ & & $-4.4 \%$ & & $-8.4 \%$ & & $-7.4 \%$ & & $-6.0 \%$ & & $-8.0 \%$ & & $-4.4 \%$ & & $-3.6 \%$ & \\
\hline
\end{tabular}


Table 4A-8. Comparison of simulations applying derived alternative constant surface coefficients, varying only window surface coefficients, in the new EnergyPlus and TRNSYS simulations versus applying Case 600 coefficients for all surfaces, versus automated heat transfer: Cases 670 and 660

\begin{tabular}{|c|c|c|c|c|c|c|c|c|c|c|c|c|c|c|c|c|c|c|c|c|c|c|c|c|c|}
\hline \multirow{2}{*}{\multicolumn{14}{|c|}{$\frac{\text { Loads Applying } 2018}{\text { Kummert (TRNSYS) }}$}} & \multirow{2}{*}{\multicolumn{12}{|c|}{ oads Applying 2017 (Case 600) Coefficients to ALL SURFACES }} \\
\hline & & & & & & & & & & & & & & & & & & & & & & & & & \\
\hline \multicolumn{2}{|c|}{ Loads } & \multicolumn{2}{|c|}{ h1iW v h0 } & \multicolumn{2}{|c|}{ h1eW v ho } & \multicolumn{2}{|c|}{ h1ieW v ho } & \multicolumn{2}{|c|}{ h2iW v ho } & \multicolumn{2}{|c|}{ h2eW v ho } & \multicolumn{2}{|c|}{ h2ieW v ho } & \multicolumn{2}{|c|}{ h1i17 v h0 } & \multicolumn{2}{|c|}{ h1e17 v h0 } & \multicolumn{2}{|c|}{ h1ie17 v h0 } & & i17 v ho & h2e & 17 v h0 & h2ie & e17v vo \\
\hline $\begin{array}{l}\text { Case I } \\
\text { Ann htg }\end{array}$ & $\begin{array}{l}\text { ho } \\
\text { g (MWh/ }\end{array}$ & $\begin{array}{l}\text { | h1iW } \\
/ y)\end{array}$ & $\%$ diff & h1eW & $\%$ diff & h1iew & $\%$ diff & h2iW & $\%$ diff & h2eW & $\%$ diff & h2ieW & $\%$ diff & h1i17 & $\%$ diff & h1e17 & $\%$ diff & h1ie17 & $\%$ diff & h2i17 & $\%$ diff & h2e17 & $\%$ diff & h2ie17 & $\%$ diff \\
\hline 670 & 6.134 & 5.977 & $-2.6 \%$ & 6.171 & $0.6 \%$ & 6.003 & $-2.1 \%$ & 6.720 & $9.6 \%$ & 5.806 & $-5.3 \%$ & 6.430 & $4.8 \%$ & 5.889 & $-4.0 \%$ & 6.171 & $0.6 \%$ & 5.914 & $-3.6 \%$ & 5.301 & $-13.6 \%$ & 5.849 & $-4.6 \%$ & 4.917 & $-19.8 \%$ \\
\hline 660 & 3.791 & 3.879 & $2.3 \%$ & 3.771 & $-0.5 \%$ & 3.859 & $1.8 \%$ & 3.686 & $-2.8 \%$ & 3.378 & $-10.9 \%$ & 3.286 & $-13.3 \%$ & 3.890 & $2.6 \%$ & 3.772 & $-0.5 \%$ & 3.871 & $2.1 \%$ & 3.736 & $-1.5 \%$ & 3.372 & $-11.1 \%$ & 3.328 & $-12.2 \%$ \\
\hline Ann clg & (MWh/y & & & & & & & & & & & & & & & & & & & & & & & & \\
\hline 670 & 6.202 & 6.006 & $-3.2 \%$ & 6.151 & $-0.8 \%$ & 5.957 & $-4.0 \%$ & 6.771 & $9.2 \%$ & 6.521 & $5.1 \%$ & 7.183 & $15.8 \%$ & 6.019 & $-3.0 \%$ & 6.151 & $-0.8 \%$ & 5.970 & $-3.7 \%$ & 7.187 & $15.9 \%$ & 6.490 & $4.6 \%$ & 7.544 & $21.6 \%$ \\
\hline 660 & 2.967 & 3.037 & $2.4 \%$ & 2.916 & $-1.7 \%$ & 2.986 & $0.6 \%$ & 3.215 & $8.4 \%$ & 3.163 & $6.6 \%$ & 3.408 & $14.9 \%$ & 3.043 & $2.6 \%$ & 2.913 & $-1.8 \%$ & 2.990 & $0.8 \%$ & 3.226 & $8.7 \%$ & 3.178 & $7.1 \%$ & 3.435 & $15.8 \%$ \\
\hline Ann ht: & $g+\operatorname{clg}(M$ & $\mathrm{u} W h / \mathrm{y})$ & & & & & & & & & & & & & & & & & & & & & & & \\
\hline 670 & | 12.336 & 11.983 & $-2.9 \%$ & 12.322 & $-0.1 \%$ & 11.960 & $-3.0 \%$ & 13.491 & $9.4 \%$ & 12.327 & $-0.1 \%$ & 13.613 & $10.4 \%$ & 11.908 & $-3.5 \%$ & 12.322 & $-0.1 \%$ & 11.884 & $-3.7 \%$ & 12.488 & $1.2 \%$ & 12.339 & $0.0 \%$ & 12.461 & $1.0 \%$ \\
\hline 660 & 6.758 & 6.916 & $2.3 \%$ & 6.687 & $-1.1 \%$ & 6.845 & $1.3 \%$ & 6.901 & $2.1 \%$ & 6.541 & $-3.2 \%$ & 6.694 & $-0.9 \%$ & 6.933 & $2.6 \%$ & 6.685 & $-1.1 \%$ & 6.861 & $1.5 \%$ & 6.962 & $3.0 \%$ & 6.550 & $-3.1 \%$ & 6.763 & $0.1 \%$ \\
\hline Pk htg & $(k W h / h)$ & & & & & & & & & & & & & & & & & & & & & & & & \\
\hline 670 & 4.216 & 3.866 & $-8.3 \%$ & 4.333 & $2.8 \%$ & 3.976 & $-5.7 \%$ & 4.409 & $4.6 \%$ & 4.363 & $3.5 \%$ & 4.551 & $7.9 \%$ & 3.818 & $-9.4 \%$ & 4.333 & $2.8 \%$ & 3.929 & $-6.8 \%$ & 3.656 & $-13.3 \%$ & 4.387 & $4.1 \%$ & 3.722 & $-11.7 \%$ \\
\hline 660 & 2.956 & 2.883 & $-2.5 \%$ & 2.885 & $-2.4 \%$ & 2.821 & $-4.6 \%$ & 2.796 & $-5.4 \%$ & 2.739 & $-7.3 \%$ & 2.601 & $-12.0 \%$ & 2.891 & $-2.2 \%$ & 2.886 & $-2.4 \%$ & 2.830 & $-4.3 \%$ & 2.826 & $-4.4 \%$ & 2.735 & $-7.5 \%$ & 2.634 & $-10.9 \%$ \\
\hline $\mathrm{Pk} \operatorname{clg}($ & $\mathrm{kWh} / \mathrm{h})$ & & & & & & & & & & & & & & & & & & & & & & & & \\
\hline 670 & 6.403 & 5.803 & $-9.4 \%$ & 6.485 & $1.3 \%$ & 5.711 & $-10.8 \%$ & 6.612 & $3.3 \%$ & 6.701 & $4.7 \%$ & 6.936 & $8.3 \%$ & 5.794 & $-9.5 \%$ & 6.485 & $1.3 \%$ & 5.711 & $-10.8 \%$ & 6.757 & $5.5 \%$ & 6.684 & $.4 \%$ & 59 & $10.2 \%$ \\
\hline 660 & 3.458 & 3.248 & $-6.1 \%$ & 3.366 & $-2.7 \%$ & 3.195 & $-7.6 \%$ & 3.447 & $-0.3 \%$ & 3.486 & $0.8 \%$ & 3.476 & $0.5 \%$ & 3.256 & $-5.8 \%$ & 3.364 & $-2.7 \%$ & 3.200 & $-7.5 \%$ & 3.466 & $0.2 \%$ & 3.497 & $1.1 \%$ & 3.505 & $1.4 \%$ \\
\hline Neyma & ark/GARL & D (Energ) & yPlus) & & & & & & & & & & & & & & & & & & & & & & \\
\hline & & & iW v ho & h1e & W v ho & h1ie & eWv ho & & iW v ho & & eWv ho & h2i & eWv ho & & i17 v h0 & h1e & e17 v h0 & h1ie & e17 v h0 & & 17 v h0 & h2e & 17 v h0 & h2ie & e17v vo \\
\hline $\begin{array}{l}\text { Case I } \\
\text { Ann htg }\end{array}$ & $\begin{array}{l}\text { ho } \\
g(\mathrm{MWh} / \mathrm{K}\end{array}$ & $\begin{array}{l}\text { h1iW } \\
/ y)\end{array}$ & \% diff & h1eW & $\%$ diff & |h1ieW & $\%$ diff & h2iW & \% diff & h2eW & $\%$ diff & |h2ieW & $\%$ diff & h1i17 & $\%$ diff & | h1e17 & $\%$ diff & | h1ie17 & $\%$ diff & | h2i17 & $\%$ diff & | h2e17 & $\%$ diff & h2ie17 & $\%$ diff \\
\hline 670 & 5.965 & 5.770 & $-3.3 \%$ & 6.020 & $0.9 \%$ & 5.813 & $-2.5 \%$ & 6.453 & $8.2 \%$ & 5.759 & $-3.5 \%$ & 6.271 & $5.1 \%$ & 5.728 & $-4.0 \%$ & 6.020 & $0.9 \%$ & 5.771 & $-3.3 \%$ & 5.151 & $-13.6 \%$ & 6.004 & $0.7 \%$ & 5.029 & $-15.7 \%$ \\
\hline 660 & 3.730 & 3.795 & $1.7 \%$ & 3.723 & $-0.2 \%$ & 3.788 & $1.6 \%$ & 3.596 & $-3.6 \%$ & 3.467 & $-7.1 \%$ & 3.341 & $-10.4 \%$ & 3.800 & $1.9 \%$ & 3.725 & $-0.1 \%$ & 3.795 & $1.7 \%$ & 3.643 & $-2.3 \%$ & 3.473 & $-6.9 \%$ & 3.393 & $-9.0 \%$ \\
\hline Ann clg & (MWh/y & & & & & & & & & & & & & & & & & & & & & & & & \\
\hline 670 & 6.593 & 6.340 & $-3.8 \%$ & 6.526 & $-1.0 \%$ & 6.276 & $-4.8 \%$ & 7.180 & $8.9 \%$ & 6.713 & $1.8 \%$ & 7.357 & $11.6 \%$ & 6.345 & $-3.8 \%$ & 6.526 & $-1.0 \%$ & 6.281 & $-4.7 \%$ & 7.535 & $14.3 \%$ & 6.540 & $-0.8 \%$ & 7.583 & $15.0 \%$ \\
\hline 660 & 3.258 & 3.286 & $0.9 \%$ & 3.193 & $-2.0 \%$ & 3.222 & $-1.1 \%$ & 3.459 & $6.2 \%$ & 3.282 & $0.7 \%$ & 3.491 & $7.2 \%$ & 3.289 & $1.0 \%$ & 3.190 & $-2.1 \%$ & 3.222 & $-1.1 \%$ & 3.478 & $6.8 \%$ & 3.268 & $0.3 \%$ & 3.496 & $7.3 \%$ \\
\hline Ann htg & $g+\operatorname{clg}(M$ & (WWh/y) & & & & & & & & & & & & & & & & & & & & & & & \\
\hline 670 & 12.558 & | 12.110 & $-3.6 \%$ & 12.546 & $-0.1 \%$ & 12.089 & $-3.7 \%$ & 13.633 & $8.6 \%$ & 12.472 & $-0.7 \%$ & 13.628 & $8.5 \%$ & 12.073 & $-3.9 \%$ & 12.546 & $-0.1 \%$ & 12.052 & $-4.0 \%$ & 12.686 & $1.0 \%$ & 12.544 & $-0.1 \%$ & 12.612 & $0.4 \%$ \\
\hline 660 & 6.988 & 7.081 & $1.3 \%$ & 6.916 & $-1.0 \%$ & 7.010 & $0.3 \%$ & 7.055 & $1.0 \%$ & 6.749 & $-3.4 \%$ & 6.832 & $-2.2 \%$ & 7.089 & $1.4 \%$ & 6.915 & $-1.0 \%$ & 7.017 & $0.4 \%$ & 7.121 & $1.9 \%$ & 6.741 & $-3.5 \%$ & 6.889 & $-1.4 \%$ \\
\hline Pk htg & $(\mathrm{kWh} / \mathrm{h})$ & & & & & & & & & & & & & & & & & & & & & & & & \\
\hline 670 & 4.125 & 3.778 & $-8.4 \%$ & 4.265 & $3.4 \%$ & 3.901 & $-5.4 \%$ & 4.320 & $4.7 \%$ & 4.299 & $4.2 \%$ & 4.471 & $8.4 \%$ & 3.755 & $-9.0 \%$ & 4.265 & $3.4 \%$ & 3.879 & $-6.0 \%$ & 3.614 & $-12.4 \%$ & 4.439 & $7.6 \%$ & 3.783 & $-8.3 \%$ \\
\hline 660 & 2.855 & 2.801 & $-1.9 \%$ & 2.861 & $0.2 \%$ & 2.806 & $-1.7 \%$ & 2.722 & $-4.7 \%$ & 2.786 & $-2.4 \%$ & 2.659 & $-6.9 \%$ & 2.805 & $-1.8 \%$ & 2.862 & $0.2 \%$ & 2.810 & $-1.6 \%$ & 2.751 & $-3.6 \%$ & 2.789 & $-2.3 \%$ & 2.695 & $-5.6 \%$ \\
\hline Pk clg ( & $\mathrm{kWh} / \mathrm{h}$ ) & & & & & & & & & & & & & & & & & & & & & & & & \\
\hline 670 & 6.828 & 6.192 & $-9.3 \%$ & 6.915 & $1.3 \%$ & 6.110 & $-10.5 \%$ & 7.077 & $3.6 \%$ & 991 & $2.4 \%$ & 7.236 & $6.0 \%$ & 6.185 & $-9.4 \%$ & 6.915 & $1.3 \%$ & 6.109 & $-10.5 \%$ & 7.158 & $4.8 \%$ & 6.890 & $0.9 \%$ & 7.271 & $6.5 \%$ \\
\hline 660 & 3.796 & 3.539 & $-6.8 \%$ & 3.626 & $-4.5 \%$ & 3.396 & $-10.5 \%$ & 3.728 & $-1.8 \%$ & 3.663 & $-3.5 \%$ & 3.617 & $-4.7 \%$ & 3.543 & $-6.7 \%$ & 3.623 & $-4.6 \%$ & 3.398 & $-10.5 \%$ & 3.754 & $-1.1 \%$ & 3.653 & $-3.8 \%$ & 3.632 & $-4.3 \%$ \\
\hline \% Diff & nces (KL & úmmert & 1 & ark)/(ave & rage) & & & & & & & & & & & & & & & & & & & & \\
\hline $\begin{array}{l}\text { Case I } \\
\text { Ann htg }\end{array}$ & \begin{tabular}{|c|} 
ho \\
g (\% diffe
\end{tabular} & $\begin{array}{l}\text { | h1iw } \\
\text { erence) }\end{array}$ & & h1eW & & | h1ieW & & h2iW & & h2eW & & h2ieW & & h1i17 & & | h1e17 & & | h1ie17 & & | h2i17 & & | h2e17 & & | h2ie17 & \\
\hline 670 & $2.8 \%$ & $3.5 \%$ & & $2.5 \%$ & & $3.2 \%$ & & $4.1 \%$ & & $0.8 \%$ & & $2.5 \%$ & & $2.8 \%$ & & $2.5 \%$ & & $2.4 \%$ & & $2.9 \%$ & & $-2.6 \%$ & & $-2.3 \%$ & \\
\hline 660 & $1.6 \%$ & $2.2 \%$ & & $1.3 \%$ & & $1.9 \%$ & & $2.5 \%$ & & $-2.6 \%$ & & $-1.7 \%$ & & $2.3 \%$ & & $1.3 \%$ & & $2.0 \%$ & & $2.5 \%$ & & $-3.0 \%$ & & $-1.9 \%$ & \\
\hline Ann clg & (\% differ & (rence) & & & & & & & & & & & & & & & & & & & & & & & \\
\hline 670 & $-6.1 \%$ & $-5.4 \%$ & & $-5.9 \%$ & & $-5.2 \%$ & & $-5.9 \%$ & & $-2.9 \%$ & & $-2.4 \%$ & & $-5.3 \%$ & & $-5.9 \%$ & & $-5.1 \%$ & & $-4.7 \%$ & & $-0.8 \%$ & & $-0.5 \%$ & \\
\hline 660 & $-9.3 \%$ & $-7.9 \%$ & & $-9.1 \%$ & & $-7.6 \%$ & & $-7.3 \%$ & & $-3.7 \%$ & & $-2.4 \%$ & & $-7.8 \%$ & & $-9.1 \%$ & & $-7.5 \%$ & & $-7.5 \%$ & & $-2.8 \%$ & & $-1.8 \%$ & \\
\hline Pk htg & (\% differe & ence) & & & & & & & & & & & & & & & & & & & & & & & \\
\hline 670 & $2.2 \%$ & $2.3 \%$ & & $1.6 \%$ & & $1.9 \%$ & & $2.0 \%$ & & $1.5 \%$ & & $1.8 \%$ & & $1.7 \%$ & & $1.6 \%$ & & $1.3 \%$ & & $1.2 \%$ & & $-1.2 \%$ & & $-1.6 \%$ & \\
\hline 660 & $3.5 \%$ & $2.9 \%$ & & $0.8 \%$ & & $0.5 \%$ & & $2.7 \%$ & & $-1.7 \%$ & & $-2.2 \%$ & & $3.0 \%$ & & $0.8 \%$ & & $0.7 \%$ & & $2.7 \%$ & & $-2.0 \%$ & & $-2.3 \%$ & \\
\hline Pk clg ( & $\%$ differe & ence) & & & & & & & & & & & & & & & & & & & & & & & \\
\hline 670 & $-6.4 \%$ & $-6.5 \%$ & & $-6.4 \%$ & & $-6.8 \%$ & & $-6.8 \%$ & & $-4.2 \%$ & & $-4.2 \%$ & & $-6.5 \%$ & & $-6.4 \%$ & & $-6.7 \%$ & & $-5.8 \%$ & & $-3.0 \%$ & & $-3.0 \%$ & \\
\hline 660 & $-9.3 \%$ & $-8.6 \%$ & & $-7.4 \%$ & & $-6.1 \%$ & & $-7.8 \%$ & & $-5.0 \%$ & & $-4.0 \%$ & & $-8.4 \%$ & & $-7.4 \%$ & & $-6.0 \%$ & & $-8.0 \%$ & & $-4.4 \%$ & & $-3.6 \%$ & \\
\hline
\end{tabular}


Table 4A-9. Comparison of simulations applying derived alternative constant surface coefficients in the new EnergyPlus and TRNSYS simulations varying only window surface coefficients versus varying all surface coefficients, Cases 670 and 660

\begin{tabular}{|c|c|c|c|c|c|c|c|c|c|c|c|c|c|c|c|c|c|c|c|c|c|c|c|c|c|}
\hline \multicolumn{14}{|c|}{2018} & \multicolumn{12}{|c|}{ ds Applying WINDOW ONLY 2018 Coeffs ( 2017 Case 600 Coeffs to all other surfaces) } \\
\hline \multicolumn{14}{|c|}{ Kummert (TRNSYS) } & & & & & & & & & & & & \\
\hline Load & & & h1iv h0 & & h1e v h0 & & lie v ho & & h2i v ho & & h2e v ho & & 2ie v ho & \multicolumn{2}{|c|}{ h1iW v h1i } & \multicolumn{2}{|c|}{ h1eW v h1e } & \multicolumn{2}{|c|}{ h1ieW v h1ie } & \multicolumn{2}{|c|}{ h2iW v h2i } & \multicolumn{2}{|c|}{ h2eW v h2e } & \multicolumn{2}{|c|}{ h2ieW v h2ie } \\
\hline Case & ho & $h 1 i$ & $\%$ diff & h1e & $\%$ diff & h1ie & $\%$ diff & h2i & $\%$ diff & h2e & $\%$ diff & h2ie & $\%$ diff & h1iW & $\%$ diff & h1ew & $\%$ diff & | h1iew & $\%$ diff & h2iW & $\%$ diff & h2eW & $\%$ diff & h2ieW & $\%$ diff \\
\hline \multicolumn{26}{|c|}{ Ann htg (MWh/y) } \\
\hline 670 & 6.134 & 6.016 & $-1.9 \%$ & 6.173 & $0.6 \%$ & 6.044 & $-1.5 \%$ & 6.778 & $10.5 \%$ & 5.805 & $-5.4 \%$ & 6.478 & $5.6 \%$ & 5.977 & $-0.6 \%$ & 6.171 & $0.0 \%$ & 6.003 & $-0.7 \%$ & 6.720 & $-0.9 \%$ & 5.806 & $0.0 \%$ & 6.430 & $-0.7 \%$ \\
\hline 660 & 3.791 & 3.803 & $0.3 \%$ & 3.773 & $-0.5 \%$ & 3.785 & $-0.2 \%$ & 3.658 & $-3.5 \%$ & 3.370 & $-11.1 \%$ & 3.249 & $-14.3 \%$ & 3.879 & $2.0 \%$ & 3.771 & $-0.1 \%$ & 3.859 & $2.0 \%$ & 3.686 & $0.8 \%$ & 3.378 & $0.2 \%$ & 3.286 & $1.1 \%$ \\
\hline \multicolumn{26}{|c|}{ Ann clg (MWh/y) } \\
\hline 670 & 6.202 & 6.066 & $-2.2 \%$ & 6.159 & $-0.7 \%$ & 6.023 & $-2.9 \%$ & 6.862 & $10.6 \%$ & 6.530 & $5.3 \%$ & 7.284 & $17.4 \%$ & 6.006 & $-1.0 \%$ & 6.151 & $-0.1 \%$ & 5.957 & $-1.1 \%$ & 6.771 & $-1.3 \%$ & 6.521 & $-0.1 \%$ & 7.183 & $-1.4 \%$ \\
\hline 660 & 2.967 & 2.935 & $-1.1 \%$ & 2.931 & $-1.2 \%$ & 2.900 & $-2.3 \%$ & 3.132 & $5.6 \%$ & 3.208 & $8.1 \%$ & 3.375 & $13.8 \%$ & 3.037 & $3.5 \%$ & 2.916 & $-0.5 \%$ & 2.986 & $3.0 \%$ & 3.215 & $2.7 \%$ & 3.163 & $-1.4 \%$ & 3.408 & $1.0 \%$ \\
\hline \multicolumn{26}{|c|}{$\mathrm{Pkhtg}(\mathrm{kWh} / \mathrm{h})$} \\
\hline 670 & 4.216 & 3.886 & $-7.8 \%$ & .334 & $2.8 \%$ & 3.999 & $-5.1 \%$ & 4.431 & $5.1 \%$ & 4.363 & $3.5 \%$ & 4.577 & $8.6 \%$ & 3.866 & $-0.5 \%$ & 4.333 & $0.0 \%$ & 3.976 & $-0.6 \%$ & 4.409 & $-0.5 \%$ & 4.363 & $0.0 \%$ & 4.551 & $-0.6 \%$ \\
\hline 660 & 2.956 & 2.836 & $-4.1 \%$ & 2.887 & $-2.3 \%$ & 2.776 & $-6.1 \%$ & 2.812 & $-4.9 \%$ & 2.738 & $-7.4 \%$ & 2.611 & $-11.7 \%$ & 2.883 & $1.7 \%$ & 2.885 & $-0.1 \%$ & 2.821 & $1.6 \%$ & 2.796 & $-0.6 \%$ & 2.739 & $0.0 \%$ & 2.601 & $-0.4 \%$ \\
\hline \multicolumn{26}{|c|}{$\mathrm{Pk} c l g(\mathrm{kWh} / \mathrm{h})$} \\
\hline 670 & 6.403 & 5.858 & $-8.5 \%$ & .487 & $1.3 \%$ & 5.775 & $-9.8 \%$ & 6.686 & $4.4 \%$ & 6.704 & $4.7 \%$ & 7.027 & $9.7 \%$ & 5.803 & $-0.9 \%$ & 6.485 & $0.0 \%$ & 5.711 & $-1.1 \%$ & 6.612 & $-1.1 \%$ & 6.701 & $0.0 \%$ & 6.936 & $-1.3 \%$ \\
\hline 660 & 3.458 & 3.121 & $-9.7 \%$ & 3.375 & $-2.4 \%$ & 3.094 & $-10.5 \%$ & 3.294 & $-4.7 \%$ & 3.508 & $1.4 \%$ & 3.342 & $-3.4 \%$ & 3.248 & $4.1 \%$ & 3.366 & $-0.3 \%$ & 3.195 & $3.3 \%$ & 3.447 & $4.6 \%$ & 3.486 & $-0.6 \%$ & 3.476 & $4.0 \%$ \\
\hline \multirow{2}{*}{\multicolumn{14}{|c|}{ Neymark/GARD (EnergyPlus) }} & & & & & & & & & & & & \\
\hline & & & h1iv h0 & & h1e v h0 & & lie v ho & & h2i v h0 & & h2e v ho & & 2ie v ho & h1il & W v h1i & h1eV & W v h1e & h1ieW & V v h1ie & h2il & W v h2i & h2el & W v h2e & h2ieh & V v h2ie \\
\hline Case & ho I & h1i & $\%$ diff & h1e & $\%$ diff & h1ie & $\%$ diff & h2i & $\%$ diff & h2e & $\%$ diff & h2ie & $\%$ diff & h1iw & $\%$ diff & h1ew & $\%$ diff & h1iew & $\%$ diff & h2iW & $\%$ diff & h2eW & $\%$ diff & h2ieW & $\%$ diff \\
\hline 670 & 5.965 & 5.805 & $-2.7 \%$ & 6.020 & $0.9 \%$ & 5.850 & $-1.9 \%$ & 6.521 & $9.3 \%$ & 5.752 & $-3.6 \%$ & 6.327 & $6.1 \%$ & 5.770 & $-0.6 \%$ & 6.020 & $0.0 \%$ & 5.813 & $-0.6 \%$ & 6.453 & $-1.0 \%$ & 5.759 & $0.1 \%$ & 6.271 & $-0.9 \%$ \\
\hline 660 & 3.730 & 3.725 & $-0.1 \%$ & 3.724 & $-0.2 \%$ & 3.720 & $-0.3 \%$ & 3.563 & $-4.5 \%$ & 3.460 & $-7.2 \%$ & 3.302 & $-11.5 \%$ & 3.795 & $1.9 \%$ & 3.723 & $0.0 \%$ & 3.788 & $1.8 \%$ & 3.596 & $0.9 \%$ & 3.467 & $0.2 \%$ & 3.341 & $1.2 \%$ \\
\hline Ann clg & (MWh/y & & & & & & & & & & & & & & & & & & & & & & & & \\
\hline 670 & 6.593 & 6.398 & $-3.0 \%$ & 6.523 & $-1.1 \%$ & 6.331 & $-4.0 \%$ & 7.280 & $10.4 \%$ & 6.757 & $2.5 \%$ & 7.498 & $13.7 \%$ & 6.340 & $-0.9 \%$ & 6.526 & $0.0 \%$ & 6.276 & $-0.9 \%$ & 7.180 & $-1.4 \%$ & 6.713 & $-0.7 \%$ & 7.357 & $-1.9 \%$ \\
\hline 660 & 3.258 & 3.189 & $-2.1 \%$ & 3.200 & $-1.8 \%$ & 3.133 & $-3.8 \%$ & 3.385 & $3.9 \%$ & 3.325 & $2.1 \%$ & 3.461 & $6.2 \%$ & 3.286 & $3.0 \%$ & 3.193 & $-0.2 \%$ & 3.222 & $2.8 \%$ & 3.459 & $2.2 \%$ & 3.282 & $-1.3 \%$ & 3.491 & $0.9 \%$ \\
\hline Pk htg & $k W h / h)$ & & & & & & & & & & & & & & & & & & & & & & & & \\
\hline 670 & 4.125 & 3.798 & $-7.9 \%$ & 4.265 & $3.4 \%$ & 3.924 & $-4.9 \%$ & 4.338 & $5.2 \%$ & 4.298 & $4.2 \%$ & 4.499 & $9.1 \%$ & 3.778 & $-0.5 \%$ & 4.265 & $0.0 \%$ & 3.901 & $-0.6 \%$ & 4.320 & $-0.4 \%$ & 4.299 & $0.0 \%$ & 4.471 & $-0.6 \%$ \\
\hline 660 & 2.855 & 2.754 & $-3.5 \%$ & 2.861 & $0.2 \%$ & 2.758 & $-3.4 \%$ & 2.717 & $-4.8 \%$ & 2.784 & $-2.5 \%$ & 2.653 & $-7.1 \%$ & 2.801 & $1.7 \%$ & 2.861 & $0.0 \%$ & 2.806 & $1.7 \%$ & 2.722 & $0.2 \%$ & 2.786 & $0.1 \%$ & 2.659 & $0.2 \%$ \\
\hline Pk clg ( & $k W h / h)$ & & & & & & & & & & & & & & & & & & & & & & & & \\
\hline 670 & 6.828 & 6.248 & $-8.5 \%$ & 6.913 & $1.2 \%$ & 6.172 & $-9.6 \%$ & 7.174 & $5.1 \%$ & 7.008 & $2.6 \%$ & 7.384 & $8.1 \%$ & 6.192 & $-0.9 \%$ & 6.915 & $0.0 \%$ & 6.110 & $-1.0 \%$ & 7.077 & $-1.4 \%$ & 6.991 & $-0.2 \%$ & 7.236 & $-2.0 \%$ \\
\hline 660 & 3.796 & 3.401 & $-10.4 \%$ & 3.629 & $-4.4 \%$ & 3.276 & $-13.7 \%$ & 3.586 & $-5.5 \%$ & 3.683 & $-3.0 \%$ & 3.491 & $-8.0 \%$ & 3.539 & $4.1 \%$ & 3.626 & $-0.1 \%$ & 3.396 & $3.7 \%$ & 3.728 & $4.0 \%$ & 3.663 & $-0.5 \%$ & 3.617 & $3.6 \%$ \\
\hline & \% Diff & Averą & ge ABS \% & Differer & nces Vers & us h0 & $\overline{\overline{A B S}(\mathrm{Ku}}$ & nmert)t & $+\mathrm{ABS}(\mathrm{N}$ & ymark)) & & & & $\overline{M a x A E}$ & BS \% Dif & ferences, & Windov & ws Onlyv & vs All Su & $\mathrm{rfs}=\mathrm{MA}$ & $\overline{\mathrm{X}(\mathrm{ABS} / \mathrm{K}}$ & ummert & ),ABS(Ne & eymark)) & \\
\hline Case & ho & & h1iv ho & & h1e v ho & & lie v ho & & h2i v ho & & h2e v ho & & 2ie v ho & h1il & W v h1i & h1eV & W v h1e & h1ieW & V v h1ie & h2il & W v h2i & h2el & W v h2e & h2ieh & V v h2ie \\
\hline Ann ht & (\% dif & nce) & & & & & & & & & & & & & & & & & & & & & & & \\
\hline 670 & $2.8 \%$ & & $2.3 \%$ & & $0.8 \%$ & & $1.7 \%$ & & $9.9 \%$ & & $4.5 \%$ & & $5.8 \%$ & & $0.6 \%$ & & $0.0 \%$ & & $0.7 \%$ & & $1.0 \%$ & & $0.1 \%$ & & $0.9 \%$ \\
\hline 660 & $1.6 \%$ & & $0.2 \%$ & & $0.3 \%$ & & $0.2 \%$ & & $4.0 \%$ & & $9.2 \%$ & & $12.9 \%$ & & $2.0 \%$ & & $0.1 \%$ & & $2.0 \%$ & & $0.9 \%$ & & $0.2 \%$ & & $1.2 \%$ \\
\hline Ann clg & (\% differ & ence) & & & & & & & & & & & & & & & & & & & & & & & \\
\hline 670 & $-6.1 \%$ & & $2.6 \%$ & & $0.9 \%$ & & $3.4 \%$ & & $10.5 \%$ & & $3.9 \%$ & & $15.6 \%$ & & $1.0 \%$ & & $0.1 \%$ & & $1.1 \%$ & & $1.4 \%$ & & $0.7 \%$ & & $1.9 \%$ \\
\hline 660 & $-9.3 \%$ & & $1.6 \%$ & & $1.5 \%$ & & $3.0 \%$ & & $4.7 \%$ & & $5.1 \%$ & & $10.0 \%$ & & $3.5 \%$ & & $0.5 \%$ & & $3.0 \%$ & & $2.7 \%$ & & $1.4 \%$ & & $1.0 \%$ \\
\hline Pk htg & $\%$ differe & nce) & & & & & & & & & & & & & & & & & & & & & & & \\
\hline 670 & $2.2 \%$ & & $7.9 \%$ & & $3.1 \%$ & & $5.0 \%$ & & $5.1 \%$ & & $3.8 \%$ & & $8.8 \%$ & & $0.5 \%$ & & $0.0 \%$ & & $0.6 \%$ & & $0.5 \%$ & & $0.0 \%$ & & $0.6 \%$ \\
\hline 660 & $3.5 \%$ & & $3.8 \%$ & & $1.3 \%$ & & $4.7 \%$ & & $4.9 \%$ & & $4.9 \%$ & & $9.4 \%$ & & $1.7 \%$ & & $0.1 \%$ & & $1.7 \%$ & & $0.6 \%$ & & $0.1 \%$ & & $0.4 \%$ \\
\hline Pk clg ( & $\%$ differe & nce) & & & & & & & & & & & & & & & & & & & & & & & \\
\hline 670 & $-6.4 \%$ & & 8. & & $1.3 \%$ & & $9.7 \%$ & & $4.7 \%$ & & $3.7 \%$ & & $8.9 \%$ & & $0.9 \%$ & & $0.0 \%$ & & $1.1 \%$ & & $1.4 \%$ & & $0.2 \%$ & & $2.0 \%$ \\
\hline 660 & $-9.3 \%$ & & $10.1 \%$ & & $3.4 \%$ & & $12.1 \%$ & & $5.1 \%$ & & $2.2 \%$ & & $5.7 \%$ & & $4.1 \%$ & & $0.3 \%$ & & $3.7 \%$ & & $4.6 \%$ & & $0.6 \%$ & & $4.0 \%$ \\
\hline
\end{tabular}


These results are further analyzed for Case 670 in Tables 4A-10 and 4A-11 for EnergyPlus and TRNSYS, respectively, and for Case 660 in Tables 4A-12 and 4A-13 for EnergyPlus and TRNSYS, respectively.

In these tables, the variation for load results applying alternative constant surface coefficients versus the automated heat transfer simulations ("h1i v. h0", etc., shown in black color) taken from Tables 4A-7 and 4A-8 are compared as follows:

- "Previous 2017" Case 600 coefficients applied to all surfaces (see the "2017" column).

- "New" coefficients applied to all surfaces (see leftmost column of the "All Surfs" columns).

- "New" coefficients only for the windows are applied to the windows and the previous 2017 coefficients for Case 600 are applied to the opaque surfaces (see leftmost column of the "Windows Only" columns).

Other columns developed for further analysis in the table - shown in blue- are (also see notes at the bottom of Tables 4A-10 through 4A-13):

- "Raw Delta" and "ABS Delta" indicate the unadjusted difference between "New" \%-difference values and "2017" \%-difference values, and the difference between those values taken as individual absolute values, respectively.

- "Max Variation Ratio" is the maximum of the absolute values of the "Raw Delta" values for "All Surfs" and "Windows Only" in a given row, divided by the current range of disagreement among the programs in the simulation trials (see the "Progs. Diff" column, values in black bold).

- The "Max Improved Ratio" is the Maximum of the "ABS Delta" values for "All Surfs" and "Windows Only", divided by the current range of disagreement among the programs in the simulation trials (see the "Progs. Diff" column). Negative values here imply overall worsening of agreement when applying the new custom constant combined coefficients (versus the "2017" coefficients) and may indicate that the effect of applying the new coefficients is lost in the noise of other modeling effects.

Values shown in dark red in Tables 4A-10 through 4A-13 indicate scenarios with the most notable effects on results.

From this analysis, we observe and conclude:

- For Case 670:

$\circ \quad$ The effect of updating the constant interior and/or exterior convective surface coefficients ( $\mathrm{h}$,conv, int and/or h,conv,ext) versus the 2017 coefficients for Case 600 is small relative to the range of disagreement among all the tested programs ("Max Variation Ratio" $<1 / 6$ and $<1 / 4$ of the range of disagreement for EnergyPlus and TRNSYS, respectively). Therefore, updating the test specification to include the new convective coefficients is not justified.

- The effect of updating the interior constant combined surface coefficients ( $h, c o m b$,int) is substantial in the heating loads for updating either all surface coefficients or only the windows, with an overall "Raw Delta v. 2017" effect of about $22 \%$ to $24 \%$ on annual heating load results for EnergyPlus and TRNSYS, respectively. This results in a 3\% to 6\% "ABS Delta v. 2017" improvement in overall agreement because of the sign change (where differences versus automated [h0] runs change from $14 \%$ difference for the " 2017 " coefficients to $+8 \%$ to $+10 \%$ difference for the "New" coefficients), depending on applying "All Surfs" versus "Windows Only" coefficients and on differences among the models. This is caused by h,comb, int, window going from 4.5 to 7.8 or $7.9 \mathrm{~W} / \mathrm{m}^{2} \mathrm{~K}$ for EnergyPlus or TRNSYS, respectively (whereas the variation of h,conv, int,window between Case 670 and Case 600 is only about 0.1 or $0.2 \mathrm{~W} / \mathrm{m}^{2} \mathrm{~K}$ for the models) - see Table 4A-6 "TRNSYS" or "EnergyPlus" values versus "Previous 2017" values. Therefore, updating the test specification to include the new interior combined coefficients is justified.

- The relative improvement in the EnergyPlus and TRNSYS models is similar for applying only the new single-pane-window interior combined surface coefficient versus varying all the interior combined surface coefficients. However, for both models, disagreement ("New" \%-differences) versus the fully automated (h0) run is slightly less when updating only the window coefficients. The reasons for this observation are not clear, but it seems reasonable to conclude that the most important aspect here is the single-pane-window surface coefficient, and that varying the opaque surface coefficients is less important relative to varying the window surface coefficients.

- Updating the exterior constant combined surface coefficients has a greater relative effect on results than updating convective coefficients in EnergyPlus (but not in TRNSYS), and less effect than updating the interior combined coefficients (seen in both models). However, for the h2ie scenario, 
annual heating load difference is reduced to about half of the range of the difference among simulation trial programs - e.g., see Table 4A-11 for annual heating "Windows Only New", scenario "h2ie vs. h0" (4.8\%) versus "Progs. Diff." (9.4\%) versus "2017" disagreement (-19.8\%). Although there is some disagreement among the models regarding the impact of varying single-pane-window exterior combined surface coefficients, it seems that if we are to update the single-pane window's interior combined coefficient in the test spec, for consistency it makes sense to update the single-pane window's exterior combined coefficient.

0 The relative effect in the models is similar for applying only the new single-pane-window exterior combined surface coefficient versus varying all the exterior combined surface coefficients. However, disagreement ("New" \%-difference) versus the fully automated (h0) run is slightly less when updating only the window coefficients. As with the interior surface, the reasons for this observation are not clear, but it seems reasonable to conclude that the most important aspect here is the single-panewindow surface coefficient.

$\circ$ Therefore, for Case 670, we recommend updating only the single-pane-window interior and exterior alternative constant combined surface coefficients in the test specification, and leaving the alternative combined coefficients for the other surfaces and the convective coefficients for all surfaces unchanged.

- Apply these as individual averages of the respective EnergyPlus and TRNSYS values as indicated in Table 4A-5 for Case 670, "h,comb,lwa,2", "Windows" (see values in the bottom portion of the table identified as "Average....").

- Update Table B4-2 (see Part I, Annex B4) and elsewhere in the Part I test specification and its informative annexes, as appropriate, to indicate these values.

\section{- For Case 660:}

- "Max Improved Ratio" and "Max Variation Ratio" are generally more sensitive for Case 660 than for Case 670 (i.e., higher values are expected for Case 660 for a given difference) because:

- Case 660's h0 basis is substantially lower than for Case 670 (e.g., 3.730 MWh versus 5.965 MWh for EnergyPlus annual heating load), so for the same MWh or kW value difference (e.g., between h1i and h0 results), Case 660 yields a larger \%-difference.

- Program G had outlying Case 660 results for Simulation Trial \#3 and was removed for the Case 660 analysis (see notes "a" and "g" in Tables 4A-12 or 4A-13), which may have artificially reduced the Case 660 "Progs.Diff" values (e.g., from 16\% to 8\% for annual heating load).

- The effect of updating the constant interior and/or exterior convective surface coefficients versus the 2017 coefficients for Case 600 is small relative to the range of disagreement among all the tested programs, with "Max Improved Ratio" $<1 / 4$ and $<1 / 3$ for annual heating loads for EnergyPlus and TRNSYS, respectively, and less than that for other loads. Therefore, updating the test specification to include the new convective coefficients is not justified.

- The effect of updating the constant interior and/or exterior combined surface coefficients versus the 2017 coefficients for Case 600 is also small relative to the range of disagreement among all the tested programs. Here the largest "Max Improved Ratio" is $<1 / 4$ for all loads for both models, with a small worsening of annual heating-load results (especially the $\mathrm{h} 2 \mathrm{i}$ result), but a corresponding small improvement to annual cooling-load results; i.e., there is no obvious overall benefit. Therefore, updating the test specification to include the new combined coefficients is not justified.

- Generally, the effects of applying constant coefficients are more pronounced in the "All Surfs" comparisons, with less effect in the "Windows Only" comparisons. This observation likely stems from larger differences in h,conv, int and h,comb, int that occur for the interior side of the opaque surfaces in Case 660 (see Table 4A-6 "TRNSYS" or "EnergyPlus" values versus "Previous 2017" values) than occur for the low-e windows, and especially the variation of h,comb, ext,floor from 3.7 to 2.5 or 2.3 $\mathrm{W} / \mathrm{m}^{2} \mathrm{~K}$ in the analysis for EnergyPlus or TRNSYS, respectively. However, applying this change in the test spec would lead to a small worsening of annual heating-load results but a corresponding small improvement to annual cooling-load results; i.e., there is no obvious overall benefit.

- Therefore, we recommend no change for Case 660. That is, do not update the alternative constant convective and combined surface coefficients, and continue applying the Case 600 alternative values for all surfaces of Case 660 . 
Table 4A-10. Observations, Case 670, EnergyPlus: Disagreements from Applying Derived Constant Coefficients Versus Automated (h0) Run, Compared with Range of Disagreement Observed for All Programs in Simulation Trial \#3

\begin{tabular}{|c|c|c|c|c|c|c|c|c|c|c|c|}
\hline \multirow[b]{3}{*}{ Case 670} & \multirow{3}{*}{$\begin{array}{c}\text { Progs. Diff. } \\
\text { SimTrial \#3: } \\
\text { (Max-Min) } \\
\text { /Mean }^{\mathrm{a}}\end{array}$} & \multicolumn{9}{|c|}{ EnergyPlus Disagreements Versus ho Simulations $^{\mathrm{D}}$} & \multirow[b]{3}{*}{ Comments re Change vs applying 2017 Case 600 Coeffs } \\
\hline & & & \multicolumn{2}{|c|}{$\begin{array}{l}\text { All Surfs } \\
\text { Raw Delta }\end{array}$} & \multirow{2}{*}{$\begin{array}{c}\text { ABS Delta } \\
\text { v. } 2017^{a}\end{array}$} & \multirow{2}{*}{\multicolumn{2}{|c|}{$\begin{array}{l}\text { Windows Only } \\
\text { Raw Delta }\end{array}$}} & \multirow{2}{*}{$\begin{array}{c}\text { ABS Delta } \\
\text { v. } 2017^{a}\end{array}$} & \multirow{2}{*}{$\left|\begin{array}{c}\text { Max } \\
\text { Variation }^{\text {Ratio }^{\mathrm{e}}}\end{array}\right|$} & \multirow{2}{*}{$\begin{array}{c}\text { Max } \\
\text { Improved } \\
\text { Ratio }^{\top}\end{array}$} & \\
\hline & & 2017 & New & v. $2017^{\mathrm{c}}$ & & & & & & & \\
\hline Annual Heating & $9.4 \%$ & & & & & & & & & & h0 = 5.965 MWh \\
\hline h1iv. ho & & $-4.0 \%$ & $-2.7 \%$ & $1.3 \%$ & $1.3 \%$ & $-3.3 \%$ & $0.7 \%$ & $0.7 \%$ & 0.14 & 0.14 & Insufficient improvement (< Range/4) for spec update of $h$,conv,i \\
\hline h1ev. ho & & $0.9 \%$ & $0.9 \%$ & $0.0 \%$ & $0.0 \%$ & $0.9 \%$ & $0.0 \%$ & $0.0 \%$ & 0.00 & 0.00 & Negligble change versus 2017 \\
\hline h1ie v. ho & & $-3.3 \%$ & $-1.9 \%$ & $1.3 \%$ & $1.3 \%$ & $-2.5 \%$ & $0.7 \%$ & $0.7 \%$ & 0.14 & 0.14 & Insufficient improvement (<Range/4) for spec update of $h$, conv,l and/or h, conv,e \\
\hline h2i v. ho & & $-13.6 \%$ & $9.3 \%$ & $23.0 \%$ & $4.3 \%$ & $8.2 \%$ & $21.8 \%$ & $5.5 \%$ & 2.44 & 0.58 & Spec update of $h$,comb, i justified; windows-only better than all surf \\
\hline h2ev. ho & & $0.7 \%$ & $-3.6 \%$ & $-4.2 \%$ & $-2.9 \%$ & $-3.5 \%$ & $-4.1 \%$ & $-2.8 \%$ & 0.45 & -0.30 & Moderate "worsening" for h2e compensates h2i, therefore (see next) ... \\
\hline h2ie v. ho & & $-15.7 \%$ & $6.1 \%$ & $21.8 \%$ & $9.6 \%$ & $5.1 \%$ & $20.8 \%$ & $10.6 \%$ & 2.31 & 1.12 & Spec update of h,comb,i AND h,comb,e justified; windows-only "better" \\
\hline Annual Cooling & $21.9 \%$ & & & & & & & & & & $h 0=6.593 \mathrm{MWh}$ \\
\hline h1e v. ho & & $-1.0 \%$ & $-1.1 \%$ & $0.0 \%$ & $0.0 \%$ & $-1.0 \%$ & $0.0 \%$ & $0.0 \%$ & 0.00 & 0.00 & Negligble change versus 2017 \\
\hline h1ie v. ho & & $-4.7 \%$ & $-4.0 \%$ & $0.8 \%$ & $0.8 \%$ & $-4.8 \%$ & $-0.1 \%$ & $-0.1 \%$ & 0.03 & 0.03 & Insufficient improvement for spec update of $h$, conv,l and/or h, conv,e \\
\hline h2i v. ho & & $14.3 \%$ & $10.4 \%$ & $-3.9 \%$ & $3.9 \%$ & $8.9 \%$ & $-5.4 \%$ & $5.4 \%$ & 0.25 & 0.25 & Improvement for $\mathrm{h} 2 \mathrm{i}<$ Range $/ 3$; windows-only better than all surf \\
\hline h2e v. ho & & $-0.8 \%$ & $2.5 \%$ & $3.3 \%$ & $-1.7 \%$ & $1.8 \%$ & $2.6 \%$ & $-1.0 \%$ & 0.15 & -0.05 & Minor "Worsening" for h2e; windows-only better than all surf \\
\hline h2ie v. ho & & $15.0 \%$ & $13.7 \%$ & $-1.3 \%$ & $1.3 \%$ & $11.6 \%$ & $-3.4 \%$ & $3.4 \%$ & 0.16 & 0.16 & Improvement for h2ie $<$ Range $/ 4$; windows-only better than all surf \\
\hline Tot.Ann.Htg+Clg & $9.7 \%$ & & & & & & & & & & $\mathrm{~h} 0=12.588 \mathrm{MWh}$ \\
\hline h1iv. ho & & $-3.9 \%$ & $-2.8 \%$ & $1.0 \%$ & $1.0 \%$ & $-3.6 \%$ & $0.3 \%$ & $0.3 \%$ & 0.11 & 0.11 & Insufficient improvement for spec update of $h$, conv, $i$ \\
\hline h1ev. ho & & $-0.1 \%$ & $-0.1 \%$ & $0.0 \%$ & $0.0 \%$ & $-0.1 \%$ & $0.0 \%$ & $0.0 \%$ & 0.00 & 0.00 & Negligble change versus 2017 \\
\hline h1ie v. ho & & $-4.0 \%$ & $-3.0 \%$ & $1.0 \%$ & $1.0 \%$ & $-3.7 \%$ & $0.3 \%$ & $0.3 \%$ & 0.11 & 0.11 & Insufficient improvement for spec update of $h$, conv,l and/or h, conv,e \\
\hline h2i v. ho & & $1.0 \%$ & $9.9 \%$ & $8.9 \%$ & $-8.9 \%$ & $8.6 \%$ & $7.5 \%$ & $-7.5 \%$ & 0.92 & -0.78 & "Worsening" for h2i; windows-only better than all surf \\
\hline Peak Heating & $12.2 \%$ & & & & & & & & & & $\mathrm{~h} 0=4.125 \mathrm{~kW}$ \\
\hline h1iv. ho & & $-9.0 \%$ & $-7.9 \%$ & $1.0 \%$ & $1.0 \%$ & $-8.4 \%$ & $0.6 \%$ & $0.6 \%$ & 0.09 & 0.09 & Insufficient improvement for spec update of $h$, conv, $i$ \\
\hline h1ev. ho & & $3.4 \%$ & $3.4 \%$ & $0.0 \%$ & $0.0 \%$ & $3.4 \%$ & $0.0 \%$ & $0.0 \%$ & 0.00 & 0.00 & Negligble change versus 2017 \\
\hline h1ie v. ho & & $-6.0 \%$ & $-4.9 \%$ & $1.1 \%$ & $1.1 \%$ & $-5.4 \%$ & $0.5 \%$ & $0.5 \%$ & 0.09 & 0.09 & Insufficient improvement for spec update of $h$, conv,l and/or h, conv,e \\
\hline h2i v. ho & & $-12.4 \%$ & $5.2 \%$ & $17.6 \%$ & $7.2 \%$ & $4.7 \%$ & $17.1 \%$ & $7.7 \%$ & 1.44 & 0.63 & Improvement for h2i > Range/2; windows-only better than all surf \\
\hline h2ev. ho & & $7.6 \%$ & $4.2 \%$ & $-3.4 \%$ & $3.4 \%$ & $4.2 \%$ & $-3.4 \%$ & $3.4 \%$ & 0.28 & 0.28 & Improvement for h2e $<$ Range/2; windows-only equals all-surf \\
\hline h2ie v. ho & & $-8.3 \%$ & $9.1 \%$ & $17.4 \%$ & $-0.8 \%$ & $8.4 \%$ & $16.7 \%$ & $-0.1 \%$ & 1.42 & -0.01 & "Worsening" for h2ie; windows-only better than all surf \\
\hline Peak Cooling & $22.8 \%$ & & & & & & & & & & $\mathrm{~h} 0=6.828 \mathrm{~kW}$ \\
\hline h1iv. ho & & $-9.4 \%$ & $-8.5 \%$ & $0.9 \%$ & $0.9 \%$ & $-9.3 \%$ & $0.1 \%$ & $0.1 \%$ & 0.04 & 0.04 & Insufficient improvement for spec update of $h$, conv, $i$ \\
\hline h1ev. ho & & $1.3 \%$ & $1.2 \%$ & $0.0 \%$ & $0.0 \%$ & $1.3 \%$ & $0.0 \%$ & $0.0 \%$ & 0.00 & 0.00 & Negligble change versus 2017 \\
\hline h1ie v. ho & & $-10.5 \%$ & $-9.6 \%$ & $0.9 \%$ & $0.9 \%$ & $-10.5 \%$ & $0.0 \%$ & $0.0 \%$ & 0.04 & 0.04 & Insufficient improvement for spec update of h,conv,l and/or h,conv,e \\
\hline h2i v. ho & & $4.8 \%$ & $5.1 \%$ & $0.2 \%$ & $-0.2 \%$ & $3.6 \%$ & $-1.2 \%$ & $1.2 \%$ & 0.05 & 0.05 & Minor variations \\
\hline h2ev. ho & & $0.9 \%$ & $2.6 \%$ & $1.7 \%$ & $-1.7 \%$ & $2.4 \%$ & $1.5 \%$ & $-1.5 \%$ & 0.08 & -0.06 & Minor variations \\
\hline h2ie v. ho & & $6.5 \%$ & $8.1 \%$ & $1.7 \%$ & $-1.7 \%$ & $6.0 \%$ & $-0.5 \%$ & $0.5 \%$ & 0.07 & 0.02 & Minor variations \\
\hline
\end{tabular}

* Colors for values: Values from Tables 4A-7 and 4A-8 and "Progs. Diff." values are shown in black (black column headers); calculated values further described in notes $\mathrm{c}$ through $\mathrm{f}$ below are shown in blue (blue column headers); dark red indicates scenarios with the most notable effects on results.

a. The range of difference among programs in simulation trial \#3 is the basis for determining significance of improvements; see note with "Max Improved Ratio".

. "... Disagreement Versus h0 Simulations" is the disagreement between using constant coefficients versus automated heat transfer for the various scenarios (h1i, h1e, h2i, h2e, etc).

c. "Raw Delta v. 2017" = "2017" - "New"; this indicates degree of change versus the previous 2017 vs. hO disagreement, but does not indicate whether the change is an improvement.

d. "ABS Delta v. 2017" = ABS(2017) - ABS(New), this indicates improventent to (or worsening of, if < 0 ) the previous 2017 vs. ho disagreement.

= Max(ABS( Raw Delta v. 2017 All Surfs"), ABS( Raw Delta v. 2017 Windows Only"))/("Progs. Diff...(Max-Min)/Mean"), this indicates degree of change for applying new coefficients relative to applying the "2017"

$=$ Max("ABS Delta v. 2017 All Surfs","ABS Delta v. 2017 Windows Only")/("Progs. Diff...(Max-Min)/Mean"); this indicates whether there is improved accuracy (if >0) related to applying new custom surface coefficients relative to applying the "2017" coefficients and whether that improvement is substantial relative to the current range of disagreement among the programs ("Progs. Diff."). 
Table 4A-11. Observations, Case 670, TRNSYS: Disagreements from Applying Derived Constant Coefficients Versus Automated (h0) Run Compared with Range of Disagreement Observed for All Programs in Simulation Trial \#3

\begin{tabular}{|c|c|c|c|c|c|c|c|c|c|c|c|}
\hline Case 670 & $\begin{array}{c}\text { Progs. Diff. } \\
\text { SimTrial \#3: } \\
\text { (Max-Min) } \\
\text { /Mean }^{\mathrm{a}}\end{array}$ & 2017 & $\begin{array}{l}\text { SYS Disa } \\
\text { Alls }\end{array}$ & $\begin{array}{l}\text { greements } \\
\text { urfs } \\
\text { Raw Delta } \\
\text { v. } 2017^{c}\end{array}$ & $\begin{array}{l}\text { ABS Delta } \\
\text { v. } 2017^{a} \\
\end{array}$ & $\begin{array}{l}\text { imulatior } \\
\text { Windor } \\
\text { New } \\
\end{array}$ & $\begin{array}{l}\mathrm{ss}^{\mathrm{b}} \\
\text { Ns Only } \\
\text { Raw Delta } \\
\text { v. } 2017^{\mathrm{c}}\end{array}$ & $\begin{array}{r}\text { ABS Delta } \\
\text { v. 2017 }\end{array}$ & $\begin{array}{c}\text { Max } \\
\text { Variation } \\
\text { Ratio }^{\mathrm{e}}\end{array}$ & $\begin{array}{c}\text { Max } \\
\text { Improved } \\
\text { Ratio }^{\top}\end{array}$ & Comments re Change vs applying 2017 Case 600 Coeffs \\
\hline Annual Heating & $9.4 \%$ & & & & & & & & & & h0 = 6.134 MWh \\
\hline h1iv. ho & & $-4.0 \%$ & $-1.9 \%$ & $2.1 \%$ & $2.1 \%$ & $-2.6 \%$ & $1.4 \%$ & $1.4 \%$ & 0.22 & 0.22 & Insufficient improvement (< Range/4) for spec update of $h$,conv,i \\
\hline h1e v. ho & & $0.6 \%$ & $0.6 \%$ & $0.0 \%$ & $0.0 \%$ & $0.6 \%$ & $0.0 \%$ & $0.0 \%$ & 0.00 & 0.00 & Negligble change versus 2017 \\
\hline h1ie v. ho & & $-3.6 \%$ & $-1.5 \%$ & $2.1 \%$ & $2.1 \%$ & $-2.1 \%$ & $1.5 \%$ & $1.5 \%$ & 0.23 & 0.23 & Insufficient improvement (<Range/4) for spec update of $h$, conv,l and/or $h$, cor \\
\hline h2i v. ho & & $-13.6 \%$ & $10.5 \%$ & $24.1 \%$ & $3.1 \%$ & $9.6 \%$ & $23.1 \%$ & $4.0 \%$ & 2.56 & 0.43 & Spec update of $h$,comb, i justified; windows-only better than all surf \\
\hline h2e v. ho & & $-4.6 \%$ & $-5.4 \%$ & $-0.7 \%$ & $-0.7 \%$ & $-5.3 \%$ & $-0.7 \%$ & $-0.7 \%$ & 0.08 & -0.07 & Minor "worsening" for h2e; but h2e compensates h2i, therefore (see next) ... \\
\hline h2ie v. ho & & $-19.8 \%$ & $5.6 \%$ & $25.4 \%$ & $14.2 \%$ & $4.8 \%$ & $24.7 \%$ & $15.0 \%$ & 2.71 & 1.60 & Spec update of h,comb,i AND h,comb,e justified; windows-only "better" \\
\hline Annual Cooling & $21.9 \%$ & & & & & & & & & & $h 0=6.202 \mathrm{MWh}$ \\
\hline h1i v. ho & & $-3.0 \%$ & $-2.2 \%$ & $0.8 \%$ & $0.8 \%$ & $-3.2 \%$ & $-0.2 \%$ & $-0.2 \%$ & 0.03 & 0.03 & Insufficient improvement for spec update of $h$,conv, $i$ \\
\hline h1e v. ho & & $-0.8 \%$ & $-0.7 \%$ & $0.1 \%$ & $0.1 \%$ & $-0.8 \%$ & $0.0 \%$ & $0.0 \%$ & 0.01 & 0.01 & Negligble change versus 2017 \\
\hline h1ie v. ho & & $-3.7 \%$ & $-2.9 \%$ & $0.9 \%$ & $0.9 \%$ & $-4.0 \%$ & $-0.2 \%$ & $-0.2 \%$ & 0.04 & 0.04 & Insufficient improvement for spec update of $h$, conv,l and/or $h$, conv,e \\
\hline h2i v. ho & & $15.9 \%$ & $10.6 \%$ & $-5.2 \%$ & $5.2 \%$ & $9.2 \%$ & $-6.7 \%$ & $6.7 \%$ & 0.31 & 0.31 & Improvement for $\mathrm{h} 2 \mathrm{i}<$ Range $/ 2$; windows-only better than all surf \\
\hline h2e v. ho & & $4.6 \%$ & $5.3 \%$ & $0.6 \%$ & $-0.6 \%$ & $5.1 \%$ & $0.5 \%$ & $-0.5 \%$ & 0.03 & -0.02 & Minor "Worsening" for h2e; windows-only better than all surf \\
\hline h2ie v. ho & & $21.6 \%$ & $17.4 \%$ & $-4.2 \%$ & $4.2 \%$ & $15.8 \%$ & $-5.8 \%$ & $5.8 \%$ & 0.27 & 0.27 & Improvement for h2ie $<$ Range/2; windows-only better than all surf \\
\hline Tot.Ann.Htg+Clg & $9.7 \%$ & & & & & & & & & & $\mathrm{~h} 0=12.336 \mathrm{MWh}$ \\
\hline $\begin{array}{l}\text { h1iv. h0 } \\
\text { h1e v. ho }\end{array}$ & & $\begin{array}{l}-3.5 \% \\
-0.1 \%\end{array}$ & $\begin{array}{r}-2.1 \% \\
0.0 \%\end{array}$ & $\begin{array}{l}1.4 \% \\
0.1 \%\end{array}$ & $\begin{array}{l}1.4 \% \\
0.1 \%\end{array}$ & $\begin{array}{l}-2.9 \% \\
-0.1 \%\end{array}$ & $\begin{array}{l}0.6 \% \\
0.0 \%\end{array}$ & $\begin{array}{l}0.6 \% \\
0.0 \%\end{array}$ & $\begin{array}{l}0.15 \\
0.01\end{array}$ & $\begin{array}{l}0.15 \\
0.01\end{array}$ & $\begin{array}{l}\text { Insufficient improvement for spec update of h,conv, } \\
\text { Negligble change versus } 2017\end{array}$ \\
\hline h1ie v. ho & & $-3.7 \%$ & $-2.2 \%$ & $1.5 \%$ & $1.5 \%$ & $-3.0 \%$ & $0.6 \%$ & $0.6 \%$ & 0.15 & 0.15 & Insufficient improvement for spec update of $h$, conv,l and/or h, conv,e \\
\hline h2i v. ho & & $1.2 \%$ & $10.6 \%$ & $9.3 \%$ & $-9.3 \%$ & $9.4 \%$ & $8.1 \%$ & $-8.1 \%$ & 0.96 & -0.84 & "Worsening" for h2i; windows-only better than all surf \\
\hline h2e v. ho & & $0.0 \%$ & $0.0 \%$ & $0.0 \%$ & $0.0 \%$ & $-0.1 \%$ & $-0.1 \%$ & $0.0 \%$ & 0.01 & 0.00 & Negligble change versus 2017 \\
\hline h2ie v. ho & & $1.0 \%$ & $11.6 \%$ & $10.5 \%$ & $-10.5 \%$ & $10.4 \%$ & $9.3 \%$ & $-9.3 \%$ & 1.09 & -0.96 & "Worsening" for h2ie; windows-only better than all surf \\
\hline Peak Heating & $12.2 \%$ & & & & & & & & & & $h 0=4.216 \mathrm{~kW}$ \\
\hline h1iv. ho & & $-9.4 \%$ & $-7.8 \%$ & $1.6 \%$ & $1.6 \%$ & $-8.3 \%$ & $1.1 \%$ & $1.1 \%$ & 0.13 & 0.13 & Insufficient improvement for spec update of $h$,conv, $i$ \\
\hline h1e v. ho & & $2.8 \%$ & $2.8 \%$ & $0.0 \%$ & $0.0 \%$ & $2.8 \%$ & $0.0 \%$ & $0.0 \%$ & 0.00 & 0.00 & Negligble change versus 2017 \\
\hline h1ie v. ho & & $-6.8 \%$ & $-5.1 \%$ & $1.7 \%$ & $1.7 \%$ & $-5.7 \%$ & $1.1 \%$ & $1.1 \%$ & 0.14 & 0.14 & Insufficient improvement for spec update of $h$, conv,l and/or $h$, conv,e \\
\hline h2i v. ho & & $-13.3 \%$ & $5.1 \%$ & $18.4 \%$ & $8.2 \%$ & $4.6 \%$ & $17.9 \%$ & $8.7 \%$ & 1.51 & 0.71 & Improvement for $\mathrm{h} 2 \mathrm{i}>$ Range/2; windows-only better than all surf \\
\hline h2e v. ho & & $4.1 \%$ & $3.5 \%$ & $-0.6 \%$ & $0.6 \%$ & $3.5 \%$ & $-0.6 \%$ & $0.6 \%$ & 0.05 & 0.05 & Minor Improvement for h2e; windows-only equals all-surf \\
\hline h2ie v. ho & & $-11.7 \%$ & $8.6 \%$ & $20.3 \%$ & $3.2 \%$ & $7.9 \%$ & $19.7 \%$ & $3.8 \%$ & 1.66 & 0.31 & Improvement for h2ie < Range /3; windows-only better than all surf \\
\hline Peak Cooling & $22.8 \%$ & & & & & & & & & & $\mathrm{~h} 0=6.403 \mathrm{~kW}$ \\
\hline h1iv. ho & & $-9.5 \%$ & $-8.5 \%$ & $1.0 \%$ & $1.0 \%$ & $-9.4 \%$ & $0.1 \%$ & $0.1 \%$ & 0.04 & 0.04 & Insufficient improvement for spec update of $h$,conv, $i$ \\
\hline h1ev. ho & & $1.3 \%$ & $1.3 \%$ & $0.0 \%$ & $0.0 \%$ & $1.3 \%$ & $0.0 \%$ & $0.0 \%$ & 0.00 & 0.00 & Negligble change versus 2017 \\
\hline h1ie v. ho & & $-10.8 \%$ & $-9.8 \%$ & $1.0 \%$ & $1.0 \%$ & $-10.8 \%$ & $0.0 \%$ & $0.0 \%$ & 0.04 & 0.04 & Insufficient improvement for spec update of $h$,conv,l and/or $h$, conv,e \\
\hline h2i v. ho & & $5.5 \%$ & $4.4 \%$ & $-1.1 \%$ & $1.1 \%$ & $3.3 \%$ & $-2.3 \%$ & $2.3 \%$ & 0.10 & 0.10 & Minor variations \\
\hline h2e v. ho & & $4.4 \%$ & $4.7 \%$ & $0.3 \%$ & $-0.3 \%$ & $4.7 \%$ & $0.3 \%$ & $-0.3 \%$ & 0.01 & -0.01 & Minor variations \\
\hline h2ie v. ho & & $10.2 \%$ & $9.7 \%$ & $-0.5 \%$ & $0.5 \%$ & $8.3 \%$ & $-1.9 \%$ & $1.9 \%$ & 0.08 & 0.08 & Minor variations \\
\hline
\end{tabular}

* Colors for values: Values from Tables 4A-7 and 4A-8 and "Progs. Diff." values are shown in black (black column headers); calculated values further described in notes $\mathrm{c}$ through $\mathrm{f}$ below are shown in blue (blue column headers); dark red indicates scenarios with the most notable effects on results.

a. The range of difference among programs in simulation trial \#3 is the basis for determining the significance of improvements; see note with "Max Improved Ratio".

b. "... Disagreement Versus h0 Simulations" is the disagreement of using constant coefficients versus automated heat transfer for the various scenarios (h1i, h1e, h2i, h2e, etc).

c. "Raw Delta v. 2017" = "2017" - "New"; this indicates degree of change versus the previous 2017 vs. h0 disagreement, but does not indicate whether the change is an improvement.

d. "ABS Delta v. 2017" = ABS(2017) - ABS(New); this indicates improvement to (or worsening of, if $<0$ ) the previous $2017 \mathrm{vs.} \mathrm{h0} \mathrm{disagreement.}$

e. = Max(ABS("Raw Delta v. 2017 All Surfs") , ABS("Raw Delta v. 2017 Windows Only"))/("Progs. Diff...(Max-Min)/Mean"); this indicates degree of change for applying new coefficients relative to applying the "2017" coefficients versus the current range of disagreement among the programs ("Progs. Diff."), but does not indicate whether there is improved accuracy.

f. = Max("ABS Delta v. 2017 All Surfs","ABS Delta v. 2017 Windows Only")/("Progs. Diff...(Max-Min)/Mean"); this indicates whether there is improved accuracy (if >0) related to applying new custom surface coefficients relative to applying the "2017" coefficients and whether that improvement is substantial relative to the current range of disagreement among the programs ("Progs. Diff."). 
Table 4A-12. Observations, Case 660, EnergyPlus: Disagreements from Applying Derived Constant Coefficients Versus Automated (h0) Run Compared with Range of Disagreement Observed for All Programs in Simulation Trial \#3

\begin{tabular}{|c|c|c|c|c|c|c|c|c|c|c|c|}
\hline Case 660 & $\begin{array}{c}\text { Progs. Diff. } \\
\text { SimTrial \#3: } \\
\text { (Max-Min) } \\
\text { /Mean }^{\mathrm{a}}\end{array}$ & 2017 & $\begin{array}{l}\text { rgyPlus } \\
\text { All S }\end{array}$ & $\begin{array}{l}\text { Disagreemer } \\
\text { Surfs } \\
\text { Raw Delta } \\
\text { v. 2017 }\end{array}$ & $\begin{array}{c}\text { nts Versus h} \\
\text { ABS Delta } \\
\text { v. } 2017^{\mathrm{a}}\end{array}$ & $\mid \begin{array}{c}\text { Windo } \\
\text { New }\end{array}$ & $\begin{array}{l}\text { tions } \\
\text { ws Only } \\
\text { Raw Delta } \\
\text { v. 2017 }\end{array}$ & $\begin{array}{c}\text { ABS Delta } \\
\text { v. } 2017^{\mathrm{a}}\end{array}$ & $\begin{array}{c}\text { Max } \\
\text { Variation } \\
\text { Ratio }^{\mathbf{e}}\end{array}$ & $\begin{array}{c}\text { Max } \\
\text { Improved } \\
\text { Ratio' }^{\prime}\end{array}$ & Comments re Change vs applying 2017 Case 600 Coeffs \\
\hline Annual Heating & $8.0 \%$ & & & & & & & & & & h0 = 3.730 MWh (vs 5.965 MWh for 670); "Progs.Diff." = 15.8\% with Prog G \\
\hline h1iv. ho & & $1.9 \%$ & $-0.1 \%$ & $-2.0 \%$ & $1.7 \%$ & $1.7 \%$ & $-0.1 \%$ & $0.1 \%$ & 0.25 & 0.22 & Insufficient improvement (< Range/4) for spec update of $h$, conv, $i^{g}$ \\
\hline h1e v. ho & & $-0.1 \%$ & $-0.2 \%$ & $0.0 \%$ & $0.0 \%$ & $-0.2 \%$ & $-0.1 \%$ & $-0.1 \%$ ] & 0.01 & 0.00 & Negligble change versus 2017 \\
\hline h1ie v. ho & & $1.7 \%$ & $-0.3 \%$ & $-2.0 \%$ & $1.5 \%$ & $1.6 \%$ & $-0.2 \%$ & $0.2 \%$ & 0.25 & 0.18 & Insufficient improvement (< Range/4) for update of $h, c o n v, i$ and $h, c o n v, e^{g}$ \\
\hline h2i v. ho & & $-2.3 \%$ & $-4.5 \%$ & $-2.1 \%$ & $-2.1 \%$ & $-3.6 \%$ & $-1.3 \%$ & $-1.3 \%$ & 0.27 & -0.16 & Somewhat worse agreement ${ }^{\mathrm{n}}$ \\
\hline h2e v. ho & & $-6.9 \%$ & $-7.2 \%$ & $-0.3 \%$ & $-0.3 \%$ & $-7.1 \%$ & $-0.2 \%$ & $-0.2 \%$ & 0.04 & -0.02 & Minor worse agreement ${ }^{\mathrm{n}}$ \\
\hline h2ie v. ho & & $-9.0 \%$ & $-11.5 \%$ & $-2.4 \%$ & $-2.4 \%$ & $-10.4 \%$ & $-1.4 \%$ & $-1.4 \%$ & 0.30 & -0.17 & Somewhat worse agreement ${ }^{\text {n }}$ \\
\hline $\begin{array}{c}\text { Annual Cooling } \\
\text { h1iv. ho }\end{array}$ & $17.2 \%$ & & & $-3.1 \%$ & $-1.2 \%$ & & $-0.1 \%$ & & 0.18 & & $\begin{array}{l}\text { h0 = } 3.258 \mathrm{MWh} \text { (vs } 6.593 \mathrm{MWh} \text { for } 670 \text { ); "Progs.Diff." = 32.1\% with Prog G } \\
\text { Insufficient improvement for spec update of h, conv } \mathrm{g}^{\mathrm{g}}\end{array}$ \\
\hline h1ev. ho & & $-2.1 \%$ & $-1.8 \%$ & $0.3 \%$ & $0.3 \%$ & $-2.0 \%$ & $0.1 \%$ & $0.1 \%$ & 0.02 & 0.02 & Insufficient improvement for spec update of $\mathrm{h}$, conv, $\mathrm{e}^{\mathrm{g}}$ \\
\hline h1ie v. ho & & $-1.1 \%$ & $-3.8 \%$ & $-2.7 \%$ & $-2.7 \%$ & $-1.1 \%$ & $0.0 \%$ & $0.0 \%$ & 0.16 & 0.00 & Insufficient improvement for update of $h, c o n v, i$ and $h$, conv, $e^{g}$ \\
\hline h2i v. ho & & $6.8 \%$ & $3.9 \%$ & $-2.9 \%$ & $2.9 \%$ & $6.2 \%$ & $-0.6 \%$ & $0.6 \%$ & 0.17 & 0.17 & Insufficient improvement (< Range/5) for spec update of $h,{\text { comb }, i^{8}}^{8}$ \\
\hline h2e v. ho & & $0.3 \%$ & $2.1 \%$ & $1.7 \%$ & $-1.7 \%$ & $0.7 \%$ & $0.4 \%$ & $-0.4 \%$ & 0.10 & -0.02 & Somewhat worse agreement $(<\text { Range } / 10)^{\mathrm{n}}$ \\
\hline h2ie v. ho & & $7.3 \%$ & $6.2 \%$ & $-1.1 \%$ & $1.1 \%$ & $7.2 \%$ & $-0.2 \%$ & $0.2 \%$ & 0.06 & 0.06 & Insufficient improvement (< Range/10) for update of $h, c o m b, i$ and $h$, comb, $e^{g}$ \\
\hline Tot.Ann.Htg+Clg & $10.4 \%$ & & & & & & & & & & h0 = 6.988 MWh (vs 12.558 MWh for 670); "Progs.Diff." = 21.5\% with Prog G \\
\hline h1iv. ho & & $1.4 \%$ & $-1.1 \%$ & $-2.5 \%$ & $0.4 \%$ & $1.3 \%$ & $-0.1 \%$ & $0.1 \%$ & 0.24 & 0.04 & Insufficient improvement for spec update of $h, c^{\circ} v, i^{B}$ \\
\hline h1ev. ho & & $-1.0 \%$ & $-0.9 \%$ & $0.1 \%$ & $0.1 \%$ & $-1.0 \%$ & $0.0 \%$ & $0.0 \%$ & 0.01 & 0.01 & Insufficient improvement for spec update of $h, c_{0}$ viv, $e^{g}$ \\
\hline h1ie v. ho & & $0.4 \%$ & $-1.9 \%$ & $-2.3 \%$ & $-1.5 \%$ & $0.3 \%$ & $-0.1 \%$ & $0.1 \%$ & 0.23 & 0.01 & Insufficient improvement for update of $h, c o n v, i$ and $h, c o n v, e^{g}$ \\
\hline h2i v. ho & & $1.9 \%$ & $-0.6 \%$ & $-2.5 \%$ & $1.3 \%$ & $1.0 \%$ & $-0.9 \%$ & $0.9 \%$ & 0.24 & 0.13 & Insufficient improvement for spec update of $h, c^{\prime}$ comb $i^{g}$ \\
\hline h2e v. ho & & $-3.5 \%$ & $-2.9 \%$ & $0.6 \%$ & $0.6 \%$ & $-3.4 \%$ & $0.1 \%$ & $0.1 \%$ & 0.06 & 0.06 & Insufficient improvement for spec update of $h, c^{\prime}$ comb, $\mathrm{e}^{\mathrm{g}}$ \\
\hline h2ie v. ho & & $-1.4 \%$ & $-3.2 \%$ & $-1.8 \%$ & $-1.8 \%$ & $-2.2 \%$ & $-0.8 \%$ & $-0.8 \%$ & 0.17 & -0.08 & Somewhat worse agreement ${ }^{n}$ \\
\hline Peak Heating & $11.1 \%$ & & & & & & & & & & $h 0=2.855 \mathrm{~kW}$ (vs $4.125 \mathrm{~kW}$ for 670$)$ \\
\hline h1iv. ho & & $-1.8 \%$ & $-3.5 \%$ & $-1.8 \%$ & $-1.8 \%$ & $-1.9 \%$ & $-0.1 \%$ & $-0.1 \%$ & 0.16 & -0.01 & Somewhat worse agreement ${ }^{n}$ \\
\hline h1ev. ho & & $0.2 \%$ & $0.2 \%$ & $0.0 \%$ & $0.0 \%$ & $0.2 \%$ & $0.0 \%$ & $0.0 \%$ & 0.00 & 0.00 & Negligble change versus 2017 \\
\hline h1ie v. ho & & $-1.6 \%$ & $-3.4 \%$ & $-1.8 \%$ & $-1.8 \%$ & $-1.7 \%$ & $-0.1 \%$ & $-0.1 \%$ & 0.16 & -0.01 & Somewhat worse agreement ${ }^{n}$ \\
\hline h2i v. ho & & $-3.6 \%$ & $-4.8 \%$ & $-1.2 \%$ & $-1.2 \%$ & $-4.7 \%$ & $-1.0 \%$ & $-1.0 \%$ & 0.11 & -0.09 & Somewhat worse agreement ${ }^{n}$ \\
\hline h2e v. ho & & $-2.3 \%$ & $-2.5 \%$ & $-0.2 \%$ & $-0.2 \%$ & $-2.4 \%$ & $-0.1 \%$ & $-0.1 \%$ & 0.02 & -0.01 & Minor worse agreement ${ }^{n}$ \\
\hline h2ie v. ho & & $-5.6 \%$ & $-7.1 \%$ & $-1.5 \%$ & $-1.5 \%$ & $-6.9 \%$ & $-1.3 \%$ & $-1.3 \%$ & 0.13 & -0.11 & Somewhat worse agreement ${ }^{n}$ \\
\hline Peak Cooling & $21.4 \%$ & & & & & & & & & & $h 0=3.796 \mathrm{~kW}$ (vs $6.828 \mathrm{~kW}$ for 670$)$ \\
\hline h1iv. ho & & $-6.7 \%$ & $-10.4 \%$ & $-3.7 \%$ & $-3.7 \%$ & $-6.8 \%$ & $-0.1 \%$ & $-0.1 \%$ & 0.17 & 0.00 & Insufficient improvement for spec update of h,conv,i \\
\hline h1ev. ho & & $-4.6 \%$ & $-4.4 \%$ & $0.2 \%$ & $0.2 \%$ & $-4.5 \%$ & $0.1 \%$ & $0.1 \%$ & 0.01 & 0.01 & Negligble change versus 2017 \\
\hline h1ie v. ho & & $-10.5 \%$ & $-13.7 \%$ & $-3.2 \%$ & $-3.2 \%$ & $-10.5 \%$ & $-0.1 \%$ & $-0.1 \%$ & 0.15 & 0.00 & Insufficient improvement for spec update of $h$, conv,l and/or $h$, conv,e \\
\hline h2i v. ho & & $-1.1 \%$ & $-5.5 \%$ & $-4.4 \%$ & $-4.4 \%$ & $-1.8 \%$ & $-0.7 \%$ & $-0.7 \%$ & 0.21 & -0.03 & Somewhat worse agreement $\mathrm{n}^{\mathrm{n}}$ \\
\hline h2e v. ho & & $-3.8 \%$ & $-3.0 \%$ & $0.8 \%$ & $0.8 \%$ & $-3.5 \%$ & $0.3 \%$ & $0.3 \%$ & 0.04 & 0.04 & Insufficient improvement for spec update of $h, c o m b, e^{\mathrm{g}}$ \\
\hline h2ie v. ho & & $-4.3 \%$ & $-8.0 \%$ & $-3.7 \%$ & $-3.7 \%$ & $-4.7 \%$ & $-0.4 \%$ & $-0.4 \%$ & 0.17 & -0.02 & Somewhat worse agreement $\mathrm{n}^{\mathrm{n}}$ \\
\hline
\end{tabular}

* Colors for values: Values from Tables 4A-7 and 4A-8 and "Progs. Diff." values are shown in black; calculated values further described in notes $\mathrm{c}$ through $\mathrm{f}$ below are shown in blue. a. The range of difference among programs in simulation trial \#3 is the basis for determining the significance of improvements, excluding Program G; see note with "Max Improved Ratio". b. "... Disagreement Versus h0 Simulations" is the disagreement between using constant coefficients versus automated heat transfer for the various scenarios (h1i, h1e, h2i, h2e, etc). c. "Raw Delta v. 2017" = "2017" - "New"; this indicates degree of change versus the previous 2017 vs, h0 disagreement, but does not indicate whether the change is an improvement.

d. "ABS Delta v. 2017" = ABS(2017) - ABS(New); this indicates improvement to (or worsening of, if $<0$ ) the previous $2017 \mathrm{vs.} \mathrm{h0} \mathrm{disagreement.}$

e. = Max(ABS("Raw Delta v. 2017 All Surfs"), ABS("Raw Delta v. 2017 Windows Only"))/("Progs. Diff...(Max-Min)/Mean"); this indicates degree of change for applying new coefficients relative to applying the "2017" coefficients versus the current range of disagreement among the programs ("Progs. Diff."), but does not indicate whether there is improved accuracy.

f. = Max("ABS Delta v. 2017 All Surfs","ABS Delta v. 2017 Windows Only")/("Progs. Diff...(Max-Min)/Mean"); this indicates whether there is improved accuracy (if >0) related to applying new custom surface coefficients relative to applying the "2017" coefficients and whether that improvement is substantial relative to the current range of disagreement among the programs ("Progs. Diff.").

g. "Max Improved Ratio" and "Max Variation Ratio" for Case 660 are more sensitive evaluations than for Case 670 (i.e., higher values are expected for 660 than 670 for a given difference) because:

1) Case 660's h0 basis is substantially lower than for Case 670, so for the same MWh or kW value difference (e.g., between h1i and h0), Case 660 yields a larger \%-difference.

2) Program $G$ was removed for this analysis (see note a), which may have somewhat artificially reduced the Case 660 "Progs.Diff" value.

h. Minor worsening of agreement when applying custom constant combined coefficients (vs 2017 coeffs) supports the hypothesis that the effect of applying them for Case 660 is lost within the noise of other effects. 
Table 4A-13. Observations, Case 660, TRNSYS: Disagreements from Applying Derived Constant Coefficients Versus Automated (h0) Run Compared with Range of Disagreement Observed for All Programs in Simulation Trial \#3 ${ }^{\star}$

\begin{tabular}{|c|c|c|c|c|c|c|c|c|c|c|c|}
\hline \multirow[b]{4}{*}{ Case 660} & \multirow{4}{*}{$\begin{array}{c}\text { Progs. Diff. } \\
\text { SimTrial \#3: } \\
\text { (Max-Min) } \\
\text { /Mean }^{\mathrm{a}}\end{array}$} & \multicolumn{9}{|c|}{ TRNSYS Disagreements Versus ho Simulations $^{\mathrm{D}}$} & \multirow[b]{4}{*}{ Comments re Change vs applying 2017 Case 600 Coeffs } \\
\hline & & & All $\mathrm{s}$ & Surfs & & Windov & ws Only & & & hax & \\
\hline & & & & Raw Delta & ABS Delta & & Raw Delta & ABS Delta & Variation & Improved & \\
\hline & & 2017 & New & & & & & v. $2017^{\mathrm{a}}$ & & Ratio $^{\top}$ & \\
\hline Annual Heating & $8.0 \%$ & $26 \%$ & $03 \%$ & $-23 \%$ & $23 \%$ & $23 \%$ & $-0.3 \%$ & $03 \%$ & & & ho = 3.791 MWh (vs 6.134 MWh for 670); "Progs.Diff." = 15.8\% with Prog G \\
\hline $\begin{array}{l}\text { h1iv. h0 } \\
\text { h1e v. ho }\end{array}$ & & $-0.5 \%$ & $-0.5 \%$ & $0.0 \%$ & $0.0 \%$ & $-0.5 \%$ & $0.0 \%$ & $0.0 \%$ & 0.00 & 0.00 & Negligble change versus 2017 \\
\hline h1ie v. ho & & $2.1 \%$ & $-0.2 \%$ & $-2.3 \%$ & $2.0 \%$ & $1.8 \%$ & $-0.3 \%$ & $0.3 \%$ & 0.28 & 0.24 & Insufficient improvement (< Range/4) for update of $\mathrm{h}$, conv, i and $\mathrm{h}$, conv, $\mathrm{e}^{\mathrm{g}}$ \\
\hline h2i v. ho & & $-1.5 \%$ & $-3.5 \%$ & $-2.1 \%$ & $-2.1 \%$ & $-2.8 \%$ & $-1.3 \%$ & $-1.3 \%$ & 0.26 & -0.16 & Somewhat worse agreement ${ }^{n}$ \\
\hline h2ev. ho & & $-11.1 \%$ & $-11.1 \%$ & $-0.1 \%$ & $-0.1 \%$ & $-10.9 \%$ & $0.2 \%$ & $0.2 \%$ & 0.02 & 0.02 & Negligble change versus 2017 \\
\hline h2ie v. ho & & $-12.2 \%$ & $-14.3 \%$ & $-2.1 \%$ & $-2.1 \%$ & $-13.3 \%$ & $-1.1 \%$ & $-1.1 \%$ & 0.26 & -0.14 & Somewhat worse agreement ${ }^{n}$ \\
\hline Annual Cooling & $17.2 \%$ & & & & & & & & & & h0 = 2.967 MWh (vs 6.202 MWh for 670); "Progs.Diff." = 32.1\% with Prog G \\
\hline h1iv. ho & & $2.6 \%$ & $-1.1 \%$ & $-3.6 \%$ & $1.5 \%$ & $2.4 \%$ & $-0.2 \%$ & $0.2 \%$ & 0.21 & 0.09 & Insufficient improvement for spec update of $h$, conv,$i^{g}$ \\
\hline h1ev. ho & & $-1.8 \%$ & $-1.2 \%$ & $0.6 \%$ & $0.6 \%$ & $-1.7 \%$ & $0.1 \%$ & $0.1 \%$ & 0.04 & 0.04 & Insufficient improvement for spec update of $h$, conv, $\mathrm{e}^{\mathrm{g}}$ \\
\hline h1ie v. ho & & $0.8 \%$ & $-2.3 \%$ & $-3.0 \%$ & $-1.5 \%$ & $0.6 \%$ & $-0.1 \%$ & $0.1 \%$ & 0.18 & 0.01 & Insufficient improvement for update of $h$, conv $^{i}$ and $h$, conv, $\mathrm{e}^{\mathrm{g}}$ \\
\hline h2i v. ho & & $8.7 \%$ & $5.6 \%$ & $-3.2 \%$ & $3.2 \%$ & $8.4 \%$ & $-0.4 \%$ & $0.4 \%$ & 0.18 & 0.18 & Insufficient improvement $\left(<\right.$ Range/5) for spec update of $h, c^{2}, i^{g}$ \\
\hline h2e v. ho & & $7.1 \%$ & $8.1 \%$ & $1.0 \%$ & $-1.0 \%$ & $6.6 \%$ & $-0.5 \%$ & $0.5 \%$ & 0.06 & 0.03 & Insufficient improvement $(<\text { Range/10) })^{n}$ \\
\hline h2ie v. ho & & $15.8 \%$ & $13.8 \%$ & $-2.0 \%$ & $2.0 \%$ & $14.9 \%$ & $-0.9 \%$ & $0.9 \%$ & 0.12 & 0.12 & Insufficient improvement $(<\mathrm{Range} / 5)$ for update of $\mathrm{h}, \mathrm{comb}, \mathrm{i}$ and $\mathrm{h}, \mathrm{comb}, \mathrm{e}^{\mathrm{g}}$ \\
\hline Tot.Ann.Htg+Clg & $10.4 \%$ & & & & & & & & & & h0 = 6.758 MWh (vs 12.336 MWh for 670); "Progs.Diff." = 21.5\% with Prog G \\
\hline h1iv. ho & & $2.6 \%$ & $-0.3 \%$ & $-2.9 \%$ & $2.3 \%$ & $2.3 \%$ & $-0.3 \%$ & $0.3 \%$ & 0.28 & 0.22 & Insufficient improvement (<Range/4) for spec update of $h$, conv,$i^{\mathrm{B}}$ \\
\hline h1ev. ho & & $-1.1 \%$ & $-0.8 \%$ & $0.3 \%$ & $0.3 \%$ & $-1.1 \%$ & $0.0 \%$ & $0.0 \%$ & 0.03 & 0.03 & Insufficient improvement for spec update of $h$, conv, $\mathrm{e}^{\mathrm{g}}$ \\
\hline h1ie v. ho & & $1.5 \%$ & $-1.1 \%$ & $-2.6 \%$ & $0.4 \%$ & $1.3 \%$ & $-0.2 \%$ & $0.2 \%$ & 0.25 & 0.04 & Insufficient improvement for update of $h$, conv, $i$ and $h, c o n v, e^{g}$ \\
\hline h2i v. ho & & $3.0 \%$ & $0.5 \%$ & $-2.5 \%$ & $2.5 \%$ & $2.1 \%$ & $-0.9 \%$ & $0.9 \%$ & 0.24 & 0.24 & Insufficient improvement $\left(<\right.$ Range/4) for spec update of $h$, comb, ${ }^{\mathrm{g}}$ \\
\hline h2e v. ho & & $-3.1 \%$ & $-2.7 \%$ & $0.4 \%$ & $0.4 \%$ & $-3.2 \%$ & $-0.1 \%$ & $-0.1 \%$ & 0.04 & 0.04 & Insufficient improvement for spec update of $h, c o m b, e^{\mathrm{g}}$ \\
\hline h2ie v. ho & & $0.1 \%$ & $-2.0 \%$ & $-2.1 \%$ & $-1.9 \%$ & $-0.9 \%$ & $-1.0 \%$ & $-0.9 \%$ & 0.20 & -0.08 & Somewhat worse agreement ${ }^{n}$ \\
\hline Peak Heating & $11.1 \%$ & & & & & & & & & & $h 0=2.956 \mathrm{~kW}$ (vs $4.216 \mathrm{~kW}$ for 670$)$ \\
\hline h1iv. ho & & $-2.2 \%$ & $-4.1 \%$ & $-1.9 \%$ & $-1.9 \%$ & $-2.5 \%$ & $-0.3 \%$ & $-0.3 \%$ & 0.17 & -0.02 & Somewhat worse agreement ${ }^{n}$ \\
\hline h1ev. ho & & $-2.4 \%$ & $-2.3 \%$ & $0.0 \%$ & $0.0 \%$ & $-2.4 \%$ & $0.0 \%$ & $0.0 \%$ & 0.00 & 0.00 & Negligble change versus 2017 \\
\hline h1ie v. ho & & $-4.3 \%$ & $-6.1 \%$ & $-1.8 \%$ & $-1.8 \%$ & $-4.6 \%$ & $-0.3 \%$ & $-0.3 \%$ & 0.16 & -0.03 & Somewhat worse agreement ${ }^{n}$ \\
\hline h2i v. ho & & $-4.4 \%$ & $-4.9 \%$ & $-0.5 \%$ & $-0.5 \%$ & $-5.4 \%$ & $-1.0 \%$ & $-1.0 \%$ & 0.09 & -0.04 & Somewhat worse agreement ${ }^{n}$ \\
\hline h2ev. ho & & $-7.5 \%$ & $-7.4 \%$ & $0.1 \%$ & $0.1 \%$ & $-7.3 \%$ & $0.1 \%$ & $0.1 \%$ & 0.01 & 0.01 & Negligble change versus 2017 \\
\hline h2ie v. ho & & $-10.9 \%$ & $-11.7 \%$ & $-0.8 \%$ & $-0.8 \%$ & $-12.0 \%$ & $-1.1 \%$ & $-1.1 \%$ & 0.10 & -0.07 & Somewhat worse agreement ${ }^{n}$ \\
\hline Peak Cooling & $21.4 \%$ & & & & & & & & & & $h 0=3.458 \mathrm{~kW}$ (vs $6.403 \mathrm{~kW}$ for 670$)$ \\
\hline h1iv. ho & & $-5.8 \%$ & $-9.7 \%$ & $-3.9 \%$ & $-3.9 \%$ & $-6.1 \%$ & $-0.2 \%$ & $-0.2 \%$ & 0.18 & -0.01 & Somewhat worse agreement ${ }^{n}$ \\
\hline h1ev. ho & & $-2.7 \%$ & $-2.4 \%$ & $0.3 \%$ & $0.3 \%$ & $-2.7 \%$ & $0.1 \%$ & $0.1 \%$ & 0.01 & 0.01 & Negligble change versus 2017 \\
\hline h1ie v. ho & & $-7.5 \%$ & $-10.5 \%$ & $-3.1 \%$ & $-3.1 \%$ & $-7.6 \%$ & $-0.1 \%$ & $-0.1 \%$ & 0.14 & -0.01 & Somewhat worse agreement ${ }^{n}$ \\
\hline h2i v. ho & & $0.2 \%$ & $-4.7 \%$ & $-5.0 \%$ & $-4.5 \%$ & $-0.3 \%$ & $-0.5 \%$ & $-0.1 \%$ & 0.23 & 0.00 & Insufficient improvement for spec update of h,comb, $\mathrm{e}^{\mathrm{g}}$ \\
\hline h2e v. ho & & $1.1 \%$ & $1.4 \%$ & $0.3 \%$ & $-0.3 \%$ & $0.8 \%$ & $-0.3 \%$ & $0.3 \%$ & 0.01 & 0.01 & Insufficient improvement for spec update of h,comb, $\mathrm{e}^{\mathrm{g}}$ \\
\hline h2ie v. ho & & $1.4 \%$ & $-3.4 \%$ & $-4.7 \%$ & $-2.0 \%$ & $0.5 \%$ & $-0.8 \%$ & $0.8 \%$ & 0.22 & 0.04 & Insufficient improvement for spec update of h,comb, $\mathrm{e}^{\mathrm{g}}$ \\
\hline
\end{tabular}

Colors for values: Values from Tables 4A-7 and 4A-8 and "Progs. Diff." values are shown in black; calculated values further described in notes $\mathrm{c}$ through $\mathrm{f}$ below are shown in blue.

a. The range of difference among programs in simulation trial \#3 is the basis for determining the significance of improvements, excluding Program G; see note with "Max Improved Ratio".

. "R Disagreement Versus h0 Simulations" is the disagreement between using constant coefficients versus automated heat transfer for the various scenarios (h11, hle, h2i, h2e, etc.).

d. "ABS Delta v. 2017" = ABS(2017) - ABS(New); this indicates improvement to (or worsening of, if $<0$ ) the previous 2017 vs. h0 disagreement.

e. "ABS Delta v. 201 = ABS("Raw Delta v. 2017 All Surfs"), ABS("Raw Delta v. 2017 Windows Only"))/("Progs. Diff. .(Max-Min)/Mean"); this indicates degree of change for applying new coeffil

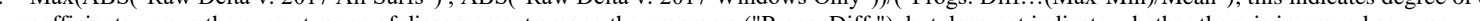

(")

( relative to applying the "2017" coefficients and whether that improvement is substantial relative to the current range or disagreement annong the programs ("Progs. Diff.").

g. "Max Improved Ratio" and "Max Variation Ratio for Case 660 are more sensitive evaluations than for Case 670 (i.e., higher values are expected for 660 than 670 for a given difference) because:

2) Program G was removed for this analysis (see note a), which may have somewhat artificially reduced the Case 660 "Progs.Diff" value.

h. Minor worsening of agreement when applying custom constant combined coefficients (vs 2017 coeffs) supports the hypothesis that the effect of applying them for Case 660 is lost within the noise of other effects. 


\section{A.4 Archival Record of Work to Develop Alternative Constant Heat Transfer Coefficients}

4A.4.1 Round 2 (Archival) Results. These results preceded the final results of Section 4A.3.3.

The Round 2 results for interior constant convective surface coefficients (applying Section 4A.3.1.1), and constant combined surface coefficients applying Idea \#2 (see Section 4A.3.2.1.2), for two sets of simulations by separate modelers using separate programs are provided in Table 4A-14.

Nomenclature for Table 4A-14 is as follows:

- Row labels are variable names defined in Sections 4A.3.1.1 and 4A.3.2.1.2 above

- Floor and ceiling values are taken from post-processing of the simulation results by the modelers. This approach applies mixed natural convection, which is a mixture of stable and unstable convection components, applying the stable or unstable regime for each time step as automatically determined from the direction of heat flow in the detailed simulations, where "stable" refers to retarded convection for rising warmer air or falling cooler air driven towards a surface, and "unstable" refers to enhanced convection for rising warmer air or falling cooler air moving away from a surface.

- All other values of h,conv,int,lwa and h,comb,int,lwa,2 (for windows and walls) are also taken from direct post-processing of the simulation results by the modelers. Values for the walls are average values for the four walls at the different orientations (north, south, east, west).

The following test cases were applied for consideration of developing the simplified constant coefficients ${ }^{3}$ :

- $\quad$ Case 600: low-mass base case with $\varepsilon=0.9$

- Case 200: $\varepsilon=0.1$ and high-conductance wall elements [Editorial note: In this archival record, the highconductance wall elements are referred to in tables as "opaque windows" or as "windows".]

- Case 900: high-mass base case with $\varepsilon=0.9$; consideration of providing separate surface coefficients for high mass was dropped per Round 1 sensitivity tests described in Section 4A.4.2.

Table 4A-14 indicates that, with the exception of the windows, the \%-differences for interior surface coefficients among the EnergyPlus and TRNSYS results are generally $<10 \%$ and often $<5 \%$. The windows have larger differences because of the different algorithms applied by the two programs for determining interior convective coefficients. For these and previous runs, the EnergyPlus modelers were applying that program's adaptation of the ISO 15099 (2003) interior surface convection algorithm. The direction and magnitude of the difference in the window convective surface coefficients is consistent with manual (spreadsheet) calculations.

\footnotetext{
${ }^{3}$ Initially, the following additional cases were run: 250 (high-conductance wall elements, $\varepsilon=0.9, \alpha=0.9$ ), 270 (clear windows, $\varepsilon=0.9, \alpha$,int $=0.9$ ), 430 (high-conductance wall elements, $\varepsilon=0.9, \alpha=0.6$ ), and 440 (clear windows, $\varepsilon=0.9, \alpha$, int $=0.1$ ). The preliminary resulting constant surface coefficients for these cases generally agreed closely enough with Case 600 (especially for clear-window cases 270 and 440 ) that development of separate coefficients was not pursued. There are also issues of impracticality with developing too many sets of constant surface coefficients.
} 
Table 4A-14. Round 2 load-weighted average interior surface convective and combined coefficients and surface-to-zone temperature differences developed from verified simulations

\begin{tabular}{|c|c|c|c|c|}
\hline $\begin{array}{l}\text { Kummert (Jan 2016) } \\
\text { Case } 600 \text { ( } \varepsilon=0.9 \text {, low mass) }\end{array}$ & Windows & Walls & Ceiling & Floor \\
\hline$\Delta \mathrm{T}$,int, Iwa (K) & 6.8 & 5.3 & 5.8 & 6.1 \\
\hline h,conv, int, Iwa $\left(\mathrm{W} /\left(\mathrm{m}^{2} \cdot \mathrm{K}\right)\right)$ & 2.4 & 2.2 & 1.8 & 2.2 \\
\hline $\mathrm{h}$, comb,int,lwa,2 $\left(\mathrm{W} /\left(\mathrm{m}^{2} \cdot \mathrm{K}\right)\right)$ & 4.6 & 1.8 & 1.8 & 3.6 \\
\hline \multicolumn{5}{|l|}{ Case $900(\varepsilon=0.9$, high mass $)$} \\
\hline$\Delta \mathrm{T}$,Iwa (K) & 6.1 & 2.5 & 3.5 & 3.0 \\
\hline h,conv, int, Iwa $\left(\mathrm{W} /\left(\mathrm{m}^{2} \cdot \mathrm{K}\right)\right)$ & 2.3 & 1.7 & 1.5 & 1.8 \\
\hline h,comb,int,Iwa,2 (W/(m².K)) & 5.7 & 2.1 & 2.7 & 3.6 \\
\hline \multicolumn{5}{|l|}{ Case 200 ( $\varepsilon=0.1$, low mass) } \\
\hline$\Delta \mathrm{T}$,Iwa (K) & 8.5 & 3.5 & 2.6 & 1.4 \\
\hline h,conv, int, Iwa $\left(\mathrm{W} /\left(\mathrm{m}^{2} \cdot \mathrm{K}\right)\right)$ & 2.6 & 1.9 & 1.9 & 1.0 \\
\hline h,comb,int,lwa,2 $\left(\mathrm{W} /\left(\mathrm{m}^{2} \cdot \mathrm{K}\right)\right)$ & 3.1 & 2.1 & 1.9 & 0.4 \\
\hline $\begin{array}{l}\text { Henninger, Witte (Mar 2016) } \\
\text { Case } 600 \text { ( } \varepsilon=0.9 \text {, low mass) }\end{array}$ & Windows & Walls & Ceiling & Floor \\
\hline$\Delta \mathrm{T}$,int, Iwa (K) & 7.5 & 5.5 & 6.0 & 6.6 \\
\hline h,conv, int, Iwa $\left(\mathrm{W} /\left(\mathrm{m}^{2} \cdot \mathrm{K}\right)\right)$ & 1.8 & 2.3 & 1.8 & 2.3 \\
\hline h,comb,int,lwa,2 (W/(m².K)) & 3.8 & 1.8 & 1.7 & 3.8 \\
\hline \multicolumn{5}{|l|}{ Case $900(\varepsilon=0.9$, high mass $)$} \\
\hline$\Delta \mathrm{T}$,int, Iwa (K) & 6.3 & 2.6 & 3.7 & 3.3 \\
\hline $\mathrm{h}$,conv, int, Iwa $\left(\mathrm{W} /\left(\mathrm{m}^{2} \cdot \mathrm{K}\right)\right)$ & 1.7 & 1.7 & 1.5 & 1.8 \\
\hline h,comb,int,lwa,2 (W/(m².K)) & 5.0 & 2.1 & 2.6 & 3.6 \\
\hline \multicolumn{5}{|l|}{ Case 200 ( $\varepsilon=0.1$, low mass) } \\
\hline$\Delta \mathrm{T}$,int, Iwa (K) & 8.8 & 3.5 & 2.6 & 1.5 \\
\hline h,conv, int, Iwa $\left(\mathrm{W} /\left(\mathrm{m}^{2} \cdot \mathrm{K}\right)\right)$ & 2.6 & 1.9 & 1.9 & 0.9 \\
\hline h,comb,int,lwa,2 $\left(\mathrm{W} /\left(\mathrm{m}^{2} \cdot \mathrm{K}\right)\right)$ & 3.2 & 2.1 & 1.9 & 0.4 \\
\hline \multicolumn{5}{|c|}{ \% Difference (Henninger\&Witte v. Kummert) } \\
\hline Case 600 ( $\varepsilon=0.9$, low mass) & Windows & Walls & Ceiling & Floor \\
\hline$\Delta \mathrm{T}$,int, Iwa (K) & $10.6 \%$ & $5.0 \%$ & $4.7 \%$ & $7.6 \%$ \\
\hline h,conv, int, Iwa $\left(\mathrm{W} /\left(\mathrm{m}^{2} \cdot \mathrm{K}\right)\right)$ & $-25.5 \%$ & $1.3 \%$ & $0.1 \%$ & $3.3 \%$ \\
\hline h,comb,int,lwa,2 (W/(m².K)) & $-18.0 \%$ & $-1.9 \%$ & $-4.1 \%$ & $4.8 \%$ \\
\hline \multicolumn{5}{|l|}{ Case 900 ( $\varepsilon=0.9$, high mass $)$} \\
\hline$\Delta \mathrm{T}$,int, Iwa (K) & $3.8 \%$ & $4.9 \%$ & $4.6 \%$ & $9.3 \%$ \\
\hline h,conv, int, Iwa $\left(\mathrm{W} /\left(\mathrm{m}^{2} \cdot \mathrm{K}\right)\right)$ & $-27.5 \%$ & $-0.4 \%$ & $-3.3 \%$ & $0.8 \%$ \\
\hline h,comb,int,lwa,2 (W/(m².K)) & $-12.5 \%$ & $-1.3 \%$ & $-4.4 \%$ & $0.3 \%$ \\
\hline \multicolumn{5}{|l|}{ Case 200 ( $\varepsilon=0.1$, low mass) } \\
\hline$\Delta \mathrm{T}$,int, Iwa (K) & $3.6 \%$ & $0.6 \%$ & $1.4 \%$ & $6.1 \%$ \\
\hline h,conv, int, Iwa $\left(\mathrm{W} /\left(\mathrm{m}^{2} \cdot \mathrm{K}\right)\right)$ & $0.8 \%$ & $-0.4 \%$ & $-0.5 \%$ & $-11.2 \%$ \\
\hline h,comb,int,Iwa,2 (W/(m².K)) & $2.1 \%$ & $-1.0 \%$ & $-0.6 \%$ & $-3.6 \%$ \\
\hline
\end{tabular}

IntSurfCoeffAnalysis...060716.xIsx; AllResults+...!A4+

Note: In this table, values for walls are taken as the average of each surface orientation rather than as an area-weighted average (which primarily affects consideration of the south wall because much of that wall area is windows). A comparison after completion of the interior surface coefficient evaluation work indicates that applying an area-weighted calculation to evaluation of vertical wall coefficients has no effect on the two significant digits reported here (maximum effect of $1 \%$ on h,comb,int,lwa, 2 for Case 600 and less effect elsewhere). This difference is too insignificant to justify rerunning the loads analysis, however, an area-weighted average is applied for evaluating vertical-wall exterior surface coefficients. 
To analyze the effect of applying the derived constant coefficients versus more detailed modeling, results were compared for detailed simulations versus simulations applying constant values developed by the modelers, applying the parametric sensitivity test scheme shown in Table 4A-15. Output for this test scheme is provided in Table 4A16. The run designations for the case inputs in the column headers of Tables $4 \mathrm{~A}-15$ and $4 \mathrm{~A}-16$ are defined as follows:

- h0: Base case run with all automated convection, applying Equation 4A-5 each time step (except for the EnergyPlus windows, where ISO 15099 (2003), Section 8.3.2.2 is applied each time step) and automated detailed surface-to-surface radiative exchange modeling; this is the benchmark for comparison of other constant-coefficient runs described below.

- h1: Constant convective coefficients (h,conv,int,lwa) with automated surface-to-surface radiative exchange.

- h2: Constant combined coefficients (h,comb,int,lwa,2) with automated surface convection and radiative exchange modeling off.

Additional sensitivity tests were run by Kummert (2015) to address the following question:

- Is it worthwhile to have a separate set of constant convective and combined coefficients for the high-mass cases?

- Answerable by running Case 900 with the constant convective and combined coefficients developed for Case 600 versus with those developed for Case 900.

Runs to address this question are defined as follows:

- h5: Same as h1, but uses the Case 600 constant convective coefficients for all cases.

- h6: Same as h2, but uses the Case 600 constant combined coefficients for all cases except Case 200.

Results by Kummert (2016) applying TRNSYS for the above input settings are shown in Table 4A-16, in the section designated as "Kummert (2016)". This table includes an additional set of results for runs applying the constant interior surface and exterior surface convective coefficients of the first-round simulation trial, designated as "2014 const hci,hce", where automated surface-to-surface radiation exchange was applied for those runs (Kummert 2014).

Table 4A-16 also includes a set of runs by Henninger and Witte (2015b, 2016) applying EnergyPlus, designated as "Henninger and Witte (2015/2016)", that independently verifies Kummert's results for the h0, h1, and h2 runs. Finally, Table 4A-16 summarizes the differences between the two sets of runs, designated as "\% $\%$-difference, Henninger and Witte 2015/2016 versus Kummert 2016". Observing the \%-differences, relatively small differences in results for cases 600 and 900 among the two models may be caused by use of the TARP algorithm for modeling window interior convective heat transfer in the Kummert model versus use of ISO 15099 for that in the Henninger and Witte models. Minor differences for Case 200 results indicate that other minor modeling differences are present. Larger \%-differences for Case 900 annual loads versus those for Case 600 may be related to the observation that when comparing the two simulation runs, both cases exhibit similar variations in $\mathrm{MWh} / \mathrm{y}$, but the base load is smaller for Case 900, resulting in the larger \%-difference. 
Table 4A-15. Input Settings for Constant Coefficient Sensitivity Tests

\begin{tabular}{|c|c|c|c|c|c|c|c|c|c|}
\hline \multicolumn{7}{|c|}{ Case 600 (low mass, $\varepsilon=0.9$ ) } & \multicolumn{3}{|c|}{$\begin{array}{l}\text { Case inputs } \\
\text { (Henninger, Witte 2015/2016) }\end{array}$} \\
\hline \multicolumn{2}{|c|}{ Windows $(\varepsilon=0.84)$} & ho & h1 & h2 & h5 & h6 & h0 & h1 & h2 \\
\hline h,ir & $\mathrm{W} /\left(\mathrm{m}^{2} \cdot \mathrm{K}\right)$ & Automated & Automated & $\mathrm{N} / \mathrm{A}$ & Automated & $\mathrm{N} / \mathrm{A}$ & Automated & Automated & $\mathrm{N} / \mathrm{A}$ \\
\hline h,conv & $\mathrm{W} /\left(\mathrm{m}^{2} \cdot \mathrm{K}\right)$ & Automated & 2.4 & $\mathrm{~N} / \mathrm{A}$ & 2.4 & $\mathrm{~N} / \mathrm{A}$ & Automated & 1.8 & $\mathrm{~N} / \mathrm{A}$ \\
\hline $\mathrm{h}, \mathrm{comb}$ & $\mathrm{W} /\left(\mathrm{m}^{2} \cdot \mathrm{K}\right)$ & $\mathrm{N} / \mathrm{A}$ & $\mathrm{N} / \mathrm{A}$ & 4.6 & $\mathrm{~N} / \mathrm{A}$ & 4.6 & $\mathrm{~N} / \mathrm{A}$ & $\mathrm{N} / \mathrm{A}$ & 3.8 \\
\hline \multicolumn{10}{|c|}{ Insulated Walls, Vertical } \\
\hline h,ir & $\mathrm{W} /\left(\mathrm{m}^{2} \cdot \mathrm{K}\right)$ & Automated & Automated & $N / A$ & Automated & $\mathrm{N} / \mathrm{A}$ & Automated & Automated & $\mathrm{N} / \mathrm{A}$ \\
\hline h,conv & $\mathrm{W} /\left(\mathrm{m}^{2} \cdot \mathrm{K}\right)$ & Automated & 2.2 & $N / A$ & 2.2 & $\mathrm{~N} / \mathrm{A}$ & Automated & 2.3 & $\mathrm{~N} / \mathrm{A}$ \\
\hline h,comb & $\mathrm{W} /\left(\mathrm{m}^{2} \cdot \mathrm{K}\right)$ & N/A & N/A & 1.8 & $\mathrm{~N} / \mathrm{A}$ & 1.8 & N/A & N/A & 1.8 \\
\hline \multicolumn{10}{|l|}{ Ceiling } \\
\hline h,ir & $\mathrm{W} /\left(\mathrm{m}^{2} \cdot \mathrm{K}\right)$ & Automated & Automated & $N / A$ & Automated & $\mathrm{N} / \mathrm{A}$ & Automated & Automated & $\mathrm{N} / \mathrm{A}$ \\
\hline h,conv & $\mathrm{W} /\left(\mathrm{m}^{2} \cdot \mathrm{K}\right)$ & Automated & 1.8 & $\mathrm{~N} / \mathrm{A}$ & 1.8 & $\mathrm{~N} / \mathrm{A}$ & Automated & 1.8 & $\mathrm{~N} / \mathrm{A}$ \\
\hline h,comb & $\mathrm{W} /\left(\mathrm{m}^{2} \cdot \mathrm{K}\right)$ & N/A & $\mathrm{N} / \mathrm{A}$ & 1.8 & $\mathrm{~N} / \mathrm{A}$ & 1.8 & N/A & N/A & 1.7 \\
\hline \multicolumn{10}{|l|}{ Floor } \\
\hline$h, i r$ & $\mathrm{~W} /\left(\mathrm{m}^{2} \cdot \mathrm{K}\right)$ & Automated & Automated & $N / A$ & Automated & $\mathrm{N} / \mathrm{A}$ & Automated & Automated & $\mathrm{N} / \mathrm{A}$ \\
\hline h,conv & $\mathrm{W} /\left(\mathrm{m}^{2} \cdot \mathrm{K}\right)$ & Automated & 2.2 & $\mathrm{~N} / \mathrm{A}$ & 2.2 & $\mathrm{~N} / \mathrm{A}$ & Automated & 2.3 & $\mathrm{~N} / \mathrm{A}$ \\
\hline $\mathrm{h}, \mathrm{comb}$ & $\mathrm{W} /\left(\mathrm{m}^{2} \cdot \mathrm{K}\right)$ & $\mathrm{N} / \mathrm{A}$ & $\mathrm{N} / \mathrm{A}$ & 3.6 & $\mathrm{~N} / \mathrm{A}$ & 3.6 & $\mathrm{~N} / \mathrm{A}$ & $\mathrm{N} / \mathrm{A}$ & 3.8 \\
\hline \multicolumn{7}{|c|}{ Case 900 (high mass, $\varepsilon=0.9$ ) } & \multirow{2}{*}{\multicolumn{3}{|c|}{$\begin{array}{l}\text { Case inputs } \\
\text { (Henninger, Witte 2015/2016) }\end{array}$}} \\
\hline & & Case & outs (Kumm & ert 20 & 16) & & & & \\
\hline \multicolumn{2}{|c|}{ Windows $(\varepsilon=0.84)$} & ho & h1 & h2 & h5 & h6 & ho & h1 & h2 \\
\hline $\mathrm{h}, \mathrm{ir}$ & $\mathrm{W} /\left(\mathrm{m}^{2} \cdot \mathrm{K}\right)$ & Automated & Automated & $\mathrm{N} / \mathrm{A}$ & Automated & $\mathrm{N} / \mathrm{A}$ & Automated & Automated & $\mathrm{N} / \mathrm{A}$ \\
\hline h,conv & $\mathrm{W} /\left(\mathrm{m}^{2} \cdot \mathrm{K}\right)$ & Automated & 2.3 & $N / A$ & 2.4 & $\mathrm{~N} / \mathrm{A}$ & Automated & 1.7 & $\mathrm{~N} / \mathrm{A}$ \\
\hline $\mathrm{h}, \mathrm{comb}$ & $\mathrm{W} /\left(\mathrm{m}^{2} \cdot \mathrm{K}\right)$ & $\mathrm{N} / \mathrm{A}$ & $\mathrm{N} / \mathrm{A}$ & 5.7 & $\mathrm{~N} / \mathrm{A}$ & 4.6 & $\mathrm{~N} / \mathrm{A}$ & $\mathrm{N} / \mathrm{A}$ & 5.0 \\
\hline \multicolumn{10}{|c|}{ Insulated Walls, Vertical } \\
\hline h,ir & $\mathrm{W} /\left(\mathrm{m}^{2} \cdot \mathrm{K}\right)$ & Automated & Automated & $N / A$ & Automated & $\mathrm{N} / \mathrm{A}$ & Automated & Automated & $\mathrm{N} / \mathrm{A}$ \\
\hline h,conv & $\mathrm{W} /\left(\mathrm{m}^{2} \cdot \mathrm{K}\right)$ & Automated & 1.7 & $\mathrm{~N} / \mathrm{A}$ & 2.2 & $\mathrm{~N} / \mathrm{A}$ & Automated & 1.7 & $\mathrm{~N} / \mathrm{A}$ \\
\hline $\mathrm{h}, \mathrm{comb}$ & $\mathrm{W} /\left(\mathrm{m}^{2} \cdot \mathrm{K}\right)$ & $\mathrm{N} / \mathrm{A}$ & $\mathrm{N} / \mathrm{A}$ & 2.1 & $\mathrm{~N} / \mathrm{A}$ & 1.8 & $\mathrm{~N} / \mathrm{A}$ & $\mathrm{N} / \mathrm{A}$ & 2.1 \\
\hline \multicolumn{10}{|l|}{ Ceiling } \\
\hline h,ir & $\mathrm{W} /\left(\mathrm{m}^{2} \cdot \mathrm{K}\right)$ & Automated & Automated & $\mathrm{N} / \mathrm{A}$ & Automated & $\mathrm{N} / \mathrm{A}$ & Automated & Automated & $\mathrm{N} / \mathrm{A}$ \\
\hline h,conv & $W /(n$ & Automated & 1.5 & $\mathrm{~N} / \mathrm{A}$ & 1.8 & $\mathrm{~N} / \mathrm{A}$ & Automated & 1.5 & $\mathrm{~N} / \mathrm{A}$ \\
\hline $\mathrm{h}, \mathrm{comb}$ & $\mathrm{W} /\left(\mathrm{m}^{2} \cdot \mathrm{K}\right)$ & $\mathrm{N} / \mathrm{A}$ & $\mathrm{N} / \mathrm{A}$ & 2.7 & $\mathrm{~N} / \mathrm{A}$ & 1.8 & $\mathrm{~N} / \mathrm{A}$ & $\mathrm{N} / \mathrm{A}$ & 2.6 \\
\hline \multicolumn{10}{|l|}{ Floor } \\
\hline h,ir & $\mathrm{W} /\left(\mathrm{m}^{2} \cdot \mathrm{K}\right)$ & Automated & Automated & $N / A$ & Automated & $\mathrm{N} / \mathrm{A}$ & Automated & Automated & $\mathrm{N} / \mathrm{A}$ \\
\hline h,conv & $\mathrm{W} /\left(\mathrm{m}^{2} \cdot \mathrm{K}\right)$ & Automated & 1.8 & $N / A$ & 2.2 & $\mathrm{~N} / \mathrm{A}$ & Automated & 1.8 & $\mathrm{~N} / \mathrm{A}$ \\
\hline $\mathrm{h}, \mathrm{comb}$ & $\mathrm{W} /\left(\mathrm{m}^{2} \cdot \mathrm{K}\right)$ & $\mathrm{N} / \mathrm{A}$ & $\mathrm{N} / \mathrm{A}$ & 3.6 & $\mathrm{~N} / \mathrm{A}$ & 3.6 & $\mathrm{~N} / \mathrm{A}$ & $\mathrm{N} / \mathrm{A}$ & 3.6 \\
\hline \multicolumn{7}{|c|}{ Case 200 (low mass, $\varepsilon=0.1$ ) } & \multicolumn{3}{|c|}{$\begin{array}{l}\text { Case inputs } \\
\text { (Henninger, Witte 2015/2016) }\end{array}$} \\
\hline \multicolumn{2}{|c|}{ Opaque Windows $(\varepsilon=0.1)$} & ho & h1 & h2 & h5 & h6 & ho & h1 & h2 \\
\hline h,ir & $\mathrm{W} /\left(\mathrm{m}^{2} \cdot \mathrm{K}\right)$ & Automated & Automated & $\mathrm{N} / \mathrm{A}$ & Automated & $\mathrm{N} / \mathrm{A}$ & Automated & Automated & $\mathrm{N} / \mathrm{A}$ \\
\hline h,conv & $\mathrm{W} /\left(\mathrm{m}^{2} \cdot \mathrm{K}\right)$ & Automated & 2.6 & $N / A$ & 2.4 & $\mathrm{~N} / \mathrm{A}$ & Automated & 2.6 & $\mathrm{~N} / \mathrm{A}$ \\
\hline h,comb & $\mathrm{W} /\left(\mathrm{m}^{2} \cdot \mathrm{K}\right)$ & $\mathrm{N} / \mathrm{A}$ & $\mathrm{N} / \mathrm{A}$ & 3.1 & $\mathrm{~N} / \mathrm{A}$ & 3.1 & $\mathrm{~N} / \mathrm{A}$ & $\mathrm{N} / \mathrm{A}$ & 3.2 \\
\hline \multicolumn{10}{|c|}{ Insulated Walls, Vertical } \\
\hline h,ir & $\mathrm{W} /\left(\mathrm{m}^{2} \cdot \mathrm{K}\right)$ & Automated & Automated & $\mathrm{N} / \mathrm{A}$ & ated & $\mathrm{N} / \mathrm{A}$ & Autc & Auto & $\mathrm{N} / \mathrm{A}$ \\
\hline h,conv & $\mathrm{W} /\left(\mathrm{m}^{2} \cdot \mathrm{K}\right)$ & Automated & 1.9 & $N / A$ & 2.2 & $\mathrm{~N} / \mathrm{A}$ & Automated & 1.9 & $\mathrm{~N} / \mathrm{A}$ \\
\hline h,comb & $\mathrm{W} /\left(\mathrm{m}^{2} \cdot \mathrm{K}\right)$ & $\mathrm{N} / \mathrm{A}$ & $\mathrm{N} / \mathrm{A}$ & 2.1 & $\mathrm{~N} / \mathrm{A}$ & 2.1 & $\mathrm{~N} / \mathrm{A}$ & $\mathrm{N} / \mathrm{A}$ & 2.1 \\
\hline \multicolumn{10}{|l|}{ Ceiling } \\
\hline $\mathrm{h}, \mathrm{ir}$ & $\mathrm{W} /\left(\mathrm{m}^{2} \cdot \mathrm{K}\right)$ & Automated & Automated & $N / A$ & Automated & $\mathrm{N} / \mathrm{A}$ & Automated & Automated & $\mathrm{N} / \mathrm{A}$ \\
\hline h,conv & $\mathrm{W} /\left(\mathrm{m}^{2} \cdot \mathrm{K}\right)$ & Automated & 1.9 & $N / A$ & 1.8 & $\mathrm{~N} / \mathrm{A}$ & Automated & 1.9 & $\mathrm{~N} / \mathrm{A}$ \\
\hline $\mathrm{h}, \mathrm{comb}$ & $\mathrm{W} /\left(\mathrm{m}^{2} \cdot \mathrm{K}\right)$ & $\mathrm{N} / \mathrm{A}$ & $\mathrm{N} / \mathrm{A}$ & 1.9 & $\mathrm{~N} / \mathrm{A}$ & 1.9 & N/A & $\mathrm{N} / \mathrm{A}$ & 1.9 \\
\hline \multicolumn{10}{|l|}{ Floor } \\
\hline$h, i r$ & $\mathrm{~W} /\left(\mathrm{m}^{2} \cdot \mathrm{K}\right)$ & Automated & Automated & $\mathrm{N} / \mathrm{A}$ & Automated & $\mathrm{N} / \mathrm{A}$ & Automated & Automated & $\mathrm{N} / \mathrm{A}$ \\
\hline h,conv & $\mathrm{W} /\left(\mathrm{m}^{2} \cdot \mathrm{K}\right)$ & Automated & 1.0 & $\mathrm{~N} / \mathrm{A}$ & 2.2 & $\mathrm{~N} / \mathrm{A}$ & Automated & 0.9 & $\mathrm{~N} / \mathrm{A}$ \\
\hline $\mathrm{h}, \mathrm{comb}$ & $\mathrm{W} /\left(\mathrm{m}^{2} \cdot \mathrm{K}\right)$ & N/A & $\mathrm{N} / \mathrm{A}$ & 0.4 & $\mathrm{~N} / \mathrm{A}$ & 0.4 & N/A & $\mathrm{N} / \mathrm{A}$ & 0.4 \\
\hline
\end{tabular}


Table 4A-16. Comparison of simulations applying detailed and equivalent constant surface coefficients

\begin{tabular}{|c|c|c|c|c|c|c|c|c|c|c|c|}
\hline \multicolumn{12}{|c|}{ Kummert (2016) } \\
\hline & & & h1 v ho & & h2 v ho & & h5 v h0 & & h6v ho & 2014 const & hcst2014 \\
\hline Case & ho & h1 & $\%$ diff & h2 & $\%$ diff & h5 & $\%$ diff & h6 & $\%$ diff & hci,hce & v ho, \% diff \\
\hline \multicolumn{12}{|c|}{ Annual Heating (MWh/yr) } \\
\hline 600 & 4.476 & 4.502 & $0.6 \%$ & 4.283 & $-4.3 \%$ & 4.502 & $0.6 \%$ & 4.283 & $-4.3 \%$ & 3.776 & $-15.6 \%$ \\
\hline 900 & 1.789 & 1.725 & $-3.5 \%$ & 1.891 & $5.7 \%$ & 1.793 & $0.2 \%$ & 1.708 & $-4.5 \%$ & 1.597 & $-10.7 \%$ \\
\hline 200 & 5.161 & 5.129 & $-0.6 \%$ & 5.229 & $1.3 \%$ & 5.166 & $0.1 \%$ & 5.229 & $1.3 \%$ & 4.846 & $-6.1 \%$ \\
\hline \multicolumn{12}{|c|}{ Annual Cooling (MWh/yr) } \\
\hline 600 & 5.701 & 5.616 & $-1.5 \%$ & 6.172 & $8.3 \%$ & 5.616 & $-1.5 \%$ & 6.172 & $8.3 \%$ & 4.361 & $-23.5 \%$ \\
\hline 900 & 2.202 & 2.142 & $-2.7 \%$ & 3.020 & $37.1 \%$ & 2.280 & $3.5 \%$ & 2.981 & $35.3 \%$ & 1.785 & $-19.0 \%$ \\
\hline 200 & 0.788 & 0.847 & $7.4 \%$ & 0.874 & $10.9 \%$ & 0.861 & $9.2 \%$ & 0.874 & $10.9 \%$ & 0.738 & $-6.3 \%$ \\
\hline \multicolumn{12}{|c|}{ Peak Heating $(\mathrm{kWh} / \mathrm{h})$} \\
\hline 600 & 3.286 & 3.163 & $-3.7 \%$ & 3.111 & $-5.3 \%$ & 3.163 & $-3.7 \%$ & 3.111 & $-5.3 \%$ & 2.807 & $-14.6 \%$ \\
\hline 900 & 2.777 & 2.512 & $-9.5 \%$ & 2.840 & $2.3 \%$ & 2.663 & $-4.1 \%$ & 2.678 & $-3.6 \%$ & 2.212 & $-20.3 \%$ \\
\hline 200 & 2.365 & 2.193 & $-7.3 \%$ & 2.243 & $-5.2 \%$ & 2.207 & $-6.7 \%$ & 2.243 & $-5.2 \%$ & 2.130 & $-10.0 \%$ \\
\hline \multicolumn{12}{|c|}{ Peak Cooling (kWh/h) } \\
\hline 600 & 6.075 & 5.447 & $-10.3 \%$ & 6.090 & $0.2 \%$ & 5.447 & $-10.3 \%$ & 6.090 & $0.2 \%$ & 4.185 & $-31.1 \%$ \\
\hline 900 & 2.884 & 2.371 & $-17.8 \%$ & 3.467 & $20.2 \%$ & 2.604 & $-9.7 \%$ & 3.324 & $15.3 \%$ & 1.884 & $-34.7 \%$ \\
\hline 200 & 1.257 & 1.232 & $-2.0 \%$ & 1.267 & $0.8 \%$ & 1.257 & $0.0 \%$ & 1.267 & $0.8 \%$ & 1.090 & $-13.3 \%$ \\
\hline
\end{tabular}

\begin{tabular}{|c|c|c|c|c|c|}
\hline \multicolumn{6}{|c|}{ Henninger and Witte (2015/2016) } \\
\hline & & & h1 v ho & & h2 v h0 \\
\hline Case & ho & h1 & $\%$ diff & h2 & $\%$ diff \\
\hline \multicolumn{6}{|c|}{ Annual Heating (MWh/yr) } \\
\hline 600 & 4.311 & 4.360 & $1.1 \%$ & 4.116 & $-4.5 \%$ \\
\hline & J & 1.6 & $-3.1 \%$ & 1.764 & $6.5 \%$ \\
\hline 200 & 5.175 & 5.143 & $-0.6 \%$ & 5.267 & $1.8 \%$ \\
\hline \multicolumn{6}{|c|}{ Annual Cooling (MWh/yr) } \\
\hline 600 & 6.031 & 5.939 & $-1.5 \%$ & 6.427 & $6.6 \%$ \\
\hline 900 & 2.496 & 2.418 & $-3.1 \%$ & 3.268 & $30.9 \%$ \\
\hline 200 & 0.834 & 0.897 & $7.5 \%$ & 0.931 & $11.6 \%$ \\
\hline \multicolumn{6}{|c|}{ Peak Heating $(\mathrm{kWh} / \mathrm{h})$} \\
\hline 600 & 3.200 & 3.126 & $-2.3 \%$ & 3.040 & $-5.0 \%$ \\
\hline 900 & 2.685 & 2.459 & $-8.4 \%$ & 2.763 & $2.9 \%$ \\
\hline 200 & 2.394 & 2.208 & $-7.8 \%$ & 2.267 & $-5.3 \%$ \\
\hline \multicolumn{6}{|c|}{ Peak Cooling (kWh/h) } \\
\hline 600 & 6.348 & 5.739 & $-9.6 \%$ & 6.353 & $0.1 \%$ \\
\hline 900 & 3.035 & 2.268 & $-25.3 \%$ & 3.565 & $17.5 \%$ \\
\hline 200 & 1.334 & 1.459 & $9.3 \%$ & 1.336 & $0.1 \%$ \\
\hline
\end{tabular}

\%-Difference, Henninger and Witte 2015/2016 versus Kummert 2016

Case | ho | h1

Annual Heating (\%-difference)

\begin{tabular}{l|l|l|l}
600 & $-3.7 \%$ & $-3.2 \%$ & $-3.9 \%$
\end{tabular}

\begin{tabular}{l|l|l|l}
900 & $-7.4 \%$ & $-7.0 \%$ & $-6.7 \%$ \\
\hline & $0.3 \%$ & $0.3 \%$ & $0.7 \%$
\end{tabular}

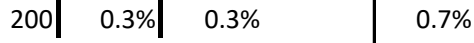

Annual Cooling (\%-difference)

\begin{tabular}{l|l|l|l}
600 & $5.8 \%$ & $5.8 \%$ & $4.1 \%$
\end{tabular}

\begin{tabular}{l|l|l|l}
900 & $13.4 \%$ & $12.9 \%$ & $8.2 \%$
\end{tabular}

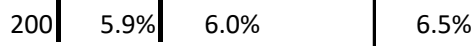

Peak Heating (\%-difference)

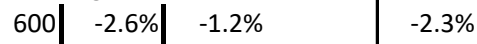

\begin{tabular}{l|l|l|l}
900 & $-3.3 \%$ & $-2.1 \%$ & $-2.7 \%$
\end{tabular}

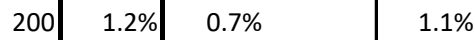

Peak Cooling (\%-difference)

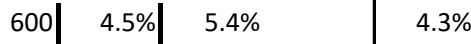

\begin{tabular}{l|l|l|l}
900 & $5.2 \%$ & $-4.3 \%$ & $2.8 \%$ \\
200 & $6.2 \%$ & $18.4 \%$ & $5.4 \%$
\end{tabular}

LoadsOutput...xlsx; Excerp...060716!M39+ 
Other observations from these results follow.

- The results for the "h1" input settings indicate the following:

- Use of the derived constant convective coefficients has relatively low impact $(<1 \%$ to $7 \%$ ) on annual heating and cooling loads versus the "h0" runs, where the larger \%-differences tend to occur for small variations among relatively small loads.

○ The results for peak heating and cooling loads have larger disagreements versus "h0", as expected when using constant surface coefficients, with a maximum disagreement for a Case 900 peak cooling load of $18 \%$ applying TRNSYS and $25 \%$ applying EnergyPlus. This is because the constant coefficients are developed based on annualized load-weighted averaging for each hour. This implies that the results agreement for specific hours (including the peak load hours) using constant coefficients versus fully automated $(\mathrm{h} 0)$ runs may not necessarily be as good as the agreement of a similar comparison for annual load results.

- All of the "h1" results have better agreement with "h0" than those applying the "2014 const" coefficients, which were derived on the basis of weather-data average annual ambient temperature. This confirms that use of convective coefficients based on load-weighted average values, or calculated from load-weighted average absolute temperature differences (checked in preliminary work not shown here), are better than those based on non-weighted average values.

- The above observations indicate that the constant interior convective coefficients derived here represent a satisfactory improvement over the convective coefficients developed for the first round of simulation trials.

- The results for the "h2" input settings indicate the following:

- Use of the derived constant combined coefficients has a greater effect on annual heating and cooling loads versus the "h0" runs than use of the derived convective coefficients. This was expected because radiative heat transfer is difficult to represent with constant coefficients, as discussed in Section 4A.3.2.

- The " $\mathrm{h} 2$ " constant combined coefficient results have better agreement with " $\mathrm{h} 0$ " than those applying the "2014 const" constant convective coefficients (which were derived on the basis of weather-data average annual ambient temperature), except for the Case 900 and Case 200 annual cooling-load results.

- The results for the " $\mathrm{h} 5$ " and " $\mathrm{h} 6$ " input settings indicate the following:

- It is not necessary to have separate sets of constant convective and combined interior surface coefficients for the high-mass cases; the coefficients developed for Case 600 are sufficient.

Based on the above observations, we decided to apply the following values of derived constant coefficients in summary Tables B4-1 and B4-2 (see Part I, Annex B4):

- Apply values from the "h1" runs for Cases 600 and 200 for setting equivalent constant convective surface coefficient $\left(\mathrm{h}_{\text {conv }}\right.$ ) values for all cases with interior $\varepsilon=0.9$ and $\varepsilon=0.1$, respectively.

- Apply values from the "h2" runs for Cases 600 and 200 for setting equivalent constant combined surface coefficient $\left(\mathrm{h}_{\mathrm{comb}}\right)$ values for all cases with interior $\varepsilon=0.9$ and $\varepsilon=0.1$, respectively. 


\section{A.4.2 Round 1 (Archival) Sensitivity Tests.}

The sensitivity tests described below were run in a different context than the Round 2 results of Section 4A.4.1. The Round 1 context applied development of combined coefficients by adding separately determined convective and radiative portions of the coefficients as: h,comb,int,lwa $=\mathrm{h}$, conv,int,lwa $+\mathrm{h}$,ir,int,lwa, 2 , where h,ir,int,lwa2 is described in Section 4A.4.2.1 (just below). Although the current combined coefficient calculation technique described in Section 4A.3.2.1.2 is more physically correct, the conclusions of the Round 1 sensitivity tests are still applicable to the final derived constant coefficients, so we have included the following related discussion.

\section{A.4.2.1 Round 1 Initial Sensitivity Tests.}

The Round 1 results for interior constant convective surface coefficients and constant radiative surface coefficients for two sets of simulations by separate modelers using separate programs are provided in Table 4A-17.

Nomenclature for Table 4A-17 is as follows:

- Row labels are variable names defined as:

- $\Delta \mathrm{T}$, lwa $=\Delta \mathrm{T}$, int,lwa (see Section 4A.3.2.1.2).

$\circ \mathrm{h}, \mathrm{conv}$, int,lwa as in Section 4A.3.1.1.

$\circ \mathrm{h}$, ir,int,lwa, $2=$ (q,ir,int,lwa) $/(\Delta \mathrm{T}$, lwa $)$,

where

$$
\begin{array}{ll}
\text { q,ir,int,lwa }= & \left.\frac{\Sigma(\mid \mathrm{q}, \text { ir,surf,hour }|*| \mathrm{q}, \text { zone,hour } \mid}{\mid(\mid \mathrm{q}, \text { zone,htg,ann }|+| \mathrm{q}, \text { zone,clg,ann } \mid}\right) \\
\Delta \mathrm{T}, \text { lwa }=\quad & \frac{\Sigma(\mid \Delta \mathrm{T}, \text { hour }|*| \mathrm{q}, \text {,zone,hour } \mid)}{(\mid \mathrm{q}, \text { zone,htg,ann }|+| \mathrm{q}, \text { zone,clg,ann } \mid)}
\end{array}
$$

and where q,ir,surf,hour; q,zone,hour; q,zone,htg,ann; q,zone,clg,ann; and $\Delta \mathrm{T}$,hour are as defined in Section 4A.3.2.1.2.

$\circ \mathrm{h}$,ir,int,lwa,3, is based on gray-body radiation approximation theory applying average temperature from detailed models, specifically:

$$
\begin{aligned}
& \text { h,ir,int, } 3=\quad 4 \varepsilon \sigma(\mathrm{T}, \mathrm{av}, \text { int }, \text { lwa })^{3} \\
& \text { where } \\
& \begin{array}{l}
\varepsilon=\text { interior surface emittance } \\
\sigma=5.67 * 10^{-8} \mathrm{~W} /\left(\mathrm{m}^{2} \cdot \mathrm{K}^{4}\right)
\end{array} \\
& \begin{array}{l}
(\mathrm{T}, \text { av,int,lwa })=\quad \frac{\sum\{((\mathrm{T}, \text { zone,hour })+(\mathrm{T}, \text { surf,hour })) / 2 * \mid \mathrm{q}, \text { zone,hour } \mid\}}{(\mid \mathrm{q}, \text { zone,htg,ann }|+| \mathrm{q}, \text { zone,clg,ann } \mid)}
\end{array}
\end{aligned}
$$

where

T,zone,hour $=$ hourly zone temperature.

$\mathrm{T}$,surf,hour = hourly surface temperature.

q,zone,hour; q,zone,htg,ann; and q,zone,clg,ann are same as defined in Section 4A.3.1.1).

○ h,comb, $2=\mathrm{h}$, conv, int,lwa $+\mathrm{h}$,ir,int,lwa,2; h,conv, int,lwa is defined in Section 4A.3.1.1.

○ $\mathrm{h}, \mathrm{comb}, 3=\mathrm{h}$,conv, int,lwa $+\mathrm{h}$,ir,int,lwa,3; $\mathrm{h}$,conv, int,lwa is defined in Section 4A.3.1.1.

- For floor and ceiling values: "Mixed" is a mixture of stable and unstable convection as determined from the direction of heat flow in the detailed simulations, where "stable" refers to retarded convection for rising warmer air or falling cooler air driven towards a surface, and "unstable" refers to enhanced convection for rising warmer air or falling cooler air moving away from a surface. Values for stable and unstable convection are determined by applying the values of $\Delta \mathrm{T}$, lwa determined by the simulations for the floor and ceiling to the algorithm of Equation $4 \mathrm{~A}-5$ with $\mathrm{a}=0.76$ and $\mathrm{a}=1.51$, respectively.

- All other values of h,conv,int,lwa, h,ir,int,lwa,2, and h,ir,int,lwa,3 (for windows and walls) are taken from direct post-processing of the simulation results by the modelers. Values for the walls are average values for the four walls at the different orientations (north, south, east, west). 
To analyze the effect of applying the derived constant coefficients versus more detailed modeling, results were compared for detailed simulations versus simulations applying constant values developed by the modelers, applying the parametric sensitivity test scheme shown in Table 4A-18. Output for this test scheme is provided in Table 4A19. The run designations for the case inputs in the column headers of Tables 4A-18 and 4A-19 are defined as follows:

- h0 (same as h0 in Section 4A.4.1): Base case run with all automated convection applying Equation 4A-5 at each time step (except for the EnergyPlus windows, where ISO 15099 (2003), Section 8.3.2.2 is applied at each time step) and automated detailed surface-to-surface radiative exchange modeling; this is the benchmark for comparison of other constant coefficient runs described below.

- h1 (same as h1 in Section 4A.4.1): Constant convective coefficients (h,conv,int,lwa) with automated surface-to-surface radiative exchange.

- h2a: Constant combined coefficients applying h,comb,2 = h,conv,int,lwa + h,ir,int,lwa,2; automated surface convection and radiative exchange modeling are both off.

- h3: Constant combined coefficients applying h,comb, $3=$ h, conv, int,lwa + h,ir,int,lwa,3; automated surface convection and radiative exchange modeling are both off.

- h4: Constant combined coefficients = constant convective coefficients of the "h1" run, applying h,comb, $4=$ h,conv,int,lwa; automated surface convection and radiative exchange modeling are both off.

In this scheme, h2a is different from "h2" applied in Section 4A.4.1. For the TRNSYS runs h0 and h1, Round 1 output varies slightly from Round 2 output (see Table 4A-16) because some minor changes were made to other simulation inputs (e.g., exterior coefficients) and different software versions were run.

Observations from the initial Round 1 results of Table 4A-19 follow:

- The results for the "h2a" input settings indicate better agreement with "h0" for the "h2a" than the "h3" runs; recall that the radiative coefficients used to develop the combined coefficients for " $\mathrm{h} 2 \mathrm{a}$ " are lower than those used to develop the combined coefficients of " $h 3$." This is an important observation, and could be related to the items discussed in Section 4A.3.2.

- The results for the " $\mathrm{h} 3$ " runs indicate the greatest disagreement with " $\mathrm{h} 0$ " of all the options, including the "h4" runs; recall that the "h4" runs remove the radiative exchange portion from the constant combined coefficients (i.e., combined coefficients of "h4" = convective coefficients of "h2a"). This disagreement indicates that using the radiative exchange coefficients that would represent an approximation for surfaceto-surface heat transfer is not appropriate for a simple representation where all heat transfers would take place between surfaces and the air; some possible reasons for this are discussed at the beginning of Section 4A.3.2.

- Regarding results for the "h4" runs:

$\circ$ The idea to take radiation out of the combined coefficients occurred because the disagreement of "h2a" versus " $\mathrm{h} 1$ " for cooling loads is still relatively high.

○ For the "h4" runs versus the "h2a" runs, there is somewhat improved agreement for annual cooling, but at the expense of more substantial disagreement for annual heating. Note: This implies that a further reduction of the "h2a" combined coefficients could be calculated to minimize disagreement versus " $\mathrm{h} 0$ ", but the disagreement may not be reducible much further based on the differences. We do not recommend applying an automated input/results optimization here because of the high cost/benefit ratio associated with limited potential for accuracy improvement, verifying results of the optimization process, and the general context of providing constant coefficients for simplified modeling methods. 
Table 4A-17. Load-weighted average interior surface convective and radiative coefficients and surface-tozone temperature differences developed from verified simulations for Round 1 sensitivity tests

\begin{tabular}{|c|c|c|c|c|c|c|c|c|}
\hline \multicolumn{3}{|l|}{ Kummert (2015) } & \multirow[t]{2}{*}{$\begin{array}{l}\text { Ceiling } \\
\text { Mixed }\end{array}$} & \multirow[t]{2}{*}{$\begin{array}{l}\text { Ceiling } \\
\text { Stable }\end{array}$} & \multirow[t]{2}{*}{$\begin{array}{l}\text { Ceiling } \\
\text { Unstable }\end{array}$} & \multirow[t]{2}{*}{$\begin{array}{l}\text { Floor } \\
\text { Mixed }\end{array}$} & \multirow[t]{2}{*}{$\begin{array}{l}\text { Floor } \\
\text { Stable }\end{array}$} & \multirow[t]{2}{*}{$\begin{array}{c}\text { Floor } \\
\text { Unstable }\end{array}$} \\
\hline \multicolumn{3}{|c|}{ Case 600 ( $\varepsilon=0.9$, low mass) } & & & & & & \\
\hline$\Delta \mathrm{T}$,Iwa $(\mathrm{K})$ & 6.8 & 5.2 & 5.7 & 5.7 & 5.7 & 6.1 & 6.1 & 6.1 \\
\hline h,conv,int,Iwa $\left(\mathrm{W} / \mathrm{m}^{2} \mathrm{~K}\right)$ & 2.4 & 2.2 & 1.8 & 1.4 & 2.7 & 2.2 & 1.4 & 2.8 \\
\hline $\mathrm{h}, \mathrm{ir}$, int,lwa,2 $\left(\mathrm{W} / \mathrm{m}^{2} \mathrm{~K}\right)$ & 3.0 & 0.8 & 0.4 & 0.4 & 0.4 & 1.4 & 1.4 & 1.4 \\
\hline $\mathrm{h}, \mathrm{comb}, 2\left(\mathrm{~W} / \mathrm{m}^{2} \mathrm{~K}\right)$ & 5.4 & 3.0 & 2.2 & 1.8 & 3.1 & 3.5 & 2.7 & 4.1 \\
\hline h,ir,int,lwa,3 (W/m² K) & 5.0 & 5.4 & 5.4 & 5.4 & 5.4 & 5.4 & 5.4 & 5.4 \\
\hline $\mathrm{h}, \mathrm{comb}, 3\left(\mathrm{~W} / \mathrm{m}^{2} \mathrm{~K}\right)$ & 7.4 & 7.6 & 7.2 & 6.8 & 8.1 & 7.6 & 6.8 & 8.2 \\
\hline \multicolumn{9}{|c|}{ Case $900(\varepsilon=0.9$, high mass $)$} \\
\hline$\Delta \mathrm{T}$, Iwa $(\mathrm{K})$ & 6.1 & 2.4 & 3.5 & 3.5 & 3.5 & 3.0 & 3.0 & 3.0 \\
\hline h,conv,int,Iwa (W/m²K) & 2.3 & 1.7 & 1.5 & 1.1 & 2.3 & 1.8 & 1.1 & 2.2 \\
\hline h,ir,int,Iwa,2 (W/m²K) & 3.3 & 1.9 & 1.4 & 1.4 & 1.4 & 2.2 & 2.2 & 2.2 \\
\hline $\mathrm{h}, \mathrm{comb}, 2\left(\mathrm{~W} / \mathrm{m}^{2} \mathrm{~K}\right)$ & 5.6 & 3.6 & 3.0 & 2.6 & 3.7 & 4.0 & 3.3 & 4.3 \\
\hline h,ir,int,Iwa,3 (W/m²K) & 4.9 & 5.4 & 5.4 & 5.4 & 5.4 & 5.4 & 5.4 & 5.4 \\
\hline $\mathrm{h}, \mathrm{comb}, 3\left(\mathrm{~W} / \mathrm{m}^{2} \mathrm{~K}\right)$ & 7.2 & 7.1 & 6.9 & 6.5 & 7.7 & 7.2 & 6.5 & 7.6 \\
\hline \multicolumn{9}{|c|}{ Case 200 ( $\varepsilon=0.1$, low mass) } \\
\hline$\Delta \mathrm{T}, \mathrm{Iwa}(\mathrm{K})$ & 8.5 & 3.5 & 2.6 & 2.6 & 2.6 & 1.4 & 1.4 & 1.4 \\
\hline h,conv,int,Iwa $\left(\mathrm{W} / \mathrm{m}^{2} \mathrm{~K}\right)$ & 2.6 & 1.9 & 1.9 & 1.0 & 2.1 & 1.0 & 0.8 & 1.7 \\
\hline h,ir,int,Iwa,2 (W/m²K) & 0.4 & 0.1 & 0.1 & 0.1 & 0.1 & 0.7 & 0.7 & 0.7 \\
\hline $\mathrm{h}, \mathrm{comb}, 2\left(\mathrm{~W} / \mathrm{m}^{2} \mathrm{~K}\right)$ & 3.0 & 2.0 & 2.0 & 1.1 & 2.2 & 1.7 & 1.5 & 2.3 \\
\hline h,ir,int,lwa,3 (W/m²K) & 0.6 & 0.6 & 0.6 & 0.6 & 0.6 & 0.6 & 0.6 & 0.6 \\
\hline $\mathrm{h}, \mathrm{comb}, 3\left(\mathrm{~W} / \mathrm{m}^{2} \mathrm{~K}\right)$ & 3.2 & 2.5 & 2.5 & 1.6 & 2.6 & 1.6 & 1.4 & 2.2 \\
\hline Henninger, Witte (2015) & dows & Walls & $\begin{array}{l}\text { Ceiling } \\
\text { Mixed }\end{array}$ & $\begin{array}{l}\text { Ceiling } \\
\text { Stable }\end{array}$ & $\begin{array}{l}\text { Ceiling } \\
\text { Unstable }\end{array}$ & $\begin{array}{l}\text { Floor } \\
\text { Mixed }\end{array}$ & $\begin{array}{l}\text { Floor } \\
\text { Stable }\end{array}$ & $\begin{array}{c}\text { Floor } \\
\text { Unstable }\end{array}$ \\
\hline \multicolumn{9}{|c|}{ Case 600 ( $\varepsilon=0.9$, low mass) } \\
\hline$\Delta \mathrm{T}$,Iwa $(\mathrm{K})$ & 7.5 & 5.5 & 6.0 & 6.0 & 6.0 & 6.6 & 6.6 & 6.6 \\
\hline h,conv,int,Iwa $\left(\mathrm{W} / \mathrm{m}^{2} \mathrm{~K}\right)$ & 1.8 & 2.3 & 1.8 & 1.4 & 2.8 & 2.3 & 1.4 & 2.8 \\
\hline h,ir,int,Iwa,2 (W/m² K) & 2.6 & 0.9 & 0.5 & 0.5 & 0.5 & 1.4 & 1.4 & 1.4 \\
\hline $\mathrm{h}, \mathrm{comb}, 2\left(\mathrm{~W} / \mathrm{m}^{2} \mathrm{~K}\right)$ & 4.4 & 3.1 & 2.3 & 1.9 & 3.2 & 3.7 & 2.8 & 4.2 \\
\hline h,ir,int,Iwa,3 (W/m²K) & 5.0 & 5.4 & 5.5 & 5.5 & 5.5 & 5.5 & 5.5 & 5.5 \\
\hline $\mathrm{h}, \mathrm{comb}, 3\left(\mathrm{~W} / \mathrm{m}^{2} \mathrm{~K}\right)$ & 6.8 & 7.7 & 7.3 & 6.8 & 8.2 & 7.7 & 6.9 & 8.3 \\
\hline Case $900(\varepsilon=0.9$, high $\mathrm{m}$ & ass) & & & & & & & \\
\hline$\Delta \mathrm{T}, \mathrm{Iwa}(\mathrm{K})$ & 6.3 & 2.6 & 3.7 & 3.7 & 3.7 & 3.3 & 3.3 & 3.3 \\
\hline h,conv,int,Iwa $\left(\mathrm{W} / \mathrm{m}^{2} \mathrm{~K}\right)$ & 1.7 & 1.7 & 1.5 & 1.2 & 2.3 & 1.8 & 1.1 & 2.2 \\
\hline h,ir,int,Iwa,2 (W/m² K) & 3.2 & 2.0 & 1.3 & 1.3 & 1.3 & 2.0 & 2.0 & 2.0 \\
\hline $\mathrm{h}, \mathrm{comb}, 2\left(\mathrm{~W} / \mathrm{m}^{2} \mathrm{~K}\right)$ & 4.9 & 3.7 & 2.8 & 2.5 & 3.6 & 3.9 & 3.1 & 4.3 \\
\hline h,ir,int,Iwa,3 (W/m²K) & 5.0 & 5.4 & 5.4 & 5.4 & 5.4 & 5.4 & 5.4 & 5.4 \\
\hline $\mathrm{h}, \mathrm{comb}, 3\left(\mathrm{~W} / \mathrm{m}^{2} \mathrm{~K}\right)$ & 6.6 & 7.1 & 6.9 & 6.6 & 7.7 & 7.2 & 6.5 & 7.7 \\
\hline Case $200(\varepsilon=0.1$, low ma & ss) & & & & & & & \\
\hline$\Delta \mathrm{T}$,lwa $(\mathrm{K})$ & 8.8 & 3.5 & 2.6 & 2.6 & 2.6 & 1.5 & 1.5 & 1.5 \\
\hline h,conv,int,Iwa $\left(\mathrm{W} / \mathrm{m}^{2} \mathrm{~K}\right)$ & 2.6 & 1.9 & 1.9 & 1.0 & 2.1 & 0.9 & 0.9 & 1.7 \\
\hline h,ir,int,Iwa,2 (W/m²K) & 0.4 & 0.1 & 0.1 & 0.1 & 0.1 & 0.6 & 0.6 & 0.6 \\
\hline $\mathrm{h}, \mathrm{comb}, 2\left(\mathrm{~W} / \mathrm{m}^{2} \mathrm{~K}\right)$ & 3.0 & 2.0 & 2.0 & 1.2 & 2.2 & 1.5 & 1.5 & 2.3 \\
\hline h,ir,int,Iwa,3 (W/m²K) & 0.6 & 0.6 & 0.6 & 0.6 & 0.6 & 0.6 & 0.6 & 0.6 \\
\hline $\mathrm{h}, \mathrm{comb}, 3\left(\mathrm{~W} / \mathrm{m}^{2} \mathrm{~K}\right)$ & 3.2 & 2.5 & 2.5 & 1.6 & 2.6 & 1.5 & 1.4 & 2.3 \\
\hline$\%$ Difference (Henninger\& & Witte v. Kum & ert) & Ceiling & Ceiling & Ceiling & Floor & Floor & Floor \\
\hline & Windows & Walls & Mixed & Stable & Unstable & Mixed & Stable & Unstable \\
\hline Case $600(\varepsilon=0.9$, low ma & ss) & & & & & & & \\
\hline$\Delta \mathrm{T}, \mathrm{Iwa}(\mathrm{K})$ & $10.9 \%$ & $5.7 \%$ & $5.3 \%$ & $5.3 \%$ & $5.3 \%$ & $8.2 \%$ & $8.2 \%$ & $8.2 \%$ \\
\hline h,conv,int,Iwa $\left(\mathrm{W} / \mathrm{m}^{2} \mathrm{~K}\right)$ & $-25.4 \%$ & $1.5 \%$ & $0.2 \%$ & $1.7 \%$ & $1.7 \%$ & $3.5 \%$ & $2.7 \%$ & $2.7 \%$ \\
\hline $\mathrm{h}, \mathrm{ir}$, int, Iwa,2 $\left(\mathrm{W} / \mathrm{m}^{2} \mathrm{~K}\right)$ & $-12.6 \%$ & $6.7 \%$ & $8.0 \%$ & $8.0 \%$ & $8.0 \%$ & $2.2 \%$ & $2.2 \%$ & $2.2 \%$ \\
\hline $\mathrm{h}, \mathrm{comb}, 2\left(\mathrm{~W} / \mathrm{m}^{2} \mathrm{~K}\right)$ & $-18.2 \%$ & $3.0 \%$ & $1.7 \%$ & $3.2 \%$ & $2.6 \%$ & $3.0 \%$ & $2.4 \%$ & $2.5 \%$ \\
\hline h,ir,int,Iwa,3 (W/m²K) & $0.8 \%$ & $0.6 \%$ & $0.6 \%$ & $0.6 \%$ & $0.6 \%$ & $0.7 \%$ & $0.7 \%$ & $0.7 \%$ \\
\hline $\mathrm{h}, \mathrm{comb}, 3\left(\mathrm{~W} / \mathrm{m}^{2} \mathrm{~K}\right)$ & $-7.7 \%$ & $0.9 \%$ & $0.5 \%$ & $0.8 \%$ & $1.0 \%$ & $1.5 \%$ & $1.1 \%$ & $1.3 \%$ \\
\hline Case $900(\varepsilon=0.9$, high & DS) & & & & & & & \\
\hline$\Delta \mathrm{T}, \mathrm{Iwa}(\mathrm{K})$ & $3.9 \%$ & $5.9 \%$ & $5.5 \%$ & $5.5 \%$ & $5.5 \%$ & $10.6 \%$ & $10.6 \%$ & $10.6 \%$ \\
\hline h,conv,int, Iwa $\left(\mathrm{W} / \mathrm{m}^{2} \mathrm{~K}\right)$ & $-27.5 \%$ & $-0.1 \%$ & $-3.1 \%$ & $1.8 \%$ & $1.8 \%$ & $1.1 \%$ & $3.4 \%$ & $3.4 \%$ \\
\hline h,ir,int,Iwa,2 (W/m²K) & $-2.6 \%$ & $5.7 \%$ & $-8.5 \%$ & $-8.5 \%$ & $-8.5 \%$ & $-6.6 \%$ & $-6.6 \%$ & $-6.6 \%$ \\
\hline $\mathrm{h}, \mathrm{comb}, 2\left(\mathrm{~W} / \mathrm{m}^{2} \mathrm{~K}\right)$ & $-12.7 \%$ & $2.9 \%$ & $-5.7 \%$ & $-3.9 \%$ & $-2.2 \%$ & $-3.1 \%$ & $-3.2 \%$ & $-1.6 \%$ \\
\hline h,ir,int,Iwa,3 (W/m²K) & $0.5 \%$ & $0.2 \%$ & $0.2 \%$ & $0.2 \%$ & $0.2 \%$ & $0.2 \%$ & $0.2 \%$ & $0.2 \%$ \\
\hline $\mathrm{h}, \mathrm{comb}, 3\left(\mathrm{~W} / \mathrm{m}^{2} \mathrm{~K}\right)$ & $-8.4 \%$ & $0.1 \%$ & $-0.5 \%$ & $0.5 \%$ & $0.7 \%$ & $0.4 \%$ & $0.7 \%$ & $1.1 \%$ \\
\hline Case $200(\varepsilon=0.1$, low ma & s) & & & & & & & \\
\hline$\Delta \mathrm{T}, \mathrm{Iwa}(\mathrm{K})$ & $3.6 \%$ & $0.6 \%$ & $1.4 \%$ & $1.4 \%$ & $1.4 \%$ & $6.1 \%$ & $6.1 \%$ & $6.1 \%$ \\
\hline h,conv, int,Iwa $\left(\mathrm{W} / \mathrm{m}^{2} \mathrm{~K}\right)$ & $0.8 \%$ & $-0.4 \%$ & $-0.5 \%$ & $0.5 \%$ & $0.5 \%$ & $-11.2 \%$ & $2.0 \%$ & $2.0 \%$ \\
\hline h,ir,int,Iwa,2 (W/m² K) & $0.5 \%$ & $-6.0 \%$ & $7.9 \%$ & $7.9 \%$ & $7.9 \%$ & $-6.6 \%$ & $-6.6 \%$ & $-6.6 \%$ \\
\hline h,comb,2 (W/m² K) & $0.7 \%$ & $-0.7 \%$ & $-0.1 \%$ & $1.2 \%$ & $0.8 \%$ & $-9.4 \%$ & $-1.8 \%$ & $-0.4 \%$ \\
\hline h,ir,int,Iwa,3 (W/m²K) & $-0.1 \%$ & $0.0 \%$ & $0.0 \%$ & $0.0 \%$ & $0.0 \%$ & $0.0 \%$ & $0.0 \%$ & $0.0 \%$ \\
\hline $\mathrm{h}, \mathrm{comb}, 3\left(\mathrm{~W} / \mathrm{m}^{2} \mathrm{~K}\right)$ & $0.6 \%$ & $-0.3 \%$ & $-0.4 \%$ & $0.3 \%$ & $0.4 \%$ & $-7.2 \%$ & $1.2 \%$ & $1.5 \%$ \\
\hline
\end{tabular}


Table 4A-18. Input Settings for Round 1 Initial Constant Coefficient Sensitivity Tests

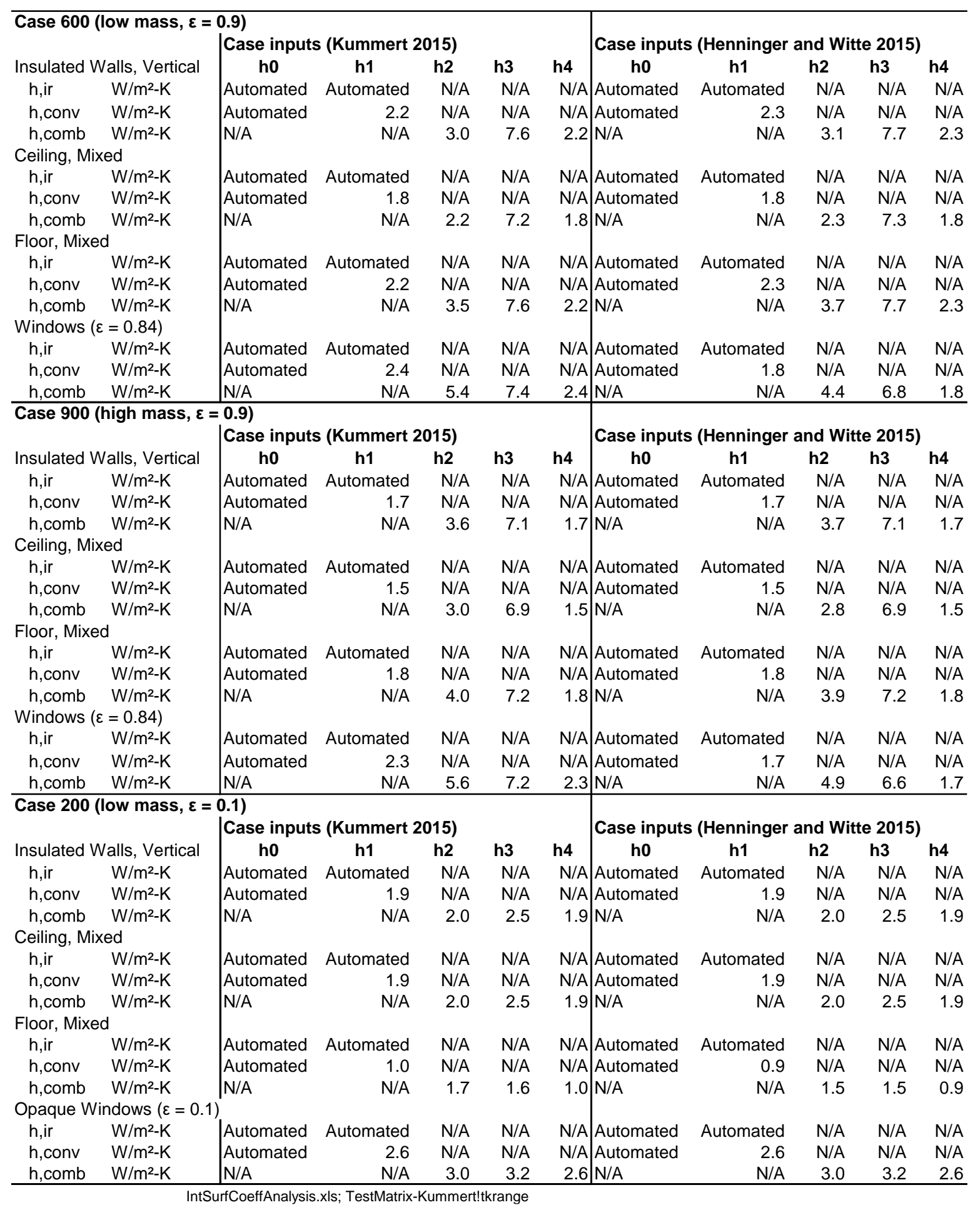


Table 4A-19. Comparison of simulations applying equivalent constant surface coefficients (Kummert 2015)

\begin{tabular}{|c|c|c|c|c|c|c|c|c|c|c|c|}
\hline \\
\hline & & & h1 v ho & & h2 v ho & & h3 v ho & & h4 v ho & 2014 const & hcst2014 \\
\hline Case & ho & h1 & $\%$ diff & h2 & $\%$ diff & h3 & $\%$ diff & h4 & $\%$ diff & hci,hce & v h0, \% diff \\
\hline \multicolumn{12}{|c|}{ Annual Heating (MWh/yr) } \\
\hline 600 & 4.457 & 4.484 & $0.6 \%$ & 4.622 & $3.7 \%$ & 5.425 & $21.7 \%$ & 3.598 & $-19.3 \%$ & 3.776 & $-15.3 \%$ \\
\hline 900 & 1.778 & 1.715 & $-3.5 \%$ & 1.905 & $7.1 \%$ & 2.197 & $23.6 \%$ & 1.193 & $-32.9 \%$ & 1.597 & $-10.2 \%$ \\
\hline 200 & 5.161 & 5.129 & $-0.6 \%$ & 5.193 & $0.6 \%$ & 5.386 & $4.4 \%$ & 5.041 & $-2.3 \%$ & 4.846 & $-6.1 \%$ \\
\hline \multicolumn{12}{|c|}{ Annual Cooling (MWh/yr) } \\
\hline 600 & 5.655 & 5.573 & $-1.4 \%$ & 6.374 & $12.7 \%$ & 7.075 & $25.1 \%$ & 5.963 & $5.4 \%$ & 4.361 & $-22.9 \%$ \\
\hline 900 & 2.175 & 2.117 & $-2.7 \%$ & 2.991 & $37.5 \%$ & 3.100 & $42.5 \%$ & 2.947 & $35.5 \%$ & 1.785 & $-17.9 \%$ \\
\hline 200 & 0.787 & 0.845 & $7.4 \%$ & 0.869 & $10.4 \%$ & 0.907 & $15.3 \%$ & 0.837 & $6.4 \%$ & 0.738 & $-6.2 \%$ \\
\hline \multicolumn{12}{|c|}{ Peak Heating (kWh/h) } \\
\hline 600 & 3.358 & 3.240 & $-3.5 \%$ & 3.377 & $0.6 \%$ & 3.734 & $11.2 \%$ & 2.921 & $-13.0 \%$ & 2.807 & $-16.4 \%$ \\
\hline 900 & 2.769 & 2.505 & $-9.5 \%$ & 3.004 & $8.5 \%$ & 3.341 & $20.6 \%$ & 2.282 & $-17.6 \%$ & 2.212 & $-20.1 \%$ \\
\hline 200 & 2.365 & 2.193 & $-7.3 \%$ & 2.227 & $-5.9 \%$ & 2.312 & $-2.3 \%$ & 2.154 & $-9.0 \%$ & 2.130 & $-10.0 \%$ \\
\hline \multicolumn{12}{|c|}{ Peak Cooling (kWh/h) } \\
\hline 600 & 6.067 & 5.439 & $-10.3 \%$ & 6.289 & $3.7 \%$ & 7.072 & $16.6 \%$ & 5.571 & $-8.2 \%$ & 4.185 & $-31.0 \%$ \\
\hline 900 & 2.858 & 2.360 & $-17.4 \%$ & 3.669 & $28.4 \%$ & 4.397 & $53.8 \%$ & 2.810 & $-1.7 \%$ & 1.884 & $-34.1 \%$ \\
\hline 200 & 1.256 & 1.231 & $-2.0 \%$ & 1.262 & $0.5 \%$ & 1.313 & $4.5 \%$ & 1.220 & $-2.9 \%$ & 1.090 & $-13.2 \%$ \\
\hline
\end{tabular}

(Henninger and Witte 2015)

\begin{tabular}{|c|c|c|c|c|c|c|c|c|c|}
\hline & & & h1 v ho & & h2 v ho & & h3 v h0 & & h4 v ho \\
\hline Case & ho & h1 & $\%$ diff & h2 & $\%$ diff & h3 & $\%$ diff & h4 & $\%$ diff \\
\hline \multicolumn{10}{|c|}{ Annual Heating (MWh/yr) } \\
\hline 600 & 4.311 & 4.360 & $1.1 \%$ & 4.454 & $3.3 \%$ & 5.116 & $18.7 \%$ & 3.484 & $-19.2 \%$ \\
\hline 900 & 1.656 & 1.605 & $-3.1 \%$ & 1.750 & $5.7 \%$ & 2.041 & $23.3 \%$ & 1.021 & $-38.4 \%$ \\
\hline 200 & 5.175 & 5.143 & $-0.6 \%$ & 5.214 & $0.8 \%$ & 5.410 & $4.5 \%$ & 5.055 & $-2.3 \%$ \\
\hline \multicolumn{10}{|c|}{ Annual Cooling (MWh/yr) } \\
\hline 600 & 6.031 & 5.939 & $-1.5 \%$ & 6.689 & $10.9 \%$ & 7.152 & $18.6 \%$ & 6.224 & $3.2 \%$ \\
\hline 900 & 2.496 & 2.418 & $-3.1 \%$ & 3.335 & $33.6 \%$ & 3.446 & $38.1 \%$ & 3.286 & $31.6 \%$ \\
\hline 200 & 0.834 & 0.897 & $7.5 \%$ & 0.924 & $10.8 \%$ & 0.964 & $15.6 \%$ & 0.889 & $6.6 \%$ \\
\hline \multicolumn{10}{|c|}{ Peak Heating $(\mathrm{kWh} / \mathrm{h})$} \\
\hline 600 & 3.200 & 3.126 & $-2.3 \%$ & 3.247 & $1.4 \%$ & 3.633 & $13.5 \%$ & 2.748 & $-14.1 \%$ \\
\hline 900 & 2.685 & 2.459 & $-8.4 \%$ & 2.912 & $8.4 \%$ & 3.243 & $20.8 \%$ & 2.165 & $-19.4 \%$ \\
\hline 200 & 2.394 & 2.208 & $-7.8 \%$ & 2.245 & $-6.2 \%$ & 2.332 & $-2.6 \%$ & 2.168 & $-9.4 \%$ \\
\hline \multicolumn{10}{|c|}{ Peak Cooling $(\mathrm{kWh} / \mathrm{h})$} \\
\hline 600 & 6.348 & 5.739 & $-9.6 \%$ & 6.566 & $3.4 \%$ & 7.307 & $15.1 \%$ & 5.794 & $-8.7 \%$ \\
\hline 900 & 3.035 & 2.268 & $-25.3 \%$ & 3.511 & $15.7 \%$ & 4.232 & $39.4 \%$ & 2.689 & $-11.4 \%$ \\
\hline 200 & 1.334 & 1.459 & $9.3 \%$ & 1.496 & $12.1 \%$ & 1.557 & $16.7 \%$ & 1.447 & $8.4 \%$ \\
\hline
\end{tabular}

(\%-difference, Henninger and Witte 2015 versus Kummert 2015)

\begin{tabular}{|c|c|c|c|c|c|}
\hline \multirow{2}{*}{\multicolumn{6}{|c|}{ 10) }} \\
\hline Case & ho & h1 & h2 & & h4 \\
\hline \multicolumn{6}{|c|}{ Annual Heating (\%-difference) } \\
\hline 600 & $-3.3 \%$ & $-2.7 \%$ & $-3.6 \%$ & $-5.7 \%$ & $-3.2 \%$ \\
\hline 900 & $-6.9 \%$ & $-6.4 \%$ & $-8.1 \%$ & $-7.1 \%$ & $-14.4 \%$ \\
\hline 200 & $0.3 \%$ & $0.3 \%$ & $0.4 \%$ & $0.4 \%$ & $0.3 \%$ \\
\hline \multicolumn{6}{|c|}{ Annual Cooling (\%-difference) } \\
\hline 600 & $6.6 \%$ & $6.6 \%$ & $4.9 \%$ & $1.1 \%$ & $4.4 \%$ \\
\hline 900 & $14.8 \%$ & $14.2 \%$ & $11.5 \%$ & $11.2 \%$ & $11.5 \%$ \\
\hline 200 & $6.0 \%$ & $6.1 \%$ & $6.4 \%$ & $6.3 \%$ & $6.2 \%$ \\
\hline \multicolumn{6}{|c|}{ Peak Heating (\%-difference) } \\
\hline 600 & $-4.7 \%$ & $-3.5 \%$ & $-3.9 \%$ & $-2.7 \%$ & $-5.9 \%$ \\
\hline 900 & $-3.0 \%$ & $-1.8 \%$ & $-3.1 \%$ & $-2.9 \%$ & $-5.1 \%$ \\
\hline 200 & $1.2 \%$ & $0.7 \%$ & $0.8 \%$ & $0.9 \%$ & $0.7 \%$ \\
\hline \multicolumn{6}{|c|}{ Peak Cooling (\%-difference) } \\
\hline 600 & $4.6 \%$ & $5.5 \%$ & $4.4 \%$ & $3.3 \%$ & $4.0 \%$ \\
\hline 900 & $6.2 \%$ & $-3.9 \%$ & $-4.3 \%$ & $-3.8 \%$ & $-4.3 \%$ \\
\hline 200 & $6.3 \%$ & $18.5 \%$ & $18.6 \%$ & $18.6 \%$ & $18.6 \%$ \\
\hline
\end{tabular}




\section{A.4.2.2 Round 1 Additional Sensitivity Tests.}

Additional Round 1 sensitivity tests were run by Kummert (2015) to address the following questions:

1. Is it worthwhile to have a separate set of constant coefficients for the high-mass cases?

- Answerable by running Case 900 with the constant coefficients developed for Case 600 versus those developed for Case 900. (This question is also addressed in Section 4A.4.1).

2. Is it worthwhile to apply separate constant convective coefficients for cases with $\varepsilon=0.1$ ?

- Answerable by running Case 200 with the constant convective coefficients for Case 600 versus those developed for Case 200. (This question is also addressed in Section 4A.4.1).

3. Is it worthwhile to apply different constant coefficients for high-conductance wall elements versus clear windows?

- Answerable by running Case 250 with the constant coefficients for clear glass of Case 600 applied to the Case 250 high-conductance wall elements versus those developed for the Case 250 highconductance wall elements.

4. Is there substantial impact from the use of separate stable and unstable convective coefficients on horizontal surfaces versus applying a single mixed coefficient?

- Answerable by running Case 600 and Case 900 with the stable/unstable floor and roof constant coefficients versus with the constant "mixed" coefficients.

The additional simulations applied the supplemental constant coefficient input scheme of Table 4A-20. The run designations for the case inputs and/or the output are defined as follows:

- h00: Same as "h0" in Section 4A.4.1. Base case run with all automated convection, applying Equation 4A5 at each time step (except for the EnergyPlus windows, where ISO 15099 (2003), Section 8.3.2.2 is applied at each time step) and automated detailed surface-to-surface radiative exchange modeling; this is the benchmark for comparison of other constant coefficient runs described below

- h01: Same as "h1" in Section 4A.4.1. Constant convective coefficients (h,conv,int,lwa) with automated surface-to-surface radiative exchange.

- h02: Same as "h2a" in Section 4A.4.2.1. Constant combined coefficients applying h,comb, $2=$ h,conv, int,lwa + h,ir,int,lwa, 2 ; automated surface convection and radiative exchange modeling are both off.

- h05 (same as h5 in Section 4A.4.1): Same as h01, but uses the Case 600 constant convective coefficients for all cases. This test corresponds to questions 1 and 2 above when using convection-only coefficients in conjunction with automatic long-wave radiative exchange calculations.

- h06 (same as h6 in Section 4A.4.1): Same as h02, but uses the Case 600 constant combined coefficients for all cases except Case 200. This test corresponds to questions 1 and 2 above when using combined coefficients.

- h07: Same as h01, but uses the separate switchable stable and unstable constant convective coefficients from Table 4A-17, for cases 600 and 900 only. This test corresponds to question 4 above when using convection-only coefficients in conjunction with automatic long-wave radiative exchange calculations.

- h08: Same as h02, but uses the separate switchable stable and unstable constant combined coefficients from Table 4A-17, for cases 600 and 900 only. This test corresponds to question 4 above when using combined coefficients.

- h09: Case 250 only. Same as h01, but high-conductance wall elements use the same constant convective coefficient as the clear window of Case 600. This test corresponds to question 3 above when using convection-only coefficients in conjunction with automatic long-wave radiative-exchange calculations.

- h10: Case 250 only. Same as h02, but high-conductance wall elements use the same constant combined coefficient as the clear window of Case 600. This test corresponds to question 3 above when using combined coefficients. 
Table 4A-20. Interior Surface Coefficient Input Settings for Round 1 Additional Sensitivity Tests

\begin{tabular}{|c|c|c|c|c|c|c|c|c|}
\hline \multirow[t]{2}{*}{ Case 600} & h01 & h02 & h05 & h06 & h07 & h08 & h09 & h10 \\
\hline & Convection $^{a}$ & Combined $^{b}$ & Convection $^{a}$ & Combined $^{\mathrm{b}}$ & Convection $^{\mathrm{a}}$ & Combined $^{\mathrm{b}}$ & Convection $^{a}$ & Combined $^{b}$ \\
\hline Floor, stable & 2.2 & 3.5 & 2.2 & 3.5 & 1.4 & 2.7 & $\mathrm{n} / \mathrm{a}$ & $\mathrm{n} / \mathrm{a}$ \\
\hline Floor, unstable & 2.2 & 3.5 & 2.2 & 3.5 & 2.8 & 4.1 & $\mathrm{n} / \mathrm{a}$ & $\mathrm{n} / \mathrm{a}$ \\
\hline Vertical Walls & 2.2 & 3.0 & 2.2 & 3.0 & 2.2 & 3.0 & $\mathrm{n} / \mathrm{a}$ & $\mathrm{n} / \mathrm{a}$ \\
\hline Windows & 2.4 & 5.4 & 2.4 & 5.4 & 2.4 & 5.4 & $\mathrm{n} / \mathrm{a}$ & $\mathrm{n} / \mathrm{a}$ \\
\hline Roof, stable & 1.8 & 2.2 & 1.8 & 2.2 & 1.4 & 1.8 & $\mathrm{n} / \mathrm{a}$ & $\mathrm{n} / \mathrm{a}$ \\
\hline Roof, unstable & 1.8 & 2.2 & 1.8 & 2.2 & 2.7 & 3.1 & $\mathrm{n} / \mathrm{a}$ & $\mathrm{n} / \mathrm{a}$ \\
\hline
\end{tabular}

\begin{tabular}{|c|c|c|c|c|c|c|c|c|}
\hline \multirow[t]{2}{*}{ Case 900} & h01 & h02 & h05 & h06 & h07 & h08 & h09 & h10 \\
\hline & Convection $^{a}$ & Combined $^{b}$ & Convection $^{a}$ & Combined $^{b}$ & Convection $^{a}$ & Combined $^{b}$ & Convection $^{a}$ & Combined $^{\mathrm{b}}$ \\
\hline Floor, stable & 1.8 & 4.0 & 2.2 & 3.5 & 1.1 & 3.3 & $n / a$ & $n / a$ \\
\hline Floor, unstable & 1.8 & 4.0 & 2.2 & 3.5 & 2.2 & 4.3 & $\mathrm{n} / \mathrm{a}$ & $\mathrm{n} / \mathrm{a}$ \\
\hline Vertical Walls & 1.7 & 3.6 & 2.2 & 3.0 & 1.7 & 3.6 & $n / a$ & $n / a$ \\
\hline Windows & 2.3 & 5.6 & 2.4 & 5.4 & 2.3 & 5.6 & $n / a$ & $n / a$ \\
\hline Roof, stable & 1.5 & 3.0 & 1.8 & 2.2 & 1.1 & 2.6 & $n / a$ & $n / a$ \\
\hline Roof, unstable & 1.5 & 3.0 & 1.8 & 2.2 & 2.3 & 3.7 & $n / a$ & $\mathrm{n} / \mathrm{a}$ \\
\hline
\end{tabular}

\begin{tabular}{|c|c|c|c|c|c|c|c|c|}
\hline \multirow[t]{2}{*}{ Case 200} & h01 & h02 & h05 & h06 & h07 & h08 & h09 & h10 \\
\hline & Convection $^{\mathrm{a}}$ & Combined $^{b}$ & Convection $^{a}$ & Combined $^{b}$ & Convection $^{\mathrm{a}}$ & Combined $^{\mathrm{b}}$ & Convection $^{a}$ & Combined $^{b}$ \\
\hline Floor, stable & 1.0 & 1.7 & 2.2 & 2.9 & $n / a$ & $\mathrm{n} / \mathrm{a}$ & $n / a$ & $\mathrm{n} / \mathrm{a}$ \\
\hline Floor, unstable & 1.0 & 1.7 & 2.2 & 2.9 & $\mathrm{n} / \mathrm{a}$ & $\mathrm{n} / \mathrm{a}$ & $\mathrm{n} / \mathrm{a}$ & $\mathrm{n} / \mathrm{a}$ \\
\hline Vertical Walls & 1.9 & 2.0 & 2.2 & 2.3 & $n / a$ & $\mathrm{n} / \mathrm{a}$ & $\mathrm{n} / \mathrm{a}$ & $\mathrm{n} / \mathrm{a}$ \\
\hline Windows & 2.6 & 3.0 & 2.4 & 2.8 & $\mathrm{n} / \mathrm{a}$ & $\mathrm{n} / \mathrm{a}$ & $\mathrm{n} / \mathrm{a}$ & $\mathrm{n} / \mathrm{a}$ \\
\hline Roof, stable & 1.9 & 2.0 & 1.8 & 1.9 & $\mathrm{n} / \mathrm{a}$ & $\mathrm{n} / \mathrm{a}$ & $\mathrm{n} / \mathrm{a}$ & $\mathrm{n} / \mathrm{a}$ \\
\hline Roof, unstable & 1.9 & 2.0 & 1.8 & 1.9 & $\mathrm{n} / \mathrm{a}$ & $\mathrm{n} / \mathrm{a}$ & $n / a$ & $\mathrm{n} / \mathrm{a}$ \\
\hline
\end{tabular}

\begin{tabular}{|c|c|c|c|c|c|c|c|c|}
\hline \multirow[t]{2}{*}{ Case 250} & h01 & h02 & h05 & h06 & h07 & h08 & h09 & h10 \\
\hline & Convection $^{\mathrm{a}}$ & Combined $^{\mathrm{b}}$ & Convection $^{a}$ & Combined $^{b}$ & Convection $^{\mathrm{a}}$ & Combined $^{b}$ & Convection $^{\mathrm{a}}$ & Combined $^{b}$ \\
\hline Floor, stable & 1.5 & 3.2 & 2.2 & 3.5 & $\mathrm{n} / \mathrm{a}$ & $\mathrm{n} / \mathrm{a}$ & 1.5 & 3.2 \\
\hline Floor, unstable & 1.5 & 3.2 & 2.2 & 3.5 & $\mathrm{n} / \mathrm{a}$ & $\mathrm{n} / \mathrm{a}$ & 1.5 & 3.2 \\
\hline Vertical Walls & 2.0 & 2.4 & 2.2 & 3.0 & $\mathrm{n} / \mathrm{a}$ & $\mathrm{n} / \mathrm{a}$ & 2.0 & 2.4 \\
\hline Windows & 2.6 & 5.7 & 2.4 & 5.4 & $\mathrm{n} / \mathrm{a}$ & $\mathrm{n} / \mathrm{a}$ & 2.4 & 5.4 \\
\hline Roof, stable & 1.9 & 2.5 & 1.8 & 2.2 & $\mathrm{n} / \mathrm{a}$ & $\mathrm{n} / \mathrm{a}$ & 1.9 & 2.5 \\
\hline Roof, unstable & 1.9 & 2.5 & 1.8 & 2.2 & $\mathrm{n} / \mathrm{a}$ & $\mathrm{n} / \mathrm{a}$ & 1.9 & 2.5 \\
\hline
\end{tabular}

${ }^{\text {a }}$ Constant convective coefficients applied in conjunction with automated infrared radiative exchange.

${ }^{\mathrm{b}}$ Constant combined coefficients applied.

Output for this test scheme is provided in Table 4A-21.

From these results we conclude the following:

1. It is not necessary to have a separate set of constant interior surface coefficients for the high-mass cases; the coefficients developed for Case 600 are sufficient.

2. It is not necessary to have a separate set of constant interior surface convective coefficients for cases with interior $\varepsilon=0.1$ (e.g., Case 200); the convective coefficients developed for Case 600 are sufficient.

3. It is not necessary to have a separate set of constant interior surface coefficients for high-conductance wall elements; the surface coefficients for clear windows developed for Case 600 are sufficient.

4. Use of separate switchable stable and unstable constant convective coefficients on horizontal surfaces yields results similar to those applying the mixed constant coefficients. 


\section{Table 4A-21. Comparison of Round 1 additional sensitivity test results (Kummert 2015)}

Note: Columns in blue font identify sensitivity tests applying constant combined interior surface coefficients; columns in black are sensitivity tests applying constant convective interior surface coefficients in conjunction with automated infrared radiative exchange, except " $h 00$ " also applies automated surface convective heat transfer calculations. A detailed description of " $\mathrm{hOn}$ " characterizations is provided in the above text.

\begin{tabular}{|c|c|c|c|c|c|c|c|c|c|}
\hline & h00 & h01 & h02 & h05 & h06 & h07 & h08 & h09 & h10 \\
\hline \multicolumn{10}{|c|}{ Annual heating loads [MWh] } \\
\hline Case 600 & 4.457 & 4.484 & 4.622 & 4.484 & 4.622 & 4.525 & 4.702 & & \\
\hline Case 900 & 1.778 & 1.715 & 1.905 & 1.781 & 1.838 & 1.736 & 1.927 & & \\
\hline Case 200 & 5.161 & 5.129 & 5.193 & 5.165 & 5.203 & & & & \\
\hline Case 250 & 5.091 & 5.131 & 5.571 & 5.230 & 5.603 & & & 5.099 & 5.527 \\
\hline \multicolumn{10}{|c|}{ Annual cooling loads [MWh] } \\
\hline Case 600 & 5.655 & 5.573 & 6.374 & 5.573 & 6.374 & 5.624 & 6.391 & & \\
\hline Case 900 & 2.175 & 2.117 & 2.991 & 2.252 & 2.934 & 2.118 & 2.977 & & \\
\hline Case 200 & 0.787 & 0.845 & 0.869 & 0.860 & 0.871 & & & & \\
\hline Case 250 & 2.874 & 2.917 & 3.218 & 2.984 & 3.208 & & & 2.893 & 3.180 \\
\hline \multicolumn{10}{|c|}{ Annual hourly integrated peak heating loads [kW] } \\
\hline Case 600 & 3.358 & 3.240 & 3.377 & 3.240 & 3.377 & 3.252 & 3.417 & & \\
\hline Case 900 & 2.769 & 2.505 & 3.004 & 2.656 & 2.904 & 2.514 & 3.023 & & \\
\hline Case 200 & 2.365 & 2.193 & 2.227 & 2.207 & 2.228 & & & & \\
\hline Case 250 & 2.888 & 2.730 & 2.883 & 2.770 & 2.902 & & & 2.715 & 2.864 \\
\hline \multicolumn{10}{|c|}{ Annual hourly integrated peak cooling loads [kW] } \\
\hline Case 600 & 6.067 & 5.439 & 6.289 & 5.439 & 6.289 & 5.519 & 6.364 & & \\
\hline Case 900 & 2.858 & 2.360 & 3.669 & 2.591 & 3.476 & 2.368 & 3.695 & & \\
\hline Case 200 & 1.256 & 1.231 & 1.262 & 1.256 & 1.269 & & & & \\
\hline Case 250 & 2.685 & 2.500 & 2.727 & 2.559 & 2.713 & & & 2.482 & 2.698 \\
\hline
\end{tabular}

\begin{tabular}{|c|c|c|c|c|c|c|c|c|c|}
\hline \multicolumn{10}{|c|}{ \%-Differences versus "h00" } \\
\hline & h00 & h01 & h02 & h05 & h06 & h07 & h08 & h09 & $\mathrm{h} 10$ \\
\hline \multicolumn{10}{|c|}{ Annual heating loads [MWh] } \\
\hline Case 600 & $0.0 \%$ & $0.6 \%$ & $3.7 \%$ & $0.6 \%$ & $3.7 \%$ & $1.5 \%$ & $5.5 \%$ & & \\
\hline Case 900 & $0.0 \%$ & $-3.5 \%$ & $7.1 \%$ & $0.2 \%$ & $3.4 \%$ & $-2.3 \%$ & $8.4 \%$ & & \\
\hline Case 200 & $0.0 \%$ & $-0.6 \%$ & $0.6 \%$ & $0.1 \%$ & $0.8 \%$ & & & & \\
\hline Case 250 & $0.0 \%$ & $0.8 \%$ & $9.4 \%$ & $2.7 \%$ & $10.1 \%$ & & & $0.1 \%$ & $8.6 \%$ \\
\hline \multicolumn{10}{|c|}{ Annual cooling loads [MWh] } \\
\hline Case 600 & $0.0 \%$ & $-1.4 \%$ & $12.7 \%$ & $-1.4 \%$ & $12.7 \%$ & $-0.5 \%$ & $13.0 \%$ & & \\
\hline Case 900 & $0.0 \%$ & $-2.7 \%$ & $37.5 \%$ & $3.6 \%$ & $34.9 \%$ & $-2.6 \%$ & $36.9 \%$ & & \\
\hline Case 200 & $0.0 \%$ & $7.4 \%$ & $10.4 \%$ & $9.3 \%$ & $10.8 \%$ & & & & \\
\hline Case 250 & $0.0 \%$ & $1.5 \%$ & $12.0 \%$ & $3.8 \%$ & $11.6 \%$ & & & $0.7 \%$ & $10.6 \%$ \\
\hline
\end{tabular}

Annual hourly integrated peak heating loads [kW]

\begin{tabular}{|l|l|l|l|l|l|l|l|l|l|}
\hline Case 600 & $0.0 \%$ & $-3.5 \%$ & $0.6 \%$ & $-3.5 \%$ & $0.6 \%$ & $-3.2 \%$ & $1.7 \%$ & & \\
\hline Case 900 & $0.0 \%$ & $-9.5 \%$ & $8.5 \%$ & $-4.1 \%$ & $4.9 \%$ & $-9.2 \%$ & $9.1 \%$ & & \\
\hline Case 200 & $0.0 \%$ & $-7.3 \%$ & $-5.9 \%$ & $-6.7 \%$ & $-5.8 \%$ & & & & \\
\hline Case 250 & $0.0 \%$ & $-5.5 \%$ & $-0.2 \%$ & $-4.1 \%$ & $0.5 \%$ & & & $-6.0 \%$ & $-0.8 \%$ \\
\hline
\end{tabular}

Annual hourly integrated peak cooling loads [kW]

\begin{tabular}{|l|r|r|r|r|r|r|r|r|}
\hline Case 600 & $0.0 \%$ & $-10.3 \%$ & $3.7 \%$ & $-10.3 \%$ & $3.7 \%$ & $-9.0 \%$ & $4.9 \%$ & \\
\hline Case 900 & $0.0 \%$ & $-17.4 \%$ & $28.4 \%$ & $-9.4 \%$ & $21.6 \%$ & $-17.2 \%$ & $29.3 \%$ & \\
\hline Case 200 & $0.0 \%$ & $-2.0 \%$ & $0.5 \%$ & $0.0 \%$ & $1.1 \%$ & & \\
\hline Case 250 & $0.0 \%$ & $-6.9 \%$ & $1.6 \%$ & $-4.7 \%$ & $1.1 \%$ & & & \\
\hline
\end{tabular}

TestMatrixResults...061715.xlsx; Results+jn060915!A41+ 


\section{A.5 Comparison of New Versus Standard-140-2017 Alternative Constant Surface Heat Transfer Coefficients and Effect on Heating and Cooling Loads.}

Updated versus prior alternative constant surface heat transfer coefficients are shown in Table 4A-22. The updated values are average values from the EnergyPlus and TRNSYS simulations that apply the calculation methodology described in previous sections of this appendix. This table provides coefficients for interior and exterior surfaces, disaggregated for surfaces with $\varepsilon=0.9$ and $\varepsilon=0.1$, where $\varepsilon$ is surface infrared emittance. The following cases of Part I were applied for developing the simplified constant coefficients: Case 600, low-mass base case with $\varepsilon=0.9$; Case 200, $\varepsilon=0.1$ and high-conductance wall elements in place of windows. Values for high-conductance wall elements with $\varepsilon=0.9$, where they occur in some of the Part I test cases, are the same as for the transparent windows. The following nomenclature applies in Table 4A-22:

- h,conv,int: interior convective surface coefficient.

- h,conv,ext: exterior convective surface coefficient.

- h,comb,int: interior combined surface coefficient.

- h,comb,ext: exterior combined surface coefficient.

- "New" indicates values of the constant annual zone load-weighted average convective and combined coefficients listed in Part I, Annex B4, Tables B4-1 and B4-2, which were developed using the process described in previous sections of this appendix.

- “1995" indicates values from Standard 140-2017 (ANSI/ASHRAE 2017), originally published in IEA BESTEST (Judkoff and Neymark 1995); these values have been applied in Standard 140 since its first version (ANSI/ASHRAE 2001).

- Blank cells: stable- or unstable-convection interior surface coefficients not applicable for the "New" coefficients and for the " 1995 " vertical surfaces.

- "n/a": not applicable, only used for the "1995" floor exterior surface coefficients.

For the "New" coefficients, which stem from more detailed evaluation than the "1995" coefficients, h,comb $\leq$ $\mathrm{h}$,conv is possible here because convective and radiative heat flows may be in opposite directions for a given surface for a sufficient number of time steps; this possibility is not accounted for in the "1995" coefficients.

Case 670 is new (not included in Standard 140-2017 or previous versions of the standard), so Table 4A-22 does not include a comparison for applying h,comb for the Case 670 single-pane windows versus applying the "1995" coefficients.

A comparison of annual heating and cooling load results applying these coefficients versus results for automated hourly calculations applying the algorithms of Section 4A.2 for Case $600(\varepsilon=0.9)$ and Case $200(\varepsilon=0.1)$ indicates the following:

- The "New" constant interior and exterior convective coefficients have better agreement versus the automated surface heat transfer calculations than the "1995" coefficients

- The "New" constant interior combined coefficients have better agreement versus the automated surface heat transfer calculations than the " 1995 " coefficients

- For the summed annual heating + cooling loads, the "New" constant exterior combined coefficients also have better agreement versus the automated hourly heat transfer calculations than the "1995" coefficients. However, and while the variations are small, for some disaggregated annual heating and cooling loads the "1995" coefficients have better agreement versus the automated surface heat transfer calculations than the "New" coefficients. This is possible because the constant surface coefficient development scheme minimizes the error in the total combined heating and cooling loads occurring during an annual simulation.

A more detailed discussion regarding comparison of loads results applying these constant surface coefficients is provided in Section 4A.3.3, with a quantitative results summary in Table 4A-4. 
Table 4A-22. Comparison of New Versus Original-Standard-140 Alternative Constant Surface Heat Transfer Coefficients ${ }^{\mathrm{a}, \mathrm{b}}$

\begin{tabular}{|c|c|c|c|c|c|c|c|c|}
\hline \multirow{2}{*}{$\begin{array}{r}\text { Surface Type } \\
\varepsilon=0.9, \text { Interior } \\
\end{array}$} & \multicolumn{2}{|c|}{$\begin{array}{l}\text { Windows or } \\
\text { High-Conductance } \\
\text { Wall Elements }\end{array}$} & \multicolumn{2}{|c|}{ Walls } & \multicolumn{2}{|c|}{ Ceiling } & \multicolumn{2}{|c|}{ Floor } \\
\hline & New & 1995 & New & 1995 & New & 1995 & New & 1995 \\
\hline$h$, conv, int $\left(W /\left(m^{2} \cdot K\right)\right)$ & 2.4 & 3.2 & 2.2 & 3.2 & 1.8 & 3.2 & 2.2 & 3.2 \\
\hline 1995 Stable & & & & & & 1.0 & & 1.0 \\
\hline 1995 Unstable & & & & & & 4.1 & & 4.1 \\
\hline$h$, comb,int $\left(W /\left(m^{2} \cdot K\right)\right)$ & 4.5 & $8.0(8.3)^{c}$ & 1.8 & 8.3 & 1.7 & 8.3 & 3.7 & 8.3 \\
\hline 1995 Stable & & & & & & 6.1 & & 6.1 \\
\hline 1995 Unstable & & & & & & 9.2 & & 9.2 \\
\hline \multicolumn{9}{|l|}{$\varepsilon=0.9$, Exterior } \\
\hline $\mathrm{h}$, conv,ext $\left(\mathrm{W} /\left(\mathrm{m}^{2} \cdot \mathrm{k}\right)\right)$ & 8.0 & 16.4 & 11.9 & 24.7 & 14.4 & 24.7 & 0.8 & $\mathrm{n} / \mathrm{a}$ \\
\hline$h, c o m b, e x t\left(W /\left(m^{2} \cdot K\right)\right)$ & 17.8 & 21.0 & 21.6 & 29.3 & 21.8 & 29.3 & 5.2 & $\mathrm{n} / \mathrm{a}$ \\
\hline \multicolumn{9}{|l|}{$\varepsilon=0.1$, Interior } \\
\hline$h$, conv, int $\left(W /\left(m^{2} \cdot K\right)\right)$ & 2.6 & 3.2 & 1.9 & 3.2 & 1.9 & 3.2 & 1.0 & 3.2 \\
\hline 1995 Stable & & & & & & 1.0 & & 1.0 \\
\hline 1995 Unstable & & & & & & 4.1 & & 4.1 \\
\hline$h$, comb,int $\left(W /\left(m^{2} \cdot K\right)\right)$ & 3.1 & 3.7 & 2.1 & 3.7 & 1.9 & 3.7 & 0.4 & 3.7 \\
\hline 1995 Stable & & & & & & 1.6 & & 1.6 \\
\hline 1995 Unstable & & & & & & 4.7 & & 4.7 \\
\hline \multicolumn{9}{|l|}{$\varepsilon=0.1$, Exterior } \\
\hline$h$, conv,ext $\left(W /\left(m^{2} \cdot K\right)\right)$ & 7.9 & 16.4 & 11.8 & 24.7 & 14.4 & 24.7 & 0.9 & $\mathrm{n} / \mathrm{a}$ \\
\hline$h, c o m b, e x t\left(W /\left(m^{2} \cdot K\right)\right)$ & 8.1 & 16.9 & 12.8 & 25.2 & 17.4 & 25.2 & 1.3 & $\mathrm{n} / \mathrm{a}$ \\
\hline
\end{tabular}

SurfCoeffAnalysis...040920.xIsx; AllCoeffs600+...!W108+

a. Example constant surface coefficients presented here apply only to the test cases, and only for test cases with south-facing windows or south-facing high-conductance wall elements. They should not be assumed to apply beyond the updated BESTEST suite.

b. Example constant interior surface coefficients assume buoyancy regime heat transfer only.

c. " $8.0(8.3)$ " indicates values of $8.0 \mathrm{~W} /\left(\mathrm{m}^{2} \mathrm{~K}\right)$ and $8.3 \mathrm{~W} /\left(\mathrm{m}^{2} \mathrm{~K}\right)$ for the window $(\varepsilon=0.84)$ and highconductance wall elements $(\varepsilon=0.9)$, respectively. 


\section{B Appendix B. Development of Informative Sky Temperature Data of Annex A1}

The sky temperature data of Annex A1 (Weather Data) are calculated based on the work of Martin and Berdahl (1984), as follows:

Tsky $\left({ }^{\circ} \mathrm{C}\right)=\varepsilon, \operatorname{sky}^{\wedge}(1 / 4) \cdot(\mathrm{T}$, air +273.15$)-273.15$, where

T,air in ${ }^{\circ} \mathrm{C}$ (from weather data)

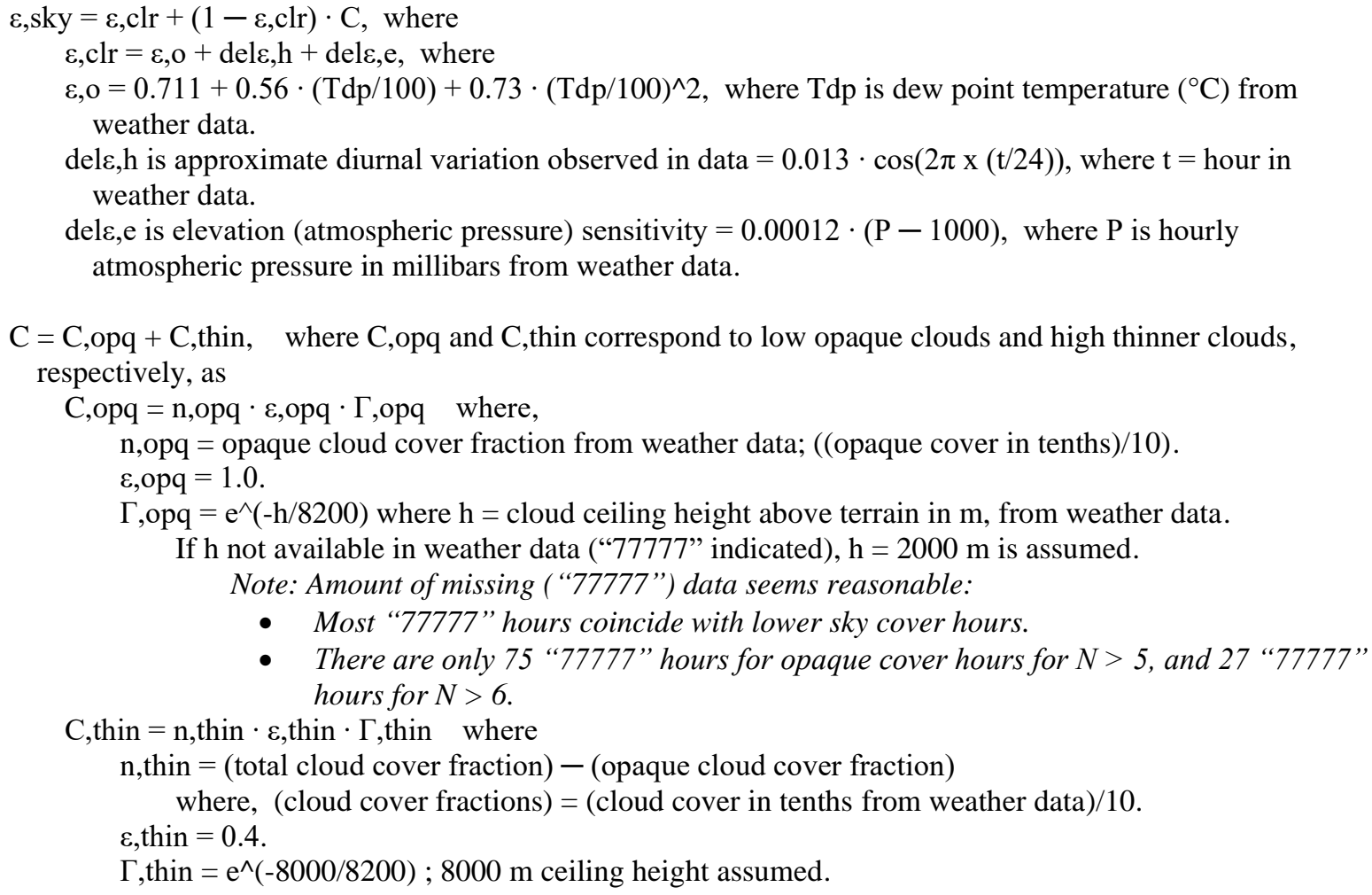

This calculation is compared with results of two other (of many possible) sky temperature calculations (Clark and Allen 1978; TRNSYS 2012 per McDowell 2015); see workbook tab "Supporting-Tsky-Calcs" within the file "TskyInformative.xlsx". A comparison of heating and sensible cooling loads (annual total and peak hour) for selected test cases for the selected sky temperature data sets was developed by GARD Analytics (Henninger and Witte 2015a), by directly inputting the full-year hourly $\mathrm{T}_{\text {sky }}$ data sets into EnergyPlus Version 8.1.0.009 (2014). The selected test cases are Case 600 (low-mass base case with clear windows) along with Case 250 (high-conductance wall elements, $\varepsilon=0.9, \alpha=0.9$ ) and Case 200 (high-conductance wall elements, $\varepsilon=0.1, \alpha=0.1$ ). The results of this sensitivity test are included in Informative Table 4B-1.

The sensitivity test results indicate that the effect of varying the sky temperature input is up to $2.6 \%$ on Case 600 annual heating and cooling loads, with less effect on peak loads. For Case 250, with high-conductance wall elements, high solar absorptance, and high infrared emittance, the effect of varying input sky temperature is greater (up to $4.4 \%$ ), while for Case 200, with high-conductance wall elements, low solar absorptance, and low infrared emittance, the effect is generally less (up to $1.6 \%$ ). 
Table 4B-1. Load Sensitivity to Variation of Sky Temperature (Henninger and Witte 2015a)

\begin{tabular}{|c|c|c|c|c|c|c|c|c|c|}
\hline Case & Using Sky Temps based on & $\begin{array}{l}\text { Annual } \\
\text { Heating } \\
\text { (MWH) }\end{array}$ & $\begin{array}{l}\text { \%Diff vs. } \\
\text { MB } 1984\end{array}$ & $\begin{array}{l}\text { Annual } \\
\text { Cooling } \\
\text { (MWH) }\end{array}$ & $\begin{array}{l}\text { \%Diff vs. } \\
\text { MB } 1984\end{array}$ & $\begin{array}{l}\text { Peak Hourly } \\
\text { Heating (KW) }\end{array}$ & $\begin{array}{l}\text { \%Diff vs. } \\
\text { MB } 1984\end{array}$ & $\begin{array}{l}\text { Peak Hourly } \\
\text { Cooling (KW) }\end{array}$ & $\begin{array}{l}\text { \%Diff vs. } \\
\text { MB } 1984\end{array}$ \\
\hline 600 & Martin and Berdahl (1984) & 4.399 & & 5.890 & & 3.269 & & 6.258 & \\
\hline 250 & Martin and Berdahl (1984) & 5.152 & & 3.219 & & 2.836 & & 2.948 & \\
\hline 200 & Martin and Berdahl (1984) & 5.201 & & 0.821 & & 2.401 & & 1.314 & \\
\hline 600 & TRNSYS 17.1 (McDowell 2015) & 4.350 & $-1.12 \%$ & 5.951 & $1.04 \%$ & 3.267 & $-0.05 \%$ & 6.258 & $0.00 \%$ \\
\hline 250 & TRNSYS 17.1 (McDowell 2015) & 5.080 & $-1.39 \%$ & 3.282 & $1.95 \%$ & 2.834 & $-0.06 \%$ & 2.964 & $0.55 \%$ \\
\hline 200 & TRNSYS 17.1 (McDowell 2015) & 5.188 & $-0.25 \%$ & 0.828 & $0.81 \%$ & 2.401 & $0.00 \%$ & 1.314 & $0.00 \%$ \\
\hline 600 & Clark and Allen (1978) & 4.315 & $-1.92 \%$ & 6.041 & $2.55 \%$ & 3.205 & $-1.94 \%$ & 6.351 & $1.48 \%$ \\
\hline 250 & Clark and Allen (1978) & 5.023 & $-2.50 \%$ & 3.362 & $4.44 \%$ & 2.767 & $-2.42 \%$ & 3.017 & $2.34 \%$ \\
\hline 200 & Clark and Allen (1978) & 5.175 & $-0.51 \%$ & 0.835 & $1.62 \%$ & 2.394 & $-0.30 \%$ & 1.335 & $1.59 \%$ \\
\hline
\end{tabular}


4C Appendix C. Calculation of Alternative Constant Interior Solar Distribution Fractions of Annex B7

Table 4C-1 shows calculations of alternative constant interior solar distribution fractions for developing Table B7-1 of Informative Annex B7 (see Part I), applying the algorithm described in Annex B7. 
Table 4C-1 Supporting Calculations for Table B7-1 of Annex B7

\begin{tabular}{|c|c|c|c|c|c|c|c|c|c|c|}
\hline \multicolumn{11}{|c|}{ Ni and No calc data (R-values in m2K/W) -- From Tables 5-11 and 5-18 } \\
\hline & & Case 600 & Case 660 & Case 670 & & \multirow{2}{*}{\multicolumn{5}{|c|}{ Case 600 inputs are blue in this table. }} \\
\hline Rext,film & & 0.05618 & 0.05618 & 0.06250 & & & & & & \\
\hline Rpane, outer & & 0.00305 & 0.00318 & $\mathrm{n} / \mathrm{a}$ & & \multicolumn{5}{|c|}{ Case 660 inputs are red in this table. } \\
\hline Rair,gap & & 0.19200 & 0.55814 & $\mathrm{n} / \mathrm{a}$ & & \multicolumn{5}{|c|}{ Case 670 inputs are green in this table. } \\
\hline Rpane,inner & & 0.00305 & 0.00305 & 0.00305 & & & & & & \\
\hline Rint, film & & 0.22222 & 0.22222 & 0.12821 & & & & & & \\
\hline$R$-val on ext side of ext $p$ & & 0.05618 & 0.05618 & 0.06250 & & & & & & \\
\hline$R$-val on ext side of int $p$ & & 0.25123 & 0.61750 & 0.06250 & & & & & & \\
\hline Total R-val & & 0.47650 & 0.84277 & 0.19375 & & & & & & \\
\hline \multicolumn{3}{|c|}{ Clear Double-Pane Window Properties } & $\begin{array}{l}\rho_{\text {win }} \\
0.206\end{array}$ & $\begin{array}{l}\mathrm{Ni} \\
0.527\end{array}$ & $\begin{array}{l}\alpha \mathrm{i}_{\operatorname{win}} \\
0.110\end{array}$ & $\begin{array}{l}\text { No } \\
0.118\end{array}$ & $\begin{array}{c}\alpha \mathrm{o}_{\text {win }} \\
0.073\end{array}$ & & & \\
\hline \multicolumn{11}{|c|}{$\rho_{\text {win }}\left(=\right.$ refl.,f) $, \alpha i_{\text {win }}, \alpha o_{\text {win }}$ from Table 5-12, hemispherical values. } \\
\hline South Clear Double-Pan & Vindows, $\alpha$,in & & 0.6 & & & & & East $/$ West Windows, $\alpha$,int $=$ & 0.6 & \\
\hline & & FFi, floor & Fraction & Fraction & Fraction & Fraction & Fraction & & & Fraction \\
\hline Surface & Area $\left(m^{2}\right)$ & to other & B1 & B2 & B3 & BR & Total & Surface & Area $\left(\mathrm{m}^{2}\right)$ & Total \\
\hline Floor & 48 & & 0.6 & & 0.026 & 0.016 & 0.6421 & Floor & 48 & 0.6421 \\
\hline Ceiling & 48 & 0.520 & & 0.125 & 0.026 & 0.016 & 0.1669 & Ceiling & 48 & 0.1669 \\
\hline East Wall & 16.2 & 0.100 & & 0.024 & 0.009 & 0.005 & 0.0382 & East Wall & 10.2 & 0.0236 \\
\hline West Wall & 16.2 & 0.100 & & 0.024 & 0.009 & 0.005 & 0.0382 & West Wall & 10.2 & 0.0236 \\
\hline North wall & 21.6 & 0.140 & & 0.034 & 0.012 & 0.007 & 0.0526 & North wall & 21.6 & 0.0526 \\
\hline South wall & 9.6 & 0.062 & & 0.015 & 0.005 & 0.003 & 0.0234 & South wall & 21.6 & 0.0526 \\
\hline South window, in & 12 & 0.078 & & 0.002 & 0.001 & 0.000 & 0.0032 & $\mathrm{E} / \mathrm{W}$ window, in & 12 & 0.0032 \\
\hline South window, out & 12 & 0.078 & & 0.023 & 0.008 & 0.005 & 0.0354 & E/W window, out & 12 & 0.0354 \\
\hline Total & 171.6 & 1.000 & 0.6 & 0.246 & 0.094 & 0.059 & 1.0000 & Total & 171.6 & 1.0000 \\
\hline South Clear Double-Pan & Vindows, $\alpha$,in & & 0.9 & & & & & East/West Windows, $\alpha$,int $=$ & 0.9 & \\
\hline & & FFi, floor & Fraction & Fraction & Fraction & Fraction & Fraction & & & Fraction \\
\hline Surface & Area $\left(m^{2}\right)$ & to other & B1 & B2 & B3 & BR & Total & Surface & Area $\left(\mathrm{m}^{2}\right)$ & Total \\
\hline Floor & 48 & & 0.9 & & 0.003 & 0.000 & 0.9031 & Floor & 48 & 0.9031 \\
\hline Ceiling & 48 & 0.520 & & 0.047 & 0.003 & 0.000 & 0.0499 & Ceiling & 48 & 0.0499 \\
\hline East Wall & 16.2 & 0.100 & & 0.009 & 0.001 & 0.000 & 0.0100 & East Wall & 10.2 & 0.0061 \\
\hline West Wall & 16.2 & 0.100 & & 0.009 & 0.001 & 0.000 & 0.0100 & West Wall & 10.2 & 0.0061 \\
\hline North wall & 21.6 & 0.140 & & 0.013 & 0.001 & 0.000 & 0.0140 & North wall & 21.6 & 0.0140 \\
\hline South wall & 9.6 & 0.062 & & 0.006 & 0.001 & 0.000 & 0.0062 & South wall & 21.6 & 0.0140 \\
\hline South window, in & 12 & 0.078 & & 0.001 & 0.000 & 0.000 & 0.0006 & $\mathrm{E} / \mathrm{W}$ window, in & 12 & 0.0006 \\
\hline South window, out & 12 & 0.078 & & 0.006 & 0.001 & 0.000 & 0.0063 & $E / W$ window, out & 12 & 0.0063 \\
\hline Total & 171.6 & 1.000 & 0.9 & 0.089 & 0.010 & 0.001 & 1.0000 & Total & 171.6 & 1.0000 \\
\hline South Clear Double-Pan & Vindows, $\alpha$,in & $\mathrm{t}=$ & 0.1 & & & & & Sun Space Case $960, \alpha$,int $=$ & 0.6 & \\
\hline & & $\mathrm{FFi}$, floor & Fraction & Fraction & Fraction & Fraction & Fraction & & & Fraction \\
\hline Surface & Area $\left(\mathrm{m}^{2}\right)$ & to other & B1 & B2 & B3 & BR & Total & Surface & Area $\left(\mathrm{m}^{2}\right)$ & Total \\
\hline Floor & 48 & & 0.1 & & 0.021 & 0.122 & 0.2434 & Floor & 16 & 0.6000 \\
\hline Ceiling & 48 & 0.520 & & 0.047 & 0.021 & 0.122 & 0.1902 & Ceiling & 16 & 0.0544 \\
\hline East Wall & 16.2 & 0.100 & & 0.009 & 0.007 & 0.041 & 0.0574 & East Wall & 5.4 & 0.0183 \\
\hline West Wall & 16.2 & 0.100 & & 0.009 & 0.007 & 0.041 & 0.0574 & West Wall & 5.4 & 0.0183 \\
\hline North wall & 21.6 & 0.140 & & 0.013 & 0.010 & 0.055 & 0.0771 & North wall & 21.6 & 0.2000 \\
\hline South wall & 9.6 & 0.062 & & 0.006 & 0.004 & 0.024 & 0.0343 & South wall & 9.6 & 0.0326 \\
\hline South window, in & 12 & 0.078 & & 0.005 & 0.004 & 0.020 & 0.0285 & South window, in & 12 & \\
\hline South window, out & 12 & 0.078 & & 0.051 & 0.039 & 0.222 & 0.3117 & South window, out & 12 & 0.0763 \\
\hline Total & 171.6 & 1.000 & 0.1 & 0.139 & 0.113 & 0.648 & 1.0000 & Total & 86.0 & 1.0000 \\
\hline & & & $\rho_{\text {win }}$ & $\overline{\mathrm{Ni}}$ & $\alpha \mathrm{i}_{\operatorname{win}}$ & No & $\alpha o_{\text {min }}$ & & & \\
\hline Low-E Window Case, $\alpha$, & & 0.6 & 0.415 & 0.733 & 0.031 & 0.067 & 0.215 & & & \\
\hline$\rho_{\text {win }}(=$ & $., f), \alpha i_{\text {win }}, \alpha o_{w}$ & win from Table & 5-19, hemis & pherical value & & & & & & \\
\hline & & FFi, floor & Fraction & Fraction & Fraction & Fraction & Fraction & & & \\
\hline Surface & Area $\left(m^{2}\right)$ & to other & B1 & B2 & B3 & BR & Total & & & \\
\hline Floor & 48 & & 0.6 & & 0.027 & 0.018 & 0.6450 & & & \\
\hline Ceiling & 48 & 0.520 & & 0.125 & 0.027 & 0.018 & 0.1698 & & & \\
\hline East Wall & 16.2 & 0.100 & & 0.024 & 0.009 & 0.006 & 0.0392 & & & \\
\hline West Wall & 16.2 & 0.100 & & 0.024 & 0.009 & 0.006 & 0.0392 & & & \\
\hline North wall & 21.6 & 0.140 & & 0.034 & 0.012 & 0.008 & 0.0538 & & & \\
\hline South wall & 9.6 & 0.062 & & 0.015 & 0.005 & 0.004 & 0.0239 & & & \\
\hline South window, in & 12 & 0.078 & & 0.001 & 0.000 & 0.000 & 0.0018 & & & \\
\hline South window, out & 12 & 0.078 & & 0.017 & 0.006 & 0.004 & 0.0273 & & & \\
\hline Total & 171.6 & 1.000 & 0.6 & 0.240 & 0.096 & 0.064 & 1.0000 & & & \\
\hline & & & $\overline{\rho_{\text {win }}}$ & & & $\mathbf{N}$ & $\overline{\alpha_{\operatorname{win}}}$ & & & \\
\hline Single-Pane Case, $\alpha$, int & & 0.6 & 0.136 & & & 0.323 & 0.101 & & & \\
\hline$\rho_{\text {win }}(=$ & $., f), \alpha_{\text {win }}$, from & n Table 5-23, & hemispherica & al values. & & & & & & \\
\hline & & FFi, floor & Fraction & Fraction & Fraction & Fraction & Fraction & & & \\
\hline Surface & Area $\left(\mathrm{m}^{2}\right)$ & to other & B1 & B2 & B3 & BR & Total & & & \\
\hline Floor & 48 & & 0.6 & & 0.025 & 0.016 & 0.6412 & & & \\
\hline Ceiling & 48 & 0.520 & & 0.125 & 0.025 & 0.016 & 0.1660 & & & \\
\hline East Wall & 16.2 & 0.100 & & 0.024 & 0.009 & 0.005 & 0.0379 & & & \\
\hline West Wall & 16.2 & 0.100 & & 0.024 & 0.009 & 0.005 & 0.0379 & & & \\
\hline North wall & 21.6 & 0.140 & & 0.034 & 0.011 & 0.007 & 0.0521 & & & \\
\hline South wall & 9.6 & 0.062 & & 0.015 & 0.005 & 0.003 & 0.0232 & & & \\
\hline South window, in & 12 & 0.078 & & 0.001 & 0.000 & 0.000 & 0.0016 & & & \\
\hline South window, out & 12 & 0.078 & & 0.026 & 0.009 & 0.005 & 0.0401 & & & \\
\hline Total & 171.6 & 1.000 & 0.6 & 0.248 & 0.094 & 0.058 & 1.0000 & Table4C-1SolFracs-121219.xlsx & x Table4C-1...! & \\
\hline
\end{tabular}




\section{D Appendix D. References for Part IV}

Alamdari, F. and G.P. Hammond (1983). "Improved Data Correlations for Buoyancy-Driven Convection in Rooms.” Building Services Engineering Research \& Technology. Vol. 4, No. 3, pp. 106-112.

ANSI/ASHRAE Standard 140-2001 (2001). Standard Method of Test for the Evaluation of Building Energy Analysis Computer Programs. Atlanta, Georgia, U.S.A.: American Society of Heating, Refrigerating, and AirConditioning Engineers, Inc.

ANSI/ASHRAE Standard 140-2017 (2017). Standard Method of Test for the Evaluation of Building Energy Analysis Computer Programs. Atlanta, Georgia, U.S.A.: American Society of Heating, Refrigerating, and AirConditioning Engineers, Inc.

ASHRAE (1981, 2001, 2009, 2013). Handbook of Fundamentals. Atlanta, Georgia, U.S.A.: American Society of Heating, Refrigerating, and Air-Conditioning Engineers, Inc. Regarding ASHRAE 2001 HoF Table 5, p. 3.12 (also ASHRAE 1981, Table 5, p. 2.12), this table is revised after 2001.

ASHRAE SSPC 140 (2015). ASHRAE SSPC 140 Meeting Minutes and SSPC 140 Building Thermal Fabric Working Group Minutes, January 26, 2015, Chicago, Illinois, U.S.A.

ASHRAE SSPC 140 (2016). ASHRAE SSPC 140 Meeting Minutes and SSPC 140 Building Thermal Fabric Working Group Minutes, June 27, 2016, St. Louis, Missouri, U.S.A.

Booten, C., N. Kruis, and C. Christensen. (2012). Identifying and Resolving Issues in EnergyPlus and DOE-2 Window Heat Transfer Calculations. NREL/TP-5500-55787. Golden, Colorado, U.S.A.: National Renewable Energy Laboratory.

Clark, G., and C. Allen (1978). "The Estimation of Atmospheric Radiation for Clear and Cloudy Skies". Proceedings of the 2nd National Passive Solar Conference. AS/ISES, pp. 675-678.

Curcija, D., and Goss, W.P. (1995). "New Correlations for Convective Heat Transfer Coefficient on Indoor Fenestration Surfaces - Compilation of More Recent Work". ASHRAE/DOE/BTECC Conference, Thermal Performance of the Exterior Envelopes of Buildings VI, Clearwater, FL.

EnergyPlus. 2014. Version 8.1.0.009. Washington D.C.: U.S. Department of Energy. www.energyplus.gov

Fohanno, S., and G. Polidori (2006). "Modelling of Natural Convective Heat Transfer at an Internal Surface." Energy and Buildings 38, 548-553. Elsevier. www.elsevier.com/locate/enbuild.

Glazer, J. (2017-2018). Personal communications with J. Neymark, including transmittal of simulation results and input files. November 2017-February 2018. Arlington Heights, Illinois, U.S.A.: GARD Analytics.

R. Henninger and M. Witte (2015a). Personal communications with J. Neymark. April 13-22, 2015. Arlington Heights, Illinois, U.S.A.: GARD Analytics, Inc.

Henninger, R., and Witte, M. (2015b). Personal communications with J. Neymark, including transmittal of simulation results. May 2015. Arlington Heights, Illinois, U.S.A.: GARD Analytics.

Henninger, R., and Witte, M. (2015-2016). Personal communications with J. Neymark, including transmittal of simulation results and input files. December 2015-February 2016. Arlington Heights, Illinois, U.S.A.: GARD Analytics.

ISO 15099 (2003). ISO 15099-2003. Thermal Performance of Windows, Doors, and Shading Devices - Detailed Calculations. Geneva, Switzerland: International Organization for Standardization. 
Judkoff, R., and J. Neymark. (1995). International Energy Agency Building Energy Simulation Test (BESTEST) and Diagnostic Method. NREL/TP-472-6231. Golden, Colorado, U.S.A.: National Renewable Energy Laboratory.

Klein, S.A., W.A. Beckman, J.W. Mitchell, J.A. Duffie, N.A. Duffie, T.L. Freeman, J.C. Mitchell, J.E. Braun, B.L. Evans, J.P. Kummer, R.E. Urban, A. Fiksel, J.W. Thornton, N.J. Blair, P.M. Williams, D.E. Bradley, T.P. McDowell, M. Kummert, D.A. Arias, M.J. Duffy (2015). TRNSYS 17 - A TRaNsient SYstem Simulation program, User Manual. Version 17.2.5. Madison, Wisconsin, U.S.A.: University of Wisconsin-Madison.

Klein, S.A., W.A. Beckman, J.W. Mitchell, J.A. Duffie, N.A. Duffie, T.L. Freeman, J.C. Mitchell, et al. [full listing above]. (2018a) TRNSYS 18 - A TRaNsient SYstem Simulation program, User Manual. Version 18.01.0001.

Madison, Wisconsin, U.S.A.: University of Wisconsin-Madison.

Klein, S.A., W.A. Beckman, J.W. Mitchell, J.A. Duffie, N.A. Duffie, T.L. Freeman, J.C. Mitchell, et al. [full listing above] (2018b). TRNSYS 18 - A TRaNsient SYstem Simulation program, User Manual. Version 18.0.17. Madison, Wisconsin, U.S.A: University of Wisconsin-Madison.

Kummert, M. (2014). ASHRAE 140 Building Thermal Fabric Tests Update, Additional Results (Sensitivity Study) and Comments, Based on Draft Version 072214. October 31, 2014. Montreal, Quebec, Canada: Polytechnique Montréal.

Kummert, M. (2015). Personal communications with J. Neymark, including transmittal of simulation results. MayJune 2015. Montreal, Quebec, Canada: Polytechnique Montréal.

Kummert, M. (2016). Personal communications with J. Neymark, including transmittal of simulation results. November 2015-January 2016. Montreal, Quebec, Canada: Polytechnique Montréal.

Kummert, M. (2017). Personal communications with J. Neymark, including transmittal of simulation results. August 2016-January 2017. Montreal, Quebec, Canada: Polytechnique Montréal.

Kummert, M. (2018). Personal communications with J. Neymark, including transmittal of simulation results. March-April 2018. Montreal, Quebec, Canada: Polytechnique Montréal.

Martin, M., and P. Berdahl (1984). "Characteristics of Infrared Sky Radiation in the United States." Solar Energy, Vol. 33, No. 3/4, pp. 321-336. Oxford, U.K.: Pergamon Press Ltd.

McAdams, W.H. (1954). Heat Transmission. New York: McGraw-Hill.

T. McDowell (2015). Personal Communications with J. Neymark, April 16-28, 2015. Madison, Wisconsin, U.S.A: Thermal Energy System Specialists.

Neymark, J., Boardman, C.R., Kirkpatrick, A., Anderson, R. (1989). "High Rayleigh Number Natural Convection in Partially Divided Air and Water Filled Enclosures." International Journal of Heat and Mass Transfer, Vol. 32, No. 9, pp. 1671-1679. Oxford, U.K.: Pergamon Press.

Neymark, J., Kummert, M., and Judkoff, R. (2019). “Developing Equivalent Surface Heat Transfer Input Parameters for Updated Standard 140/BESTEST Thermal Fabric Test Cases." Proceedings of Building Simulation 2019. Rome, Italy. Sep 2-4, 2019. International Building Performance Simulation Association.

Rowley, F.B., A.B. Algren, and J. L. Blackshaw (1930). "Surface Conductances as Affected by Air Velocity, Temperature and Character of Surface." ASHVE Transactions, Vol. 36. American Society of Heating and Ventilating Engineers (predecessor of ASHRAE).

TRNSYS (2012). Version 17.1. Madison, Wisconsin, U.S.A: University of Wisconsin. http://sel.me.wisc.edu/trnsys/ or Madison, Wisconsin, U.S.A: Thermal Energy System Specialists. http://www.trnsys.com/ 
U.S. DOE (2015). EnergyPlus 8.3.0. Washington, D.C.: U.S. Department of Energy. Posted by National Renewable Energy Laboratory, Golden, Colorado, U.S.A. https://github.com/NREL/EnergyPlus/releases/tag/v8.3.0

U.S. DOE (2017). EnergyPlus 8.8.0. Washington, D.C.: U.S. Department of Energy. Posted by National Renewable Energy Laboratory, Golden, Colorado, U.S.A. https://github.com/NREL/EnergyPlus/releases/tag/v8.8.0

U.S. DOE. (2018). EnergyPlus Engineering Reference. Washington, D.C.: U.S. Department of Energy; Urbana, Illinois, U.S.A.: University of Illinois; Berkeley, California, U.S.A.: University of California and Lawrence Berkeley National Laboratory.

Walton, G.N. (1983). Thermal Analysis Research Program (TARP) Reference Manual. Washington, D.C.: U.S. Department of Commerce, National Bureau of Standards, National Engineering Laboratory, Building Physics Division,

Witte, M. (2016). Personal communications with J. Neymark. December 2016. Arlington Heights, Illinois, U.S.A.: GARD Analytics.

Yazdanian, M., and J. Klems. (1994). "Measurement of the Exterior Convective Film Coefficient for Windows in Low-Rise Buildings." ASHRAE Transactions 100(1) 1994. Atlanta, Georgia, U.S.A.: American Society of Heating, Refrigerating, and Air-Conditioning Engineers, Inc. Also published as LBL-34717. Berkeley, California, U.S.A.: Lawrence Berkeley National Laboratory. http://eetd.lbl.gov/sites/all/files/publications/34717.pdf 



\section{Argonne}

\section{Energy Systems Division}

Argonne National Laboratory

9700 South Cass Avenue, Bldg. 362

Lemont, IL 60439-4832

www.anl.gov 